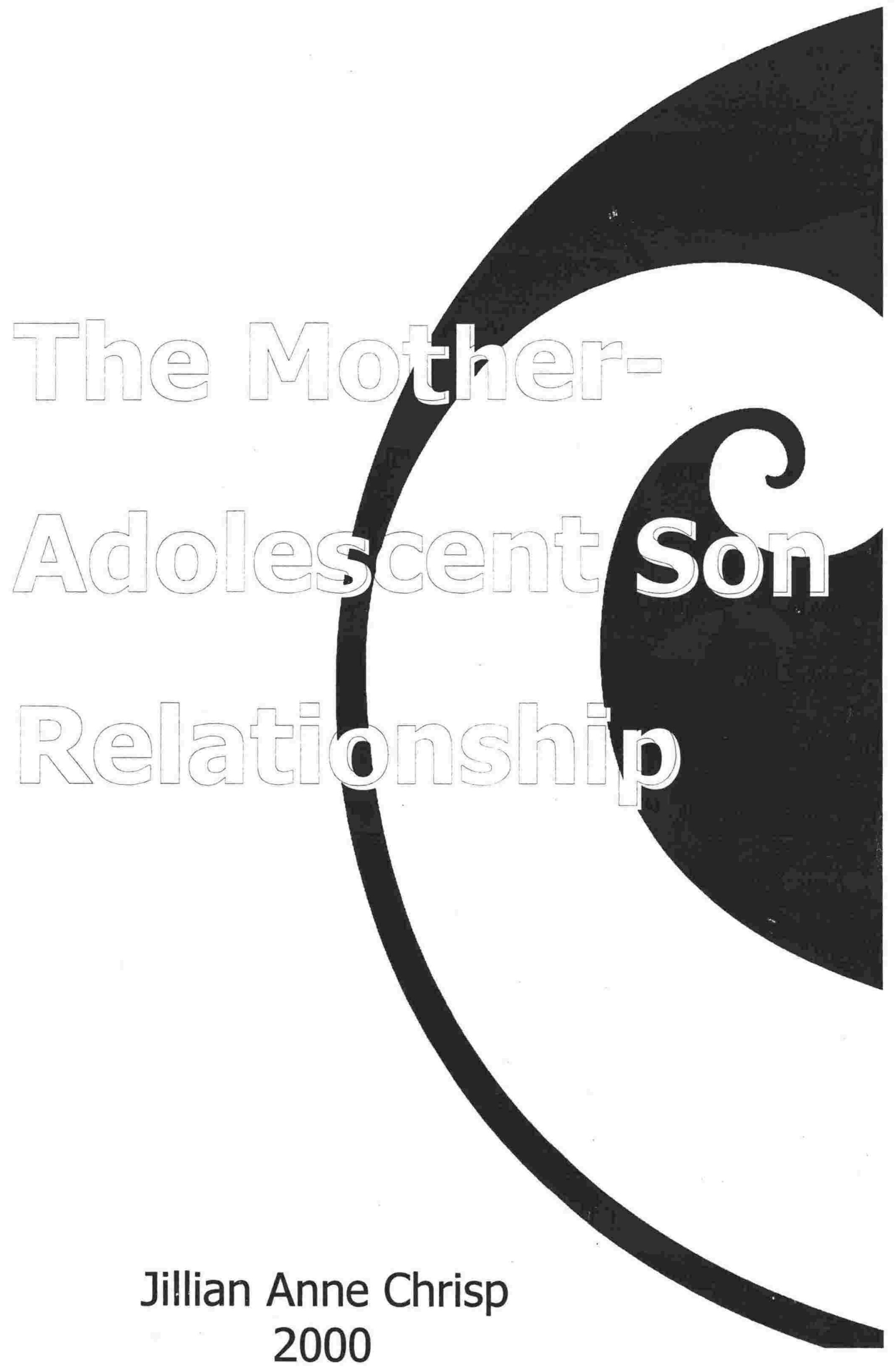




\title{
THE MOTHER - ADOLESCENT SON RELATIONSHIP
}

\author{
by
}

\section{Jillian Anne Chrisp}

\author{
A thesis \\ Submitted to the Victoria University of Wellington \\ in fulfilment of the \\ requirements for the degree of \\ Doctor of Philosophy \\ in Women's Studies
}

Victoria University of Wellington 
VICTORIA UNIVERSITY OF WELLINGTON 
Adrienne Rich, feminist, writer, researcher and mother once stated, "if I could have one wish for my own sons, it is that they should have the courage of women" (1976, p.214).

Current statistics demonstrate that adolescent boys are more likely to be unemployed, to die from suicide or bad health, to have long term psychological problems, to contribute in disproportionately large numbers to crime statistics. One of the explanations for this situation that is gaining currency in Aotearoa New Zealand, Australia, Canada, the UK and the USA, is that the current generation of boys is fatherless. The 1996 census counted 168,255 one-parent families, accounting for 17.7 percent of all family structures. Of these 83.1 percent, or a total of 139,819 one-parent families, were headed by women. Mothers from intact heterosexual relationships report experiences of ostensibly raising their children on their own. And yet there is silence about the mother, her realities and the integral part she has to play in addressing the highlighted concerns. It appears she is encouraged to withdraw any influence she may have on the adolescent son and actively promote involvement by the father.

The research project investigates the mother and adolescent son relationship, the interventions to this relationship and the impact of these interventions on the mother and son. Using feminist participatory action research theory, as distinct from action research, it is concerned with the following methodological questions; deconstructing the 'participant-empowerment' agenda; examining the insider/outsider relationship, when the subject-object relationship between researcher and researched that occurs in conventional research is converted into a subject-subject relationship; and negotiating a community and social-change based feminist research project that is also located within the academy.

The research methods used in the project include a longitudinal focus group, focus group sessions and interviews that were audiotaped and transcribed, semistructured individual one-off interviews that were audiotaped and transcribed, journaling, drawing interpretation and a review of literature. 
The findings of this study demonstrate that the mother-adolescent son relationship is disrupted by marginalising and disenfranchising interventions and that these interventions disempower the mother. The research has shown that a major agent in the incapacitation of the mother-headed family is the lack of adequate resources available. The insufficiency of State support for the family intensifies these difficulties. The research has shown that the strength, confidence and enhanced self-esteem of the mother contributes positively to her ability to parent her adolescent son. The participants have also been able to demonstrate that the diversity of family and community structures can provide necessary and positive role models for male children.

By combining participatory action research with feminist research principles, the project also provides a transferable example of the ability of these two approaches to inform and enrich each other. 


\section{ACKNOWLEDGEMENTS}

Without the support and assistance of a number of people this thesis would not have reached completion. I would like to thank my supervisors, Alison Laurie and Professor Margaret Clarke for their academic challenge and support and believing that it could be done. I am grateful for the unreserved support of my colleagues within Te Kura Tu Tangata, the School of Social Sciences. I am thankful for the research grants provided by both Victoria University of Wellington and Waiariki Institute of Technology - Whare Takiura that enabled the fieldwork components to be accomplished. Others have contributed at specific times throughout the research. I would like to thank art therapist, Maureen Woodhouse, who supervised components of the drawing interpretation project; Dr. Celia Briar, who provided a combination of social policy analysis and harp music; Phillida Bunkle, who supervised the first year of the project before entering parliament; and Dr. Kay Morris-Matthews who provided essential contribution at the finishing stages of the project. I acknowledge those people whose expression is music and who have accompanied me unknowingly through countless long hours at the computer. I acknowledge also the many people who forwarded articles, references, data, and other useful material. I am indebted to Tony who spent hours turning this dissertation from an awkward manual tome into an automated production.

I acknowledge my dear and very special friends; Sonya and Barbara, who contributed long hours of last minute editing; Heather, whose wisdom and courage has contributed to this work; and Ann, who has supported me throughout its duration. I acknowledge Lardy, my lifelong friend and companion, whose own story as a mother of adolescent sons is inspiring; my parents and family who have lived through this work in numerous ways, my son's father, Roger, and Ben, a fine young man who embodies hope for this planet. Finally I recognise the group of mothers who participated in the project. Although I am unable to name them they will know who they are and when reading this will know how much I acknowledge their belief in me to carry this dissertation to its end. I look forward to the next stages we have planned together when we will work to disseminate this research in ways that are accessible to a wider audience. 


\section{TABLE of CONTENTS}

ABSTRACT ........................................................................................ it

ACKNOWLEDGEMENTS ......................................................................... lii

TABLE OF CONTENTS ……………………............................................. iv

LIST OF FIGURES ............................................................................... viii

LIST OF APPENDICES ............................................................................

METHODS OF REPORTING RESEARCH DATA .............................................

PREFACE - THE NATURE AND SIGNIFICANCE OF THE RESEARCH ..................... 1

THE NATURE OF THE RESEARCH PROBLEM .............................................. 1

THE SIGNIFICANCE OF THE STUDY ......................................................... 5

STRUCTURE OF THE DISSERTATION ............................................................ 8

PART ONE: INTRODUCTION ...................................................................

CHAPTER 1 - HISTORICAL AND CONTEMPORARY CONTEXTS .......................... 13

MOTHERHOOD AND ADOLESCENCE ...................................................... 13

HISTORICAL CONSTRUCTIONS OF MOTHERHOOD ...................................... 13

Definitions of Mother and Motherhood .......................................... 13

Mythical and Psychoanalytical Interpretations of the Mother ............. 15

Historical Developments of Motherhood as Institution ......................... 18

CONTEMPORARY CONSTRUCTIONS OF MOTHERHOOD ............................ 25

Contemporary Feminist Constructions of Motherhood ....................... 25

Contemporary Constructions of Motherhood by the State .................. 29

Fundamentalist New-Right Constructions of Motherhood .................... 31

CONSTRUCTIONS OF ADOLESCENCE ..................................................... 33

Definitions and Historical Constructions of Adolescence ................... $\quad 34$

Contemporary Constructions and Images of Adolescence and Adolescence and Mothers ............................................................ 37

Definitions of Adolescence for the Mother-Adolescent Son Project ...... $\quad \mathbf{4 0}$

CHAPTER SUMMARY ......................................................................... 41

PART TWO: THE RESEARCH ACT ................................................................

CHAPTER 2 - RESEARCH THEORY AND METHODOLOGY ................................ 45

THE CHOICE OF RESEARCH THEORY AND METHODOLOGY ........................ 45

The Relationship Between Participatory Action Research and Feminist Research ............................................................................ 46

The Feminist Participatory Action Research Model ............................ 48

THEORETICAL AND METHODLOGICAL CONSIDERATIONS ........................... $\quad 55$

Problematising Empowerment ..................................................... 57

The Insider/Outsider Dichotomy ..................................................... 63

The Academy - Community Continuum .......................................... 76

CHAPTER SUMMARY ....................................................................... 82

CHAPTER 3 - SPECIFIC RESEARCH PROCESSES .......................................... 85

DESIGNING AND IMPLEMENTING THE RESEARCH PROCESS ....................... 86

The Longitudinal Focus Group .................................................. 86 
Journaling ....

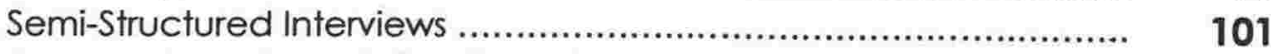

The Drawing Interpretation Project .......................................... 104

One-off Focus Group ........................................................ 109

LINK BETWEEN METHODLOGICAL OBJECTIVES AND RESEARCH PROCESSES

Empowerment of Women through Individual and Social Change .... $\quad 110$ Involvement of Participants in the Research Process ..................... 113

Benefits to the Participants of Involvement in the Project ............... $\quad 115$

Engagement in the Research Process ......................................... $\quad 117$

Using a combination of Research Methods to enhance Rigour ........ 117

Situating the Stories within Historical and Structural Contexts ........... $\quad 120$

COLLECTING THE DATA ........................................................... 120

Interviews and Focus Group Sessions ..................................... 120

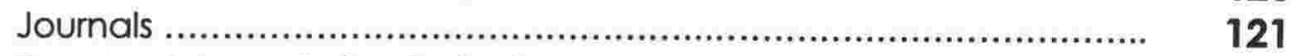

Drawing Interpretation Project .............................................. $\quad 121$

Review of Literature ....................................................... 121

COLLATING AND ANALYSING THE DATA ....................................... 122

Data Reduction and Display .................................................. $\quad 122$

Conclusion Drawing and Verifying ........................................ 125

VALIDITY AND CREDIBILITY ........................................................ 127

CHAPTER SUMMARY ............................................................. 130

PART THREE: THE RESEARCH FINDINGS .............................................. 131

CHAPTER 4 - THE MOTHERS AND THEIR SITUATIONS ................................... 133

WHO ARE THE MOTHERS? ......................................................... 133

The Longitudinal Focus Group .............................................. 133

Those Involved in Individual Interviews ..................................... 135

BACKGROUNDS AND BEGINNINGS ........................................... 137

SOCIO-ECONOMIC SITUATION FOR MOTHERS .................................... 143

Socio-Economic Status of the Mothers in the Study ........................ 144

Socio-Economic Status of Single Mother Families .......................... 146

CONTROLS IMPOSED BY PUBLIC SECTOR GROUPS ............................. 157

The Judiciary .................................................................. 157

The Social Welfare System ..................................................... 161

The Education Sector .................................................... 162

Mental Health Professionals and Agencies ............................... 164

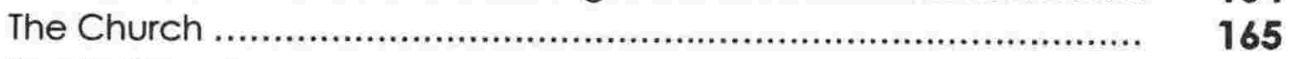

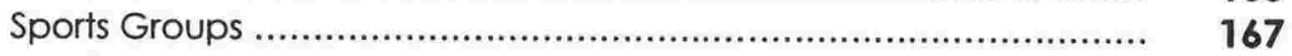

SPECIFIC SITUATION FOR LESBIAN MOTHERS .................................... 168

Lesbian Mothers as Parents of Sons ............................................. 171

Lesbian Mothers of Sons and Contacts with 'Other' Lesbians ............. 176

SPECIFIC SITUATION FOR SINGLE MOTHERS ....................................... 180

The Desire to Parent Effectively ................................................ 182

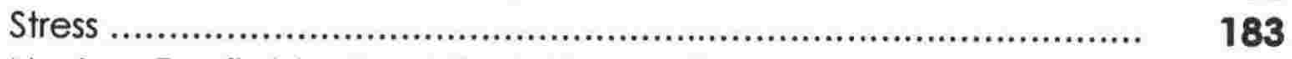

Nuclear Family Ideal and Single Parent Stigma .......................... 184

Disadvantages of Single Parenting ......................................... 186

Benefits of Single Parenting .................................................... 188

CHAPTER SUMMARY ............................................................ 191

CHAPTER 5 - MOTHERS, SONS AND FATHERS ........................................ 193

MOTHERS TALK ABOUT THE SONS ..................................................... 193

The Nature of Mothers' Relationships with their Sons ...................... 193 
Mothers' Perceptions of their Son's Attitudes Toward Them .............. 196

Disruption to the Mother-Adolescent Son Relationship .................. 198

Mothers Discuss their Sons and Friendships ............................... $\quad 210$

Mothers Discuss their Sons and Body Image ............................... 211

Mothers Discuss their Sons and Education .................................. 213

Mothers Discuss their Sons' Physical Changes and Sexual Awareness 216

Mothers Discuss their Sons and Alcohol, Drugs, Safety and Suicide ... $\quad 217$

Mother's Hopes for their Sons ................................................. 225

Mothers Views of the Ideal Situations to Raise Sons ....................... 225

Parenting Strategies in the Mother-Son Relationship ..................... 228

MOTHERS TALK ABOUT THE FATHERS ............................................. 232

Mothers Discuss the Father-Son Relationship ............................... 233

Custody, Access and Related Financial Issues .......................... . 239

Fathers and Parenting Support ................................................... 241

MOTHERS TALK ABOUT THE SIGNIFICANCE OF BROTHERS .................... 242

CHAPTER SUMMARY .................................................................... 243

CHAPTER 6 - THE BOYS' STORY, THE DRAWING PROJECT ........................... 245

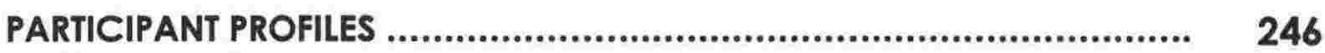

The Schools ......................................................................... 246

The Geographical Area ....................................................... 247

METHODS OF DATA COLLECTION ................................................. 247

ANALYSIS ONE: DOMINANT, CONNECTED, INSIGNIFICANT AND INVISIBLE 257

Categories of Analysis One ................................................... 257

Findings of Analysis One ..................................................... 265

ANALYSIS TWO: FAMILY-AS-ANIMALS DRAWINGS ............................. 267

Categories of Analysis Two ..................................................... 268

Findings of Analysis Two ...................................................... 269

ANALYSIS THREE: COMMENTARY ON KINETIC-FAMILY AND FAMILY-AS- 276

ANIMALS DRAWINGS

Themes from Drawing Commentaries ................................... 277

Findings of Analysis Three .................................................. 296

IIMPLICATIONS OF FINDINGS AND THE LINK WITH THE MAIN PROJECT ...... 297

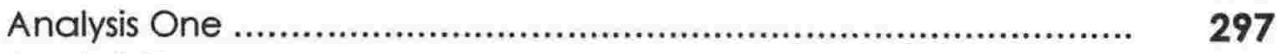

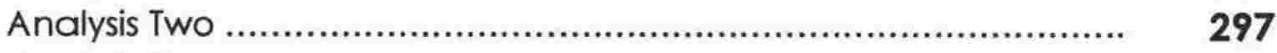

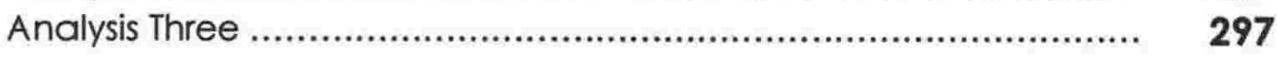

CHAPTER 7 - FATHERLESSNESS AND MASCULINITY .................................... 301

FATHERLESSNESS AND FATHER ABSENCE ........................................ 301

The Mothers' Voices ................................................................. 302

The Sons' Voices ................................................................... 307

The Fathers' Voices ............................................................. 309

Analysis of the Father-Need Discourse ................................. $\quad 312$

MASCULINITIES $\quad 315$

The Masculinity Dilemma for Mothers ...................................... 317

The Initiation of the Sons into Manhood ................................... 319

CHAPTER SUMMARY ................................................................... 324

CHAPTER 8 - THE UNDERMINING OF THE MOTHER ................................... 325

UNDERMINING OF THE MOTHER $\quad 325$

Undermining by the Fathers ................................................. 325

Undermining by the Sons ......................................................... 328

Father/Son Collusion in the Undermining of the Mother ................. 330

Undermining by 'Society' ........................................................ 331 
Mothers Undermining of Themselves

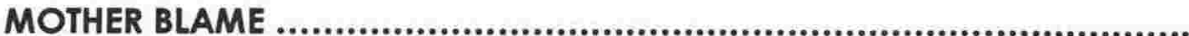

Blame by 'Society' ............................................................. 342

Blame by Professionals ..................................................... 343

Blame by Sons ............................................................... 344

Blame by Fathers .......................................................... $\quad 345$

Blame by Family ........................................................... $\quad 345$

Self Blame ................................................................. 346

CONFIDENCE AND SELF-ESTEEM ISSUES ....................................... 347

Factors that Diminished Mothers' Confidence ............................. $\quad 347$

Factors that Enhanced Mothers' Confidence ............................ 349

Link Between Confidence and Effective Parenting ....................... 351

THE NEED FOR SUPPORT STRATEGIES ............................................. 352

Friends and Family .............................................................. 353

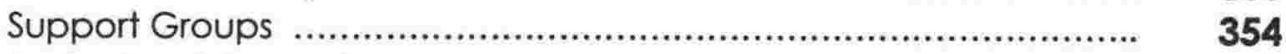

Professional Support ............................................................. 355

CHAPTER SUMMARY ............................................................ 356

PART THREE: THE RESEARCH CONCLUSIONS ............................................ 359

CHAPTER 9 - RESEARCH FINDINGS, LIMITATIONS, STRENGTHS AND FUTURE DIRECTIONS

OVERVIEW OF THE RESEARCH PROJECT ......................................... 361

Purpose of the Research ........................................................ 361

Rationale for the Research ................................................. 362

The Research Context ........................................................ 362

The Research Participants ....................................................... $\quad 362$

Methodological Objectives and Research Processes .................. $\quad 364$

Data Analysis ............................................................... 364

LIMITATIONS AND STRENGTHS OF THE RESEARCH PROCESSES ................... 365

Longitudinal Focus Group - Limitations and Strengths .................. 366

Semi-Structured Interviews - Limitations and Strengths .................. 368

The Drawing Interpretation Project-Limitations and Strengths ....... $\quad 369$

Limitation of Involvement in Academic Research ......................... $\quad 371$

Validity Scoping for the Project as a Whole ............................... 371

SUMMARY OF FINDINGS AND IMPLICATIONS .................................... 373

The Impact of Socio-Economic Factors on the Mother-Adolescent Son Relationship

The Impact of Historical and Contemporary Constructions of 'Motherhood' and 'Adolescence' on the Mother-Adolescent Son Relationship

The Impact of Fatherlessness on the Mother-Adolescent Son Relationship

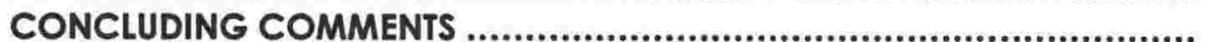

APPENDICES 


\section{THE NATURE AND SIGNIFICANCE OF THE \\ RESEARCH}

\section{THE NATURE OF THE RESEARCH PROBLEM}

In February 1995, a woman sat in a courtroom before a family court judge and beside, but not too close to, her estranged husband. Somewhere, out in another world, was the son they both loved dearly and for whom they could not together decide a future.

This eleven year old boy had lived with his mother since he was born and with both parents for the first eighteen months of his life. Holidays and weekends in every year since had been times for visits with his father. Now this geographically separated family was faced with the decision about the boy's future. The father, although recognising the sound beginning that had been given to his son, felt he could offer this boy what he now needed to continue his life as a young man. The mother, although recognising the crucial part the boy's father played in the boy's life, was convinced that the richness and diversity of the community that had been built up around and by her son was too important to give away.

The son? The most difficult part for the son was that, as his parents could not agree, he had to make a decision that most children were not faced with until much older. The dilemma for him was not so much where he wished to live, but that he had a choice. It was fortunate that both parents supported him no matter what he decided to do and that the professionals who worked with him were skilled at their work, most of the professionals that is. The judge presiding over the family court fell short of demonstrating an 'unprejudiced' judgement. As he summed up at the end of the hearing he stated to both parents and others listening that he was concerned that the current generation of boys was being raised by women. He then proceeded with a pointedly sententious homily.

This is my story and from it the mother-adolescent son research project was conceived. Having raised my (now) sixteen year old son on my own from the time he was twenty months old I have been interested in the increasing social phenomenon of the single family, and more particularly those situations where 
women raise boys. I have not been able to take an impersonal stance toward this position. My own sensibilities as a mother, and my upbringing as a reasonably conventional middle class woman, has often left me with some guilt as I have pondered over the possible impact my single parent status could have been having on my son; what gaps, what disadvantages were being created in his life as a result.

My situation as a single mother of a boy became problematic at the point where the challenge to my involvement as the prime caregiver of my son was made public. As he reached his intermediate school years an application for custody of him by his father appeared before the court. This process brought with it an actualisation of what for me had previously been intellectual and generalised musings. During the hearing the judge, appointed to act without prejudice, questioned the appropriateness for me as a mother to raise my eleven year old son. This was not because I was an incompetent parent, nor because the young man was having difficulties, but because I was his mother. This statement from the judge offered no strategy or useful way forward. In his mind the only way I, as a single mother, could parent this young man as he reached adolescence was to separate from him. Ironically appreciation must be given to this, now retired, judge. If it were not for his announcement on that day this research project would not have taken place. The issue that was raised at that time, my sense of marginalisation and disempowerment as a single mother of an (almost) adolescent son, became the research problem. The strength of the judge's concern, and its being raised in such a way (as the facilitator in a mediation conference between my son's father and me), began for me a desire to investigate the issue further: its history, its foundation, how wide-spread it was, how it manifested itself, and what impact it was having on mothers and on the relationships between mothers and their sons.

I discovered that this experience was not uncommon. I have worked in tertiary education with women for twenty years. Some of them had expressed anguish, uncertainty, anger and much frustration with the attitude of people around them to their status as single mothers, particularly in relation to raising boys. The stories from these women had revealed several themes: a concern to 'do the right thing', the doubt they began to have in their ability to parent as their sons grew older, the 
pressure some felt from the sons' father for increased if not total involvement with their sons, the invalidation of themselves as they were socially isolated while supporting their sons in male-dominated arenas and the financial struggle to provide for their son's growing needs often against the background of a more affluent father. Initial talking with some of these mothers, reflecting on similar situations and reading preliminary literature lead me to believe that other mothers experienced similar feelings of marginalisation, disempowerment and invisibility. Furthermore, I gained the impression that the marginalisation of mothers also impacted negatively on the sons.

From my early reading I also began to realise that to describe any family structure other than that of the nuclear family as viable was going to be a difficult task, even more so to discuss the role of mothers raising sons as potentially positive. In developing this research project I have had to define its scope in order that it may be manageable and therefore I have discounted some avenues I could have taken. It has been tempting to want to investigate what is best for boys. Surely my son would have benefited from that. However I realised that I needed to leave this outside the brief of the research as it fitted more appropriately in the domain of the child developmentalist and child psychologist. I also resisted the temptation to examine the concern as it was expressed through all stages of a boy's life, and have focused on the adolescent years. This is the time, it has seemed, when the role of mothers in the raising of boys is principally challenged.

The research objective was developed from this initial exploration of the problem. The objective was to investigate the mother and adolescent son relationship in Aotearoa New Zealand, the interventions to the relationship and the impact of these interventions on the mother and on the son. It was hoped that the investigation would achieve several goals. The first was that it would give rise to a more in depth understanding, or at the least a recognition of the problematic of the mother-son relationship and the pressures on it, in order that practitioners and policy-makers would be more fully informed. The second was to involve mothers who were also experiencing marginalisation and disenfranchisement as mothers of adolescent sons in the investigation in order that their own situations would be enhanced. 
Once the objective and goals of the research were formed, and as part of the thesis proposal, I undertook an initial exploration of the literary basis on which the issue was grounded. I explored the works of several theorists who made a strong case for the need of a 'present' father. Jungian analysts, Corneau (1991) and Pedersen (1980), discussed the absent father in psychological terms. They argued that a boy's separation from the mother and his identification toward the father was necessary for his development into adulthood. I read Sigmund Freud's work, particularly in regard to the Oedipal syndrome. Although his theoretical formulations were framed in the context of a Victorian society of a hundred years ago, his ideas have had powerful influence throughout the century on contemporary understandings of mother-son and father-son relationships. I also read the work of psychologist, Bruno Bettelheim (1984), who likewise invests much importance on the presence of the father.

I reviewed the findings of two Australian research projects that looked at the role of fathers in the family. One of these projects, by Russell (1983, cited in Bassof 1995), challenged the traditional stereotypical view of fathers. In doing so, however, he reinforced the dominance of the nuclear family structure by stressing the equally important roles of mother and fathers in childrearing. The other project, by Wilson (1990), investigated single-father families. As part of his analysis he challenged the work of child development theorists such as Bowlby, Jolly, Parsons and Spock who have portrayed the nuclear family as a prerequisite for the healthy social development of children. In affirming the single-parent family as valid, Wilson asserted that fathers could substitute the mother role by managing a primary care giving role with their children. Fathers, he contended, are "as competent as mothers in meeting the basic needs of infants" (1990, p.133). Wilson attempted to use the arguments of feminist writers such as Frieden and French, against the motherhood myth, to support his claim that "many men have motherly qualities" (1990, p.133) and can therefore replace women in the childrearing process. By making the claim that mothers and fathers are interchangeable, Wilson supports the argument that a mother could also provide the basic requisites for a young person's healthy development. The task, for this project was not to argue the case for the replacement by women and men of each other in the process of child rearing but to investigate the concern that boys raised by women will, because of that fact, be disadvantaged. 
The methodology selected to deal with the research problem was feminist participatory action research, which is discussed fully in Chapters Two and Three. As part of the first stage in participatory action research cycle, the reconnaissance stage (Figures. $2.1 \& 2.2$ ), initial reading, talking with mothers of adolescent sons and reflecting on my own experiences highlighted the following questions:

- Is it necessary for a boy to separate not only from his mother, but also to downgrade her and her world, in order to develop into a healthy adult male?

- Is the mother seen as separate from the public predominately male world and therefore incapable of providing the stimulus and knowledge to support him to be part of this world?

- What is the agenda for the expression of father-need and the concern about fatherlessness and father absence?

- What impact does the public concern about fatherlessness have on the mother and on her ability to parent?

- What impact does the public concern about fatherlessness have on the son?

These questions provided background points of reference throughout the remaining research cycles.

\section{THE SIGNIFICANCE OF THE STUDY}

This research project is about the mother-adolescent son relationship, a relationship that is fraught by the conflicting agendas discussed above. Throughout time motherhood and the role of the mother has been constructed predominately by social and economic requirements. Although a definition of adolescence as a construct seems tenuous, it does seem to be a period that is difficult for mothers and sons. Current health, education, crime, accident and suicide statistics in this country seem to suggest that young males, in particular, are having difficulty. An analysis of Aotearoa New Zealand society shows that women, with or without the fathers, are raising the majority of young males. It 
also seems clear that the attack on the mother-adolescent son relationship has intensified during the past two decades.

This research has significance in three respects. Firstly, it is the only piece of academic work that has been undertaken in Aotearoa New Zealand and, as far as I know, in the world that has addressed the issue of the marginalisation and the undermining of the mother of adolescent-sons. It has occurred at a time when a principal explanation for the negative statistics surrounding adolescent males throughout the Western World, the United Kingdom, Canada, the United States of America, Australia and Aotearoa New Zealand, is fatherlessness. Those making these claims public are predominately male professionals in education, welfare, mental-health and justice, right wing political parties, church groups and the fathers themselves. The mothers' voices have not yet been heard in any significant way. It is hoped that the ongoing dissemination and publication of material from this project, and continued research in the area, will allow mothers' perspectives to contribute to the debate. I believe these stories have needed to be written. The women involved deserve validation of who they are as mothers. Institutions such as education, justice, health and social welfare, need to rethink the reasons for their concern about mothers raising sons. The diversity of family and community structures can provide necessary and positive role models for male children. Mothers, just because they are women, do not become inadequate caregivers as their sons reach their adolescent years.

Secondly, the project by amalgamating participatory action research with feminist research principles, has developed and tested a research methodology that has, to date, not been commonly used. (This discussion occurs in Chapter Two). As the research has progressed, papers on both content and research methodology and process have been generated (Appendix Preface 1). Although most of these include conference presentations, and subsequent publication in conference proceedings, three have been as a result of invitations to contribute to refereed publications.

The third, and maybe most important, area of significance of the research has been for participants. Discussion about the benefit to the participants, and whether the personal and collective objectives they had for being involved in the project have 
been met, is reported in Chapter Three. As one of the participants, this research has also had personal significance. Participants were involved to the extent that they were able. My own contribution was quantitatively larger than that of the others and my own gain from the project was also larger. Although we all shared the objectives, an added objective for me was the potential achievement of a doctoral degree. On a personal level the research has contributed to the decisions I have made, and the options I have chosen in my years as a mother to an adolescent son. I believe it has also impacted on my son. An early personal journal entry illustrates my wondering about the effect of this impact.

What will happen to [Son] in the middle of all this? Will the focus on 'our situation' accentuate its differences? Will it make him self-conscious? Whilst I work on the computer, or in my mind, the research is relatively invisible to him. However beginning the fieldwork and bringing mothers and sometimes their sons into our house gives it tangibility. (Personal Journal, October 17, 1996)

Now, five years later, I can only be thankful for the life that we have shared. Whether because of the research, or despite it, this child has grown into a fine young man who will doubtlessly challenge the inequities between women and men in his world.

My own background as researcher is as a white, middle-class, lesbian mother from Aotearoa New Zealand with an adolescent son. This project has, by necessity, reflected my own values. The women involved have come from both Maori and Tauiwi' backgrounds. The re-telling and analyses of their experiences has been through a facilitated and collaborative process. It is hoped that the research methods used have allowed the participants to have as much control as possible over the processes and the outcomes of the project. If this has indeed been so then maybe they will have had more control over what choices have existed for them and maybe a generation of boys will mature with respect and admiration, not only for the women that have gone before them, but also for the women with whom they share their worlds.

\footnotetext{
${ }^{1}$ Tauiwi, in this context, refers to citizens of Aotearoa New Zealand who are not Maori.
} 


\section{STRUCTURE OF THE DISSERTATION}

The preface has offered an introduction to the research problem and discussed its significance at three levels; its contribution to a unique problem, its use of two distinct research methodologies that are uncommonly utilised in combination and its personal significance to the participants.

The remaining research project is reported in four parts and includes nine chapters. Part One offers historical and contemporary contexts to the two main constructs contained in the research question, motherhood and adolescence. These contexts have not only directly and indirectly pervaded the research activities but they also offer a framework within which the issues have been addressed. Part Two explains and discusses the research theory and methodology that has informed and underpinned the project. Chapter Two examines the choice of research methodology used for the project and discusses key theoretical and methodological considerations. Chapter Three outlines the specific research tools used in the development and implementation of the project and in the collection and analysis of data. It explores the credibility and validity of the research processes and identifies the likely sources of error and bias.

Part Three has been divided into five chapters, each representing a component of the research findings. Chapter Four provides an overview of the mothers who were involved in the project. It outlines the issues for them as a whole group and then looks separately at those issues that relate to two specific groups, lesbian mothers and single mothers. In Chapter Five the mothers describe their relationships with their sons and the perceptions they have of their sons attitudes toward them. They explain the disruptions they experience to their relationships with their sons. The mothers discuss also their perceptions of their sons' lives and outline the fears, concerns and hopes they have for them. They ponder about the ideal situations to raise their sons and offer their thoughts about the place of male role models. In Chapter Five the mothers also turn their attention to the fathers by considering the father-son relationship. They highlight some of their own issues in relation to the fathers, such as custody, access and related financial issues in separated situations and parenting support. The chapter ends by mentioning another family dynamic, that of the significance of (particularly) older brothers. 
Chapter Six focuses on the results of an interpretive drawing project and highlights the perceptions of boys toward their mothers, their fathers and themselves. Chapter Seven examines fatherlessness as articulated by the mothers, the sons and the fathers and analyses the discourse that surrounds 'father-need'. It touches on the masculinity dilemma for mothers and sons and leads on to Chapter Eight, which describes the major impacts of these constructs on the mother. Chapter Eight also examines the effects of the undermining and blaming of the mother on her confidence and self-esteem and suggests support strategies outlined by the mothers.

Part Four concludes the thesis with a summary of the research findings, the limitations and the strengths of the research and possible directions for future research. All appendices are listed at the end of Part Four and are followed by a list of references that have been used directly, and indirectly, throughout the work. 


\section{Part 1}

INTRODUCTION 


\section{CHAPTER 1}

\section{HISTORICAL AND CONTEMPORARY CONTEXTS}

\section{MOTHERHOOD AND ADOLESCENCE}

Chapter One establishes the historical context for the research project by looking at the constructural development of motherhood and adolescence. The first section examines the primacy and the fall of the mother according to mythical and psychoanalytical interpretations. It discusses the historical development of motherhood as an institution during three chronological periods: pre-nineteenth century, the nineteenth century and the twentieth century. It follows with a discussion of contemporary constructions of motherhood. The second section overviews historical accounts of adolescence and discusses some of its contemporary expressions.

\section{HISTORICAL CONSTRUCTIONS OF MOTHERHOOD}

\section{Definitions of Mother and Motherhood}

Although constructing meaning using differing explanations, most feminist theorists address the concept of 'motherhood' in one, or both, of two categories, the biological and the social. Socialist feminist, Diana Gittens (1994, pp.67-74), suggests that biological motherhood is the carrying of, and giving birth to, a child from which moment motherhood becomes socially constructed. Adrienne Rich (1986), instrumental in advancing analyses about motherhood with her book, Of Woman Born: Motherhood as Experience and Institution, identifies two categories of motherhood. The first category, she suggests, involves "the potential relationship of any woman to her powers of reproduction and to children" and the second category, "the institution, which aims at ensuring that the potential - and 
all women - remain under male control" (1976, p.270). Feminist theorist, Rosemarie Tong, stresses the need to distinguish categories and definitions of motherhood in order that issues of status and function can be deconstructed and theorised. She challenges socialist feminist, Alison Jaggar, for example, who defines mothering as "any relationship in which one individual nurtures and cares for another" (1995, p.84) for making invisible the biological dimension of motherhood (1995, pp.84-94). Paula Nicolson, Senior Lecturer in Health Psychology at the University of Sheffield, suggests that concepts of motherhood are amplified by "popular and powerful belief systems surrounding the notion of 'maternal instinct"' (1997, p.383). Maternal instinct, she argues, is a socially constructed myth defining women's identity from childhood.

Socialist feminist, Natalie J. Sokoloff (1984, pp.259-266), defines motherhood as the work of bearing and rearing children and as an institutional experience organised by patriarchal Western capitalism. She explores the physical (housework) and emotional (nurturing) work of women in the home, termed by Jessie Bernard (1974) as "motherwork", and relates it to the paid workforce. Sokoloff argues that the types of employment traditionally chosen by women and the expectations of women to 'mother' men at work is derivative of an institutionalising of motherhood. Her argument at this point differs with that posed by Jaggar who maintains that the concept of motherhood cannot be converted from the private to the public sphere. For all the similarities, Jaggar argues, between mothers in paid work and mothers in the home, "exploited workers do not suffer in the same way as oppressed wives" (as cited in Tong, 1995, p. 64). Heidi I. Harmann (1984, pp.341-357) addresses the concept of motherwork using a Marxist-feminist analysis, extending Jaggar's argument by considering the family as a place of struggle, as a "location where production and redistribution takes place" (1984, p.342). She highlights the outcomes of time-use surveys carried out in the United States that demonstrate the role of mother and wife as one that benefits the patriarchal societal structures by doing, on average, seventy percent of the housework and the majority of childcare (1984, p.53).

However defined, motherhood has an impact on women's lives. An idealised view that motherhood is the most important job in the world co-exists alongside the often-disdainful images of mother and motherwork. Roziska Parker (1995) 
overviews the motherhood dilemma by describing women's experiences of being caught up in the contradictions and constraints of motherhood, the ambivalence about their role as mothers, their children and the limited power allowed them by patriarchal society. Most theorists mentioned above also recognise the impact of the institution of motherhood on those women who may not fit the biological category of mother by bearing their own children.

\section{Mythical and Psychoanalytical Interpretations of the Mother}

Further explanations of motherhood have been presented through psychoanalysts, Jungian analysts and mythologists such as J.J. Bachofen (1861), Bruno Bettleheim (1976) Robert Briffault (1927), Joseph Campbell (1959), Sigmund Freud (1913) and Erich Neumann (1949 \& 1955). The works of these men have been interpreted by feminist writers Judith Arcana (1984), Barbara Ehrenreich \& Deirdre English (1979), Adrienne Rich (1986), and Olga Silverstein (1994) in the development of discourse around the primacy and the fall of the mother. The following section offers an overview of these interpretations.

Rich contends that "throughout most of the world, there is archaeological evidence of a period where Woman, was venerated in several aspects, the primal one being maternal". "Goddess worship prevailed," and "myths depicted strong and revered female figures" (1986, p.93). Feminist Christian, Catherine Chrisp (1999), in her unpublished text, Travelling with Sophia, suggests that at the arrival of the Hebrews in Canaan (1200BC) there were cycles of worship that included goddesses. Archaeological evidence, she contends, has uncovered confirmation of this in the form of icons, artefacts, shrines and sanctuaries that depict the mother. Rich's earlier work supports this contention suggesting that "prepatriarchal religion acknowledged the female presence in every part of the cosmos" (1984, p.107) and that out of "the earth-womb vegetation and nourishment emerged, as the human child out of the woman's body" (1986, pp.107-108).

Arcana makes reference to accounts of the Great Mother, the creator, from Egypt, Ua Zit, from India, Shakti, from Sumer, Ama Tu An Ki, from Greece, Nikta, from North America, Sussustanako, from Britain, Danu, from Babylon, Aruru and from China, Nu Kwa (1984, pp.83-185). Worship of these manifestations of the Great 
Mother was not opposite to that of father worship, Arcana argues, but it recognised the Mother as the source of life and death. Rich, overviewing Joseph Campbell's work on primitive mythology quotes says "the fear of menstrual blood and isolation of women during their periods, rites of birth and all the lore of magic associated with human fecundity" (1986, p.103) created a mystery of motherhood that was profound. Briffault, Rich suggests, attributes men's belief in the danger and the mystery of woman to the prohibitions imposed on them by women during menstrual and childbirth taboos. This position is supported by Neumann who accords the creation of the first human culture to the domestication of the male through these exclusions.

The fear produced by these beliefs, according to Rich's interpretation of Neumann's analysis, signifies a link between the periods of matriarchal worship and the breakdown of the Mother-God. The male, (as cited by Neumann in Rich, 1986, p.118). wants the mother "for his emotional sustenance even while somewhere within him he fears castration and death at her hands. ... Patriarchy is by nature always trying to 'kill the dragon' in its negation of women" Rich extends this historical analysis to relate it to the chronological development of the human. When the father asserts his paternity, she claims, "we begin to see emerging the process through which he compensated for - one could say, took revenge for - his previous condition as son-of-the-mother" (1986, pp.118-119).

Arcana argues that the demise of the ancient worship of the Mother came with the "father-god and trinity of the Judaeo-Christian era in the West" (1984, p.186). The Old Testament, she suggests, "explains in detail how the priests of Yahweh, the father God, attempted to eradicate the old religion ... and how they created a new morality based on father right and the concept of women and children as their property" (1984, p.187). "The old trinity of the goddess, the three-faced Hecate of the triple crossroad (Maiden, Mother and Crone)," Arcana writes, were adapted to become the "three male personalities to cover all the manifestations of the new male god" (1984, p.189) which was reflected in the stories of the time. American therapist, Olga Silverstein, citing Campbell maintains that, "mythologies are all conditioned by ... social necessity" (1994, p.9). Previous legends and stories of ancient societies had reflected societal cultures by telling of the worship of the Mother. Likewise tales were created that reflected God, the father. 
Patriarchal monotheism, Rich claims, "stripped the universe of the female divinity and permitted woman to be sanctified ... only and exclusively as mother (1986, p.119). Arcana overviews the rise of Christianity out of Judaism, which, she poses, "runs parallel to and blends with the rise of the male influence in the old religion itself" (1984, p.188). She tells the story of Vashti, the queen of the early patriarchal king, Ahasuerus, who was deposed and banished for not obeying her husband and was replaced by Esther, worshiper of the father god. She describes also the status of the Madonna who continues to be worshipped - but only as the mother of a god, and one whose sexual powers have not been aroused through the physiological mysteries of conception $(1984$, p.190). Neumann in an essay called Psychological Stages of Feminine Development (as cited by Rich, 1986, p.111) maintains that women and femininity are accused by patriarchal cultures, such as Judeo-Christianity, Mohammedanism and Hinduism, of being the carriers of evil.

Silverstein offers a version of the story of the Greek hero, Orestes who, when accused of matricide, is defended by Apollo who claims, "the mother is no parent of that which is called her child," merely "nurse of the new planted seed that grows" (1994, p10). She suggests that the rejection of, not just the individual mother, but also the principle of mother itself is, a symbolical way of ridding oneself of all feminine influences. "The feminine, Apollo is telling us," says Silverstein, " is no natural part of man. That ... is the real meaning of mother denial" (1994, pp.10-11). According to Mycean myth, interprets Rich, Apollo had to defeat a female dragon before he could enter Delphi, which became his shrine (1984, p.118). In Sigmund Freud's highly publicised story of Oedipus, he demonstrates the need of the son to overcome the mother. As argued by Silverstein, it was "neither [Oedipus] nor his mother who set the train of tragic events in motion, but his father by choosing to sacrifice his son's life to preserve his own" (1994, p.11). Arcana continues the theme of the dominance of the son over the mother, tracing it "through legends in which the hero (son) mocks, challenges, sometimes rapes and finally kills the mother, who is queen, priestess and goddess" (1984, p.192).

Silverstein uses the story of a more contemporary fairy tale, Hansel and Gretel, one of a series in which women are passive figures waiting deliverance by a man such as, Snow White, Cinderella, Sleeping Beauty, Rapunzel, to illustrate a 
further way in which the mother figure is exterminated. She uses the lessons in this story to illustrate five morals put forward by these fairy tales. The first, that bad women control good men, the second, that bad women seduce helpless children, the third, that women feed on young boys, the fourth, that the young girl triumphs over the older woman (witch) and finally, that the father and children would be happy if they could get rid of the (step) mother (1994, p.13).

Ehrenreich and English offer a detailed account of the persecution of women in their roles as wise women, healers and midwives in the fifteenth to twentieth centuries (1979, pp.29-88). During this period, they claim, the Church, in association with the State, both of which controlled the training and practice of medics, saw to it that womanhood was systematically stripped of one pivotal function, the intimate involvement in the cycle of birth, life and death.

In her summation of the fall of the mother Rich argues that the creation of the patriarchal family has violated the fundamental human unit, the mother and child. "Woman in her full meaning," she declares, "is domesticated and confined within strictly defined limits." As the maternal "she remains an object of mistrust, suspicion, misogyny in both overt and insidious forms. And the female generative organs ... have become a prime target of patriarchal technology" (1986, p.127).

\section{Historical Developments of Motherhood as Institution}

Although the divisions between mythical and historical interpretations are not always succinct, a separate examination of the history of motherhood is important to the context of the mother-adolescent son research project. Marxist-feminist, Ann Ferguson (1997, pp.39-60), offers an historical explanation of the development of motherhood as an institution from a material feminist approach. She builds her examination on the relationship between three dominant systems economic class, racial/ethnic and sex/gender. Although she situates her discussion within American history, Ferguson offers a useful framework for an analysis of the development of motherhood across the Western world. She breaks her examination into three chronological periods; father patriarchy (pre-1800); husband patriarchy (1800-1900) and public/capitalist patriarchy (1900 - 1980). These three periods provide a structure for the remainder of this section. 
Relations between men and women during the father patriarchy period, Ferguson claims, were characterised by "a combination of economic, political/legal and childbearing structures in which the father owned property and dispensed it at will to his children, the land to sons and a lesser dowry to daughters" (1997, p.49). The father maintained his dominance through the dispensing of property and his status as the religious and moral head of the household. Ferguson's claims are supported by Rich who argues that "the core of patriarchy is the individual family unit which originated with the idea of property and the desire to see one's property transmitted to one's biological descendants" (1976, p.272).

Father patriarchy in America, according to Ferguson, began with the settlement of white Europeans, primarily English religious puritans, who established a mode of agricultural production based on family households. The pattern was similar, although occurring slightly later, in Aotearoa New Zealand. The household produced primarily for its own use and couched the pragmatic reality of producing children to continue the economic unit as the 'sacred calling of mother' (Rich, 1986, p.43). The high mortality rate meant that large numbers of children needed to be born to ensure enough live adults to maintain production. Motherhood did not exist as a vocation. Women carried and raised children while contributing to productive labour. Although biologically these women were mothers, they were uninvolved in mothering as an act of socialisation. Ferguson suggests that women had little power over raising children and proposes several reasons. Firstly, children at around seven years old were sent to work and live on relatives' farms. Secondly, although the fathers were not involved with their children, they remained in control of the ideology of parenting by being involved in 'breaking of the will' practices. Thirdly, early weaning at the arrival of the next child severed any development of the first stages of mother-child bonding (1997, pp.49-50).

By the nineteenth century, according to Rich,

voices rise against the working mother and in praise of the 'mother at home'. These voices reach a crescendo just as technology begins to reduce the sheer level of physical hardship in general and as the size of families begins to decline. ... The idea of full-time, exclusive motherhood takes root, and the 'home' becomes a religious obsession. (1986, p.44) 
Ferguson describes the second period, husband patriarchy, as a time when the shift from rural production to commercial and industrial capitalism instigated a "new ideology of motherhood ... the moral motherhood/cult of domesticity" (1997, p.51). Although Ferguson and Rich seem to agree that there was a shift in the concept of motherhood, their explanations vary. Ferguson argues that the changes occurred in a complicit relationship between the State, that was endeavouring to arrange the public and private spheres, the Church, that wished to enhance woman's moral character by raising spiritual status and middle-class women, who sought to gain greater power than they had enjoyed as mothers in the previous period (1997, p.51). Marxist, Frederick Engels (as cited in Rich, 1986, pp.110-112), maintains that the domestication of motherhood was part of the ideology of private ownership and male economic supremacy and that the ultimate moving power of all historical events is economic development of the society and the struggle of classes against each other. Rich challenges the masculine bias of Engel's analysis, but it appears she agrees with his perspective that changing economic ideologies and structures impacted on the separation of roles and on the exploitation and ownership of the mother as private property Anthropologist, Robin Fox (as cited in Rich, 1986, p.113), argues that the changes in motherhood ideology stemmed from the basic female function. The gestation period required by women and the preoccupation with bearing and nurturing children necessitated "a system whereby the mothers, thus incapacitated, had to be protected"

Both Rich and Ferguson recognise the differences for groups of women in the actualising of their roles as mothers during this period. Whilst it could seem, they suggest, that white middle-class women benefited from the domestication of motherhood, working-class women were forced for economic reasons to work outside the home (Ferguson, 1997, pp.53-54; Rich, 1986, pp.41-55). Sokoloff supports this by arguing that motherhood as a full-time ideal was class and strata based. "The ideal women's role", she maintains, was "exemplified by the wives and daughters of entrepreneurs and capitalists" (1983, p.261). Working class women worked for long hours, leaving children home "in the care of a six, or seven, year old daughter, a grandmother or a neighbor's hired child" (Rich, 1984, p.48). Ferguson points out the ironical position for white working class families who, whilst working to contribute to the family income, seemed to sanction the concept of moral motherhood as well. She cites an explanation argued by socialist 
feminist, Heidi Hartmann (1981), as rationalisation for this. According to Hartmann, late nineteenth century trade union movements (composed of male members) attempted to create a family wage in order to cut competition from women wage workers and to enable men to keep wives at home to provide services that made it possible for them to continue to be employed. Women were warned that absence from home caused harm to children and that, if they failed to provide comforts at home, their husbands would go elsewhere.

For working mothers Rich explains, "as public opinion became aroused over the fate of children whose mothers worked in mills, efforts were made to set up nurseries $^{1 "}$ (1986, p.49). Strong opposition from State, and Church-supported moral motherhood ideologues, frustrated these efforts on the grounds that nurseries would violate the "sanctity of the domestic hearth" (1986, p.49). Sokoloff describes "the responsibility of women as full-time wives/mothers/homemakers" as "a uniquely twentieth century construct"; an attempt by "male owners of industry, male workers and male-dominated unions in the $19^{\text {th }}$ and $20^{\text {th }}$ centuries to make work 'men's work' and the unwaged sphere as 'women's work"' (1983, p.259). The role of the state in this transition was to pass legislation protecting men as wage earners, child labour laws and to create the family wage. Women, according to Sokoloff, did not simply give up their traditional roles. She suggests that there were three fundamental elements of the new ideology that women needed to accept. Firstly, that children require full-time adult attention. Secondly, that women are especially equipped to provide this care for children and by doing so enable their husbands to continue work outside the home and thirdly, that the rewards woman reap are derived from this worthwhile work (1984, p.260).

The third and current period, public/capitalist patriarchy, is, according to Ferguson, predominately influenced by welfare state corporate capitalism (1997, p.54). The advent of the consumer economy, she suggests, has meant that mothers no longer undertake tasks traditionally associated with mothering work, such as,

\footnotetext{
${ }^{1}$ The Rudolph Steiner education structures that are still operating around the world were set up as a result of his concern about the children of cigarette factory workers in Germany.
} 
sewing, cooking, cleaning and looking after dependents. The public school system has taken children away from the home for longer periods of time and has had an increasing role in the development and socialisation of them. Suburban living patterns and individual ownership of houses separate households. Rich (1986) and Ferguson (1997) both describe the loneliness of 'housebound' mothers as a new phenomenon that has developed from this period due to their separation from networks of other women.

Shifts in social emphases during the early stages of the twentieth century also meant that children were handed to state education structures for increasing periods of time and that women were precluded from being occupied on a full time basis raising them. Incongruously, they were also not encouraged to work outside of the home. Instead the increased amount of time available to women was spent in enhancing the science of motherhood and wifehood. The home, suggest Ehrenreich and English, was to "attain industrial standards of discipline, efficiency and thrift. ... Private life becomes an end in itself, and effort in the outer world becomes merely instrumental to greater private fulfilment" (1979, p.190).

Allied to this change was the emergence of 'experts'. As had occurred during the fifteenth and sixteenth centuries, when medical experts captured the roles of healer and 'midwife', experts in the 'science' of childcare emerged. Ehrenreich and English suggest that the emphasis on motherhood as pathology "reinforced the child-raising experts' heroic image of themselves as public health crusaders" (1979, p.204). They describe the attempts by psychoanalyst, Rene Spitz, to trace childhood disease to a disorder in the mother. Included in his book The First Year of Life (1965), for example, is a connection between colic and "primary anxious overpermissiveness" and between faecal play and "cyclical mood swings of the mother" (Ehrenreich and English, 1979, pp.204-206). Silverstein (1994, pp.19-32) argues that that a serious attack on mothers began in the middle of the twentieth century with books that were extremely popular at the time, such as Philip Wylie's Generation of Vipers (1942), psychiatrist David Levy's Maternal Overprotection (1957) and psychiatrist Edward Strecker's Their Mothers' Sons (1951) Levy, for example, used twenty case studies of treatment and follow up for children harmed by the 'maternal overprotection syndrome' (as cited by Silverstein, 1994). Of these 
twenty cases, nineteen cases involved boys. The procedures Levy promoted in his treatment of 'maternal overprotection syndrome' included psychotherapy with the mother, in order that she learn to "releas[e] the child from her 'infantilising' influence" and with the father in order that he learn to "utiliz[e] his authority as a father" (1943, p.200). Similarly, Strecker, uses Wylie's term 'momism' to derogatorily define "the woman who has failed in the elementary mother function of weaning her offspring emotionally as well as physically" (1951, p.13). Describing in detail the emasculation of sons and husbands by mothers, Strecker advocates an essential separation between the mothers and sons.

American feminist, Cynthia Comacchio argues that the World Wars contributed to the pressure for the family to reform itself. The central image of the family after the wars, she claims, was "the family besieged" and its salvation was in the hands of "it's traditional heart and centre: the mother. ... The chief ideologues of [this] maternalism, sanctioned as appropriate commentators on morality, arbiters of social custom and guardians of the nation's health", she declares, "were medical doctors" (1997, p.307). The complicity between the medical profession and the State meant that mothers were new and improved educated, modernised, upgraded and reformed so that the family could meet the needs of the modern industrial society while preserving traditional form, function, gender roles and relations of inequality (Comacchio, 1997, p.314). John Bowlby's 1950 study Maternal Care and Mental Health, (as cited by Ehrenreich and English, 1979) which concluded that children experienced maternal deprivation if there was less than full-time provision of maternal attention, was, the "final, most devastating accusation against the rejecting mother" (1979, p.206). Good mothering, Bowlby concluded could be defined as that demonstrated by the mother who provided "constant attention day and night, seven days a week and 365 in the year" (cited in Ehrenreich \& English, 1979, p.207).

The popularisation of Freudian ideas also impacted on the domestic role of the mother, evolving it into one of sexy housewife. According to Ferguson, mothers were required to "balance their affectionate involvement with their children by an equally intense, sexually intimate ... relationship with their husbands" (1997, p.55). If women did not meet the demands of their husbands they were stigmatised as sexually repressed. The confusion and ambiguity for mothers must 
have been immense. On the one hand mothers were entreated to return to the home as full time mothers and to become sexual mates as wives and at the same time they were warned against intimacy with their children, particularly with their sons. Freud's psychoanalytical theories also contributed to concern about the damage caused by the closeness of mothers to their male children causing them to become homosexual (Ehrenreich \& English, 1979, p.211). After the war mothers' anxiety about the effect they were having on their children was made worse by Benjamin Spock's Dr Spock's Baby and Child Care (1945). This text advised mothers not be too permissive and affectionate particularly with their sons. Boys were clearly mostly at risk from the mothers' femaleness.

It was not until many years later, in the 1950 s, when child-psychologist, Bruno Bettelheim (as cited by Jaggar \& Rothenburg, 1984) made the call for the reinstatement of the father's standing in the family. As argued by Bettleheim, the father has greater objectivity (than the mother), "can be trusted in all emergencies ... [and] is known to think beyond the problems of the moment to their farreaching implications and consequences"(1984, p. 311). This, he believed, was crucial for the balanced upbringing particularly of the male child. He argued also that the father at that time felt less of a father even though he was more involved with his children than was his father" (1984, p.306). Bettleheim based this contention on his belief that modern children have all they want and do not recognise the father's pivotal role as breadwinner. The solution he posed involved the father reasserting himself as protector of the family and teacher of the children in preparation for survival in the 'outside' world.

Fathers will have to accept ... that their contribution will be less immediately obvious to the young child than the mother's. But how important to the child to have a father whose greater objectivity can be trusted ... to be able to rely on the judgement of a father who is known to think beyond the problems of the moment to their far-reaching implications and consequences. $(1984$, pp. 310 311)

Bettleheim's implications are clear. The worth of the father is in his objectivity, which, he argues, is greater than the mother's, and his ability to address the 'big' picture. Rich's analysis of Bettelheim's presumptions is that they originate from 
the desire of men to compensate for the lack of male power expressed in the devaluation of motherhood (1986, pp.113-114).

In summary and, according to Comacchio, there has been a deliberate move toward modernisation of motherhood during the twentieth century particularly in industrial-capitalist countries of North America, Western Europe, Australia and New Zealand (1997, p.322). She suggests three fundamental processes that have been central to the modernising of the mother. These are the public recognition of the mother-centeredness of the nations' welfare; education and supervision of the mother by an emerging group of professional workers; and the promotion of education and supervision through state regulation.

\section{CONTEMPORARY CONTRUCTIONS OF MOTHERHOOD}

Mothers' experiences of, and their relationships with, their worlds, are influenced by the definitions accorded to them by societal structures. Feminist theorists and practitioners have significantly contributed to deconstructions of contemporary motherhood including the most recent challenge to definitions of motherhood presented by the escalation in birth technologies. The state in Aotearoa New Zealand from 1987 to 1999 , in the form of a National Party (right wing conservative) led government, initiated social policy developments that have promoted the nuclear family. The resurgence of moral majority fundamentalist Christian pro-nuclear family lobby groups has contributed to these developments. The next section addresses these three areas.

\section{Contemporary Feminist Constructions of Motherhood}

Explanations and constructions of motherhood by feminist theorists have been varied and, at times, oppositional. Feminist theory and practice has tended, by most feminist academics, to be broken into categories that have responded to dominant paradigms privileging specific oppressions; ethnicity, class, culture, sexual orientation, physical abilities, age, religion and "one's nations place in the international order" (Maguire, 2000, p.60). Recognising that differences occur within, as well as between, these constructions, the next section overviews 
contemporary feminist analyses of 'mother', 'motherhood' and 'mothering' by several of the more significant feminist writers in this field.

Feminist writers, such as Humm (1992, pp.181-192), Jaggar \& Rothenberg (1984) and Tong (1995) ascribe the origins and development of liberal feminist thought to theorists such as Mary Wollstonecraft, who wrote in the late eighteenth century, John Stuart Mill and Harriet Taylor Mill, in the nineteenth century and Betty Friedan and Zillah Eisenstein, in the early to mid 1900's. Applying a liberal feminist framework to motherhood and 'mother-work' results in approaches such as; the challenging of attitudes that perceive housewives as nonworking women; the same imbursement for women mothering to that paid to men in the public sphere and the involvement of men in mothering work. To this end Alix Kates Shulman outlines an agreement drawn up with her husband to equally divide the children-work and home-work (1984, pp.311-315) and Ann Crittenden Scott discusses the idea of a salary for housewives (1984, pp.315-319). Rosemarie Tong, challenging these liberalist notions of motherhood and claims that "many liberal feminists advocate the formation of androgynous personalities" ... in order to "liberate women, and men, from the culturally constructed cages of masculinity and femininity" (1995, p.31). Feminist writer, Melissa Benn, also questions the benefit that equal opportunity has meant to mothers and motherhood. She argues,

Betty Friedan's honourable heirs, modern mothers, are no longer slaves to domestic values. ... They still work at night on the unfinished thesis - and it will be finished. They struggle on with professional training ... write articles, do locum work. They want to work and continue to work, but always at a disadvantage, one hand tied behind their back. (Benn, 1996, p. 2)

Chodorow (1978) criticises the first-wave of feminists who theorised that the problem of motherhood would go away once women went out to work. She contends that the treatment of women stems from the Western ideology that the familial is the exclusive and primary location for women, with women being primarily defined as wives and mothers (1984, pp.361-362). The marginalisation of motherhood, Chodorow argues, originates from her location within the sexual division of labour. "Even when men and women cross into each other's spheres their roles remain different. ... Women's work in the labor force tends to extend 
their housewife, wife or mother roles" (1984, p.363). She develops her argument suggesting that "the isolated nuclear family of contemporary capitalist society creates specific personality characteristics in men" (1984, p.364), preparing them for participation in a male dominant family requiring little emotional investment from them and for participation in a capitalist world of work. Mothers, she claims, are therefore are left to expend subordinated emotional energy in the nurturing of the husband and children.

Paula Nicholson, Senior Lecturer in Health Psychology at the University of Sheffield, supports Chodorow's view of the nurturing responsibilities of the mother and argues that contemporary motherhood traditionally exists with the clearly prescribed social context of heterosexuality and marriage, (1997, pp.375398). She extends this view by problematising motherhood for those outside of the nuclear family structure, "single parents, black mothers, working mothers, lesbians, the poor and working class" for whom, she suggests, "the model of the married two-parent, 2.4 children household may no longer be the norm but is still the most powerful image of the family" (1997, p.391). Acknowledging the tensions and dilemmas for mothers within non-nuclear family structures Nicholson maintains that feminism has been instigative in exploding the myths portraying women's happiness within the confines of motherhood and heterosexuality. Ruthe Thompson, University of Arizona, also raises questions about the politics and practices of mothering and motherhood in a doctoral dissertation on mothers, subjectivity and the novel. She argues that motherhood has undergone scrutiny by academic feminists who have defined it as a "troubling and contradictory, but ultimately transcendent, experience". She continues her analysis to argue that motherhood "especially on the subjective level ... finds its way into prefaces, introductions ... that employs the figure of hard-fought battles in motherhood to suture the reader into identifying with [the text]" (1997, pp.204205).

Thompson's point is interesting. Why, when the sanctity of motherhood within the framework of the heterosexual nuclear family has been an oppressive legacy handed to us by a patriarchal culture, does she maintain that "academic feminists work hard at published assurances of their own motherhood" (1997, p.210)? Her argument, contrary to that of Nicolson's, seems to suggest that the bind between 
motherhood as theorised by feminist academics, and motherhood as experienced by feminist mothers, hasn't yet been negotiated. Whether this is agreed to by other feminist academic mothers or not, it is the experience of some of the mothers in this project as later chapters will indicate.

Ann Oakley, who studied sixty-six first-time mothers, argues that motherhood is a socially conditioned, pervasive and oppressive myth influencing all women and men based on the belief that "all women need to be mothers, all mothers need their children [and] all children need their mothers" (1974, p.186). She contends that without this social and cultural conditioning women would not be trapped into motherhood, that they could chose to be social mothers and that children could chose the adult with whom they would establish an intimate relationship. She contends also that multiple, or communal, parenting is effective as one-onone parenting (1974, pp.187-203).

In The Dialectic of Sex Shulamith Firestone claims that the oppression of mothers is rooted in the biological inequality of the sexes. She supposes that when women and men cease to play different roles in reproduction sexual roles would be eliminated. She also believes that when "technology is able to perfect 'artificial' ways for people to produce, the need for the biological family will disappear and, with it, the need to impose genital heterosexuality as a means of ensuring human reproduction" (1995, p.74). Firestone's ideal however does not take into account the complexities of control and ownership of these technologies. Feminists from (particularly) radical feminist perspectives such as Alice Adams (1995), Rita Arditti (1984), Margaret Atwood (1985), Gena Corea (1985), Andrea Dworkin (1983), Shelley Minden (1984), Mary O'Brien (1981), Janice Raymond (1991, 1996), Adrienne Rich (1986), Robyn Rowland (1992) and Renate Klein (1989, 1991) warn about the dangers that reproductive technologies pose to women. O'Brien and Rich, for example, argue that men's alienation from reproductive power gives women the unique power to create life and that men, through a patriarchal system, seek to control women's reproduction with technology. Radical feminists, according to Tong, "believe that reproductive technology poses an enormous threat to whatever powers women still possess and that biological motherhood ought not to be forsaken in favour of artificial motherhood" (1995, p.81). 
Rowland argues that motherhood is "a powerful ideology in a patriarchal pronatalist society" (1991, p.248). Assumptions are made, she maintains, that "mothering is a natural life progression and is a necessary part of womanhood" (1991, p.249). Given this notion of 'essential motherhood' women who are deemed unable to have children are particularly vulnerable to reproductive technologies. Although supporting women's right to choose, and agreeing that reproductive technologies should increase the choices available to women, Arditti, Klein and Minden (1984, pp.1-7), argue that those who control the invention and production of these technologies do so in their own interests. "How can women choose freely in a society where the right to choose must be bought," they question, "where population control is racist ... where a woman isn't 'real' without a husband and child" (1984, p.2)? Although it is not the task of this research project to debate the pros and cons of reproductive technologies, the correlation between women's primary culturally constructed identities as familial, the increase of infertility and the development of birth technologies is evident. The number of women who choose to be mothers through birth technology processes is increasing. This must raise questions about post-technology motherhood, about re-definition of mother and motherhood and about "the importance or otherwise of the genetic and gestational links to the child one rears" (Tong, 1995, p.94).

Thompson is correct in maintaining that motherhood has been discussed, analysed, dissected and strategised by feminists over the ages. Because of the pervasiveness of motherhood ideologies in patriarchal societies it has perhaps been one of the earliest focus of analysis for feminist theorists. Doubtless this will continue for as long as feminists experience the dilemmas and tensions surrounding motherhood in their own lives.

\section{Contemporary Constructions of Motherhood by the State}

The move over the past seven years in Aotearoa New Zealand to minimise the social responsibility role of the state and the evolving of government agencies from service providers to service coordination, is leaving an increasing gap in service provision for families in this country. Ongoing practices under Children, Young Persons and their Families Act 1989, an initially successful coalition of the family, the state and public interest in the protection of children, is under threat as 
private, community and iwi service providers are being encouraged to work with children at risk with little additional funding and support. The Employment Services and Income Support Act (1998) and the subsequent changes to benefit funding have decreased the support available for mothers receiving the Domestic Purposes Benefit. Key policy initiatives and developments of the National Party led government in Aotearoa New Zealand from 1996 to 1999 include policies and resultant legislation such as Welfare to Well-Being, Strengthening Families, Youth Income Support, the Conjugal Status Bill, the Child Support Bill, the Code of Social and Family Responsibility, the Community Wage and an ongoing restructuring of the Department of Social Welfare. Appendix 1.1 illustrates this situation through two narratives. The first narrative gives an overview of the above legislation and the second narrative tells the story of the mothers involved in the project as they perceive, and respond to, the social political stances and decisions of this government.

In 1997 the previous Commissioner for Children, the late Laurie O'Reilly, offered a directional lead for state responsibility for children and families. He stressed his concern about the segmentation of services and policies for families and children, the preoccupation with outputs and the disregard for the needs of children and families. He cited examples of broken promises made to the Commission for Children such as, the lack of progress made on a policy for children promised in 1990 , a promised budget of $\$ 300,000$ each year for three years that was reduced to the same total over three years. O'Reilly petitioned the government with five requests. Firstly, that the commission was granted more power for investigation and advocacy. Secondly, that effective policy, backed up by applied research, is developed and implemented. Thirdly, that priority must be given to address the emotional illiteracy of many New Zealand males. Fourthly, that legislation needs to get away from the conflicting states of custody and access to look at how each parent can beneficially contribute and fifthly, that practical considerations such as financial issues and poverty levels need to be addressed (O'Reilly, Radio New Zealand, September 20, 1997). Unfortunately, even three years later, little progress toward any of these requests has been made.

Debating the government social responsibility agenda, Aotearoa New Zealand social policy analyst, Mike O'Brien, argues that, 
the focus is on individual responsibility, not social responsibility, despite the way in which the term is dressed up. It is in fact necessary to dress it up as 'social responsibility' because an exclusive emphasis on individual responsibility would unmask the agenda and interests. (1999, p.ii)

At the point of writing it is too early to establish the reaction of the new Labour (centre-left, liberal) Government ${ }^{2}$ to these legislative developments.

\section{Fundamentalist New-Right Constructions of Motherhood}

The move of the National Party-led Government toward right-wing monetarist politics including a social agenda toward self-reliance and independence from the state occurred at the same time as the pro-nuclear family lobbyists increased their public voice. Each added momentum to the other. At a public level the pronuclear family has been quick to react to any sense of alternate opinion.

In a structured sense, fundamentalist organisations have developed. The Christian men's movement The Promise Keepers, for example, has attracted thousands of men to its rallies in the United States, Australia and Aotearoa New Zealand. One of the listed seven promises of this organisation is to "build a strong marriage and family through love, protection and biblical values" by "uniting men through vital relationships to become godly influences in their world" (1996, p.1). Among the multiple sites in the Internet about Promise Keepers the following quotes can be found. Tony Evans co-editor of Seven Promises of a Promise Keeper in The Progressive, August 1996, argues that "the demise of our community and culture is the fault of sissified men who have been overly influenced by women". Bill McCartney, founder of Promise Keepers in The Progressive, August 1996, adds "[w]e're raising our children at a time when it's an effeminate society. It's not the proper climate".

An example of the type of literature used by fundamentalist new-right groups is Secrets of Fascinating Womanhood, written and published by Tauranga preacher,

\footnotetext{
${ }^{2}$ A Labour Government was elected to govern Aotearoa New Zealand in November, 1999
} 
David Cory. This book, driven by right-wing fundamentalist Christian ideologies, including the sanctity of the heterosexual, nuclear family, is aimed at women. It was extremely popular in the early 1990s being used by groups of women as a tool to save and enhance one's marriage ${ }^{3}$. Of the ten secrets women were to work through Secret Number Six reads,

Your God-given role is that of Mother and Homemaker. Enjoy it

Motherhood - the most noble and important work on earth. Our natural feminine instinct is to enjoy domestic work, as little girls do when they play with dolls and doll's houses. But when we're crowded for time by going out to work, or by poor organization, we are robbed of that enjoyment. Feminine skills you can do at home to save money. $(1989, \mathrm{p} .90)$

Over the past decade across much of the Western World, the concern about fatherlessness and particularly fatherless boys has attracted people and generated texts such as America's Robert Bly, Iron John: A book about men (1991), Sam Keen's Fire in the belly: On being a man (1991) and David Blankenhorn's Fatherless America (1994). Aotearoa New Zealand has contributed with its own protagonists such as Canterbury, family therapist Don Rowlands, Counsellor Warrick Pudney, who has written, Absent Fathers, Angry Sons (1994), founder of the Essentially Men Programme, Rex McCann, who has written, Fatherless Sons (1999) and Stuart Birks (1999a \& 1999b), prolific writer and anti-feminist proponent for the rights of fathers. Peter Zohrab has created the organisation, $N Z$ Men for Equal Rights, who claims that feminism is "the State ideology whereby women have rights, men have responsibilities and children have their lives ruined" (World Wide Web, site last updated September 24, 2000). His organisation is also concerned about child abuse by females and domestic violence against men. Other such organisations have been created, such as SPERM (The Society for the Protection and Encouragement of Righteous Manhood), FREE (Father's Rights and Equality Exchange), FACT (Fathers are Capable Too), DADI (Dads against

\footnotetext{
${ }^{3}$ I first came across this book when a Women's Studies student doing an "Independent Mothers" class brought it as an example of a strategy to develop confidence and self-esteem.
} 
the Divorce Industry), Fathers Without Children (Canada), Families Need Fathers (UK), and Fathering the Future (Australia).

A tour of seminars and speaking engagements in this country in 1997 by Australian family psychologist, Steve Biddulph, with his book 'Manhood: An action plan for saving men's lives', helped to escalate concern among professionals working with families, politicians and the public in general. Hailed as "the man the Australian men's movement has been waiting for" (1995, flyleaf) he attracted prime media attention in this country. The cover of this Manhood claims that Biddulph "is to men in the ' 90 s what Germaine Greer was to women in the '70s". The media coverage surrounding the visit highlighted an 'alarmingly poor situation for men' and included long lists of statistics to exemplify this; low levels of health, high representation in the crime statistics, unemployment and suicide rates. Chapter Seven of this thesis discusses the pro-father lobby and fatherlessness in more detail. Suffice to say at this point that the rhetoric that accompanies this pro-father lobby has helped to further construct mother as a marginalised and reduced identity.

\section{CONSTRUCTIONS OF ADOLESCENCE4}

According to William Simon, Professor of Sociology at the University of Houston Texas, the century old concept of adolescence "encompasses dramatic variations across time and culture at almost every level of application" (1996, p.59). He suggests that there are five various 'constituencies' for whom adolescence is significant. The first group comprises those professionals who specialise in the production and commodification of knowledge and wisdom regarding adolescents. The second group is made up of those who are parenting or supervising adolescents. The third group includes those who market and service goods to adolescents. The fourth group is made up of the adolescents themselves and the fifth group, those who have been adolescents and have sought to find meaning for their experiences as adolescents. For each of these groups engagement with adolescence is different. Although this thesis is primarily

\footnotetext{
${ }^{4}$ Further literature about the construct of adolescence is included in Chapters 5 to 7 as it relates to specific issues raised by research participants.
} 
focused on the experiences of the second group, it is hoped that it will be of benefit to all groups, but the third.

Philosophers, Christian theologists, psychologists, human development theorists, sociologists and anthropologists also have varying interpretations and accentuations on adolescence as a construct. This section is in two parts. It will firstly outline the historical development of adolescence and secondly address some of its contemporary constructions in the western world of which Aotearoa New Zealand is part.

\section{Definitions and Historical Constructions of Adolescence}

It is commonly held by human development theorists such as Bee (1998), Brofenbrenner (1979), Kaplan, (1988), Lerner (1987 \& 1993), Papalia \& Olds (1998) and Simon (1996) that the science of adolescence is relatively new. Lerner, for example, maintains that the escalating scientific activity devoted to adolescence has occurred "synergistically with the recognition within society of the special developmental stages of this period" (1998, p.3). Psychologist John Conger, however, reports early interest in this period of a male's life among early Greek philosophers such as Plato and Aristotle. Aristotle, Conger maintains, described the young as,

prone to desire and ready to carry any desire they may have formed into action. Of bodily desires it is the sexual to which they are most disposed to give way. ... They are changeful too, and fickle in their desires. ... They are passionate, irascible, and apt to be carried away by their impulses. ... They regard themselves as omniscient and are positive in their assertions. (Keill cited by Conger, 1988, p.4)

Conger continues his discussion of the early beginnings of adolescence as a concept with the following passage from Le grand propriertaire de tout choses (1556), an encyclopaedia of scientific knowledge,

[After infancy and childhood] follows the third age, which is called adolescence, which ends according to Constantine in his viaticum in the twenty- 
first year, but according to Isidore it last until twenty-eight. ... This age is called adolescence because the person is big enough to beget children. (Aries cited by Conger, 1988, p.5)

In a seventeenth century volume, The Office of Christian Parents (1616), youth was defined from fourteen to twenty-eight years and was a time when the clergy were concerned about behaviour and morality. "The dominant theme of seventeenth-century writings by clergymen and others was the need to help undependable youth master their unruly impulses" (Spacks cited by Conger, 1988, p.6).

Conger, however, does support the generalised belief that the social and economic influences of the industrial revolution separated the stages of childhood and adulthood to such an extent and in such a manner that a visible category of segregated youth developed (1988, pp.6-10). He quotes Aries who commented, "it is as if, to every period of history, there corresponded a privileged age and a particular division of human life; 'youth' is the privileged age of the seventeenth century, childhood of the nineteenth, adolescence of the twentieth" (1988, p.9). If, as Aries suggests, the twentieth century was the time of adolescence, the influences in the Western world during this time have been many. They have included two major world wars, a depression, laws abolishing child-labour, an increase in school-leaving age, the conservatism of the 1950's, the permissiveness of the 1960's and 1970's, increased access to drugs, alcohol, and vehicles during the last two decades of the century and accompanying high unemployment and poverty levels.

Historian, Joseph Kett, offers an age and stage definition of adolescence as "the period after puberty during which a young person is institutionally segregated from casual contacts with a broad range of adults" (1967, p.36). Other writers describe adolescence as the period in the lifetime in which individuals are most likely to be alienated. Psychologist, Calabrese (1987), points out that adolescence is conducive to alienation because of the tension between childhood freedom and adult responsibility in the period in which it exists. Human development theorist, Helen Bee, considers that experts on adolescence divide the period of adolescence into two sub-categories. Early adolescence as the first sub-category is defined, she 
reports, by "a time of transition in which significant change occurs in virtually every aspect of the child's functioning". Late adolescence is a time of "consolidation, when the young person establishes a cohesive new identity" (1998, p.328).

Likewise influential development theorists, Austrian psychoanalyst, Sigmund Freud, Swiss psychologist, Jean Piaget and German-born American psychoanalyst, Eric Erikson maintain that adolescence is the period when identities are developed and are acted out through the formation of sub-cultures. The Encyclopaedia Britannica (http://www.britannica.com) offers a cursory overview of contemporary teachings of these three 'experts'. According to the Britannica, Freud's theories were based on the notion that children were born with a psychological energy called libido. He named the stage of development that related to adolescence, the 'genital stage' where, he ascertained, that mature gratification is gained in a heterosexual love relationship with another. Emotional problems in adolescence and adult, Freud believed, stemmed from either deprivation or excessive gratification during early stages of childhood. This perhaps explains his obsession with the mother-son relationship ${ }^{5}$. Influenced by Freud, and adding to his biological and psychosexual factors, Erikson included psychosocial and social factors to the theories of personality development. Devising eight stages of development, Erikson considered that specific psychosocial demands confronted the individual at distinct periods throughout its life. Although not recognising a specific stage called adolescence Erikson maintained that between Stage Four (school age) and Stage Five (young adult hood) the individual should be finding their place in the world through 'industry'. Once that has been achieved the individual is to enter into the institution of marriage and family in order to perpetuate the species. The ability to mature and to move to the next stage without personality problems, according to Erikson, relied on the resolution of conflict at the previous stage.

\footnotetext{
${ }^{5}$ Refer also discussion of the impacts of Freudian theories addressed earlier in this chapter and in Chapters 5 and 7.
} 
Psychologist, Jean Piaget, advocated a development approach that involved learning and intellectual functioning. His theories rested on the perception that a child develops through a series of four stages until s/he is able to think as an adult. Piaget's fourth, formal, stage characterises the adolescent and adult. As with Freud and Erikson he did not articulate a specific chronological age of adolescence, but acknowledged it as a time when the individual is able to function cognitively in a "rational and systematic manner about hypothetical problems" (retrieved September 2000 from the World Wide Web). Piaget theorised that the ability of a child to move between stages is reliant on its ability to interact with objects in the environment.

As does Freud, Erikson and Piaget, American psychologist, Lawerence Kohlberg (1976, as cited by Bee, 1998) claims a universal applicability of his theory of moral development. Of the three levels, 'preconventional morality', 'conventional morality' and 'principled postconventional morality, the adolescent, Kohlberg claims fits into the second level where they are expected to meet the expectations of the family, be good for it's own sake, fulfil certain duties and uphold laws. The highest level, according to Kohlberg, is attained by people such as Mother Theresa whose "moral reasoning was based on universal and ethical principles" (1998, pp.289-291).

\section{Contemporary Constructions and Images of Adolescence and Adolescence and Mothers.}

During the five years of the mother-adolescent son project several participants, of whom I was one, maintained a journal of our experiences raising sons. In this journal I documented the changing symbols of my son's world, including his language, music, appearance, values, beliefs, attitudes, and behaviours. I wrote about one of the first large (non-alcoholic) parties he had at the end of his intermediate years, wondering what constituted safe sexual behaviour when it came to girls (November 30, 1996). I remember the polar bear posters in his room being taken over by supermodels, Cindy Crawford and Pamela Anderson (August $26,1997)$ and listening to ancient Celtic music in the study upstairs while the words "Alice! Alice! Who the fuck is Alice!" blasted up the stairwell (September $21,1997)$. I noted his dark glasses and beanie when he went to the movies one 
night and his organisation of the phone to extend into his room (November 22, 1997). At the end of 1998 he, and his friends, were captured by the pulp-cartoon, Southpark'. One of the key songs in this series was Kyle's Mom is a Stupid Bitch. This was the time he also wanted an earring, could not understand why I was not prepared for him to host an alcoholic party, spent his clothing allowance on labelled clothes and began to articulate thoughts about politics and justice for young people. During 1999 a piercing in his tongue added to that already in his ear, and his world became packed with activities that connected him with his friends. The labelled clothes went out and second-hand gear and grunge came in. In 2000 his hair has turned from green to purple to black, he is into the seventies era. He chairs the student council and his values are strengthening as he challenges what he perceives as the hypocrises of the adult world.

What is a contemporary construction of adolescence? Is there a contemporary construction of adolescence? Epstein's edited text, Youth culture: Identity in a Postmodern World (1998) is useful to the discussion of this next section. Lecturer at Kent State University, Epstein is purported to be an internationally recognised expert on youth culture. In this text sociologist David Locher argues that the youth sub-culture of the 1990's in the United States has failed to come together. Using the development of youth music as an example, he discusses the multiple identities of young people and multiple constructions of adolescence that have resulted in a disparateness and non-connectedness among young people (1998, pp.100-117). In another article in the same text Professors of Philosophy, Steven Best and Douglas Keller, use the popular American TV series Beavis and Butthead (also shown in Aotearoa New Zealand) to provide "all-too-real indications of how many white youth think and feel as they vegetate in front of the television ... and how their frustration drives them to extreme behaviour" (1998, p.74). Beavis and Butt-Head have no family and live alone day and night in a shabby house being enculturated by television and media culture. While watching stage divers in a punk video, Beavis and Butt-Head hold the following conversation,

Butt-Head: That would be cool if the guy jumped offstage and nobody caught him, huh huh, and he smacked his head on the floor.

Beavis: Yeah, and then his head would crack open, heh heh, and there would be like blood everywhere, and brains. That would be cool. 
Butt-Head: Yeah. What if someone starting slipping around on his brains and blood?

(as cited by Best \& Keller, 1998, p.76)

Best \& Kellner express their concern that Beavis and Butt-Head is an example of "the catastrophic effects on the current generation of youth raised primarily on media culture" (1998, p.81). As icons of popular teen culture these characters also, I believe, perpetuate and maintain the negative aspects of the adolescent culture. In whose interests are these representations made? Maybe those in the media world benefit? I do not believe it is the young people and it is not their mothers or sisters or female friends. Epstein suggests that the "portrayal of [adolescence] in the mass media has focused on the more spectacular events and has continued the practice of labelling entire groups of young people as 'problems' because of these incidents" (1998, p.21). He challenges those working with adolescents and theorising adolescence to move away from the ideation of youth as a problem to an analysis of societal structures and their impacts on young people.

Human development theorists, Papalia and Olds (1998), also question the universality of the expected trauma associated with adolescence. They cite studies on adolescence in non-western cultures, for example, undertaken by anthropologist, Margaret Mead, which concluded that in a culture that "provides a gradual, serene transition from childhood to adulthood, adolescent rebellion is not typical" (1998, p.384). Papalia and Olds cite also a study of mid-western American boys aged between twelve and fourteen years old, by Daniel Offer (1969). This study found that although there was bickering between the boys and their parents there was little turmoil. In a follow up study five years later Papalia and Olds report that Offer \& Offer found that less than twenty percent of the participants experienced a tumultuous adolescence.

So what of the above? One aspect that most developmental theorists seem to agree on is that adolescence is a time of change, a time when young people become independent from parents and identify with peers in search for a personal identity. It seems that this time can be destructive and traumatic or can be managed in a way that enables young people to experiment, express their individuality and separate from adults in a healthy and constructive manner. Researcher Miranda 
Yates undertook a study based in the United States of America that examined the link between political development and identity formation in adolescents. Analysing the outcomes of a year-long social justice program with predominately black American middle and lower-class families during 1993-1994, Yates found that the social justice program "encouraged youth to think about not only the political implications of their experiences, but also their own political role in society" (1998, p.11). A discussion during 2000 with my son indicated a similar theme. In this discussion he maintained that young people needed something to fight for; that they needed a cause, a reason for being. Analysis of the struggles of previous generations of young people including world wars, economic depression, 'peace not war', nuclear disarmament and freedom from social restriction could suggest that existence for current generations has little meaning. The large number of young people ${ }^{6}$, with and without school uniform, that were part of the S11 (September, $11^{\text {th }}$ ) protests at the September 2000 World Economic Forum in Melbourne, Australia, was astounding. Those I spoke with were articulate, focused and seemed to have a clear overview of the issues that were presented. Perhaps the increasing concern about the environment may capture some.

Although there has been strong critique, predominately from feminist and social scientists, about the theories developed by Freud and Erikson, and modified and adapted by more current writers such as those mentioned above, they still seem to underpin teacher, social worker, health practitioner and counselling and parenting training in this country. They have also appeared to impact on the constructs, frameworks and responses of the mothers within this study.

\section{Definitions of Adolescence for the Mother-Adolescent Son Project.}

For the purposes of this project adolescence has had several meanings. In the Drawing Interpretation Project the period after childhood was divided into two distinct age ranges, pubescence $(10-13 \mathrm{yrs})$ and adolescence $\left(14-18 \mathrm{yrs}^{7}\right)$. This

\footnotetext{
${ }^{6}$ These young people were predominately white, which is perhaps not surprising with the current situation in Australia, but they seemed to come from both poor and middle-class backgrounds.

${ }^{7} \mathrm{I}$ am not suggesting that adolescence ends at this time, but that the maximum age of the males in the drawing project was 18 yrs.
} 
division was made in recognition of the predominant thinking that adolescence falls in two sub-categories and in order to capture the general ages of those attending intermediate and secondary level schools. The term 'teenager' is sometimes used throughout the thesis to discuss the male 'at adolescence'. In this case 'teen' refers to the nomenclature of the age, that is thirteen, and fourteen. More importantly it is the concept of adolescence, rather than the age, that is significant for the research.

\section{CHAPTER SUMMARY}

The constructions and experiences of motherhood and adolescence, as they relate to the study, have been articulated by the mothers but, in the multiple ways that have been described in this chapter, they have been determined by the ideologues and practitioners who maintain social control in the environment within which we have been raising our sons. It is these within contexts that the mother-adolescent son research has been framed. 


\section{Part 2}

\section{THE RESEARCH \\ ACT}




\section{CHAPTER 2}

\section{RESEARCH THEORY AND METHODOLOGY}

The selection of the research methodology appropriate for a research question and objective is a central part of any research exercise. This chapter discusses the factors that influenced the choice of model used in the project. It describes the model and then discusses some of the key theoretical and methodological considerations that arose from its use.

\section{THE CHOICE OF RESEARCH THEORY AND METHODOLOGY}

The development of the theoretical framework for this project has been evolutionary. In deciding a direction for the choice of the research methodology it was necessary that the process of the research activity was consistent with the objective underpinning it, namely, the emancipation of mothers who parent adolescent sons. Sociologist Roslyn Bologh (as cited in Reinharz, 1992), advances the notion that "the objective [of research] is not the product but the process, not a new final identity or institutional arrangement but the movement beyond a given identity or institution" (1992, p.178). Given this notion, the research method selected to work with the issues arising from the research question of this project was required to meet six criteria. Firstly, empowerment of women through individual and social change; secondly, involvement of participants in the research processes, including the collation, analysis and dissemination of information; thirdly, benefit for participants from their involvement in the project; fourthly, engagement of the participants in the research process being as important as the final product; fifthly, a combination of research methods to enhance rigour in the research process; and, lastly, an emphasis on participants' realities and stories within the broader framework of the research issues.

It can be argued that my own life experiences and training, academic and applied, led me to prioritise the above as key objectives determining a research methodology long before the initiation of this project. It can also be argued that the search for a research process occurred once the core of the research problem 
was decided. Whether it was either or both of these, it made sense that the research theory involved feminist principles and that the method included processes of individual and social action. A further key factor in the selection of a research methodology was my own involvement in the issue. As a mother of a teenage son I was at the same time researcher and research subject. Action research, which required the involvement of the researcher in the issue/s researched, was an obvious choice. The research methodology I have used combines feminist research principles and practices with a participatory action research model. I have termed this feminist participatory action research ${ }^{1}$. The combined approach ensures validity of the many methods employed within the project as they contribute toward the rigour of the research process.

\section{The Relationship Between Participatory Action Research and Feminist Research}

In literature on participatory action research and on feminist research there seems little recognition from each of the other. Australians Atweh \& Kemmis, well renowned in the participatory action research field, recently published a series of articles discussing action research, social justice and partnerships, including one by Fazal Rizvi. Rizvi writes,

with the work of feminist scholars like Nancy Fraser and Iris Marion Young a new mode of thinking about social justice is clearly emerging. ... This new paradigm is concerned to focus attention ... on issues of identity, difference, culture domination and recognition" (1998, p.54).

Although perhaps new to Rizvi, feminists have been grappling with issues of difference, and multiple identities for years. The inclusion of this article in such a text, however, illustrates an emerging recognition among some action researchers that feminist epistemology can contribute to the enhancement of the action research model. I attended the Ninth World Congress on Action Learning and

\footnotetext{
1 By using the nomenclature, "participatory action research" I am referring to a specific research method (Figure 2.1), rather than to the inclusion by feminist researchers of participatory methods in feminist research processes.
} 
Participatory Action Research, in Melbourne in September 2000. This four-day congress sub-titled "Reconciliation and Renewal" included over one hundred and seventy presentations, involving keynote addresses, papers, workshops and poster-presentations, and attracted almost three hundred delegates from throughout the world. Of these conference presentations one only addressed the intersection between feminisms and participatory action research. This paper was presented by Dr. Patricia Maguire from Western New Mexico University, as a result of the concerns raised about their invisibility by women participants at the previous Action Learning and Participatory Action Research Congress in Cartagena, Columbia. The Handbook of Action Research: Participative Inquiry and Practice (2000) includes Maguire's paper as a chapter. Maguire begins her commentary by declaring,

many recent primers still offer little discussion of how feminist scholarship informs action research (Calhoun, 1994; K.Collins, 1999; Kemmis \& McTaggart, 1988; McNiff, 1993; Selener, 1997). Susan Noffke (1998) and Alison Bowes (1996) note that there are only rare instances of action research and feminist theory engaging each other. (2000, p.59)

Apart from the attention given to it by Shulamit Reinharz (1992 \& 1997), Maria Mies (in Bowles and Klein, 1983) and contemporary works, such as the Journal of Sociological Research by feminists Alison Bowes (1996) and Beth Humphries (1997), it does not seem that participatory action research per se has had currency among feminist theorists and researchers. There is much evidence of theorising about empowerment, emancipation and social justice for women, as explored more fully later in the chapter. Feminist participatory action research as such, however, appears little in the literature explored as part of this dissertation. Reinharz outlines five types of "feminist research with an explicit action connection" (1992, p.180). She names these action research, participatory / collaborative research, prevalence and needs assessment, evaluation research, and demystification. Each of these types has one or two elements in common with the methodological objectives that had been stipulated for the mother-adolescent son project. These elements included; simultaneous action and evaluation in 'action research'; input by the people studied into the research processes and data analysis in 'participatory/collaborative research', determination of the specific desires of a group of people in 'needs assessment research'; appraisal of the effectiveness of 
actions in 'evaluation research'; and the belief that obtaining knowledge creates the potential for change in 'demystification research' (1992, p.191).

Although each of Reinharz's categories had elements in common with the approach I wished to take, no one category fully encompassed it. I could find neither a feminist participatory action research model nor a guide about how to practice it $^{2}$. My task was to select from among the multiple strands of feminist research those that could achieve the methodological objectives of the research and combine them with selected elements of participatory action research. As both feminist and participatory action research encourage a multiplicity of approaches, I believed it was possible to develop a research methodology that had integrity to both approaches despite the differences between them. The following section discusses the nature of the feminist participatory action research method that developed from these beginnings.

\section{The Feminist Participatory Action Research Model}

Participatory action research involves ongoing processes of individual and collective political and social change; investigation, definition, reflection, and redefinition of a multiplicity of truths. In participatory action research processes are directed by the participants. Participation is the strength of this type of research and is also its limitation. Whilst promising ownership of the research, participant directed action research can also be corrupted by the values, attitudes and beliefs of the community/society to which the participants belong. Although feminist research is informed by various theoretical underpinnings, its one constant is that it recognises, and seeks to redress, the gender imbalance between women and men.

Feminists such as Nancy Hartsock (1987, 1990, 1997), Dorothy Smith (1987, 1992), and Liz Stanley (1990a, 1992, 1997a, 1997, 1997c), promote feminist standpoint theories arguing that power differences among women, as well as

\footnotetext{
2 This was illustrated further when I attended and offered papers at the New Zealand Women's Studies Association Conferences in 1997, 1998 \& 1999 and at New Zealand Action Research Network Conferences in 1997,1998 \& 1999 and realised the uncommonness of this approach.
} 
between women and men, create inequitabilities in social relationships, access to resources and influence in decision making. The theorising of 'woman', as highlighted by Stanley (1990, pp.29-36), requires analysis of the multiple standpoints of women enabling, for example, black women to describe and theorise their truths in relation to their experience and struggles against racist oppression, and enabling lesbians to articulate their experienced explanations of heterosexism and homophobia. Hartsock argues that "standpoint is not simply an interested position (interpreted as bias) but is interested in the sense of being engaged" (1987, p.159). It is the nature of the relationship between people with which standpoint theory is concerned, particularly when power elements of the relationships are ignored or rendered invisible. Hartsock contends also that standpoint theory is based on five principles. Firstly, that socio-economic status structures the functioning of social relations. Secondly, that systems of domination alter the perceptions of each group toward the other and that these are affected by the power imbalance in the relationship. Thirdly, that the ruling class (or ruling gender) organises the systems within which each all groups participate, and therefore needs to be recognised and navigated. Fourthly, that the oppressed group requires support from research and education to change the inequitable relations. Lastly, that the adoption of a standpoint "exposes the real relations among human beings as inhuman, points beyond the present and carries a historically liberatory role" (1987, pp.159-160).

As argued by Kay Morris Matthews, Associate Professor of Women's Studies, Victoria University Wellington, when "feminist standpoint is the basis of the researchers' analyses, it is they who have the power to interpret and represent other lives" (1994, p.10). If Hartsock's definition of standpoint is not merely the notion of perspective but entails the researcher to engage in liberatory practices and political and social change, then the recognition of feminist standpoint theory within a participatory action research approach must necessitate the recognition and negotiation of the researcher/researched relationship.

The contribution of feminist sociologist, Dorothy Smith, to feminist standpoint theory develops the analysis of social relations. Smith argues that those involved in examining social relations are also involved in constructing and interpreting the social processes and social relations which make up their everyday lives (as cited 
by Stanley, 1990, p.34). The mothers in the mother-adolescent-son project, for example, whilst individually and collectively examining their lives and experiences during the project were also contributing to new constructions of their relationships. That is, relationships between themselves and their sons, with their sons' fathers and in the myriad other interactions that make up their lives. Hartsock stresses also that political activism is an imperative of feminist research methodology. "It is only through struggle against an exploitative system, such as male domination, that one can come to understand its strength and resilience" (1987, p.157). If women are to be emancipated, she argues, feminist politics must be a part of feminist research methods

The feminist participatory action research model that was chosen to meet the key methodological criteria of this project is one that combines two key concepts. It syndicates the notion of 'difference', as explained through feminist standpoint theory, with a participatory action research process that recognises that the participants bring the multiplicity of their individual life experiences with them into the research act. Decisions about the choice of research tools and techniques have been made with the recognition that exploration of the participants' experiences is crucial to the generation of realities against which hypotheses about mothers and adolescent sons can be developed and tested. The research tools and techniques were chosen to enable the participants to describe and make sense of their own realities and to develop their own individual and collective strategies toward change. Accordingly, the research model included a feminist politics agenda recognising that a deliberate outcome of the research processes would be individual and, hopefully, collective change for mothers of adolescent sons.

The central impulse behind participatory action research is understood to lie in the efforts of disempowered groups to attain social justice through planned research. The first use of the term in the United States is found in the writings during the 1940s of social psychologist, Kurt Lewin and the United States Commissioner of Indian Affairs, John Collier, who used it as a way to counteract racial prejudice and promote democratic forms of leadership in the workplace (as reported by Zeichner \& Noffke, 1999). Lewin developed a helical model in which each cycle in the spiral included planning, acting, observation and reflection and impacted on subsequent cycles. The social justice element of participatory action research 
appeared to become diluted in the 1960s when (as reported by Zeichner \& Noffke, 1999), the model was adopted by academics in the United Kingdom such as John Elliot, Lawrence Stenhouse, Jean Ruddock and Clem Adelman and used for the development of student-focused curricula and teaching practice. Australian academic, Stephen Kemmis, spent time with Elliot and others in the United Kingdom and in the late 1970 s took action research with him to Deakin University, Australia. Kemmis and his Australian colleagues, including researcher Robin McTaggart from James Cook University, developed a series of schoolbased projects using action research as a base. They conceptualised the action research model as a series of cycles and defined it as:

A form of collective self -reflective enquiry undertaken by participants in social situations in order to improve the rationality and justice of their own social or educational practices, as well as their understanding of these practices and the situations in which these practices are carried out. (1988, p.5)

\section{Figure 0-1: Lewin's Action Research Model}

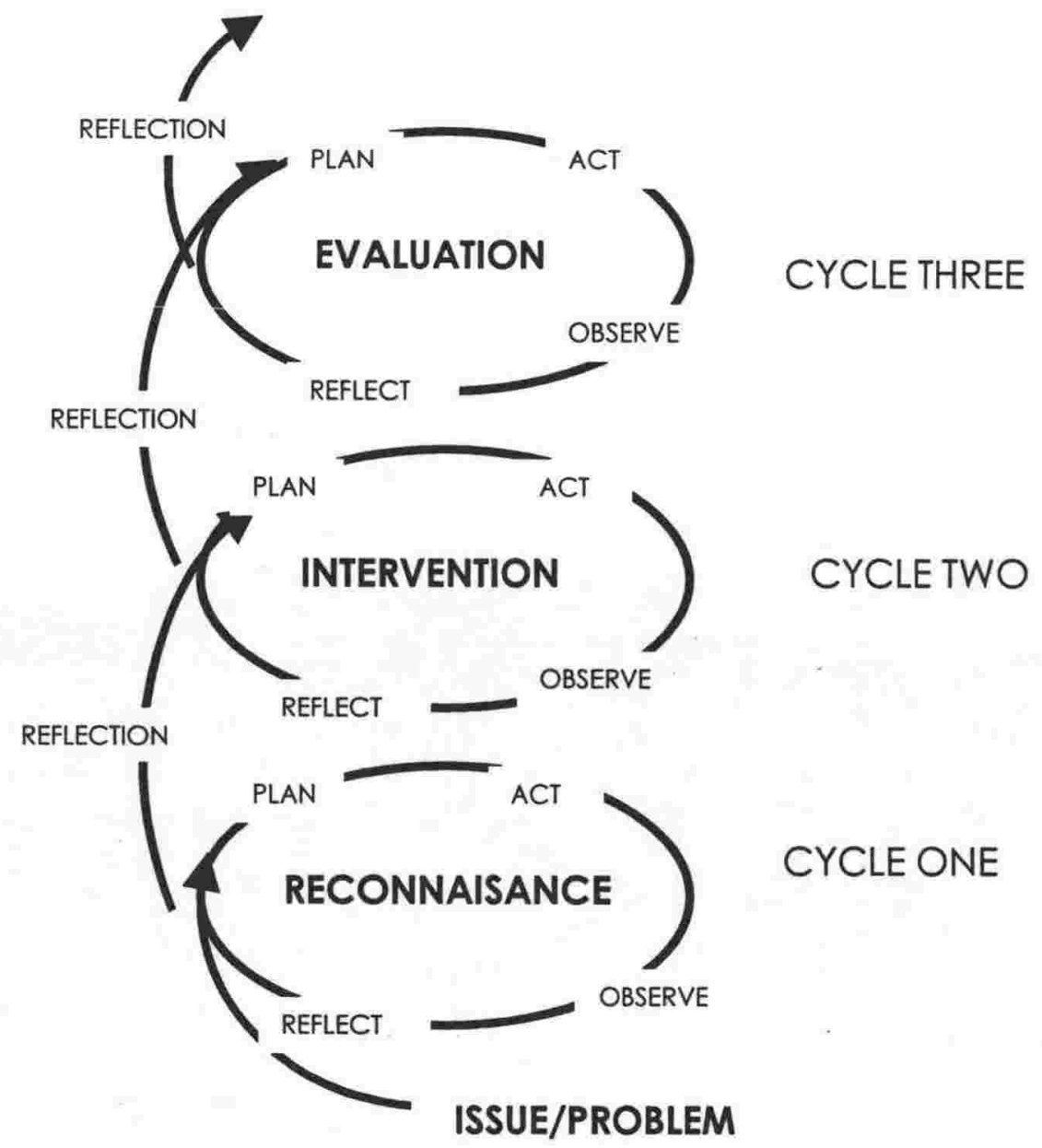


The social change element in participatory action research was probably most influenced by the work of people such as Frantz Fanon $(1967,1990)$ and Paulo Freire $(1970,1994)$ with projects that were associated with adult education and literacy movements, land ownership, environmental contamination and unemployment in third world countries such as Latin America, Africa and Asia. In this research tradition, social change is an overt agenda and integral to the research process. This agenda is explicit in its commitment to economic and social justice issues in both the larger social context and the research process itself. As the political is conceptualised in terms of power issues, a major political focus in this tradition involves shared power over knowledge issues. The research is 'from' and 'with', rather than 'on', with full participation by those affected by the research process. Participants' knowledge is valued and developed; using skills appropriated from dominant groups, and is then transformed to serve the interests of the larger community. According to American participatory action researcher, Phillip Reason, participatory action research has two objectives. The first objective is to "produce knowledge and action directly useful to a group of people through research, adult education and socio-political action" and the second objective is to "to empower people through a second and deeper level through the process of constructing their own knowledge" (1994, p.328).

Participatory action research theory, as distinct from action research, is concerned with two further dynamics. The subject-object relationship between researcher and researched that occurs in conventional research is converted into a subjectsubject relationship. The following section addresses some of the dilemmas of this approach when it discusses the insider/outsider relationship. It is also concerned with a rigorous deconstruction of the 'participant-empowerment' agenda. It is these considerations, the construction and ownership of knowledge, which, I believe, offer a link between participatory action research theory and feminist research theory.

The feminist participatory action research model developed for this project is an adaptation of Lewin's action research model and is illustrated in Figure 2:2. The model begins with the recognition that for mothers raising adolescent sons in a society that is constructed by dominant androcentric paradigms is problematic. The resulting Issue/Problem is that a group of mothers raising adolescent sons in 
Aotearoa New Zealand experience marginalisation, disempowerment and invisibility.

Figure 0-2: The Feminist Participatory Action Research Model Developed for the Mother-Adolescent Son Project
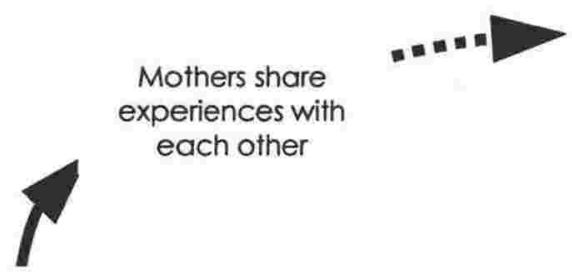

New knowledge is reflected on

Mothers share

experience of

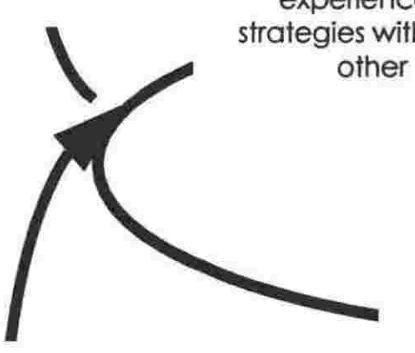

other

Strategies are evaluated

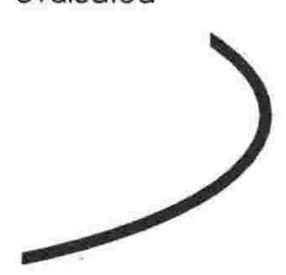

CYCLE THREE

\section{EVALUATION \\ New Knowledge is formed and New Theory is constructed}

Strategies are reflected on

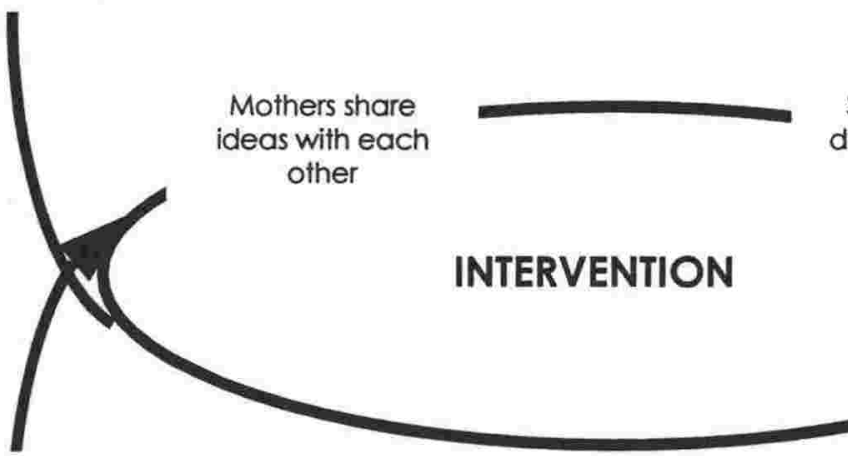

Strategies are developed from the ideas
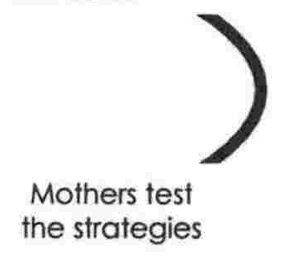

CYCLE TWO

Explanations,

analyses are

reflected on

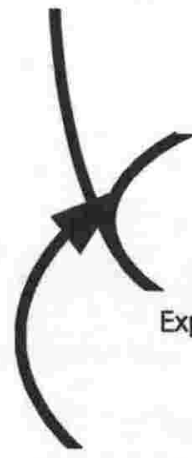

ISSUE/PROBLEM

Marginalisation, disempowerment, invisibility for mothers of adolescent sons are sought
Mothers' experiences of mothers and adolescent sons not adequately explained by these paradigms
Commonalities and differences are recognised

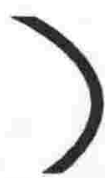

Observations are made

\section{CYCLE ONE}

\section{RECONNAISANCE}

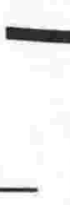

Knowledge about mothers and adolescent sons constructed through dominant androcentric paradigms 
The first research cycle, the Reconnaissance Cycle, begins with the mothers exploring the issue, observing the commonalities and differences and reflecting on these, creating analyses, suggesting and testing strategies and developing new knowledge and theory. The first cycle leads onto the second - the Intervention Cycle. The detail of the activity in the second cycle is determined by the results of the testing of the new knowledge and theory developed in the first phase and begins with the mothers talking with each other about their experiences of applying the new knowledge and theory. The second cycle leads onto the third - the Evaluation Cycle - and then onto the fourth cycle, which begins another phase of reconnaissance, intervention and evaluation. As with the process of change, the number of cycles is infinite. They can continue in numerous directions, testing and evaluating various strategies as determined by the participants. In this sense, the research findings are part of the ongoing process rather than being an end in themselves.

Rina Benmayor, Research Director of Cultural Studies at the City University of New York, describes using similar action reflection models of research that involve extracting information, analysing data and returning the reworked information to the participant community. This research model, she asserts, generates a benefit for the participants that is qualitatively different from the linear paradigm of other research models (1991, pp.159-174). Participants do not depend on the outcomes of the research to benefit from it. By being involved in the project they are gaining knowledge from shared information and experiences.

Process based research requires an additional role of the participant/researcher, that of facilitator. Times for reflection need to be integrated into the research activity in order that participants recognise and develop their individual and collective points of achievement and change. Reinharz claims that "changing the researcher is not a common intention in feminist research, [but] it is a common consequence" (1992, p.194). In this research project change of the researcher and participants $i$ s one of the intentions. The evaluation points provide the opportunity for the participants to recognise and reflect on changes and to explore the implications for their practices as mothers of adolescent sons. 
Inappropriate, researcher driven research carried out with disempowered groups can have the effect of accentuating their powerlessness ${ }^{3}$. This model of research, operating symbiotically with action, has the ability to change that which it is investigating by the very act of the investigation. The reflection on this action offers an in-transit redefinition of the worlds in which the participants operate. The act of obtaining knowledge creates the potential for change. When participants are responsible for defining, modifying, directing and evaluating the research they are involved in, the outcomes can become powerful and far reaching. This research strives to put women and a specific invisible 'group' of women on the agenda.

\section{THEORETICAL AND METHODOLOGICAL CONSIDERATIONS}

The project has used a combination of research methodologies informed by feminist theory and epistemology. I have sought to make sense of the contradictions of undertaking research for a 'higher' qualification whilst responding to the need for change at a community level by endeavouring to narrow the gap between community-based action and feminist scholarship. The project has used the resources and skills of the two institutions involved, while avoiding an exclusively academic base. It has attempted to continually link with the community as its reference point recognising the experience, and encouraging the participation, of women seeking to make change. At times for me as researcher and participant this has meant a sense of multiple identities as the demanding but part time research takes me into the university environment for supervision, academic challenge and support and then relocates me in the public and private realities of motherhood. My own processes, as well as those of the participants, have contributed to the material available for analysis.

The beginnings of the discussions as they relate to the methodological considerations of this project are introduced in Chrisp (1997). Three specific concerns were raised at that point; the participant/researcher relationship; the

\footnotetext{
${ }^{3}$ For example, research 'on' women by men, 'on' Maori by Pakeha. This is discussed in the following section on The Insider/Outsider Dichotomy.
} 
adequate documentation of situation and transition and the evaluation of points of achievement. These discussions were continued in two further papers (Chrisp, 1998c, 1999b). At this stage I realised that I needed to take into consideration the contradictions inherent in the emancipatory research process, that it was naive and delusionary to expect that the intention to empower would necessarily engender empowerment. For the research processes to have the ability to facilitate social change that was liberating for the participants, it was necessary to acknowledge that they were fluid and multifaceted and needed to be grounded by the participants.

One objective of the feminist participatory action research process is emancipatory individual and collective change. Feminist methodologist, Patti Lather, talks of empowering "through empirical research designs which maximise a dialogic, dialectically educative encounter between researcher and researched". She suggests that our intent as feminist action researchers is to "use our research to help participants understand and change their situations" (as cited by Reinharz, 1992, p.175). The realisation of this objective has called for an analysis of social structures, and the relationships between them, embodied by those of us who have been involved in the research. Each member in the project has presented a context. We have posed individual truths, offered varying observations of the worlds we inhabit and our own ideas of how we are perceived within those worlds. Our 'standpoints', although shared in part by others in the project, have been unique.

As the research process developed, the acknowledgement of our differences was enriching. I had realised that by not attending to the relationship dynamics among those of us involved, subjectivities and prejudices that were reflected outside the project would be perpetuated within in it. The power relationships between us as a group were not equal. As my involvement in the project was quantitatively larger than that of the other participants, the research practices could not be based on the assertion that equitability necessitated equal contribution. I needed to recognise that my position as 'principal' researcher was privileged and if possible to use it to facilitate and support collective change. The next sections of this chapter document my endeavours to create equitable research processes within these constraints. 
I restrict my discussion of the methodological considerations of the project to the headings below, although I do not intend to suggest that they are discrete categories. They aim only to provide a framework through which the discussion is organised. The first of these, problematising empowerment, attempts to deconstruct the notion of empowerment, to dispel the myths that surround it and to find meanings that have useful application to the research project. The second, the insider/outsider dichotomy, discusses the negotiation of power, the notion of agency, the positions of the researcher and researched and who can be a knower in the research process. The third, the academy/community continuum, discusses the issues and implications of the positioning of this project within the university context, as a prerequisite for an academic qualification.

\section{Problematising Empowerment}

The concept of empowerment was popularised several decades ago in the liberation and community development discourses of Frantz Fanon $(1967,1990)$ and Paulo Freire (1970, 1994). Feminist theories and pedagogies have for generations sought to adhere to the emancipatory objective of 'empowerment' for women. Action researchers contend that action research can be empowering, liberating and emancipatory. But, what is empowerment? The status of empowerment as a sacrosanct tenet of individual, community and social development makes it difficult to scrutinise. However, scrutiny is unavoidable. A research process that declares empowerment as an objective becomes questionable when there is not rigorous attention given to what is meant by it. Participants, as they engage in a research project, rarely abandon the nature of relationships that exist outside of it.

Michel Foucault argues that projects may aim "to loosen, or even to break [constraints], but none of these ... can simply, by its nature, assure that people will have liberty. ... Liberty is a practice" (1993, p.162). Foucault argues further that if resistance to oppressive structures and practices succeeds, the oppressive structures and practices, rather than being negated, will continue - within a new set of identities (as cited by Hartsock, 1990, p.170). Although feminists, such as reported by Hartsock (1990, pp.157-175), are critical of Foucauldian theories of power, there is also concurrence with the concept of power as unstable. Beth 
Humphries, researcher and lecturer in Applied Community Studies at Manchester Metropolitan, for example, describes liberty as something that cannot,

be conferred [nor] gained once and for all. ... [It] is culturally and historically specific; and [it] is grounded in the struggle for survival of the most disadvantaged and the poorest, not in the privileging of the researcher or other groups as the norm or referent. (1997, para. 4.10)

Power dynamics can enter the research process with the participants and, if not examined and negotiated, may disrupt the potential for emancipatory change. It is unrealistic, I believe, to expect that the research process can be shielded or operate separately from the structural inequities that exist outside of it. The social change research project would not be necessary, should equal access to power and resources be a reality for all people. It seems to me then, that the task of the researcher and the research group is to acknowledge the power relationships that impact on the project and the participants within it and to actively involve these dynamics in the research processes. McTaggart responds to those critical of the potential harm that power imbalances can cause within the participatory action research process by asking "is the mere possibility of a power play a reason not to work with people, people who would regard themselves patronised by the suggestion that they could not walk away from work in progress if they were being used or victimised" (McTaggart, 1994, p.326)? Although I agree with McTaggart's assertion that those who are disempowered by the research process have the choice to walk away, I contend that the choice is not always a realistic one. McTaggart's claim that individual freedom exists within the research activity implies that he assumes an existence of individual freedom outside of it. If this were the case there would not be the need for research with an empowerment agenda. It is concerning that McTaggart, as one of the contemporary authorities of participatory action research in Australasia, can maintain that access to an empowered position is via individual choice.

Humphries discusses the contradictions in the culture of empowerment. She suggests that current discussion of empowerment is located within existing socially powerful groups and is "not the oppositional agency of the poor and disenfranchised but the enforcement of the concerns of hegemonic groups" (1996, 
p.13). Likewise Dr Maureen Gillman, Senior Lecturer at the University of Northrumbia, addresses the empowerment dilemma describing it as "masquerading as a radical and anti-oppressive practice. ... It also embraces dominant ideologies of personal achievement and individual responsibility" 1996, p.112). I recognise the irony of quoting Humphries and Gillman. As I engage in this research project from the privileged positions of employed middle-class, Pakeha and academic what distinguishes my processes as valid? The following section will concentrate on this question by addressing two arguments: firstly, the deficiencies of comparing empowerment and disempowerment as two separate and opposing states, and secondly, the necessity to expose those research practices that intend, but do not practice, empowerment.

There is a long history of debate among feminist theorists and practitioners over the concept of empowerment and the ideal processes and strategies to achieve empowerment. A central component in this debate has been the deconstructing of power and power relations with a view to developing practices that are freeing for women. An overview of some of these discussions is included in Bell \& Klein (1996), Humm (1992), Jaggar \& Rothenberg (1984), and Tong (1995).

Historically, feminist analyses tended to compare the gender category 'woman' with that of 'man'. They claimed the concept of the 'sisterhood' as that which represented a shared identity among women and which gave them power in the solidarity it seemed to create against a male dominated world. Those identifying outside of the category 'woman', which was white, middle class and heterosexual, were classed as 'other'. From the 1980s lesbian and black feminist activists such as Charlotte Bunch (1987), bell hooks (1995), Audre Lorde (1992) and Adrienne Rich (1986) challenged this position of 'other' assigned to them. In their challenge to the feminist movement, these feminist activists posited the view that dualistic paradigms such as male/female, heterosexual/lesbian and white/black did not allow the varying identities within each position to be evident. With this lack of analysis of difference within the category 'woman', they suggested, it was assumed that all women had similar access to power. Charlotte Bunch used the term "nonaligned feminism" (1987, p.46) to highlight the varying experiences of a diversity of women within the feminist movement. Although she was specifically addressing her resistance to the left/anti-left debate within the feminist movement 
at that time, Bunch was also challenging the exclusion and invisibility of lesbian realities. She and other lesbian feminists separated themselves from the mainstream women's movement because "it had been made clear...that there was no space to develop a lesbian-feminist politics and life-style without constant and non-productive conflict with heterosexual fear, antagonism and insensitivity" (Bunch, 1987, p.175).

Similarly black lesbian feminist, Audre Lorde, argued that by emphasising gender as the division, feminism denied racism and the recognition of black woman's difference. If "white women ignore their built-in privilege of whiteness and define woman in terms of their own experience alone," she wrote, "then women of colour become 'other', the outsider whose experience and tradition is too 'alien' to comprehend" (1992, p.49). bell hooks, Professor of English, New York, develops Lorde's statement by entreating white feminists to "consistently challenge white power-feminism so that [black women's] radical agendas are not completely erased by those white women who continue to support racism and white supremacy" (1995, p.102). Ngahuia Te Awekotuku, Maori, lesbian and Professor of Maori Studies at Victoria University of Wellington, acknowledges a personal dilemma when situating herself within the feminist context. On the one hand she rejects an association with those she observes as "white heterosexual careerists on the feminist platform" (1996, p.60). On the other hand, her resolve to be part of the international community of women, working with, and for, women requires her to claim the 'feminist' categorisation. Her resolution has been to give 'feminist a definition outside of that which is predominately accorded it and one that reflects her self-ascribed identities, "Maori. Lesbian. Feminist. Radical" (1996. p.60).

In the last ten years post-structuralist discourses have been developed by those feminists who have wished to negotiate a way around, and between, the multiple positionings of women. There has been rigorous debate between the proponents of post-structuralism, who see categories as fluid social constructs (Flax, 1990, 1997; Fraser and Nicholson, 1993, 1997; Nicholson, 1990; Scott, 1993), and those who see activism as reliant on the need to determine fixed positions of power and powerlessness (Bell \& Klein, 1996; Brodribb, 1992; Hartsock, 1987, 1990, 1997; Humphries, 1997; Stanley, 1990a, 1990b; Waters, 1996). The pluralities in the 
position 'woman' do need articulating and managing before there can be any notion of liberation for women. Feminists, who operate from notions of inequality (most commonly defined within cateories of gender race class and sexual

inuitupincity or existences and unereiore peipetuatung oppression oy limiting people to categories with fixed notions of opportunity. Alternatively post-structural feminists are challenged for their inability to identify and name structures of domination, thereby rendering them impossible to challenge.

Black feminist, Razia Aziz, declares a both/and stance when addressing the challenges aimed at the potential immobility created by post-structuralist thinking. Post-structuralism, she claims, "does not immunize us from the responsibility to locate ourselves relative to the political movements of our time. ... If a feminism of difference is to compete with reactionary forces ... it needs to incorporate both the deconstruction of subjectivity and the political necessity of asserting identity" (1992, p.304). Bell and Klein argue similarly. In a compilation of works by academics, political activists, community workers they challenge the inability of post-structuralism to forward the feminist cause. One of the contributors, Denise Thompson suggests that "the concept of a 'post-modern' feminism is a contradiction in terms because, while feminism is a politics, post-modernism renders its adherents incapable of political commitment" (1996, p.325).

Just as it is not feasible for feminists to develop effective ways of working toward the liberation of women from a dualist paradigm based on gender, so too is it defective to locate empowerment and disempowerment oppositionally (Humphries, 1996, p.7) as is often the case in discussion about the empowerment agenda of action research. The interdependence of relationships between empowered and disempowered groups makes strategies based on either/or analyses ineffective.

This research project has been built on the recounted experiences of mothers of adolescent boys, including a small group of women (one of whom is the researcher) who have been involved in an ongoing way with the project for four years. The interactions among this group of women exemplify the discussion about the intention to empower and the reality of the practice. The development of 
the research process and analysis of the findings has required us to recognise our multiple identities as mothers of adolescent sons. Within the project group power relations have varied according to ownership of and familiarity with the project, research ability, levels of difficulty with sons, and the amount of time and support available to the participants to be involved. As individuals relating to the 'rest of society', group members have been accorded value corresponding to such identities as ethnicity, socio-economic status and sexual orientation. As a group of mothers of adolescent sons yet another identity has been accorded us.

The abstract for the research proposal included the following statement, "It is hoped that through the project, participants will gain personal and collective insight and in turn help to challenge prejudices, contribute to the construction of new knowledge and impact on current social and political practices" (Chrisp, 1996, p.2). The intention to develop a research process that involves the empowerment of these mothers (myself included) is evident. But what of the practice? Kum-Kum Bhavnani, Associate Professor of Sociology at the University of California, writes "raising voices does not constitute empowerment, unless the analysis then produced takes full account of the power context in which the views have been expressed" (as cited by Bowes, 1996, para. 2.4).

An examination of the research processes within this project uncovers a multiplicity of tensions and contradictions. I am aware of the paradox of my own complicity in what I critique. That is, I am one of the subjects of the research, but I am also the facilitator of the research. One of the objectives of the research has been to develop strategies that will enhance our positions as mothers of adolescent sons. Nevertheless, as much as I aim to facilitate an empowering process with project participants, as facilitator I also maintain a position of control. The intention to empower can convey an implication that the participants are the receivers and the researcher is the one who bestows the power. One of the research participants wrote in her journal, "I remember that at our first group meeting I expressed the need to have a voice and that I hoped that you, Jill, would be a voice for women". Thankfully she went on to say,

the fact that I wanted you to be a voice for me implies that I didn't have a voice of my own. Since that time my attitude has changed quite markedly. ... because 
I have gained confidence that I already have a voice - my own. (4, February 1998 ).

The requirement for participation by individuals and groups in the planning, action, observation and reflection stages of the action research process offers one way of ensuring that the 'researched' make sense of the constraints within their own environments and test strategies deliberately to rid themselves of these constraints. The problematising of empowerment discourses leads us to investigate more closely the relationship between the key players in the research act.

\section{The Insider/Outsider Dichotomy}

The insider versus outsider comparison can refer to the difference between those who have experienced the issue(s) versus those for whom there has been no direct experience. It can also refer to the dichotomy of 'powerless insiders' and 'powerful outsiders', and of 'dominant' and 'other'. As has already been discussed, the creation of positions that are oppositional limits the ability for effective analysis. For this purpose, however, it is worthwhile examining the tensions and contradictions that become apparent when discussing the privileging and legitimising of voices within the research project, the negotiation of power and the agency of position. As described in the previous sections, feminist history recounts the many endeavours made by early feminist researchers to have women's experiences heard and validated and to develop paradigms other than those privileged by the patriarchy. As 'objectivity', 'fact' and 'truth' have traditionally been held as tenets of effective research, feminist qualitative work has been indicted as soft, incomplete and lacking in rigour and thoroughness. Of the many suppositions inherent in this view, one that is predominant claims that useful results can be gained only with distance from, and lack of contamination by, the subject.

Over the past twenty years growing numbers of researchers are recognising the dangers, particularly in the human sciences, of presumption in undertaking research 'on' groups from an outsider's position. Feminist researchers who take this stance suggest that the supposed 'value neutral' approach of conventional 
research is in fact "often a simple cover for patriarchy" (Oakley as cited by Reinharz 1992, p. 261) and that objectivity is the biased stance of privileged white males. Increasingly groups and communities that have been researched 'on' by visiting academics are resisting these approaches. These groups have realised that little has changed as a result of the research to improve their conditions or address their concerns. A current example in Aotearoa New Zealand is the resistance by Maori to being researched by non-Maori. Schools developing Maori research methodologies and practices at universities and whare waananga such as Auckland (Graham Hingangaroa Smith and Linda Tuhiwai-Smith) Massey (Mason Durie), Victoria (Ngahuia Te Awekotuku and Tania Rei) and Waikato (Russell Bishop) have been initiated. Growing numbers of Maori students are rewriting Maori epistemology. Although too numerous to list, and many are not yet published, the work of these students is beginning to appear in conference publications, journals and books reviews and in academic curricula.

Trinh Minh-ha, Professor of Women's Studies, University of California, and Associate Professor of Cinema at San Francisco State University, offers useful comment on the insider/outsider relationship in her paper Outside In Inside Out. She describes the fluidity of the insider/outsider position contending that the researcher,

looks in from the outside while also looking out from the inside. Like the outsider, she steps back and records what never occurs to her the insider as being worth or in need of recording. But unlike the outsider she also resorts to non-explicative, non-totalising strategies that suspend meaning and resist closure. (1991, p. 74)

Minh-ha also challenges the dichotomous relationship of the insider/outsider construct by being "both-in-one insider/outsider" (1991, p.75). Dr. Ranginui Walker, Professor Emeritus Maori at Auckland University, adds a note of caution to the claim that insider researcher is more valid than that undertaken from an outsider position when "the tools both are using are viewed by [insider] Maori as coming from the same deficit tool box" (as cited by Waitere-Ang \& Rahui, 1998, p.184). The necessity to change the 'tools' in order to rebuild new structures is encapsulated by Audre Lorde, when she argues, "the master's tools will never 
dismantle the master's house" (1992, p.54). Those 'inside', whilst conditioned by, and utilising, the structures of oppression, will not create new and equitable power relations or epistemologies. "The old patterns," adds Lorde, "no matter how cleverly rearranged to imitate progress, still condemn us to cosmetically altered repetitions of the same old exchanges" (1992, p.54). Hine Waitere-Ang and Maria Rahui, Maori Studies, Massey University, add to this when they write about their experience of being participants and researchers for a masterate thesis project in Maori Studies at Massey University. They ask, "how does the research process impact on those attempting to hold to their cultural identity while making the transition from being the object of study to positioning oneself as the researcher" (1998, p.184)? In an attempt to explain the relationships within and between the insider and outsider locations they have developed a research framework. Although the framework divides relationships into four fixed positions, I believe it goes a long way toward representing this debate. Figure 2:3 illustrates a section of the Waitere-Ang \& Rahui framework,

Position One: The researcher comes from a group different from the researched and dominant to it. Waitere-Ang and Rahui describe the researcher position as one of coloniser where "the objects of study are cast incapable of analytical understanding of their own lives and the forces that shape them" (1998, p.185). The assumption of this position is that accounts of a group undertaken by the 'expert' objective researcher are superior to accounts from people from within the researched group.

Position Two: The researcher is a member of the researched group, but undertakes the research from within a set of criteria established by the outsider and dominant group. This researcher is accorded ease of access to information from within the group but uses 'outsider' processes and parameters. Ironically the research outcomes, perceived by the outside group as generated by an authentic insider, are accorded increased validity. This insider-authenticity validation by the outside group further reinforces the dominant and deficit view.

Position Three: The researcher is a member of the researched group, but unlike the previous position, also recognises and negotiates her external status. This researcher develops a critical view of the dominant paradigms and challenges 
these presenting alternative explanations in collaboration with the research participants. The levels of this collaboration vary and attempts at representation can hide differences.

Position Four: The researcher is a member of the researched group but recognises that the insider position is not homogeneous and does not claim representation. "The knowledge of [insider] groups is more dynamic and diverse that can be encapsulated in any one person or research project" (Waitere-Ang \& Rahui, 1998, p.187). Research undertaken within this position results in the development and articulation of new knowledges that are authentic to the researched.

\section{Figure 0-3: Position of the Researcher and Researched}

(Source - H. Waitere-Ang \& M. Rahui, 1998, p.184)

\begin{tabular}{|c|c|c|c|c|}
\hline & Position 1 & Position 2 & Position 3 & Position 4 \\
\hline $\begin{array}{l}\text { Posifion of } \\
\text { Researcher }\end{array}$ & $\begin{array}{l}\text { External to the } \\
\text { group. } \\
\text { "Objective } \\
\text { rational } \\
\text { obsenver". } \\
\text { Coloniser }\end{array}$ & $\begin{array}{l}\text { Inclusion of } \\
\text { ethnically diverse } \\
\text { researchers. } \\
\text { Outside group } \\
\text { accords insider } \\
\text { validity }\end{array}$ & $\begin{array}{l}\text { Insider status } \\
\text { claimed and, in } \\
\text { collaboration, } \\
\text { representations of } \\
\text { the insider group } \\
\text { are generated }\end{array}$ & $\begin{array}{l}\text { Insider status } \\
\text { claimed. Insider } \\
\text { position not } \\
\text { necessarily seen } \\
\text { as homogenous. }\end{array}$ \\
\hline $\begin{array}{l}\text { Position of } \\
\text { Researched }\end{array}$ & $\begin{array}{l}\text { Subjective } \\
\text { object that the } \\
\text { research } \\
\text { process acts on }\end{array}$ & $\begin{array}{l}\text { Fundamentally } \\
\text { unmodified } \\
\text { although seen as } \\
\text { needing an } \\
\text { advocate }\end{array}$ & $\begin{array}{l}\text { Seen as a } \\
\text { participant in the } \\
\text { research process. } \\
\text { Varying levels of } \\
\text { collaboration } \\
\text { advanced }\end{array}$ & $\begin{array}{c}\text { Role of } \\
\text { participant } \\
\text { mediated by } \\
\text { cultural } \\
\text { parameters. } \\
\text { Collaboration } \\
\text { integral to } \\
\text { process. }\end{array}$ \\
\hline Outcome & $\begin{array}{l}\text { Normative } \\
\text { accounts } \\
\text { validated from } \\
\text { external sources } \\
\text { derived from } \\
\text { Western } \\
\text { epistemological } \\
\text { ontological } \\
\text { and axiological } \\
\text { positions. }\end{array}$ & $\begin{array}{l}\text { Normative } \\
\text { accounts further } \\
\text { entrenched through } \\
\text { endorsement of } \\
\text { outcomes by } \\
\text { researchers of the } \\
\text { same ethnicity as } \\
\text { group studied. }\end{array}$ & $\begin{array}{l}\text { Alternative } \\
\text { explanations/the } \\
\text { ories advanced, } \\
\text { mediated by } \\
\text { participant } \\
\text { understandings }\end{array}$ & $\begin{array}{l}\text { Cultural } \\
\text { epistemological, } \\
\text { axiological and } \\
\text { ontological } \\
\text { philosophies } \\
\text { articulated. }\end{array}$ \\
\hline
\end{tabular}

Although my personal philosophical objective locates me within Position Four of this model, my experience as researcher within the mother-adolescent son project has fluctuated between Positions Two and Four. The rest of this chapter will discuss the reasons for the fluctuation by addressing some of the dilemmas of undertaking research from an insider position for academic study. The 
insider/outsider dichotomy will be dealt with in four separate parts. The first part will examine the construction of 'otherness', which details the marginalising of the researched. The division between objective fact and subjective experience will be considered next, followed by a discussion of the 'power' relationships among and between those inside and outside of the research project. An examination of the impact on the project of the multiplicity of positions of the researcher as researched concludes this section.

One difficulty associated with insider/outsider discourse is that it tends to create an 'othering' of difference. Those described as inside are viewed as different, situated outside the dominant societal norm and constructed as deficient. Patricia Maringi G. Johnson, Senior Lecturer in Maori Education at Massey University contributes to the increasing voices of Maori who are challenging discourses that define "differences negatively and as marginalised and othered" (As cited by Waitere-And \& Rahui, 1998, p.29). She describes how Pakeha, as the dominant ethnic group in Aotearoa New Zealand, have used their privilege as researchers to decide what counts as difference and used these definitions of difference to describe, analyse and construct Maori "ways of knowing and being, so that [Maori] barely recognise [them]selves in the final reports" (As cited by WaitereAnd \& Rahui, 1998, p.34).

Feminist social researchers have been grappling with how to manage 'woman' as an object of enquiry for the past decade. Those who experience their chosen identities as invisible have increasingly challenged research strategies that assumed 'woman' as an identifiable subject. For them it has been important to recognise and declare the differences between women, including their multiple and contradictory identities. Along with the declaration of difference, an examination of the power relationships and connections between positions of difference is necessary. The danger of ignoring these relationships comes close to the creation and demotion of 'other' as described by Johnson. An ongoing obligation of this research project has been to find the balance between the highlighting of differences and creating a marginalised 'otherness'.

The object/subject divide is another factor for examination in the insider/outside debate. Bhavani, commenting on feminist endeavours to develop emancipatory 
practices, suggests, "persuading the academy that experience must be integral to social analyses ... can mean that experience becomes privileged, and thus becomes the claim to an unchanging truth" (1997, p.44). Privileging experience as the truth works well to challenge traditional superiorities of scientific empiricist thought. The danger of advantaging experience over observation, however, is that it can also silence disagreement and make difference within the group invisible, as demonstrated in the third position in Waitere-Ang and Rahui's framework above. Bhavani describes her experiences of erasure, denial, invisibility and tokenism as a black woman when 'women's experience' is represented as a global sisterhood of commonalties, when 'the truth' of experience does not allow for the uncovering of inequitable practices between and among (in this case) women (1997, pp.27-49).

In concurrence with Bhavani's caution about the privileging of experience, several considerations need to be made with regard to this project. Merely giving voice to our experiences as mothers of adolescent sons through the use of interviews, oral histories and focus group sessions is insufficient. Liz Stanley, Professor of Sociology at Manchester University asks how experience can be compared across different groups when "being a woman has such different resonance, entails different experiences, is constructed through different forms of social expression and regulation" (Stanley, 1997b, p.1). In this project I have needed to develop a research framework that could, firstly, situate the participants against a background of the distortions and limitations accorded to mothers of adolescent sons and, secondly, make visible the differences between the participants.

Linda Tuhiwai-Smith, Associate Professor in Education and Director of the International Research Institute for Maori and Indigenous Education at Auckland University, challenges the claim of 'authentic' as it is assigned by the dominant group to the insider group. Addressing the relationship between research and indigenous peoples, she argues,

criteria used to assess the characteristics of authenticity are frequently the topic of conversation and political debate [that] are designed to fragment and marginalise those who speak for, or in support of, indigenous issues, [and] have the effect of also silencing and making invisible the presence of other groups within the indigenous society. $(1999$, p.72) 
There is a further consideration in the objectivity versus subjectivity debate. The creation of these as oppositional implies that they are not able to work together in the research act. Distinguishing the objective/subjective split, Trinh Minh-ha speaks of 'subjective reasoning' and 'subjective feeling' (1991, p.74), the former from an outsider position and the latter the insider. Although I question the implication that the 'insider' is unable to reason, Minh-ha's recognition that subjectivity exists inside and outside the researched group and that all positions are interpretive, is useful. With the recognition that absolute objective truths do not exist inside or outside, the possibility of connection between the positions can exist. Minh-ha affirms this co-existence when she describes the researcher as "two sides of a coin" (1991, p.75). The two positions co-exist in a complimentary relationship. She takes the discussion further by defining subjectivity as a "science of the subject" and declares that,

[a]wareness of the limits in which one works need not lead to any form of indulgence in personal partiality, nor to the narrow conclusion that it is impossible to understand anything about other peoples since the difference is one of essence. (1991, p.76)

An either/or relationship between insider and outsider positions does not allow for the potential of either to create and inform the other. In the interaction of experience and analysis, practice and theory, it must be possible for the researcher to invite discussion of personal experience or the recounted experiences of the researched whilst also scrutinising the social institutions that act to shape individual and collective identities and experiences. If knowledge is objectified by the combining of a number of individual and group experiences, then a symbiotic relationship between objectivity and subjective experience must exist. The research method used in the mother-adolescent son project is based on participation and action. Separate individuals have worked together to determine a reality from the subjectivity of their perspectives. This reality may be challenged. Having been created by a specific group it does not claim to reflect the realities of another. Whilst recognising the non-generalisability of the research outcomes an arrival at a shared reality is imperative for the collective social or political change agenda. Maybe this location can be defined as subjective/objectivity. 
As well as being the principal researcher in this project I am one of the participants. In the research process I, too, am subject. This has highlighted a number of issues around the researcher-researched relationship. I am a participant but I am also more involved in the project than the other participants. I also have more to benefit from it, as this society privileges academic achievement by enhancing individual access to resources and well paid positions for those with 'higher' qualifications. This raises questions such as: Who is the research for? Whose voice is privileged? How is information used? Who benefits from it? These questions developed as key guiding points as the work progressed.

Stanley discusses the relationship dynamic among women when academic research and theorising occurs. "Theory with a capital T", she suggests, is

one produced by theorists who are supposed experts on the relationship between categories and thus on the 'real meaning' of social experience and behaviour. Here 'academic feminism' becomes the legitimation for a new form of expertise, that of feminist theoreticians over 'mere women'. Whether as an intended or unintended consequence, feminist social scientists working with such assumptions necessarily position themselves as experts on and over other women's experiences. (1990, p.24)

Stanley's concerns about the colonising of women's experiences by academic theorists were taken seriously within the project. There were factors contributing to the contexts of the relationships that impacted on the information gained from that interaction. For example, after an interview session, participant expressed a feeling that she hadn't been 'clever enough', that she hadn't 'given me' enough information to work with. "I have only told you my story" (1), she said. Her statements concerned me for several reasons. Apart from the fact that she was not recognising the significance of her own story and demonstrating little ownership of the project, she was also putting herself in a position of inferiority to the project and to me as a researcher. Another wrote in her journal,

I was so concerned that maybe I was in the group under false pretences and that I should withdraw. It worries me that I seemed to have gained so much (which 
was completely unexpected but maybe hoped for unconsciously) but where are you with your goal for the project. (1, April 1997)

This participant did not initially measure the degree of her worth by her contribution to the project as a mother to an adolescent son, but rather by her 'academic' contribution. Her statement generated a further question. If the information produced by her was filtered by a wish to offer something she defined as worthwhile, what had been left out? The research 'findings' were deficient. These comments indicated to me that I needed to approach the research differently. An unequal power division was operating between the insider/outsider, researched/researcher positions. I needed to negotiate before effective and justifiable research practices could occur. It was important for me to recognise the difficulties arising from outsider and insider positions connected in such a way that empowerment would become an injection of power from powerful outsiders to powerless insiders (Long \& Long, 1992). The deliverer/saviour relationship is a trap for researchers working with emancipatory paradigms. My concerns about the initial comments recorded above were dispelled, however, by further entries in participant journals. They demonstrated at least two emancipatory dynamics. The first was the process of learning and the benefits articulated by the participants from being a part of a working group of other mothers of adolescent sons. The second was that the mothers believed they could access their own personal power and speak for themselves. They did not require an intermediary and therefore avoided the potential dependency on the researcher to speak for them.

An examination of the multiplicity of the positions of the players in the research act offered one way of uncovering some of the complexities of being engaged in empowerment based research. In order to facilitate effective research processes, I needed to understand my roles within the project and the contexts of my relationships with the other participants. One issue facing me in the working relationship with the other participants was a philosophical clash with my own training. Training I have undertaken in interviewing and effective listening has stipulated the use of open ended questions, of keeping one's own issues and agenda out of the interaction, of reflecting the speaker, of keeping their issue/story in front. A few months into my first round of interviews the participants at a group 
session asked for more input from me in the discussion. They wanted to know who I was, how the issues we were talking about affected me and what were my own issues. I realised at that point that if I expected women to tell me about their lives at a personal level, that they deserved in return a willingness from me to share with them information about my personal life and feelings. I realised, too, that unless I was prepared to take the risk of making myself vulnerable in the process, I was acting as if I had superior understanding. It was this elitism that could have caused for us as researcher and researched the loss of potential empathy that is possible between people with similar life experiences. Researcher Cynthia Chataway, reports Maguire, worked to silence herself in order that she did not influence the participants in the participatory action research project she was part of. She discovered however that maintaining one's silence "[did] not just allow space for the other to speak, it [could] also be an act of power that force[d] the other to carry the burden of speaking or acting if any relationship [was] to be maintained" (as cited by Maguire, 2000, p.64).

Reinharz supports the notion of self-disclosure, contending that it promotes "meaningful conversations" by "reformulating the researcher's role in a way that maximises the engagement of the self " (1992, p.34). Likewise Kathryn Anderson, Associate Professor of Speech Communication and Director of Women's Studies at West Washington University and long-term writer on woman's oral history, discusses the methodological shift that oral history interviews demand, "from information gathering where the focus is on the right questions, to interaction, where the focus is on process, on the dynamic unfolding of the subject's viewpoint" (1991, p.23). Conversely social work researchers Bombyk, BrickerJenkins and Wedenoja, caution against interviewer disclosure because of the potential restrictions that it can have on the interaction. They discuss the importance of pace and watching for clues to gauge the readiness or desire of the participants to know the researcher (1991, p.33). Anderson expands on this by warning the interviewer against stepping outside an attentive, facilitatory role to one of director. The director role, she suggests, can have negative effects by prioritising the researcher's agenda and by being potentially invasive of privacy. Claiming that the impersonal interview is neither possible nor desirable, Oakley rejects classical sociological interview methods that claim objectivity and neutrality. Referring to her experience conducting interviews for a project on 
childbirth she describes interviewing women as a 'contradiction in terms' (1981. pp.30-61). The women Oakley interviewed frequently wished to engage with her in a way that was outside the conventional research methods she had been taught.

Clara Greed Senior Lecturer in the Department of Surveying at Bristol Polytechnic, discusses her experience as a feminist surveyor undertaking research on the position of women in surveying. She states, "I am studying a world of which I am part, with all the emotional involvement and accusations of subjectivity that this creates" (1990, p.145). Greed effectively describes my experience with this project, as the weight of another woman's pain has sometimes made a mockery of the boundaries that have existed in the relationship. For example, the research has raised many issues for participants including those that have been hidden, forgotten or unconscious. It has not been appropriate for me, as researcher, to fill a therapeutic or social worker role. However I have constantly questioned where my responsibility lay. What was my role when a mother painfully described the physical and emotional abuse of her fifteen year old son toward her? How was I to respond when another mother discussed her fears about her son's 'unusual' sexual activities? What was I doing when women offered their innermost thoughts during individual interviews or group discussions and I spent the next stage objectifying them ${ }^{4}$

One of the benefits of the formation of the longitudinal focus group has been the links that have developed between the women outside of the formal research times. For example, at a group session near the end of the first year one of the participants sparked a discussion about Christmas by talking of the emotional and financial difficulty she had been experiencing as a single mother at that time. That year she received several calls and offers of company from other women in the participant group. For the following years Christmas became an ongoing topic of discussion and a time for the developing of survival strategies.

\footnotetext{
${ }^{4}$ Part of the nature of the research, and that it demanded the formation of relationship among participants of the research meant that I was not able, or willing, to disassociate myself from the difficulties they were experiencing. Although it was not my role to endeavour to meet the needs of the participants, the Code of Ethics required that appropriate support be offered.
} 
I experienced a further set of issues in my role as researcher within the project being both 'inside' and 'outside' of the project. I am a mother who has raised a son from his twelfth to seventeenth years and ridden the roller coaster of his adolescence during the length of the project. As I have worked with mothers who were also experiencing, or reflecting on, their own positions as mothers of adolescent males, I was also intensely involved in the exploration, analysis and theorising of my own experience. I began the research motivated by a feeling of powerlessness as a single mother of a teenage boy facing the Aotearoa New Zealand judicial system. Five years later, I have spent hours talking with mothers, boys, academics and practitioners, gathering information through visual, audio, video and electronic media, reflecting and writing, and raising my son. Has my growing exposure to the issues, my investigations, reflections and analyses created an expertise that takes me outside the problem and set me apart from the realities of the 'other' mothers? Has it made me a different mother? Has it set me apart from the way my own realities as a mother would have developed had I not begun this process?

If these questions have answers at all, they have not appeased the tensions I have felt as a researcher in this context. Asking the questions, however, has assisted me to ensure the congruency of the methods used in the research processes by continually modifying and enhancing them. Asking the questions has also demanded an ongoing examination of my own positions in the multiple activities of the research project. The complexities of my positioning are evident when I attempt to describe my identity. For example, as I related to the research project I was all of, but not limited to, a woman, a mother, lesbian, a student, a teacher, a manager, chair of the local secondary school Board of Trustees and a researcher. In electing, or being granted, any one of these categories in a particular situation, the possibility of the multiple other categories has existed. Each category, and combination of categories, has been varyingly legitimised carrying with it a differing, chosen and/or conferred, status in the negotiation of power and in the right to be a knower. During the research process varying identities belonging to me were privileged at any one occasion. This has impacted on outcomes produced from each research instance. 
In a study of young feminist women, Helena Court, including herself as a participant and grappling with her simultaneous roles as researcher and researched, claimed that "a number of difficulties arose out of this decision to be both researcher and researched". By making her analysis more transparent for the reader, her "decision to be both researcher and interviewee actually worked to increase the strength of my voice in the thesis" (1995, p.129). Whilst seeking for ways to negotiate the fluidity of her positions as researched and researcher, Court refers to the work of Chela Sandoval's "shifting gears strategy" which, she explains, enables her to "read the current situation of power and of selfconsciously choosing and adopting the ideological form best suited to push against its configurations" (as cited by Court, 1991, p.23).

Likewise for the individual members of the researched group a multiplicity of identities was operational at any one time. We had in common a shared identity as mothers of adolescent sons. Apart from that a wide range of variables including socio-economic status, ethnicity, age, academic education, and sexuality marked our differences. As researcher, I endeavoured to ensure that our shared identities did not generalise our experiences whilst simultaneously working through the differences to find those points of commonality from which strategies for change could be developed.

The research methodology developed for this project needed also to be cognisant of the social structures that impacted on the project and its processes. This meant avoiding a researched only focus. As structural analyses illustrate, empowerment of individuals and groups at all levels of the system can facilitate and support social change strategies. For example, the members of the longitudinal participant group describe a sense of strengthening abilities to mother their adolescent sons. However, if the practitioners who work with them, the teachers, the counsellors, the lawyers and judges, are not themselves empowered to develop effective and equitable practices in working with the mothers or their sons, then the potential for structural change is limited. This project was charged with the responsibility to develop strategies for structural as well as personal change and to discover the link between structural determination and individual agency. 


\section{The Academy-Community Continuum 5}

Midway through the doctoral research project, as my student-relationship with the university began to develop more structure and some urgency, further methodological challenges emerged. To be able to produce a successful doctoral dissertation, the research needed to be legitimated by the university. This created a set of complex contradictions. The needs of the university, my needs within the university context, and the needs of the project participants and the 'community' of mothers raising adolescent sons seemed disparate. Although the issue of incongruities in the relationship between the academy and the community is not a new problem for researchers interested in transformative research practices, it is one that requires attention. The dilemmas are many. As academics, relying on the academy for a living, we can respond to its demands in order to maintain our position within it while, at the same time, recognising that this thwarts or diverts our energies that could be used for community and social change. We may seek to be legitimised by the academy, and to benefit from our connection with it, whilst also wishing to challenge its hegemonic practices. We may use the academy to validate research findings whilst recognising that this quest for validation could colonise the research.

Stanley links the institutionalised processes of gate keeping that determines academic production with a materialist analysis of production. She outlines the similarities between modes of production in societies and "the academic mode [that] has a particular set of politics and ideology as part of the conditions of its existence" (1990a, p.4). For academics in the tertiary sector to compete effectively within the academic market, to be promoted and to stay employable, production and publication is required. Within most of the tertiary institutions in Aotearoa New Zealand publication is an outcome of job performance. Stanley argues that, as reflected in the competitive models outside the academy, the resources required to produce published material are also not equitably distributed. Hierarchical

\footnotetext{
${ }^{5}$ One could argue that the academy was within the community. For the purposes of this discussion I am defining community as that which is made up of the collection of individuals and groups outside of the organisation of the institution. This definition recognises that individuals move between the categories, community and academy. When classed as community, however, these individuals and groups have little influence or direct benefit from being associated with the academy.
} 
differentiations exist within the organisation, between types of disciplines, between students and teachers and between levels of qualifications sought and taught. Mary Jo Deegan and Michael Hill, teachers of Sociology at the University of Nebraska, also refer to the effect of external agencies of control, "professional organisations, collegial friendships and access to capital and time" (1991, p.325), on academic expectations. Linking this with Stanley's suggestions that academic production correlates to market forces, the theme of information production and control develops further. A potential outcome for this project is that a government driven economically and socially by right wing market forces could resist the recommendations from this work; one of which proposes that a major factor influencing current negative statistics for adolescent boys is the poverty of the single mother family.

It is not only the time and energy that is required to maintain the production, but the manner in which the work is produced, the packaging. In other words, the publication source for academic accolade is not the New Zealand Women's Weekly, The New Zealand Listener or even the long-standing New Zealand feminist magazine, Broadsheet. Yet it is these sources that are most accessible to the mothers with which I wish to communicate. Australian Anna Yeatman, the first Professor of Women's Studies at the University of Waikato, Aotearoa New Zealand, acknowledges that in some disciplines, "such as Women's Studies and Maori Studies - [academics] are accountable also to extra-university constituencies of those who make claims on them through shared political and movement affiliation" (1997, p.140). She also defends the right for academic feminists to communicate in academic language. Multi-lingualism, or communicating across "different contextually bound dialects and modes of rhetoric" (1997, p.140), as a key strategy for bridging the academy/community gap provides one position to work from. Interestingly, and disturbingly, Yeatman does not perceive that all academic disciplines have accountability to communities outside the university.

Theresa Ann Sears, Associate Professor of Spanish and Literature at the University of Missouri USA, writes about institutional feminism and women within the academy. She builds on the dual accountabilities, the intellectual and the political, described by Yeatman by adding a third, the personal. "Attempting to 
formulate a philosophy", she says, "that is at once therapeutic, ideological and analytical ignores the inherent contradictions between the methods that each implies" (1997, p.269). Sears falls short of offering a way through the dilemma of multiple identities and conflicting accountabilities. However the argument she makes that there are multiple dimensions to 'feminist' is useful.

I reflect on some of my earlier thinking when I was involved in establishing Women's Studies at the local tertiary institution. My questions at that time were similar. I had been involved in community development work with women in one of the suburbs who talked about the perceived lack of access to tertiary education. With them I had been part of a district-wide research project examining the Learning Needs of Women in [city]. One of the outcomes of this project was the establishment of a multi-faceted Women's Studies programme. The programmes attracted a wide range of women including those who were operating at survival level both physically and emotionally. Although, through the Social Welfare funded Training Incentive Allowance ${ }^{6}$ course fees and course-related costs were covered for women on the Domestic Purposes Benefit ${ }^{7}$, issues of feminist theory and epistemology were far away from the immediate priorities of most. This motivated me to question the connections between "the street, the kitchen sink, morning coffee in the women's space, and discussions about whether postmodernism is post-feminist" (Chrisp, 1992, p.62)? Were we an agent of social change or a source of the de-radicalisation of women? We were teaching students, at various levels, to deconstruct sexist, heterosexist, racist contexts and structures and yet we contributed to, and personally benefited from, an organisation that used sexist, heterosexist and racist practices.

Considering the requirement for political change to ensure that progressive curricula and pedagogies are supported within the academy, American academic Joy James maintains that few academics are willing to "engage in the type of activism and restructuring necessary to supplant tokenism. ... Privilege may reduce our primary preoccupation in academia to struggles for accreditation and

\footnotetext{
${ }^{6}$ A government training benefit granted to long term beneficiaries.

${ }^{7}$ A government benefit granted to single parents.
} 
legitimacy from the intellectual representatives of the 'new' world order" (1996, pp.43-44). I contend that if the community is not recognised within the institution, or if certain privileged societal sectors only are recognised, then education serves no other purpose than to continue the existing structures of discrimination. Likewise research processes and paradigms that are compliant with the norms of academic legitimacy are also in danger of perpetuating those very structures they may claim to be challenging. Reflecting on the passage of male and female action researchers in the academy, Maguire argues that male action researchers have been able to progress through the university structures with more support and privilege than their female counterparts. "Feminist-inspired action research", she claims, "challenges us to consider how we create spaces for all voices to be heard as well as how we use our voices to unsettle power differentials wherever encountered" (2000, p.64).

A further perspective is offered by Daphne Patai, Professor of Women's Studies at the University of Massachusetts, who discusses the ethical incongruities of the "dual allegiances" (1991, p.138) confronting feminist researchers when using other women as subjects of research. The tensions, as she sees them, reside in the contradictions between the obligation of feminist scholars to their academic disciplines and institutions, and within which they wish to have impact, and the feminist objective of transformation politics. She challenges the emancipatory claims of 'empowering' research designs that stem from the academy:

The problem for us academics, who are already leading privileged existences, resides in the obvious fact that our enjoyment of research and its rewards constantly compromises the ardour with which we promote social transformation. At the very least, it dilutes our energy; at the most, it negates our ability to work for change. ... [It is not] possible to write about the oppressed without becoming one of the oppressors. (Patai, 1991, p.139)

Donna Matahaere-Atariki, teacher in Community Studies and Family Studies at Otago University, Aotearoa New Zealand, expands on the potential for the academic to perpetuate oppressive practices as she describes the tensions she experiences as a Maori woman within the academy. "In our desire to speak on behalf of our silenced [Maori] sisters, we may be in danger of participating in 
their continued exclusion" (1998, p.73). She describes one experience of being perceived by non-Maori as available to speak on, be knowledgeable about and representative of any issues that confront all Maori women:

I am not suggesting that we remain silent - this is an abuse of the privilege we accrue as academic women - but in our readiness to speak on behalf of Maori women we must be attentive to those mechanisms of power that allow us to speak yet also distance us further from other Maori women. (1998, p.73)

Likewise Linda Tuhiwai Smith reflects this theme as she discusses the impact of the representation and re-contextualisation of Maori images, social customs and stories through formal academic structures. She suggests that the way she and other Maori, "re-present [them]selves to [them]selves and to others, has clear implications for notions such as authenticity and traditional tikanga or customs" (1998, p.102). How does research driven within an academic context maintain integrity to its sources? My own research project offers an example of potential colonisation. As researcher I have been involved in parallel activities. Firstly I have facilitated a collaborative research process that has had development outcomes for the participants and secondly I have collated and represented the information. As a mother of an adolescent son researching the lives of mothers and adolescent sons I was able to claim an insider privilege. I was more likely to be regarded as an ally by the participants of the project than someone who is not a mother of adolescent boys. The participants were encouraged to respond to me as someone who had some experiences in common with them and who could identify with issues they raised. This created a relationship of trust and solidarity and the level of disclosure was enhanced. As I worked to enhance the level of trust the participants had with me, however, I was also gathering information that was to contribute to the dissertation written from this research, a dissertation that must be legitimised by the institution within which I am enrolled if I wish to achieve a doctoral degree.

Deegan and Hill recognise the tensions for the doctoral student when they write about "the student's search for a professional self "within the "bureaucratic and capitalist milieu" of the institution. Although in their article they are primarily discussing the development of the professional writer, Deegan and Hill also note 
the existence of a powerful structure of authority and legitimisation within the academic world (1991, p.325). Immunity to this process is difficult, they argue, particularly when endorsement is sought from the institution. It is tempting to ensure that the findings of the mother-adolescent son research project are constructed and represented in ways appropriate to the expectations of the academy. If I do not meet the expectations, the work is perceived as invalid. If I do meet them, however, and if the academy accepts lived experience as a contributor to authenticity, it will grant me 'insider expert' status and accord added authority to the outcomes. Decision makers in relevant policy and practice areas may use the research to develop and resource new or amended policies and procedures. If the realities of the researched have been concealed in the process of gaining academic sanction, these policies and procedures may not meet the needs of the researched.

In addition the researched could be limited in their ability to challenge the research outcomes. The justification for questioning authenticity, that it has stemmed from a researcher who is outside the research and therefore alien to it, is not valid. The research has been undertaken by 'one of their own' and representation is assumed. The researched may have identified the issues but through a process of 'legitimisation' are alienated from the outcomes. They are fed back their own answers but the answers may be unrecognisable and unidentifiable. If so, deficit views become further entrenched. Position Two in the model advanced by Waitere-Ang and Rahui (Figure 2-3) illustrates this process.

McTaggart describes his experience with the Deakin University and Batchelor College Teacher Education (D-BATE) Programme "Investigating Bicultural Education in Aboriginal Schools". He writes of his attempts to negotiate the community/academy divide by working to resist "criteria which would legitimate research in academic eyes [and] to pose a way of working which [would] make research reporting credible and useful to participants and others" $(1998$, p.8). Is this an ideal or is it realisable? I have yet to find a research project, participatory or otherwise, that is not affected by the contexts within which it strives to exist. The D-BATE programme may have contributed to change in teaching practice and knowledge bases among Aboriginal communities in the Northern Territories of Australia. The writing about this programme, however, has attracted challenges 
originating from a variety of sources. McTaggart (1998) reports being challenged by the academy for the large amounts of time spent in the project without producing publications, by the Aboriginal teachers for the seeming self-serving motivation of academy-based researchers and by the Northern Territories Department of Education who required that the department be involved in editing Aboriginal students' work.

There are further tensions in the relationship between the academic and community worlds. Using a capitalist model, on which the societal structures of modern Western societies are predominately based, commodities increase in value the more scarce they are and the more currency they earn. Competition for professional positions predetermines an increased valuing of post-graduate qualifications and those who hold these qualifications have an investment in maintaining their scarcity. If desired knowledge and skill transfer was the responsibility and domain of all people, the academy would lose its ability to monopolise the ratification of specific knowledge and the favouring of those who hold that knowledge. It is not, therefore, in the interest of the academy to ensure that knowledge and skill acquisition becomes a community owned and directed benefit.

The social change oriented researcher operating from within the academy is caught between opposing forces and motivations. For some this brings the research to a standstill; the researcher can never 'get it right'. My challenge is to continue knowing that I am not going to get it right. My hope is that maybe I will get it more right than last time. For the sake of the participants the risk needs to be an informed one. The tensions require constant deconstructing, the complexities must be explored and acknowledged openly and the dilemmas made transparent. Along with the search for new or uniquely reworked knowledges there is, I contend, a need for the exploration of new research processes and ways of representing the knowledges.

\section{CHAPTER SUMMARY}

Speaking to an artists' and writers' convention as a black political leader in the struggle to free indigenous Africans, Sekou Toure is reported in Fanon to have 
said, "there is no place outside [the] fight for the artist or for the intellectual who is not himself concerned with and completely at one with the people in the great battle of Africa and of suffering humanity" (1990, p.166). In this chapter I have attempted to theorise the methodological choices made for this project by recognising the difficulties related to empowerment oriented research, the complexities of being 'inside' and 'outside' the researched group and the dilemmas of undertaking social change research within the academy. Methodological issues rising from this research have included five themes. Firstly, that the research needs to be informed by structural analyses. Secondly, that methodological processes and tools that enable this analysis to occur must be determined. Thirdly, equitable participation in research does not necessarily mean that research participants contribute equally. Fourthly, that there is an obligation on the researcher to solicit sanctioning of the research by the structures of legitimisation in a way that does not silence or boundary the voices of the researched. Lastly, that exploitation of the research subjects through the research processes and agendas must be avoided. 


\section{CHAPTER 3}

\section{SPECIFIC RESEARCH PROCESSES}

Chapter Three describes the processes developed for the project in response to the issues discussed in Chapter Two. It outlines the research methods and processes engaged in the project. These included; semi structured interviews with twentyone mothers of adolescent sons, a longitudinal focus group with seven mothers of adolescent sons, journaling with the longitudinal focus group and drawing interpretation with one hundred and seventy six boys. Throughout the project an exploration of existing writing, research and other published material has been ongoing. This material has contributed to the methodological, theoretical and content components of the work. The first section of this chapter outlines the research design and comments on the outcomes. The second section links the methodological objectives of the project as outlined in Chapter Two to those specified by the longitudinal focus group. The following two sections describe the process of collecting, collating and analysing the data gathered from the fieldwork. The final section addresses issues of validity and credibility as they apply to the research methods utilised.

As a member of the longitudinal focus group, I have been 'in the text' of this research. This has created issues around the sometimes-conflicting roles of researcher and researched. These issues have been addressed in Chapter Two. The personal and academic supervision contracts developed during the project included the need to be guided through these insider/outsider tensions. As with the others in the longitudinal focus group, my research journal has reflected my own growing awareness of myself as a mother of an adolescent son and as a researcher. 


\section{DESIGNING AND IMPLEMENTING THE RESEARCH PROCESS}

\section{The Longitudinal Focus Group}

The main research tool for this project was a longitudinal focus group of mothers of adolescent sons who progressed through the feminist action research model. This group would meet throughout the duration of the project, contributing to the research data through individual interviews, journaling and group discussions. It was formed from an advertisement placed on August 16, 1996 in the local newspaper that read,

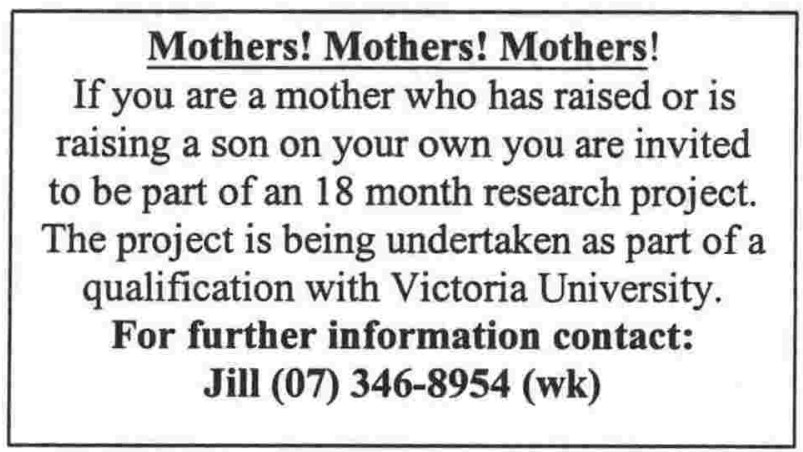

Six women responded to the advertisement and on September 24, 1996 they met with me to discuss the project, my reasons for initiating it, my expectations and the expectations of the research as it related to the university. We also discussed the reasons mothers had responded to the advertisement. As part of this meeting we also negotiated the following:

- Group Contract - Ground Rules (Appendix 3.1).

- Foci of the semi-structured individual interviews (Appendix 3.2).

- Interview Contract Form (Appendix 3.3).

- Code of Ethics (Appendix 3.5).

- Schedule of individual interviews. Timetable for the next group sessions.

- Methods of collecting data.

The Group Contract was designed by members to establish an agreed understanding of the way they wanted the group to operate throughout the project. The development of a group contract is a common method used by facilitators and 
groups to ensure that safety and trust is maximised and that the work of the group is enhanced.

The foci of the semi-structured individual interviews aimed at providing a loose structure to the interviews. Although informants were encouraged to tell their own stories, the questions provided a framework from which comparisons could be made and themes drawn. They also guided discussion around the specific issues of the research topic.

The Interview Contract Form offered individual informants some ownership of the interview material. It was given in conjunction with a summary of the implications of the Privacy Act (1993) to the interviewee (Appendix 3.4). The contract form was discussed before the interview took place. However a number of the interviewees chose not to complete some of the details and sign the contract until the interview was completed or they had read their transcript. Several felt that until they knew what had come from the interview they were not sure whether, or how, they wanted the recorded material to be used, how they wished to be identified or whether they wished to withdraw from the process.

The development of a Code of Ethics was an important aspect of the research process. The project had received ethical approval from Victoria University of Wellington and was guided by the ethics of that institution. However, because of the nature of the project and the potential for personal information to be disclosed, it seemed important to involve the longitudinal focus group participants in writing an ethical code for themselves. The additional components they specified were incorporated into the project Code of Ethics. These concerned:

- Care against any abuse of power of the participants by the researcher or the research process.

- Availability of support for participants should it be required as a result of their involvement with the project.

- Provision for information dissemination

- A process which included a transfer of skills.

Concrete examples of support for the participants involved the payment of transport costs, the provision of meals at focus group meetings, stamps and 
envelopes for the return of transcripts and the ability for participants to transfer to me the charges for phone calls when required.

At this first meeting women also discussed their reasons for being part of the group. The objectives they had for the research were outlined as follows:

Mother 1 had a son in his late teens and although she felt that she had parented him well as a single mother, she also felt blamed for some difficulties they had experienced. She was involved in the group because she wanted people to know that single parents can do a good job.

Mother 2 had a seven year-old son and wanted an open relationship with him, as his father wasn't there. She was involved in the group because she wanted to learn to be a better parent.

Mother 3 had two sons in their middle and late teens. She felt very positive about how she was raising her sons. She felt that she had broken a cycle of dysfunction by leaving her alcoholic husband. She was involved in the group because she wanted people to know that single parents could do it.

Mother 4 had two sons in their early and mid teens. She was involved in the group because she felt single mothers of adolescent sons needed more of a voice because of the strain on the family and on parenting. She believed that institutions and politicians needed to know the realities, and injustices, of raising sons as a single mother. She also wanted the issue to be aired on the Kim Hill Show'.

Mother 5 had a son in his early teens. She was involved in the group because she wanted to share issues of raising sons with other single mothers. She felt that men treat women differently because they are single, that women were subject to 'put downs'. She also wanted to improve the way she parented her son.

Mother 6 had a son in his early teens. She was involved in the group because she felt that the situations for mothers raising sons were not recognised. She wanted to

\footnotetext{
${ }^{1}$ The Kim Hill Show is a state-funded National Radio programme that is run from 9.00 am to 12 noon each weekday morning and includes interviews with key people around current issues.
} 
talk with other women about their experiences and strategies. She also wanted to develop ways to effectively parent her son.

Mother 7 had a 10-year-old son. She was involved in the group because she wanted to have a voice. Her solicitor was the only person who had heard her story and she had much feeling and emotion about her experiences. She had felt worn down by constant put downs and fighting with the boy's father who did not acknowledge or want involvement with his son. She wanted to talk with other women about their experiences and strategies, and to develop her own ability to parent effectively.

Although there were individual differences among the women, the common objectives developed by the group were to:

Objective 1: talk with other women about their experiences as single mothers of raising adolescent sons

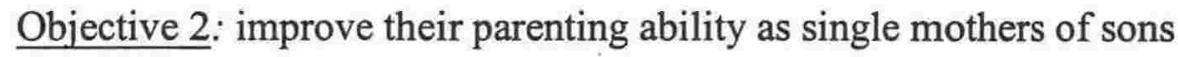

Objective 3: highlight the issues facing mothers of adolescent sons

Objective 4: improve the situation for single mothers of sons

The group also talked about how the above objectives would be reached and how the information they had would be collected and collated. It was at this point that the decision was made to use semi-structured individual interviews, audiotaped focus group discussions and individual journaling.

It was decided that I would interview all participants before the following group meeting. This would allow each participant to tell her own story in confidence. None of the interview transcripts would be available to other group members. It would also give mothers a chance to focus on the issues before the next group discussion began. During 1997 the results of the individual interviews from this group were transcribed along with the one-off individual interviews that had been carried out with mothers from throughout Aotearoa New Zealand. In February 1998 the themes from the combined transcriptions were discussed with the group. 
This group of mothers became the sounding board for other information that was collected throughout the project. A focus group is defined by Carl Davidson, founder of an Auckland-based research company and Martin Tolich, senior lecturer in Sociology at Massey University, as "a group discussion focused around particular issues" (1999, p.123). According to Davidson and Tolich focus groups provide a "powerful technique for gaining an insight into the opinions, beliefs and values of a particular segment of the population". The strength of focus groups, they contend, is in "the relative freedom that the group situation gives participants to discuss issues of concern" (1999, p.123). Lynne Alice, then Associate Professor in Women's Studies at Massey University, suggests that focus groups have become popular as a feminist research tool because they "have as their basis a promotion of the value of investigating social situations through subjective knowledges and the life experiences of the respondents" (1999, p.65). Dr Anita Gibbs, research officer at the University of Surrey compares focus groups, which she suggests "elicit a multiplicity of views and emotional processes within a group context" with individual interviews, which she says "aim to obtain individual attitudes, beliefs and feelings" (1997, p.2). The emphasis with focus groups is, according to Gibbs, on the interaction of the group members.

Much of focus group research to date has involved one-off sessions with a range of groups offering varying perspectives on one issue. A recent research project in Aotearoa New Zealand, for example, was undertaken by researcher Rae Julian (1998) as part of the 'Fathers Who Care: Partners in Parenting Project' on behalf of the Office of the Commissioner for Children. This project, Focus on Fathers, used seven focus groups of men and seven of women who met once. Each focus group was differentiated from the others by gender, ethnicity, age of participants and children, employment, family status etc. Feminist researcher, Gill Callaghan, used a similar focus group method when she investigated the interaction of gender, class and place in women's experience. She organised eight focus groups of women who were already attending mother and toddler groups. She met once with each group to facilitate a discussion about the participants' experiences of work and domestic relations. Participants in these focus groups were encouraged to talk about issues that shaped their experiences and consciousness. By using focus groups in this way Callaghan saw value in the lack of anonymity and the avoidance of "some idealised objective account" (1998, para. 4.4). 
Charles Waldegrave (1999), director of the Family Centre Social Policy Research Unit, used a focus group method similar to that used in this project, as part of a study of poverty in Aotearoa New Zealand. He created two sets of focus groups, one group for women only and the other for both women and men. Each group held three sessions. During each session discussion was held about poverty issues specific to the group. Similarly, the mother-adolescent son project has used a focus group model with a sociological research objective. The group of seven women, whose homogeneity included gender, marital status and mothering boys, met for eleven sessions over a period of three and a half years. The group used the cyclical participatory feminist action research approach. This approach gave participants the opportunity to be part of a process that involved sharing their experiences as mothers of adolescent sons, analysing these experiences, collecting information, developing group and individual strategies to test over the next period of time, and planning subsequent activities. These evaluation points were integral as they determined an ongoing auditing of the research processes. The participants did not have to depend on 'final' outcomes of the research to benefit from it. By being involved in the project the members of the group were gaining knowledge and enhancing their skill base.

As a participant-facilitator of the group sessions I encouraged ownership of the project by the other participants and devised with them a process for collecting, collating and making sense of the information. My dual participant/researcher role meant that the gathering and collation of information involved my story. I was also part of the change. The evaluation points in this project have provided the opportunity for all participants to recognise and reflect on the changes in their positions as mothers of adolescent sons and to explore the implications these changes have had to their on-going decisions and activities. The act of obtaining knowledge has created potential for change in the issues the research was investigating. The research operating symbiotically with action has changed that which it was investigating by the act of the investigation. The groups' responsibility for defining, modifying, directing and evaluating the research has created the potential for powerful and far-reaching consequences.

Eleven group discussions were held between September 1996 and November 1999. Six of these sessions were audiotaped. For the five sessions that were not 
audiotaped, written notes were kept. These tended to be workshop-type sessions and involved:

- An initial meeting to establish the group (September 24, 1996).

- Analysis and development of the themes collated from audio-taped transcripts (February 19, 1998).

- Collation and discussion of the Drawing Project outcomes (May 24, 1998).

- Review of the chapter structure and material written to date. (June 26, 1999).

- Discussion about future directions. (December 4, 1999).

The following two figures provide a summation of the longitudinal focus group research processes. Figure 3.1 shows the chronological interaction between the individual interviews, the drawing project and the group sessions. Figure 3.2 presents an overview of the outcomes of the eleven focus group sessions, the key issues raised during each one including issues of research process. The details of the outcomes of these group sessions contribute to Chapters Four, Five, Seven and Eight. 


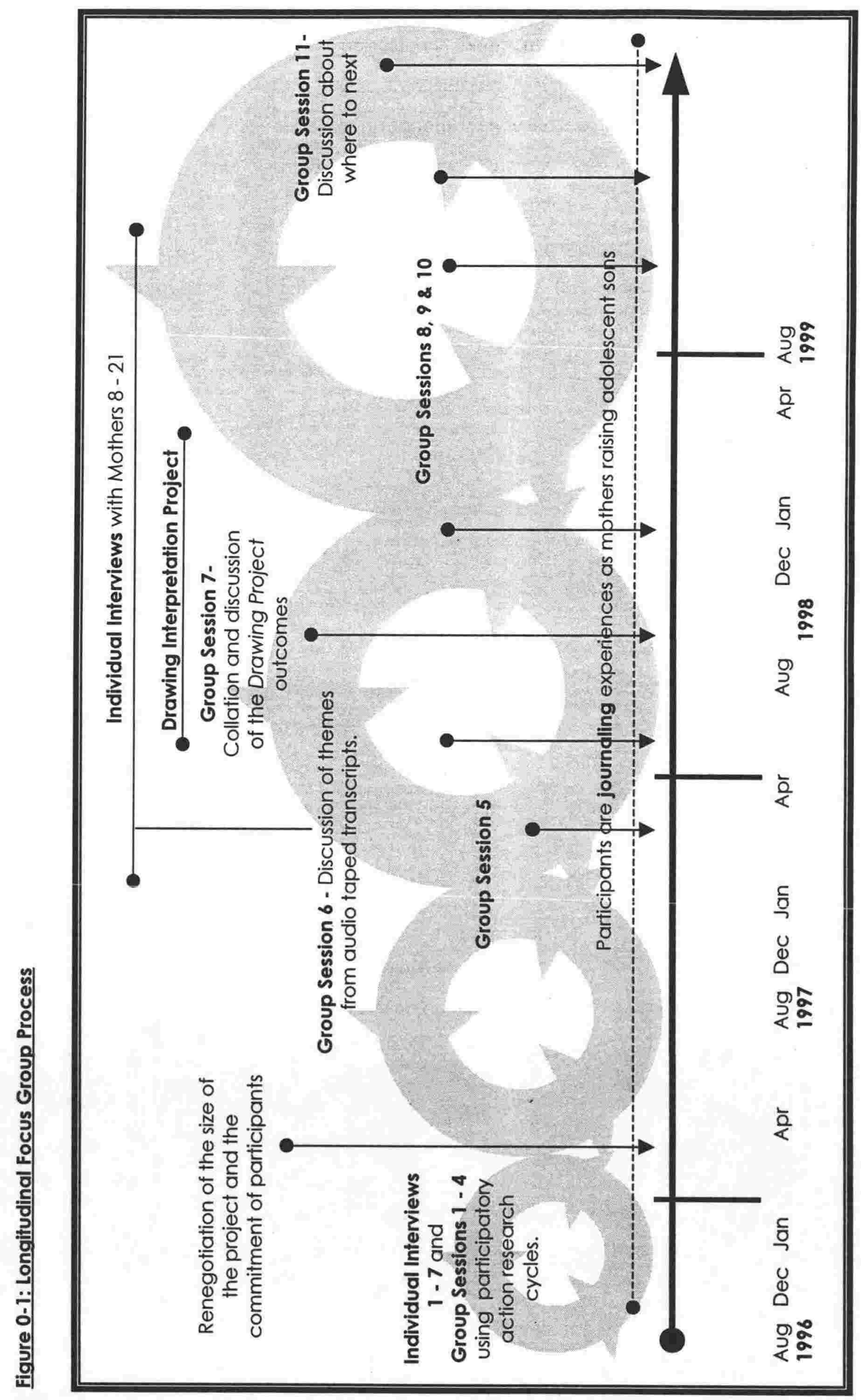




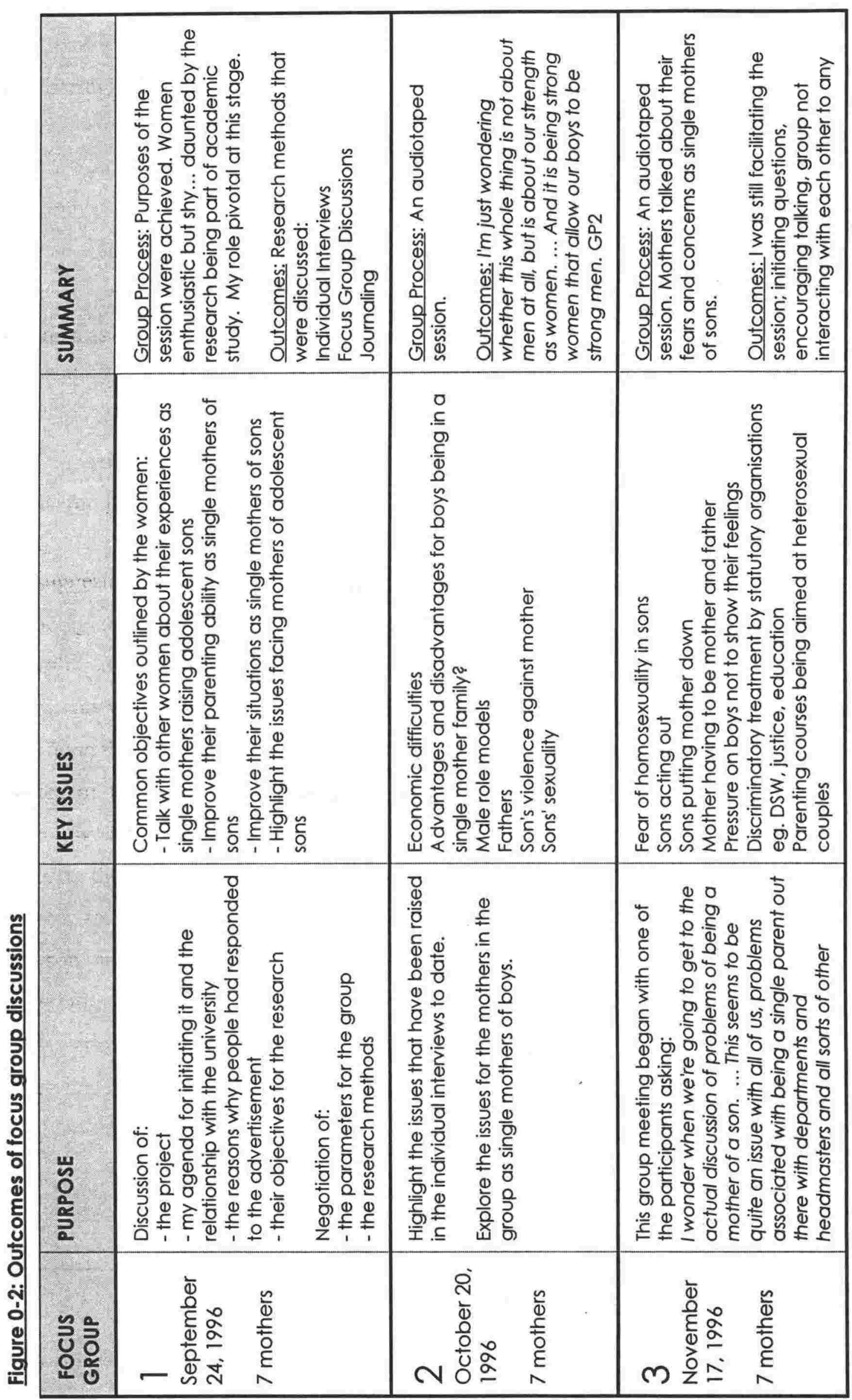




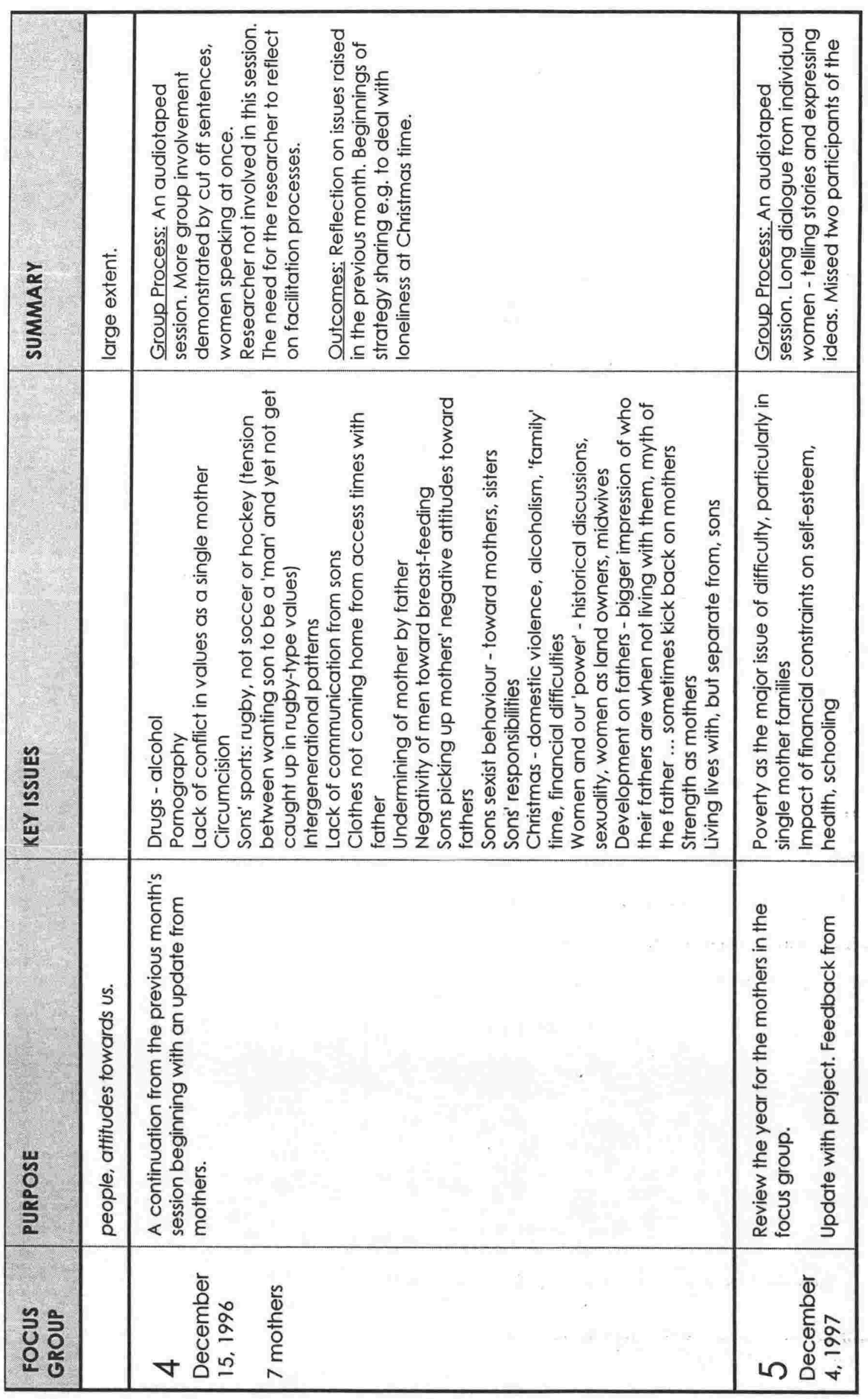




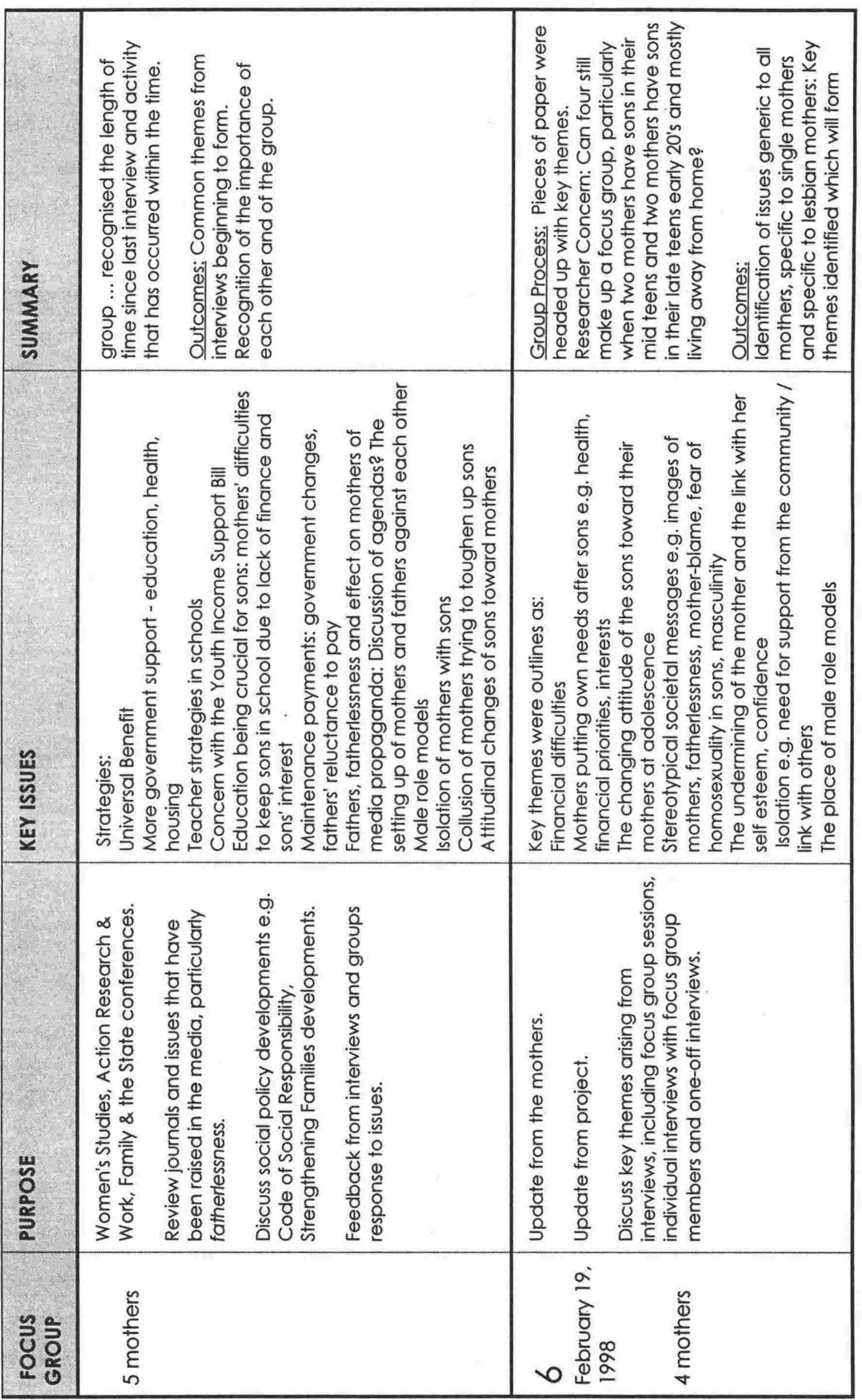




\begin{tabular}{|c|c|c|c|c|c|c|c|c|c|}
\hline 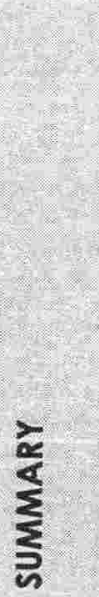 & 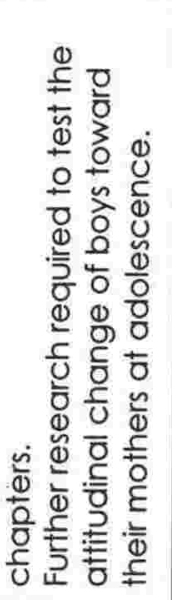 & \multicolumn{4}{|c|}{ 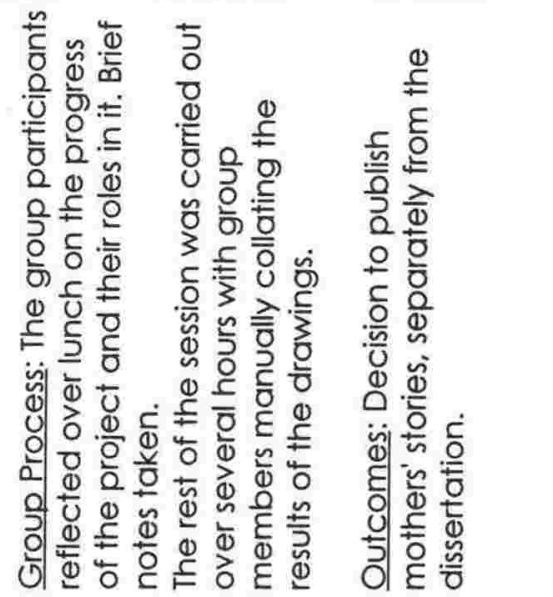 } & \multicolumn{3}{|c|}{ 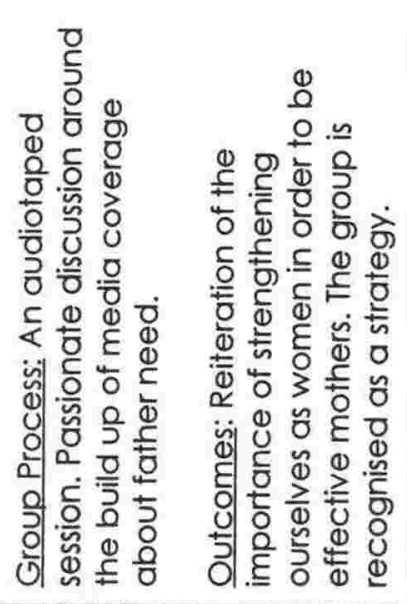 } & 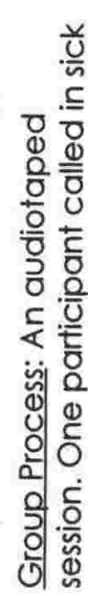 \\
\hline 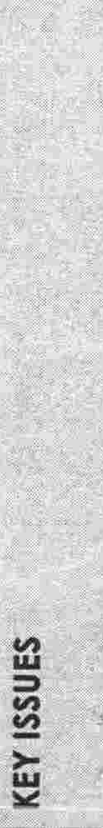 & 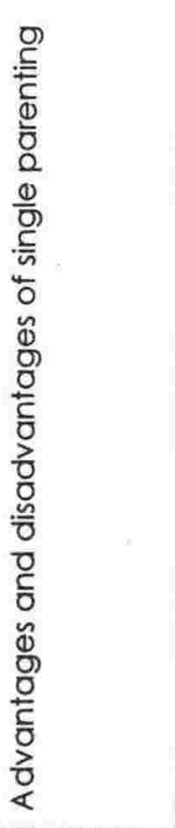 & 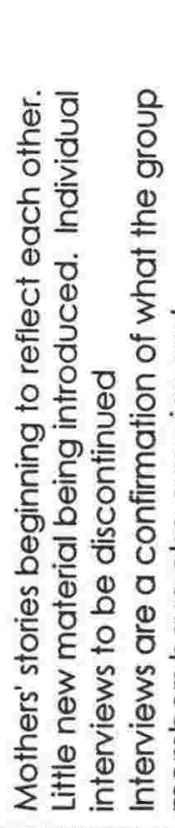 & 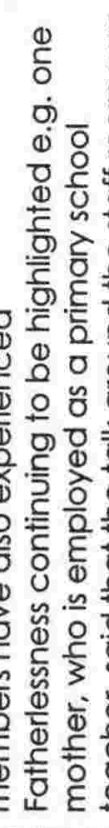 & 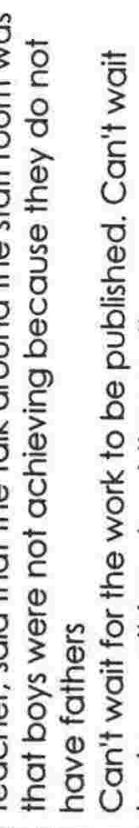 & 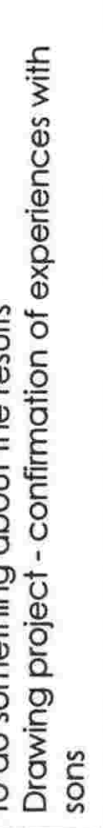 & 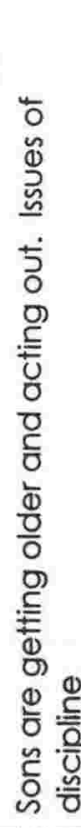 & 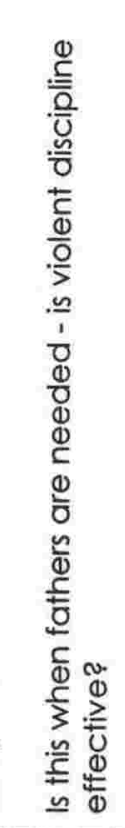 & 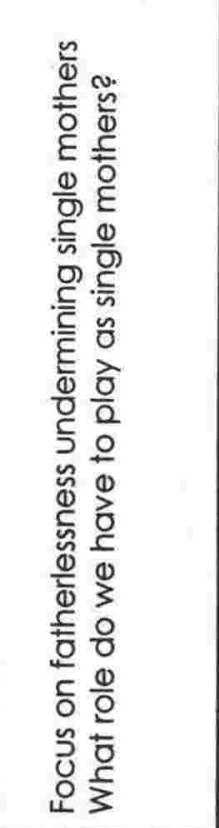 & 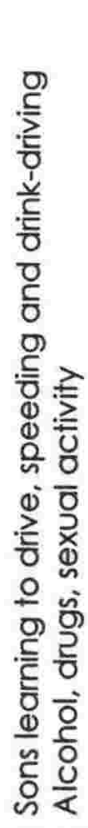 \\
\hline $\begin{array}{l}\frac{w}{5} \\
\frac{\alpha}{\alpha} \\
\frac{\alpha}{a}\end{array}$ & & 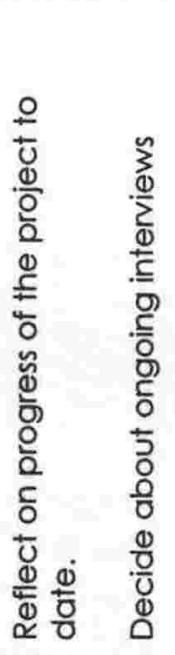 & 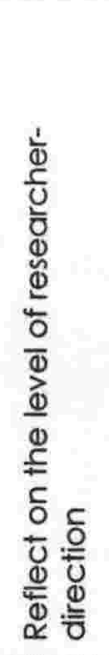 & 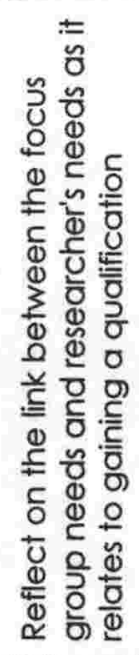 & 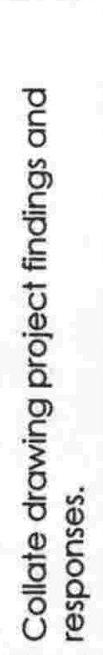 & 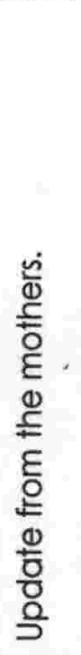 & 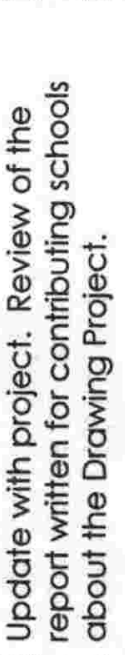 & 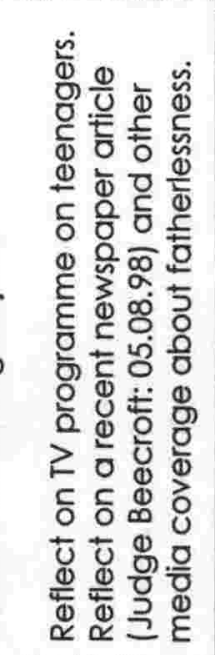 & 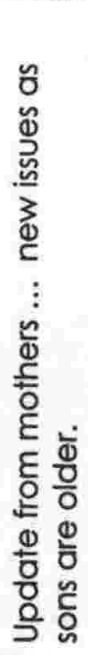 \\
\hline 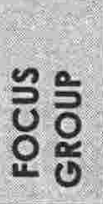 & & 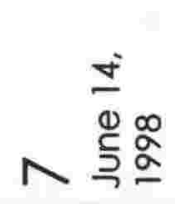 & 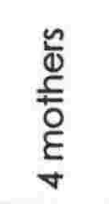 & & & & 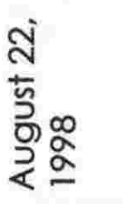 & 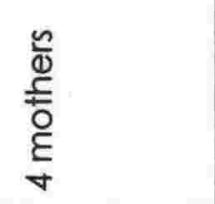 & $a$ \\
\hline
\end{tabular}




\begin{tabular}{|c|c|c|c|c|c|c|c|c|c|c|c|c|c|}
\hline \multirow{2}{*}{ 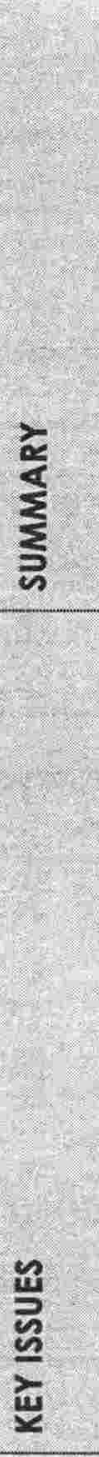 } & \multicolumn{3}{|c|}{ 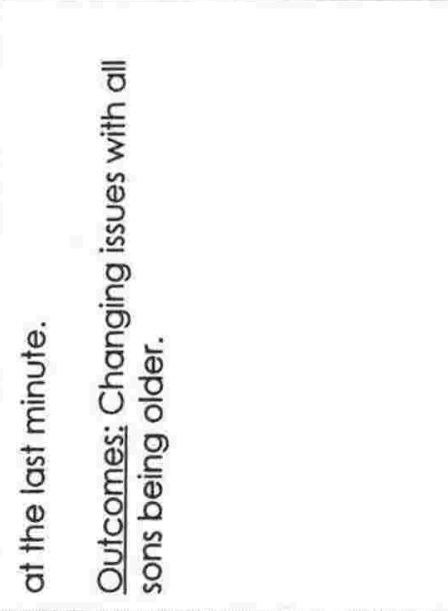 } & \multicolumn{5}{|c|}{ 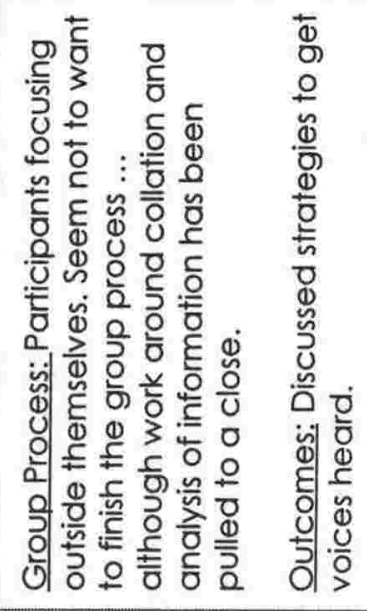 } & \multicolumn{4}{|c|}{ 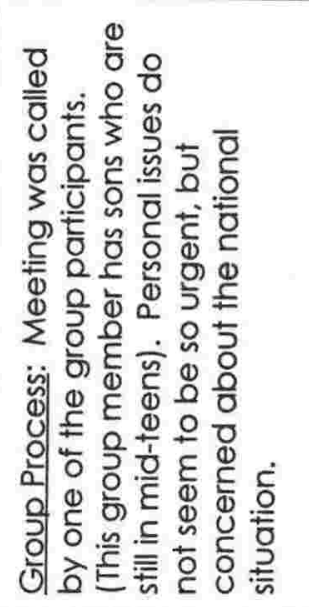 } & 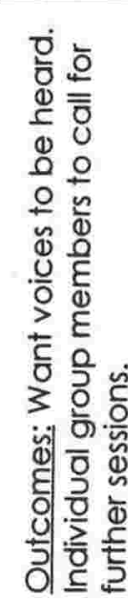 \\
\hline & 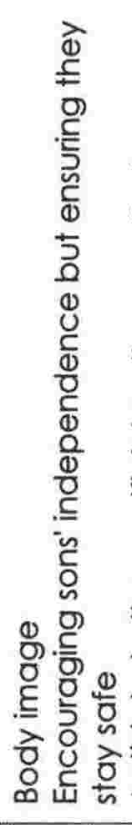 & 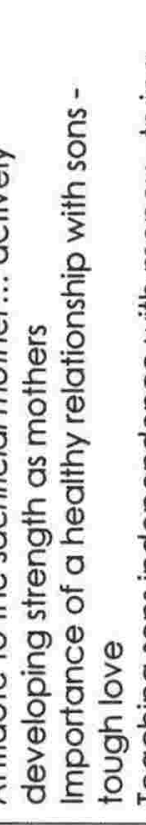 & 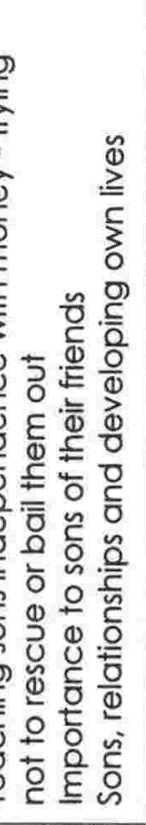 & 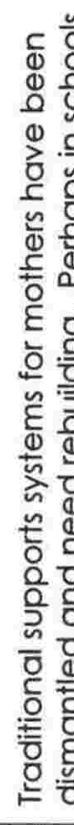 & 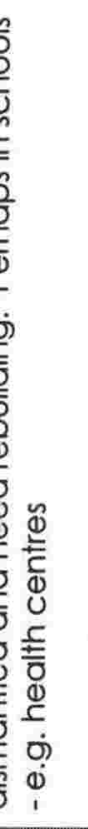 & 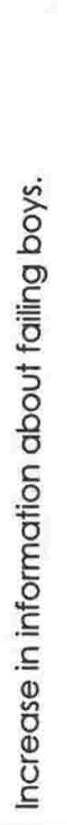 & 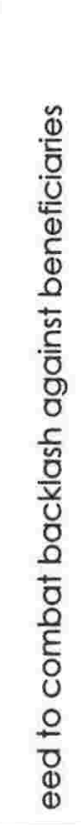 & & 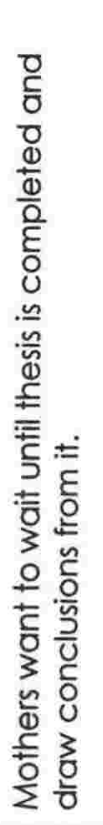 & 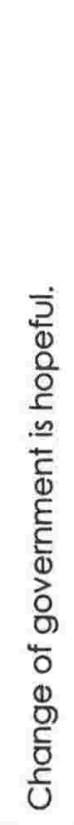 & 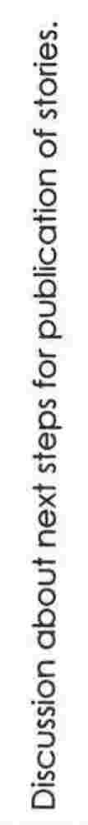 & 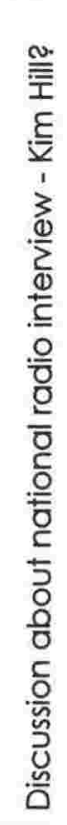 & \\
\hline $\begin{array}{l}u \\
\text { ő } \\
\frac{\alpha}{\alpha} \\
\frac{\alpha}{2}\end{array}$ & 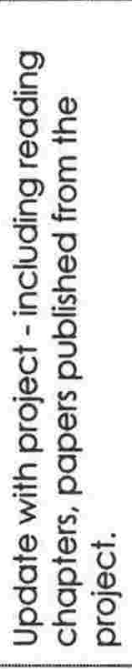 & 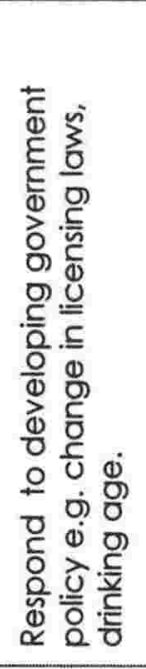 & 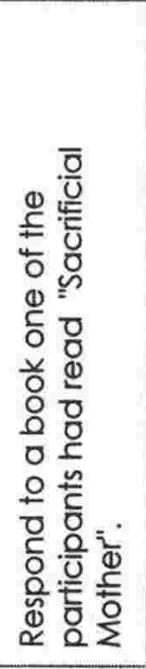 & 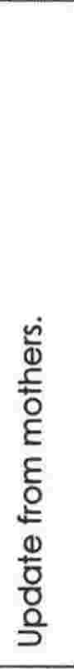 & 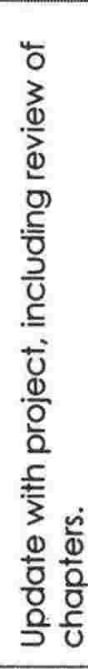 & & 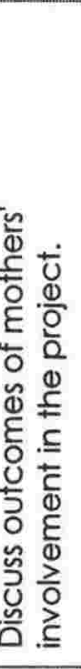 & 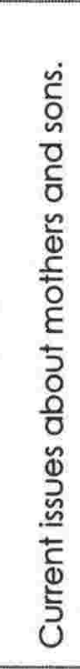 & 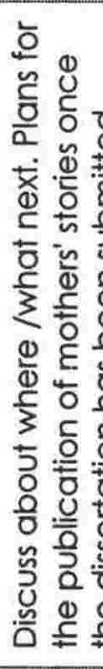 & & & & \\
\hline 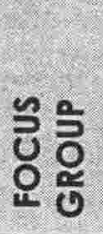 & 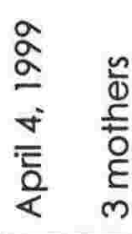 & & & & $\begin{array}{l}\sim \\
\stackrel{0}{5}: ~\end{array}$ & & 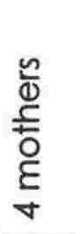 & & - & 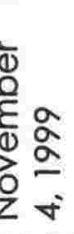 & 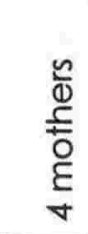 & & \\
\hline
\end{tabular}




\section{Journaling}

It became evident early in the project that being involved in the research was motivating changes for participants. Questions raised either in one-on-one interviews or within the focus group sessions were catalysts for thinking processes that altered the way we responded to and acted upon our worlds as women and as mothers to our sons. I wanted to capture these changes as reflection and process points of the research, and invited the participants to create their own research journals with a request that they would be part of the documentation of the situation and transition of the participants. Although the journals were to be about us as women and as mothers of sons, there was no structure provided for their contents. The ideas that generated from discussion about what to incorporate into the journals included; personal comments and reflections, experiences, difficulties and successes, and responses to external factors.

As I could not assume that all participants would be comfortable expressing themselves in this way, journaling could only be optional. As it transpired, all participants were initially keen and the reflection that occurred through initial journaling activity contributed to focus group discussions. However, only three of the four participants from the remaining group chose to continue with their journals and submit them as part of the collective data for the project. The journals that were submitted have provided a rich source of data about the ongoing experiences of these participants and the links between their experiences and their public and private contexts.

Louise Corti, research officer at the University of Essex, suggests that diaries in social research can be "used to supplement interview data to provide a rich source of information on the respondents' behaviour and experiences" (1993, p.1). British health researcher $\mathrm{H}$. Elliot reports on her use of diaries in a sociological research project on the health levels of participants. She describes a 'diary-interview' method in which diarying and interviewing is undertaken simultaneously and suggests that the usefulness of journals lies in their ability to access "phenomena which are not amenable to observation because they ... take place outside set time or environmental boundaries and are likely to be altered by the presence of an observer" (1997, para.2.8). The diary-interview method described by Elliot seemed most aligned to the use of journals in the mother-adolescent son project 
As with the participants in the project Elliot also found that "[s]ome informants warmed to the task of diary-keeping more than others". In her study of women's health experiences one of the participants withdrew (from the diarying component of the research) after one week, as she "could not see the point in writing about her 'boring' life" (1997, para. 4.3).

Elliot claims that the use of diaries/journals ${ }^{2}$ is as yet undeveloped in social research, which is partly substantiated by the dearth of methodological literature available that refers to it. A recent social research publication, Social Science Research in New Zealand (1999), for example, does not mention either diaries or journals as a research method. Neither does the American sourcebook, Qualitative Data Analysis (1994), nor Reinharz's popular feminist research text Feminist Methods in Social Research (1992) document the use of journaling in research. There is sound potential in using journaling as a method of data gathering and in hindsight, more extensive use of journals could have been possible in this project.

As suggested by Reinharz (1992), change for the researcher can be a consequence of being involved in a research project. The recording of my own story has contributed to the documentation of the project. I have attempted to recount the situations within which I have found myself, my responses to these and the questions that have emerged from my responses. Whilst listening to the ongoing stories of the mothers' experiences I have also been in an evolving state of parenting. Recording my own processes, standing back and scrutinising my own context, the factors impacting on it and my responses to these has provided another set of unique experiences. Activities around me, particularly relating to my son and his friends, have intruded into my thinking while writing this dissertation and have consequently influenced this work. When these situations seem particularly pertinent I have included them as part of the material in the following chapters.

\footnotetext{
${ }^{2}$ I use these terms synonymously. I am yet to read that there is a significant difference in more than terminology.
} 


\section{Semi-Structured Interviews}

Although journaling has been relatively ignored as a social science research tool, debate about interviewing is profuse. The range of interviewing styles is extensive. Interviews can be used for qualitative and quantitative research and, as a methodology, can be located at various points along a continuum from structured to unstructured. They can involve ethnographic models (Rubin \& Rubin, 1995; Sissons, 1999; Stacey, 1991) where the researcher is involved with the interviewee over a period of time; surveying models that involve structured, usually superficial, questions with many interviewees (Hoek and Gendall, 1999); oral history methods that involve the relating of life experiences and personal narratives (Gluck \& Patai, 1991; Marin-McDonald, 1999; Moodie, 1998; Stanley, 1992); and unstructured interviews (Opie, 1999; Reinharz, 1992 \& 1997; Rubin \& Rubin, 1995) that are shaped by the interviewees' direction and priorities.

In the case of this project the interviews were semi-structured and involved the interviewees in oral history, storying current situations and analysing their own social and structural contexts as mothers of sons ${ }^{3}$. The themes for the semistructured interviews are shown in Appendix 3:2. In all, not including the eleven focus group sessions, twenty-seven interviews were held with twenty-one women. Most interviews were between sixty and ninety minutes long with several continuing for slightly longer. The interviewees who were not part of the focus group became involved in the project in different ways. They were either directly invited by the members of the focus group, or offered to contribute because they had heard about the project. Three responded to a notice posted at a community centre in Auckland (Appendix 3:7), four approached me after papers had been given at various conferences, six became involved through word-of-mouth and one was the transcriber of the initial set of six audiotapes ${ }^{4}$. The remaining seven were part of the focus group.

\footnotetext{
${ }^{3}$ For further discussion on the use of oral histories in feminist participatory action research refer Chrisp, J. (2000a)

${ }^{4}$ It was appropriate that she ceased to transcribe for the project after this point. It is interesting to note that sections of her interview are interestingly reflective of the comments from the interviews she had transcribed.
} 
The interviewees lived in six different areas in the North Island of Aotearoa New Zealand. In all cases I travelled to the areas where they lived and the interview was held at a venue acceptable to the interviewee. Before each interview began, the potential interviewee was briefed about the project and had the opportunity to clarify any issues she may have had. The participant was given a copy of the Code of Ethics and a summary of the Privacy Act 1993 that explained how she, as the person interviewed, was affected by the Act (Appendix 3.4). The participant was invited to sign an interviewee contract form that assured confidentiality and safety and sought clarification about such things as interviewee name, inclusion/exclusion of certain information and disposal of interview tapes (Appendix 3.3).

Two different people transcribed the interviews. Each of them signed a Contract for Services (Appendix 3.6), part of which included a commitment to the ethical standards of Victoria University of Wellington and the Code of Ethics developed specifically for the project. Once the interviews were transcribed, a copy of the transcript was sent to each interview for verification and editing (Appendix 3.8) along with a stamped addressed return envelope. Once returned, they became part of the project data. At this point in the process there was an unexpected outcome. Several of the participants expressed how things had changed for them since the interview had occurred and that the reading of the transcript had provided an effective point of reflection.

For me reading the transcript has been a very good benchmark and aid to reflection. I'm so much happier and clearer and I think less hard on myself than I was a year ago. Doing the tape forced me to attempt to articulate, clarify and then resolve some painful things. (10)

In a paper discussing an action research literacy project with Puerto Rican women in East Harlem, New York City, Rina Benmayor talks of the act of telling one's own story as an "active component in the process of transformation" (1991, p.164). Describing the life history account as "more than a vehicle for documenting and interpreting the past" she talks of "the potential of testimony as a research strategy to study [and impact on] affirmative, empowering identities and practices" (1991, p.164). For one participant this process of transformation occurred during the interview. Early in the tape she describes herself as "quite 
bossy and pretty domineering". Later in the interview she says, "I've realised that I've used that word domineering. In fact it's probably not what it was. That was what we're conditioned to believe, whereas in fact ... we're being strong" (8).

A less positive outcome from the return of the transcripts was the concern expressed by participants about their seeming lack of coherency. One wrote, "this is the first time I've received a transcript of an interview with me. I was horrified by my ravings; I wonder how you make sense of it at all (9). Another wrote, "a bit incoherent I thought but if you can get something out of it that's great" (11) and another, "lots of it seems to me like absolute "gobbly-de-gook". Occasionally I appear to manage stringing a full sentence together" (8).

It has been a bit of a marathon going through this. I was quite shocked to reread it. The level of disjointed sentences being very high suggests that I must have been quite anxious while I was being interviewed. (18)

I do hope you find some pertinent material amongst my ramblings. I was most embarrassed to read all the useless fillers such as 'you know'. I hope I don't always talk so disjointedly. I suspect the emotion I felt may have impacted on my communication. (21)

The experience of these participants is affirmed by the work of oral historians such as Gluck \& Patai (1991) and others in Women's Words: The Feminist Practice of Oral History. In this text Anderson \& Jack, Minster and ChanfraultDuchet, for example, theorise the differences between the oral word and the written word. Chanfrault-Duchet argues that the construction of the narrative is a preconscious process, that it is the combination of the voice, sound and silence that provides the material for analysis (1991, pp.89-90). I wrote to the above participants and explained the nature and style of communication in an unstructured interview when it is translated through the written word without the intonations, the silences and the missing of non-verbal explanations that are obvious in a face-to-face encounter. I assured them that the material was useful. In retrospect, informing participants when reading their transcripts to expect a level of disjointedness and seeming incoherence, may have reduced their concerns. 


\section{The Drawing Interpretation Project}

Drawing is an essential part of most children's lives. Drawing is also the talk of children, a way to express their ideas and fantasies about the world they live in. Drawing is a way of expressing and defining their experiences with life, a way of exploring and explaining their environment. (Oppawsky, 1991, p.125)

During the interviews, the focus group sessions and in the journals mothers had described a change in the attitudes of their pre-adolescent sons toward them that became increasingly negative and diminishing as the boys grew into their teens. The participants in the longitudinal focus group were keen to uncover the boys' perceptions of their mothers as they grew through these years. In order to achieve this a research tool was required that could be used with a large number of subjects and at the same time could elicit a depth of response. Realising that boys were not likely to engage effectively in interviews and that surveys would be most unlikely to provide the level of information required, I decided to try a method of drawing interpretation. Drawing interpretation has been more commonly used as a projective technique in therapy and psychodiagnostic testing than as a means of data collection, which posed interesting dilemmas to this research project. I planned to work with groups of males, which made it impractical to use the drawings in conjunction with dialogue, as is the most common practice with therapeutic uses of drawing. However I was keen to see whether drawings could be used for gathering information from a large number of informants such as was requisite for this project.

I met with Maureen Woodcock, an Auckland-based art therapist known nationally for her use of art and play for therapy and diagnosis purposes. Her initial questions reflected a concern about the use of drawing interpretation in the context $I$ have described above, particularly with regard to the potential superficiality of drawing analysis when there could be no interaction from the drawer. Her own work usually involves the use of drawing with one person at a time so the meanings of the works can be developed and extended with that person. The problem we faced in our discussion was whether this method could be adapted for my purposes. The impracticality of talking with each boy about his drawings made self-interpretation impossible and I was aware that this would compromise any claim to definitive interpretation. The reference material that had been collected for our first session 
was primarily focused on the use of drawing interpretation when working with victims of abuse, violence and separation. However among it were some clues about a possible direction. Once we were able to talk outside of the therapeutic model and look at the drawings as a means of collecting information, rather than as a tool toward an individual's disclosure, we recognised that it would be possible to make superficial analyses of each piece of work and that these could be used to make sense alongside the collective works.

In order to work with the potential simplification or misconstruction caused by using diagnostic tools for this project, I wanted to find material that would help me make the leap from the use of interpretative drawings as a tool of therapy to their use as a tool for data collection. A project initiated by American teacher, Emmalou Van Tilburg (1987), was useful as an example of the use of children's drawings outside the therapeutic context. Van Tilburg designed a tool using drawings to evaluate the effectiveness of an educational programme used by children who were alone after school. She recognised that little research had been conducted on the use of drawings as part of data collection and looked at four potential limitations. The first was that the skill of the artist would determine the effectiveness of the drawing. The second was that the drawings would reflect the child's attitudes of the moment. The third potential limitation she identified was that no one drawing tool could test for comprehensive data. The fourth was the difficulty of conclusive interpretation.

In considering the skill level and developmental stage of the drawer it is generally accepted that children's drawings evolve in their sophistication, as the child grows older. Psychodiagnostic therapists, for instance, maintain that trauma at any stage in a child's development can mean the maturation process is arrested, causing the child to draw at the level and age that the trauma occurred, particularly when the subject of the drawing causes the child to revert. It seemed to me at the initial untried stages of the project that any potential reversion in the drawing style or skill level would not impact negatively on the quality of the data collected. Although recognising that retrogression may motivate questions in a therapeutic situation, I did not think that it would become a limitation for this project. I was not so much interested in the skill or drawing age of the participant - how they had drawn - but in the content of the drawings - what they had drawn. 
The second potential limitation identified by Van Tilburg and discussed also by American-based art therapist Elizabeth Koppitz (as cited by Van Tilburg, 1987, pp.421-427), was that drawings would reflect the child's attitudes of the moment and that these may change from one moment to the next as the child is influenced by what may have most recently occurred for them. However, I did not foresee that the participant's reflections of most recent events would cause the findings of this project to be deficient. I was more interested in gaining a broad description of the attitudes of males at various ages. With large enough numbers in each age cohort I anticipated that a generalised representation across each age cohort could be made.

Van Tilburg found in her research that children's drawings did provide valuable and valid information. She suggests that the use of drawings in this way can provide data that otherwise may not be collected by providing an "alternative look at an individual's world of attitudes, values and perceptions of reality" (1987, p.3). The difference between the use of drawing in Van Tilburg's research and that of an art therapist was in her process of interpretation. "Any relationships found were reported," she writes, "but there was no attempt to explain them in terms of psychological state" (1987, p.2). Likewise the processes of interpretation underpinning the drawing project within my research involved identifying the nature of the relationships among the figures in the drawings and did not attempt to declare meaning. William Evans, Assistant Professor of Human Development, and Jackie Reilly, Extension Specialist, both from the University of Nevada, have also used drawing interpretation. Evans and Reilly used drawings as a method of programme evaluation with school-age children. Their aim was to find a creative way of including students' attitudes and feelings into the evaluative process. They comment, "[the drawing activity] while conceptually linked to individual diagnostic purposes, focuses on program effectiveness rather than individual assessment" (1996, p.3).

The third potential limitation, that no one tool could test for comprehensive data was addressed by using two complimentary drawing tools. Woodcock and I examined a number of drawing activities and decided on two that would work well together: the Kinetic Family Drawing (K-F-D) and the Family As Animals Drawing (F-A-A-D). It was intended that each drawing would syndicate the 
findings of the other. The drawings were centred on a consistent theme but required the application of different drawing techniques.

The fourth potential limitation, the instability of drawing interpretation, was addressed in part. The variety of tools developed for analysing the drawings aimed at increasing the reliability of interpretation. These tools involved a combination of interpretative measures including Graphomotor Factors, Projective Drawing Factors, Drawing-a-Person Analysis, House-Drawing Analysis and Tree-Drawing Analysis (Appendix 3.9). Although the diversity of possible analyses was reduced with a combination of interpretive tools, categorical meaning was not possible. Firstly, the nature of the administration of drawing meant that it was not practicable to have the boys explain their drawings. Secondly, as argued by Foucault, interpretation is unstable and fluid (1977, 1982). Although contextualising his discussion within discourses of power relations, Foucault contends that interpretation of text, art, music and other imagery is governed by cultural domination. His contention is supported by Roland Barthes (1961) who argues that the reading of the photograph, for example, is 'historical'. As with Foucault, he claims that interpreted meaning is governed by the values and ideologies of the interpreter. Concurring with Foucault and Barthes, I recognised that the tools used for the interpretation of the drawings had been developed by theorists and practitioners who brought with them their own cultural biases. Likewise, in the administering of these tools of analysis my own bias, and that of the therapist-supervisor, were additionally influential. It is for this reason that conclusive meanings for each drawing have not been alleged. Rather, it has been intended that suggestions of meaning, and general themes of significance, have been highlighted.

American psychodiagnostic therapist, Donald Ogdon (1989), recommends two strategies for enhancing the accuracy and reliability of interpretation. The first, he suggests, is the use of a configuration of symbols for interpretation of the drawings (Appendix 3.9). The second technique is the consideration of verbalisations by the drawer to accompany the drawings. Both of these techniques were taken into account during the activity and analysis of the drawings. For practical reasons, particularly the impossibility of effectively capturing fifteen to twenty-five voices in one room, I chose not to audiotape the drawing sessions. 
However, attention was given to contextual factors: the profiles of the students, the environment within which the drawings were completed, the level of motivation for doing the drawings, the comments that were made while drawing, the other people present in the room, the time and day and what other students were doing in the school at the time.

The students involved in the project came from a primary, an intermediate and a secondary school in a medium sized city in Aotearoa New Zealand. These schools have a contributory relationship, with the majority of students from the primary school moving through the intermediate school to the secondary school. This meant that the student participant groups originate from similar socio-economic and geographical situations, which for the purposes of this project have added to a contextual consistency between the age cohorts. An initial letter (Appendix 3.10) was sent to the principals of each school inviting participation. As all principals were agreeable to taking the next step I met with them individually to discuss the most appropriate system of parental/student consent for each school. A second letter (Appendix 3.11) was sent confirming participation and including a draft consent form (Appendix 3.12).

The required consent was obtained from the schools, Boards of Trustees, parents and the students themselves. Participants were identified in a range of ways according to what was appropriate and practical for each age group. At the primary and intermediate schools I worked with groups of boys taken from several classes selected according to the age groups I was requesting and by the willingness of specific teachers to have class time used for the project. Students who did not wish to be involved, or whose parents/caregivers did not wish them to be involved, would not attend these sessions. It was also decided, after discussion with the teacher, that we would not separate the five and six year old boys from the girls as it would be more difficult to explain to them the reasons for this ${ }^{5}$. At the secondary school, students volunteered for each session. These sessions involved students aged from thirteen to eighteen years.

\footnotetext{
${ }^{5}$ Although the drawings of the five and six year old girls have been saved for possible later work they have not been included in the analyses for this project.
} 
The exercises were designed to determine how the participant perceived the relationships between members of his family, however he defined that group. In the first exercise, the 'Kinetic-Family-Drawing' (K-F-D), the participant was asked to draw his family doing something. A pencil, eraser and a sheet of A4 paper were provided. Each person drawn was identified and labelled by his or her role in relation to the participant - brother, mother, father, mother's boyfriend/girlfriend, sister, aunt or other'. In the second exercise, the 'Family-as-Animals-Drawing' (FA-A-D), the participant was asked to draw each member in his family as an animal. The drawing was completed using coloured pastels and a sheet of A3 paper. Again each person drawn was identified and labelled by their role in relation to the participant and also by what animal was depicted. For correct pairing, each drawing was identified by the participant's initials and age in years and months.

\section{One-Off Focus Group}

In May 1999, a one-off focus group of twenty-six participants met for a one-hour session to discuss the drawing project. The group included practitioners working with families and children; teachers, counsellors and therapists, psychologists and social workers; and mothers and fathers of adolescent sons. Participants responded to an open invitation. The invitation indicated that permission for comments to be used to contribute to the data collection would be sought from group discussion. The focus group session began with a twenty-minute power point presentation and included an overview of the drawing interpretation project, methods of analysing the drawing and a summary of outcomes. The topic was then opened for discussion. Two observers recorded the discussion in long hand. The data gathered at the drawing project focus group session was included in the analysis of the drawings used by the longitudinal focus group.

\footnotetext{
${ }^{6}$ In the case of the younger children the teacher or I wrote the labels under instruction from the drawer.
} 


\section{LINK BETWEEN METHODOLOGICAL OBJECTIVES AND RESEARCH PROCESSES}

Six criteria determined the methodological objectives for the project. These included the empowerment of women through individual and social change, involvement of participants in the research processes, engagement in the research process being as important as the outcomes, that there is benefit to the participants from involvement in the project, that a combination of research methods is used to provide rigour in the research process and that the stories are situated within historical and structural contexts. Each of these are taken in turn and related to the research processes used in the project.

\section{Empowerment of Women through Individual and Social Change}

As discussed in Chapter Two, the concept of empowerment is problematic. To intend empowerment in a research project can, without critique and close monitoring of the processes and relationships, perpetuate the inequities that exist between those with and without 'power'. The researcher's role in this methodological tension is fraught with difficulty. These difficulties were evident throughout the process of this project.

Two of the four objectives identified by the longitudinal focus group at the beginning of the project related to improving the collective circumstances for mothers of sons. Focus Group Objective Three was to highlight the issues facing mothers of adolescent sons. A positive result was reported. The participants felt that as the project had progressed they had been more conscious about issues to do with mothers and adolescent sons. They chose to speak out when they felt they could, socially, in their workplaces and to their families. To date, however, although it has been discussed, there have been no joint public comments from the project. As researcher I have presented seminars, papers at conferences and contributed to various publications (Appendix Preface 1). When the dissertation is completed, the longitudinal focus group members plan to write a collection of stories that will have appeal to people that may not be interested in reading the dissertation. This process will instigate another set of cycles in the participatory action research process. 
It is difficult to gauge whether the focus group objective to improve the situation for single mothers of sons has been achieved through the project. Each of the mothers, who stayed with the project throughout its entirety, reported improvement in the behaviours and well being of their sons, with their parenting and their relationships with their sons and in their own confidence and selfesteem. As no 'control' group existed, it is not possible to determine whether or not these improvements were as a result of involvement in the project, whether other factors impacted on their situations such as the increased age and maturity of the sons, the increased experience of the mothers and the improved financial situations of the families. Several sons had left home to live independently, which contributed to an improvement in the financial situations for their mothers. One mother, not previously in paid work, found full-time employment that was satisfying and increased the family income. I suggest that a combination of 'external' occurrences and the mothers' involvement in the project impacted on the mother-adolescent son situations.

In the tenth session of the focus group, two of the mothers reflected on specific strategies they had used as a result of being part of the project. One mother, a primary teacher, observed the added stress for mothers when their children's clothes went missing at school. (Although untested, the supposition could be made, that that the levels of stress of these mothers are linked to the amount of finance available to the family.) To address this issue the teacher-participant developed and implemented a system in her classroom to ensure that all children went home with the clothes they brought to school. Although she did not undertake specific research to determine the effects of this system, the anecdotal evidence strongly supported the decrease in stress in parent-child relationships. As with participatory action research methodologies, this issue could have been developed into a 'spin-off piece of research. It was discussed with members of the focus group and with the principal of the school but the energy and resources of the group has prohibited action on it to date?

\footnotetext{
${ }^{7}$ This participant is at the moment finishing an undergraduate degree and has some interest in enrolling in a masters degree. Supervision and support has been offered through the ongoing activities of the project.
} 
Another mother, a librarian, observed that particular books were increasingly being issued from the district library. These included titles such as Raising Boys and Manhood written by Australian therapist, Steve Biddulph (1995), Between Mother and Sons written by. Evelyn Bassoff (1995) and others about parenting boys and teenagers, fathering, and empowering men. When discussing some of these titles in the focus group sessions she realised that much of this material was not supportive of mothers of boys. She has been keen to review other books in order that she can suggest additional titles to members of the public and to those staff responsible for library purchasing.

At times the task of providing alternative perspectives to those of the more common and pervasive voices about mothers parenting adolescent boys seemed overwhelming. As one of the mothers put it, "we feel like such a small voice amongst a constant barrage" (GP10). She was talking about the ongoing judgments made about her in her role as a single mother and as a single mother of boys. A provincial newspaper, for example, approached me with a request for information about the findings of this project. A decision made through phone discussions among the focus group members was that although we were not ready yet to formally release the material, we would offer a release about a component of the work, fatherlessness. The journalist expended much energy in getting the article right and it was well done. Titled, Father 'Figures' Challenged, the article began, "Talk of fatherlessness is not helping to ease New Zealand's high levels of male under-achievement, juvenile crime and youth suicide. ... We need to challenge current populist and unresearched thinking that the major cause of the problems for young men is the absence of the father" (February 5, 2000). The article stressed the need for practitioners and policy-makers to recognise underlying issues such as poverty, emotional well-being, lack of social support and isolation of the care-giving parent. This began a barrage of protest from certain members in the community. One man phoned the Chief Executive Officer of my workplace protesting the fact that the institution financially supported the research. Others wrote letters to the editor stating things as, the single mother is a "poor substitute for the stable family of two parents besotted with love for their children" (February 10, 2000a). The local Anglican priest headlined his weekly comment, Canon's Roar, with "Two parent families the ideal". He quoted from neoconservative social scientists, David Popenoe (1996), author of Life Without 
Father: Compelling New Evidence that Fatherhood and Marriage are Indispensable for the Good of Children and Society and David Blankenhorn (1995), author of Fatherless America: Confronting our Most Urgent Problem, both of whom are renown for their Christian fundamentalist pro-nuclear family stances. A beneficial outcome of the press release was the stories that appeared in the newspaper over next several nights in which the reporter covered the experiences of other mothers of sons. A key theme raised by these mothers was the lack of public and private sector services prepared or able to offer practical support for sons with whom they were having difficulty.

\section{Involvement of Participants in the Research Process}

Figures 3.1 and 3.2 give an overview of the focus group participants' involvement in the research processes. From the original focus group of seven, four remained at the end of the four-year fieldwork period. At the end of the first year, between the fourth and fifth group sessions, three mothers discontinued their involvement in the group. Mothers 5 and 7 moved away from the area to larger city centres. Mother 2 had wished to be part of the group to develop skills to parent her sevenyear-old son and found that the direction the group was taking did not meet this need.

Although one member of the ongoing group chose not to continue her journal throughout this time, she was no less involved than the other participants. (Chapter Two includes my argument that equitability in the research does not necessitate equal contribution). The sons of this participant were aged seventeen and nineteen when the project began and so the timing of her parenting was not congruent with the timing of the project. She contributed enormously to focus group discussion however and, as a primary school teacher, integrated many of her developing strategies into her classroom practices.

Participants were involved to the extent that they were able. My own contribution was quantitatively larger than that of the others and my own gain from the project was also larger. Although we all shared the objectives, an added objective for me was the potential achievement of a doctoral degree. If empowerment through participation was a key tenet of the project, there could not be an insistence on a certain level of involvement. It was at the discretion of the participants to match 
their needs of the project with their level of involvement. The mothers were involved in the project in a variety of ways. They attended focus group discussions, wrote in the journals, linked discussion material, strategised within their own (public and private) situations, made connections with each other outside of organised group sessions and identified and collected resource materials for contribution to the data.

\section{Figure 0-3: Representation of Focus Groups 2 \& 3}

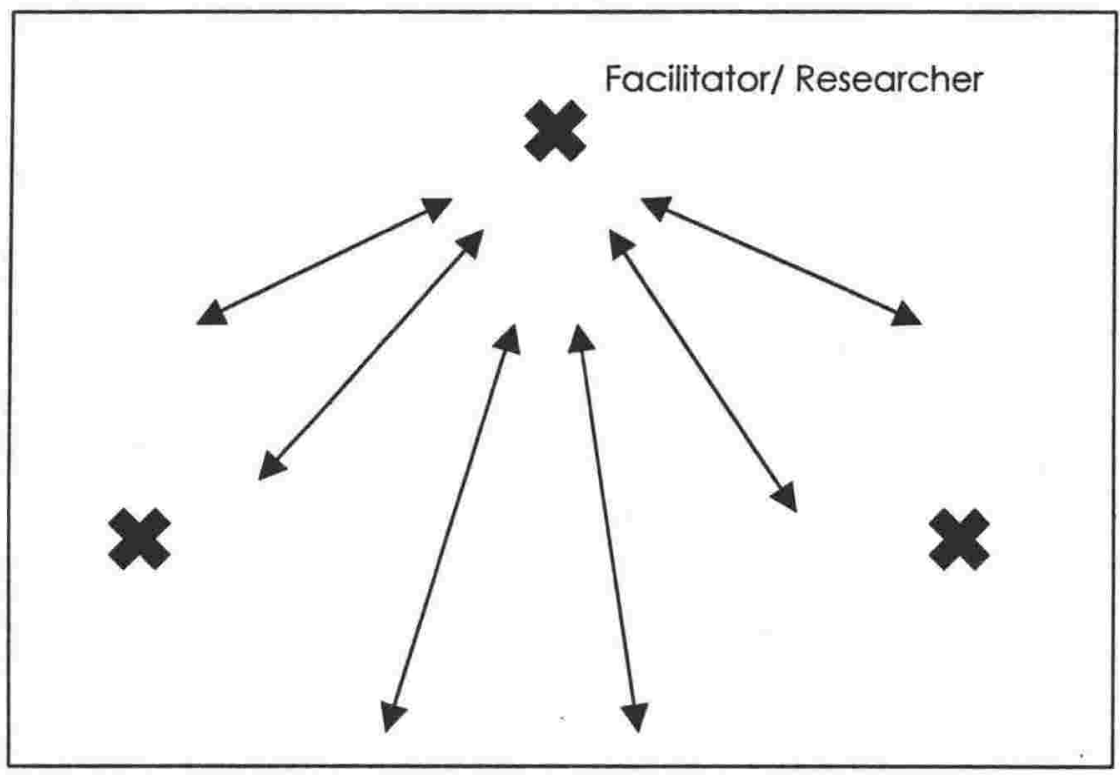

Although it was difficult to ascertain the impact of my involvement on the group, the fourth focus group session, from which I was absent, reveals a change in the discussion dynamic. Until this time the direction of communication tended to be focused on me as facilitator (as typified by Figure 3.3).

Although the discussion in the fourth focus group was initially uncertain and there were breaks in discussion at times, the direction of communication was as depicted in Figure 3.4. The flow of communication among the women seemed more spontaneous and less cautious. Participants talked directly with each other, rather than through the facilitator and there was much hilarity and liveliness. Although one participant is shown in this diagram to have contributed less, she was actively part of the discussion as she offered affirmative comments and laughed along with the others. Thankfully the sessions after this time reflect a similar dynamic. It is difficult to establish why, but several suggestions could be mooted. Group members may have become more trusting and comfortable with 
each other, as is normal in a healthy group development process. A demystification of the project as academic research may have occurred, lessening the timidity of the participants. My absence for the fourth session may have given the participants the chance to gain control and ownership of the project. Whatever reason, or combination of reasons is relevant; this session seemed to be a defining moment in the level of involvement of the participants.

Figure 0-4: Sociogramatic representation of the first 10 minutes of Focus Group 4
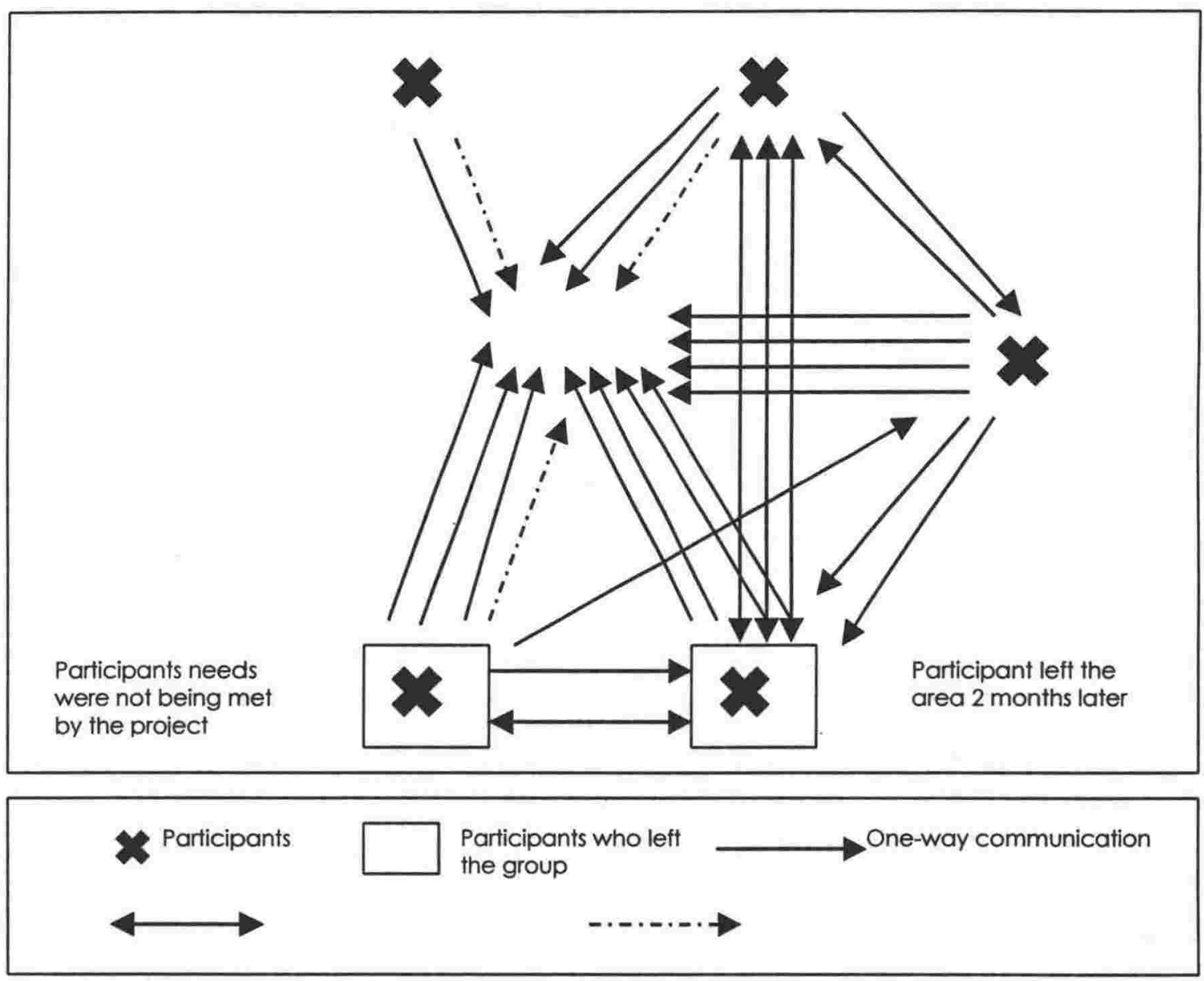

\section{Benefits to the Participants of Involvement in the Project}

From the reflections by the mothers at the latter stages of the project, components of longitudinal focus group objectives one and two were met. The participants had been able to talk with other women about their experiences of raising adolescent sons as single mothers (Focus Group Objective One) as indicated by this participant. 
Coming here and talking, helps you to be more objective. I find that in the modern way or life and everything's so hectically busy and people are working, well I'm working and I'm bring up kids and all of that. You get smothered by it all. I find that I just get totally; like being washed over by a wave all the time and I can't sort of stand back sometimes and be objective. Coming and talking like this really helps. It really does. (GP9)

Those who had sons still living at home reported an improved ability to parent their sons (Focus Group Objective Two).

I think that was something else that has been good about this process. It's been a bit of confidence building, because I didn't feel especially confident in what I was doing after the early days of the separation and it did help me to have a bit more, to believe in myself in what I was doing. (GP9)

The entries in this participant's journal reflect the changes that she made throughout the project.

Through the two face-to-face interviews we have had and through the very great deal of thought I have given to all that has arisen in my mind...I see myself in a much more positive light. (4, October, 1996)

Things have certainly moved on since last I wrote. It amazes me - every time I give some thought and attention to this process and then go away ... when I come back I have this huge sense of having shifted. (4, April 1997)

And so it has been for me parenting my own son and being a mother of a son. I am not sure that I would have reflected on my parenting of him as much as I have without being involved in the project. I know that I would not have had a group of women such as this one that has intentionally grappled with the issues and supported each other in the process. Having a means to find expression for my feelings about the marginalisation of our positions as mothers of adolescent sons has had several beneficial side effects. I haven't dumped my occasional anger and frustration on my son or anywhere else destructive. I have been able to identify more with the intricate situations of other mothers. This has been useful in my employment as a lecturer within the social sciences and also in my involvement in the Board of Trustees of my son's secondary school. 


\section{Engagement in the Research Process Being as Important as Outcomes}

The methodology chosen for the project has meant that the research process has constituted a significant part of the project. At various points along the way reviews of the project have determined the direction of the next steps. For example, the themes highlighted from the first set of interviews were refined and progressed by the focus group in order that they could contribute to the next set of interviews. The Drawing Project, initiated to test one of the key indications that had emerged from the interviews and focus group sessions after the first year of the project, is another example of the process impacting on the direction and outcomes of the research. The previous section discussed the benefit of the research to the participants. These benefits have resulted from the engagement of the mothers in the research, rather than the outcomes. It is unlikely that the outcomes will have direct value to the participants. By the time there is the opportunity for the outcomes to impact on the practices of those who work with families, or on the societal attitude toward mothers with adolescent sons our days of parenting adolescents will be principally over.

\section{Using a Combination of Methods to Enhance Rigour in the Research Process}

The research methods that were used in the project included the use of a longitudinal focus group, focus group sessions and interviews that were audiotaped and transcribed, semi-structured individual one-off interviews that were audiotaped and transcribed, journaling, drawing interpretation and the review of literature. The theoretical approach that informed the research methodology used in this project has necessitated the use of a combination of methods. Feminist researchers Lather (1991), Reinharz (1992) and Stanley \& Wise (1990), suggest the following rationale for the use of multiple methods in research. Firstly, to increase the thoroughness and value of the research through triangulation by bringing different kinds of evidence into relation with one another. Secondly, to elicit multiple realities by being responsive to the people studied, and thirdly as a way of combining personal positions within structural frameworks.

Participatory action research seeks to be responsive to the participants and situations. In this research method, the specific methods used during each cyclical 
stage are determined by the evaluation of what has gone before and require a flexibility of approach. Teachers and action researcher practitioners, Kenneth M. Zeichner from the University of Wisconsin-Madison and Susan Noffke from the University of Illinois (1998), discuss the development of research strategies by the participants that include employing multiple ways to gather specific information that will fit the particular context in which the research has been carried out. Qualitative research methodologists, Matthew Miles and Michael Huberman (1994), also discuss the benefits of using multiple methods. They suggest that testing the results from one location with those of another in order to examine the level of their peculiarity has the potential to deepen the level of analysis and explanation. They extend this discussion of multiple methods to include the potential enhancing of outcomes that can occur by linking qualitative and quantitative data. The benefit of this linkage, they suggest, is to validate, interpret, clarify and illustrate qualitative findings. Although this research project uses methods from both qualitative and quantitative frameworks, it is important to resist using quantitative research methods as a means of enhancing validity and scientific credibility to those findings derived from qualitative methods. One of the contributions of feminist research theorists, for example, is the challenge to claims that quantitative research is 'real research' because it is uncontaminated and objective. They have proven bias in the collection, collation and analysis of statistical data and, furthermore, suggest that the non-declaration of this bias is more dangerous than the declared biases that influence qualitative data. The methodological research methods used in this project have aimed at meeting key objectives of triangulation, responsiveness to research participants and context, and recognition of personal and structural realities. Figure 3.5 stylises the relationships between the specific research methods used in the project. 


\section{Figure 0-5: The triangulation of specific methods used in the project}

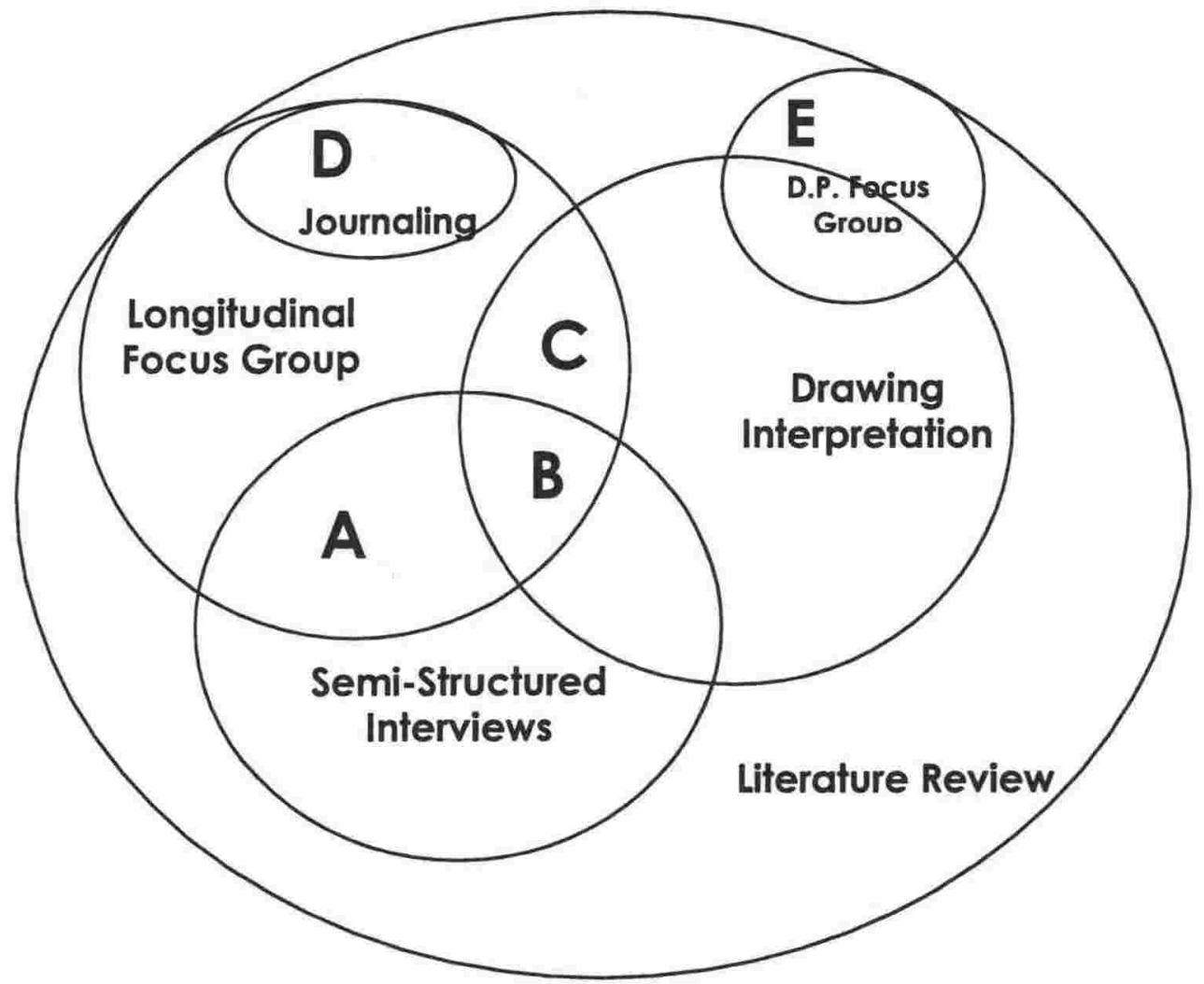

The area marked ' $\mathrm{A}$ ' refers to the combining of two methods; longitudinal focus group processes and semi-structured interviews. It includes such things as the initial interviews undertaken with longitudinal focus group participants and the analysis that these participants gave to the data collected from one-off interviews. Area 'B' refers to the combining of three methods; longitudinal focus group processes, and semi-structured interviews and drawing interpretation. This includes activities such as the syndication of information from the interviews with findings from the drawing project and the analysis of the participants in the longitudinal focus group. Area ' $\mathrm{C}$ ' refers to the combining of two methods; longitudinal focus group processes and drawing interpretation. It includes such activities as the initiation and planning of the drawing project by the longitudinal focus group participants. Area ' $D$ ' refers to the journaling undertaken by the longitudinal focus group participants and area 'E' refers to the one off focus group that was established to discuss the drawing project results. The outer circle depicts the literature review that underpinned and informed every aspect of the research process and content. 


\section{Situating the Stories Within Historical and Structural Contexts}

The data gathered from the primary methods, interviews, journaling and drawing interpretation, has been set against structural and historical accounts found in secondary sources such as books, journals, newspapers, magazines and the internet. Chapter One has included an historical overview of the origins of motherhood and adolescence and the development of societal structures in this country, while further chapters discuss the current social and economic policy factors that impact on the situations for mothers of adolescent sons. An attempt has been made to contextualise the mothers' realities within the periods in which they were raising their sons and to explore the impact of intergenerational influences on families and family members.

\section{COLLECTING THE DATA}

The data for the mother-adolescent son project was collected through the research methods discussed previously. That is, audiotaped interviews and focus group sessions, written journals, drawings and literature review.

\section{Interviews and Focus Group Sessions}

Interviews and focus groups sessions were recorded onto separate ninety-minute audiotapes. In the field notes taken at each session the date and time, the venue and any situational factors that appeared to impact on the interview were included. Examples of these situational factors include; an ill son in another room in the house, a large photograph of a son on the wall facing the interviewee; the phone ringing; familiarity, or otherwise, between the interviewer and interviewee; and holding the interview in an unfamiliar motel room. Each tape of an individual interview was marked with the name of the interviewee and the date. The tapes of the group sessions were marked with the date and the number of the group session.

The tapes were transcribed onto hardcopy and computer disc. Once the transcriptions were edited and approved by the interviewees, the computer disc copies of the interviews were entered into a qualitative data analysis software package called NUD*IST. The hardcopies were read in conjunction with listening 
to audiotapes and used for making notes about voice intonation, pauses and background sounds.

\section{Journals}

The journals contributed to data collection in two respects. Firstly, their authors referred them to them during the focus group sessions and secondly they were submitted and photocopied to be included as part of the written data collection.

\section{Drawing Interpretation Project}

The initials and age in years and months of the drawer identified each drawing completed in the drawing interpretation project. After each session the two drawings from each male were paired and assembled by chronological age into three A3 folders, one each for the primary, intermediate and secondary schools. Notes were made of the contexts of each session, the questions the participants asked and, as much as was practically possible, the discussions they had amongst themselves.

Each school principal was invited to present a brief written profile of their school. The profile included the Decile Rating 8 , size, ethnicity of the student community and what they considered to be the most concerning factors for the male students. A focus group of practitioners and parents was convened and, once permission had been granted, the group discussion was used as part of the data. Two observers were appointed to record in hard copy the questions, key points and issues that were raised.

\section{Review of Literature}

An annotated bibliography was developed from literature reviewed during the project. The bibliography included the reference, where literature was found and/or stored and a brief summary of the pertinent material. References and

\footnotetext{
${ }^{8}$ The Decile Rating is a funding measure for each school. The Ministry of Education using a random sample of students and linking their socio-economic status against the latest census figures sets the Decile Rating annually.
} 
reference material were also recorded directly into draft material as it was being written.

\section{COLLATING AND ANALYSING THE DATA.}

Miles and Huberman suggest that the act of data collection and analysis consists of "three concurrent flows of activity: data reduction, data display and conclusion drawing/verification" (1994, p.10). They offer a model (Figure 3.6) that describes the movement of the researcher between these three actions. This model provides a useful structure on which to address the components of data analysis for this project.

\section{Figure 0-6: Components of data analysis: Interaction Model} (Source - Miles and Huberman, 1994, p.12)

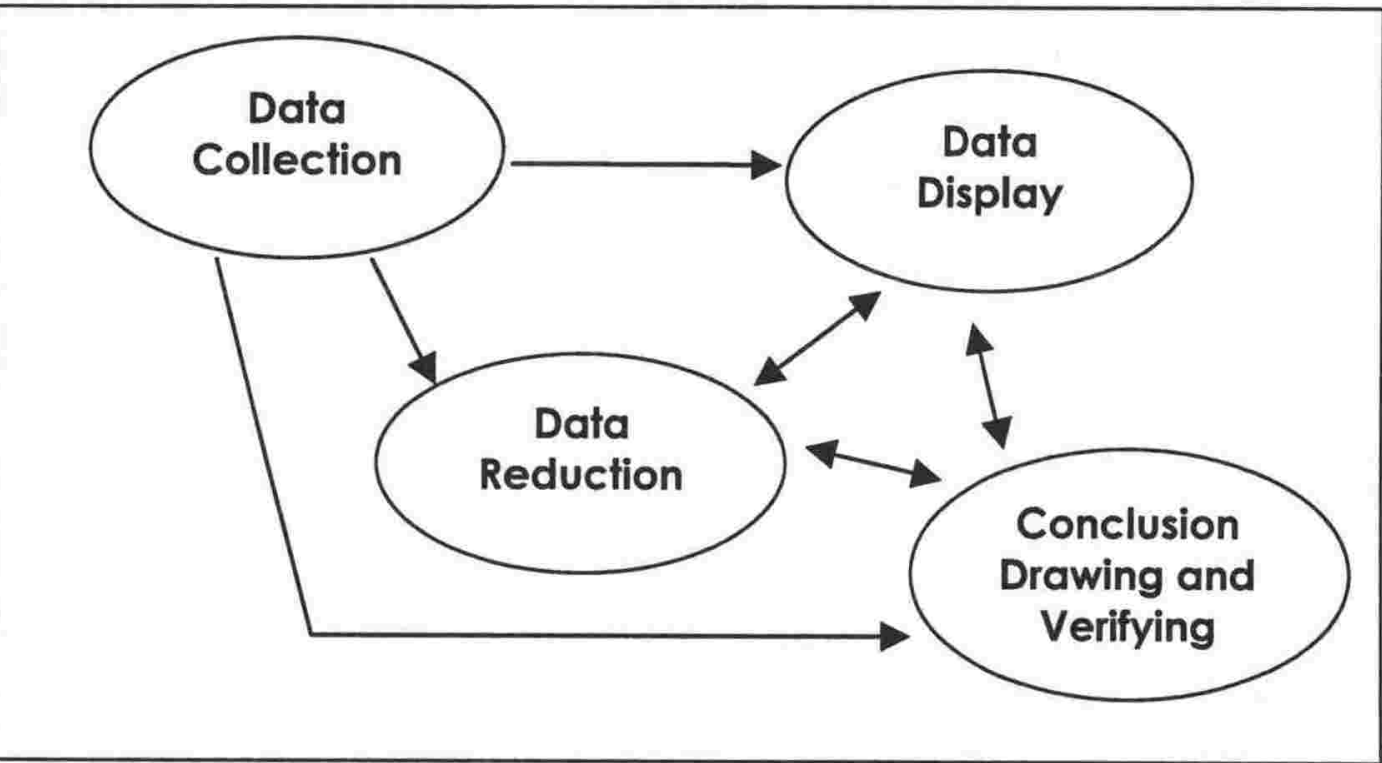

\section{Data Reduction and Display}

The data for the project has undergone numerous stages of reduction. Throughout the project it has been collated, analysed by the focus group and then used for the design of the following stages, collated and analysed and so on. The discussion and activity involved in the focus group analysis has also contributed to the data

\footnotetext{
${ }^{9}$ The record relating to the collation and analysis of the Drawing Interpretation Project can be found in Chapter Seven.
} 
collection. The data was analysed in three key ways. In the first instance a thematic conceptual approach (Miles \& Huberman, pp.131-133 \& 246) was used make sense of the data. Once the first two sets of transcriptions were returned by the interviewees, they were collated.

During the collation of the interview material, issues raised by each of the mothers were highlighted and marked on the hard copy. In gathering the information from the interviews, I had initially planned to read the transcripts without listening to the tapes. However, during a visit to the Oral History section of the Alexander Turnbull Library in November 1996, I was challenged by the content of a presentation given by curator, Hugo Manson. Manson explained that listening to the interviews was crucial to the understanding of the interview material. I realised that by reading the transcripts I had been missing the silences, the intonations, the pauses and the background noises even with the system of coding that had been designed for the written records. After this point hard copies of the scripts were read while their accompanying tapes were listened to. Key issues began to emerge from the first set of transcripts and focus group discussions. The comments made by the participants during this session were recorded. These issues were clustered into themes and checked against the results of further interviews and focus group discussions and also against secondary literature sources. The focus group participants decided, after the collation of data from the first set of transcripts, to test one of the key themes that interested them all. From this the drawing interpretation project was initiated.

Once the themes had become clarified I used the computer assisted qualitative data analysis software, NUD*IST, to advance the analysis. Shortly before I was ready to use it the institute within which I work had undertaken a usefulness analysis of qualitative data analysis software (QDAS) and that resulted in the selection and purchase of NUD*IST. It consequently made practical sense for me to use the package for this project. Literature on the subject of comparing QDAS also seemed favourable. Christine Barry, British computer data-analysis expert, has evaluated NUD*IST with a second common qualitative data analysis software package, Atlas/ti, and as a result describes the following advantages of NUD*IST:

- It consists of an hierarchical structure which can be reorganised in stages. 
- It includes project management tools.

- Its structure makes it easy to apply coding scheme.

- Documents can be annotated, edited or appended.

- Results of searches become codes that can be noted and searched.

- It involves systematic exploration of ideas, questions in the data with sophisticated searching. (1998, para. 8.4)

I used this software to create a hierarchical Index Tree Root (Figure 3.7) using the themes to form possible chapters and sections and sub-sections of chapters ${ }^{10}$. 
time. The analysis of these issues contributed further information to the research findings.

The quantitative material from the three hundred and thirty nine drawings in the drawing project was analysed using clustering, counting, contrasting and comparing and noting relations between variables (Miles and Huberman, pp. 219222 \& 253-258). That is, the drawings were analysed using the tools indicated in Appendix 3.9 and plotted onto a table of clusters. The cluster groupings included: the relationship depicted, a commentary of the drawings and the type of animal depicted (Appendix 3.14"). Instances of certain clusters were counted to create a further set of tables. Examples of these are demonstrated in Appendices 3.15 and 3.16. The results of these tables were developed into graphs that demonstrate variables for comparison. A number of these graphs are used in Chapter Six to demonstrate the findings of the drawing project.

\section{Conclusion Drawing and Verifying}

In the final stages of interviewing, it became evident that there were no further themes emerging. In consultation with the longitudinal focus group I decided to cease interviewing and to finalise the deduction process. The conclusions of the fieldwork are presented in the following chapter.

The Drawing Project had aimed at including between one hundred and fifty five and two hundred males (Appendix 3.10). By the time all age groups were covered the total number of male participants was one hundred and seventy six. At this point the fieldwork for this project was concluded.

\footnotetext{
${ }^{10}$ As this work was being finalised the contents pages make clear that the current dissertation structure has moved to some extent from the original Index Tree Roots and Nodes. However, this does not reduce the benefit of NUD*IST with its ability to create data analysis frameworks.

"The tables of this first level analysis of results for the 339 drawings were reviewed by art therapist, Maureen Woodcock.
} 

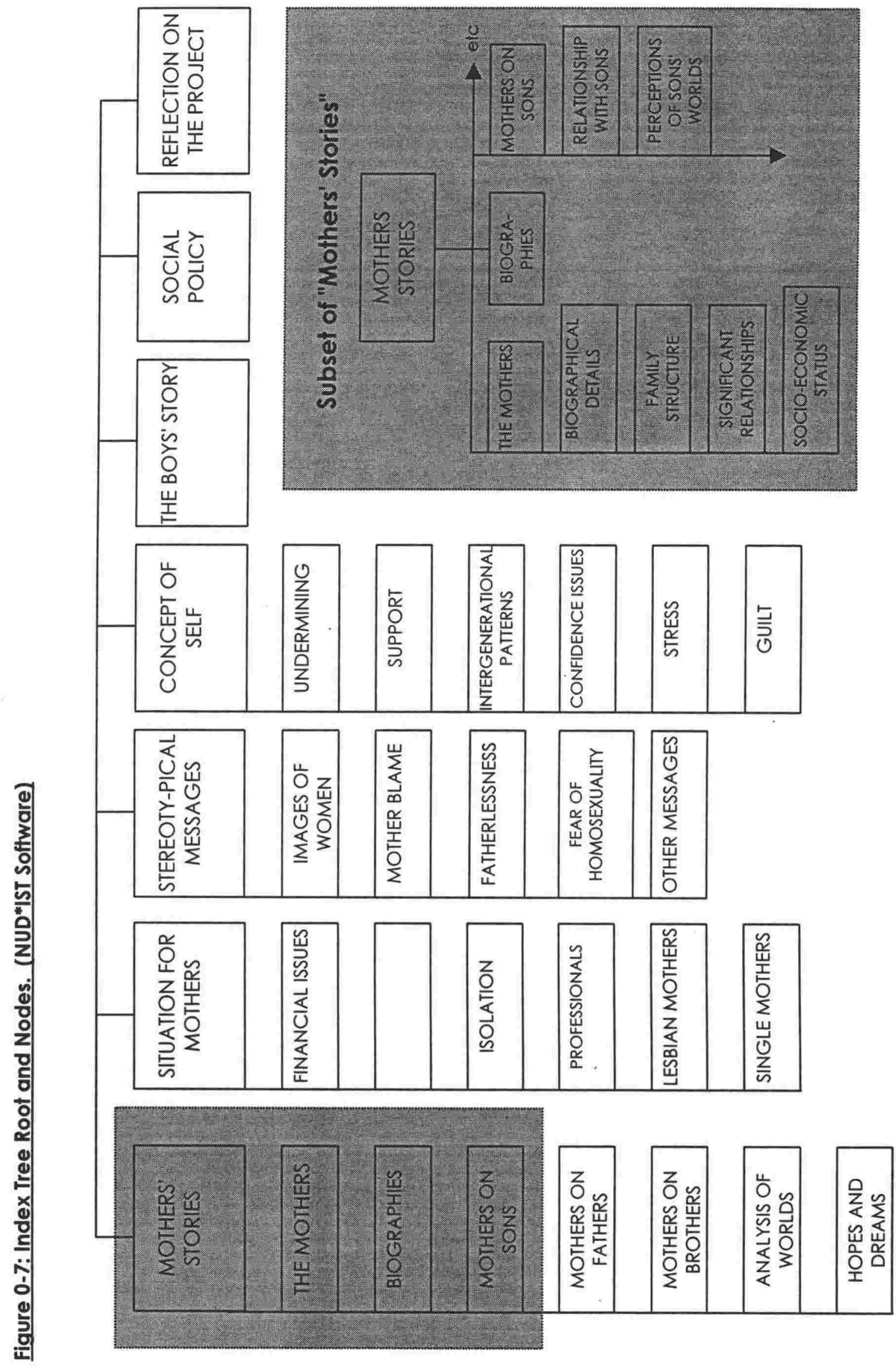


\section{VALIDITY AND CREDIBILITY}

The validity and credibility of the type of research that has been used for this project is frequently questioned. Principal challenges have included a concern that qualitative research methods are not reliable because they do not involve statistical analysis or deductive, hypothesis-testing methods of inquiry. There is an increasing amount of discourse, predominately by feminist, practitioner and process-based researchers that propose counter challenges. Advocates of qualitative research contend that generalisation is not only unachievable but that the quest to achieve standardisation creates 'realities' based on false and constructed assumptions. Reinharz, for example, challenges what she perceives as the 'male' image of the 'quest for truth' $(1992, \mathrm{p} .211)$ and suggests that the traditional scientific objective of finding the truth perpetuates the myth that the social sciences are free of bias. Reinharz proposes that feminist multimethod researchers enjoy the process of discovery and do not try to separate the process of research from the product of the research. This process, she suggests, enables the researcher to focus on documenting contextually specific knowledges rather than 'the truth' (1992, p.211-213). McTaggart challenges dominant standards of validity testing that "hinge upon the combination of two key quests: the quest for generalisation and the quest for causality" both of which are irrelevant to the participatory action research project (1998, p.6). Similarly McTaggart supports the necessity to find alternative determinants of research verification.

Professor of Education of the Smith Research Centre at Indiana University, Egon G. Guba (1989), argues also that the conventional criteria for judging the validity of research, internal and external validity, reliability and objectivity, are not always appropriate for qualitative research. He suggests that alternative criteria could involve; credibility that can be verified by such activities as prolonged engagement, persistent observation, peer debriefing and progressive subjectivity, transferability that requires the researcher to provide a complete database in order to facilitate transferability judgements on the part of others, dependability that requires the researcher to detail any changes or shifts in the way the research was conducted and confirmability that requires the researcher to provide a detailed record of the research processes and the contexts of those involved in the collation and analyses. 
Aotearoa New Zealand based educational action researchers, Roberta Hill and Phillip Capper, term the processes they have utilised in action research as 'analytic induction' which they define as a combination of deductive and inductive practices. "This involves," they propose, "moving back and forth from principles to specific cases and from cases to specific principles, modifying the principles to take account of cases" (1999, p.248). American-based practitioner researchers, Eisenhart and Howe (1992), outline six general standards for determining the validity of educational research (as cited by Zeichner and Noffke, 1998). The standards they pose are as follows; that the data collection and analysis techniques are appropriate to answer the research questions and are driven by them; that they are competently applied; that the research is built on theoretical tradition and/or contributes to some substantive or practical area; that the research has external value and is important for informing and improving practice, that the research also has internal value particularly as it relates to research ethics; and that the research is comprehensive and has an overall clarity, coherence and competence.

In a paper presented at the 1999 Association for Qualitative Research Conference, researcher and psychologist, Bob Dick, stated that action research draws on sources of rigour such as "the use of multiple methodologies, multiple sources of information, multiple processes for data collection and analysis comparing data and interpretations to those from other sources" (1999, p.1). A further five criteria of validity are proposed by educational researchers Anderson, et al., (cited in Zeichner and Noffke, 1998, unpublished manuscript). Much of what they propose is similar to American feminist researcher, Patti Lather's work (1991) on research as praxis. The first criterion is democratic validity, the extent to which the research is done in collaboration with all parties who have a stake in the problem under investigation and multiple perspectives and interests are taken into account. The second is outcome validity, the extent to which actions occur that lead to a resolution of the problem under study or the completion of a research cycle that results in action. The third is process validity, the adequacy of the processes used in the different phases of the research such as data collection, analysis and including the method of triangulation as a guard against viewing events in a biased way. The fourth is catalytic validity, a term coined by Lather (1991) to mean the level of empowerment in the research processes of the research participants. The fifth criterion is termed by Anderson, et al, is dialogic validity, 
meaning the degree to which the research promotes a reflective dialogue among all of the participants in the research.

R.M. Herschell of University of New England, Australia, proposed in his unpublished $\mathrm{PhD}$ thesis a set of principles for qualitative researchers. These reiterate much of what has been listed above including; the declaration of subjectivities; identification and critical discussion of all aspects of research; triangulation; development and critical evaluation of theoretical frameworks; and integration of theory and practice. He adds a further validity principle, mentioned also by Guba (1985), which involves the "inclusion of the data base in the research report" (1999, p.4).

Stanley suggests that two factors are central to "accountable feminist knowledge" (1997 p.214). The first, she argues, is the need for recognition and explanation of the situation of the researcher, and the second is the need for a thorough explanation of what the three main research processes, observation, description and explanation, mean within the research act. In her claim that knowledge is situational, that people are involved in doing the investigating, observing, theorising, concluding and explaining, Stanley proposes that the knowledge must be influenced by their viewpoints and perspectives. Research validity, she implies, is dependent on the rigour with which the impact of the context on the research and researchers is acknowledged (1997, pp.214-217). Lather's explanation that credible research can be measured by "the degree to which the research process re-orients, focuses and energises participants toward knowing reality in order to transform it" (1991, p. 68) builds on that of Stanley's. Reinharz writes of the works of researchers such as Margaret Hagood (1963), Mirra Komarovsky (1985), Phyllis Chesler (1972), Renate Klein (1986) who have used multimethod triangulatory research in order to enhance the research rigour and be responsive to people studied.

American CAQDA researchers, Kelle \& Laurie, offer a contrasting view about the search for validity in qualitative research. They propose that "the aim of the validation process is not to prove the perfect agreement between results and reality ... but to identify possible sources of error" (1995, p.22). Their comment about research validity complies with the process focus of participatory action 
research, which necessitates ongoing evaluation and improvement of the research processes. Research validity, using this model, is reliant on the rigour with which gaps are identified and the research process is scrutinised and improved.

The limitations of the mother-adolescent son project, and the unresolved questions that remain, are discussed in the Chapter Nine.

\section{CHAPTER SUMMARY}

In this chapter I have discussed the administration, collecting and analysing of the research processes used in the project, that is, semi-structured interviews, longitudinal focus group activities, journaling, drawing interpretation, and the review of literature. At the beginning of their involvement in the project the participants in the longitudinal focus group outlined their reasons for taking part. This chapter has links these participant objectives with the methodological objectives of the project and reflected on their outcomes. The final section has discussed issues of validity and credibility of the research processes and their administration. 


\section{Part 3}

\section{THE RESEARCH FINDINGS}




\section{CHAPTER 4}

\section{THE MOTHERS AND THEIR SITUATIONS}

Chapter Four provides an overview of the two groups of mothers involved in the project, the longitudinal focus group and the group of mothers who were involved in one-off semi-structured interviews. The chapter is divided into five sections. The first section describes all participants, including an overview of demographic details, the structure of their families, the contact between the sons and fathers of the families and their socio-economic status. The second section gives a brief bibliographical summary of each participant. The third section presents the situations for all mothers including the nature and impact of their economic situations and their experiences of key professional groups. The fourth and fifth sections focus on the specific situations for lesbian mothers and for single mothers respectively.

\section{WHO ARE THE MOTHERS?}

The participants in the project were divided into two groups (Figure 4.1). The first group, the longitudinal group, consisted of seven women (including the researcher) who first met in November 1996 and continued to meet as a group until November 1999. The majority of the fourteen mothers in the second group were involved in one-off interviews held between 1997 and 1999. Several took part in follow up interviews.

\section{The Longitudinal Focus Group}

The longitudinal group came from one geographical location in Aotearoa New Zealand. The population of this provincial district is 65,000. In 1996 the percentage of single parent families in this district was 23.7 percent of all families 
compared with a 17.7 percent for Aotearoa New Zealand as a whole'. The unemployment rate was 9.6 percent compared with 7.7 percent for Aotearoa New Zealand as a whole. Income levels were similar in this district as they were for the national levels. That is, 58 percent of people aged 15 years and over had an annual income of $\$ 20,000$ or less, compared with 58.6 percent and 6.4 percent who had an income of more than $\$ 50,000$ compared with 7.3 percent for Aotearoa New Zealand as a whole. The percentage of people receiving a government benefit was higher than the national average, that is, 22.5 percent compared with 19.6 percent for Aotearoa New Zealand as a whole.

The members of the group ranged in age from late twenty to mid forty. They had all been born in Aotearoa New Zealand with five identifying as Pakeha, one as Maori and one as Pakeha/Maori. During the four years of the project all mothers in the longitudinal focus group were raising their sons as single mothers. Their sons ranged from seven to nineteen years old at the beginning of the project and all lived with their mothers. Five of the mothers had one child and two of the mothers had three children, two of whom were males. Three of the group identified as lesbian and four as heterosexual. Although all the mothers had various partnerships during this time only one of the lesbian mothers lived with her partner.

Four of the mothers had parented on their own from the birth of their sons. Of those who separated from the boys' fathers one separation occurred when the child was a toddler, and two when the sons were in their adolescent years. Of the three families whose parents separated, the sons of two families maintained regular and ongoing links with their fathers. In the third situation both sons made contact with their father when they were nineteen. Of the remaining situations one son had not met his father and the other sons had irregular and infrequent contact with their fathers. At the commencement of the project four of the mothers earned an annual taxable personal income under $\$ 12,500$, two between $\$ 12,500$ and $\$ 35,000$ and one over $\$ 35,000$. These income categories have been taken from an amalgamation of categories used in the NZ Census 96. In 1996 the proportion of all people earning an annual taxable personal income in the two categories, under

\footnotetext{
' The following statistics have been taken from the NZ Census 96, Statistics New Zealand.
} 
$\$ 12,500$ and between $\$ 12,500$ and $\$ 35,000$ was just over 40 percent each. Four of the group owned their own houses and three lived in rented accommodation. Four of the group owned cars over ten years old, one over fifteen years old and two relied on pushbikes and public systems for transport. The mothers of the younger boys had attracted the lowest incomes.

\section{Those Involved in Individual Interviews}

The group of mothers involved in individual interviews came from various rural and urban areas throughout the North Island of Aotearoa New Zealand. Most ranged in age from mid-thirty to mid-fifty with one having recently turned sixty. Ten mothers in this group classified themselves as New Zealand Pakeha while four claimed nationality from European and Asian countries. The sons of this group ranged from eleven to thirty two years old at the time of the initial interviews. Nine of the mothers in this group identified as heterosexual. Three lived with the fathers of their sons and one with a second husband. Of the five mothers who identified as lesbian, two lived with their partners.

Of this group, one mother had all children living elsewhere and five mothers had at least one son living elsewhere. Of the six mothers who had sons living elsewhere, one son lived with his father while the others were living independently. Of the eleven families whose parents had separated, all had some contact with their fathers. One son lived with his father. The nature of the contact between the sons and the fathers of the remaining families ranged from regular and ongoing to irregular and infrequent. Several of the sons over eighteen years old moved between the mother and the father. At the time of interview seven of the mothers earned an annual taxable personal income under $\$ 12,500$, four between $\$ 12,500$ and $\$ 35,000$ and three over $\$ 35,000$. At the same time the households of three of the mothers earned under $\$ 12,500 \mathrm{pa}$, five between $\$ 12,500$ and $\$ 35,000$ and six over $\$ 35,000$. All but three of the mothers owned their own homes and all but one had access to a car. 


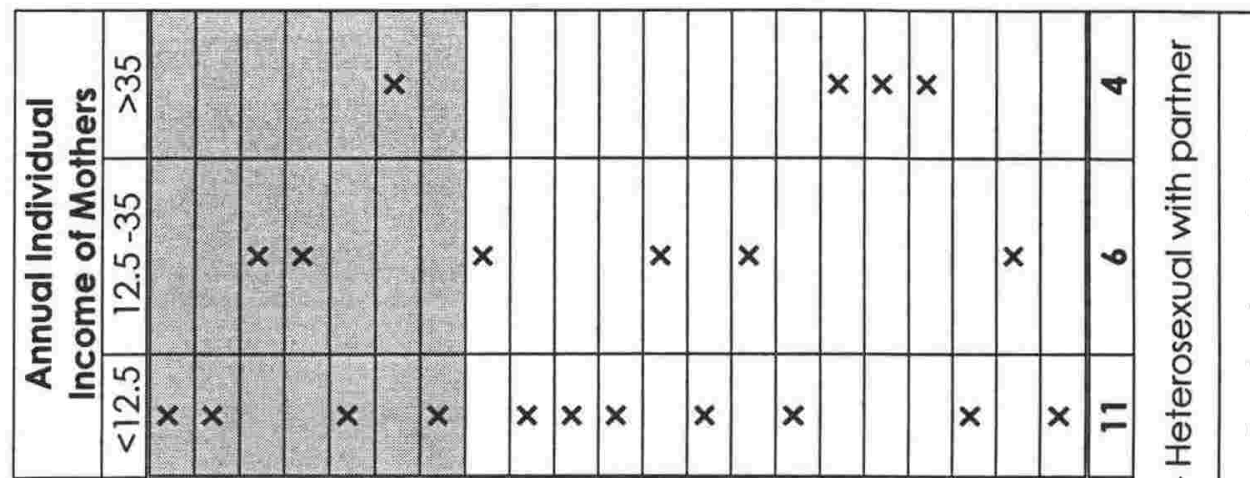

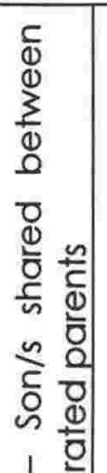

흥 응

ํㅗ 돈

ত̄

$x \times x \times \times$ 至 离

起

$\stackrel{n}{\mathrm{v}} \times \operatorname{x}$

$x \times$

$x \quad x$

응

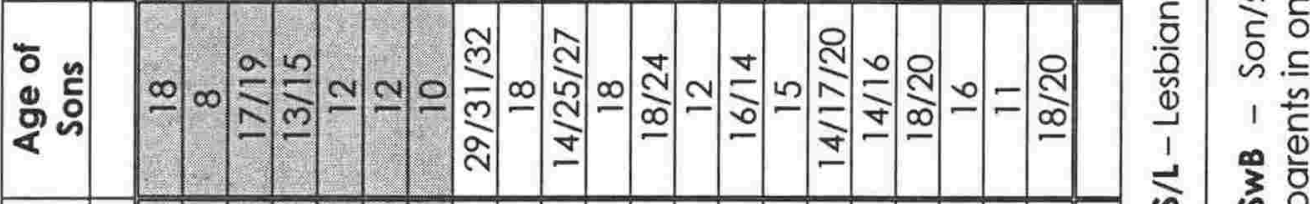

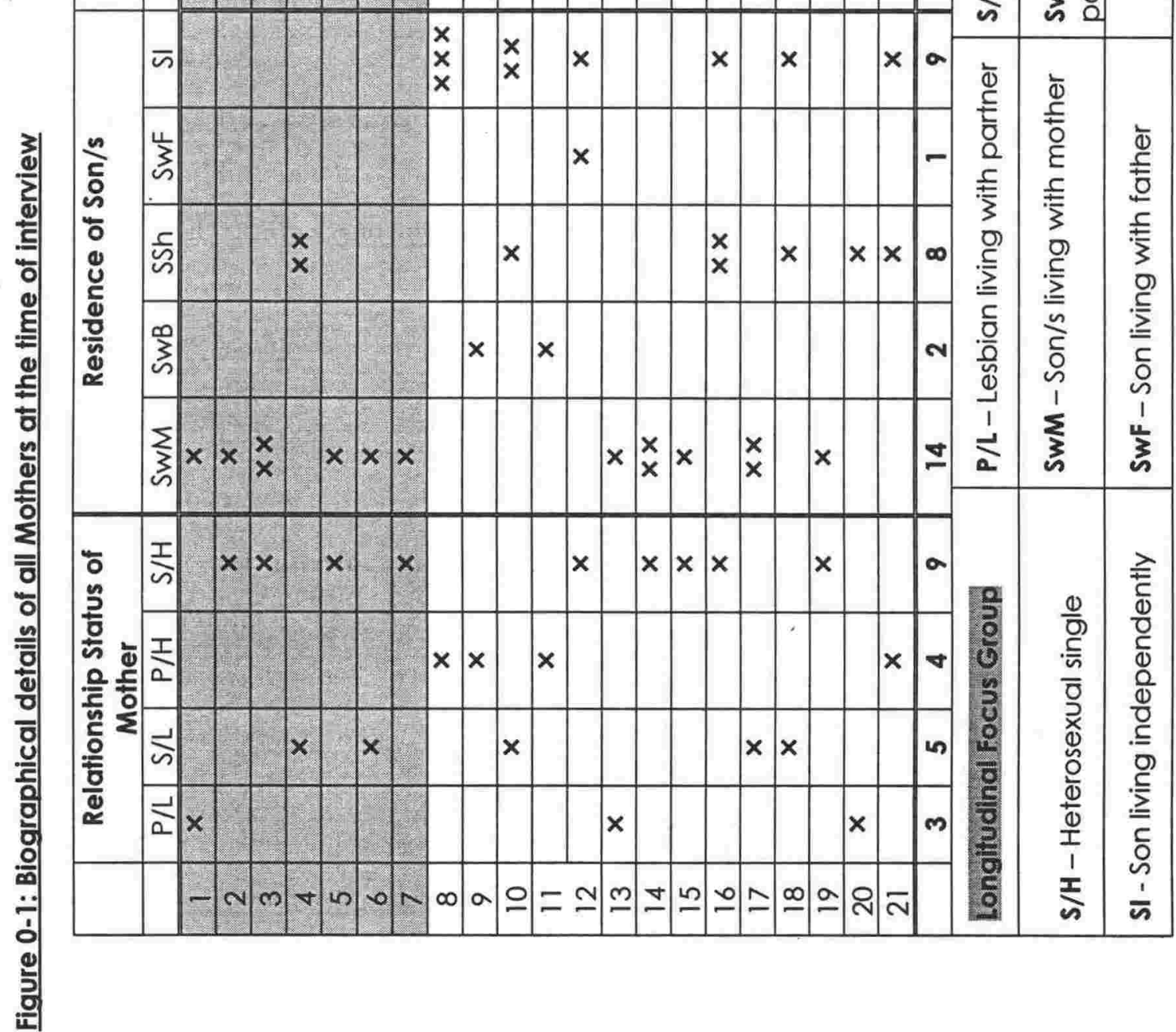




\section{BACKGROUNDS \& BEGINNINGS}

The following summaries include salient points of the lives of the mothers as they relate to the project. They stem from the mothers' own accounts of their stories.

Although Mother 1 did not plan her pregnancy she chose to continue with it. She lived in a home for single mothers through the birth of her son and for six months after. Resisting the pressure from staff in the 'Home', from the Social Welfare Department and from her own family to give her baby away by adoption, she applied for the Domestic Purposes Benefit (DPB). Once the DPB was granted to her, she left the home for single mothers and raised her son on her own. Physical and social isolation, ill health and financial difficulties dominated the next eleven years for her. When her son was sixteen, the mother formed a relationship with a woman who moved in to live with them.

Mother 2 worked and travelled around the world until she met the father of her son and accidentally became pregnant. The father was alcoholic and showed little commitment to the mother and the unborn child. He left when the mother and baby were in the maternity hospital. She says,

It was hard actually when he left because here I was with a baby and I had to get on with it. With what Social Welfare was able to give I actually got out and applied for a Housing Corporation home, and that is how I ended up in this place here.

At the time of the interview the son was seven and, although he had spent time with his father the occasions were irregular and occurred at the infrequent whim of the father.

Mother 3 was married when she had her children. Although alcoholic, the father stopped drinking during the births of the first two sons. He was not able to sustain this abstinence, however, and started drinking again after five years. The mother reports,

It was nearly four years that I hung in there hoping that it would stop, and then I finally came to the realisation that things were progressing past the 
alcoholism towards violence and drug dependency. It was the violence more than anything that made me decide it was time to get out.

The DPB offered security to this mother, who for the first time in eleven years reports that she had some control over her life. After this time she had several (male) partners. The antagonism expressed by her children toward these men discouraged her from living with anyone.

Mother 4 had strong beliefs about the importance of marriage and family life. Nonetheless she reports that the marriage "didn't work from the day the first baby was born. But I kept clinging onto it because I had this real incredible commitment to him, I was just determined it was going to work." The escalation of physical and emotional violence over the next twelve years and living in perpetual fear finally became too much for her and she ended the marriage. From this point she parented four children on her own coping with financial difficulties, working part-time and being subsidised by the DPB. When the sons reached fifteen they each chose to live with their father. At eighteen years old the older son has moved back with his mother. Although recognising her lesbianism for the first time during the project, this mother did not develop a relationship.

When Mother 5 became pregnant the father of the child offered to marry her. However, apart from feeling unsafe about his drinking and drug taking, she also felt that being pregnant was no reason to get married. The DPB offered her a way to support herself and her baby. She moved from the place where she had been living to environment an environment she believed was more suitable for her child. She rented a Housing Corporation home and looked for part-time employment to subsidise her benefit. Although she joined Playcentre, she felt she did not fit as a single mother and became increasingly socially isolated. She struggled with financial hardship, was not able to afford her own transport, and felt unable to afford the cost of entertaining people in her own home.

Mother 6 had her son in a nuclear family situation. Her husband's affairs began when their son was newly born and the marriage ended when he was two years old. The son's involvement with both parents was recognised as important and although he lived with the mother regular access was organised with the father. Initially drawing the DPB the mother began part and then full-time employment. 
Although living with her (female) partner for several years she has spent most of her son's life parenting him on her own.

Mother 7 was thirty-six when she accidentally became pregnant to a man with whom she had been having a relationship. Believing that they would marry each other she visited him with her news, to be told that he was returning to live with his wife. She had been brought up to believe that "no one in [her] family had ever been on a benefit but had always worked hard to put a meal on the table and pay the bills". Accordingly she did not initially consider applying for the DPB. She lived in the city for the first six years of her son's life. Her life was an emotional and financial struggle while she cleaned houses and sold her previously accumulated assets to survive. By capitalising on family property, and in order to provide a healthy and safe environment for her son, she moved into the country where she bought some land, a cottage and animals.

Mother 8 had her first child when she was twenty-seven. She spent the first ten years full-time parenting her three children. As her husband's income supported the family she didn't seek paid employment outside the home. When the youngest son went to school she began voluntary work. In her interview she described an ongoing 'absence' of her husband who worked long hours, belonged to several service clubs, played a lot of sport, and had little to do with the children.

Mother 9 became pregnant when she was a teenager. Her Catholic parents encouraged her to marry the father of her unborn child who was also in his teens. She remembers thinking in the morning of her wedding day "this is so ridiculous! Somebody's gonna make the decision for the rest of my life". However she went along with the process like a "good Catholic girl". With ongoing extended family support, although sometimes described by her as "over-protection", she continued to raise her son with his father, home-schooling him until he was twelve years old. At the time of the interview her son was nineteen.

Mother 10 also had her first son when she was young having left home to live with his father. "There was no gap between establishing my own identity and between becoming a mother," she reflected, "I doubt whether I had established much of an identity at all". Several years and another son later, she came out as lesbian and became actively involved with the women's movement. Financial 
difficulty was an issue throughout her life with her sons. She believes that this has permanently impacted on their decisions as teenagers and young men. She had a third son when the older two were in their teens. This time she felt she was ready to parent. Her employment situation is not constant but this, she explains, is by choice.

Mother 11 had two children to the man with whom she continued to live. Other adults and children have been a constant part of this family's life including periods of time living in community situations with other families. Both parents have worked inside and outside the home for negotiated periods of time. The mother also studies and is politically active, working particularly with women.

Mother 12 finished full-time employment when her three children were born, and became involved in Playcentre and Parents Centre. When her youngest son was ready to start school she returned to part-time work and, as he became older, fulltime work. Her husband left unexpectedly when the youngest child was ten. She continued to raise the children on her own. She remembers being constantly traumatised by the breakdown of the marriage and worn-out by the demands of full-time work and full-time home and children. After several years the sons moved to live with their father, instigating years of tension with their mother. Eight years later at the time of the first interview, and another year after that at the time of the second interview, this tension had not been resolved.

Mother 13 had her first child when she was fifteen and her second child nine years later. For the first fourteen years she worked with her husband and their business and supplemented the family income with extra part-time employment. Realising that the relationship wasn't working for anyone in the family she moved away. Believing her income was too uncertain she left the children with their father. From an unsuccessful background in the formal education system she enrolled at a university. It wasn't long before her son asked to live with her, and then followed a period of intense poverty. She was living with her son and (female) partner at the time of the interview.

When Mother 14 became pregnant the father wanted her to have an abortion. Instead, pursuing "the fairytale life ... where Mum and Dad and all the kids were happy and it would be like that forever after" she got married. Needless to say the 
fairytale eluded her and shortly after the second son was born she decided she could not continue with the relationship. Although she has since raised the boys on her own their father lives in the same street. The boys and their father negotiate contact with each other, which at the time of the interview when the boys were fourteen and sixteen, seemed to be sporadic. Throughout the twelve years this mother has been parenting on her own she has had casual employment to supplement her benefit.

Mother 15 was a tertiary student when she married. Although entering the marriage feeling strong and independent this mother became increasingly exhausted by a relationship that she described was psychologically abusive and draining. Four children and eight years later the marriage ended. Although custody of the children is shared between the parents, the relationship between the parents is acrimonious and between the children and the father increasingly so. The mother continues to study and, unable to secure full-time paid employment, works part-time.

Mother 16 had her children, three boys and a girl, into a nuclear family structure. From the birth of the children her husband became increasing violent. When the youngest was eight she left the relationship taking out non-molestation against the husband and custody orders for the children. One of the supports she had used over the last years of the marriage was part-time university study. Once she left the marriage she continued her study, became professionally qualified and has since been in full-time employment. Throughout their teens the have boys lived with their father and mother at various times. Although having several relationships she reported that she has not lived with any of her (male) partners.

Mother 17 separated from the father of her sons when the youngest was three years old. Although the relationship between the adults was initially difficult and the sons remained living with the mother, both parents believed that the children should have access to each of parent. This arrangement has been maintained throughout the years since. Working full-time for most of her sons' lives this mother has lived both on her own and with her (female) partner.

Mother 18 had three children by the time she realised that her relationship wasn't working and that she shouldn't be married. She and her husband were involved in 
the management of the local church and were a well-known family in the rural area within which they lived. Although she tried "desperately to fit into this mould to save the marriage", after nineteen years of "not fitting", she finally left. The following years, she reported, were full of conflict over property, acting-out teenagers and constantly changing addresses. This mother was employed fulltime, continued her tertiary study and was the main financial support for the children. Her (female) partner lived with the family for a short period of time but difficulties between the partner and the children ended this.

Mother 19 extricated herself from a relationship after twelve years of severe physical and emotional violence. Involved in tertiary study and working part-time she sought a protection order, rented a home and moved with her two teenage children. Although the daughter opted for supervised access with her father, at the time of the interview the son had refused to see him. Finances are tight and the mother continues to seek full time employment.

Mother 20 described herself as "probably the highest paid solo parent in New Zealand" while she was married. Her three children had very little contact with their father whose work and sporting interests kept him away from the home. After ten years of a self-labelled dysfunctional marriage this mother ended the relationship and later created a home with her (female) partner. Both parents share custody. At the time of the interview the mother was employed part-time and continuing tertiary study.

Mother 21 reported working in her husband's business when she became pregnant with her first-born. She continued working part-time and, as the house was attached to the business, the father was able to have some contact with the children. However after the birth of the third child the family moved away from the business and this mother "saw [her] role as being almost like a sole parent but with the financial support". The father preferred to parent from a distance and spent an increasing amount of time away from the family. After several affairs, when the children were twelve, fourteen and sixteen the father left to live with another woman. The children spent time with both parents until they were old enough to leave home. The mother continued her tertiary study and when the youngest was fifteen she remarried. 


\section{Bambi's Mother}

It may seem strange that a character popularised by Disney is included in this list. The creation of a nameless mother in 1928 by mythologist, Felix Salten, seems significant. Salten begins his book with the birth of Bambi. Much attention is given to describing the birth in intricate detail - the environment, the forest friends, the tiny fawn's first experience of the world. The mother is hardly mentioned and when she is it is with reference to her son. She is the vessel by which this 'boy' was born. Freud claims that "a mother is only brought unlimited satisfaction by her relation to a son; that is altogether the most perfect, the most free from ambivalence of all human relationships" (as cited by Arcana, 1983, p.209). And so, the reason for the existence of Bambi's mother's is to bear a son the fledgling king. Her story will also appear in the chapters ahead.

\section{SOCIO-ECONOMIC SITUATION FOR MOTHERS}

A key issue relating to the women in the study was that of their socio-economic status. The Equal Worth Report (1999), written from a study commissioned by the Australian Commonwealth/State and the New Zealand Standing Committee of Advisors for the Commonwealth Office of the Status of the Status of Women, investigated the following nine indicators; equity in owner-occupied housing, equity in rental property, interest-bearing assets, dividend yielding assets, accumulated superannuation, equity in unincorporated business, home contents, motor vehicles and non-housing debt. The findings as they related to Aotearoa New Zealand show that females on average hold approximately 85 percent of the wealth holdings of males $(1999$, p.26). Categorisation of females into family type and age grouping shows further discrepancies. Within all broad categories of family groupings the mean wealth of males is higher than that of females by 15 percent. The difference between males and females increases to 33 percent for families with dependent children and increases still further to 47 percent when in comparing single male parents and single female parents. The relative wealth position of females, the 'Equal Worth Report' found, deteriorates from the 30-39 age groups (Figure 4.2). 


\section{Socio-Economic Status of the Mothers in the Study}

The household and individual incomes of mothers in this project are shown in

Figure 4.3. The graphs of the mothers in the project report annual taxable income. Given the findings of the 'Equal Worth' report, it can be assumed that the wealth of the project mothers, compared to that of fathers and compared to either gender without dependent children, is less.

\section{Figure 0-2: Income Levels by Gender and Age-Aotearoa New Zealand 1998}

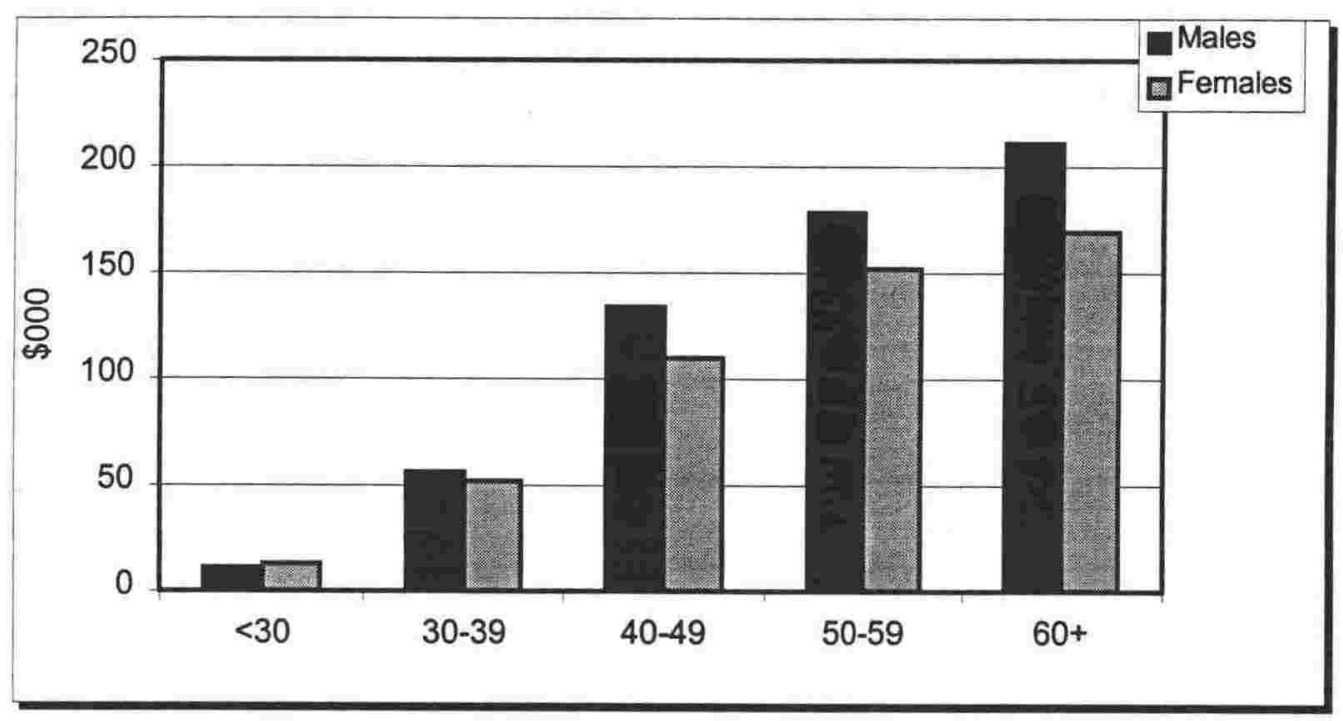

The following section discusses the specific situation of single mother families. Although the financial situation of the single mothers was reportedly worse than that of those in two parent households, the latter group also reported difficulty.

I think it's harder for people with teenagers now who because they're. students they've got to stay at home and they don't have any finances for the next few years. (9)

[The lack of income] was a lot of stress for our family and I found that really hard at different times and there just wasn't enough to go around. I've worried about that sometimes in terms of the kids being a little bit too worried about money or where it might come from. ... The stress with money and stuff continued for some time after because we were on unemployment for a couple of years. The repercussions of that in terms of overpayment and things, it's still 
been worked out now over 5 or 6 years later, so yeah it was a very traumatic time that time. (11)

Figure 0-3: Income Levels of Mothers in the Project

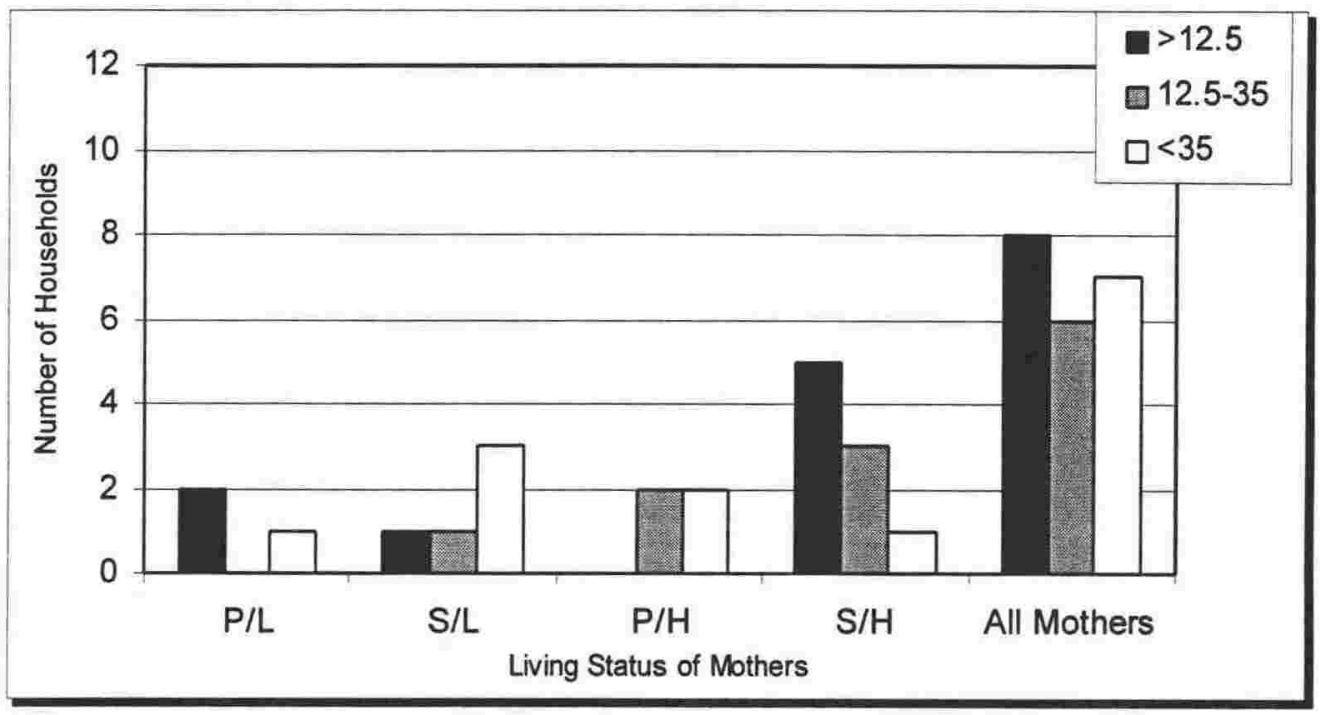

GRAPH 1: Household Income (\$000)

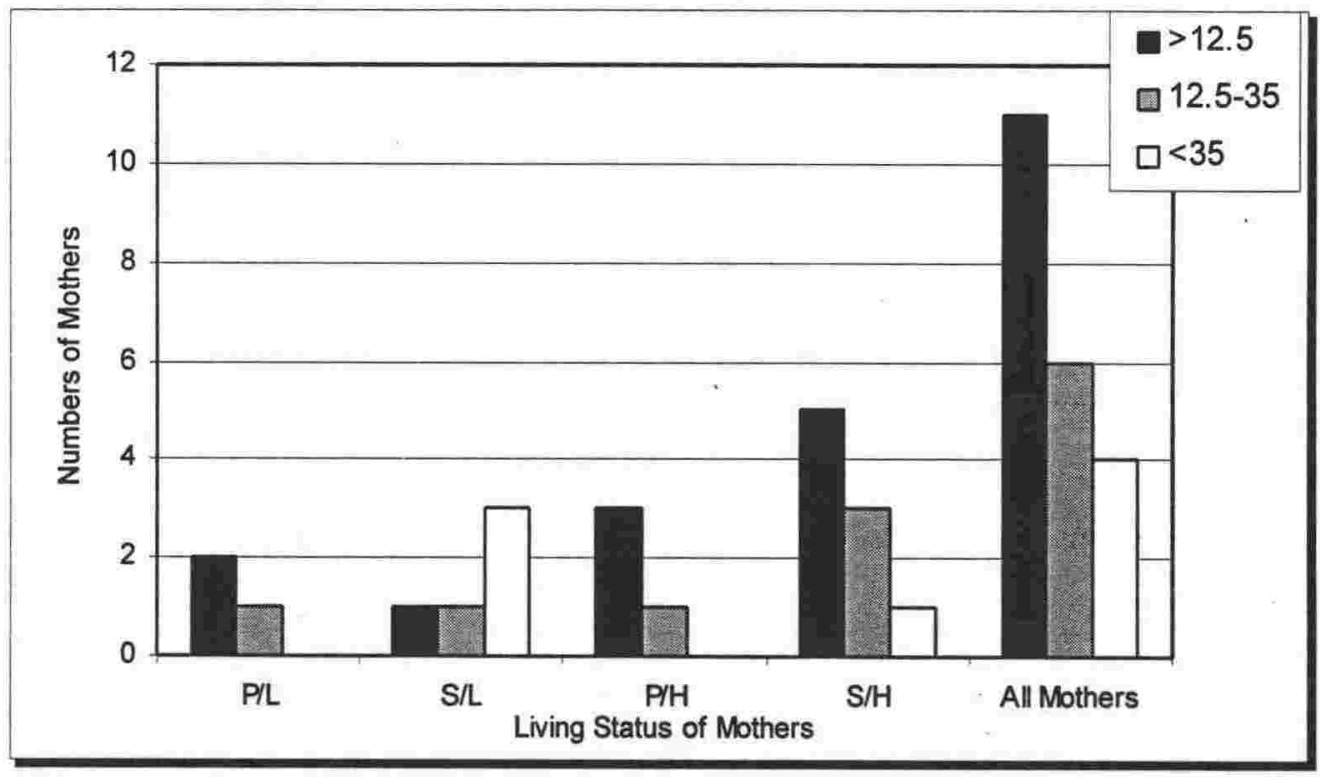

GRAPH 2: Individual Income (\$000)

\begin{tabular}{|l|l|}
\hline $\mathbf{P} / \mathbf{L}$ - Lesbian living with partner & $\mathbf{P} / \mathrm{H}$ - Heterosexual with partner \\
\hline $\mathbf{S} / \mathbf{L}$ - Lesbian single & $\mathbf{S} / \mathrm{H}-$ Heterosexual single \\
\hline
\end{tabular}




\section{Socio-Economic Status of the Single Mother Families}

All but one of the single mothers interviewed spoke of the financial difficulties they faced, whether they were fully reliant on a benefit, whether they subsidised their benefit with part-time employment or whether they lived exclusively from income they earned. Some women had not had the opportunity whilst raising children to train, update their existing training or retrain for a career or employment that would pay well enough to support a family.

The move toward privatisation and a user-pays economy by the previous government over the past decade has severely disadvantaged single mothers. Adequate income for the increasing costs associated with education, health and safe and appropriate housing is often out of reach. Figure 4.4 illustrates the decrease in social welfare expenditure on benefit support against Gross Domestic Income from 1991 to $1997^{2}$. When compared to the following graph in Figure 4.5 indicating an increase in the number of beneficiaries from 1996 to 1998 , the per recipient situation looks even worse ${ }^{3}$. Figures from studies in the USA, England and Wales reported by Paula Nicholson, from the University of Sheffield, indicate that the number of single-parent families in those countries is also increasing. In England and Wales, for example, the reported increase was from 8 percent in 1971 to 20 percent in 1994 (1997, p.391). In a collection of papers written for the 'Work, Family and State Conference' at Massey University, Palmerston North in 1997, Celia Briar, Kay Goodger, Robyn Munford and Michael Bittman provide solid reference material that identifies the concerning financial and social positions for women and children and the lack of concrete support for them by the state or by the community.

\footnotetext{
${ }^{2}$ The government cut the Domestic Purposes Benefit in 1991.

${ }^{3}$ Domestic Purposes Payment makes up approximately 13 percent of this total.
} 
Figure 0-4: Social Welfare Expenditure 1991 - 1997 Aotearoa New Zealand (Source - Department of Social Welfare: http:www.stats.govt.nz)

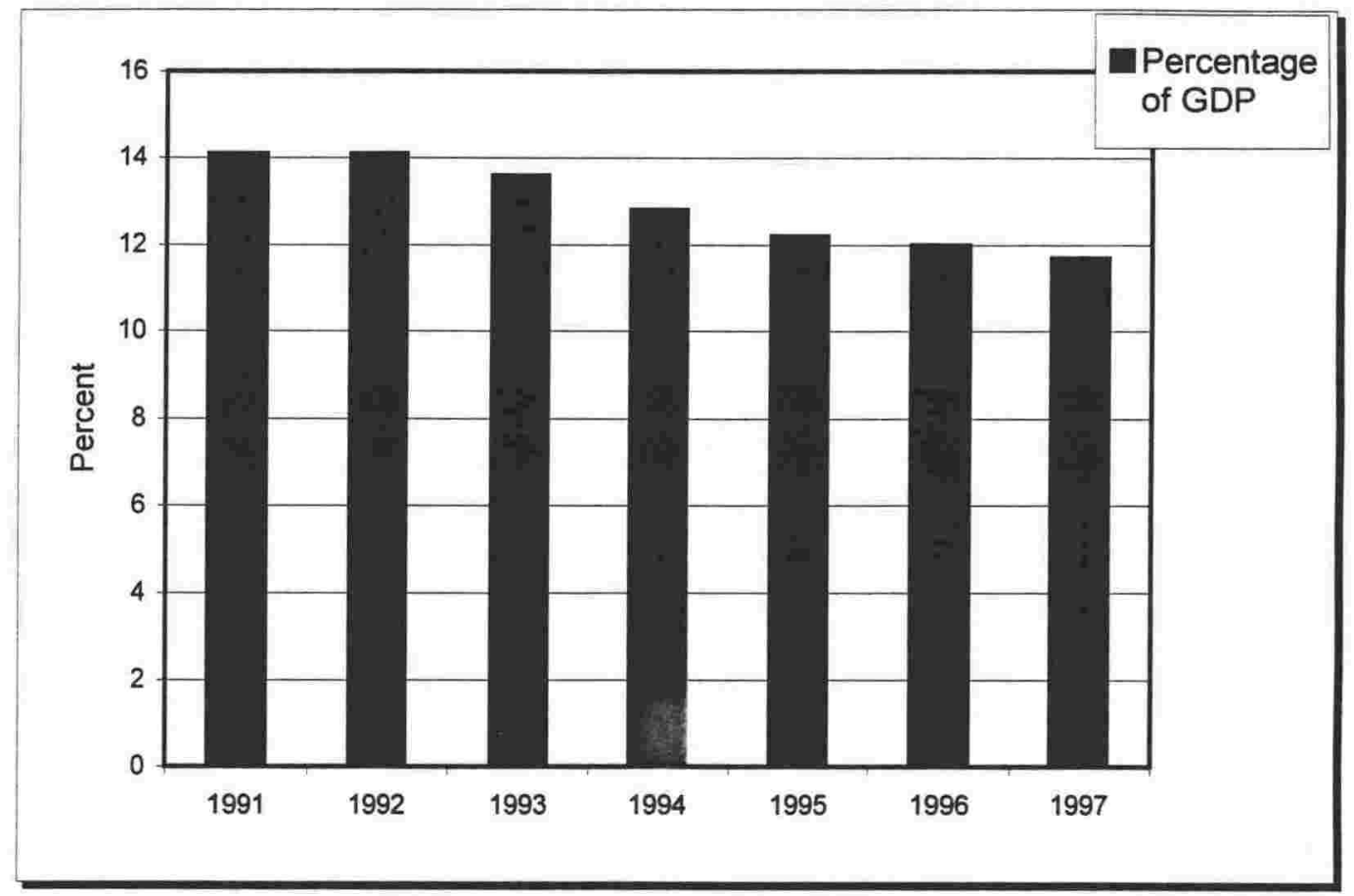

Figure 0-5: Number of Benefits 1991 - 1998. Aotearoa New Zealand (Source-Department of Social Welfare, Statistics New Zealand 1991 - 1998: http:www.stats.govt.nz)

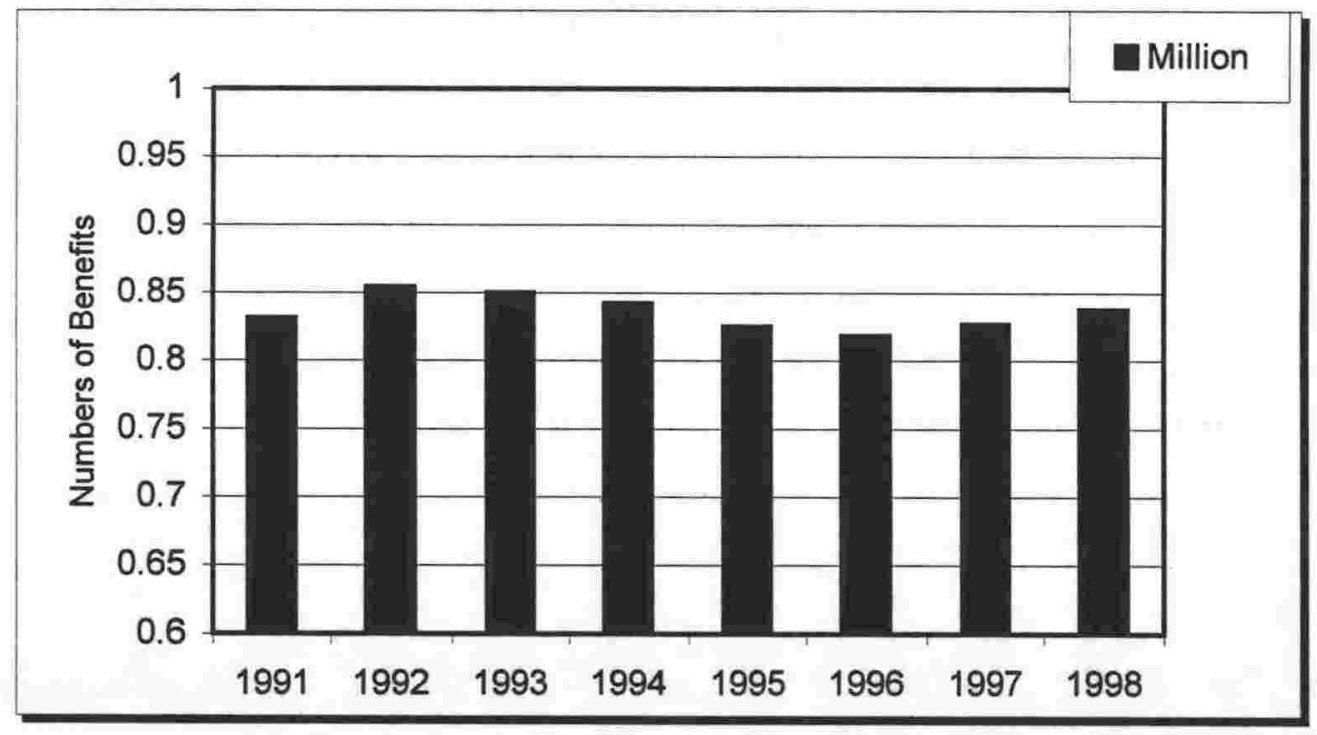

Before the change of government in Aotearoa New Zealand, and before he became Minister of Social Welfare, Steve Maharey put the following question to the House,

If the Government has been increasing spending, can the Minister explain why the NZ poverty measure and his own Social Policy Agency report that a third of 
all NZ children live in poverty, $73 \%$ of all single-parent families live in poverty and that the number of Maori households living in poverty has doubled since the 1990's? (Hansard 68, March 24, 1999, p.15595)

Alliance member, Grant Gillon, asked a similar question to the then Minister of Housing.

Does the Minister agree that the accommodation subsidy system is creating a privileged class of private landlords and that we now have a national waiting list of 7,000 people to get into a State house, and how can it be a privilege for a solo mother in Auckland to pay $\$ 220$ a week in rent, yet receive only $\$ 230$ a week on the DPB?" (Hansard 74, Questions for Oral Answer, 26 May 1999, p.16938)

Needless to say there was no response from either Minister. Nor, of course, had Maharey or Gillon asked these questions to solicit one. They were making a point about the poor situation for (particularly) single parent families in this country. These effects of socio-economic hardship on the ability of single mothers to parent their sons effectively cannot be underestimated. According to Meg Wilkes Karraker, from Minesota Council on Family Relations, "some of the most negative impacts of divorce are inextricably tied up with economic deprivation" (1995, p.3). Quoting from research undertaken in the USA by Duncan and Hoffman (1985), she says that male post-divorce income averages 90 percent of their pre-divorce income whereas female post-divorce income averages 67 percent of their pre-divorce income. In addition, states Karraker while mother-headed families represent 16 percent of United States families, they also constitute 46 percent of the household living below the poverty level.

The project mothers, particularly those living on a benefit, reported difficulties providing for the basic needs of their families. It seemed that the lack of these basics impacted in several ways. Physically the health and well being of family members declined, impeding the sons' abilities to successfully achieve at primary, secondary and tertiary study, and consequently to compete for rewarding and adequately-paying employment. The costs associated with maintaining social contact with others isolated the family. Psychologically the families battled with external and internal pressures. Externally the single-mother families were battered due to their non-conformity to the privileged structure of the white 
heterosexual nuclear family. This reportedly occurred within the communities and groups in which the families lived and related. It is also, I believe, produced and sustained by those who determine social and economic direction. Internally it seemed as if the tensions that make up part of any family were amplified by the lack of resources available to the family members, the low-self esteem generated by that and the lack of a second supportive adult.

Mothers reported the impact of the lack of available resources on their sons in several areas. The significant areas of financial struggle as reported by these mothers included: housing, food and clothing shortages; limited access to education, health and transport systems; and an inadequacy to fully support their sons' co-curricula interests.

I [had to sell] the family home when [Sons] were 11,13 and 15. ... [1] bought another house. ... it was just this tiny little dogbox of a house and it was ghastly, absolutely ghastly. ... being jamb- packed into a tiny little house. It wasn't good for me, it wasn't good for these kids. ... It was a year of a great deal of stress for the kids, for the boys in particular, because they were fighting all the time. It was horrible. And I felt I was losing them too. I really did. That was a bit scary that year. (3)

It was so hard. Here's this kid who's 17, and here I am piddling along on $\$ 300$ a week trying to pay a mortgage and bring up these kids. ... Somehow we got through. (GP3)

I was sort of looking at a carrot and a leaf of silver-beet and something in the fridge and thinking I wish I could eat it but got to keep it for [Son's] vegetables. I was really on the breadline. (7)

Difficulties as they related to education of the sons included the cost of school fees and school activities, the need to leave school prematurely in order to earn an income and the difficulty of access to tertiary education.

It was a constant struggle. Not only is it hard to get the fees together but I knew that my kids didn't have enough clothes to last ... four days or a week at a camp. They simply didn't own enough pairs of shoes ... often the letters would come home; two pairs of shoes. (GP4) 
The trouble is that when they get older they don't accept that. School trips and that. I have gone off to bed crying because I couldn't afford to send him on a school trip which he wanted to go on. (GP2)

I'm standing there saying 'but you can't [leave school], you're too young, you're only 16'. 'I'll be 17 next week Mum, I'm going'. And he did. I'm quite convinced that the financial constraints that we were living under forced that on him. (3)

They had no pocket money my older two boys. We never had that sort of money. They had no holidays ...so they went out and earned their own pocket money and the second one started work at 15 because he couldn't get up and go to school and he didn't really want to be at school. (10)

I made it quite clear that I just wouldn't have the money to put them through University and if they wanted a career they would either have to get a job and pay for it themselves. ... I sort of broached the idea about the Navy or the Army. (14)

Mothers also reported an inability to access appropriate health care.

Now that it's so expensive [to go to the doctor] that we actually hold off that point of going to get help for it because the money is so short that our kids need it rather than we need it for other things. ... Women are a lot more sick than they would've been. ...I never want to go back to that situation of being desperately ill and not being able to do anything about it. (GP4)

You got sick when you could afford to get sick. You just are not allowed to get sick until you've got a holiday coming up and then the body relaxes ... but up until then I just fight it all the time. (3)

Mobility was also reportedly hindered by the lack of money.

I couldn't afford to run my car every day... carpool. ... leave home at 7.45am. ... I wasn't getting home till it was dark and [son] used to get the bus to and from school so he was at home by himself for a good two hours before I got home. That just freaked me out, I was never quite sure whether everything was gonna be okay. (13) 
If we had a car we would have less money, but then because we haven't got a car [son] can't go and do a whole heap of stuff that he would like to do. Even to go to the [waterfront] for tea, you can't do that because ... you could walk down there and have tea and walk home, but by the time that happens you're looking at $8 o^{\prime}$ clock and you are both stuffed. (GP3)

A majority of these mothers talked about the stress that financial difficulties placed on themselves and on their sons, particularly when they worked to supplement their income.

I seem to be always working, I'm always tired and I just keep hoping that there's a light at the end of the tunnel and when they get into the Navy they will be gone, and I would have done my job. (14)

Physically it's exhausting. It really is. I have only been back school teaching two years because I knew that it would be emotionally demanding so in that interim eight years before I went back to school teaching I had a clerical job that was $8.30-4.00$. I walked in and walked out, because I knew that I couldn't cope with the demands of school teaching plus running a household. But the pay was dreadful. I have never earned more than $\$ 20,000.00$ a year. (3)

Several of the mothers felt as if the self-esteem of their sons was impaired because of the lack of money available to the household.

Low self esteem [was caused] ... because they don't have enough lunch. They don't have enough clothes. They can't bring the money to go on the school trip and it's really hard for those kids. ... The children know in the class who the ones are that will always not have the money, the $\$ 2$ for the class trip, who will always not have the money to be able to afford to buy the books. (GP4)

And then what you're seeing at school is the impact of those kids who don't go, who miss out on that kind of kid-bonding stuff and all that goes with it? Kids in my class go. I pay out of my own money. I won't let kids in my class not go. I just see it as reinforcing low self-esteem and no confidence in those particular children, particularly the boys. (GP4) 
We couldn't afford a $\$ 100$ pair of shoes, the Doc Martens and fancy clothes that all his mates had. He couldn't go for a weekend to wherever he wanted to like his mates could because we just didn't have the financial [ability]. (GP9)

For this mother, her "biggest worry about parenting alone and that it was actually the children that missed out". (20)

In most households mothers reported spending whatever money was available on their children rather than on themselves.

I think it is easier to spend $\$ 10$ on a T-Shirt for [son] than it is to spend $\$ 10$ on a T-Shirt for me. (5)

I was making sure that [son] had the best of everything. I was doing without myself so I sort of basically started to fade away to nothing and my house started to suffer a wee bit. (7)

One of the more poignant group discussions about the lack of money available to mothers was do to with Christmas.

\section{Christmas, I hate Christmas.}

- I hate Christmas too.

I still get depressed prior to it (Christmas) but I think that's mainly cause of the messages you get on TV, I've never been able to afford you know, to buy even a ham one poor ham.

- What do you see on the TV and what do you see on the streets and what messages come out and what are the Christmas carols all saying? ... Togetherness, a partner and it's going to be lovely, you're going to be able to buy everything that you want for your kids, you're gonna have enough food on the table, you're gonna have enough money to put petrol in the car to go over to the beach and have a wonderful day and buy everybody an ice cream.

That's not the reality. (GP 4)

A three-year study by Jacques D Lempers and Diana S Clark-Lempers began in 1996, through the Iowa State University, included an evaluation of the effect of economic hardship on mother-son dyads. A sample of 188 sixth graders (including 92 males), and 210 eight graders (including 106 males), and 390 of 
their families participated in the study. The first wave of findings, reported in 1997 , found that "financial strain on the mothers led to a decrease in the quality of the mother-child relationship, as perceived by the children" (Lempers \& ClarkLempers, 1997, p.2). This finding, endorsed by other studies cited by the authors, Clark-Lempers et al. 1990; Conger et al. 1992; Elder et al. 1985; Lempers et al. 1989 , reflected the experiences of the mothers from this project.

[The lack of money] affects relationships between [son] and me. I come out of Income Support feeling really irritable. ... It really grated on me about what I had to say and what I had to show them and what I had to do. I was really a nasty person. ... The worry of it too it gets at me. (7)

It was a mixture of emotions. Sometimes he would get very depressed over it [lack of money]. ... He would get angry and slam doors. I just felt angry. (GP9)

I think it's really a critical issue [lack of money] because we've had a lot of stress around money in our family and at times it hasn't been very healthy for the kids in terms of the stress. (11)

I was working nine tenths so I was virtually full-time. ... It was pretty demanding doing that full-time and caring for the kids on my own and coping with all the trauma that was happening but I was too scared to stop. In retrospect and in terms of looking after family relationships I think I should've gone on the $D P B$, and said to hell with the finances. (12)

The experiences of these mothers are supported by Lynette Ebborn, who from her own experiences as coordinator of a Solo Women As Parents support centre in Christchurch Aotearoa New Zealand, claims that a family living in poverty prioritises the material needs of that family over the emotional needs (New Zealand Herald, September 5, 1997). In other words, the quality of relationships between family members becomes less important to the family system than does the effort that is required to find enough money to live on. The mothers in the project also reported that their inability to adequately finance their children's needs damaged their sense of self-esteem. 
[Sons] have said to me that there must be something wrong with me that I can't provide better. I was really hurt about it. (GP3)

Is often thrown back at women too ... as an abuse issue for example. 'We had a neglected childhood because you didn't provide us with the financial ability to do this, that or the other'. (GP4)

In order to meet the costs of providing for their families, mothers attempted to supplement their income. Those relying on the Domestic Purposes Benefit as their main source of income did not typically account for their extra earning with the government.

I go out and I buy clothes at Red Cross. ... Nice, perhaps label, clothes and then I would knock them off through the other shops that sell on your behalf for double the money. ... because the clothes go for 70 cents, and we are running around picking these clothes up. That's another way I find to make ends meet. (2)

So I actually had her boys for something like three years. So that worked really well, and I was getting this extra bit of money. ... It supplemented my income and it mean that the kids, my children came home from school and had the stability that they needed. (3)

Statistics from the 1996 Census of Population and Dwellings, collated by Kay Goodger of the Social Policy Agency, show that single mothers have increasingly assumed part-time paid work (defined as 1-29 hours per week) and full-time paid work (defined as 30 or more hours per week) (Figure 4.6). Goodger also cites Department of Social Welfare statistics that showed an increase in DPB recipients earning additional income from 19 percent in July 1996 to 22 percent in June 1997 (1997, p.92-98). 


\section{Figure 0-6: Proportion of single parents employed by gender}

(Source - NZ Census of Population and Dwellings - 1986, 1991 \& 1996)

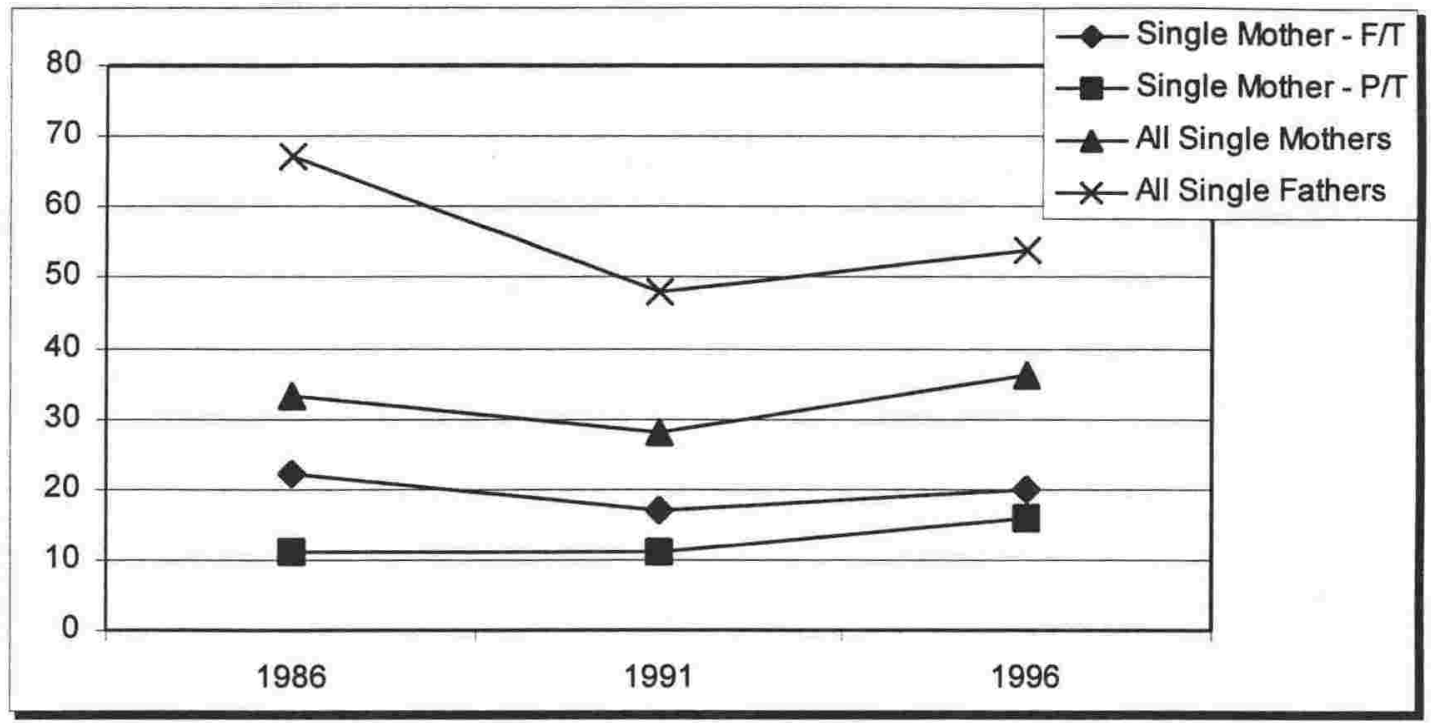

Additional mobilisation problems due to financial difficulties reportedly isolated the mothers and families further. Ferguson reflects this when she claims that the growth of suburban and urban living patterns are depriving mothers of the supportive networks of other women (1997, p.54).

We were very lonely and it was very isolating out there as well because the car I had cost me $\$ 10$ to get into town, it was a real hungry thing and I was broke as so we couldn't go anywhere, we couldn't do anything (13)

I feel there is so much isolation in today's society. Everyone lives in their little houses and half the time you don't know your neighbours. ... It's just the isolation and the lack of adult support. (4)

Shame and humiliation of not being 'as good as' others caused tension between mothers and sons.

He tended to back off from socialising with the kids who were able to afford to go on camps and that. He wouldn't bring them home because he felt embarrassed because we had odd squares of carpet in the house. ... It was clean, but it looked like a dive to him. And of course all his other mates had posh carpet throughout and televisions in every room, and all this sort of stuff. It did hit him a lot. (GP2) 
One of the major financial concerns the single mothers in the project reported was that of the seeming inequitability of their situations compared to those of their children's fathers.

I would just like to express one thing that I find that really bugs me a lot. The kids are always saying 'I want these clothes' ... or 'why are you always poor', 'why don't you get a better job', all these things and my husband appears to be really well off. They put a lot of pressure on me because of that inequity, and I find that quite a difficult thing. (GP2)

He pays child support. Pays exactly what IRD tells him to. But he still seems to be a lot better off. (GP3)

The boys actually ... saw their father gaining assets. ... having lots of holidays ... not giving them anything. ... They had school fees, there were uniforms, there were school trips, there were the usual things that we have to pay for. They noticed their father financially absent from their lives as well as emotionally absent. (18)

Chapter Five discusses child support and related financial issues between the mothers and the separated fathers of their sons. For this discussion it is enough to emphasise that it is the poverty level of many mothers that inordinately multiplies the stress-filled task of raising teenage sons. Although the mother-adolescent son project did not specifically investigate socio-economic factors and their relationship to the well-being of the family structure, the comments of this group of participants have indicated that the lack of resources and their experiences of poverty were a major debilitating factor in their ability to parent. These effects of socio-economic hardship on the ability of single mothers to parent their sons effectively cannot be underestimated.

Really it is a reflection on society because they are always saying parenting is so important, we know the family is so important, but when it comes to putting the money where the mouth is they obviously don't think that because they were quite happy to cut the benefits back, and see women really struggle. (GP1) 


\section{CONTROLS IMPOSED BY PUBLIC SECTOR GROUPS،}

Participants described the controls imposed on them and on their situations by professionals and professional organisations. The next section in this chapter addresses those most commonly reported, the justice, social welfare, education, mental health, religious and sports sectors. It does not attempt to analyse the primary sources ${ }^{s}$ of the predominant values, attitudes, beliefs and cultures represented and reinforced by these sectors but gives an account of the reported impact they have had on the research mothers.

\section{The Judiciary}

Contact between participants and the judiciary occurred in several general situations. These included, the dissolution of partnerships and subsequent negotiations regarding custody of children and distribution of property, the purchase of property and the legal validation (or otherwise) of relationships. Changing legislation in Aotearoa New Zealand has also had indirect impact on these mothers as they have raised their sons over the past twenty years. An example of changing legislation that has impacted particularly on single mothers is demonstrated by Mark Henaghan (1999a, pp.110-121), Associate Professor of Law at the University of Otago. It involves the 'welfare of the child' principle that has been central to decision-making about who should have custody and/or access to children when parents are separated. Henaghan, in concordance with Ferguson's contention ${ }^{6}$, argues that early twentieth century common law practices clearly declared the father as the legal head of the household and with children under his control. Father-right was thought to be best for children because it protected them from divided authority between the father and the mother. As the century progressed, according to Henaghan, two other principles emerged; the mother principle, which applied to the placing of younger children with their

\footnotetext{
${ }^{4}$ For the purposes of this study 'the public sector' constitutes those people/organisations whose activities involve working with families and children, such as within justice, education, mental health, social welfare, religious groups and sports.

${ }^{5}$ If using a Structural Analysis method, as has been developed by Phillipe Franchette for example, the source of the influences, the agents of persuasion and those of enforcement would be theorised. Differences would be apparent according to worldview, theoretical position and basis for analysis (ie. Socio-economic status, ethnicity, gender, family structure etc)

${ }^{6}$ Refer Chapter One for further discussion on husband patriarchy
} 
mother and the father principle, which applied to the placing of boys five years or older with their father. These principles, suggests Henaghan, were based "on the belief that children need the nurturing of a mother when young and that a boy needs the guidance of a father when he gets older" (1999a, p.112). The principles applied until 1981 when an amendment to the Guardianship Act, s.23 (1) (A) stipulated that there was to be "no presumption in law that one parent is better able to care for children because of their sex" (Henaghan, 1999a, p.112). Although attitudes from this period still persist among individuals and groups, the consequences of this change in legislation has meant that parents and children have become involved in sometimes hugely complex negotiations through the Family Court. Often a mother in this situation finds herself requiring the support of a lawyer to convince the Family Court what they believe is best for the children. While there is, as Henaghan $(1999 \mathrm{~b}, \mathrm{p} .51)$ points out, social, political and psychological disagreement about what is in the best interest of the child and while the judiciary continues to be predominately male, the proceedings and decision-making processes of the Family Court can often alienate the mother. One mother reported,

I think the attitude that I've experienced with male judges has been denigrating to me as a woman. I haven't liked the way they've spoken to me. ... They've been patronising. They've been unsupportive. ... They generally made me feel that they feel that they are superior in every way and as a woman I don't have rights. (16)

Mason and Quirk (as cited by Henaghan, 1999b, p.117) studied the outcomes of one hundred contested custody cases in Aotearoa New Zealand from 1960 to 1995. Although the statistical breakdown from the survey did not include gender or age of the children, it indicated that in contested custody cases in the first half of the 1990's more fathers than mothers were awarded custody of their children.

In 1984, a study was undertaken of sixty North American mothers who had been their children's primary caretakers and were custodially challenged between 1960 and 1981. This study showed the custodial vulnerability of "good enough" mothers (as defined by the study) and the ease with which a domestically violent father, or one with no previous involvement in care of the child/ren, could win custody. 
Figure 0-7: Outcomes of Custody Cases in Aotearoa New Zealand from 1960 $-1995$

(Source - Mason \& Quirk, 1997)

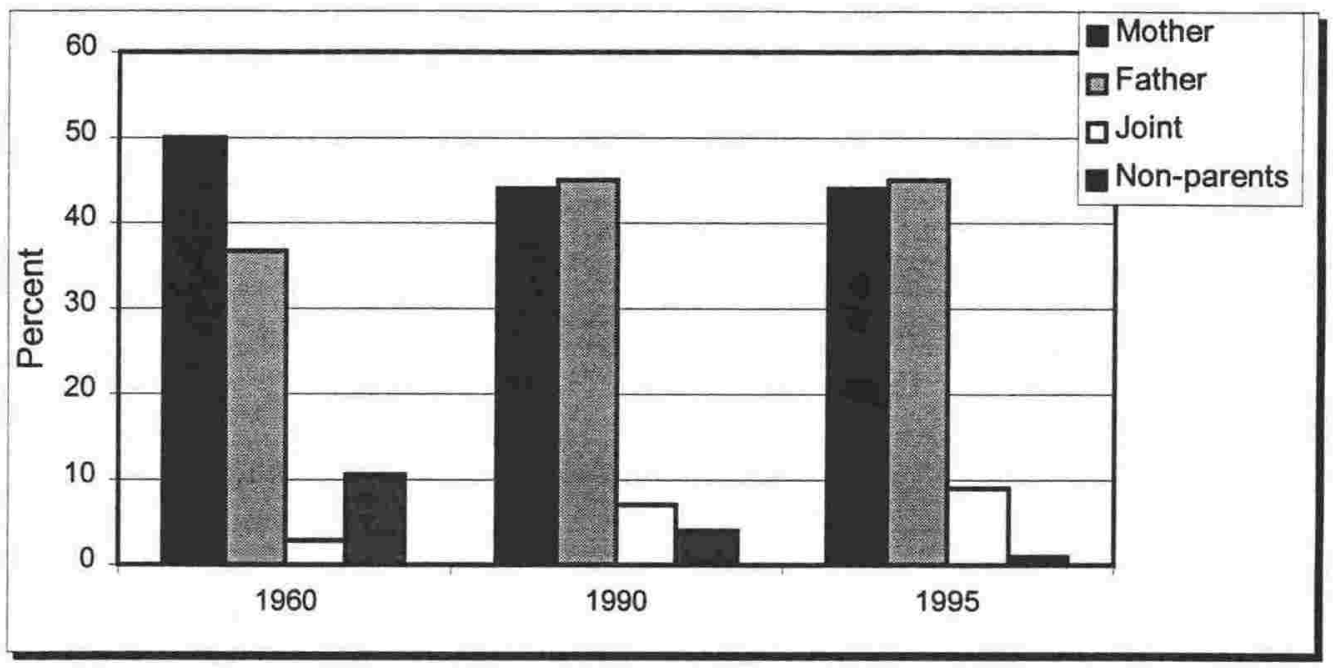

In 1993 Fraser, Fish and Mackenzie from St Thomas University, Fredericton, undertook a further study on child custody. They examined the effects of homophobia, subject gender, and gender and sexual orientation of the petitioning parent, on attitudes about judgements in child custody cases (retrieved July 3 , 1997 from the World Wide). The results indicated that the one hundred and six male and one hundred and sixty eight female subjects involved in the study were less likely to favour a homosexual parent winning custody compared to a heterosexual parent winning custody. This was particularly true for the male subjects of the study. Although the authors of the subsequent report acknowledge that the subjects of the study were university students, and that further research into a population that includes lawyers and judges is required, they claim a level of generalisability from this group to the (mostly male) members of the judiciary.

The mother-adolescent son project participants spoke of their feelings of being ignored by the judiciary and of the collusion between the legal fraternity and their children's father.

They [judge] always seem to think that the father has got a right. Even with the lawyer it was the same. ... He is not really interested in working things out.

Even the lawyer said to me. Now he was a male. 'We've got to give [son's Father] time to get his act together. (2) 
A further concern of the participants was the inequitable distribution of property once the marriage was dissolved.

I had to fight for my matrimonial property settlement. ... It's very hard to stand up in court and prove that you've put 20 years of hard work into a farm that's been producing a crop so to speak and prove that as a woman you've had some important role to play in that. (16)

I was separated in [date] and divorced in [two years later] and between separation and divorce a lot of the family finances had been redistributed such that when it came to settlement ... comparative to my husband ...I was socio-economically disadvantaged. (20)

I think there was quite a bit of stuff that I didn't know about in terms of the property and the business and I think he'd hidden quite a lot of money ... He ended up with a very expensive section, a thirty thousand dollar $4 x$ wheel wagon, a trip overseas, another house that he bought and god knows what else.

Strong lobbying within Aotearoa New Zealand over the past ten years has seen minor changes being made to property division on the breakdown of a marriage partnership. The Social Services Parliamentary Select Committee considered similar changes for de facto relationships during the first half of 2000 .

The cost of engaging the legal system has been a debilitating factor for some mothers in their dealings with the legal profession.

It cost me nearly fifteen thousand dollars in mortgages to fight my battle. Five thousand dollars for the last two battles and another one coming up. I'm going to get Legal Aid and when I sell my home it comes off my money. (7)

In most instances the mothers did not, or could not, take the financial risk to seek support. Although financial support is made available through a Legal Aid scheme in Aotearoa New Zealand, as the above participant indicated, the costs incurred are taken from any assets the mother may own or end up by owning. 


\section{The Social Welfare System}

The Social Welfare Department is another institutional system that has claimed ongoing authority over families. Those who create social policy and those who implement and enforce it determine and reward certain family structures, sanction certain behaviours of family members toward each other and privileges the position of the nuclear family within societal structure. Chapter One outlines recent initiatives by governments in Aotearoa New Zealand such as 'Welfare to Well-Being - Beyond Dependency', 'Strengthening Families', the 'Code of Social Responsibility', 'Child Support' and 'Community Wage'. Numerous restructurings of the Social Welfare Department under the previous National Party led government of the past decade reflect a move to withdraw state support from families. One participant expressed her experience of this change as follows,

Your Case Manager would bend over backwards to help you in any way she could. They don't seem like that anymore. (2)

Other participants described their experiences of being involved with Social Welfare systems as being shameful and regulatory.

I still have this awful feeling that every time I walk into ... Social Welfare. I just felt like, felt like I was dirty. This terrible feeling of having to go onto Social Welfare. (7)

Children \& Young Persons. ...I said "don't you think it's hard enough being a single parent without having this shit thrown at us?" (GP3)

Social Welfare seems like a great bloody ogre sometimes, but if they get a sniff at the fact that you're not coping, I just have a feeling that they could come in there and take [children] away. (GP3)

Participants also talked about the lack of accessible financial support from the state, particularly when it involved attempts to subsidise their benefit with other income. 
I've got a layoff period ... they're not going to give me any money until 13 January because of my holiday pay which is also covering my overdraft and rates and things like that so we're going to be pretty desperate.

I think it really sucks when the Government actually takes away the money. I think to myself that it is giving people less wanting to go out there and work because they ... will tax you and in the end you are only working for $\$ 40$ which might be a whole week. (2)

I only received maintenance after 1992 once the Inland Revenue Act came in. Inland Revenue claimed against the kids' father's income. He was assessed at $\$ 40$ a month for three children. But you don't actually see that as an extra anyway because of the benefit, it goes to Social Welfare. (14)

\section{The Education Sector}

A third major institution that influenced the situation for mothers was the formal education system, at both policy-making and implementation levels. This influence was apparent in several areas. The first of these involved the potential of teachers and curricula, hidden and open, to influence children's thinking and belief systems.

[Son] comes from a single parent home and all he can see in these [school reading] books are these mums and dads and kids, and how can he relate to that because his story is different. (6)

I actually keep well away from the school. Although I really love being around Pakeha people, and I have got some terrific Pakeha friends, the school - it is just that some kids have more of an advantage over some other children, and I tend to get a bit resentful towards I guess kids who do well, and only wish that mine could do that. (2)

One of the most exciting things was the letter that I got from school recently to say that he had been selected for a gifted learning problem solving group ... the first topic was gender roles in woman's work. ... The next topic they're going to do is entitled non-traditional families (20) 
The second influence concerned the apparent judgement by teachers and principals about those mothers who did not conform to the nuclear family mould.

I was having heaps of difficulty with one of the teachers up there. They were turning everything around and it was my fault. They really had me believing that I was the cause of all the problems. ... If I had gone up with a husband, I don't think they would have given me so much of a run-around. (5)

I was at a meeting one day and this lady, a school teacher [said] ... that the boys with single parents were actually real trouble makers in the classroom. (GP2)

I remember parent interviews ... and the teacher saying "where's their father" ... and wanting to involve their father. I felt a sense of being 'second in command' and filling in until father came along. (18)

In a letter written to the editor of the New Zealand Herald, in response to an article about boys falling behind at school Warkworth woman Elizabeth Foster wrote,

All those women who successfully reared sons from birth to adulthood had better see the error of their ways because, let's face it, the Education Review Office report says women might not "fully appreciate the specific needs of boys". (New Zealand Herald, 02.08.99)

Comments about the impact of the education sector on mothers also included the exclusion of some children from school activities because they were unaffordable.

[The Principal suggested that I] could make arrangements and pay $\$ 1$ a week. I thought 'for God's sake, how patronising can you be'. I suppose too it was a poke at me being a parent who wasn't coping, and to think that I could send along $\$ 1$ a week with my then 17 year old son to hand over to the office. (3)

He actually became Head Boy of the secondary school he went to. I found that difficult too because of the financial constraints. I wasn't able to maintain his higher profile as I felt I should have to support him at school. He was involved with organising the end of year prize giving and ball, and I wasn't able to go to 
it. It was a fairly formal affair, flash hairdos and nice clothes and all that sort of stuff. I was just out of my league. I couldn't do it.

I have gone along to SPELD ${ }^{7}$ but I can't afford the fees, so I have got to think of other ways of doing it [supporting son with reading difficulty].

\section{Mental Health Professionals and Agencies}

Over the past century in particular, the science of the mental and emotional well being of humans has evolved into a profession producing influential theorists and practitioners such as Sigmund Freud, David Levy, John Bowlby and Bruno Bettleheim. As illustrated in Chapter One, these people at varying times have contributed to 'ideal' perceptions of the structure of the family, its structure and of the roles of members within it. More recently writers and practitioners such as Australian therapist Steve Biddulph, American psychoanalysts Robert Bly and Sam Keene, British researcher, Adrienne Burgess and Aotearoa New Zealand Counsellor, Warrick Pudney have also contributed to the debate particularly as it has related to the position of fathers in the family. This debate is discussed in more depth in Chapters Five and Seven.

The research participants talked of the alienation they felt by the mental health systems and the practitioners they encountered within them.

The Counsellor didn't do me very well on that one. [The sons'] Dad's a very articulate guy who's had heaps of counselling himself and knows all the techniques so he was able to manoeuvre the situation. (12)

The psychologist was taking [father's] side against [me]. (2)

Silverstein \& Rashbaum and Canadian social worker, Karen Swift, have examined the collusion of mental health theorists and practitioners with the father against that of the mother. Further contributions have been made by writers such as Rich, Chodorow, Parker and Nicholson who, although not practicing in the mental health fields, have made incisive comment on the effect of patriarchally-focused 
psychoanalysis on mothers and children. The following comment from one of the mothers illustrates the more subtle ways that practitioners in the mental health field can privilege the heterosexual nuclear family as the ideal family structure.

It [parenting class] wasn't aimed at single parents, it was aimed at both parents and most of the people there were couples. (5)

The reported messages of invisibility and marginalisation this mother experienced convinced her that her status as a single mother was not only disadvantageous to her son, but, as the other parent/partner was the only recognised support person, assistance would be unavailable to her.

\section{The Church}

Traditionally the church was reputed to be one partner in a trilateral relationship with the State and the medical professional during the breakdown of the role of women as midwives and healers during and beyond the fifteenth century (Ehrenreich \& English, 1978; Ferguson, 1997; Rich, 1986). The influence of certain sectors of the Christian church in determining the moral standard of society seems to have increased in the western world over the past 20 years with the growth of movements motivated by New Right fundamentalist theology. Groups such as The Moral Majority, The Promise Keepers, which were initiated in the United States of America, have spread to other western countries such as Britain, Australia and Aotearoa New Zealand. In Backlash: The Undeclared War Against Women, American writer Susan Faludi (1992, pp.257-289), presents an overview of the latest rise of the New Right in America and the link between key political and church leaders. She describes the invocation, often used by New Right ministers during the late 1980 's and early 1990 's, of the biblical verse: Ephesians 5: 22-24 - "The husband is head of the wife, even as Christ is the head of the Church" (1992, p.264). One of the mothers in this project, who had reportedly been a trustworthy supporter of the local church within which her husband was an 'elder', stated,

I began to leave the Church in about '85 because I couldn't bear it any longer. I couldn't bear the mould. It just didn't fit in me. (18) 
Other project mothers also spoke of the 'high' moral ground held by church leaders and followers.

$\mathrm{He}$ [minister] said 'I can't bring myself to baptise a child of a single parent not with the attitude that you've got ... you're not marrying the man'. [I told him], 'I've no intention to he's gone back to his wife'. Well that was the finish. (7)

It wasn't a planned pregnancy. ... We were both brought up as Catholic families. ... Six weeks later we were married. It was arranged for us by our parents. We didn't even really talk about it. (9)

The local Vicar's wife came over the year before the child was born and said that we should marry so [the child] had parents who were married. (10)

Apart from local versions of Christian-based movements like the Promise Keepers, other fundamentalist churches have established themselves in Aotearoa New Zealand, particularly in areas of low socio-economic households. These churches, which are headed by heterosexual men ${ }^{8}$, use music, church community activities, schools for couples and children to persuade their congregations to return to traditional family values. Pastor Brian Tamaki, founder of a series of fundamentalist churches in Aotearoa New Zealand and Australia, was reported in national newspapers and appeared on national television in the beginning of 2000 , saying that the lack of male leaders in the country and the increase in fatherlessness was the 'work of the devil'. Fortunately Television New Zealand did not allow Tamaki to continue with two programmes, in a scheduled television slot, called "our fatherless generation". Tamaki's main thrust in these series was that the fatherless generation is "a sad state of affairs reflected in the fact that we have a female prime minister and female leader of the opposition" (as reported by Kim Newth, Sunday Star Times, March 5 2000).

\footnotetext{
${ }^{8}$ Every Saturday evening the local paper advertises the church services being held the following day. The majority of advertisements include a photograph showing the 'pastor' with 'his wife' at his side.
} 


\section{Sports Groups}

A further group noted by the participants as influential to their situation as mothers of sons was that of the sports sector. It seemed, from the mothers' comments, that they had a place supporting the sports activities of their sons when the sons were young but that public support (that is other than providing a 'plate' ${ }^{10}$, washing uniforms, transporting players) was not encouraged or sought when the sons were older, and/or were playing at higher and more competitive levels. This mother reported, for example,

[Son] gave me a notice requesting support from parents. [Son] is playing First $X I$ cricket for the school and I had sent a note saying I could be at cricket for these dates and could support then. I don't know how many other women put their names down, but when the list came back there were three names on it, and they were all men. One of the men had his name down four times. Nowhere did my name appear on that list. I thought, okay what is this about. I checked with [Son] about whether he had taken my notice in and he had. I though 'okay, is that because it was the First XI If it was the Third XI or the girls cricket would I have had a place?' ... At primary school I was really encouraged to be involved with the cricket team and the soccer team. (6)

The gender discrimination was also demonstrated by a further comment,

The ref. comes out and says who are the linesmen. It's linesmen [my underline] that they want. Not a woman running up and down the line. Sometimes the coach will ask if there is a ref here, and they immediately look to the men.

Other mothers were concerned about the safety of the sports their sons became involved in, but felt pressure from coaches, teachers, family members and their sons to silence their concerns. Involvement in sports activities, particularly rugby, seemed indicative of their growing male hood.

\footnotetext{
${ }^{10}$ Sometimes the food that is contributed to a specific occasion in Aotearoa New Zealand is called a 'plate'. Occasionally notification is advised by the use of the phrase, "Ladies a Plate".
} 
I had great difficulty with sports ... like rugby. ... I had to make a conscious effort not to say to my kids 'you are not playing rugby, I think it is too dangerous, you will get a broken neck'. (3)

I decided that [Son] would play soccer instead of rugby and I was questioned by not only his father, but also his grandfather. "Why do you want him to play soccer? Why isn't he playing rugby a good-old man's sport?" (7)

These observations not only demonstrate the enforced separation of mother and son at pubescence, they also describe the elitism of specific male sports, particularly rugby and cricket which are the two predominant sports codes for males in Aotearoa New Zealand.

[I found it difficult] when he was about 15-16 and he was playing rugby. I couldn't believe the kudos he got for that from so many different types of people.

The influences of the justice, social welfare, education, mental health, religious and sports sectors on the general situations for mothers in this project have been outlined by them. It is my contention that the individual sectors, although having specific and situational influences on these mothers, have also operated collectively to create an overall authority about the preferred standards of behaviour for mothers in Aotearoa New Zealand.

\section{SPECIFIC SITUTATIONS FOR LESBIAN MOTHERS}

Feminist and lesbian mother of a son, Robin Morgan, wrote, "few subjects so provoke anxiety among feminists as the four-letter word sons. Yet that subject goes to the crux of power and of patriarchy, even though it grazes the living nerves of love" (1997, p.38). This section is in two parts. The first discusses the situation for lesbian mothers, as parents of sons, and the second looks at lesbian mothers of sons, as lesbian. I do not address questions of the rights of lesbians to parent. This has been otherwise examined by writers such as San Franciscan gay rights activist, Phyllis Burke (1993); British writers, researchers and lesbian mothers, Gillian Hanscombe and Jackie Foster (1982); Lynne Harne (1993) and San Franciscan, Jess Wells (1997). 
Figure 4.8 illustrates the specific situations of the lesbian mothers in the project at the time of the first interview and includes relationship status, residence and age of their sons and the household income. For the purposes of this study I am regarding those mothers who are lesbian as those who self-identified as lesbian. I do not explore or debate the concepts, or definitions, of lesbianism. Statistics highlighting the incidence of lesbian mothers of sons do not exist in Aotearoa New Zealand. In order to estimate the occurrence of lesbian mothers of sons in this country I combined statistics gathered by the 1996 Census of Population and Dwellings in Aotearoa New Zealand. In the breakdown of family types, a total of 949,497 families $^{11}, 354,585$ were couple-only families; 426,567 were two-parent families and 168,255 were one-parent families (Figure 4.9). Of the two parent families, 684 were same-sex couples ${ }^{12}$. (The statistics however do not distinguish between gay or lesbian parents.)

Figure 0-8: The Lesbian Mothers, Sons, Relationship Status and Household Income

\begin{tabular}{|c|c|c|c|c|c|c|c|c|c|}
\hline \multirow{2}{*}{ Mother } & \multicolumn{2}{|c|}{$\begin{array}{l}\text { Relationship } \\
\text { Status }\end{array}$} & \multicolumn{3}{|c|}{ Residence of Sons } & \multirow[t]{2}{*}{$\begin{array}{l}\text { Age of } \\
\text { Sons }\end{array}$} & \multicolumn{3}{|c|}{$\begin{array}{l}\text { Annual Income of } \\
\text { Household in } 1000 \text { s }\end{array}$} \\
\hline & $\mathrm{P} / \mathrm{L}$ & $S / L$ & SwM & SSh & $\mathrm{SI}$ & & $<12.5$ & $12.5-35$ & $>35$ \\
\hline 1 & $x$ & & $x$ & & & 18 & $x$ & & \\
\hline 4 & & $x$ & & $x$ & & $13 / 15$ & & $x$ & \\
\hline 6 & & $\bar{x}$ & $x$ & & & 12 & & & $x$ \\
\hline 10 & & $x$ & & $x$ & $x$ & $14 / 25 / 27$ & $x$ & & \\
\hline 13 & $x$ & & $x$ & & & 12 & $x$ & & \\
\hline 17 & & $x$ & $x$ & & & $14 / 16$ & & & $x$ \\
\hline 18 & & $x$ & & $x$ & $x$ & $18 / 20$ & & & $x$ \\
\hline 20 & $x$ & & & $x$ & & 11 & & & $x$ \\
\hline TOT & 3 & 5 & 4 & 4 & 2 & & 3 & 1 & 4 \\
\hline \multicolumn{5}{|c|}{$\mathrm{P} / \mathrm{L}$ - Lesbian living with partner } & \multicolumn{5}{|c|}{$\mathrm{S} / \mathrm{L}$ - Lesbian single } \\
\hline \multicolumn{5}{|c|}{ SwM - Son/s living with mother } & \multicolumn{5}{|c|}{$\begin{array}{l}\text { SSh - Son/s shared between separated } \\
\text { parents }\end{array}$} \\
\hline \multicolumn{5}{|c|}{ SI - Son living independently } & & & & & \\
\hline
\end{tabular}

Of the one-parent families, women headed 83.1 percent, or a total of 139,819 families (Statistics New Zealand, retrieved August 2, 2000 from the World Wide Web). Of the one-parent families there were no statistics gathered that

\footnotetext{
"The 1996 Census defined a family as two or more people living in the same household and who comprised either a couple, or at least one parent/child relationship or both.

${ }^{12}$ Statistics New Zealand suggests that this figure may be "understated because of the inconsistency in the way people have responded to the census question". (Retrieved April 22, 2000 from the World Wide Web. http://www.stats.govt.nz/4c2/c2f3286d88a2563b4c25659a00829ea4)
} 
differentiated the lesbian mothers from the heterosexual mothers. However if five to ten percent ${ }^{13}$ of the single-parent population is lesbian, I would suggest that this number of lesbian parents would be between 6990 and 13980. Although there are also no statistics to determine the number of same-sex couples with children who are lesbian couples, I would guess that a large majority of the 684 families would be headed by women. For the purposes of this exercise, estimation could set the number at 600 lesbian couples raising children. If this number were added to the 6990 to 13980 sole-parent families with lesbian mothers the number of lesbianheaded families could be estimated at between 7590 and 14580. If this number were to be divided in half ${ }^{4}$ to gauge the number of lesbian-headed families with male children, a conservative total could be estimated between 3795 and 7290 . Although conjecture this number constitutes a significant population grouping. As the 1996 Census in Aotearoa New Zealand was the first to include a question about same-sex couples, it is not possible to determine whether the number of lesbian-headed families has increased or decreased.

This estimated number might also be larger. That is, the percentage of male children born to lesbian mothers may be more than the 49.5 percent national average as argued by Jess Wells, American author and lesbian mother of a son, who claims that "a sociologically and biologically driven phenomenon is producing a disproportionate number of male children" (1997, p.ix). born to lesbian mothers. She argues that lesbians who undergo donor insemination have at least 65 percent chance of bearing a son. She bases her contention on the differing characteristics of male and female sperm. That is, once entering the vagina the male sperm travels more quickly toward the egg than the female sperm. The female sperm on the other hand has more resilience and lasts longer in the uterine

\footnotetext{
${ }^{13}$ Estimates of the number of lesbian populations vary widely, making this question largely unanswerable. One of the reasons for this difficulty is the definition of 'lesbian'. Several American studies have indicated percentages from 2 to 10 percent. Kinsey in the 1950 s created a six-point scale from exclusively homosexual to exclusively heterosexual. Based on this scale he suggested that $2-6 \%$ of women rated as exclusively homosexual (1953). The Ganon \& Simon (1973) and the Hunt (1974) studies found similarly. The Yankelovich Monitor Survey (1993) indicated that $5.7 \%$ of the population was gay/homosexual/lesbian. On an equivalent basis in Aotearoa New Zealand Stewart (1993) argues that a significant proportion of the $10 \%$ gay and lesbian community are raising children. Apart from the lack of an agreed definition of lesbian, further reason for the difficulty of gaining conclusive measurement is due to underreporting. The above studies have argued that social, family and religious censure, legal statutes, jeopardizing of jobs, housing and reputations have made declaring lesbianism a risk.
}

${ }^{14}$ September 1999, 100 out of 203 in the population was male. (NZ Stats. Quarterly Population count) 
environment. This difference between male and female sperm increases the likelihood of a male child being conceived if insemination occurs close to ovulation and a female child being conceived if the sperm has to wait in the uterus before ovulation occurs. To enhance the chance of a successful insemination ${ }^{15}$, and to reduce the financial risk of an unsuccessful insemination, Wells contends, lesbians tend to go through the process on the day of ovulation and therefore increasing the likelihood of conceiving male children. Wells also claims that there is an increasing number of lesbian-headed families in the United States of America (1997, p.ix). The incidence of lesbian mother of sons in Aotearoa New Zealand, if following the USA trend, is likely to increase.

\section{Figure 0-9: Family Structures in Aotearoa New Zealand}

(Source - Census of Population and Dwellings 1996: http:www.stats.govt.nz)

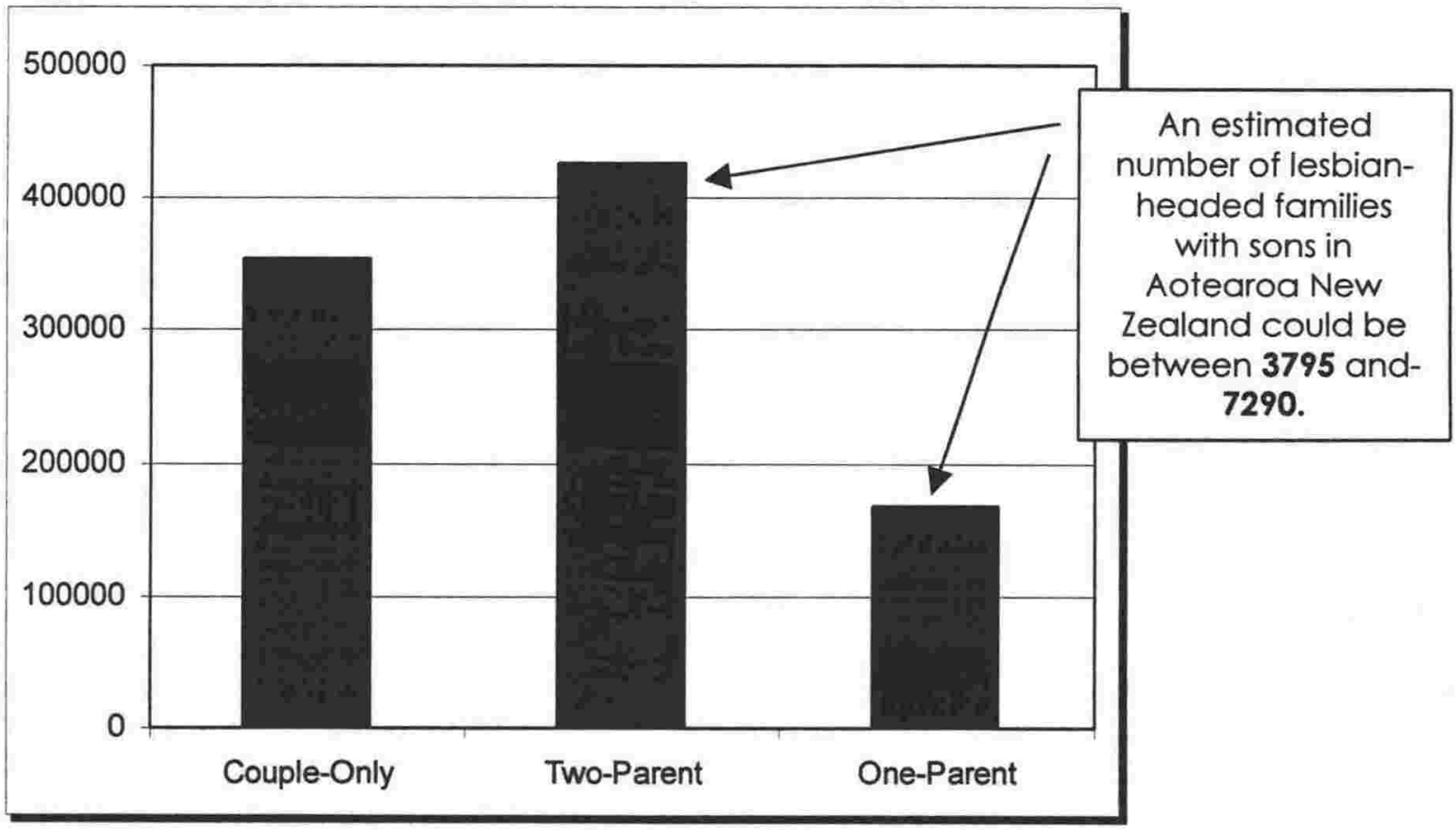

\section{Lesbian Mothers as Parents of Sons}

One of the issues for the lesbian mothers in the project was the experience of raising sons against background of patriarchy, and that the sons have the potential to become part of the systems that further marginalise lesbian mothers. As

\footnotetext{
${ }^{15}$ Factors such as the stress on sperm of the freezing and quarantine processes mean that insemination has a high percentage of failure.
} 
reported by the mothers, societal sanction is not granted to lesbian mothers, to those employed outside the home or to those receiving welfare benefits. As discussed by the lesbian mothers, we wished to reject the patriarchal status quo that has inhibited our own opportunities and yet did not want the options available to our sons to be limited. There was astonishment at the adulation and opportunities presenting themselves to the sons. For example, one woman said about her rugby-playing son,

It just really blew me away ... the world opened to this young man in a way that it doesn't open to a young woman. (9)

Another, reflecting on her son's options said,

I think there is a power. I'm not sure if I've got the right words but I think the world just opens to the growing male (21).

For the lesbian mother, the tension existed with the desire of a mother for her son to fulfil his potential and also the need to have him resist those opportunities accorded to him because he is male by a society that denies women and girls these same opportunities. The mother needed not only to negotiate these tensions but also to face an intimate relationship with a male, which for some was not unproblematic. Wells for example, after having gone through the process of sperm selection to ensure a female child, was shocked when she discovered after having a sonogram that she was carrying a boy. "I wept," she says, "I sobbed to my friends [at] the thought of spending the rest of my life with a boy" (1997, p.20). Although none of the lesbian mothers in the study regretted the existence of their sons, the complexity of raising them was evident.

Who is lesbian ${ }^{16}$ ? Who is lesbian as parent? As lesbian and mother I sit at this computer and write with the television in the background commentating a trinations rugby test. I acknowledge the political distastefulness of rugby. I was part of the anti-apartheid protests that succeeded in stopping the South African Springbok rugby tour in this country in 1981. I abhor the difficulty that the Black

\footnotetext{
${ }^{16}$ Refer footnote 13 above.
} 
Ferns (women's rugby world cup winners) have had to get airtime and sponsorship. Yet I am, by choice, caught up in the nationalism of an international rugby series. I can hear the rattle of plates in the kitchen as my son gets lunch. Although playing rugby for his school, he is ambivalent about the culture that goes with it in his world. One of my partner's sons has made rugby his life leaving this country to establish another life after having been recruited by an overseas professional rugby club. The other son combines playing rugby with an astonishing music talent. I am 'just a mother.' We are just mothers. Not different from, nor the same as, any other mother. And yet it seems I am different. I am not commonplace. I have rules that I have chosen to play by in order to protect my son from ridicule. I am 'out' at my work place, with my friends and with my family. With my son's friends, and within his world, I am hidden. I chair the Board of Trustees of the secondary school he attends, but when partners are invited to school functions I go on my own. When the house fills, as it increasingly does, with my son's male and female friends I feel totally visible as mother and equally as invisible as lesbian.

The mothers in the research project expressed similar feelings of contradiction about their sense of self and about being public as lesbian in their sons' worlds.

I think it [being lesbian] gave me a particular sort of added feeling of selfhatred. How was I going to integrate the bits of me that were important because I have no doubt, my kids are really important to me? (10)

[Son's] got good reason to be [nervous] because my oldest daughter just got sheer shit at the school she was at when they found out that her mother was gay. ... He told me a story about a little boy who walked into the classroom recently and one of the girls was sitting on the knee of another girl and he said, "oh you're nothing but a big fat lesbian like your mother. (20)

I didn't want to be who I was, who I am. I didn't want to be a lesbian. ... The messages I got as I was growing up [were that] you are evil; you are going to go to hell. [if you were lesbian]. So I couldn't face the fact for years that I was a lesbian. (1)

The following graffiti was written on the dictionary of a fourteen-year-old boy by one of his 'friends'. Although this young man was not ashamed or embarrassed, 
and reportedly retaliated in kind, the message is clear. To be labelled 'gay' is meant to be an insult. One of my son's peers commenting about how he didn't like the teachers at his school said, "all the teachers are gay". "How gay", is another put-down expression often used by these young males.

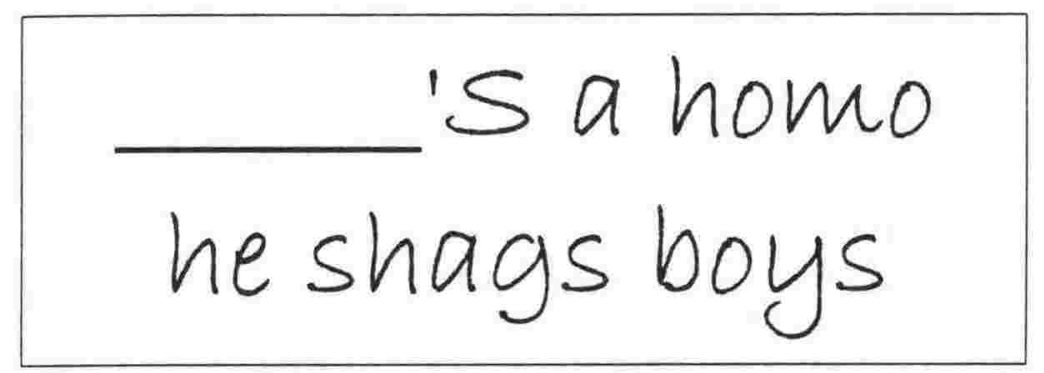

For some of the mothers in the project, the homophobic abuse came from the fathers of their sons.

[Father] had had the whole stereotypical thing that it would be very, very, very sick for [Son] to grow up in my lifestyle - he ran the risk of becoming homosexual. ... [Father] was going to fight custody on the basis of the lesbianism. (20)

Other mothers felt reluctant to discuss their lesbianism with their sons for fear of inviting a negative reaction from them.

I am terrified to go into it [being lesbian] too much in case I have a negative reaction from the boys. ... I don't wish to be rejected by them ...[I know I am] buying into society's values. (17)

[Being lesbian has] never ever been discussed [with son]. It was just something that gradually became okay became normal and part of our lives and I probably should discuss it with him but I think I'm too scared to because if he does have a problem I don't know quite know what I can do about it. (13)

[Son] used to come out with all of it. Just repeat it. I was a dirty filthy rotten lesbian out of [Son's] mouth. (20)

The following quote was from a son who, reportedly, was accepting of his mother and yet seemed to be so by excusing her behaviour. 
I told him straight out - I am a lesbian. 'Oh that's okay mum, I still [underline added] love you.' (1)

Another of the complexities for lesbian mothers with sons is that of how to parent them. The mothers talked of wanting to raise their sons to behave differently from most of the men in their lives. They spoke of their struggle to do so, about the dilemmas they experienced wanting to encourage their sons to resist prescribing to a macho form of maleness and yet not wanting to have them alienated from their friends or the worlds that could acknowledge and affirm them. Rich, describes it as follows, "the fear of alienating a male child from 'his' culture seems to go deep, even among women who reject that culture for themselves every day of their lives" (1986, pp.204-205). Arcana also discusses the collusion of mothers in the rearing of macho men by suggesting that "we have allowed ourselves to assist in male socialisation that oppresses and demeans women, and lessens the humanity of men. Some of that assistance is deliberately contrived to protect our children from penalty, to ensure that they will be safe and successful adults" (1983, p.118). Silverstein speaks of the ancient maternal betrayal as we, she suggests, "sacrifice our very beliefs about right and wrong, abandoning our sons to the prevailing culture" $(1994$, p.51). She argues that as mothers we take on the myth that homosexuality may result from too close a relationship between mother and son (1994, pp.137-138).

Gillian Hanscombe and Jackie Foster, British writers, researcher and lesbian mothers undertook early research with lesbians and families. They recount a conversation with one mother who describes the way she negotiated the parenting of her son.

$\mathrm{He}$ is by nature a most affectionate, gentle, tender young man. I knew that we live in a rough, tough and cruel world. If I allowed this gentleness to flourish as it was, he would be destroyed. I was quite harsh, tough and hard with him. (1982, p.129)

This issue was also discussed at one of the longitudinal focus group sessions. One of the mothers felt that she "had to put the male dominant side" (1) into her parenting and another was aware of the external pressure to ensure that boys were 'staunch', 'tough' and 'independent'. She felt that, 
They need to be all these things because that's what we see men out there are like but in doing so we're giving our boys over to the world that will damage them (6)

Another mother, who did not identify as lesbian, felt that by simply by being a single mother put her son into jeopardy. She stated,

I have lived the past years thinking that because I'm bringing my son up ... my son is going to turn into a poof. I get all these masculine things for him like guns etc. ... I even thought twice about getting him to piano lessons. (7)

Appallingly, this attitude was confirmed by several of the other single mothers who were concerned that parenting boys, as mothers on their own, would encourage homosexual preferences in them and that homosexuality was a perversity. Thankfully other members of the focus group challenged these views.

The fear that if they don't play rugby and are being raised by their mothers that they'll turn out to be gay ... you've gotta get them into doing blokes things. (GP2)

I think that one of the messages that we get given is that if we are close to our sons, we're going to turn them into queers ... homosexuals. (3)

Although there are commonalities with other mothers of sons, this section has emphasised the specific issues that face lesbian mothers with sons; the opportunities for males that do not exist for females, the apprehension (and sometimes fear) of being visible, the multiple complexities of parenting a new generation of men, the insistence on the need of a son to have a father and the fear that lesbian mothers produce homosexual males. The following section addresses another area of significance that was highlighted by the research findings; that of the discomfort some of the mothers felt, as mothers of sons, with other lesbians.

\section{Lesbian Mothers of Sons and Contact with 'Other' Lesbians}

Robin Morgan describes the experiences of taking Blake, her (primary-school aged) son, to women's gatherings. "I got targeted," she explains, "for being a 'living contradiction' - a radical ... who had compounded the sin by mothering a 
son" (1997, p.43). For one of the participants in the project, Morgan's experience was also her own.

I didn't have a lot of friends who had any interest in sons. ... Lots of lesbians aren't interested in children. Lots of lesbians aren't interested in boys. In the 1980 's there were lots of lesbians who thought we weren't a real lesbian if we had sons, particularly sons who were around all the time. (10)

American writer and lesbian mother of two sons, Laura Davis (1997, pp.120-123), recounts tales of the early days where women-only-spaces were claimed by feminists causing lesbians with boy children to be an outcaste minority. Although in the United States of America, according to Davis, there are lesbian playgroups, lesbian parent support networks and a more accepting social climate, Aotearoa New Zealand is sadly void of such options. Although there are active lesbian communities, particularly in urban areas, there is little happening for lesbian parents and particularly not for lesbian mothers of sons. As one of the project mothers stated,

There's just not enough general support and certainly not from the lesbian community. ... [I would like] to say to the lesbian community, "okay some of us have got children" and even if we're not [prepared] to be baby sitting they can be more affirming us. (18)

In her anthology of stories from lesbian mothers of sons, Wells has reprinted posthumously an excerpt from the works of Audre Lorde. After being informed by the organisers of a lesbian-feminist conference that no boys over ten could be present Lorde wrote the following letter,

Sisters, Ten years as an interracial lesbian couple has taught us both the dangers of an oversimplified approach to the nature and solutions of any oppression as well as the danger inherent in an incomplete vision.

Our thirteen-year-old son represents as much hope for our future world as does our fifteen-year-old daughter, and we are not willing to abandon him to the killing streets of New York while we journey west to help form a lesbianfeminist vision of the future world in which we can all survive and flourish. I 
hope we can continue this dialogue in the near future, since I feel it is important to our vision and our survival. $(1997$, p.35)

All-women space has been hard won and Lorde herself acknowledges the need for occasions to be with women, or all-black groups, only. Conversely, if we are to raise sons that will contribute to a generation of men who value women, we need not only to parent them effectively but we require the support from other lesbians.

A related issue that was identified during the research was the difficulty for lesbian mothers, particularly of boys, to develop partnerships. One of the participants experienced this with two potential partners.

My partner wanted me to live with her and she couldn't take the package deal which was my teenagers as well so my relationship ended. (18)

My second relationship ended up with my teenagers disliking my partner so much that she didn't like to come back to my home any more. I had many messages of advice from lesbian feminists to do my own thing - leave the boys to their devices - leave them to their father etc. My partners both told me I was too soft and I needed to be tougher on the [boys]. (18)

Another recognised that having children would inhibit her chances of having relationships with certain women.

It also means there are some woman who I would never have a relationship with because of [non-acceptance of my sons]. There've been a couple of women in my life who I realised $[$ Sons] made a lot of difference. (10)

Several of the lesbian mothers in the project reported also an increased isolation was generated by difficulties developing intimate relationships.

Kate Rendell (1997, pp.193-195) discusses the prejudices of courts involving custody issues with lesbians raising children. She cites three causes for their concern; the ostracism and harassment from other children; concern that they will develop psychological problems; and fear that the children will grow up to be lesbian or gay. Although the last concerns are based on unjustified prejudice, the 
first two are distressing commentaries on the realities for some lesbian families. It is almost impossible to parent effectively and creatively while being abused and stigmatised and while few support systems appear accessible.

I can't identify anywhere in my community where there's support available for [lesbian] women raising boys on their own, except for friends that are mostly ... seem to be sending them off to boarding school when they get big and angry and difficult to handle which seems awfully sad. (20)

I think I would've liked to have been able to talk more about the feeling of being blamed a lot more and I would've liked to have had some strong support from other women which I did get some of it, I did get some support... but my friends are all busy - everyone is busy - so snippets of support was what I got. (18)

No there wasn't a hell of a lot of support then [son's adolescence]. ... would have appreciated any kind of backup at that stage? (1)

Lorde argues, "we are jointly responsible for the care and raising of the young since that they be raised is a function, ultimately, of the species" $(1997$, p.36). It is sad that collective responsibility does not seem to be generally recognised within the lesbian communities of which the project mothers are a part.

Public attitudes toward lesbian parents are being challenged by a new generation of politicians. An article, for example, in the New Zealand Listener, a current weekly news magazine produced in Aotearoa New Zealand, discusses the positive impact that the recent change in government could have to legislative reform for same same-sex couples. In this article Chris Carter, law-reform protagonist and the first openly gay MP, overviews some of the legislative inequities for same-sex couples. Supporting the right for lesbians to be parents he is quoted, "saying that gays and lesbians don't make good parents is actually a little like bolting the stable door - there are already thousands and thousands of gays and lesbians who are good parents already" (as cited by Matthews, March, 2000, p.29).

Throughout the anthology of thirty-six stories in Wells, throughout the accounts from Burke, Hanscombe and Forster and throughout the interviews with the eight lesbian mothers in this project, there is not one who talks of regret at having a son. We are parents unlike any others, and this is most evident in the mothering of our 
sons. There is potential for a new generation of men to be raised significantly different from their counterparts brought up within patriarchal families. There is also potential for lesbian mothers to be continually discriminated against as discussed. It is not only the mothers who will bear the impact of this prejudice, but as presented by Aotearoa New Zealand photographer, Myra Hauschild, and writer, Pat Rosier (2000), the sons will experience the effects as well.

\section{SPECIFIC SITUATIONS FOR SINGLE MOTHERS}

Figure 0-11 illustrates the specific situations of the single mothers in the project at the time of their first interview. It includes the residence of the sons, the age of the sons and the household income. The majority of these mothers had their sons living with them at the time of the first interview and for a majority their income was below $\$ 12,500$ pa.

Figure 4.10 shows the gender breakdown of single families at the 1986, 1991 and 1996 Censuses of Population and Dwellings in Aotearoa New Zealand. The 1996 census counted 168,255 one-parent families, accounting for 17.7 percent of all family structures. Of these 83.1 percent, or a total of 139,819 one-parent families, were headed by women (Statistics New Zealand, retrieved August, 1998 from the World Wide Web). Amounting to almost one third of the number of two parent

Figure 0-10: Single-Parent Families by Gender - Aotearoa New Zealand 1996 (Source - Census of Population and Dwellings 1996: http:www.stats.govt.nz)

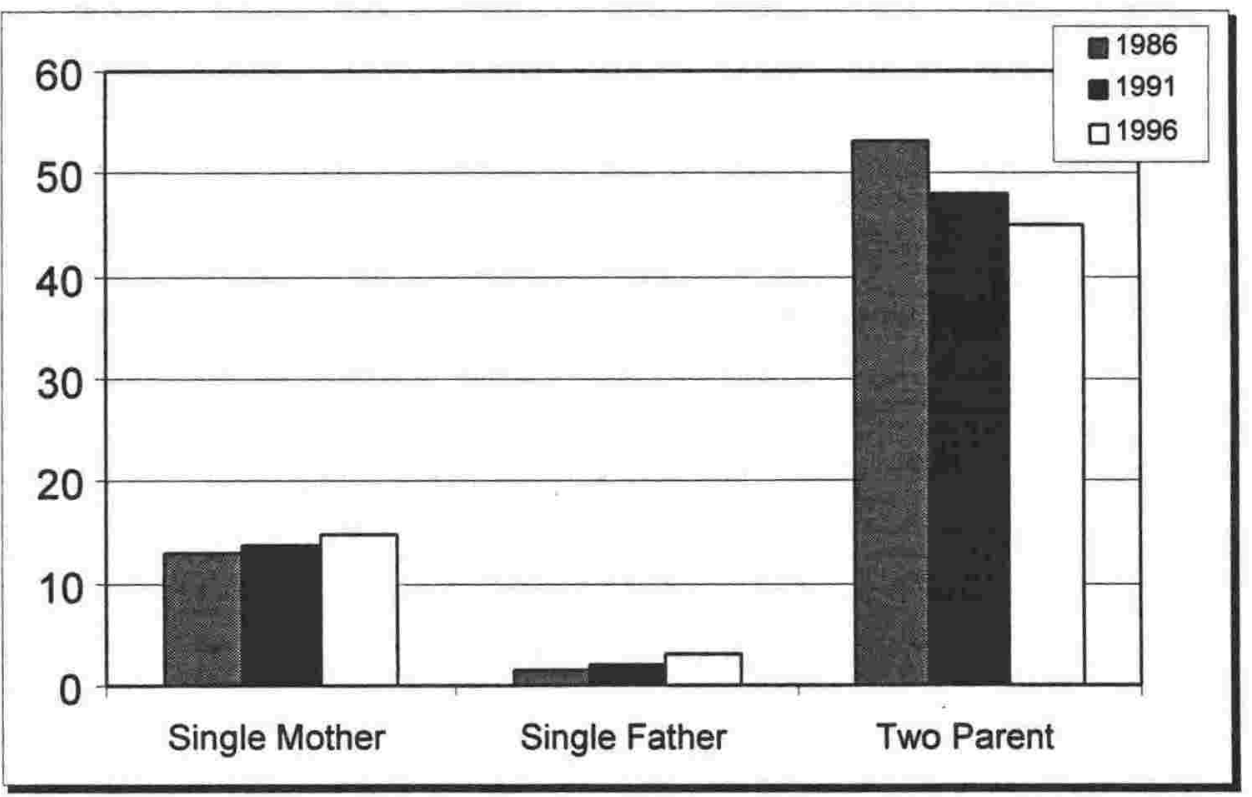


families, single mother families constitute an increasing proportion of total families. The breakdown of mothers with sons is not available. However, the incidence of male births compared with female births has averaged close to 48.5 percent over the past two decades. Given that a larger proportion of single parents have more than one child, it can be safely assumed that more single mothers are raising male children than not.

Figure 0-11: The Single Mothers, Sons, Relationship Status and Household Income

\begin{tabular}{|c|c|c|c|c|c|c|c|c|}
\hline \multirow[b]{2}{*}{ Mother } & \multicolumn{4}{|c|}{ Residence of Sons } & \multirow[t]{2}{*}{$\begin{array}{l}\text { Age of } \\
\text { Sons }\end{array}$} & \multicolumn{3}{|c|}{$\begin{array}{l}\text { Annual Income of } \\
\text { Household in } 1000 \text { s }\end{array}$} \\
\hline & SwM & SSh & SwF & SI & & $<12.5$ & $12.5-35$ & $>35$ \\
\hline 2 & $x$ & & & & 8 & $x$ & & \\
\hline 3 & $x \times$ & & & & $17 / 19$ & & $x$ & \\
\hline 4 & & $x \times$ & & & $13 / 15$ & & $x$ & \\
\hline 5 & $x$ & & & & 12 & $x$ & & \\
\hline 6 & $x$ & & & & 12 & & & $x$ \\
\hline 7 & $x$ & & & & 10 & $x$ & & \\
\hline 10 & & $x$ & & $x \times$ & $14 / 25 / 27$ & $\mathrm{x}$ & & \\
\hline 12 & & & $x$ & $x$ & $18 / 24$ & & $x$ & \\
\hline 14 & $x \times$ & & & & $16 / 14$ & & $x$ & \\
\hline 15 & $x$ & & & & 15 & $x$ & & \\
\hline 16 & & & $x \times$ & $x$ & $14 / 17 / 20$ & & & $x$ \\
\hline 17 & $x \times$ & & & & $14 / 16$ & & & $x$ \\
\hline 18 & & $x$ & & $x$ & $18 / 20$ & & & $x$ \\
\hline 19 & $x$ & & & & 16 & $x$ & & \\
\hline & 12 & 4 & 3 & 5 & & 6 & 4 & 4 \\
\hline
\end{tabular}

\begin{tabular}{|l|l|}
\hline SwM - Son/s living with mother & $\begin{array}{l}\text { SSh - Son/s shared between separated } \\
\text { parents }\end{array}$ \\
\hline SwF - Son living with father & SI - Son living independently \\
\hline
\end{tabular}

The following section highlights the issues that relate specifically to the single mothers in the study. These issues include, the desire to parent effectively, the stigmatisation of non-conforming to the nuclear family structure and the disadvantages and advantages of being single mothers. 


\section{The Desire to Parent Effectively}

One of the factors of single parenthood reportedly experienced by the mothers was the additional pressure to parent effectively. Additional that is, to the pressure a mother in a heterosexual partnered situation may experience. They talked of how fatherlessness-speak, and the rhetoric about the limitations of the single mother family had intensified feelings of inadequacy and guilt. Lynette Ebborn, coordinator of the Aotearoa New Zealand support centre Solo Women As Parents, challenges the blaming of single mothers for deficient parenting. She wonders "how fatherlessness would be viewed if there was a sudden economic need for all fathers to be deployed elsewhere" suggesting that "women raising children on their own would then be 'stout-hearted' and 'patriotic'" (New Zealand Herald, 1997). The single mothers in the project reported,

I feel like there's a little bit more pressure on me to make sure nothing goes wrong and that everything's smooth. (3)

I get into a little panic every-time something goes wrong or if he does something or he seems to go very quiet. I get really scared that ... I've made a mistake ... that maybe he would be better off if I'd left him with [father]. (13)

It quite often worries me a bit ... [that he has] stuff inside him and I know it's there ... there's not a male there. He doesn't have anyone to unload it on to. (1)

A common question asked by single mother participants was,

Is this teenager acting out behaviour as a result of being brought up by a single parent family or is this just the usual part of the process of growing up teenage behaviour? (5)

Papalia and Olds maintain that, "some conflict between parents and teenagers is normal". They add that this conflict and is also more likely to be acted out in conflict with mothers than fathers, "perhaps because mothers have been more closely involved with their children" (1998, pp.384 - 385).

The single mothers also reported the benefit of the availability of male adults to their sons. 
He just has so much respect for his grandfather and for my two brothers and I just figure that he wouldn't need a father at all. He gets everything he needed from the other males in my family. (14)

This one significant other for [son] was an amazing young man and he just let [son] all over him. (20)

Some of the mothers had experienced particularly negative circumstances with the fathers of their sons and expressed relief when the relationship ended.

My kids have not suffered from not having their particular father on the scene. I think they would've grown up to be very unhappy, mentally unhealthy people had he stayed around. (3)

This mother went on to describe how she felt herself becoming more of a person, more of a woman and a mother without the constant undermining she had been subjected to by a violent, alcoholic husband.

\section{Stress}

In addition to the difficulty caused by financial scarcity, another theme expressed by the single mother participants was that of the exhaustion and stress of parenting on their own. One mother reportedly felt,

big disappointment that [my ex-husband and I] haven't been able to share the role of parenting cause I feel I take the larger share of it. (14)

and another that she "had to put the male dominant side (7) into her parenting. Others felt that a father would command more respect from the sons than they themselves received and questioned,

Are these boys giving me a hard time simply because I'm their mother and I don't have in their eyes as much authority as perhaps a man might have or is it just usual teenage argy bargy. (4)

Would he do this if his father standing in front of him, would he answer a father, back this way? Would he dare do it to a man? (5) 
The stress on the mothers in the project was reportedly increased by the stigma some felt by being part of a family structure that did not conform to the heterosexual nuclear family model sanctioned by Aotearoa New Zealand society.

\section{Nuclear Family Ideal and Single Parent Stigma}

Some mothers felt excluded, or excluded themselves, from situations where 'couples' were the norm.

They're all married friends, so I tend not to get invited to gatherings where there are always husbands and wives. I do feel isolated. (14)

If I have any female friends who are married ... as soon as the husband comes home I split, only for the reason of what if they think I like their husband. (5)

Others felt as if they were inferior because they were single mothers.

You're [labelled] as a 'solo mother'. His teacher has asked about his father and things like that as if it's a problem. (13)

For me personally the messages are like you are a second-class citizen. (5)

I got a lot of messages about what a shame it is and how hard it must be for you without a husband, without a father. ... They [sons] did feel ... there was a sense of shame ... of being only with a mother. (18)

You were sort of shunned because you were single. There was a real stigma. (1)

The implication is that somewhere along the line these kids are missing out whether they are boys or girls. (GP2)

It was very isolated. I think I was also afraid of too many people knowing [that the marriage had ended]. (18)

Having started off being a single parent in 1985 the climate of New Zealand then was that basically why should they get the DPB. So it was very difficult for me to publicly acknowledge that I was one of "these people" on "the DPB". The stigma of it all. (3) 
I grew up with the belief that you grow up and get married and have children. You don't do it the other way around. ... It was really hard dealing with what other people would say, the whispering behind your back, because I was brought up with not having children out of wedlock. So there is still a really big stigma with single parents now so it was even worse back then. (14)

A lady ... said that the 12 year olds with single parents are really obnoxious little shits. I told you about that last Sunday in the group meeting, how a teacher said that they cause more problems than the other children. (5)

Mothers used a variety of strategies in order to survive. One strategy was to pretend 'normality'.

I was reluctant to go along [to 'Playcentre']. ... I got asked what my husband did. ... I told some lies. I definitely told some sort of fantasy. (7)

I didn't actually tell them at school for three months afterwards that he [husband] had gone. I couldn't face the fact that I was a single parent. To me it was just such a stigma. (3)

Another survival strategy was to withdraw and isolate.

I was so proud. I didn't want to say anything. ... I became extremely isolated and very depressed. (7)

This mother had her own difficulty in accepting her single parent status.

I'm such a believer in family ... two people being responsible for the raising of their children. ... I had to come to terms with the fact that family means also single parent family. (14) 


\section{Disadvantages of Single Parenting}

Apart from the stigma of not conforming to a nuclear family structure, single mothers reported further disadvantages. These included, the lack of parenting support, the lack of male input to parenting, the expectations they had of their sons, difficulty 'fitting in', over conforming to a 'good' parent mould, the potential intensity of single child and mother relationship and difficulty forming new partnerships. The following quotes include the mothers' reporting on each of these issues.

Lack of parenting support,

I also don't have the backup sometimes when I would just like someone else to say, '[Son] come on, get your act together'. ... Or sometimes just to be able to have a break. (5)

I think that a purely logistical thing is that you have got another adult around the workload is halved, or theoretically the workload is halved. ... But just the fact that he was there meant that potentially we could back each other up. (4)

There are some times ... when we are sick. There are times when they are going to have to do some fending for themselves. (GP2)

I remember when my children were young worrying about what if I was killed in a car accident. My kids are only 10,12 and 14.... My parents are too elderly to take care of them. [and husband is alcoholic]. (GP3)

Lack of Male Input,

I guess some of the negatives were that [Son] is quite a practical sort of a person and there wasn't a male person around to be a model for those sorts of things. (3)

I consider [Son] to be quite disadvantaged through not having a male figure in his life. ... such as sport. Mum has always been on the sideline for soccer ... for tennis ... at every prize giving ... everything. It is always Mum that's there. (7)

Expectations, 
We expect our boys to be more responsible than if there was another man around the house. (6)

For [Son] to keep an eye out on the younger ones if I am busy. ... They have gone into the caregiver role where they have to watch out for and amuse the other children. (GP2)

It really makes him [Son] feel ten feet tall I think when I call him my other half. (7)

I am expecting them to ... help within the house. ... They are going to grow up and leave home sometime. They are not going to have a woman running around after them. (GP2)

\section{Difficulty fitting in,}

I think being a single parent's got a lot to do with it, [being accepted into a rural community]. I'm sure it has. (7)

I only went out to women's things and I still do even now. I don't go out to many things that involve couples. (4)

\section{Over-conforming,}

I've always felt that being a single mother I had to work twice as hard and be twice as good to not take any criticism. (GP3)

I try and over-compensate. I think that because he is a kid of a single mother, I don't want him to miss out. (6)

I had very very high expectations of them in terms of their behaviour at school ... [and] when they were with other people. I did not want the shame of ... the finger being pointed at me as being the woman on her own bringing up these boys. (GP3)

Intensity,

A single mother with one child has to be beneficial. ... He has my undivided attention usually. I think that he's extremely lucky but then the bad thing is that 
he's got me all the time. The down side for [Son] is that he doesn't have anywhere else to go [when mother is angry with son or not emotionally available to him]. (7)

Difficulty forming new relationships,

They [sons] didn't like either of them [partners]. ... They were the main reasons why the partnerships didn't continue and I am not prepared to compromise my values on parenting my children for the sake of having a man in my life. (3)

There was a bit of jealousy there, like "you're not taking my time away from my mum". (GP2)

\section{Benefits of Single Parenting}

Mothers also reported advantages parenting on their own. These included; reduced opportunity for double parenting messages, added feeling of family, enhanced self-esteem, the chance for quality relationships with their sons, the chance to make a change and relief from the termination of a destructive situation. The following quotes include the mothers' reporting on each of these issues.

The lack of double parenting messages,

Well I think it would have been worse if my husband and I stayed together. ... I think it would've been more damaging for them to have had [Father] and coming from different philosophies, different places, difference disciplines, different ways at looking at the world, different ways of treating children or difference beliefs. (18)

So I haven't got me saying one thing and then him going to someone else and getting something else. So I haven't got that. (5)

He doesn't have any conflict of the two-parent thing where one parent says one thing another parent disagrees. (7) 
The positives have been that I don't believe that they have had to deal with two parents who may be giving them different messages about their developing sexuality, developing independence. (3)

I certainly find easier now that there's no man in the house because my ideas, my values, my principles aren't questioned constantly. (20)

I still would rather rear my son on my own I think. ... Because there is none of this someone telling me what to do with him. (2)

The feeling of family,

Their friends describe me with feedback "Your Mum is really neat she lets us do this and it's good coming here cause it feels like home." I get a bit sick of it I suppose at times on weekends now and again but it does feel like a family. I mean there's not doubt about it now at this stage that we are family. ... [We] were never a family. (18)

Enhanced self-esteem,

I stand up for myself now. I won't take so much shit. ... If I was married now ... I would be just a blithering mess. I would probably be in a mental institution. So at least I had enough sense and enough courage within myself to say, I'm not going to be treated that way. (5)

When I was married I used to disassociate a lot and the kids still tell me how I used to go into my bubble and how unavailable I was. ... [now] able to be much more 'present'. (18)

I think that the positive thing for me was that I challenged all that, and I really dealt with all that stuff, all those issues. So that now I don't feel that I am living a shell. I am living the real me. (4)

$I$ [am stronger now than when I was with his father] because I felt like I knew it wouldn't work anyway. Our values were quite different. He was into selling pot and all that pub scene. (2)

The chance to develop quality relationships with son(s), 
I think the really good positive thing is that we have a lovely relationship which is something that probably very few boys with two parents would have [with a mother]. (7)

[The boys are] very caring. I like to think that they are a bit different from the usual run of the mill boys at that age. I think it is because they have only had one model and that has been me I guess. (3)

Having been through that experience myself I feel that it was probably that those years of parenting on my own ... were probably the most rewarding of all of my parenting years and certainly in terms of building a relationship with the children. (21)

The chance to make a change,

I think there are wonderful positives and the opportunity to make a change,[raising a boy as a single mother]. [Son's] very helpful around the house and does a lot of things that are traditional gendered. He has a good role model in my oldest daughter's boyfriend and he's you know it's really exciting, it feels a little bit like social engineering. (20)

It's skills for life. ...They are going to grow up and leave home sometime. They are not going to have a woman running around after them. (GP2)

There is no way I am going to clean his room. He cleans his own bathroom. There is no way that I am a slave to him. (GP2)

Maybe ... they will be more responsive and receptive to how a woman feels as well. (GP2)

An advantage or disadvantage for [Son] to being raised on his own? I think he is really lucky. He has an amazing life. His relationship with his father is important. ... He is masculine and he is soft and gentle. I think there are lots of advantages. (6)

Relief from the termination of a destructive relationship,

I was destitute and the children were because he was drinking the money before we got it, and he was a civil servant in those days and earning good money. It 
was just awful. Terrible stuff. So he went. I went on the DPB and for the first time in eleven years I had the security of my own money, and the control back. (3)

In a sense there was a rebuilding of the family. There was kind of a family feeling happening and I can remember quite distinctly feeling that it was much better. It was much easier to be a single parent, much easier. That was when I actually began to do my parenting. (18)

\section{CHAPTER SUMMARY}

Two key areas impacting on mothers' situations have been outlined in this chapter. The first of these is the level of financial resource available to the household and the impact of this on basic needs such as housing, food and clothing, education, health and mobility. All, but one of the single mothers interviewed reported severe financial hardship. The second involves the controls imposed on families by public sector groups such as the judiciary, the social welfare system, the education sector, mental health agencies, the church and sports groups.

The situations of two specific groups of women, lesbian mothers and single mothers, have been highlighted. Lesbian mothers raised issues of identity as lesbian mothers of sons; the difficulties experienced parenting sons as lesbian; exclusion by lesbian communities and the complications of maintaining relationships.

The major issue for single mothers was poverty. They reported the impact it had on themselves, the sons and the relationship with their sons. This group also highlighted their desire to parent effectively, the stress related to being a single parent and the impact of the nuclear family ideal. They saw single parenting as disadvantageous due to factors such as the lack of adult support they received, the lack of male input for their sons, being excluded socially, being excessive with their sons and the difficulty of forming relationships. Conversely the mothers also believed that there were advantages in being single parents. They considered that single parenting avoiding double parenting messages, that the lack of tension of a negative relationship created a more relaxed household and did not erode their self-esteem, that they had the opportunity to develop quality relationships with 
their sons and that they had the opportunity to challenge their sons stereotypical messages of masculinity. 


\title{
CHAPTER 5
}

\section{MOTHERS, SONS AND FATHERS}

\section{MOTHERS TALK ABOUT THE SONS}

\begin{abstract}
Women create men. We carry them inside our bodies feeding them with our food, sharing our precious oxygen with then. We labour to bring them to birth, then lift them up into our arms, and hold them against our breasts. ... They grow from babies to boys and then to 'young men'. Soon ... they are adult men, culturally empowered to dominate us. How does this happen? Are we a pack of demented masochists, urging them toward misogyny? (Arcana, 1983, p. 54)
\end{abstract}

This quote by American researcher, writer and mother, Judith Arcana, introduces the next section in which the mothers in the project talk about their relationships with their sons. The mother's responses have included comments about the nature of the relationship, their perceptions of their sons feelings toward them, the perceived changes in their son's attitudes and behaviours toward them, their fears and concerns about their sons and the strategies that mothers found useful in raising their sons.

\section{The Nature of Mothers' Relationships with their Sons}

The mothers reported varying relationships with their sons. Those who reported positive relationships spoke of the connection they felt with them, and the importance of the communication between them.

In terms of expressing his own emotions he finds it very hard but I do know that he and I have always been close. (21)

[Sons] are all very affectionate ... [They] lie across my lap watching telly and there's a lot of physical closeness. (10) 
He would spend hours talking about everything and anything. (1)

We talk a lot ... he likes to talk about what's going on ... even his physical relationships and things like that. (9)

It is interesting to note that although the sons of these mothers are aged between eleven and twenty years, the mothers describe the intimacy and connection they experience with their sons as a positive phenomenon. They do so against a cultural and sociological climate that declares that closeness between a mother and son is contaminating to him and that it sissifies him making him soft, weak and dependent (Bales, 1996; Biddulph, 1996 \& 1998; Blankenhorn, 1992; Keen \& Bly, 1991; Pudney, 1994; Tacey, 1997). It is notable also that the relationships between these mothers and sons were acted out through an emotional intimacy and through talking and discussion. This can be contrasted with the descriptions of the fathers' relationships with the sons that are described predominantly as activity-focused.

One mother tried to explain this difference by saying,

He's really caring but not to the point of being sparmy, and I don't mean sissy by sparmy. Not a greaser. He's not a grease He's quite independent. (20)

Several of the mothers talked about the contribution their sons made to the running of the household.

We were like flatmates and he did his own ironing and he'd sometimes do mine.

He would go and do the supermarket shopping. (21)

None of the mothers, who reported their son's usefulness around the house, had daughters living with them. It would be interesting to explore further whether sons tend to contribute more to the operation of the house when they do not live with their sisters. For example, another mother whose two younger daughters lived with her reported the unwillingness of her sons, who normally lived with their father, to help around the house at all. 
They always sit back and let me do the housework when they come and stay with me. ... They say 'it's your job mum'... it's this thing about [being] a mother, [it] automatically makes you a slave in the house. (4)

Several single mothers wondered whether the positive relationship they had with their sons was due to their being an only parent.

We have a lovely relationship which is something that probably very few boys with two parents would have ... we're quite often one-on-one. (7)

Those who reported antagonistic relationships with their sons described behaviours that ranged from emotional to verbal and physical abuse.

He gets really 'mouthy', like I'm a fucking bitch, or I'm a fucking arsehole. (5)

He has been through this phase of bullying. He will hit his younger siblings if they annoy, and ... he was trying to have a go at hitting me too. (4)

Like what comes out of the mouth. .... I have had to learn to see past the words, and see it as some sort of superficial something, letting off steam or something. (4)

They just wanted to be angry and they had a right to be angry. They had been through hell really and I was the only thing that they could focus their anger on. So I got the whole lot. (18)

The behaviours reported by mothers (4) and (18) came soon after the separation between the parents. Research confirms that children's anger can be a result of parent separation. Dr Cecilia Wetolicky, counsellor from Western Australia, describes the following common symptoms demonstrated by adolescent children of divorced parents. These include, for example, anger at others, oppositional behaviour, rebelliousness, defiance, breaking of rules and testing of limits, destructiveness. (1996, retrieved September 2000, from the World Wide Web). A highly publicised American-based study on the effects of divorce on children was undertaken by Judith Wallerstein, a Californian clinical psychologist. This study involved one hundred and thirty one middle-class children, between two and six years old, and their parents. Involving interviews with children and their parents, 
the study began in the early 1970 s and continued for twenty five years. The results of this study supported the view that divorce contributes to acting-out behaviours of children.

Outcomes of interviews and discussion with the project mothers, suggest that post-parent separation the anger is expressed toward the mother rather than the father. This may be explained by statements from The Royal College of Psychiatrists (United Kingdom) which indicate that the incidences of behavioural problems of children from separated parents increase "before or after visits to the non-resident parent" (2000, p.1). Given that the majority of post-divorce custodial parents are mothers this may also explain the mothers' experiences and as it relates to this research project it could be suggested that the event of parental separation can be disruptive to the mother-child relationship. This mother described the difficulties she experienced with access arrangements.

Very seldom did [Father] actually keep to the arrangements, so then of cause they'd [the children] get upset and I'd be the only one there to yell and scream at. (14)

In summary, the nature of the relationships between mothers and adolescent sons, as evidenced by the interviews with the mothers did not indicate a correlation between the nature of the relationship and the status of the mother. That is, both single and partnered, lesbian and heterosexual mothers reported positive and difficult relationships.

\section{Mothers' Perceptions of their Son's Attitudes Toward Them}

A number of the mothers reported a perception of their sons' negative attitudes toward them. That is, they didn't believe that their sons held them in very high esteem. In some of the situations the mothers described their sons' disapproval of who they were. In other situations the mothers believed that their sons perceived them in stereotypical ways.

One of the most common themes expressed by the mothers was that they believed their sons thought they were dominating and controlling, a "bossy bitch" (11) and 
"pretty domineering" (8). A further perception mothers had of themselves from their sons' attitudes was that they were empty-headed and garrulous.

For a long time he was really giving me a hard time saying that I have absolutely no memory and I was hopeless and no brain, and this kind of thing.

That I talk a lot and go on a lot, probably say I go on a lot. Someone who just makes a lot of wild sort of ravings; that's just another silly woman ranting and raving, going on about nothing. ... I've learnt to be quiet a lot you know in situations where you're just wasting your time and just setting yourself up. (9)

Mothers felt also as if they had work roles stereotypically ascribed to them by their sons.

I just felt like I was the maid around the house. There to do the washing, the dishes, the cooking, the cleaning, and that was all I was there for. (1)

One woman painfully described how her son had "accused [her] of child abuse ... saying things like women also abuse children it's not just men". She also voiced her suspicion that her son had been influenced by his father.

[He is] picking up on issues that ... a 16 or 17 year old would normally not be

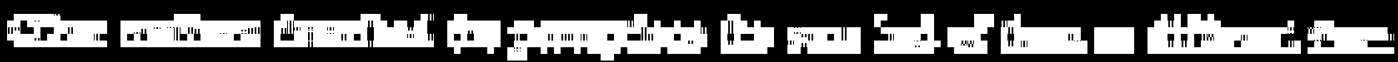

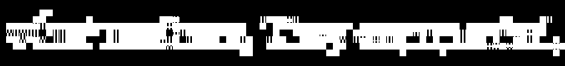

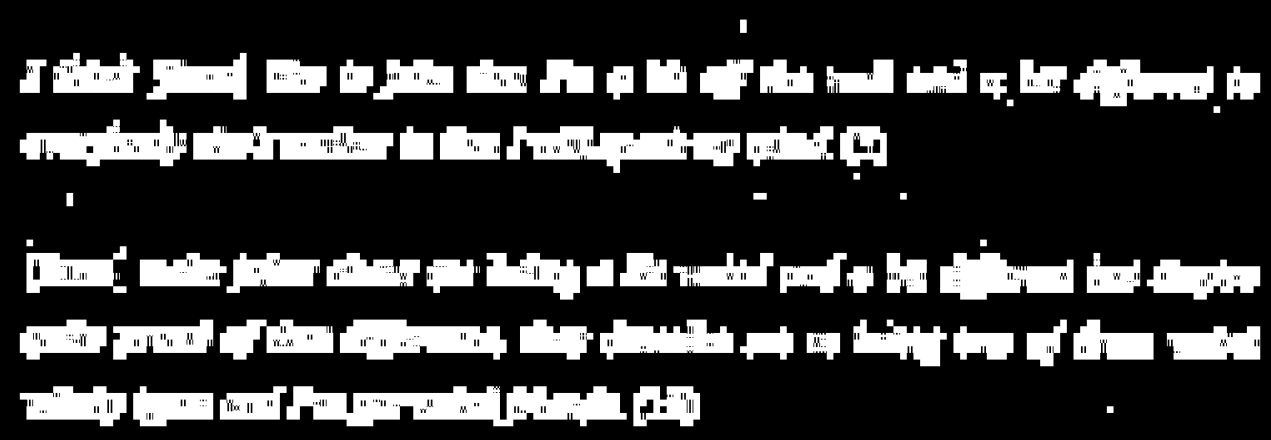

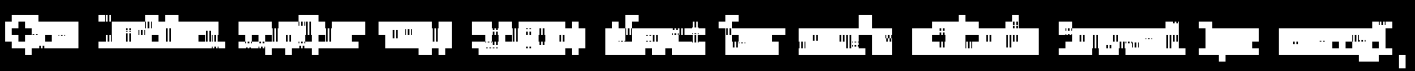

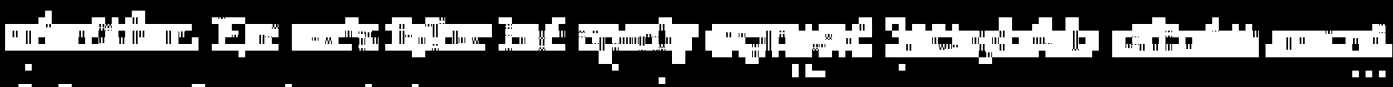

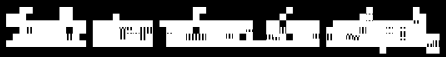


is [Son] wondering whether he should be thinking what his father says he should" (20)?

One of the mothers, who felt as if her sons appreciated who she was, described this in relation to the amount of work that she did.

[They recognise that I am the] breadwinner and the one that keeps the family and having to work quite hard. (18)

In one of the Family-As-Animals drawings in the Projective Drawing Project a $13 \mathrm{yr}$ old boy depicted his mother as an ant wrote the following beside his drawing,

My Mum represents an ant because she carries more than her own weight and works hard. (F-A-A-D, 13yrs)

It is to be remembered that these comments are the mothers' perceptions of the attitudes of the sons toward them. It is not possible to establish whether these comments reflect the mothers' feelings about themselves, or whether these are messages directed at them by their sons. An analysis of the mothers who reported that their sons perceived them as bossy and domineering revealed that, although numerically insignificant, the sons who lived with their fathers were disproportionately over represented. It could be suggested perhaps that the boys who chose to live with their fathers may not have had a positive relationship with their mother. Although it is not possible to prove within the parameters of this study, the question of the role of the father in the generation, or perpetuation, of these perceptions must be queried.

\section{Disruption to the Mother-Adolescent Son Relationship}

One of the predominant issues generated from the individual interviews and group discussions with the mothers, and supported by the results of the Drawing Interpretation Project (refer Chapter 6), was that there was a perceived change in the attitudes and behaviours of their sons toward them at adolescence. This change was expressed in several ways. While the common change was that of the withdrawal of their sons, mothers also reported an increasing lack of cooperation, 
acting out, expressions of mother-shame and an increasing identification of the sons with the male world. This section recounts the mother's descriptions of these changes and the reported impacts on the mothers. It also includes discussion about healthy processes of separation, including those initiated by the mothers themselves.

Those who felt their sons' withdrawal described it as follows,

It's not as close as it was ... there's a bit of a reserve there that never used to be there. ... he's just getting to an age where he's actually starting to like a bit more time by himself. [He is] not quite as forthcoming with his feelings. (13)

More than anything I think he withdrew. There was a distance. ... [He was] not communicating or not particularly sharing anything with me, not angry just almost 'not thereness'. (11)

This withdrawal had a strong impact on the relationship some mothers had with their sons. As discussed previously, mothers reported that the nature of their relationship with their sons was one of talking and communication. Once this was disrupted, by the son's introversion described as a normal stage of adolescent development by human development theorists such as Flanner, Montemayor \& Eberly (1994), Laursen (1995) and Steinberg (1988), the mother-son relationship floundered.

Mothers reported that their sons became less cooperative and ignored them.

[I had been] able to discipline the kids but there came a time in the boys' lives when they began to ignore that. ... that changed at 13,14 . (4)

It was stormy at times. It was difficult when they were 13,14 and $15 \ldots$ they were often jockeying for power with me, which I think is perfectly normal at that age. (3)

Discipline was hard. It was easy when he was little, but as he got older he would rebel and wouldn't listen. [He was] about twelve. He would just turn away from me, storm off to his room and slam the door. (1) 
The sons also demonstrated behavioural difficulties.

I think it is getting harder now...He is getting a lot of stuff from school. Verbal abuse comes from him for no reason at all. (5)

He ended up in Court. He ended up kicking some plants on a roundabout at the end of last year so he's had to do Community Service. (16)

Other sons reportedly acted as if they were ashamed of their mothers.

Walking down the street the other day with [son] and we were walking quite close. Our hands knocked together and he said 'get away'. (14)

They wanted to be sure that I wasn't going to embarrass them ... by shouting from the sideline or at a sports match, or acting in a scatty manner or something like that. (21)

Without exception the changes described by these mothers occurred when the sons were between twelve and sixteen. According to traditional white western human development theory this is also a natural stage in the development of a young man. The rise in conflict between parents and teenagers has been documented by a number of researchers (Flanner, Montemayor \& Eberly, 1994 as cited by in Bee, 1998; Laursen. 1995; Steinberg, 1988). Steinberg, a key American researcher in the area of adolescent development, suggests, for example, that the "discord, far from being a negative event, may instead be developmentally healthy and necessary - a part of the process of individuation and separation." (as cited by Bee, 1998, p. 308). Bee also reports that the parentadolescent son conflict is "more likely to be with mothers than fathers, perhaps because most mothers have been more closely involved with their children" (1998, p.385).

Chapter One of this dissertation includes discussions by Epstein (1998), Meads (1998), Offer (1969) and Papalia \& Olds (1998) who argue that the trauma typically associated with adolescence is not as universal as it is alleged. These theorists claim that the separation between adolescents and parents can occur smoothly if societal attitude is supportive. The "teenager" in Aotearoa New Zealand society still seems to attract negative labels. The mothers' attitudes 
towards their sons' changing manner and behaviours varied. Some felt hurt and others were confused as they worked to negotiate the inconsistencies.

He wanted to spend more time with his mates. Not that I resented that. What I resented was that he cottoned on to their parents. They were tops. 'Oh, They've just got so much more money" and 'they have nicer food than us'. It hurt, then at the same time, there was nothing that I could about it. (1)

I can sit in a room and feel uncomfortable with [Son] now sometimes which I never had ... I'm probably more wanting [Son] to think I'm an okay person or something. (9)

Other mothers reportedly initiated the separation.

If we're in town I'll be really respectful of his space particularly if it's a Friday ... when his mates are in town. There are some rules and I do buy into them. (GP5)

I felt that I needed to give [Father] some space to form his own relationship [with his son]. I felt that I was taking too much responsibility for all that ... and I actually withdrew a little bit. (11)

What was happening for Bambi's mother at this time? Salten describes the way she pushes Bambi away as he nestles against his mother for comfort chastising him saying, "You aren't a baby any more" (1928, p.61). American-based feminist therapist, Olga Silverstein, discusses ways mothers can become caught up in the belief that their son will only succeed when separated from the world he has inhabited with her from birth. She lists the following behaviours. The mother treats him in such a way to ensure he does not become a 'sissy' or a 'mummy's boy'. She subjugates her own sense of self, believing that she is inappropriate to be raising a male child - of modelling any of the qualities that will be important to his successful development. She either obliterates her 'self by rendering it invisible or by living through her son and 'his' world. She fears exercising control over her son out of a belief that she may emasculate him. She encourages his domination of her and the world she occupies. She believes in the male ownership of the child. The boy belongs to the father and is the mother's gift to the father and sometimes to her own father. She elevates her son, raising him to a position 
superior to her, sometimes intentionally making herself 'dumb' before him. She believes in the myths that homosexuality may result from too close a relationship between mother and son (1994, pp. 137-138).

These behaviours, as described by Silverstein, give a message to the son that diminishes the mother and her world. One of the project mothers described how she would play with her eight-year-old son. "I will do some of the things that he might like to do like play soccer." She went on to say, "I will let him win of course" (2). This collusion of the mother with the sons, to perpetuate the domination of male, is a theme that has recurred many times in the interviews. The following mothers expressed the elevation of their sons in their relationship in another way by describing their sons as replacement adults.

He helps make these decisions quite well. So he takes on a man's size job really.

Mine actually goes into the role of protector. Yes, he gets very protective when other men are around. (GP 2)

One mother commented,

There's a sense that it's special to have a son. I hope it's not something from the whole society where having a son [is more special]. I'd hate to think it was that.

Arcana describes the mother as the 'contractor rather than the architect' of her son's development. Mothers merely become part of the larger plan - a plan that "oppresses and demeans women and lessens the humanity of men" (1984, p. 118) by ensuring that masculinity, as prescribed by societal norms and values, is continued through their sons. This collusion of the mother has been made evident by the participant group discussion at the beginning stages of the project. One of the mothers was discussing how she was saving to send her son to a boys' boarding school.

He will go in Form 1.... It's an all-male school. ... There will be men in his life, and lots of boys, but mainly the men - the masters, teachers and house tutors. ... He doesn't really like the idea. (7) 
From what I have observed, this mother and her ten year old son have a very important relationship. She has bought an old cottage in the country and they have numerous animals, and a very full and rich life. Rich asks, "do we fear that they [the sons] will somehow lose their male status and privilege, even as we are seeking to abolish that inequality" (1986, p. 205)? The following comment signals that this mother believes that there is a certain amount of physical closeness between mothers and sons that is appropriate.

They made their own boundaries and moved naturally away from hugging and too much physical contact with me - I didn't have to initiate that. (18)

Too much contact for whom? Too much contact for what? Where did she get her concept of the appropriate amount of intimacy between her son and herself? When I questioned her further on this she was unable to explain anything other than it was "just a feeling" (18). The issue of the social construction of behaviours between the mother and son is an important one, but seems not to be addressed by developmental theorists. The most commonly used tale to interpret the mother-son relationship is that of Oedipus popularised by Freud through his interpretation of the "defamation of the tragic Theban queen, Jocasta and her son, Oedipus' (as cited by Arcana, 1984, p. 183).

The Oedipus story, as retold by Arcana (1984, pp.182-214) and Daly (1992, p.7), begins with Joscata, matrilineal queen of Thebes, who has a son, Oedipus, with her cousin, Laius. After the prediction of an oracle that Oedipus would kill him, Laius abandons his son in the wild having first pierced his feet and bound them together. (Oedipus in Greek means swollen or club foot). A shepherd finds the boy and takes him to the childless king and queen of Corinth to raise as their own. An oracle speaks again telling the young man, Oedipus, that he would kill his father and marry his mother. In order to prevent this happening Oedipus leaves the place of his childhood and wanders in self-imposed exile. Without knowing his birth father Oedipus meets Laius in a fight and kills him. Continuing on to further fulfil the prophecy Oedipus solves the riddle of the Sphinx' causing her to

${ }^{1}$ The Sphinx sat at the gate of the Greek city of Thebes questioning all people who wished to enter or exit and devoured those who answered incorrectly. 
disappear. Saving the city of Thebes he was crowned king. The queen is Joscata. Many years later a plague struck Thebes and the link is made with the death of Laius. Oedipus instigates a search for the killer only to discover that it is he. When Joscata realises that her husband was her son she hung herself and Oedipus, who had blinded himself with the golden brooches of her cloak, is banished and again becomes a wanderer.

This story lends itself well to Freud's declarations that the mother-son relationship is by nature regressive and must be disrupted in order that the sons may gain entry into the adult world. He contends that masculinity can be achieved only through the separation of the son from the mother. Although Freud's theoretical formulations were framed in the context of a Victorian society of a hundred years ago, his theory of the Oedipus complex has been extremely influential particularly as it has related to theory and practices of the family. More detailed discussion of Freud's influence on constructions of motherhood and male children is included in Chapter One. Rich, maintains that mothers who have never read Freud, are,

raising their sons in the belief that to show them physical affection is to be seductive, that to influence their sons against forms of masculine behaviour they as women abhor, is to 'castrate' them or to become the ... domineering' creature that their sons will have to reject in order to become mentally healthy. (Rich.1986, pp.195-202)

Freud's postulating has permeated current theory, behaviour and 'common knowledge' around parent-child, particularly mother-son, relationships.

In another story Robin Kahukiwa, Aotearoa New Zealand-based writer and artist, describes the tricks Maui used to increase his powers and domination over the female world. In his desire to have power over his grandmother, Mahuika, Maui uses trickery to gain her fingernails of fire, knowing that without them Mahuika is powerless. As she gives her fingernails to Maui one-by-one he douses them in water and extinguishing their fire. It is not until Mahuika gives him the final one, she realises his trickery. Maui also starves his ancestress, Murirangi-whenua, until she gives him her enchanted jawbone with which he shapes a club to beat the sun into submission, and a hook to fish up the North Island of Aotearoa. "The mana of Murirangi-whenua was diminished by her symbolic action of passing in her 
knowledge" (1984, p. 77). As Maui's number of conquests increases, his wish for all power grows and he desires to conquer that which was most powerful of all, Hine-nui-te-po, the goddess of death. ${ }^{2}$

Biddulph contemporises this theme of the separation of the son from the mother and the necessary destruction of her world, in his books Manhood: An Action Plan for Changing Men's Lives (1995) and Raising Boys (1997). Whilst claiming in these texts to be facilitating true relationships between men and women his duplicity is evident when he includes the following material that demonstrates and supports the disruption of the mother-sons relationship.

The mother encourages the child to play with the blocks and at least construct ...some sort of rough structure. Typically, at some stage, the father will transform himself into a roaring monster-cum-bulldozer, knock over the bricks and provoke peals of delight in the child. (1995, p.117)

Biddulph further augments his assertion that mother-son separation is necessary when he continues with the following statements,

Many boys at this age [14] start to have problems with their mother. The son knows deep down he must break free from her. (1995, p.121)

As early as six or seven years of age, the primary identification of the boy must switch. He will love ... his mother but he is not 'hers' any more. He actively wants to be with, and be like, his father. (1995, p.115)

Biddulph claims that there are three stages of boyhood; Stage One from birth to six years, Stage Two from six to fourteen years and Stage Three from fourteen years to adult. In Stage One, according to Biddulph, the boy primarily belongs to his mother but during Stage Two, he "looks more and more to his father for interest and activity" (1997, p. 6). I am emphasising Biddulph's work for several reasons. Firstly, his profile was highlighted when he toured Aotearoa New

\footnotetext{
${ }^{2}$ This final act was also his demise. The sound of the birds laughing at the sight of Maui creeping into the goddess's widespread legs wakes Hine-nui-te-po who closes her legs and crushes him. Erich Neumann in 'Origins of Consciousness' New York, Pantheon Books, 1964, describes how the myths represent the fear of women, women being synonymous for death - "darkness, the void, the bottomless pit...Mother, womb, the pit and hell are all identical" (63)
} 
Zealand in 1997 and then in 1998 when he returned as one of the key note speakers speak at the National Family Law Conference. During this time he appeared on the front cover of a weekly national magazine, the New Zealand Listener (May 3-9, 1997), he had an extended interview on the New Zealand National Radio (May 13, 1997), and was the invited guest to speak at several educational institutions in the country.

Secondly, neither of Biddulph's books mentioned above have a research base. They include a small bibliography of books and articles. His material is sourced predominantly from the clients he works with. Given this, it is concerning, to realise the underlying assumptions and belief systems on which Biddulph bases his work and more so to recognise the influence he has had with policy makers and people working with families in this country. For example, shortly after Biddulph's 1997 visit Deborah Morris, then Minister of Youth Affairs and Associate Minister of Women's Affairs, described fatherlessness "as the leading cause of declining child well-being in our society and the engine driving our most urgent problems" ${ }^{3}$ (September 6, 1997). In a speech several months later she restated her concern, "we often seem to go out of our way to avoid the connection between our more pressing social problems and the absence of men in the lives of our kids" (November 16, 1997). She then indicated that the issue of fatherlessness in Aotearoa New Zealand would be one of the key foci of the Ministry of Youth Affairs for the following period of time.

In the story of Bambi, Salten creates a dramatic separation in the relationship between Bambi and his mother by killing her. Ironically, while she is attempting to protect her son from hunters she is shot and dies. From this point, Salten wishes the reader to understand, Bambi is free to begin the journey toward his adult malehood.

Mothers interviewed for the project discussed the importance of negotiating the separation with their sons whilst not allowing themselves to be diminished.

${ }^{3}$ This is a direct quote from Blankenhom's Fatherless America (1994). 
He is needing to establish a difference and I think that we need to walk through so that. Our differences are marked which is important but they [can't be] inferiority or superiority. His world is no more superior to mine. (GP5)

Rich recognises the need for the differentiation between the son and his mother and devotes a chapter to the exploration of how this is played out. Hers is a debate between the recognition of necessary separation, which is an essential part of a child's development, and the prescribed definitions about who, and what, this separated fledgling man should and should not be. "We need to understand that there is a difference between handing our sons over to patriarchy on its term, figuratively or literally allowing them to victimize us as tokens of their manhood; and helping them to separate from us, to become themselves" (1986, p. 211). Rozsika Parker discusses the importance of the mother relationship in the construction of both sexes. She argues,

\footnotetext{
feminist psychoanalytic theorists argue that women are no longer 'only mothers'; they bring complex and diverse identifications to their mothering. ... Her history as an individual, her 'womanness' as opposed to her 'motherness', carves out the space between herself and her child, previously understood to have been created by the father, or by the son's dis-identification process. (1995, p. 234)
}

Three mothers with sons in their late teens and early twenties talked about how the relationship with their sons had gone through a difficult separating time and was being re-established.

I can look back now and think oh hell I'm glad I've gone through that and I've got my son back. He can communicate with me and he's not afraid to show his emotions. ... They sort of become human again. (GP 4)

My boys are like that, exactly the same. You sort of go full circle. I never thought he would though. (GP 4)

Some of the single mothers reflected a series of concerns that were unique to them. They wondered whether their sons should be with their fathers or in a nuclear family environment. They also wondered about how they would manage their sons on their own and they acknowledged their discomfort about the likeness 
between their sons and their ex-partners. Those who were concerned about the upbringing they have been able to give their sons reported,

I get into a little panic every time something goes wrong. I get really scared. ... Maybe he would be better off if I'd left him with [Father] right at the start. (13)

I'm aware that there have been other things which I was never ever going to give them, like stability of the nice domestic life and regular holidays. Those sort of things. (10)

One mother seems caught between wanting to maintain control over her eightyear-old son and her fear of teaching him to be violent.

I get very tired and I get worried with myself. I am very strict on that boy discipline wise and I smack him more than I probably should have to. I am worried sick that he will be the wrong sort of person or become a violent sort of person (2)

Another was worried about her ability to cope with her son when he reached adolescence.

He's so determined in so many ways that I will need help and if I know right now that I haven't got the help now from anyone I'm not going to have it when he's a teenager. (7)

A further disruption to the mother-adolescent son relationship was the intergenerational patterning between the fathers and the sons. Mothers, particularly those who had experienced negative relationships with their sons' fathers, found it difficult when their sons began to exhibit their fathers' mannerisms and behaviours.

I just get so angry with him. ... He's just so totally like his father sometimes. ... He has a lot of qualities that I just hate in [Father] and that makes it really difficult. (14)

Some of the patterns of behaviour exhibited were about non-communication. 
His father is like that. ... He can't talk about the personal things. ... It's always this bravado, this macho image. (GP 4)

Other patterns of behaviour included crudity.

One of the hard things ... [Son] is starting to pick up some of the mannerisms that his father has ... [including] drinking habits and the language and the joke telling. (20)

Several mothers also reported their sons' demonstration of their fathers' violence and alcoholism.

Probably [Son] has used me as a bit of a scapegoat because his father gave him a hard time, used to give him real hidings with his belt, both the boys.

- Do you have a fear that the boys could turn out as their father?

Yes, I have had that fear. ... [Son] has been through this phase of bullying and he will hit his younger siblings if they annoy, and ... he was trying to have a go at hitting me too. (4)

So they learnt to actually criticise me ... seeing what their father had done. ... I felt that they had actually continued on the criticism that their father had started ... So I kind of took on this whole belief that I was weak and I couldn't do this and I wasn't a very good mother. So I became very guilt-ridden about being; horrendously guilt-ridden. (18)

I would say heaps of negatives because it's really perpetuating a cycle. They grow up with that role model, and they go into marriage and adulthood with the same expectations and it is just a continuing thing. (4)

Parallels between the boys and their relationships ... in terms of alcoholism. That was a real worry to me because at one stage both boys were involved with young women whose fathers were alcoholics, and even now my daughter is involved with a boy whose father is an alcoholic. ... They are growing up to be adult children of an alcoholic. (3) 
[Son] has got this role model from [Father]. If he hit me, the son felt he had the right to hit me too. ... But the kids were hit a lot by their father and this boy seems to have got the idea that because he was hit, he could hit. (GP2)

\section{Mothers Discuss their Sons and Friendships}

When mothers in the project examined their perceptions of their sons' worlds they discussed four key areas. These included, friendships, body image, sexuality and schooling. An analysis of the discussions in the area of friendships resulted in the recognition that for boys to attract other boys as friends they needed to be sporty and to be demonstratively macho. That is, the mothers who reported that their sons were loners reported also that they tended not to engage in sport.

He's not into much of the way of sport, he's not terribly confident sporting-wise. ... He thinks that he hasn't got any friends. (13)

One of the mothers talked about the difficulties that both her sons experienced.

[Son 1] avoided sports like the plague. [Son] had a bit of a struggle through school with social relationships. ... I think he was quite a loner.

[Son 2] got picked on, and he wasn't interested in sport, which is a way of being part of a group and blending. (12)

The mothers also talked about the type of behaviours they observed of their sons when they were with their peers.

A lot of it is peer pressure don't you think. ... Last weekend because one boy was doing this women business with cupping their hands, they all felt that they needed to do it. (GP 2)

I heard his mates talk quite rudely. Terrible language! Terrible! All the bodily parts and the ' $f$ ' word. All that sort of started to be used by his mates last year.

The boys at school have obviously passed on some message to him that he's gotta be a man and sort his own problems out and don't be woose ... be a cry baby. (1) 
I think it's probably quite a tough call for a man to be caring, nurturing, and loving. I know that for [son] he feels he has to be something else out with his friends ... staunch and tough. (6)

He was put in a class with kids who rubbished him a lot for his interests which were very computer orientated and sort of very nerdy. He found it really difficult and towards the end of that year. I got really worried about him because he seemed depressed and he said something about dying. (11)

One mother wondered whether her sons got "such a hard time [because] they didn't conform to the kind of macho tough boy image" (12). Silverstein suggests that bonding for a boy with his peer group is crucial for the consolidation of his sense of male-masculinity and his beginning independence. However, she warns, "many parents are so convinced of the necessity of allowing a boy to find himself through his relations with his peers that they resign from their child's life prematurely" (1994, p. 139). Mothers in the project reported that their ability to maintain the necessary boundaries around their sons' activities with their friends was frustrated by the realisation that the peer group rejected their worlds and their values. They also felt overwhelmed and alienated by the accentuated macho behaviour demonstrated by their sons when with their friends.

\section{Mothers Discuss their Sons and Body Image}

Mothers talked also about the efforts made by their sons to conform to a particular physical image. This conformity included the need to wear certain clothes and hairstyles and the need to have a particular body shape and facial features. The need to conform seemed to intensify for the boys in their adolescent Comments from the mothers reported a connection between the boys' sense of self-esteem and their physical image.

At the moment [son] has a most incredible consciousness of other people's opinions. I have to have such-and-such clothes. I have to do my hair this way. (4)

He spends ages in the bathroom doing his hair every morning. I mean it's ten or fifteen minutes holding up the bathroom while he gets everything just right. (GP2) 
Daniel had bad acne for a few years. That was really hard for him. (9)

He's going to the gym and I know that he feels better about himself now because he wanders around with just his undergruts on. (6)

For some boys, the mothers reported, their shyness prevented them from taking part in physical activities with other boys.

My son won't even do Phys Ed at [Boy's] school, and I really think it's this business of taking your trousers off. (GP 2)

He's refused to go swimming for years at school, because he's got pimples on his back. He wouldn't say why he wouldn't go swimming and he said, "I'd rather do a detention every week than go swimming." (GP 9)

Human development theorist, James Marcia, who worked with Erikson's conceptions of the adolescent identity process ${ }^{4}$, suggests that shyness and lack of confidence is a normal stage of adolescent development linked with rapid physiological and hormonal changes (1980). Several of the mothers reported that they believed the level of self-esteem and confidence of their sons was commensurate with their conformity, or otherwise, to a stereotypical masculine body image. That is, those boys who were tall, strong and athletic seemed to be more confident than those who were short, puny and non-athletic. Research in the United States shows that the "earlier a boy's development [including height, muscle development and hair growth] the more positive his body image, the better he does in school, the less trouble he gets into and the more friends he has" (Duke et al. as cited by Bee, 1998, p.277).

The cost of raising sons was another issue addressed by the mothers and one that contributed to tension in the mother-son relationship. One mother (6) reported arriving at the supermarket to discover that Clearasil ointment, Clearasil face wash, Brut spray, Brut Deodorant and shaving cream had been added to the family shopping list.

\footnotetext{
${ }^{4}$ E.H.Erikson, along with J. Piaget, is one of the American 'fathers' of lifespan development theory. Their work spans from the 1930 s to the 1970 s and has been the basis of the development of more current work.
} 
The pressure to respond to these and similar requests, which are seemingly so connected to the self-esteem of one's son, must be enormous and, if disposable income is limited, the pressure and tensions would be accentuated. One mother, who felt the pressure to buy expensive clothes for her son so he wouldn't feel outof-it at school, made the following comment,

In the last couple of months he's mentioned he would like a couple of labelled Tshirts or sweatshirts just so that he's got something cool to wear on mufti day at school. The kids that he seems to associate with all seem to come from quite well off families so maybe he just feels he needs to keep up a little bit there. (13)

This mother was a tertiary student and on a low income. Her inclination was to allow her son to stay home from school for that particular day. One wonders whether school management personnel take this issue into account when they are planning a mufti day. ${ }^{5}$

\section{Mothers Discuss their Sons and Education}

The under-achievement of boys in the formal education system is an issue that is attracting attention by policy makers and educationalists. Quoting New Zealand School Certificate exam results the Education Review Office publication The Achievement of Boys states, "girls currently outperform boys at school against most measures of achievement" $(1999$, p.6). The publication suggests that there are several influences that impact on boys' achievement at school. These include external factors on boys' attitudes such as family influence, TV and other mass media and a macho peer culture and internal factors such as the lack of male role models in the home through the growth of single parent families (1999, pp. 6-7). Biddulph claims that,

Boys today, already underfathered, and beginning to show problem behaviour, come into a school environment that is largely feminine. They fit in poorly and tend to form an anti-school sub-culture. $(1999$, p.7)

\footnotetext{
${ }^{5}$ Mufti Day is a fund raising event for intermediate or secondary schools. Students are charged, usually several dollars, for the opportunity to wear their street clothes in place of the usual uniform
} 
Although it is difficult to refute the above, the mothers in the project offer another perspective, one that seems to be endorsed by the national executive member of the Post Primary Teachers' Association responsible for the coordination of boys' issues, Ron Miller. Miller argues that

the problems faced by boys are not the fault of women and girls. ... Boys are noisier, chaotic, base, bent; theirs is a culture of physicality and humour. But they are fragile creatures, too. ... Girls need success - power, this is self-evident. Boys need nurturing, this is less so. (1999, pp.2-3)

One mother felt that her child was limited in his ability to express himself by expectations of the school.

He is not allowed to be who he is. He has to be who they want him to be. He is a real kind and caring person, but it's like when he gets angry at school he doesn't know how to express it, and they are really not allowed to get angry at school either. And they are wondering why the children are leaving school and they are having all this trouble. It is because they are not listening to what the children have to say. This is not only for [son], it is for other children as well. ... He has to be who they want him to be. He has to fit into that mould. (5)

Another of the mothers discussed the incongruities between the valuing of cooperation as articulated by the school and the competitive system that governs most school activities.

The whole school system, everything that they're taught now is about competition and the individual. They're taught to co-operate. Well they're told ... but there's this push at them all the time to be as good as they can be and you've gotta win. He gets so upset if he can't be competitive. He doesn't like it if he feels he's not up to scratch around sport and things like that. ... I'm just worried that the society that we've got is not really that friendly towards anyone who isn't in that strive, strive, strive mould. (20)

The achievement of boys at school is an enormously complex area. Although examination of this issue has not been part of the mother-adolescent son research there are implications for mothers of the lack of achievement of boys at school. These are worth mentioning briefly. For example, one of the reasons given for 
boys' failure at school is fatherlessness (refer the aforementioned ERO report). The head of Social Sciences at Melville High School, Aotearoa New Zealand, argues that "the absence of a father figure can have an effect on boy's education and behaviour" (Gerritsen, 1999, p.5).

A further reason given for the lack of success of boys at school is the shortage of male teachers and the need for male role models (Sarah Farquhar, 1999). Linda Woon, Head of the Rotorua Principals' Association, counters these claims by recognising the differing development stages of girls and boys. Girls, she argues, have an earlier scholastic advantage in literacy and boys have an advantage in spatial and kinaesthetic areas. "There are strategies", she believes, "that help boys through ... teaching/learning styles without going 'overboard' on what is shaping up to be the next bandwagon. ... [Female teachers] should not be made to feel that they have somehow let society down, yet again!" (1999, Cover page).

Woon's suggestion that teachers feel blamed for the failure of boys is reflected by the comments of the project mothers' who also report feelings of culpability for failure their sons may have at school. The suggestion that boys need fathers to succeed in their formal schooling undermines the confidence of the mother by contributing to a belief that she cannot adequately prepare her son for his future. The reason for the failing of boys at school is inadvertently blamed on the mother because the father is not present. The cruel irony becomes apparent when the findings of this project show that it is principally the mothers who have taken on the responsibility of raising the sons. This seemed to be the case whether the father was living with the family or whether he was separated from it.

The NZ Council for Educational Research released the findings of the third stage of The Competent Children Project in September 1999. This project has also brought into question the claims made by the proponents of the belief that absent fathers equates to unsuccessful boys. One of the latest and key findings of this project has been that, "a mother's education has more effect on a child's performance than a fathers" (New Zealand Herald, September 28, 1999). In addition post-graduate work undertaken by Auckland University masters student, Maureen Rutledge, concluded that boys' literacy problems are not a new phenomenon. Progress and Achievement Tests were conducted in 1968 to a 
sample of nine hundred students from Standard 2 to Form 2. The tests "showed significant gender differences in reading achievements that favoured girls" (Bullen, 1999). The under achievement of boys in education is a complicated issue and one, I believe, that needs further investigation. Boys with (capable) fathers and schools with (effective) male teachers may be advantageous, but when offered as an antidote to boys' educational failure the complexity of the problem is obscured

\section{Mothers Discuss their Sons' Physical Changes and Sexual Awareness}

A further issue for the sons, as perceived by the mothers, was the physiological and social changes that occurred at early adolescence. According to developmental theorists boys experience a growth spurt at around fourteen years old, which is usually two years later than that of girls. The early stages of pubertal change occur in both genders at around the same time (Brooks-Gun \& Reiter as cited by Bee, 1998, p.276). It could be suggested then that boys between twelve and fourteen years, although become sexually aware, would be shy and uncomfortable around the (taller) girls of their own age. The mothers discussed the growing sexual awareness of their sons and the embarrassment with it.

I would want to talk to them [about sex] and they wouldn't want to talk about it. It was too embarrassing. ... They consider it all very private. (4)

That was a big thing for him ... having a girlfriend. He didn't have a girlfriend for a long time. (9)

The values of this mother, although she recognised that this time for her son was one of exploration and change, made acceptance of her son's choices difficult.

He is right into boobs at the moment. And there is [an international model] poster on the wall - voluptuous looking blond creature. ... I guess fantasies are the beginning of a boy's sexual experience. It just clashes with my own values. (GP 2)

As the interviews with the mothers progressed over the four years of the study it became apparent that there was a link between the self-esteem of their sons and the quality of their relationships with their mothers. The levels of self-esteem for 
adolescent males seemed to fluctuate according to their ability to attract friends, their body image, the resources available to dress themselves 'in style' and their ability to cope with pubescent changes. At this already tenuous time in the mother-adolescent son relationship, these extra pressures can be the breaking point, particularly when levels of disposable income are low or non-existent.

\section{Mothers Discuss their Sons and Alcohol, Drugs, Safety and Suicide}

The mothers' fears and concerns for their sons focused predominantly on safety issues. These included; alcohol and drugs, driving, safe sex, anti-social activity, low self-esteem and suicide.

And as I write this, I am negotiating with my own son about drinking, openness, trust and safety. He has gone to join his mates for the evening. I am afraid for him. ... Two weeks ago an older brother of one of his friends drove off the road and killed himself. He was several times over the legal alcohol limit. I find it very difficult to negotiate the divide between allowing independence and setting reasonable boundaries. (Own Journal, September 28, 1999)

In 1998 The Ministry of Youth Affairs commissioned a piece of research called Young Male Risk Behaviours. This research included findings on the rate of accident and alcohol/drug hospitalisations for males and females (Figure 5.1). 
Figure 0-1: Accident and Alcohol /Drug Hospitalisations Among Males: 1991 - 1995 (Source: Ministry of Youth Affairs, 1998)
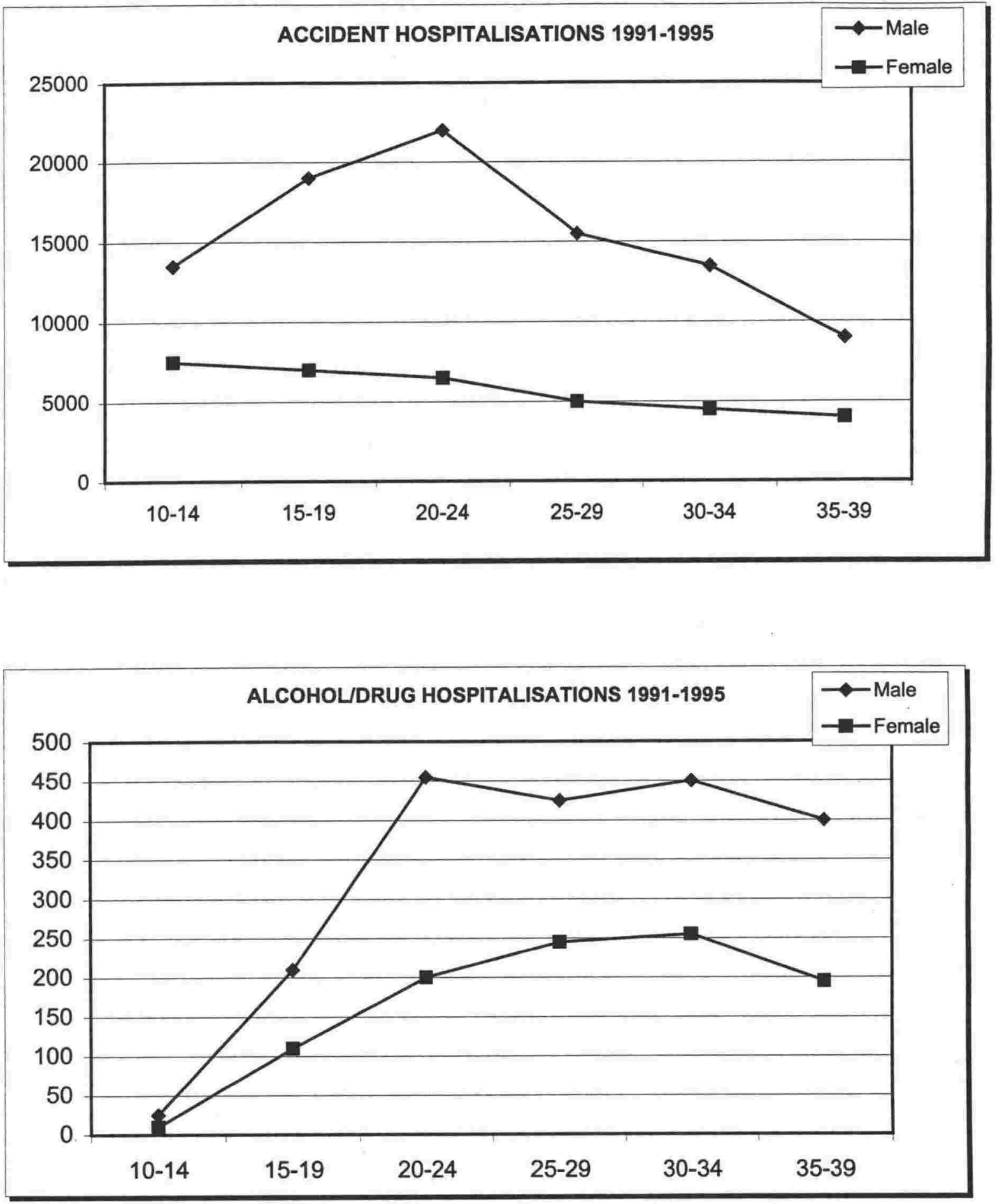

Although the highest number of recorded hospitalisations registered was in the twenty to twenty-four age group, the numbers of hospitalisations increase sharply for males from ten to twenty years. Mothers in the project reported that school was one place where boys were exposed to alcohol and drugs. 
[Son] was already in High School and had been offered drugs to buy from kids in his class. ... He told me about it and talked about it ... was aware his older brother who he cares about very deeply had a drug problem at one stage. (10)

The mothers who felt concerned about alcohol and drugs also expressed some helplessness about their ability to control the situations their sons chose to be part of.

He was starting to really assert his independence. On Saturday nights he would go out. He had started to go to parties, and they were starting to drink. I don't know where they were getting the alcohol. ... They just felt I was over reacting and that everybody else was doing this and [told me to] chill out ... or just relax. (21)

Several boys had fathers who had alcohol and/or drugs problems. This was another source of concern for the mothers of these boys.

[Sons'] father is an alcoholic. You have a greater than $60 \%$ chance of inheriting that. (3)

[Father] has taken a lot of drugs over the years and drank a great deal and [Son] would go and visit him and say he drank a lot. One the thing I really feared was this thing about drugs and alcohol. (10)

Driving was a well-founded concern for the mothers, particularly when connected with drinking and peer pressure. The Young Male Risk Behaviour Report identified that "the most significant cause of death and hospitalisation for young males [was] road related injury"(1998, p.15). Although males aged fifteen to twenty five years made up eight percent of the population, they sustained twenty three percent of road deaths and injuries in 1993.

They're on my back all the time now about wanting to get their license, and [Son's] 16. [He says], what's it gonna feel like when I'm gonna be the only person in school next year without my license? (14)

There's something about boys. They seem to see cars as great big real fun toys and I am just horrified. Now [Son] is just dying to get his foot to the floor and 
make the wheels spin, which is very bad for the car, but it's worse from the safety aspect of the kids. (GP 9)

Mothers also expressed concern about their sons becoming involved in criminal behaviour.

[Son] really went off the rails. He ended up in Court for a minor offence for which he got diversion. I didn't know anything about that. (16)

Another mother refused to conspire with her son's drinking and driving.

[On a] couple of occasions [Father] had to go and bail him out of Jail for D.I.C. I refused to go. I had got to a point where I had said to him 'I'm not going I've had enough'. (8)

The scoping review of the Young Male Risk Behaviours Report identified risk behaviour by young males as being:

- developmentally normal and time-limited for most males

- $\quad$ characterised by certain 'rites of passage'

- $\quad$ different for a small group of males with 'problem behaviours' (1998, p.2)

John Eastwood, writer of this report, describes the group of males with problem behaviours as those who "had impoverished and disadvantaged childhoods". He recognises also the difficulties of reaching this at risk group "while the broader underlying causes of the problem behaviour are not being addressed" (1998, p.12). This statistical evidence vindicates the fear and concerns of the mothers for their sons' safety. It also supports my claim that the ability of mothers to keep their sons safe is dependent on the support they receive from society-wide social and economic policy and interventions.

A further issue that concerned the mothers was the lack of self-esteem of their sons. The decrease in self-esteem at the onset of puberty, as described by human development theorists, has been discussed already. 
Well he's just got such a complete lack of self-esteem. He just doesn't believe in himself at all. (14)

We had the suicidal time. He had two years of that. Knocking himself down. ... Putting himself down. (1)

The decrease in self esteem at the onset of puberty has been mentioned previously. Social Science research suggests additional factors that are contributing to the increase of suicide among young people in Aotearoa New Zealand are impacting on young people. According to the New Zealand Health Information Service the youth suicide rate in Aotearoa New Zealand ranks as one of the highest rates compared to other OECD countries. (1997). Figure 5.2 shows the latest youth suicide deaths by gender and ethnicity in Aotearoa New Zealand. Ministry of Health research (1997) offers the following factors as explanation for these statistics.

- Social and educational disadvantage.

- A history of exposure to multiple family and parental disadvantages during childhood and adolescence.

- The development during adolescence of significant mental health problems or adjustment difficulties.

- Exposure to a serious or stressful life event immediately prior to the suicide. (1997)

The Kia Piki te Ora o te Taitamariki component of the Ministry's Youth Suicide prevention strategy suggests the following additional factors for Maori youth including; the impact of institutional factors such as mainstream education systems; cultural and historical factors such as social dislocation and breakdown of whanau support and cultural identity. The Ministry of Health Suicide Prevention Strategy also reports on growing international evidence confirming that young gay, lesbian and bisexual people have higher rates of suicidal behaviour. 
Suggested additional factors reported include the lack of support for sexual orientation and the discrimination faced by young gay and lesbian people. The suggestions by the Ministry of Health Suicide Prevention Strategy that alienation and discrimination contribute to the incidence of young Maori, gay, lesbian and bisexual suicide could give a possible clue about the impact of single-family status on males. Similar stigmatisation of (particularly) boys from single-mother households could also contribute to feelings of alienation and low self-esteem.

Figure 0-2: Youth suicide deaths (15-24 yrs), by ethnicity/gender/age/100,000 pop (1997)

(Source: New Zealand Health Information Service)

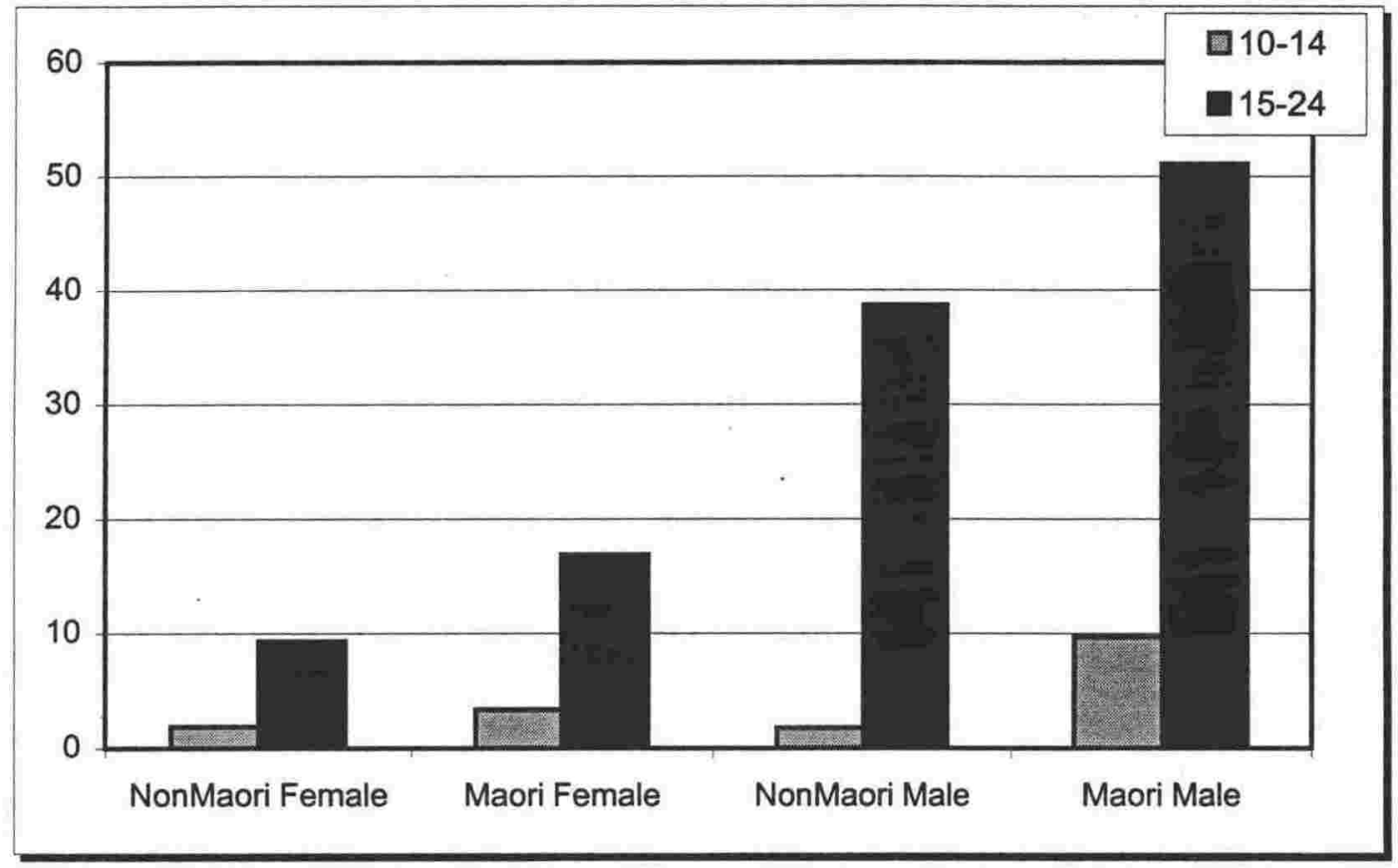

Although the analysis from the Ministry of Health describes social, family and parental disadvantage as contributory factors to youth suicide rates, it does not identify 'fatherlessness' as a reason. This is contrary to claims and misinformation espoused by some sector groups. Claims it appears that have been pervasive enough to have been internalised by professionals and by the mothers themselves.

[Son] went through a whole time where all he would talk about was, dying and how he was going to do it and what toys he would ... have in his coffin with him and all this sort of stuff. He just talked about it all the time. It made me fell really guilty and I didn't know what to do about it and in the end he actually 
went to a Counsellor. ... That's when it all came out that it was my fault and he wouldn't be having these problems if I hadn't of kicked Dad out. So it's all my fault. (14)

There were several different reactions from the mothers about the impact of separation on their sons. Some believed that the separation had been beneficial to the sons because it ended the direct impact of the fathers' destructive behaviours due to alcohol and drug addictions, violence and abuse. Others felt as if access visits following separation forced the otherwise reluctant father to actively participate in parenting. Others felt as if out of necessity they had become stronger and more competent parents. Some mothers believed that as long as access arrangements were effectively worked out between both parents, then the sons had the best of each parent.

I think for them it was exactly the same as [it was for] me. It was just a huge relief to have this person out of their lives and to get some stability. (3)

Several of the mothers reported the difficulty their sons had with the stigmatisation of being part of a 'broken' family.

All it took ... was for one other boy to say 'I know about your Mum and Dad breaking up'. And [son] saying 'oh I didn't want to talk about it' and they said 'it's all right we still like you'. ... From that point on he just reintegrated with his old peer group and he's just never looked back. (20)

[Son] was still trying to pretend to his friends that his parents hadn't separated. He was actually lying to his friends and saying his mother worked away from home a lot. (18)

Mothers spoke of the efforts of their sons to compensate by developing close links with a family outside of, and as well as, their own.

[Son] moved on to forming a close bond with that peer's mother and father, which they still maintain to this day. That relationship with their peers' mother and father was totally independent of me, and still is. It was very, very healthy for them. (3) 
One of the sons demonstrated the immediate impact of his parents' separation by reportedly going out of control.

He set fire to a meter box and of course he found himself in Court. ...He was not a happy boy at all. That was just after I left. (16)

Most of the mothers reported distress among their sons immediately after the separation. The length of time it took for them to successfully adjust to the separation seemed to depend on several factors. These included; the ability of the parents to prioritise their son's needs post-separation, the effectiveness of the communication between the parents, the sons contact with both parents and the consistency of expectations between the parents about the sons.

We both talked about the need for access. Never at any point did I want to cut him off from access. ... At no time did I want what had happened to us to interfere with the children. (21)

Weekend access began immediately. We both knew that involvement with both parents was crucial ... could keep personal stuff out of the relationships between the boys and us. (17)

The Counsellor draw up a contract for both of us when and how things would be exchanged like clothing, what time of the day where we would meet, that the children weren't to be the communicators, information or negotiation facilitators. (20)

Although generalisation outside of the project is inappropriate, the sons in this study who it was reported felt the stigma of being from a 'broken family' were Pakeha and had previously lived in families that earned a regular income. Could the privileging of the heterosexual nuclear family be more pronounced by white middle-class Aotearoa New Zealand? Could the drop in, particularly disposable, income concordant with the majority of single mother situations be experienced more acutely for children previously used to an income earning environment? 


\section{Mother's Hopes for their Sons}

When asked about their hopes for their sons the mothers included such things as an ability of their sons to be able to form good relationships, having self-esteem intact and personal fulfilment. They defined good relationships as those that involved a healthy intimacy, a valuing of others and a respect for women.

I would like them to be able to be loving individuals, able to form really good relationships with women. I would like to see them have stable sexual relationships and have a satisfying relationship with children, but to be able to relate to women on lots of other levels too; to see women in a really positive light. (4)

They also wanted their sons to value themselves, to feel good as men and to realise their own aspirations.

Just a sense that whoever you are is okay. And that you can have emotions, and you don't to go and play rugby or drink heaps of beer to be a man. (5)

I also feel a responsibility to make them feel good about themselves as men (16)

I just want him to be happy. I want him to get as far as he can. I've got no great ambition for him to be wealthy or anything like that I just want him to be able to fulfil whatever it is that he wants to do. (13)

One mother echoed the thoughts of the majority of the mothers when she summarised her hope for her sons as; being able to establish good support systems, having a strong sense of who they are and being comfortable with themselves and their relationships with male and female. (17) Rich adds to this mother's hope for her sons. "If I could have one wish for my own sons," she says, "it is that they should have the courage of women" (1986, p. 214).

\section{Mothers Views of the Ideal Situations to Raise Sons}

When mothers were asked about the ideal situation to raise their sons a predominant theme that emerged was their desire to be living in some form of community. The form of community was perceived in a variety of ways. One 
mother felt that her son needed a community of other children and adults in the form of a boys' boarding school.

I've put us into isolation and what we really should have is a closer community. I'm still determined to give him Boarding School. ... .I feel that's going to be like a family for him to be at school, living with other kids ... especially being able to bring somebody home to the farm. (7)

Several other mothers felt that they would like their families to be part of a larger community.

I would like to be living in a much more community oriented [situation]... rather than boxed off in my little house. I would really like to live in a community situation where the raising of children was shared a lot more amongst a group of adults. (4)

Others talked of the involvement of the extended family and the added advantage of having contact with a variety of positive role models.

I think he's been fortunate to having two really big extended families which see each other a lot. .... He's had the benefit of coming from a mostly female family and a lot of quite strong loud women as well as the sort of sporty [men]. He's had the opportunity to see different aspects. (9)

Citing a study of two hundred and fifity four urban African American adolescents human development theorists, Papalia and Olds suggest that parental support may be more important that family structure. The study undertaken by Zimmerman, Salem \& Maton (1995), showed findings that were contrary to popular claims about the negative impact of fatherlessness. They found that,

those adolescent boys living with a single mother were no more likely than those in two-parent, step parent, or extended family households to use alcohol or drugs, to become delinquent, to drop out of school or to have psychological problems. The only difference was a positive one: sons in single-mother households experienced more parental support than other youths. (as cited by Papalia \& Olds, 1998, p.387) 
The importance of the wider community to support single mothers was also raised by the project mothers. In discussions on this theme there seemed to be no specific difference between the single and (male or female) partnered mothers in their desire for some form of community.

I see no reason why a woman ... can't successfully raise sons or daughters with sufficient support. I think this comes down to our community where we make sure that we've got the role models ... and the parenting support. (21)

Although discussion of financial issues is included in the previous chapter it is suffice to say at this point that several of the mothers, single and partnered, felt as if the major barrier to their ability to raise their sons effectively were the financial difficulties the family experienced. The ideal, as reported by them, would be to have a sufficient level of income.

Two of the mothers felt that the ideal situation to raise their sons was within a nuclear family structure.

The ideal situation is two parents but I think today's world you need two very strong parents and I feel that sometimes my strength is just not strength enough.

Conversely this mother recognised that it was not enough to have parents living together with the children. She believed they also needed to be competent parents and to raise the sons as part of a household in which women and children were also valued. She described her ideals situation to raise a son as,

a house where he who makes the gold doesn't rule. A house where patriarchy doesn't rule. A house where the life isn't consumed, energies aren't consumed by trying to make everything all right while men do exactly what they please. (20)

Some mothers also felt that there was not an ideal situation to raise sons and that adolescence was a naturally 'difficult' development stage.

[T]hings can go wrong whether it's mother and father bringing the kid up, or whether you are a mother or a father on your own. (1) 
I would say $99 \%$ of what my boys have gone through, and what everybody else's boys will go through is normal ordinary kid stuff. It is not single parent stuff. (3)

\section{Parenting Strategies in the Mother-Son Relationship}

A number of the mothers felt as if it was up to them to develop effective relationships. They offered various strategies. One mother felt that she needed to be worthy of her son's trust.

I guess the big thing that came up was that trust. ... Let your sons realise that they can trust you, that if they tell you secrets not to go telling people those secrets. (16)

She and other mothers also described their endeavours to value their sons for who they were.

I accept him as important no matter how bad he might have been. ... He's still my son and I still loved him. (16)

They just needed somebody who loved them warts and all I suppose. (8)

Others felt as if their availability to their sons was another way they could develop effective relationships with them.

They needed somebody to be there when they were feeling a bit grumpy when things were going wrong for them. ... [It was important] that there was always somebody there [who] could go to. (8)

It's really really important you know to be there to listen. I think in the older stage that my kids are in now it's even more important to be around and listening. (11)

Two mothers talked of enhancing their relationships with their sons by providing a nurturing environment through the preparation of food. 
It's been such a relief for my son. ... I think the violence was much bigger than [I realised] I created a sense of belonging and he needed that. He started to invite friends and I'd make pancakes. (19)

He used to like the lunches I made him. ... I loved doing that. It was one way I could show how much I loved them was the preparation of food. I don't how the hell I found the time to do it but I did it. (8)

Those mothers who had been involved in an aspect of human relations and human development training felt that they had gained necessary skills to support teir parenting.

Making connections through counselling gave me a deeper insight into the mother/son relationship. ... [It] helped me to look at my own behaviour and my own relationships with the boys ... [and] gave me some more support and strength. (16)

It's quite useful to know things about what stages kids are supposed to be at and not to take things personally, these shut downs and cut offs. (6)

If it hadn't been for my training [where] I learnt so much ... about relationships, psychology and education I might not have been able to cope.

Mothers also sought external supports to provide the parenting they wished to give their sons.

I think that once he goes off to boarding school I can start to relax a wee bit and take on the responsibility on a weekend basis. (GP 2)

And it also helps you put your own problems in perspective talking to these other women with teenage kids. (GP 5)

Elements of the parenting strategies discussed by these mothers are also supported by American researcher, Diana Baumrind (1971 \& 1996). Baumrind studied one hundred and three children from pre-school to adolescence over a period of ten years. She identified four different parenting styles and described typical behaviour patterns of children raised according to each. 
- Authoritative Parental Style - characterised by high levels of control, nurturance, maturity, demands and communication.

- Authoritarian Parental Style - characterised by high levels of control and maturity demands and low levels of nurturance and communication.

- Permissive Parental Style - characterised by high levels of nurturance and low levels of control, maturity demands and communication.

- Neglectful Parental Style - characterised by low levels of nurturance, control, communication and maturity demands.

\section{Figure 0-3: Parenting Styles}

(Source: Lamborne, S.D., Steinberg, K.J. \& Dornbusch, S.M. 1991. As cited by Bee, 1998. 310)

\begin{tabular}{|l|c|c|c|c|}
\hline \multicolumn{5}{|c|}{ STYL OF PARENTING } \\
\hline Outcome Measure & Authoritative & Authoritarian & Permissive & Neglectful \\
\hline Self-Reliance & 3.09 & 2.96 & 3.03 & 2.98 \\
\hline Psychological Symptoms & 2.36 & 2.46 & 2.43 & 2.65 \\
\hline School Misconduct & 2.16 & 3.26 & 2.38 & 2.43 \\
\hline Drug Use & 1.14 & 1.38 & 1.69 & 1.68 \\
\hline
\end{tabular}

NOTE: Each number represents the average score on a 4-point scale where 1 always indicates a low amount of the particular behaviour, and 4 means the maximum amount. In each row any pair of numbers with different sub-scripts are significantly different from one another.

From this table it can be seen that on all accounts the authoritative parent rates as the most effective parent. Adolescents with authoritative parents were more selfreliant and had fewer psychological systems, behaved better at school and did not abuse drugs. Relating this scale to earlier discussion in the chapter highlights several factors. Firstly, it is difficult for a mother to insist that her son keeps himself safe or acts in a non-macho manner when his peers accentuate unsafe, macho behaviour particularly when they are together. Secondly, it is doubly difficult when the father encourages unsafe behaviours. One mother (8) recalled 
the reaction from a father to his son's pain "For God's sake be a man", he exclaimed and then challenged the mother for making a "sissy" out of the son. Thirdly, as discussed previously, a difficult financial situation for the family can accentuate the tension in the mother-adolescent sons relationship. Overall, as was highlighted by the mothers, disruptions to their relationships with their sons can prevent the mother developing an effective parenting style.

During discussions in the longitudinal focus group, the mothers uncovered a crucial determinant in their ability to parent their sons. As well as trustworthiness, availability, the creating of a nurturing home environment, skills training and the use of external supports the most resounding set of opinions expressed by the mothers was that their own strength and determination was a major element in their success as mothers. That is, the strength, confidence and enhanced selfesteem of the mother contributes positively to her ability to parent her adolescent son and maintain an effective relationship with him. As one mother described,

This business of the physical lashing out was really early this year, so that was [when he was] 14. I must say that he has gone through a real change lately. I think it is partly my attitude, because I have gone through a real change (4)

As part of the longitudinal focus group this mother (4) recorded the development of her relationships with her sons in her journal. The following entries reflect the changes that she made throughout the project.

Through the two face-to-face interviews we have had and through the very great deal of thought I have given to all that has arisen in my mind ... I see myself in a much more positive light. (4, October 1996)

Things have certainly moved on since last I wrote. It amazes me - every time I give some thought and attention to this process and then go away ... when I come back I have this huge sense of having shifted. (4, December 1996)

Others methods used by the mothers to demonstrate authority with their sons included the importance of their personal strength and their ability and preparedness to establish boundaries. 
[Son] says, "it's only $\$ 10$ mum, come on, oh, but you love me mum" ... tries to grease around me and of course, he expects mum to melt and mum sort of melts inside, but I'm still not going to do it. (1)

I've firm boundaries and have the firm authority but not authoritarianism, [Son] has choices about most of the way he spends his time and he makes sensible choices. (20)

Being aware that it [adolescent separation] will happen and making sure that we do things for ourselves - that we start to value ourselves more. [My accentuation] (9)

Valuing and looking after themselves as they parented their sons was a common theme that emerged as the research developed, particularly with the mothers in the longitudinal group.

I am the only thing that my kids have got basically and if I go under they go under. There's no way I'm gonna let my kids go under. (GP 4)

I think I've tried to [do something] then I thought nah to hell with this I'm gonna get exhausted. If I go under we all go under so I had to look after me. (3)

A further discussion of confidence issues for mothers and the impact on the mother-adolescent son relationship is included in Chapter Eight.

\section{MOTHERS TALK ABOUT THE FATHERS}

The discussion in this section is divided into three themes. The first involves the father and son relationship, the second discusses custody, access issues and financial arrangements with the sons' fathers and the third, the parenting support of the fathers.

Salten describes Bambi's first encounter with his father. 
The stately stag [father] passed close to the children and Bambi's mother and Aunt Ena. He passed by in silent splendour, holding his noble head royally high and honouring no-one with so much as a glance. (Salten, 1988, p.44)

To placate Bambi in his disappointment that his father did not stop to talk to him, Bambi's mother lets him know that one-day, "when he is big enough and has proven himself", his father will approach him. From this point in the story it is Bambi's mother's role to ensure that the uniting with his father occurs.

\section{Mothers Discuss the Father-Son Relationship}

As with Bambi's mother, the majority of the mothers in the project were anxious that the sons had positive and ongoing contact with their fathers. They supported and sometimes engineered this contact happening. Reports of the nature of the father-son relationships were both positive and negative. The mothers who reported that the relationships their sons had with their fathers were positive lived both with and away from their sons' fathers. In contrast with the nature of the reported mother-son relationships that involved intimacy and connection, the father-son relationships tended to involve physical activity.

Their father started taking them skiing and flew them down to [the South Island]. (20)

[Son] was very good at squash and that was the other thing that brought them together. (8)

Several fathers, particularly those who did not live with their sons, endeavoured to develop the relationship by spending money on them.

He did spend on them I think to sort of compensate like buying a little car. (20)

The reasons for fathers favouring physical activities with their sons and spending money on them could be multiple. Stereotypically, the fathers may have been brought up unable to develop relationships that involved inter-personal communication and so 'doing things' was a way of connecting with their sons. Those fathers who were not living with their sons on a full-time basis tended to have more disposable income than the mothers. Additionally society measures 
success of an individual by the level financial achievement. Perhaps the amount of money fathers had was a way of proving their 'manliness' to their sons.

One mother talked of the satisfaction she felt about the relationship between her son and his father.

They're not like that...stereotypically bloke-ish. [Father] is very sure of himself with his maleness. I've always felt a sort of a comfort with who he is. [There is a] lot more intimacy in their [father-son] relationship. (11)

Mothers also reported a significant number of ways that the relationship between fathers and sons broke down. One of the ways the mothers reported this occurring was through the denigration of the son by the father.

[Son] was just playing and [Father] said he looked like a poof. (5)

[Son] was quite put down by his father in many, many ways. He would say 'I came fifth out of all the country' and his father would say, 'who do you want to impress, why are you showing that?' ... [Son] shut down. (19)

Some of the mothers believed also that the fathers were not able, or prepared, to maintain a disciplined relationship with their sons,

They didn't have to go to bed. They didn't have to do their homework. They were allowed to do what they liked and [Son] really went off the rails. He ended up in Court. (16)

Others had difficulty with some of the fathers' values and the impact of these values on their sons.

On the wall was this disgusting picture, which I could only say was pornographic. [Son] said 'look at that' and the father sort of made a big joke of it. (7)

He said, 'Dad's taking me to a strip joint'. ... I can't stop him. I'm feeling uncomfortable about it at the same time (1). 
A further way that the mothers reported the damage of the father-son relationships was through the high expectations of the sons by the fathers. These expectations seemed to be more pronounced with the sons' sporting achievements.

He was picked as a representative player ... [was told he needed] to try and lose some weight. One day he got quite upset about it ... he said that Dad was so happy with me doing it and I don't want to let him down. (9)

Their father had put a lot of pressure on. ... He was a high achiever himself. I guess the father's pride [was] in their achievements. They needed to be right at the top for him to be really interested in what they were doing. (20)

A key theme for mothers was the lack of communication in the relationship between the fathers and their sons.

[Son's] quite an affectionate kid. ... You can sit and talk to him for ages. ... He liked doing that. [Father] didn't like doing anything like that. (13)

The boys tell me now they don't know him. They don't really know their Dad. They say they can't relate to him. There's no intimacy there. (18)

Although Chapter Six reports the findings of the Drawing Interpretation Project, I have selected two portrayals of the father-son relationship drawn by twelve and fourteen year old males (Figure 5.4). Although the reasons are unknown the tension, and animosity, in these relationships seem apparent. Mothers also reported the father-son relationships as competitive, conflictual and violent.

[Father-Son relationship] Seems to me to be one of always trying to impress each other. (14)

He's doing more of an authoritarian thing with him at the moment and I don't think that's always appropriate I think that's where the stress is coming from in their relationship. (11)

If they refused, he'd give them a bloody good hiding. ... They've got this fear thing of him, so they're that scared that they'll do [what their father wants]. (4) 
Figure 5.4: 12 and 14 Year Old Males' Depictions of the Father-Son Relationship (Source: The Drawing Interpretation Project)
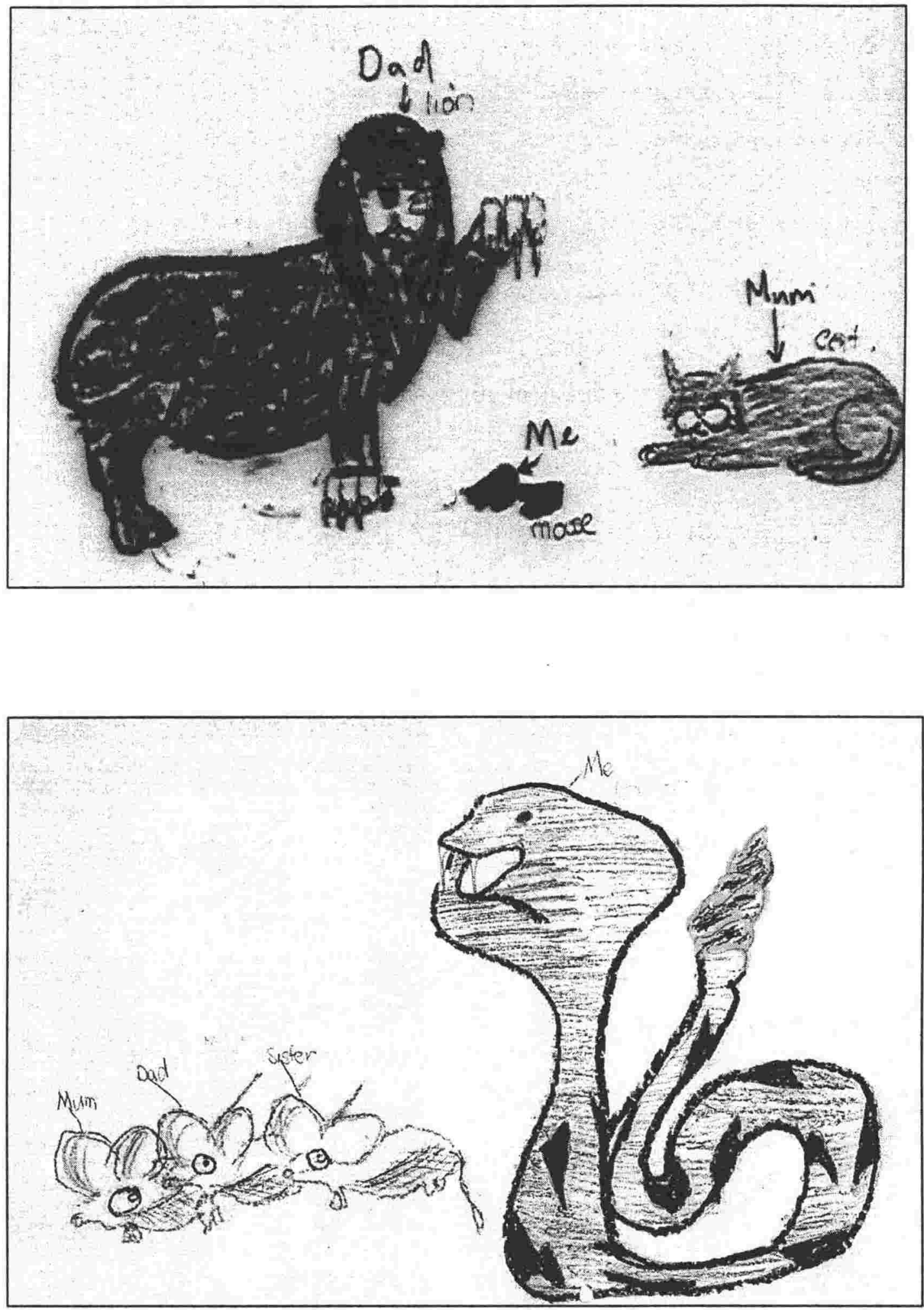
The late Laurie O'Reilly, when he was Commissioner for Children, initiated a project in 1995 called Fathers Who Care: Partners in Parenting. One of the strands of this project, facilitated by researcher Rae Julian, included discussion with members from focus groups organised by gender and ethnicity. The respondents were invited to offer their views on the characteristics of a 'good' father and a 'not okay' father. As with reported comments from the mothers of this study, the qualities of a 'good' father were defined as showing love, giving time and commitment to his children, being fair and consistent, displaying selfawareness and providing a role model. The 'not okay' father was defined as absent, a poor disciplinarian, bullying and dominant, denigrating of children, having few personal values, having low self-esteem and behaving in sexually abusive manners.

As already briefly examined there has been an increasing amount of publicity given to fathering nationally and internationally over the past decade. New Zealand economist and researcher, Paul Callister, recognises the national and international concern about father absence, but says, "in parallel, there has also been a growing interest in creating greater opportunities for positive involved fathering" (1999, p.23). It is this distinction, I believe, that separates those movements that wish to reclaim the centrality of the father to the family, particularly for male children, and those that advocate diverse family structures and equitable co-parenting models.

All groups of mothers; single, partnered, lesbian and heterosexual, talked about the lack of contact their sons had with their fathers.

My husband wasn't around a lot. He was in Real Estate and worked quite long hours. He belonged to Rotary and he was still playing a lot of sport so he really didn't have a lot to do with the children. (8)

He did have reasonable access and he still has, but he chooses not to exercise it. It would be lucky if we see him twice a year. (2)

Ironically for some, several of the fathers became committed to fathering once they found themselves either part or full-time parenting on their own. 
Once we were separated, it was a huge wake-up call ...he became the person to the boys I wanted him to be while we were married. (17)

Some mothers felt that the lack of contact with the father affected the self-esteem of their sons, particularly when it seemed as if he made other children a priority.

It had an impact on his self-image that he wasn't worth as much as the other kids. Every so often there'd be an expensive holiday or something like that but nothing consistent ... He was aware he was treated differently and it was painful for him (10)

Biddulph (1996 \& 1998), Birks (1999), Blankenhorn (1992) and others claim that mothers prevent fathers from having contact with their sons. These mothers report differently. They talk of their efforts to ensure a relationship between the sons and their fathers.

When [father] and I separated I just didn't want my boys to grow up not knowing their father. ... I made sure I went to great lengths that he had the opportunity to visit them. I'd spent years forcing him to be a father just so that the boys would know that they did have a father. (GP 5)

I actually encouraged [contact with their father] because I felt that ... their father had been so absent from their lives they needed him there regardless of what I thought of him as a person or as a role model. (20)

When the boys reached early adolescence, the mothers indicated a further trend. They reported that the fathers' interest in their sons appeared to increase.

As soon as the children became a bit older their father who was very devoted to them read them lots of stories and played [with them]. When they were little just wasn't there for them. (10)

One mother recounted with concern, a conversation her ex-partner had with their son.

[Father to Son], when you turn a certain age [13 or 14 years], I will take you down to the pub. 
and added,

... being a man isn't about going to the pub and getting sloshed, or smoking dope. (2)

In another situation the father of a family had been 'absent' at work, at service clubs or at sporting events. When two of the sons, began to act out in turn, at around fifteen and sixteen years, he became involved with them.

We then sat down as a family and talked about it. ... I thought shit this is great. This is how it should be all the time before it gets to a head. (8)

Likewise, the sons themselves in some cases indicated that they wanted to increase the contact they had with their fathers at this time.

When he was 14 he would still talk to me about things but it was really important for him to spend time with his Dad. ... Also his Dad got a boat, just a little runabout, and they started going fishing together. It was really neat. I welcomed it. (9)

\section{Custody, Access and Related Financial Issues for Mothers Separated From the Sons' Fathers}

Although there were custody and access arrangements that worked, one of the issues that gave separated mothers the most grief was the lack of commitment from fathers to access and custody arrangements with their sons.

Virtually from the time he left ... he has no contact with us. Over the last twelve years the contact has been very, very minimal (3).

The really hard part was when they'd be sort of sitting on the doorstep waiting for him to pick them up then we'd get the phone call that he wasn't coming or sometimes there wasn't the phone call. (14).

This mother also reflected the feelings of several of the other mothers when she reported how the sons' distress was aimed at her, 
They'd get upset and I'd be the only one there to yell and scream at. ... I was the one that was yelled and screamed at all the time. (14)

One mother was so concerned at her son's distress that she took the matter in her own hands.

He couldn't [cope with it] because in fact there wasn't a choice. His father was the one who was always making the choice. So I just said..."okay I'm choosing [son] you need time-out". The certainty really helped. (10)

Reacting to a Shared Parenting Bill devised by ACT MP, Muriel Newmann, reporter, Kim Newth, raised an obvious question. "Should feuding couples" she asked, "be expected to bury their differences and share their kids?" (Sunday Star Times, March, 2000). Needless to say the Bill initiating a diverse range of public responses, from counsellors and psychologists, Family Court lawyers and judges, politicians, academics, men's groups and parents. The answer to the question from the mothers in the project seemed to suggest that there was no one ideal custody/access solution and that a child's time split fifty:fifty between parents (as mandated by the Bill) would not become effective by the simple passing of an act of parliament.

Linked with the lack of commitment of spending time with their sons, some of the fathers reportedly gave the sons large gifts but showed reluctance about offering financial support for the son's upbringing.

I get pissed off because what is one big Christmas present when there is a whole year that has gone by when I might have needed help with buying shoes or clothes that [son] might need. There's none of that kind of support. (2)

One father refused to support his son financially unless it was by, "order of the court (7). Another seemed reluctant to finance a home for his children during access times.

In all those years we'd been separated and divorced, he hasn't bought a bed, ever. Even the time when they were staying with him... there was no bed, they were sleeping in camp beds, sharing settee. (15) 
An article in the Aotearoa New Zealand Dominion newspaper (as reported by Frean \& Swain, July 1998) released figures from the Social Welfare Department in 1998 indicated that 458,000 dependent children in Britain were living with single working mothers who receive no financial contribution from non-resident fathers. Although the intention of the article was the concern by The Child Support Agency and the British Government that the state was required to shoulder the costs, it also indicated the failure of fathers to financially support their children. In response to these figures, Danielle Turney, a researcher from University of London, stated in her key note address to the Child Abuse and Neglect Conference (1998) that "if fathers could not, or would not, be included in solving the problems, the Government needed to provide safety net services to relieve often-impoverished situations" (as reported by Young, September 1998).

\section{Fathers and Parenting Support}

A third set of issues reported by mothers was to do with the lack of personal and parenting support they received from resident or non-resident fathers. Mothers felt as if they took more than their fair share of the parenting support required by the sons.

It was always me that was making pizzas and washing cars. ... It was me that took the boys down to the Yacht Club on Sunday morning, got them all rigged up and waited while they did their yachting. I used to beg him to go. ... The boys need to know that [father] was supportive of them but if he didn't like doing those sort of things he didn't do it (16)

I went to hospital to be with [sick son] because he was still totally breast-fed. [Husband] insisted that my place was at home cooking his tea. ... [He wanted me to] forget the baby in the hospital. [He said] the nurses will look after him and we had a big fight about that. (14)

They also reported the reluctance of the fathers to help out with the sons while the mothers were elsewhere.

I was working about 30 hours a week approximately. ... He wouldn't be around. ... So I had to get baby-sitters. ... He joined lots of groups ... the Council, the Rotary (18) 
Ironically, in this case, it was the father's involvement in community service groups that made him unavailable to care for his children. One father, it was reported, pursued custody of his two teenage sons but seemed not to be interested in claiming the same with his daughter. (The project alludes to the idea that fathers take more interest in their adolescent sons than their daughters, but it was not tested.)

He wasn't [interested in having his daughter to live with him]. ... See it was almost like he didn't want to deal with a teenage daughter whereas it's been something different with the boys. (12)

Further key issues for the participants in their discussion of the fathers are included in Chapter Seven.

\section{MOTHERS TALK ABOUT THE SIGNIFICANCE OF BROTHERS}

The findings of the Drawing Interpretation Project suggested that older brothers seemed to have increased significance for early adolescent males. Mothers' accounts appeared to support this.

They're [brothers] close. They've been close ever since the day [son] was born. Yes, they are influencing each other. (12)

He adores his brother ... lives in his brother's shadow (17)

My oldest son who does the fathering at the moment. Your youngest son is living in that place and it's your oldest son that's mostly... the key adult (10)

Although an exploration of the brother relationship was not included within the parameters of the Interpretive Drawing Project, it would be interesting to follow this issue with further research. 


\section{CHAPTER SUMMARY}

This chapter has addressed the nature of the mother adolescent-son relationships as reported by the mothers. It discussed the mothers' perceptions of their sons' attitudes toward them, and the predominately negative changes that occurred in these attitudes as their sons entered adolescence. Without exception the changes described by these mothers occurred when the sons were between twelve and sixteen years old. The chapter also reports on the concerns that mothers about their relationships with their sons and the strategies they used in enhancing the relationships. One of the major findings of this project was the realisation that the strength, confidence and enhanced self-esteem of the mother contributes positively to her ability to parent her adolescent son and maintain an effective relationship with him. There was no significant pattern linking the nature of the relationship between mother and son and the status of the mother. That is, single and partnered, lesbian and heterosexual mothers reported positive and difficult relationships with their sons.

The mothers also reported on their perceptions of their sons' worlds, including issues about friendships, body image, school and sexuality. An analysis of the discussions in the first area, that of friendships, resulted in a perception that in order for boys to have friends they must be involved in sports and show macho behaviours. The mothers who reported that their sons were loners reported also that they tended not to engage in sport. They stressed the significance of body image to the self-esteem of their sons and the cost of ensuring that they conformed to the standard seemingly set by their peers. The achievement of boys in education, although a major and complex issue, is mentioned only briefly in this thesis. One of the reasons given for the under achievement of boys is the absence of the father. This research challenges that argument, suggesting that it is just another contribution to the fatherlessness agenda.

When the mothers discussed their hopes for their sons they included their desire for their sons to be able to form healthy, positive relationships and beneficial support systems. They also wanted the sons to have their self-esteem intact, to have a strong sense of who they are and to be comfortable with themselves. Their fears and concerns about their sons were numerous, with the foremost issue being 
that of safety. Alcohol and drugs, driving, safe sex, anti-social activity, low selfesteem and suicide were mentioned. The impact of stigmatisation of particularly boys from single-mother households was another possible contributory factors to feelings of alienation and low self-esteem. There were several different reactions from mothers about the impact of separation on their sons with the conclusion that effective access arrangements between both parents contributed most to a positive outcome. 


\section{CHAPTER 6}

\section{THE BOYS' STORY - THE DRAWING PROJECT}

During the interviews a number of the mothers described the attitudinal change of their pre-adolescent sons toward them. The change, they reported, became increasingly negative and diminishing as the boys entered their pubescent years. I was interested to find out whether these feelings stemmed from the need for mothers to come to terms about the normal processes of separation of their sons from them or whether 'the sons' began to perceive their mothers as inferior and insignificant at this stage. I understood that it could be difficult for me to determine the perceptions of young males by interviewing them. I was certain that the results would be influenced by their knowledge that I was one of the subjects of my questions to them. I recognised also that, as they were not the focus of this work, I did not have the scope or resource to gain more than a superficial awareness of their viewpoints.

Drawing-Interpretation seemed to be one way to work with large numbers of young males. By interpreting young males' drawings of their mothers and of themselves in relation to their mothers, and by eliciting representations from them, I was able to gain as comprehensive an understanding as possible within the parameters I had established. The Drawing-Interpretation Project involved the performing of two drawing exercises by one hundred and seventy six male students aged five to seventeen years. The development and administration of the assessment tools for the project are described in Chapter Three. Generalities were elicited from the correlation of drawings within age cohorts and from comparisons drawn between the age cohorts. 


\section{PARTICIPANT PROFILES}

The 176 male students were distributed within the age range as outlined in Figure 6.1.

Figure 0-1: Age Range of Student Participants

\begin{tabular}{|l|l|l|l|l|l|}
\hline $\begin{array}{l}\text { Age of students } \\
\text { in years (incl) }\end{array}$ & $\begin{array}{l}\text { Number } \\
\text { students }\end{array}$ & $\begin{array}{l}\text { Number } \\
\text { Drawings }\end{array}$ & $\begin{array}{l}\text { Age of students } \\
\text { in years }\end{array}$ & $\begin{array}{l}\text { Number } \\
\text { students }\end{array}$ & $\begin{array}{l}\text { Number } \\
\text { Drawings }\end{array}$ \\
\hline Five/six & 13 & 13 & Thirteen & 34 & 68 \\
\hline Seven/eight & 17 & 34 & Fourteen & 15 & 30 \\
\hline Nine/ten & 12 & 24 & Fifteen & 25 & 50 \\
\hline Eleven & 24 & 48 & $\begin{array}{l}\text { Sixteen/ } \\
\text { seventeen }\end{array}$ & 16 & 32 \\
\hline Twelve & 20 & 40 & Total & 176 & 339 \\
\hline
\end{tabular}

Although gender and age were the only two factors used in selecting individual participants, the major socio-economic factors impacting on their lives can best be illustrated by descriptions of the school and geographical contexts.

\section{The Schools}

The students involved in the project came from a primary, intermediate and secondary school in an Aotearoa New Zealand city of around 65,000 people (NZ Census, 1996). These schools have a contributory relationship, with the majority of students from the primary school moving through the intermediate school to the secondary school. Consequently the student participants originate from similar socio-economic and geographical situations, which for the purposes of this project have ensured a contextual consistency between the age cohorts. The school populations are described in Figure 0-1.

\section{Figure 0-2: Ethnicity and Decile Rating of Contributing Schools}

\begin{tabular}{|l|l|l|l|l|l|l|l|}
\hline \multirow{2}{*}{ School } & \multirow{2}{*}{$\begin{array}{c}\text { Age of } \\
\text { Students }\end{array}$} & \multicolumn{5}{c|}{ Ethnicity (percent of total students) } & \multirow{2}{*}{$\begin{array}{c}\text { Decile } \\
\text { Rating }\end{array}$} \\
\cline { 3 - 8 } & & Maori & Pakeha & Pac. Is. & Asian & Other & \\
\hline Primary & $5-11$ & 46 & 46 & 5 & 2 & 1 & 4 \\
\hline Intermediate & $11-13$ & 64 & 33 & 2 & 0 & 1 & 2 \\
\hline Secondary & $13-18$ & 51 & 47 & 1 & 1 & 0 & $2 \mathrm{~F}$ \\
\hline
\end{tabular}


The Decile Rating ${ }^{12}$ for schools in Aotearoa New Zealand ranges from $1-10$ (with 1 being the lowest). As Figure 6.2 indicates the Decile Ratings are low for the intermediate and secondary schools and at a low average for the primary school.

\section{The Geographical Area}

The catchment area for the three schools is made up of rural and urban communities and are profiled by statistics taken from the 1996 New Zealand Census as follows,

- Mean household income less than $\$ 50,000$

- $30-50 \%$ of residents receiving income support

- $10-20 \%$ of household have no motor vehicle

- More than $10 \%$ of households defined as "high occupancy"

- $20-40 \%$ dwellings rented or leased

- Unemployment rate $5-10 \%$

- More than $30 \%$ of population with no formal academic qualification

- More than $30 \%$ of all families are one-parent families

- Up to $20 \%$ of households with no telephone

- NZ Dep96 score of $6-10$ points. $^{3}$ (with $6-8$ being 'above average deprivation' and 9-10 'very high deprivation'

\section{METHODS OF DATA COLLECTION}

Two strategies for enhancing the accuracy and reliability of this project are discussed in Chapter Three. They are, the employment of a configuration of symbols for the interpretation of the drawings and an attention to the

\footnotetext{
${ }^{1}$ The Decile Rating is a funding measure for each school. The Ministry of Education using a random sample of students and linking their socio-economic status against the latest census figures sets the Decile Rating annually.
}

\footnotetext{
${ }^{3}$ The NZDep96 index of deprivation has been developed by the Health Services Research Centre to "measure" relative deprivation in different areas. It combines data from: Level of Income, Income through a means tested benefit, Transport, Living Space, Owned home, Employment, Qualifications and Communication. The NZDep96 average national score was constructed to be 5.5 points.
} 
verbalisations that accompany the drawings. Both these were taken into account during the analysis of the drawings. Each Kinetic-Family-Drawing (K-F-D) and Family-As-Animals-Drawing (F-A-A-D) was paired per participant and analysed using a combination of interpretative techniques illustrated in Appendix 6.1. This analysis included three key processes. The first analysis involved determining how the student had represented the mother and/or father and/or self (and/or any other family member) using the categories 'Dominant', 'Connected', 'Insignificant' and 'Absent. The second analysis involved identifying the specific animals drawn in the F-A-A-D for the mother and/or father and/or self (and/or any other family member). The third analysis involved identifying and commenting on any significant factors that may have been included in each drawing

Notes were taken during the drawing sessions. The notes included recording the questions the participants asked and, as much as was practically possible, the discussions they had amongst themselves. This information was used in the collating of data by the longitudinal focus group and in the analysis of the drawings. For discussion of the findings of the Drawing Interpretation Project the male participant and producer of the drawings is identified as Self. 
Figure 0-3: Kinetic-Family-Drawing (K-F-D) 1

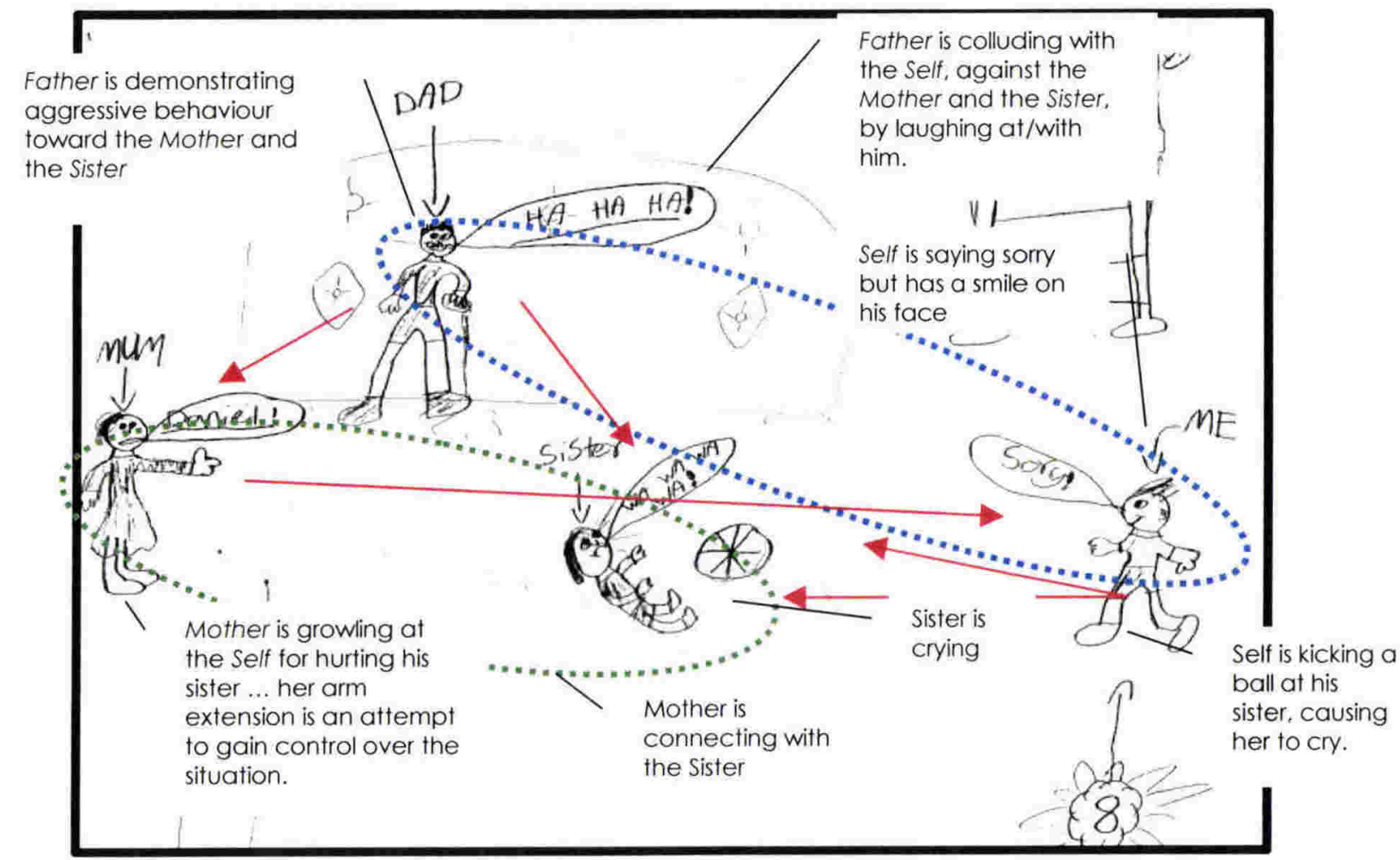

Commentary: This eight-year-old boy is kicking a ball at his Sister. The Sister is crying and the Mother is objecting. The boy's father is laughing at what is happening.

\section{Techniques Used To Analyse the Drawing:}

1. K-F-D Actions: The arrows indicate a movement of energy from one person to another. That is, Self against Sister, Mother against Self, Father against Mother and Sister. The dotted lines indicate a connection between people. That is between Father \& Self and Mother \& Sister.

2. K-F-D Characteristics: Distinguishing features of figures. Note is taken of the Mother's extended arm, Self's extended foot, the pleased/happy expressions on the faces of Father and Self, the angry expression on Mother's face and sad expression on Sister's face.

3. K-F-D Styles- The use of space. Father has been drawn in the dominant position at the top of the page. He is semi-encapsulated by the couch.

4. K-F-D Symbols - Heat, Light and Warmth: A 'sun' symbol is focused toward the Self. This can indicate a range of emotions, for example, anger, power $\&$ control, the need for love.

Analysis Outcomes Significant for this Project: In this drawing Self and Father are connected and dominant. Self is actively aggressive. Father is passively aggressive. The family is segregated by gender. 


\section{Figure 0-4: Kinetic-Family-Drawing (K-F-D) 2}

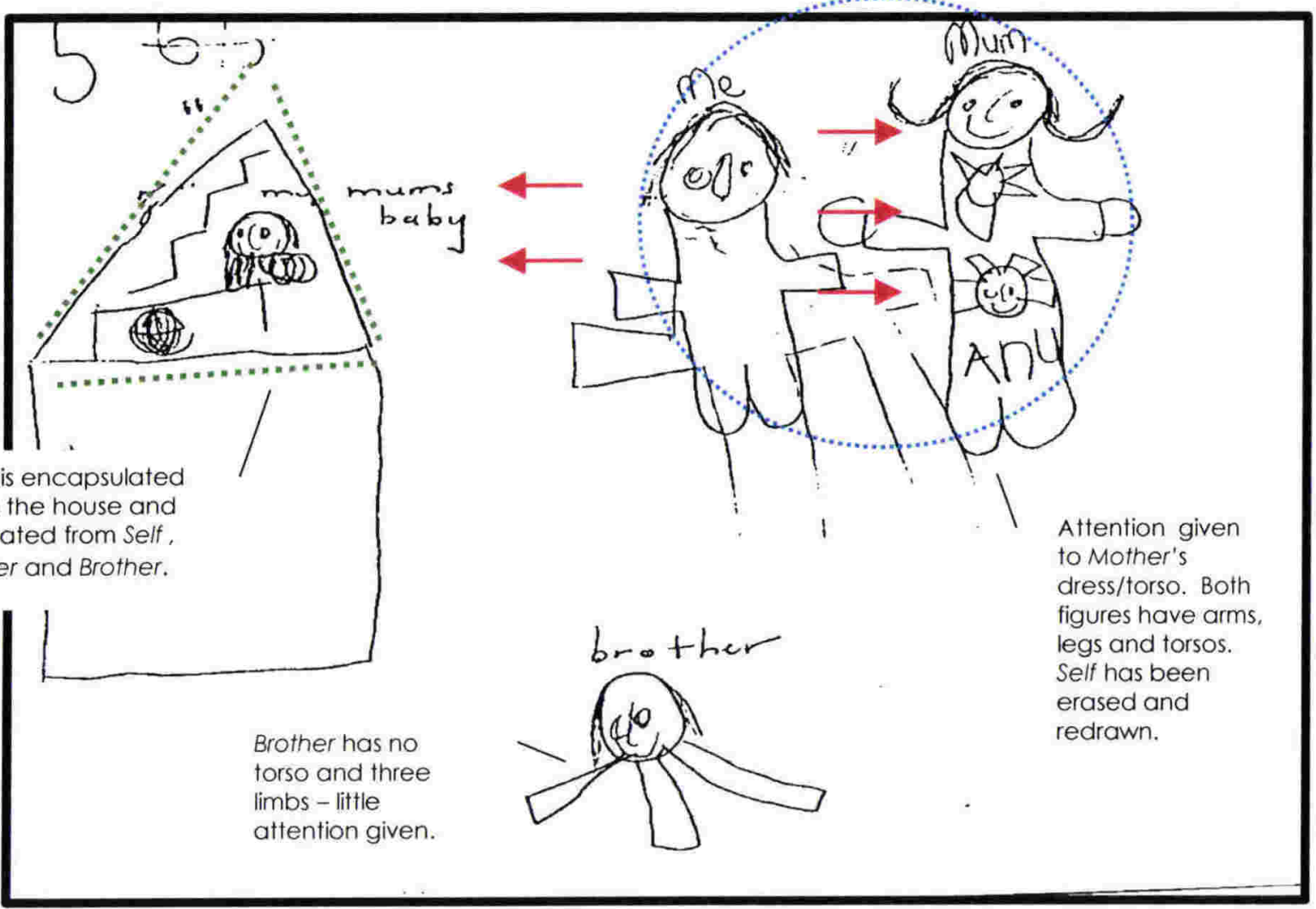

Commentary: This five-year-old boy has placed himself beside his Mother. He has drawn his "Mum's baby" inside the house. His Brother has also been drawn.

\section{Analysis Techniques Used:}

1. K-F-D Actions: The arrows indicate a movement of energy from one person to another. That is, from Self to Mother and Self to Baby. The dotted lines indicate a connection between the Self and Mother.

2. K-F-D Characteristics: Self, Mother and Brother 'hanging' figures. Not stabilised by underlining/structure.

3. K-F-D Styles -The use of space. Baby has been encapsulated inside the house. Self and, Mother are at the top of the page in a dominant position.

4. K-F-D Symbols - Heat, Light and Warmth: Sun' symbols is have been drawn on the Mother's clothes. (Refer previous drawing)

5. Individual H-F-Ds: Detail has been given to Mother's dress, face and hair. Little attention has been given to the brother.

6. Drawing Techniques: Self has been erased and redrawn. Baby has a scribbled/shaded body.

Outcomes Significant for this Project: Self and Mother are connected. Father absent. Brother is insignificant. Self's attention is on the Mother who has been drawn with detail. He has drawn himself between the Mother and the Baby who he has 'locked away' in the house. 


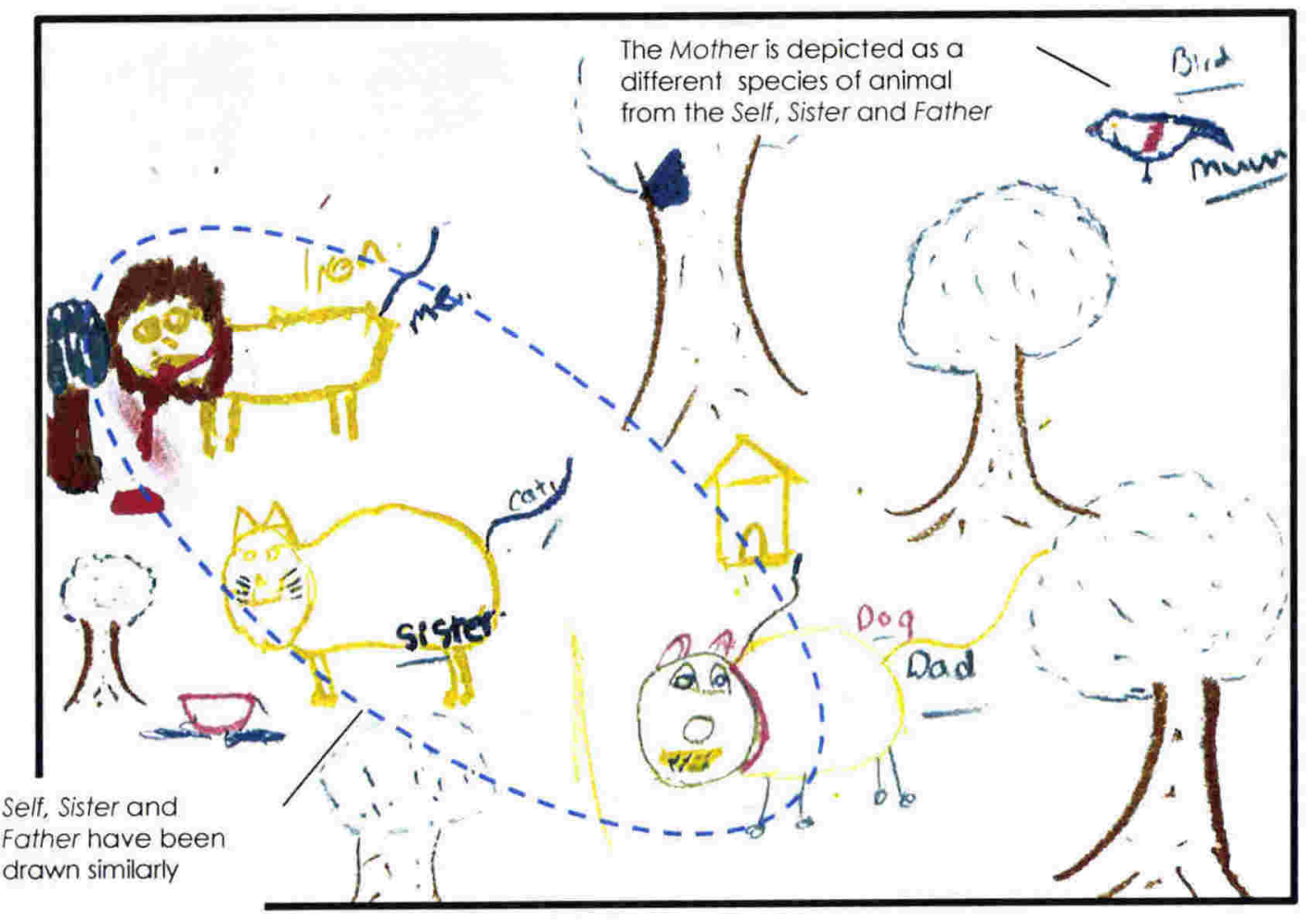

Commentary: This fifteen year old has drawn himself as a lion with blood coming from his mouth. His Sister is a feeding cat. His Father is a dog tied to his kennel and the Mother is a bird.

\section{Analysis Techniques Used:}

1. K-F-D Characteristics: Self, Sister and Father have been drawn in similar poses, facing the same direction, with similar stances and appendages. The Self has been drawn with blood dripping from his mouth. The Mother, although drawn as a bird in the sky, has no wings.

2. Drawing Techniques: Three of the animals - lion, cat and dog - have been drawn with the same basic colour.

3. K-F-D Styles-The use of space Self and Mother have been drawn at the top of the picture. However the nature, size and characteristics of the Self indicate dominance.

4. $K-F-D$ Symbols: There is an extensive use of the tree symbolising strength and sexual prowess. The tree connected to Self is the only one that has been has been coloured boldly.

5. Family As Animals: The use of animal types, stances and colour is significant.

Outcomes Significant for this Project: Self, Father and Sister are connected. Self is dominant, powerful and aggressive. Mother is insignificant and vulnerable and disconnected from the rest of the family. 


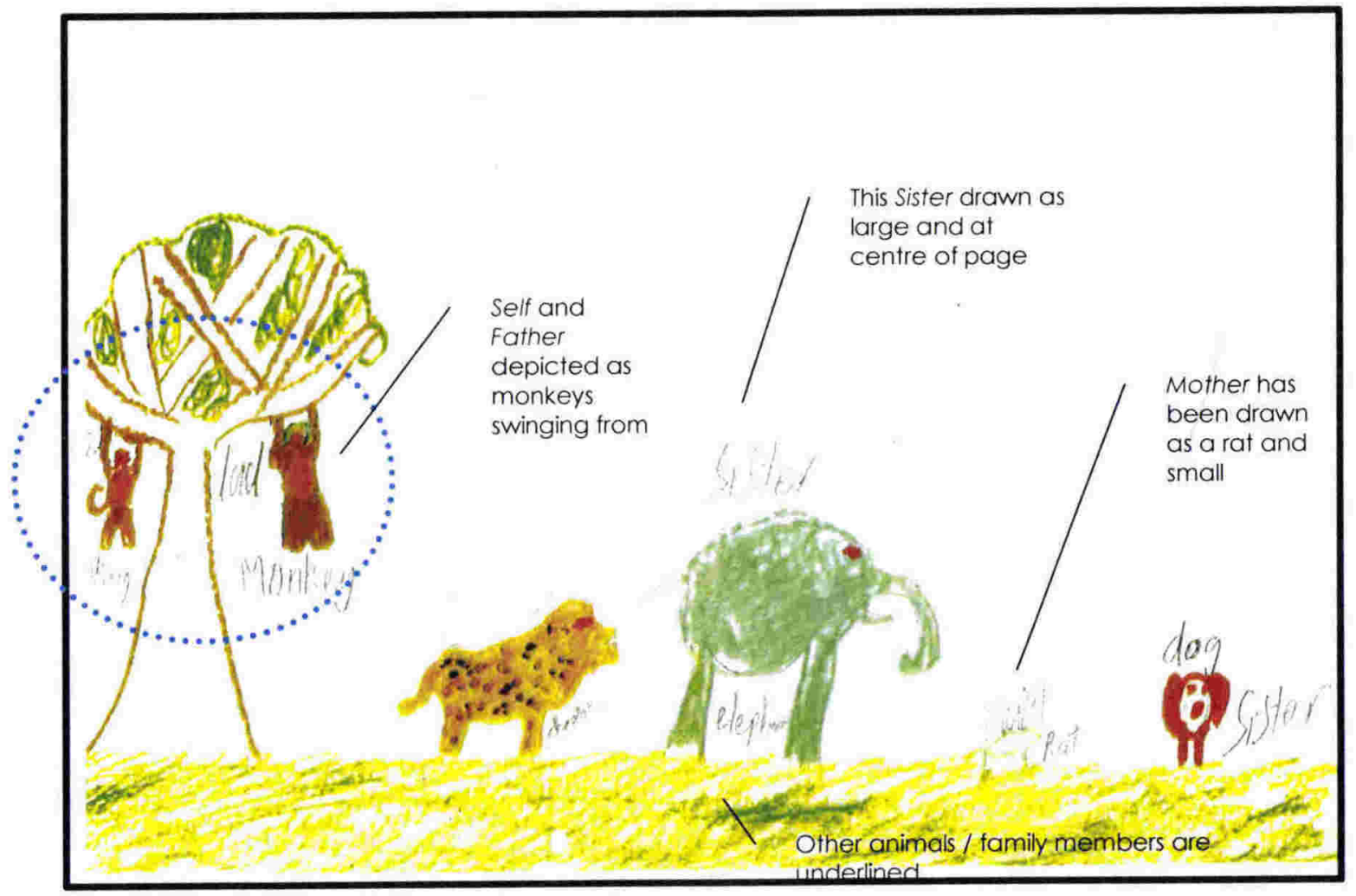

Commentary: This eleven year old has drawn himself as a monkey hanging from the branches of a tree. He has drawn his Father likewise. His Brother (cheetah), two Sisters (elephant \& dog), and Mother (rat), are standing on the ground. Mother is the smallest animal and Sister the largest.

\section{Analysis Techniques Used:}

1. $K-F-D$ Characteristics: Self and Father have been drawn as monkeys in similar poses and separated from the rest of the family. Other family members are underlined by the grass and connected.

2. Drawing Techniques: The two monkeys have been drawn with the same colours and poses.

3. K-F-D Styles-The use of space: The Sister has been drawn as the largest and is in the centre of the picture. The Self and the Father are elevated and hanging onto a tree. The Mother is drawn as the smallest and the only animal who is not coloured in.

4. Family As Animals: The use of animal types and colour is significant.

Outcomes Significant for this Project: Self and Father are connected. Mother is insignificant, vulnerable and undesirable. Dominance cannot be concluded. (The matching K-F-D does not clarify the drawer's intent, both Self and Sister appear dominant.) 


\section{ANALYSIS ONE: DOMINANT, CONNECTED, INSIGNIFICANT AND INVISIBLE}

\section{Categories of Analysis One}

The categories in this first analysis have been defined as follows,

Dominant: The figure that is drawn in such a way that it overshadows the other figures (Drawings 1, 2 \& 5)

Connected: The figure drawn most closely associated to Self. (Drawings 3 - 7)

Insignificant: The figure portrayed with least importance. (Drawing 7)

Absent: The figure (mother/father or self) not present in the drawing. (Drawing 3)

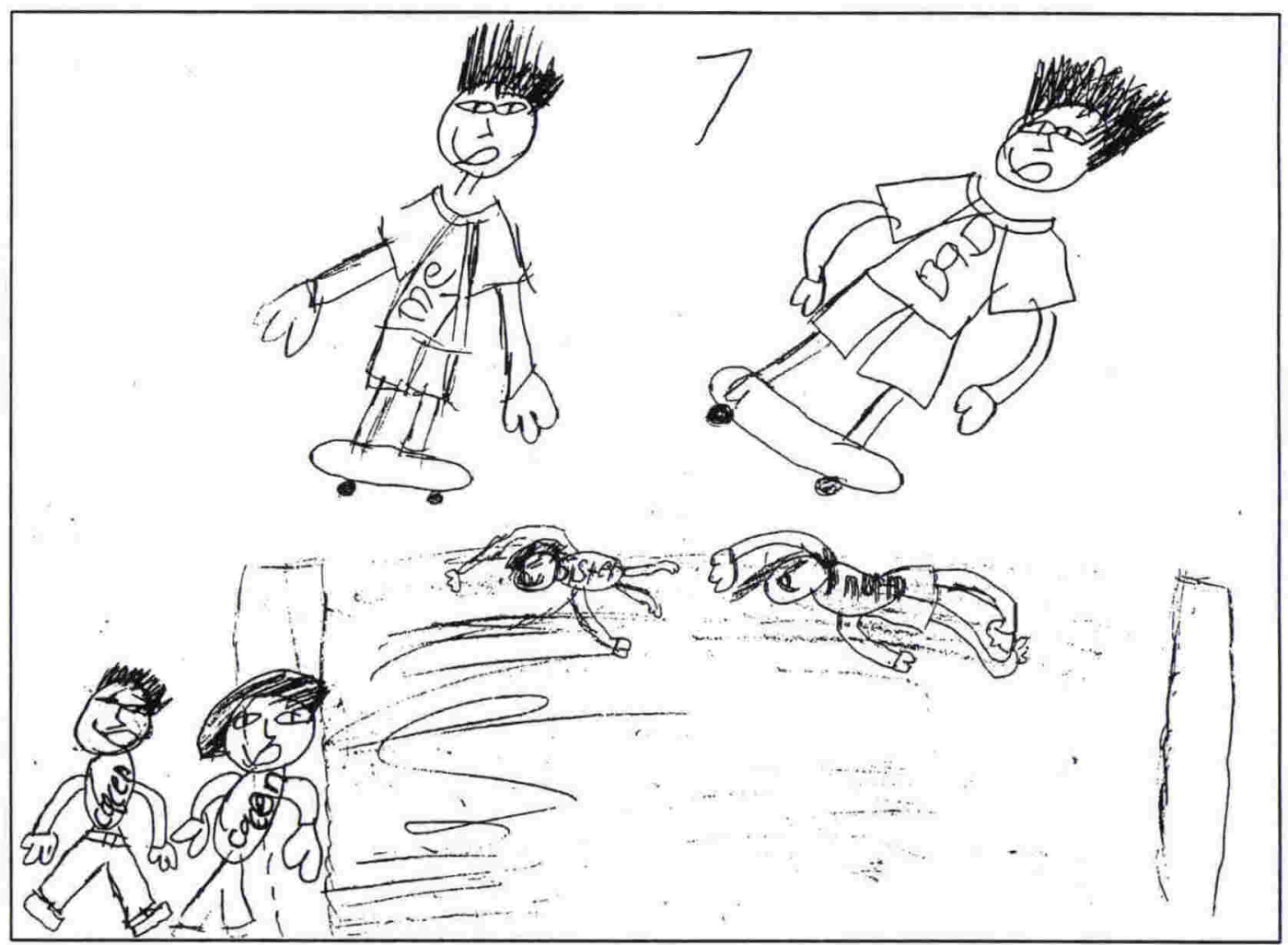

Drawing 1: (K-F-D, 7 yrs) Self and Father dominant over Mother and Sister. Self and Father connected. 


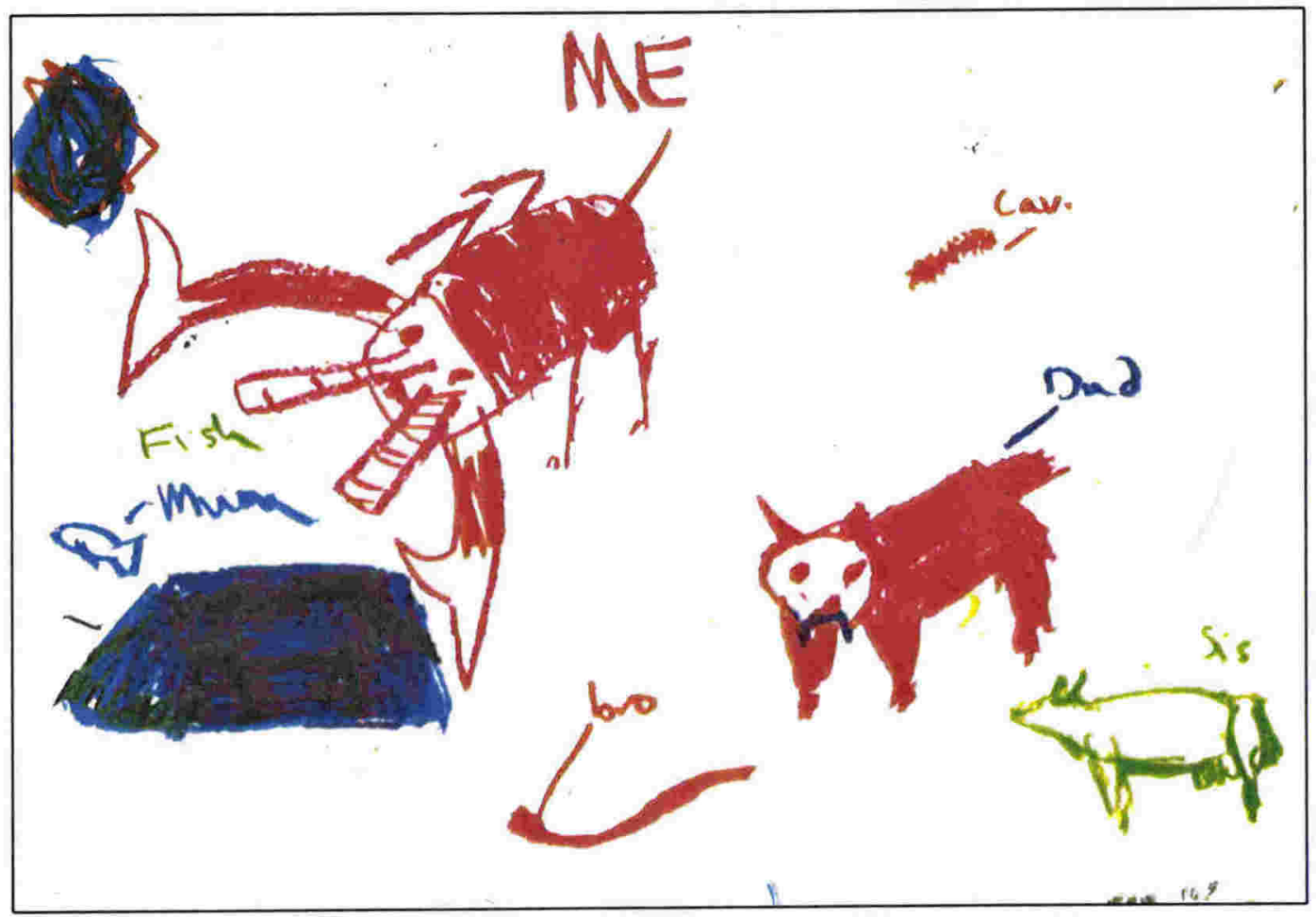

Drawing 2: (F-A-A-D, 14 yrs) Self dominant over Mother. Self connected with Father.

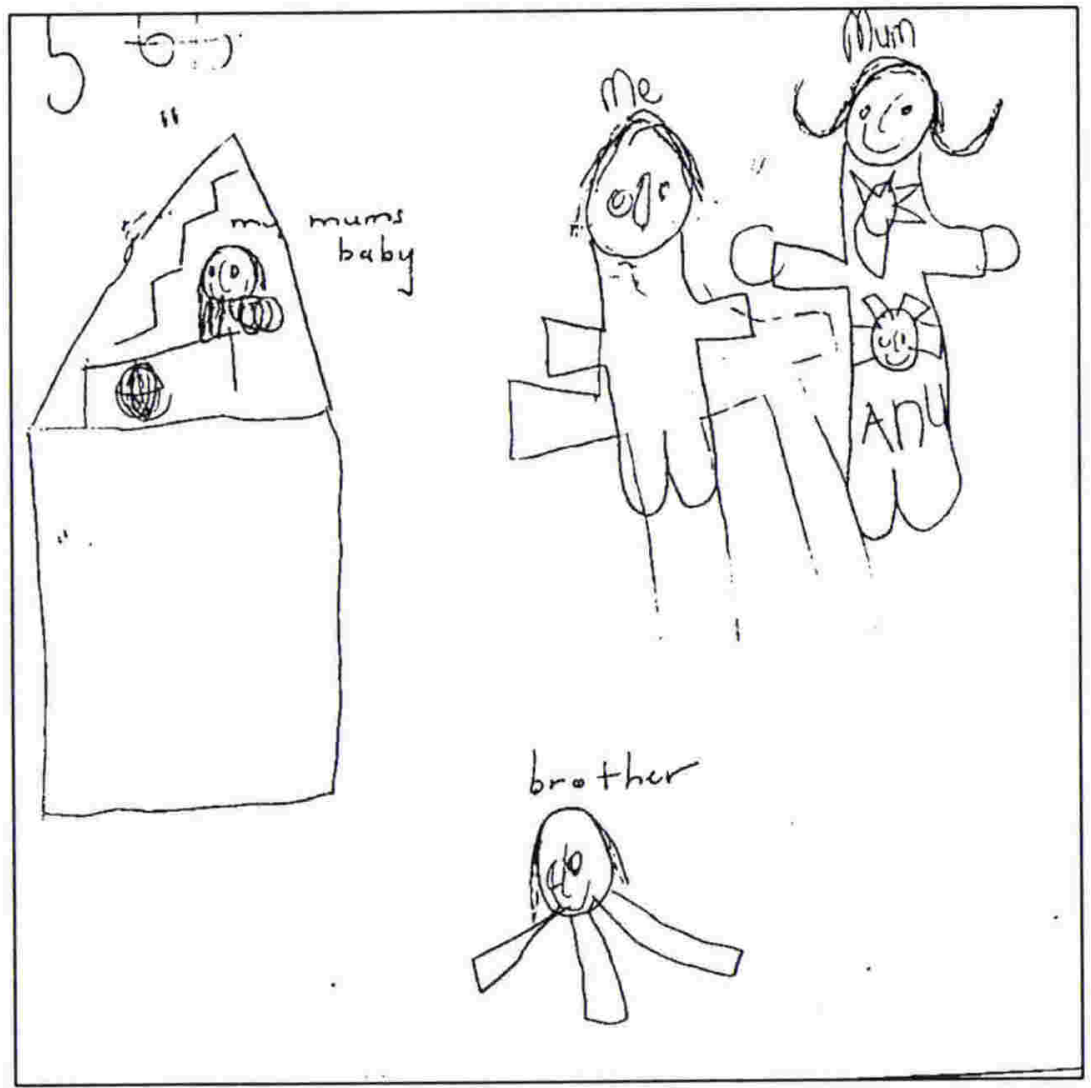

Drawing 3: (K-F-D, 5 yrs) Self and Mother connected. Father Absent. 
Chapter 6: The Boys' Story

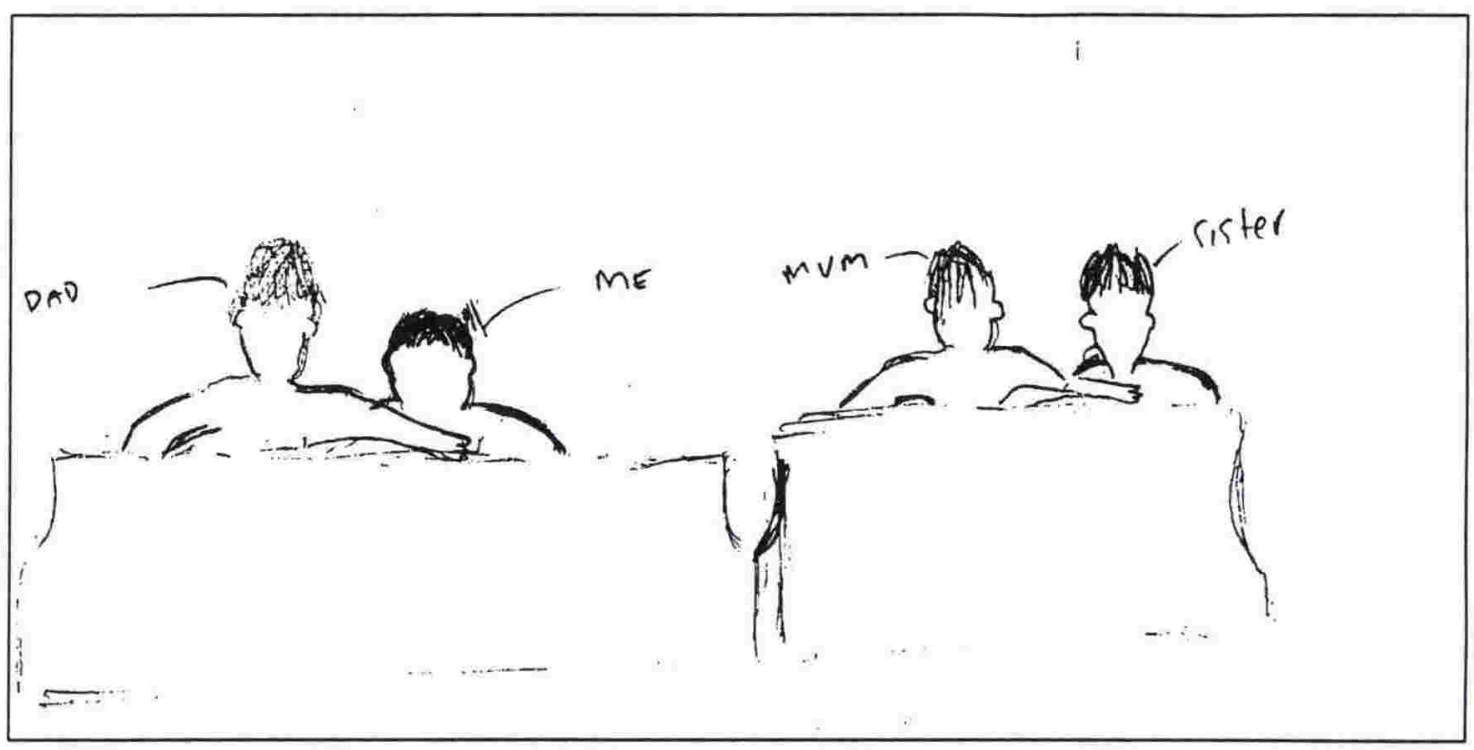

Drawing 4: (K-F-D, 13 yrs) Self and Father connected. Mother and Sister connected.

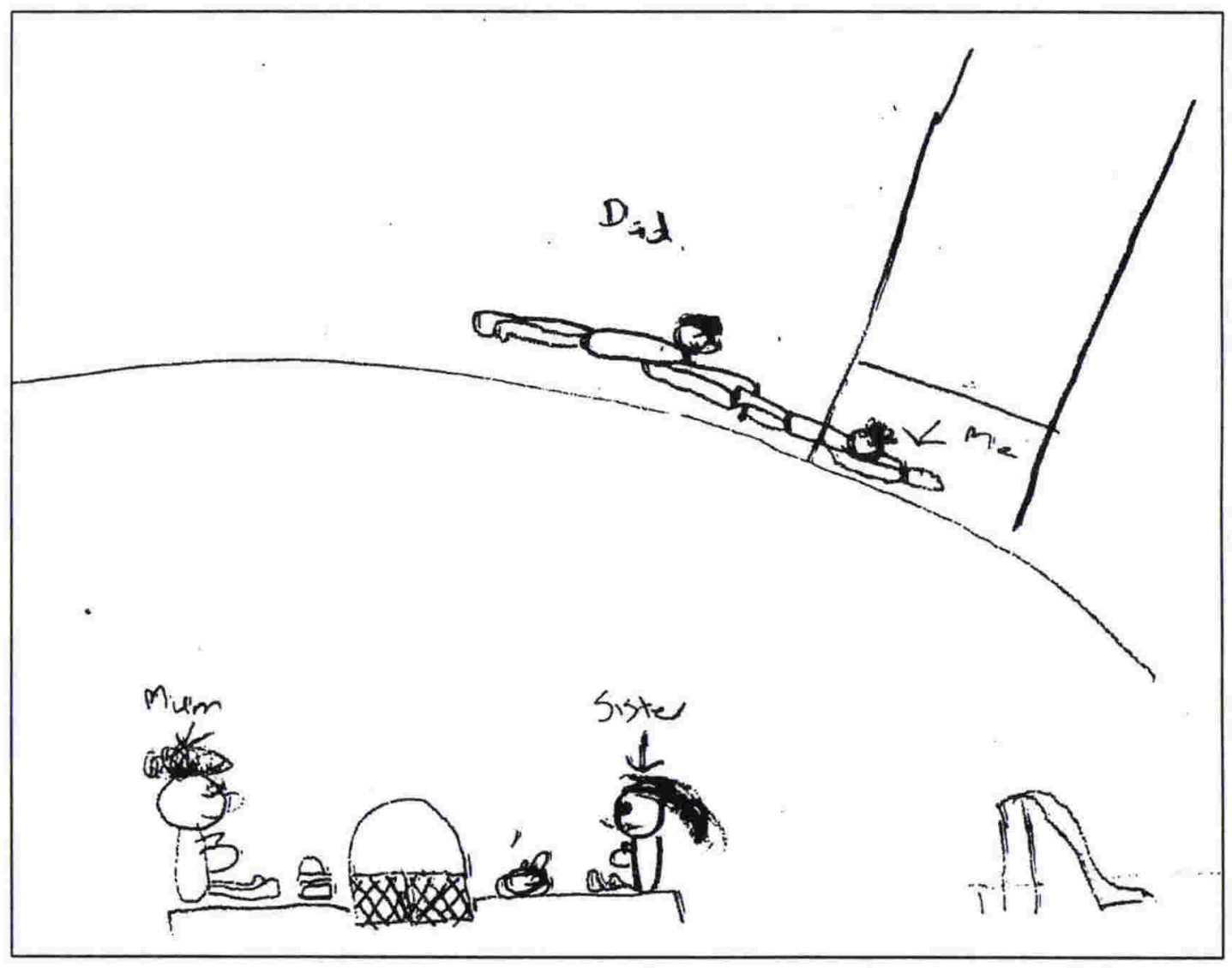

Drawing 5: (K-F-D, 13 yrs) Self and Father connected. Mother and Sister connected.

261 

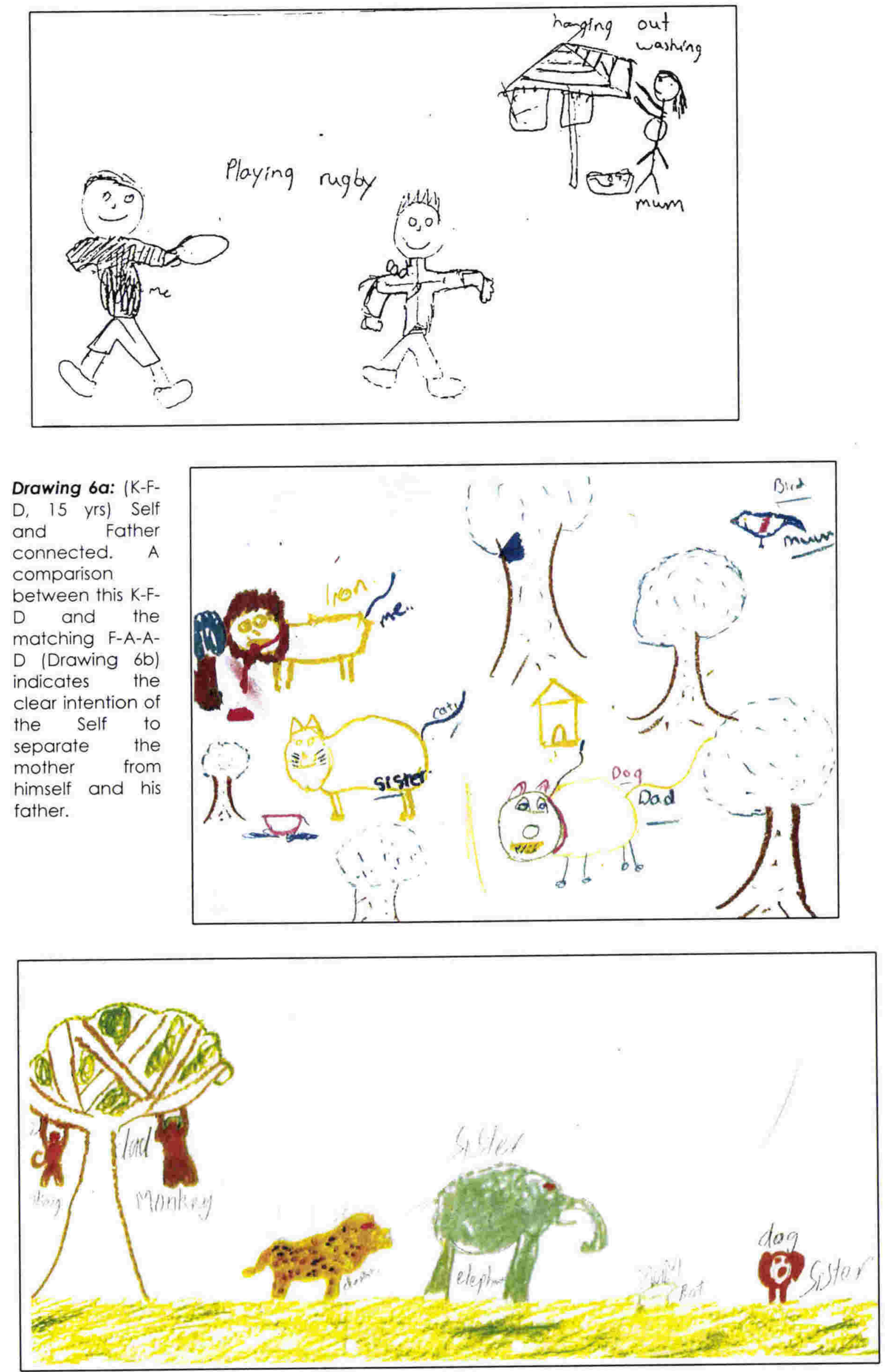

Drawing 7: (F-A-A-D, 11 yrs) Self and Father connected. Mother insignificant. 


\section{Findings of Analysis One}

Figure 7 (Graphs 1 to 4 ) describe the status portrayed by the participants of their mother, father and of themselves. According to human development theorist Helen Bee, experts on adolescence such as Brofenbrenner (1979), Brooks-Gunn (1988), Kaplan, (1988), Keniston (1970), Lerner (1987 \& 1993), and Simon (1996) argue for the division of the period of adolescence into two sub-categories. "Some label these as adolescence and youth others as early and late adolescence (1998, p.328). Adolescence as a construct is discussed further in Chapter One. For ease of discussion in this research project and in order to match the age-groups with the three stages of schooling from which the subjects were drawn I have used the following terms to represent the following age categories: Childhood from five to nine years Pubescence from ten to thirteen years and Adolescence from fourteen to seventeen years. - all ages are inclusive.

\section{Figure 0-7: Analysis One (Graphs 1 - 4) Shown in percentages.}

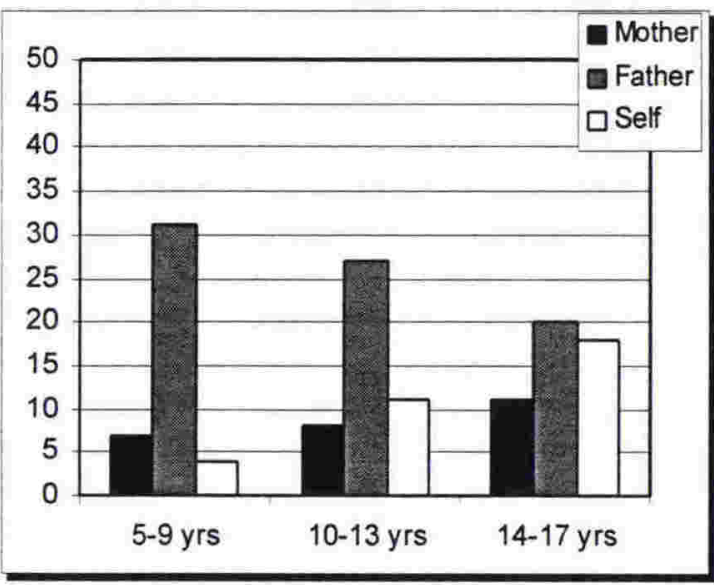

Graph 1: Dominance

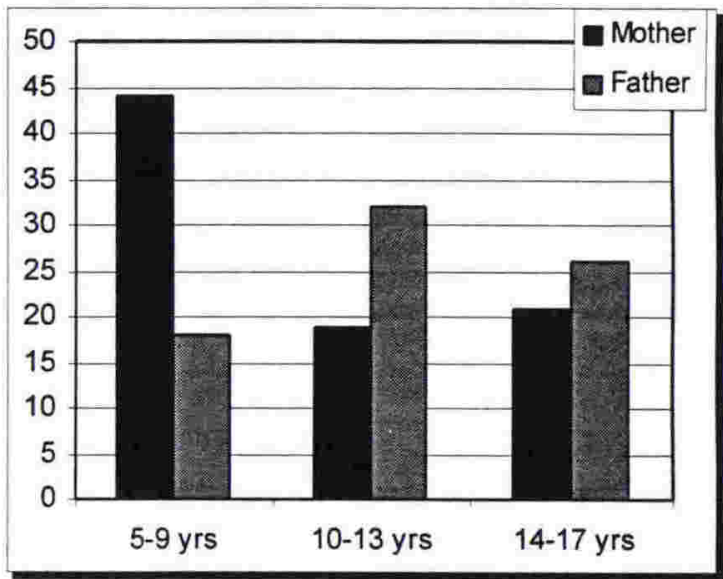

Graph 2: Connection

\section{Graph 1: Dominance}

It appears that, although the Father is more dominant at all ages, his dominance decreases from childhood to adolescent periods. Conversely, although the dominance of the Mother is consistently less than that of the Father, it increases from the childhood to adolescent periods. The Self is portrayed as less dominant than both parents in childhood, however becomes more so than the Mother at pubescence and the difference between them increasing at adolescence. 


\section{Graph 2: Connection}

The connection between the Self and the Mother is highest in childhood, and more than double that between the Self and the Father. This changes drastically in the pubescent period with the connection between the Self and the Father almost double than that between the Self and the Mother. In the adolescent period the difference decreases but the connection with the Father is still greater.

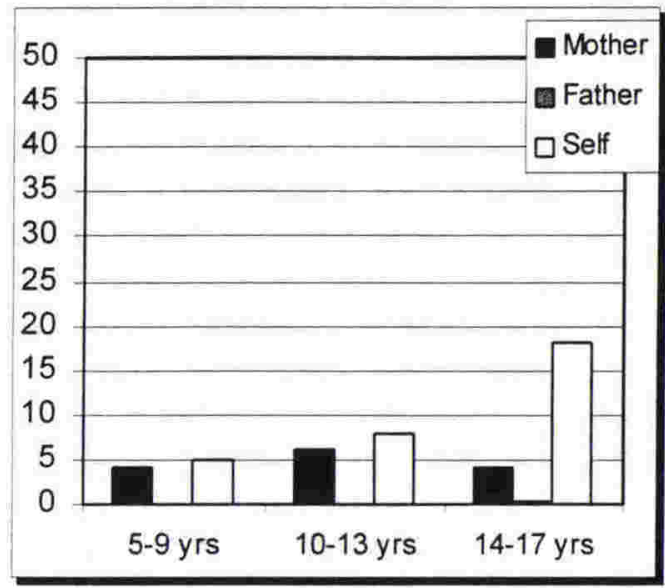

Graph 3: Insignificance

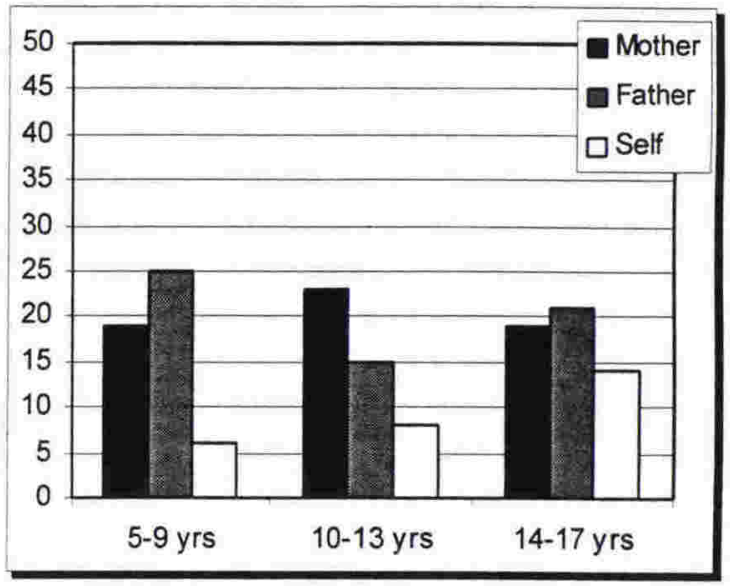

Graph 4: Absence

\section{Graph 3: Insignificance}

The insignificance of the Mother is highest at the pubescence period while that of the Father appears once only in the adolescent period. The insignificance of the Self increases considerably through the age periods.

\section{Graph 4: Absence}

The absence of the Mother is also highest at pubescence, while the Father is less absent (most present) at the same time. The Father is noticeable by his absence in the childhood period. The absence of the Self increases through the age periods.

These findings are an analysis of the categories of dominance, connection, insignificance, and absence as they relate to three age periods, childhood, pubescence and adolescence. At this stage the following generalisations can be made.

The Self and the Mother: The childhood period is portrayed as the time when the mother is more dominant than the son and when he has the highest level of 
connection with her. Her insignificance at this stage is relatively low. The dominance of the Mother increases slightly at pubescence but the connection the son has with her drops by more than half. The Mother is most insignificant and most absent at pubescence

The Self and the Father: The Father is portrayed as more dominant than any other person at all age periods. He is most absent during the childhood period and least absent at pubescence. The connection between the Self and the Father in the childhood period is less than half of that between the Self and the Mother, and is the lowest of the three periods. The connection between the Self and the Father increases dramatically in the pubescent period. This is also the period that the absence of the Father drops to the lowest point. At adolescence the connection between the Self and the Father is still more than that between the Self and the Mother, however the dominance of the Father is only slightly more than that of the Self. This is the first time also that there is any indication of the insignificance of the Father, albeit small.

The Self: The participants drew themselves as increasing in dominance from the childhood to adolescent periods. Although their dominance is portrayed as more than that of the Mother for the first time at pubescence, the gap between them at adolescence is widened. A similar, but much more consequential trend is indicated by the participants as they describe their perceived insignificance. That is they see themselves as more insignificant than the Mother and the Father at all periods, with a dramatic increase at adolescence. Their absence, although less than both parents, also increases through the age periods.

\section{ANALYSIS TWO: FAMILY-AS-ANIMALS-DRAWINGS}

The symbolic meanings of animals used in this analysis have been developed by Family Psychologists, Byron and Carol Norton, (1988). With the utilisation of these symbolic meanings it has also been necessary to take into consideration the variations of meaning from drawer to drawer. For example, a thirteen year old drew his Mother as an ant and wrote the following comment alongside the drawing; "My Mum represents an ant because she carries more than her own weight and she works hard". The same participant depicted his Father as a lion 
and wrote, "my Dad is a lion because he is strong and fearless" (13:134). If the two animals, an ant and a lion, were to be compared, it could be assumed that the Mother was depicted as relatively insignificant. Although I believe this comparison has merit, the drawer's written explanation offers a different nuance to the interpretation. (Note: The key observations in the third analysis take into account specific explanations included with each drawing). Likewise, another thirteen year old described his 'spider' Mother as a "good mother [with] many eyes, always looking out for me, keeps web clean, provides food". Beside his pig stepfather, he wrote, "eats a lot [and is] always happy" and beside the drawing of himself, a bear, he wrote "kind and gentle if left alone, needs some space" (13:20).

In order to minimise the potential for misinterpretation of the drawer's intent with the F-A-A-Ds, the analyses have been refined by comparing each one with the matching K-F-Ds and by referring to the field notes taken during each session.

\section{Categories of Analysis Two}

From the results of the F-A-A-Ds I have organised the animals drawn by the participants into the following categories:

Powerfulness/Strength/Aggression: $\quad$ alligator, bull, shark, gorilla, lion/lioness, wolf, rhinoceros, dragon, whale, wildboar, alien, crab, crayfish, dinosaur, eagle, crab

Vulnerability/Timidity/Powerlessness: fish, mouse, baby animals (kitten, lamb), rabbit, chicken, cat

Undesirability/Awkwardness: rat, pig, bat, warthog, hippo, elephant, ant, duck, dragon, frog, cockroach, whale, opossum, fly

\footnotetext{
${ }^{4}$ The code refers to the age of the drawer and the participant number in that year. '13:13' denotes a 13 year old boy who is number 13 of the 13 year olds. '13:20' denotes a 13 year old boy is number 20 drawing of the 13 year olds.
} 
Industriousness:

Awareness of Sexuality:

Sociability:

Other:

\section{Findings of Analysis Two}

Figure 6.8 (Graphs 5 to 14) demonstrates the animal groupings portrayed by participants of their Mother, Father and of themselves. The first set of graphs, 5 to 10 , portray each of the above categories by age of the male. These graphs are grouped in order from the animal category that has the largest number to the animal category that has the smallest number. The second set of graphs, 11 to 14 , portray each age of the male and include all animal categories. The age categories used in the first analysis, childhood, pubescence, and adolescence, are repeated with these graphs. bee, dog, horse, elephant, spider/ant, beaver, squirrel

snake, eel, 'platterpussy'

dolphin, seal, sheep

butterfly, mermaid, angel, swallow, unicorn, deer. 
Figure 0-8: Analysis Two (Graphs 5 - 10) Shown in Percentages

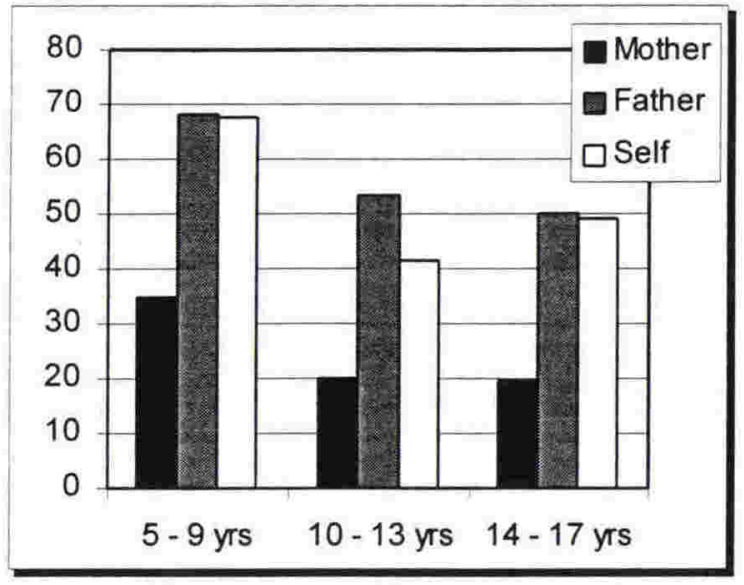

Graph 5: Powerfulness/Strength

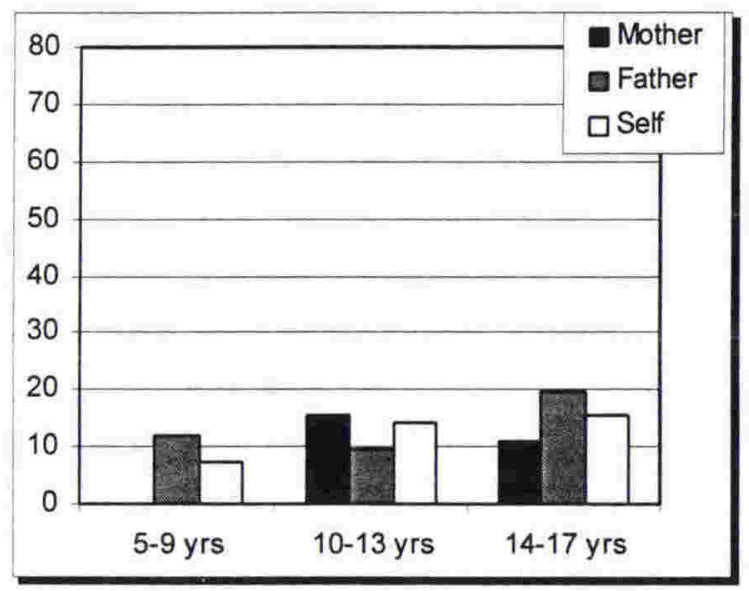

Graph 7: Undesirability

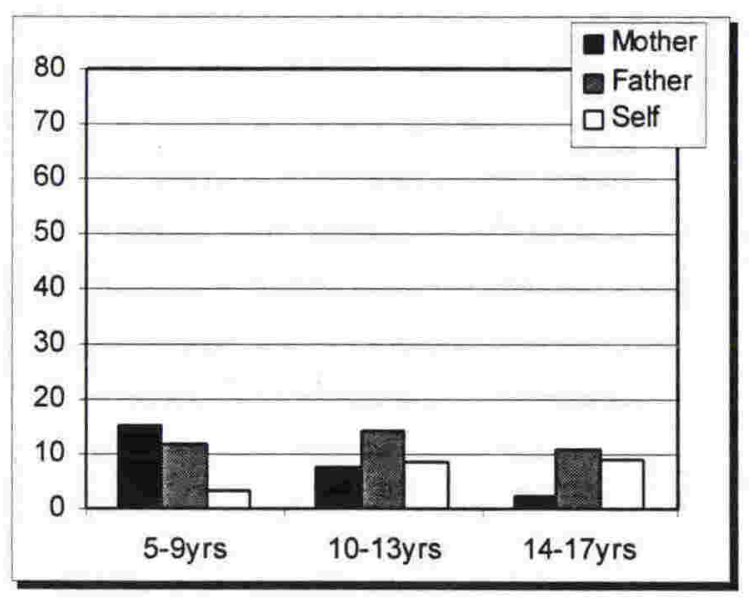

Graph 9: Attention to Sexuality

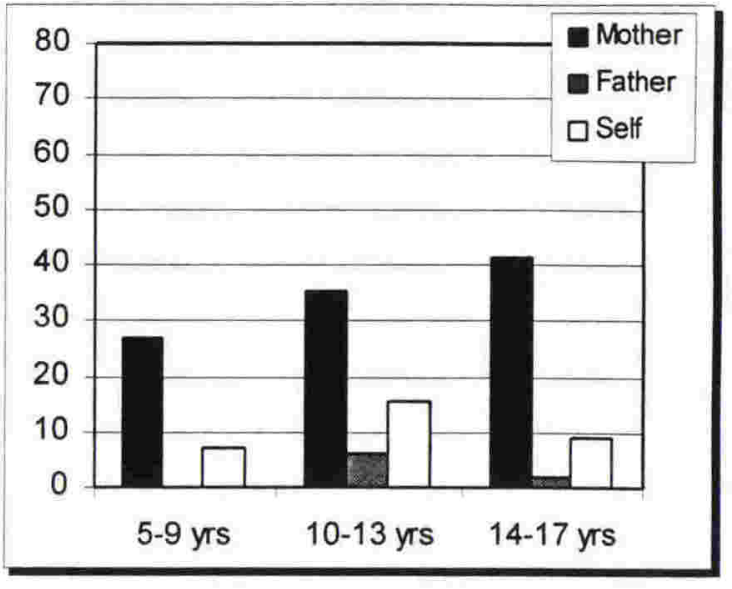

Graph 6: Vulnerability/Timidity

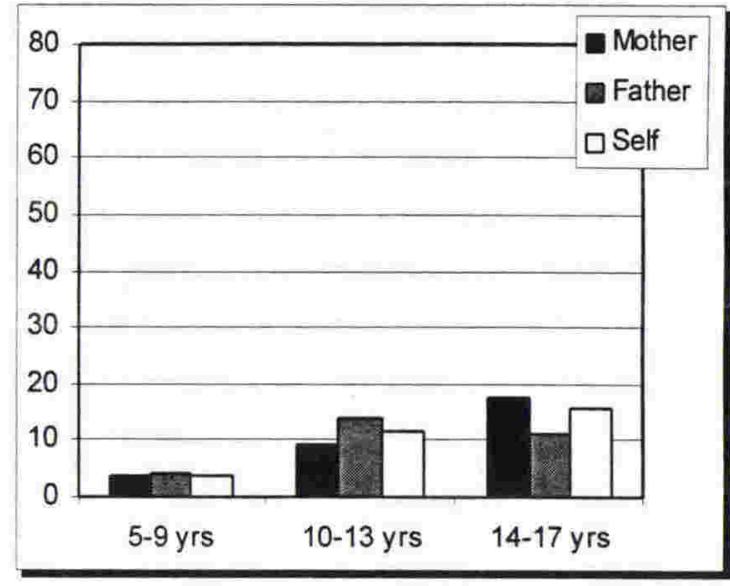

Graph 8: Industriousness

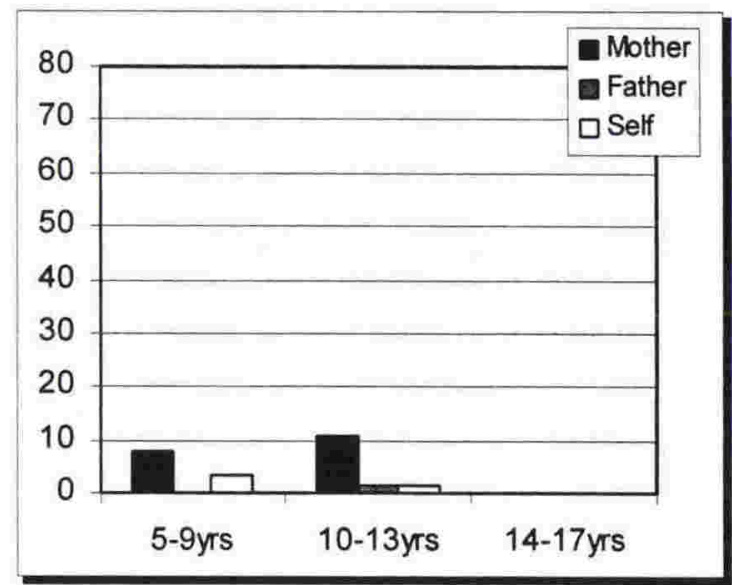

Graph 10: Sociability 


\section{Graph 5: Powerfulness/Strength/Aggression}

At all stages the Father is portrayed as most powerful. However he is most powerful when Self is in the childhood period and is least powerful when the Self is in the adolescent period. There is little difference in aggression between the Father and the Self at the childhood and adolescent periods, but a difference is shown between them at the pubescent period. This is also the period where the Self is portrayed as least powerful. At all stages the Mother is portrayed as the least powerful and her powerfulness decreases as the Self moves from childhood to adolescence.

\section{Graph 6: Vulnerability/Timidity/Powerlessness}

At all stages the Mother is portrayed as most vulnerable and timid and this increases through each age period. The Father does not appear vulnerable and timid at childhood and appears less than ten percent so at both other stages. Although the Self is also portrayed as less than ten percent vulnerable and timid in the childhood and adolescent stages he is most vulnerable at the pubescent age.

\section{Graph 7: Undesirability/Awkwardness}

In this graph the Father is depicted as most undesirable at adolescence and least so at pubescence. In comparison the Mother appears as most undesirable at pubescence, not at all during the childhood stage and less than half that of the Father at adolescence. From childhood to adolescence the Self has depicted himself as increasingly undesirable.

\section{Graph 8: Industriousness}

There is a steady increase in industriousness from childhood to adolescence for the Mother and the Self. The Father's industriousness peaks at pubescence, and is marginally more than the Mother and Self at childhood. At pubescence the Father is portrayed as nearly five percent more than the mother and three percent more then self. At adolescence the Mother is depicted as most industrious, the Self a second and the Father least.

\section{Graph 9: Attention to/Awareness of Sexuality}

Although a relatively small percentage of figures were included in this category, the Mother and Father are predominately depicted as 'sexual' at the childhood stage and decreasingly so through to adolescence. The reverse is so for the Self as 
it appears that he pays increasing attention to his sexuality as he moves through the stages from childhood to adolescence. At pubescence and adolescence the attention to the sexuality of both parents is similar. At childhood more attention is given to the sexuality of the Mother than that of the Father.

\section{Graph 10: Sociability}

The smallest number of figures was portrayed in the category, 'sociability. Hence the percentages in this graph are relatively insignificant. Comparatively however, the Mother appears as the most sociable during the childhood and pubescent stages, the Father appearing once only during the pubescent stage. As with the Mother, the Self is depicted as a little sociable during the childhood and more so during the pubescence stage. No figures appear in the adolescent period.

The following graphs (11-14) give an indication of the most predominant characteristics of the mother, father and self at each of the age periods. They do not need separate explanation but are useful in that they order the data in a manner that accentuates the differences between each of the age categories and demonstrates the areas depicted most commonly. Areas to specifically note are as follows,

At all ages: The Father and Self are the most powerful and the Mother is the most vulnerable.

At Childhood: The Mother is more powerful than she is vulnerable. The Father and Self are more powerful than the Mother and equally as powerful as each other.

At Pubescence and Adolescence: The Father and the Self are depicted as the most powerful. The Mother is more vulnerable than she is powerful at both stages but increasingly so at adolescence. The undesirability characteristic is also accentuated for the Father at adolescence. It also increases for the Self at pubescence and adolescence. 


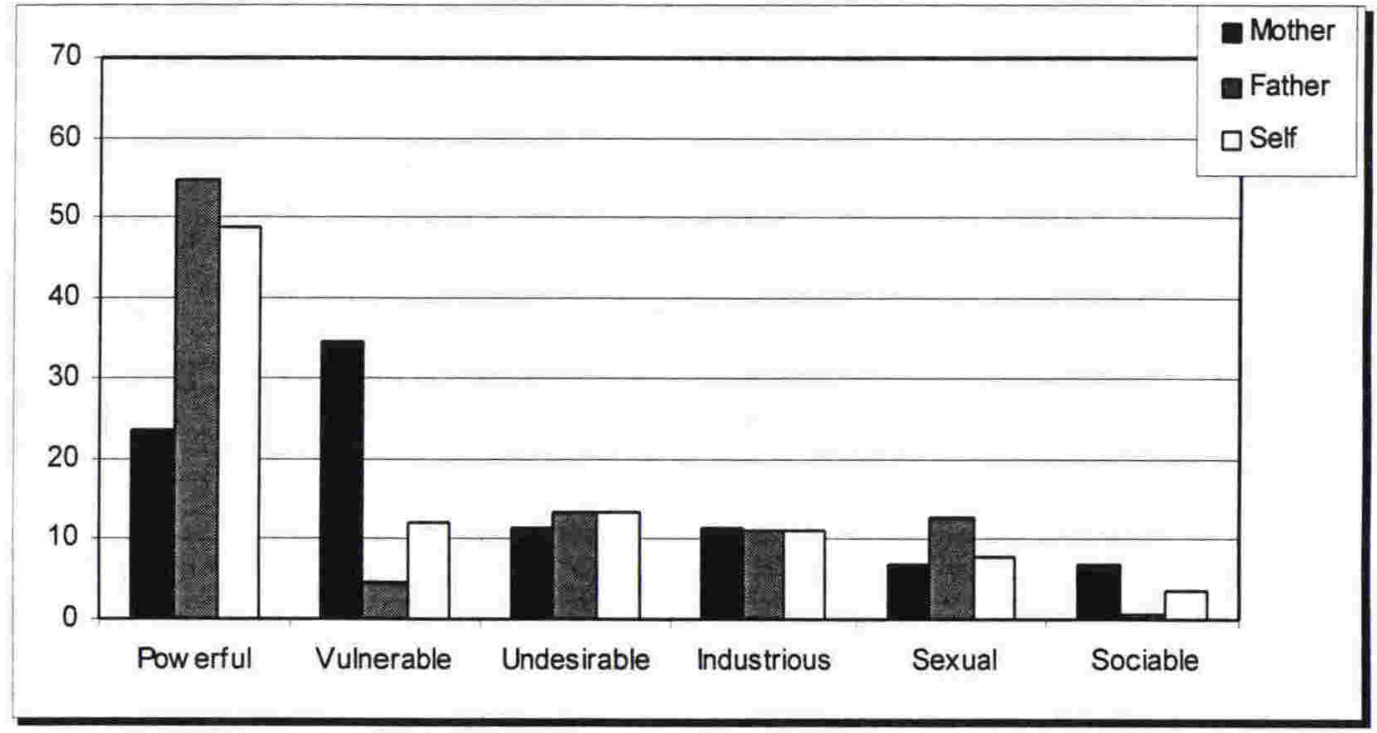

Graph 11: Mother, Father and Self at all ages

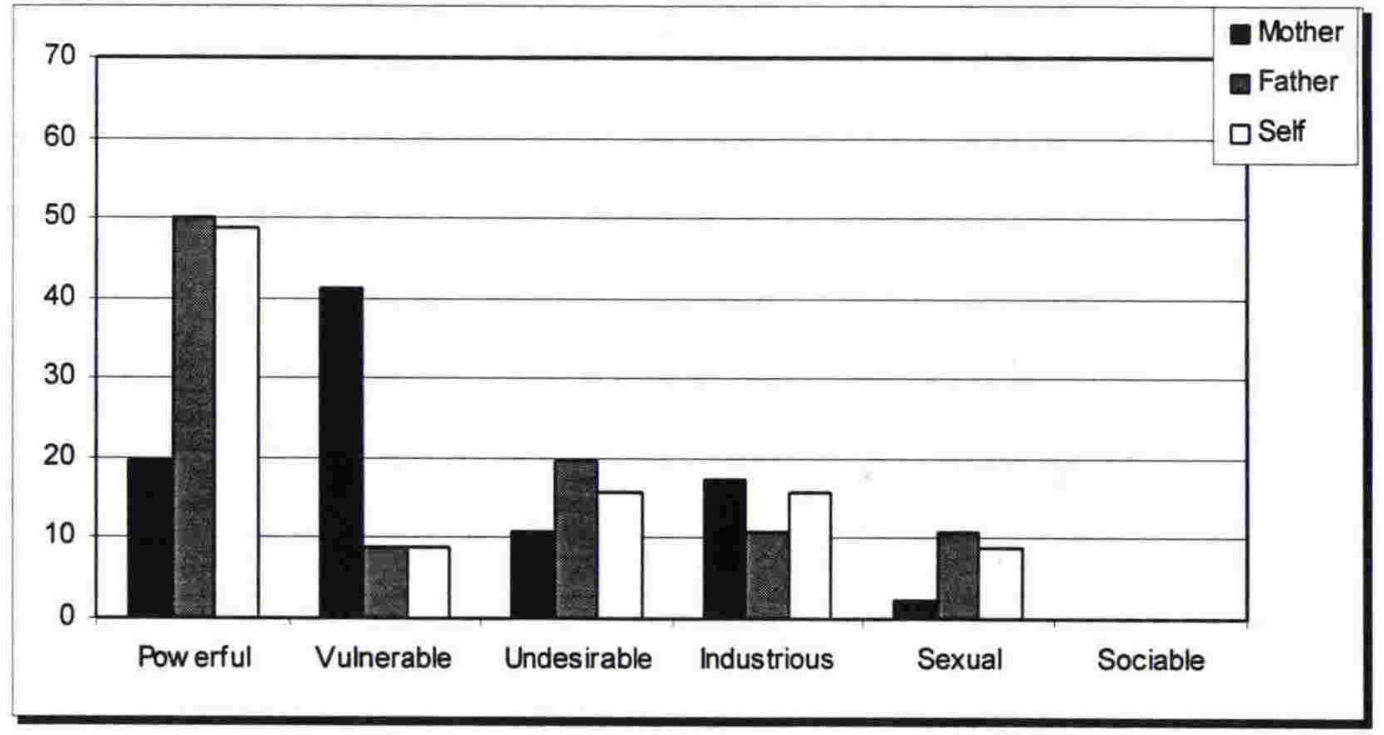

Graph 12: Mother, Father and Self at Childhood 


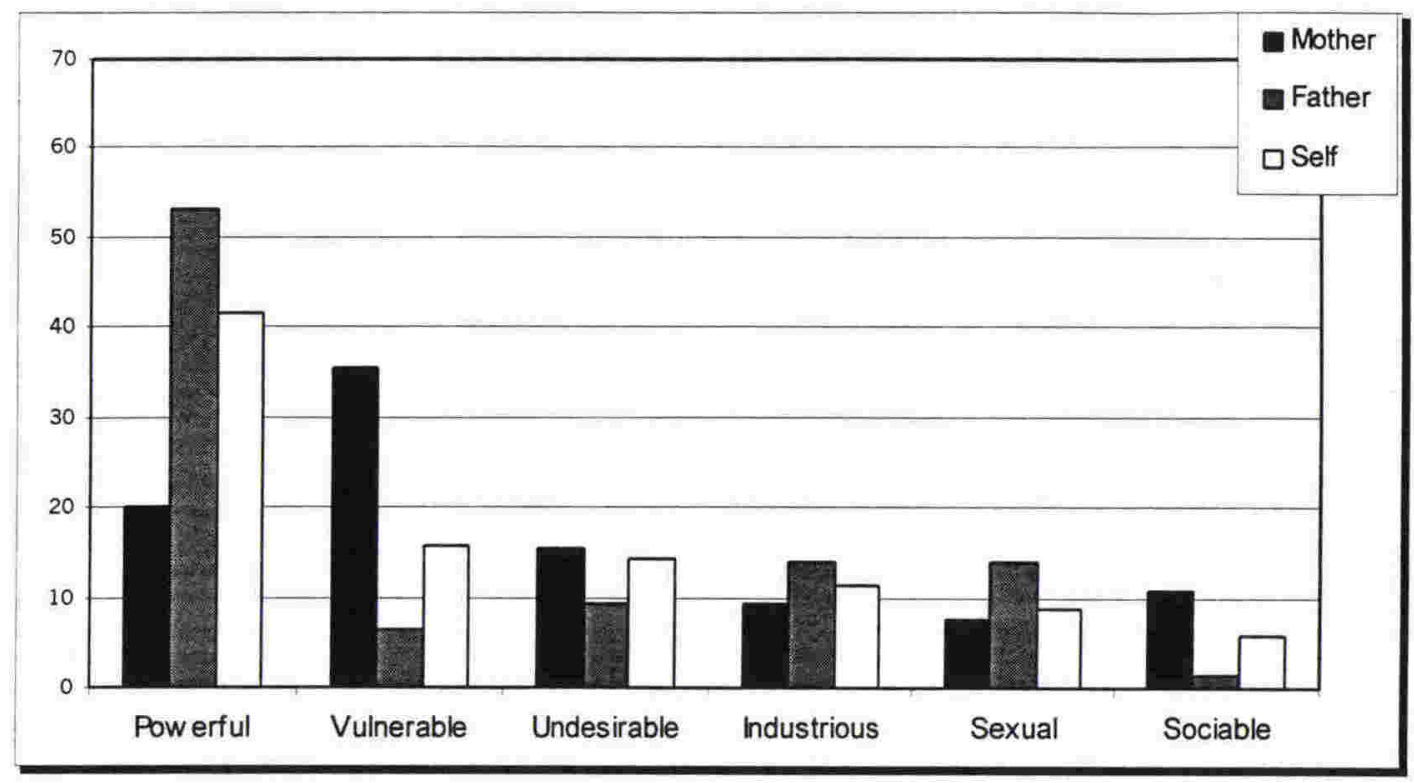

Graph 13: Mother, Father and Self at Pubescence

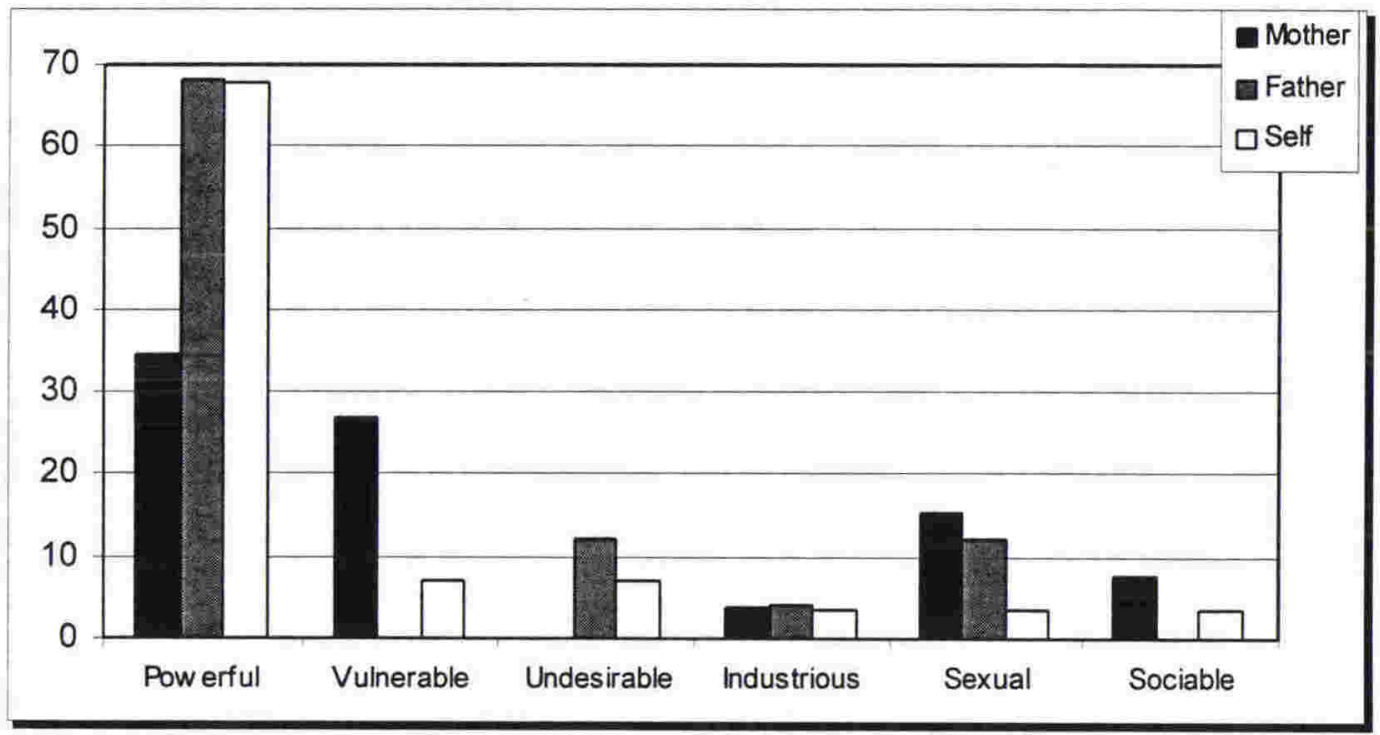

Graph 14: Mother, Father and Self at Adolescence

As stated these findings are an analysis of the categories of $\mathrm{p}^{\text {owerfulness, }}$ vulnerability, undesirability, industriousness, awareness of sexuality and sociability as they relate to three age periods, childhood, pubescence and adolescence. At this stage the following generalisations can be made.

Of the one hundred and thirty two animal drawings of the Mother, she is represented in de-escalating order as shown in Graph 15. When the Self is in the childhood period the Mother is portrayed as least vulnerable and most powerful. At this stage the Self is also most aware of her sexuality. When the Self is in the pubescent period the Mother is portrayed as most undesirable of the age periods 
and also as the most sociable (although these numbers are relatively small). When the Self is in the adolescent period the Mother is portrayed as the most vulnerable, the most industrious and the least powerful.

Of the one hundred and thirty five animal drawings of the father, he is represented in de-escalating order as shown in Graph 16. When the Self is in the adolescent

FIGURE 6.10: Predominant Characteristic of the Mother, Father and Self (Graphs 15 - 17)

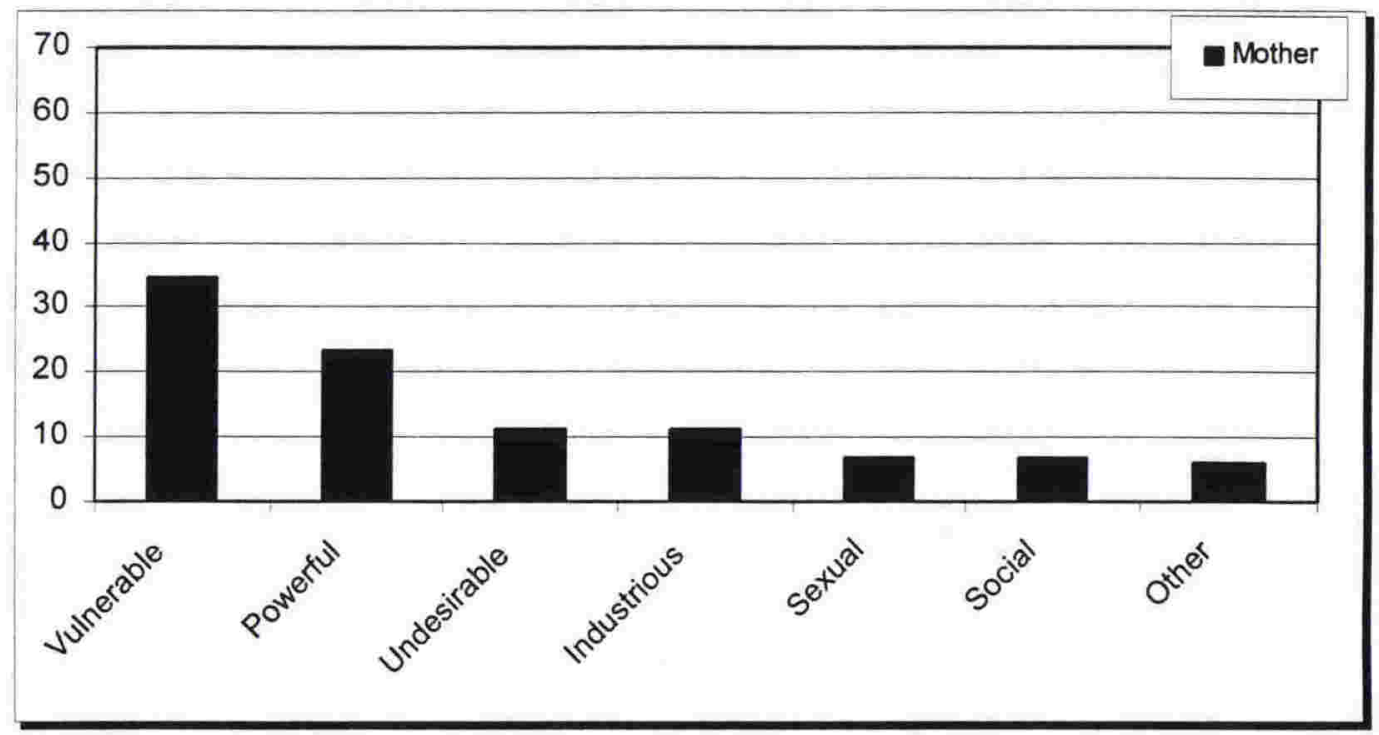

Graph 15: Portrayal of the Mother

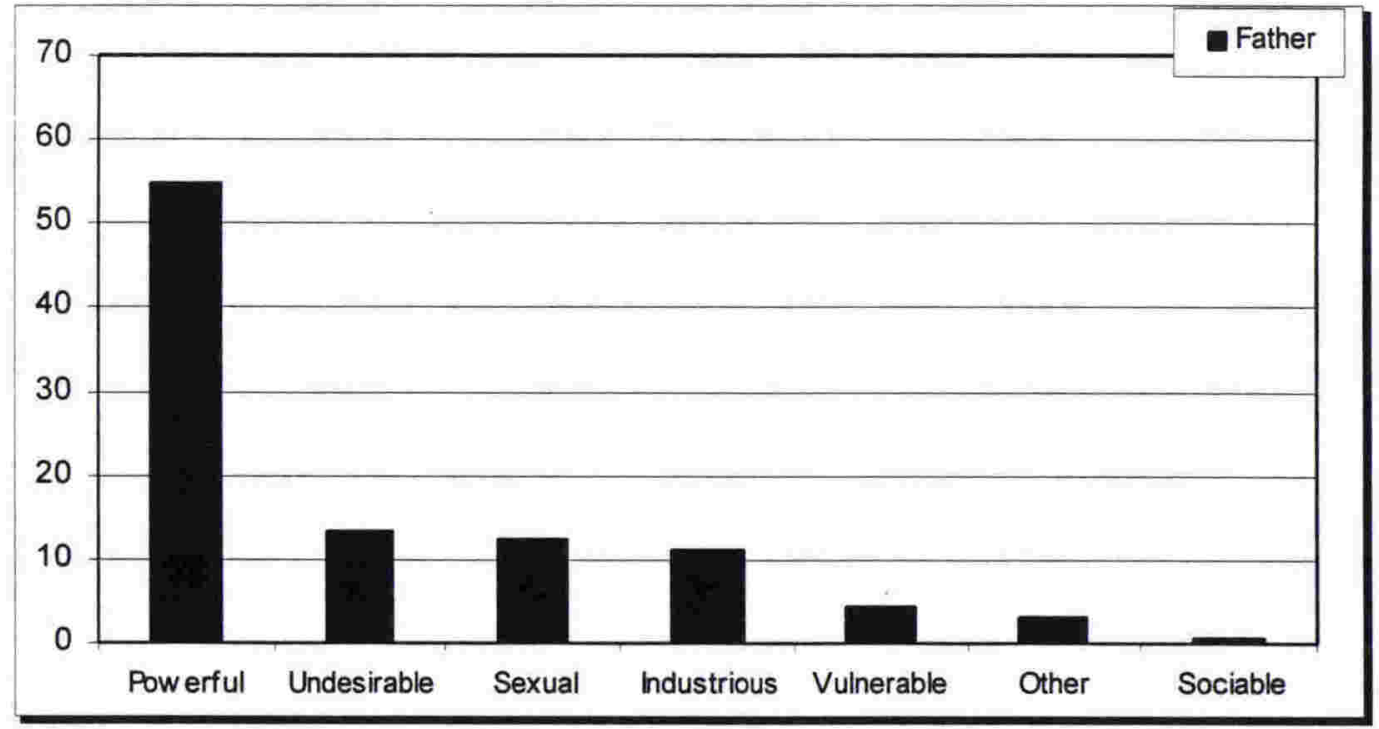

Graph 16: Portrayal of the Father

period the Father is portrayed as the most powerful and the least industrious. At this stage the Self is most aware of his Father's sexuality and does not depict him as vulnerable or sociable. The Father is described as least undesirable, most 
industrious and most sociable when the Self is in the pubescent period but at the adolescent period he is least powerful and most undesirable.

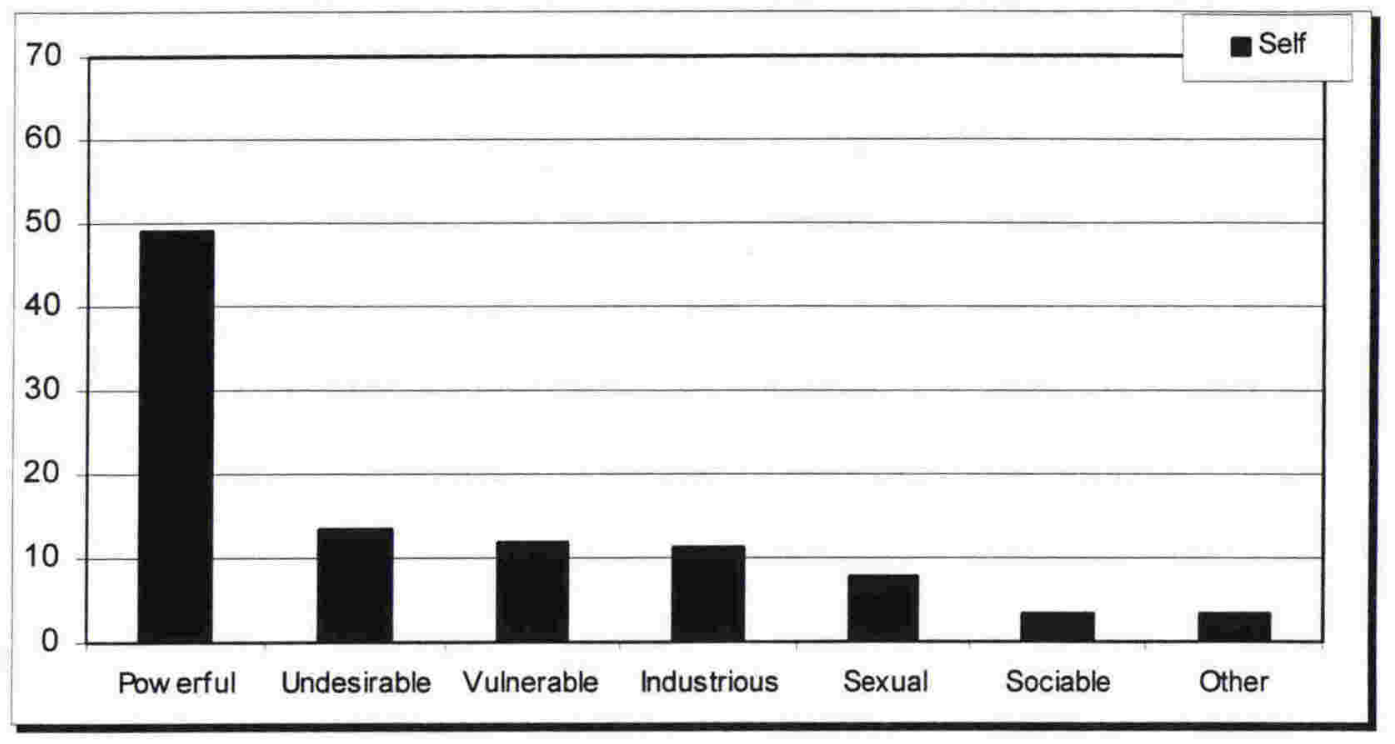

Graph 17: Portrayal of the Self

Of the one hundred and forty five animal drawings, the Self is represented in deescalating order as shown in Graph 17. At childhood the Self portrays himself as the most powerful, the least industrious and the least undesirable. At this stage he is also least aware of his own sexuality. At pubescence he depicts himself as the least powerful, the most vulnerable and the most sociable. At adolescence he sees himself as the most undesirable and most industrious. There is insignificant difference in his awareness of his own sexuality between pubescence and adolescence, both of which are more than twice that indicated at childhood.

\section{ANALYSIS THREE: COMMENTARIES ON KINETIC-FAMILY AND FAMILY-AS-ANIMALS DRAWINGS}

The third level of analysis was undertaken by using the techniques outlined in Appendix 6.1 to make brief commentaries on each drawing. For the purposes of this project I have specifically noted those commentaries that will contribute to further comprehension of the overall topic, and which offer clarification to the first two analyses. 


\section{Themes From Drawing Commentaries}

The themes most commonly depicted by the drawings covered areas such as; gender separation within the family, stereotyping of roles and activities within the family, the importance of the brother to the pubescent male and his portrayed aggression of the brother, the denigration and insignificance but also the aggression of the Self and the dysfunction of family groups. From early age the participants portray a separation between genders within the family, although it more commonly appears during the pubescent and adolescent years. Drawings 1 , $2,4,5,6 \& 7$ on previous pages illustrate some ways this has been represented. Others have included content of activity with mother and sisters one side and father and self/brothers other, use of position and proximity (Drawing 6), animal type and colour and absence of any female member of the family (Drawing 9) particularly in pubescence (refer Graph 4).

In a number of circumstances the genders are valued inequitably. That is the males are shown as dominant as shown in Drawings 10a and 10b or successful, aggressive and conspiring against females as shown in Drawings 1, 2 and 5 .

Although separateness was depicted from the early years, incidences of the stereotyping of roles within the family didn't appear until the participants were 12 years old. Examples included the females (predominately the mother) involved in household activities (Drawings 7 and 11), males depicted as active and women as passive (Drawing 4), males watching TV, drinking, lazing while being waited on by female or while women working (Drawing 9) and males on their own involved in traditional 'male' activity - hunting, fishing, four-wheel driving (Drawing 9).

Overall the brother-figures are depicted more often than are the sisters. However, a notable factor relating to the significance (either dominant or connected) of the brother is the positioning of the brother in the family system when the mother and/or father are absent (Drawings 12a K-F-D and 12b F-A -A-D). There are more instances of the connection or domination of the brother at adolescence, but there is a notable increase in the highlighting of the brother at pubescence when the father is absent as Figure 6.10 indicates. 
Graph 18 highlights the significance of the brother for the self at pubescence when the father is absent. The Drawing Project does not identify the age of the brother, and the graph does not indicate the nature of the relationship, whether it is connected or dominant. It could be assumed that the older brother would be predominately dominant, and younger connected which raises a question about the 'brother factor' for the fatherless family.

\section{Graph 18: Incidence of Father and Mother Absence when Brother is Significant}

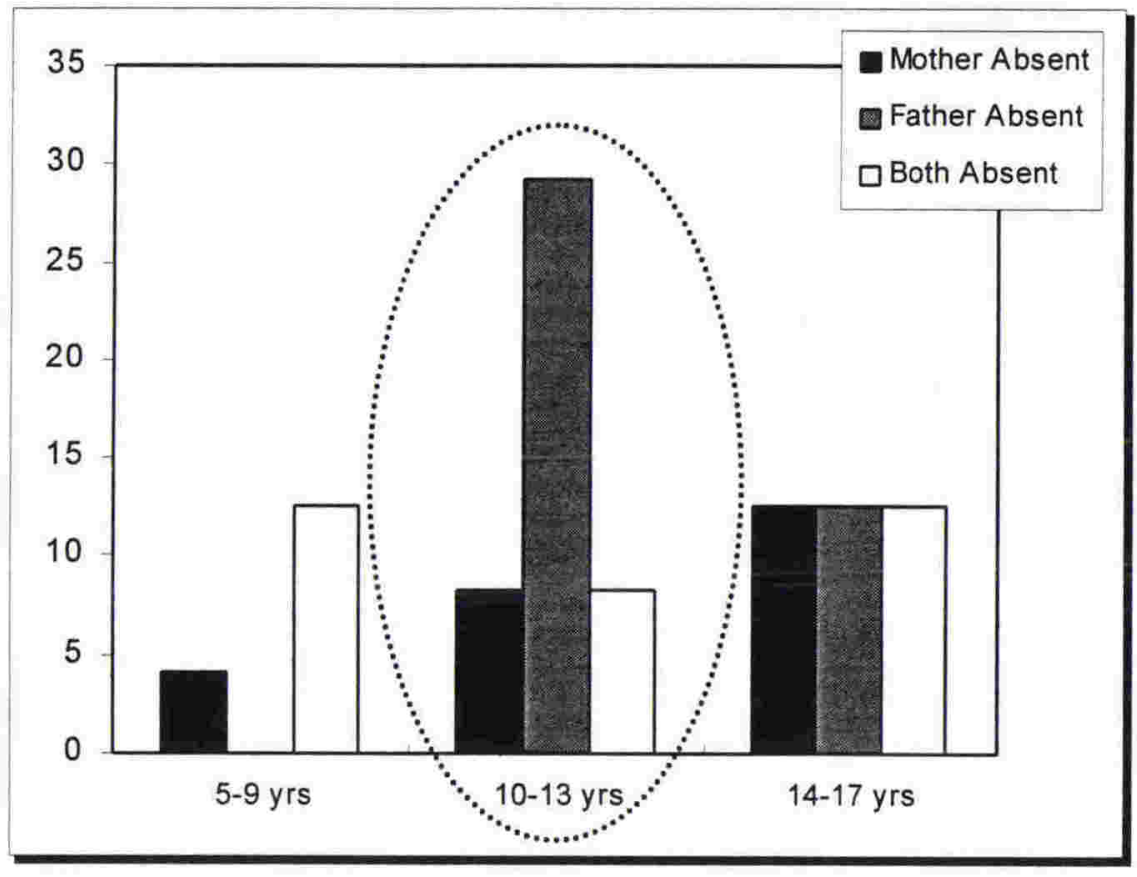

At pubescence there is a noticeable indication of the Self being depicted in manners that are degrading or demonstrate insignificance. That is, the Self is drawn as shaky, disconnected, floating away, with half an outline, as disproportionately small, hidden, as a label only, cut from the page once the drawing has been completed, as a worm, cockroach, weasel, ant, pig and rat (Drawings $13 \& 16$ ).

I looked for a connection with low self-esteem and father-absence but none was evident. That is, in one of the fifteen drawings of the Self depicted as insignificant the Father was absent, in two the Mother was absent and in the remaining twelve both parents were drawn. A further theme that seemed prominent through the pubescence and adolescence periods was the depiction of Self as aggressive. With 
almost half of the drawings the aggression is aimed toward the female in the family, the sister or mother (Drawings 1,2 and 5) and in a number there is an illustrated collusion with the father (Drawings 1 and 5). In one drawing the aggression is aimed at the brother, in two at the family as a whole (Drawing 14) and in the remainder at no one in particular. Again I looked for a link between father-absence and aggression and again none was evident. In one instance the father is absent, in two the mother is absent and in one both parents are absent. The remaining drawings include both parents.

Woodcock, the supervising art therapist, was particularly interested in the level of family dysfunction depicted in the drawings and, although noting comments made in Chapter Three referring to the lack of commentary and interpretation of the drawings by the participants themselves, several themes have been generated from the drawings. These themes include, sexual and physical abuse, tension through violence, alcoholism, drugs, war (Drawings 15 - 19) and the complications of restructured families (Drawing 20).

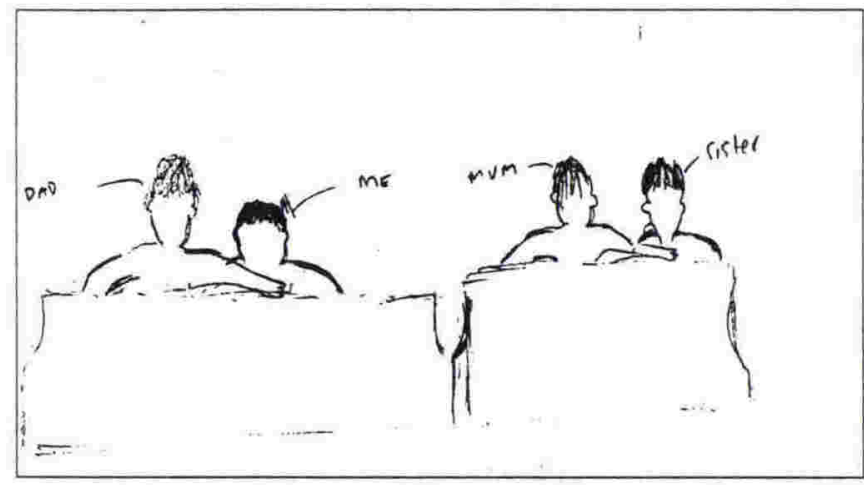

Drawing 8: (13 yrs, K-F-D) "Dad \& Me, Mum \& Sister" watching TV.

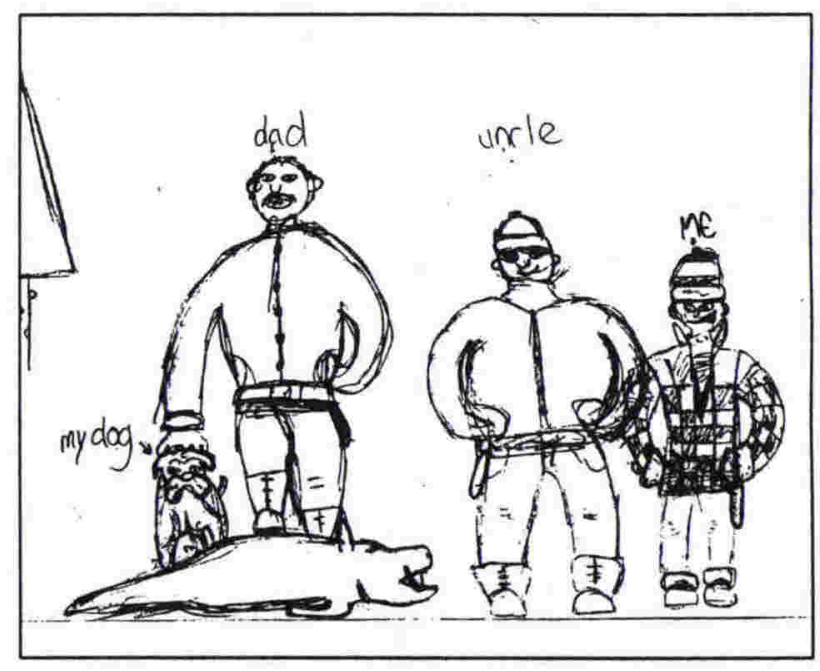

Drawing 9: (KFD 12 yrs) "My dog, dad, uncle, me." 


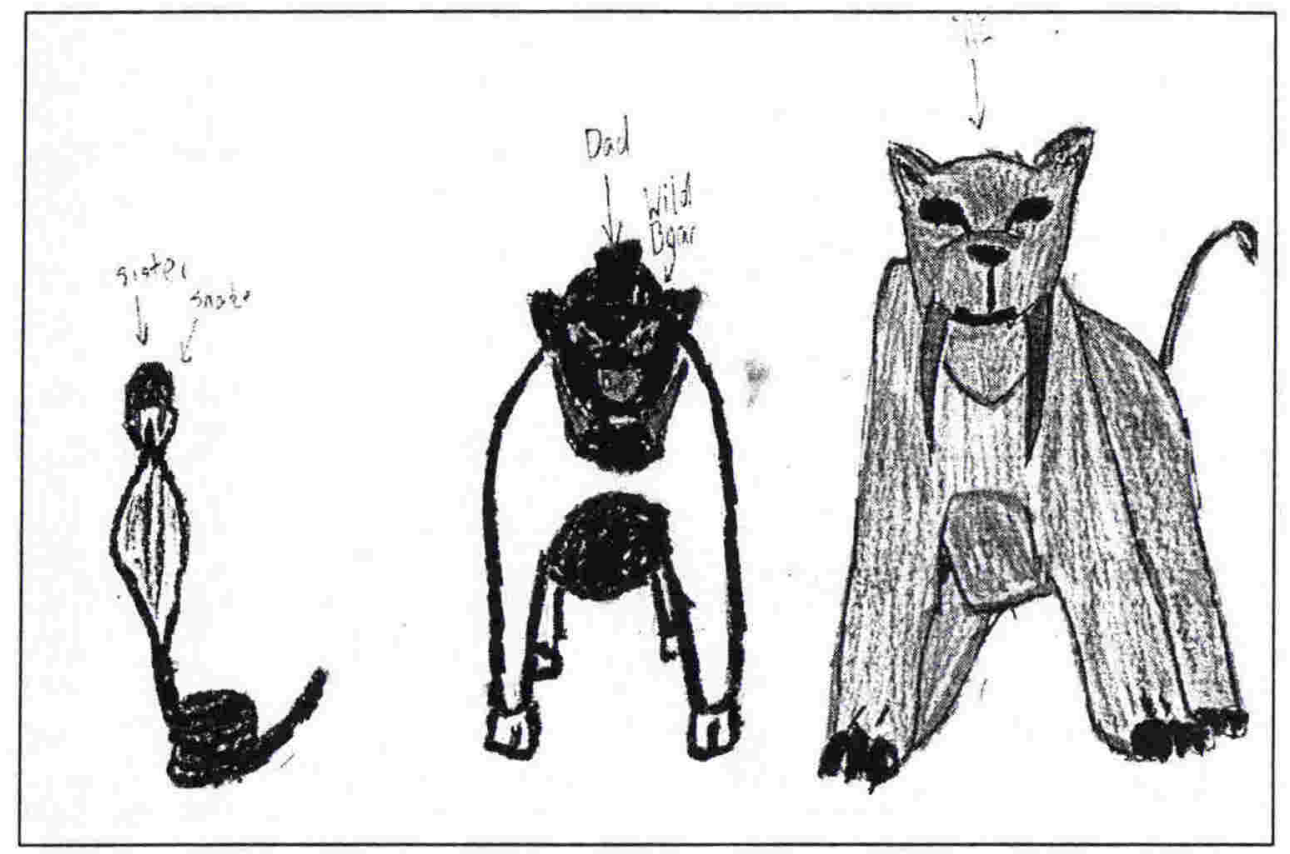

Drawing 10a \& 10b: (F-A-A-D, K-F-D,15 yrs) In the K-F-D Self demands a sandwich from sister, "Make me one too!", as he watches TV with his Dad. In the F-A-A-D Self (sabre tooth tiger) and father (wild boar) continue their connection with each other as they dominate the sister (snake).

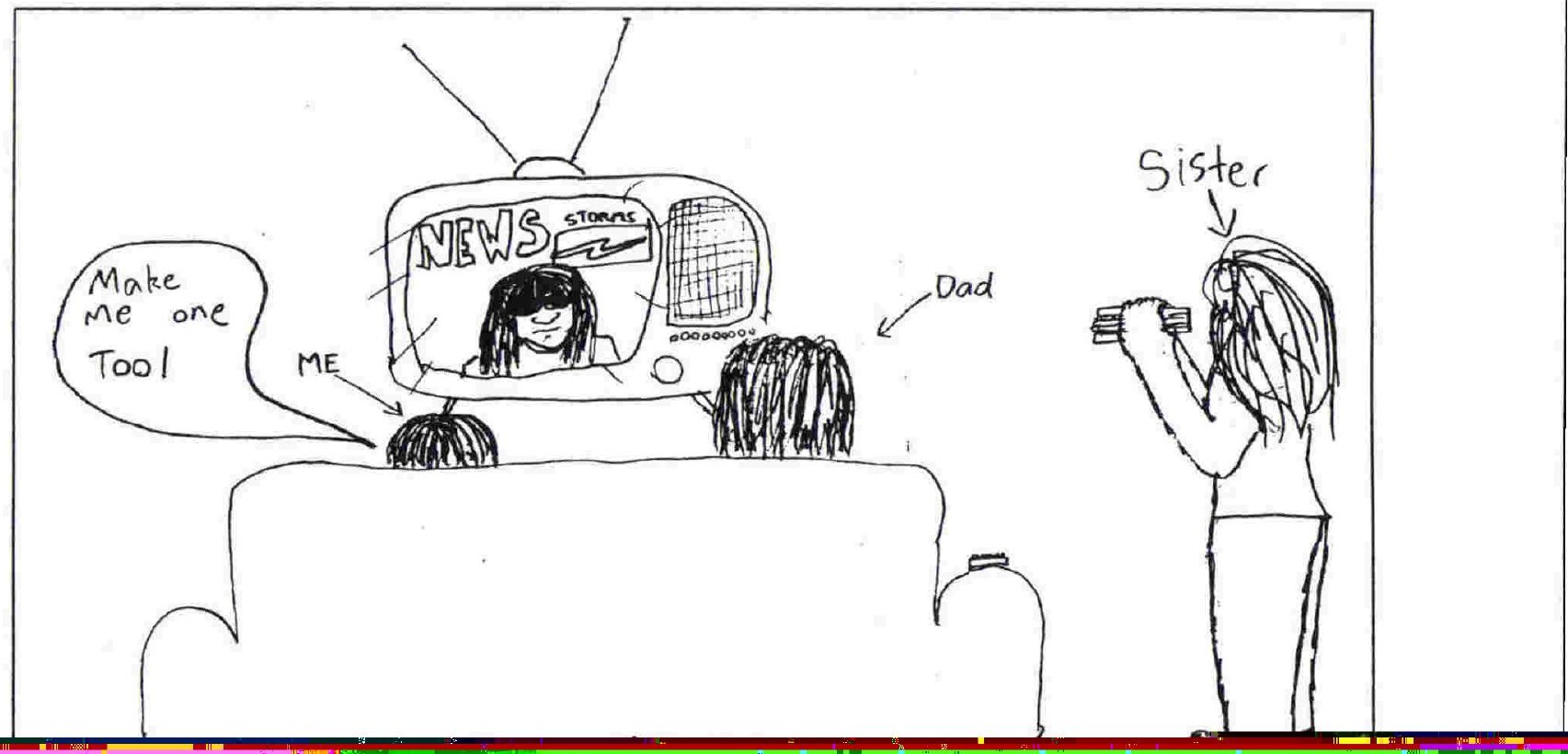

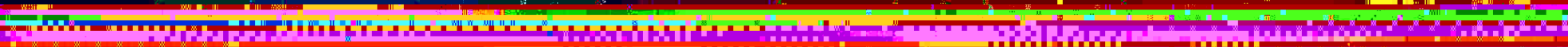

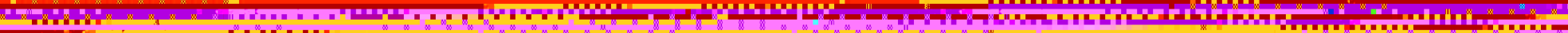
2.

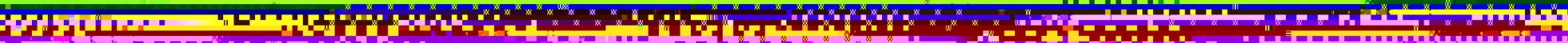

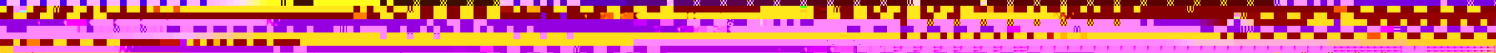




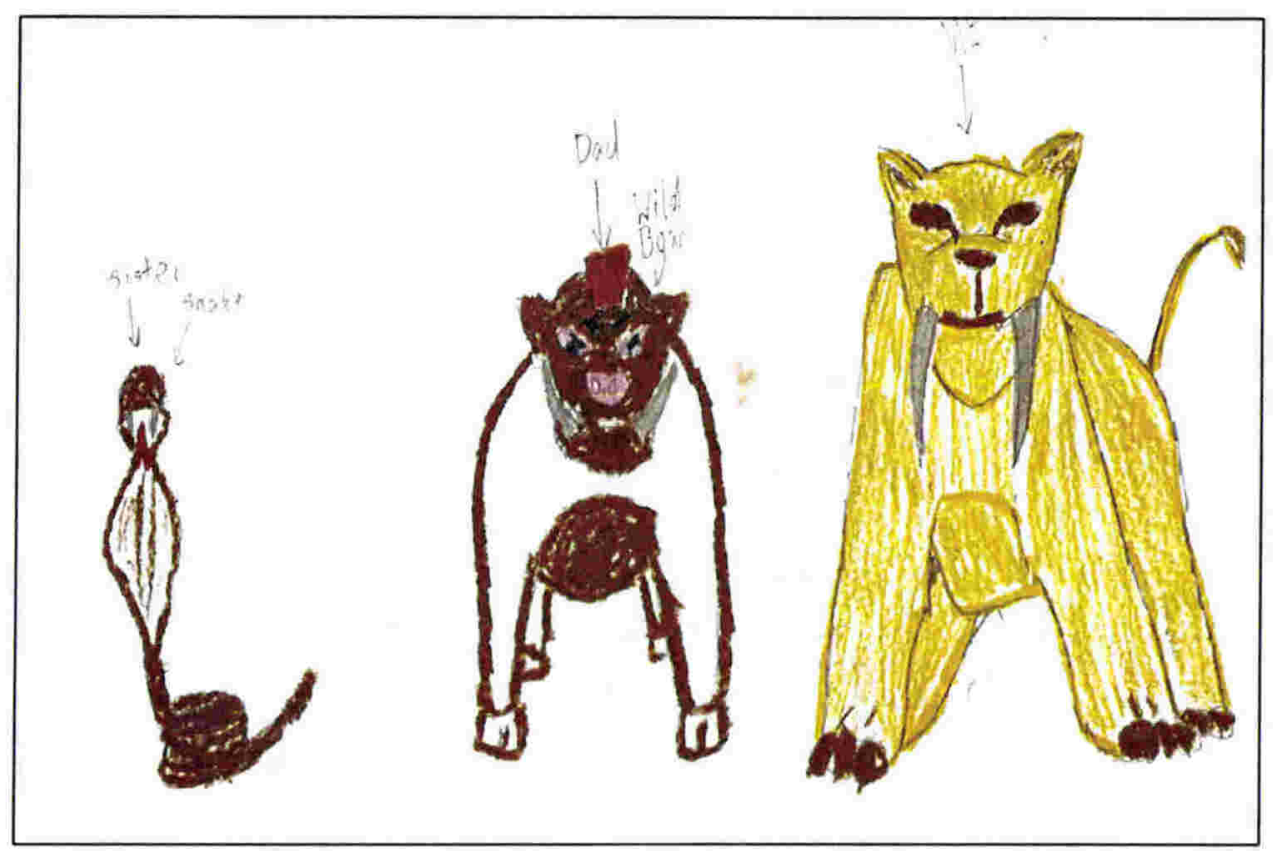

Drawing 10a \& 10b: (F-A-A-D, K-F-D, 15 yrs) In the K-F-D Self demands a sandwich from sister, "Make me one too!", as he watches TV with his Dad. In the F-A-A-D Self (sabre tooth tiger) and father (wild boar) continue their connection with each other as they dominate the sister (snake).

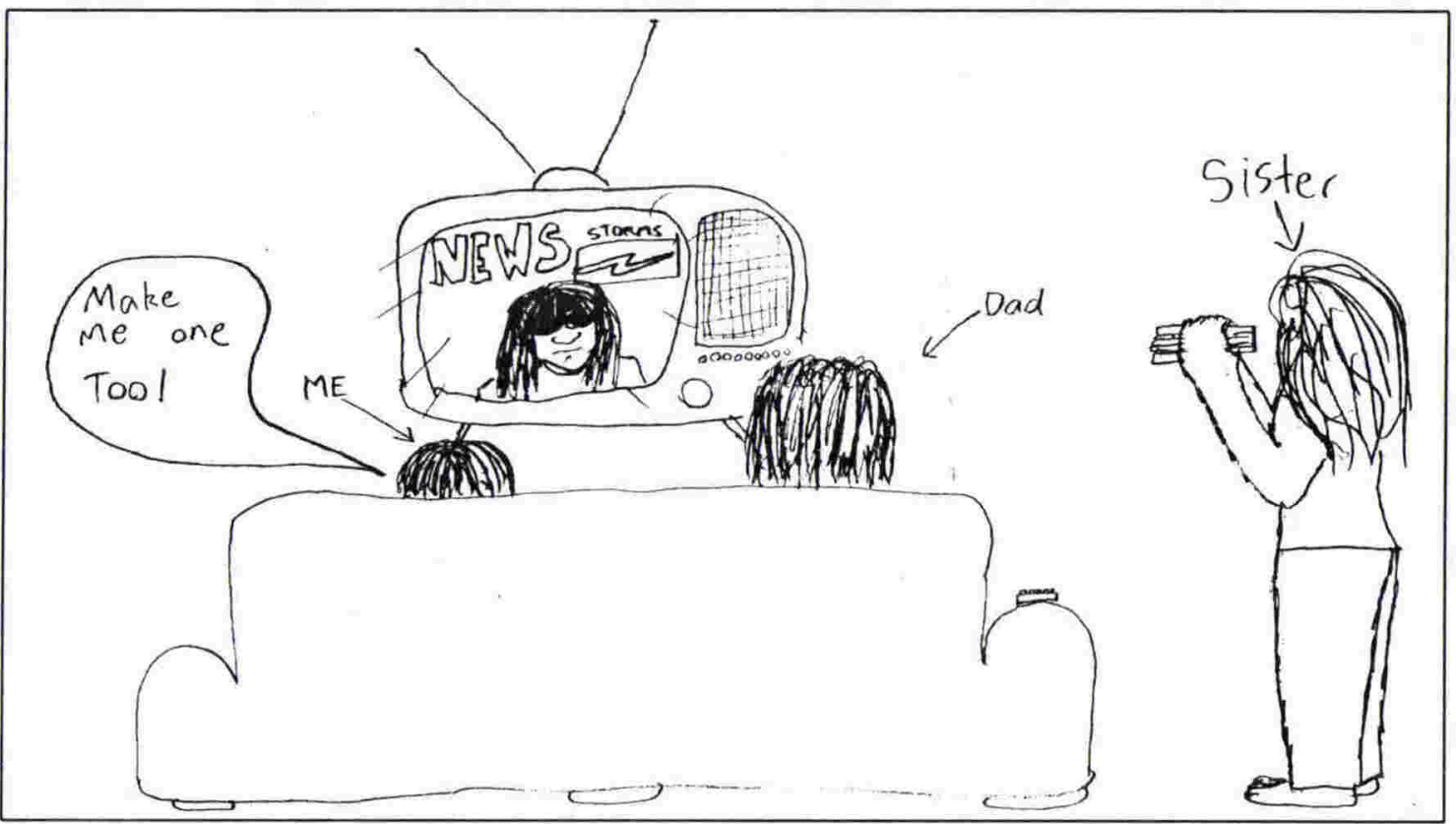




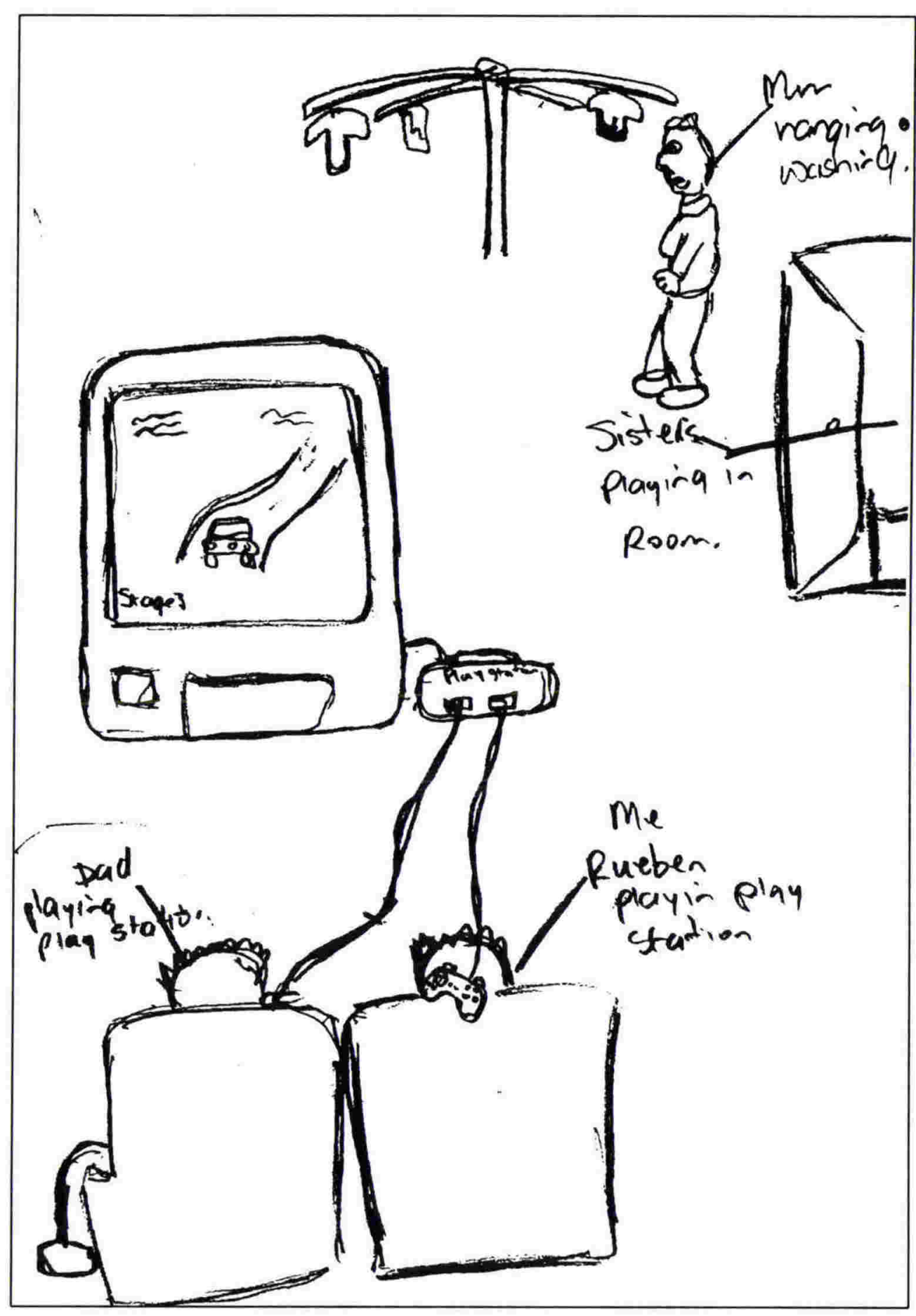

Drawing 11: (K-F-D, 13 yrs) The Self and Father are "playing play station", while the Sister plays in her room and the Mother hangs out the washing. 


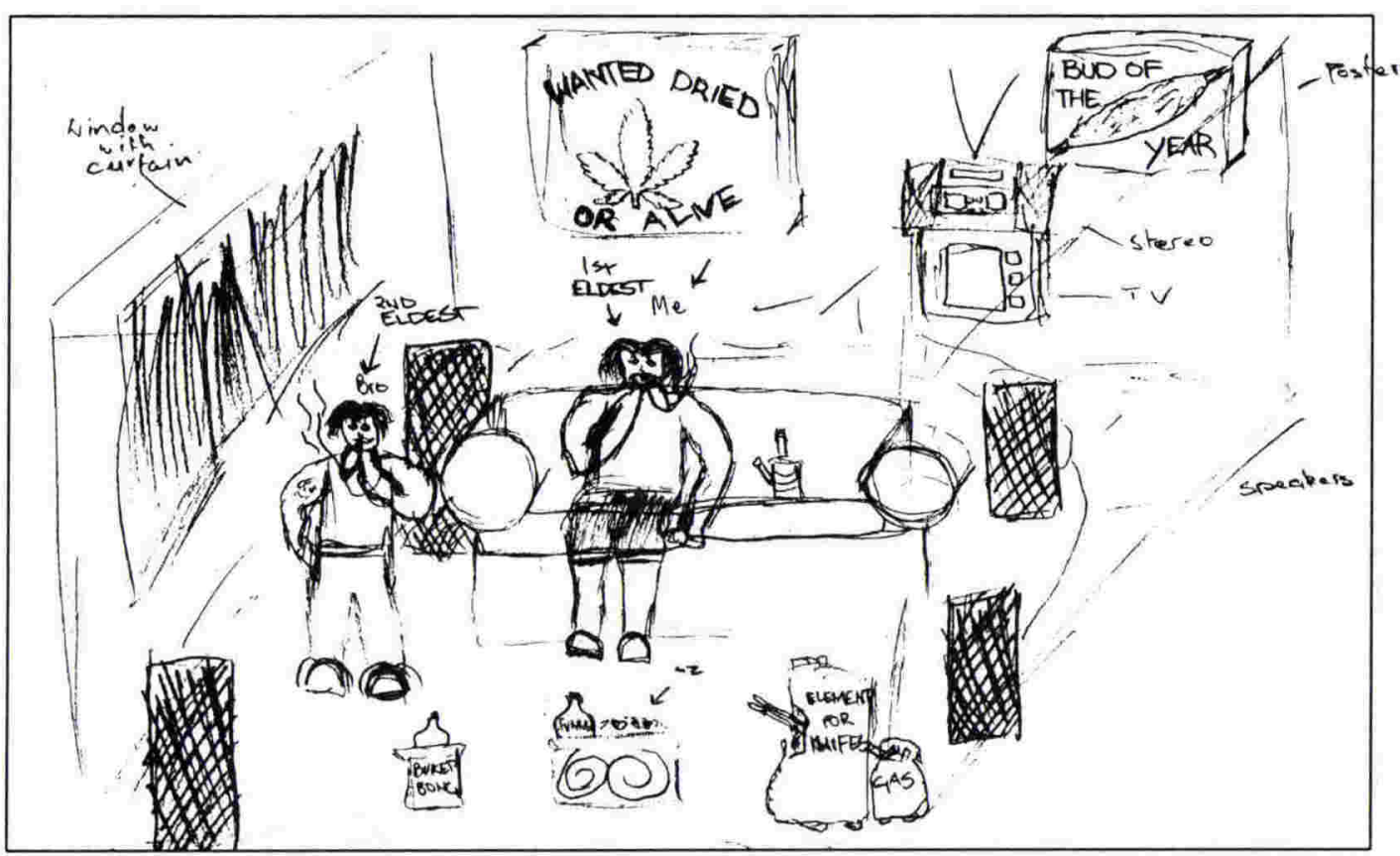

Drawing 12a \& 12b: (K-F-D \& F-A-A-D, 15 yrs) Above the Self as "Ist eldest" brother is smoking marijuana with the "2nd eldest" brother. In the drawing below the Self (eagle) is ready to attack his 'bro'.

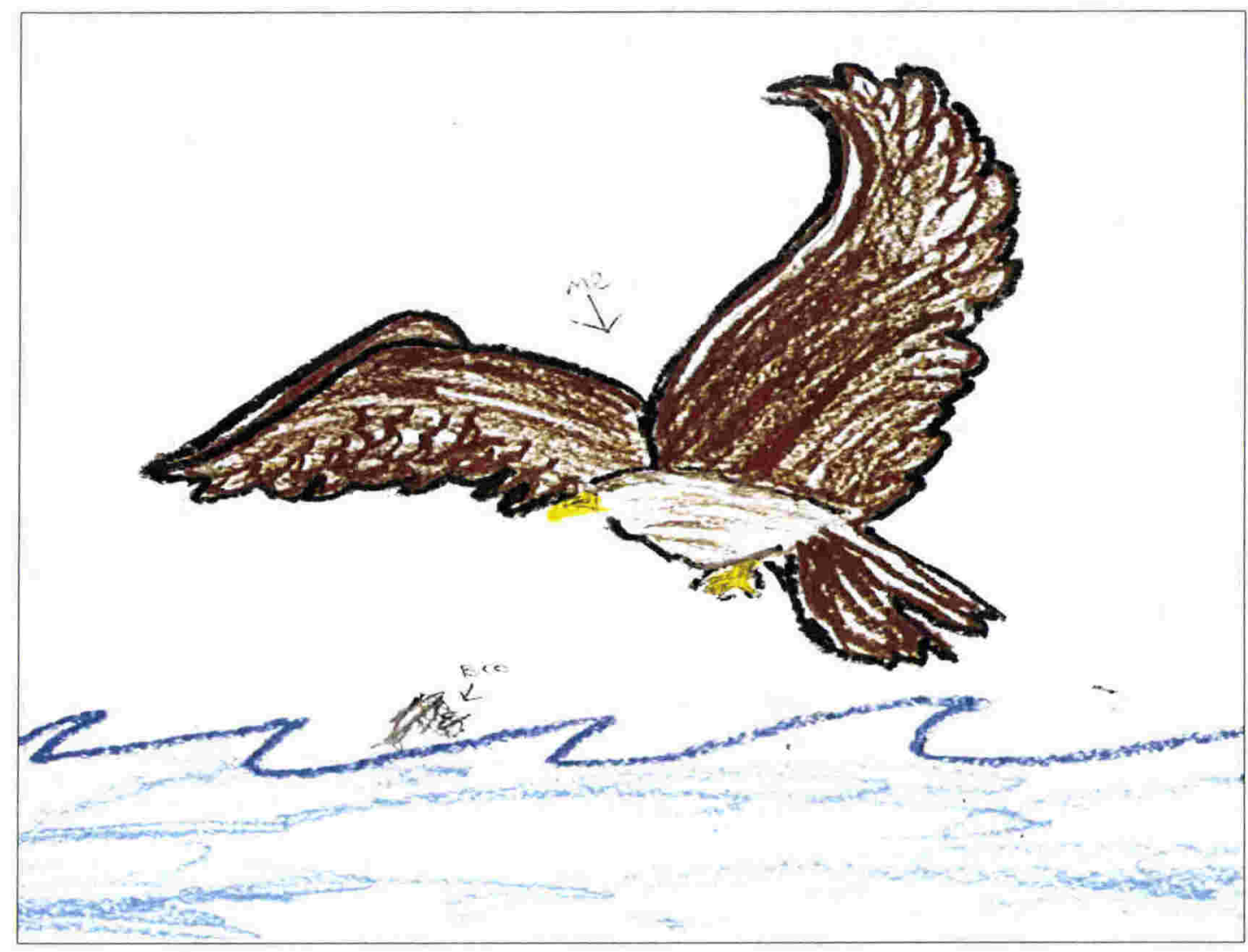




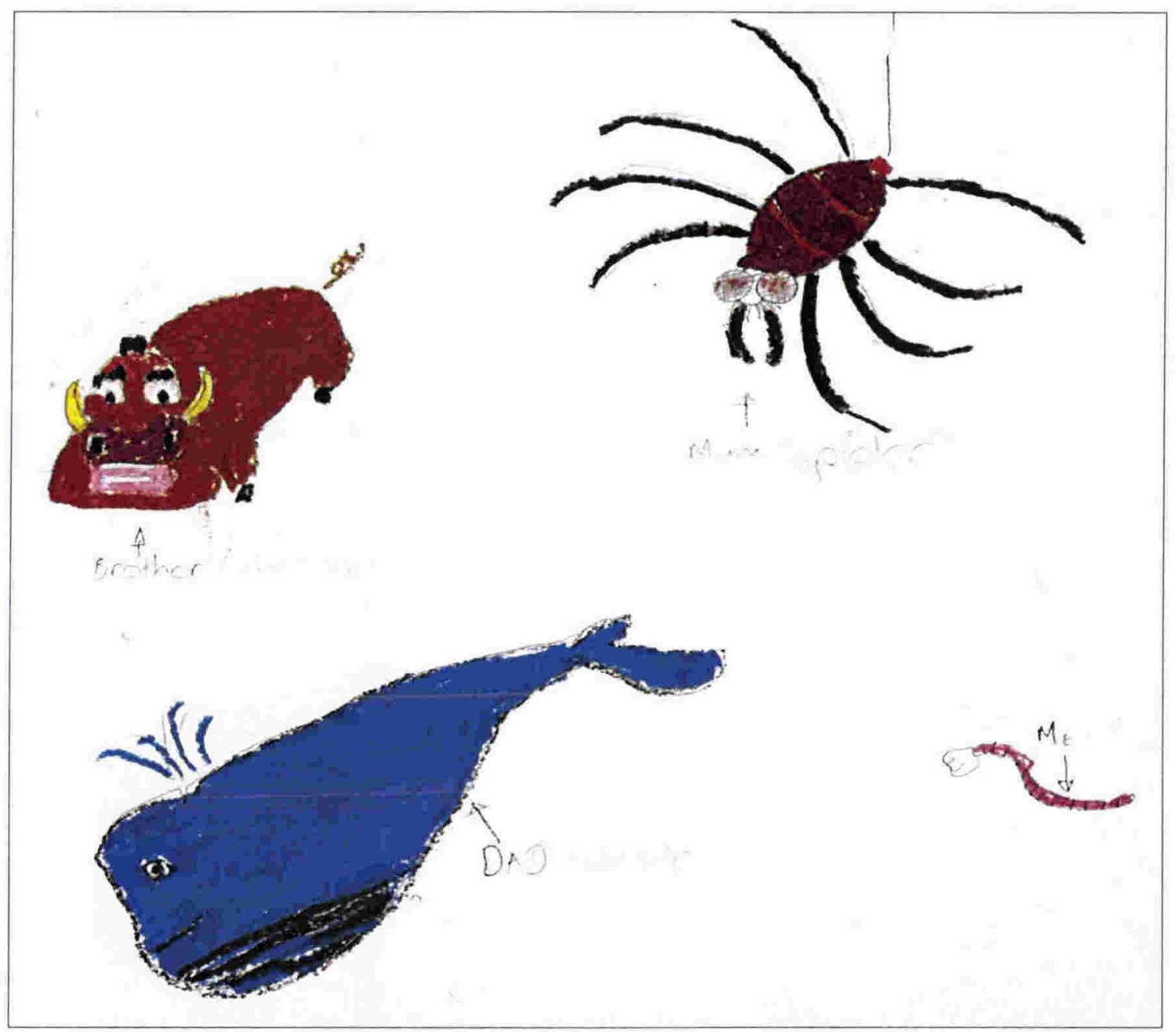

Drawing 13: (F-A-A-D, 15 yrs). Brother (warthog), Mother (spider), Self (worm) and Father (whale) 


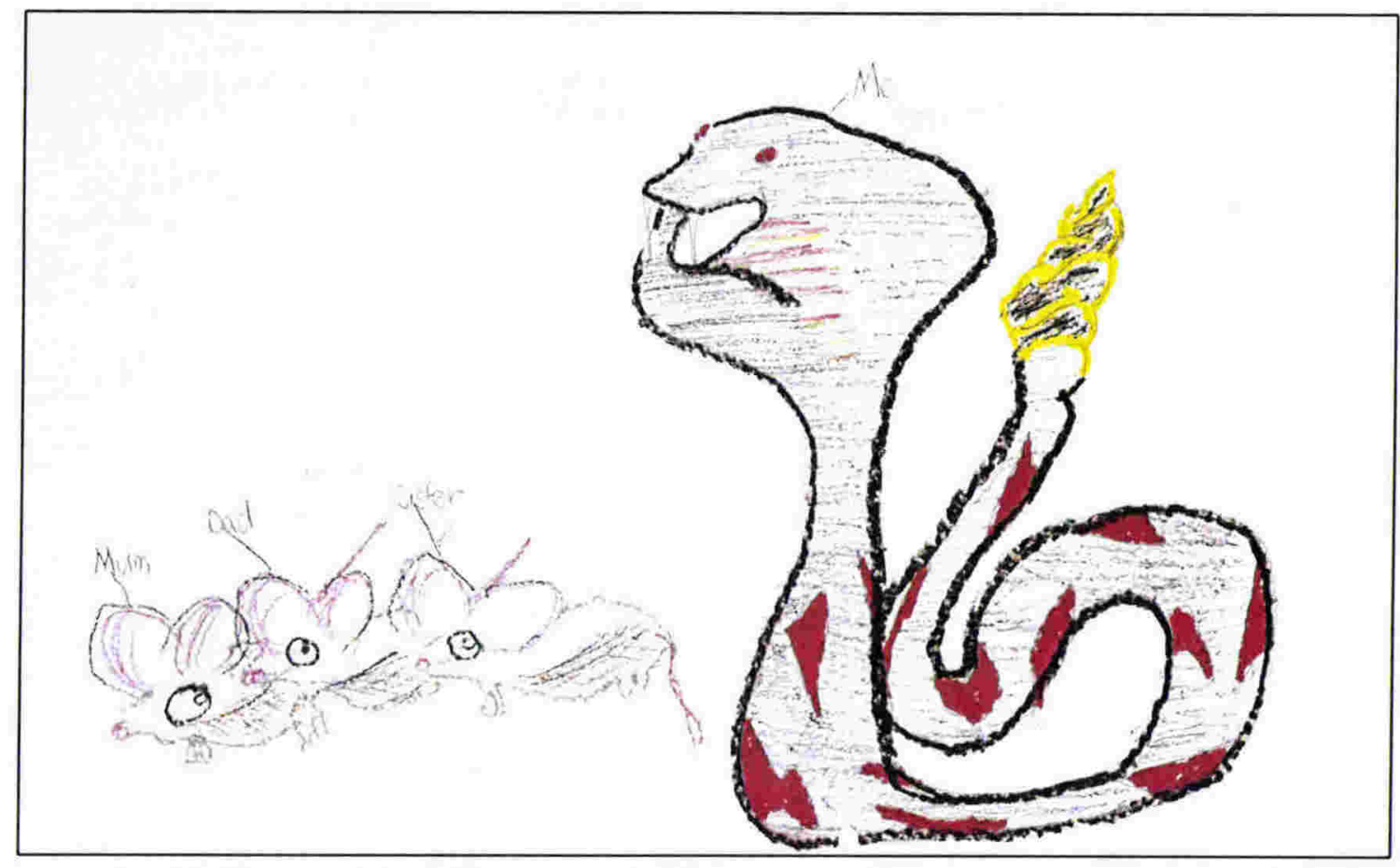

Drawing 14: (F-A-A-D, 14 yrs) The Self (snake) is preying on his Mother, Father and Sister (mice).

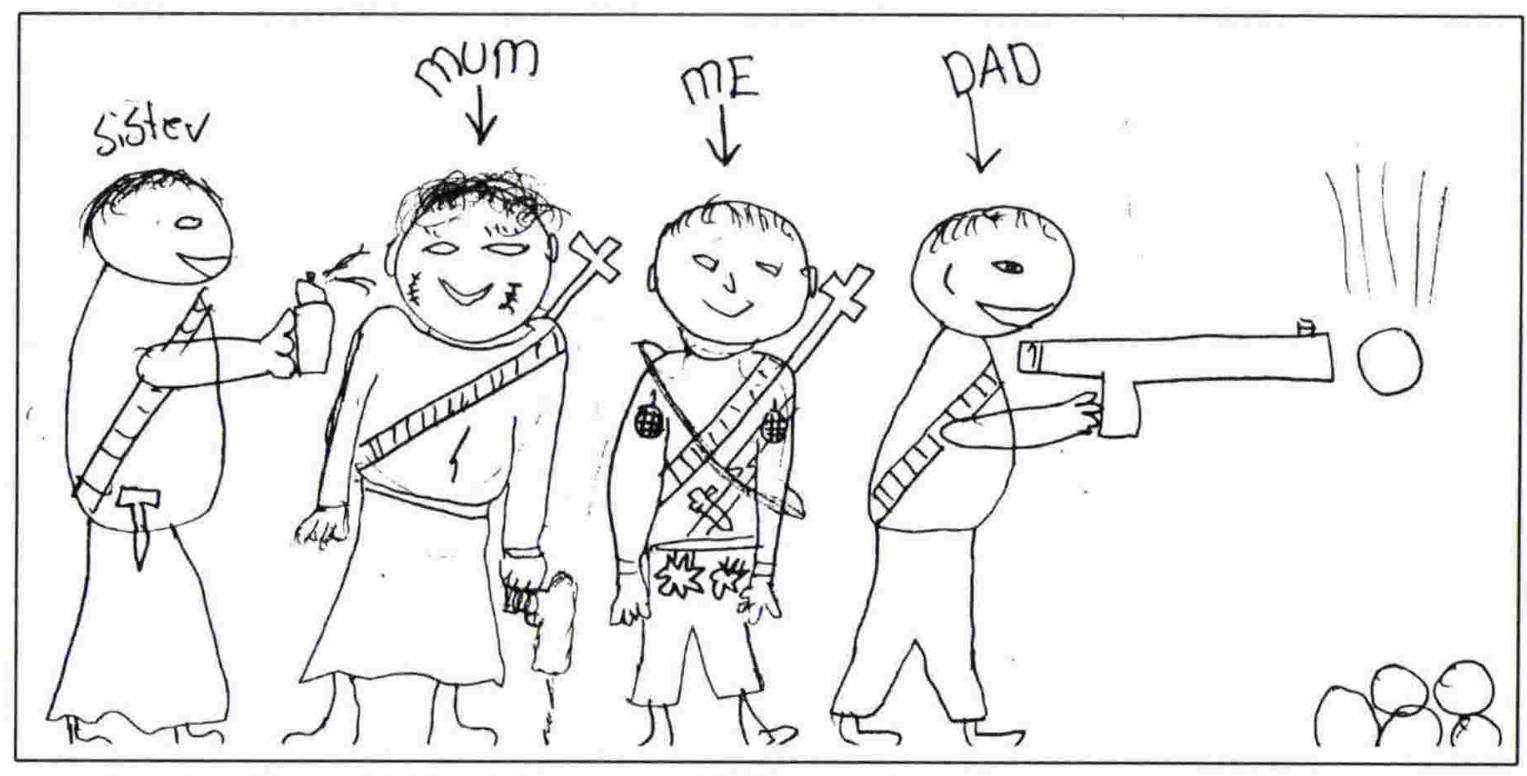

Drawing 15: (K-F-D, 11 yrs). Mother and Self connected. 


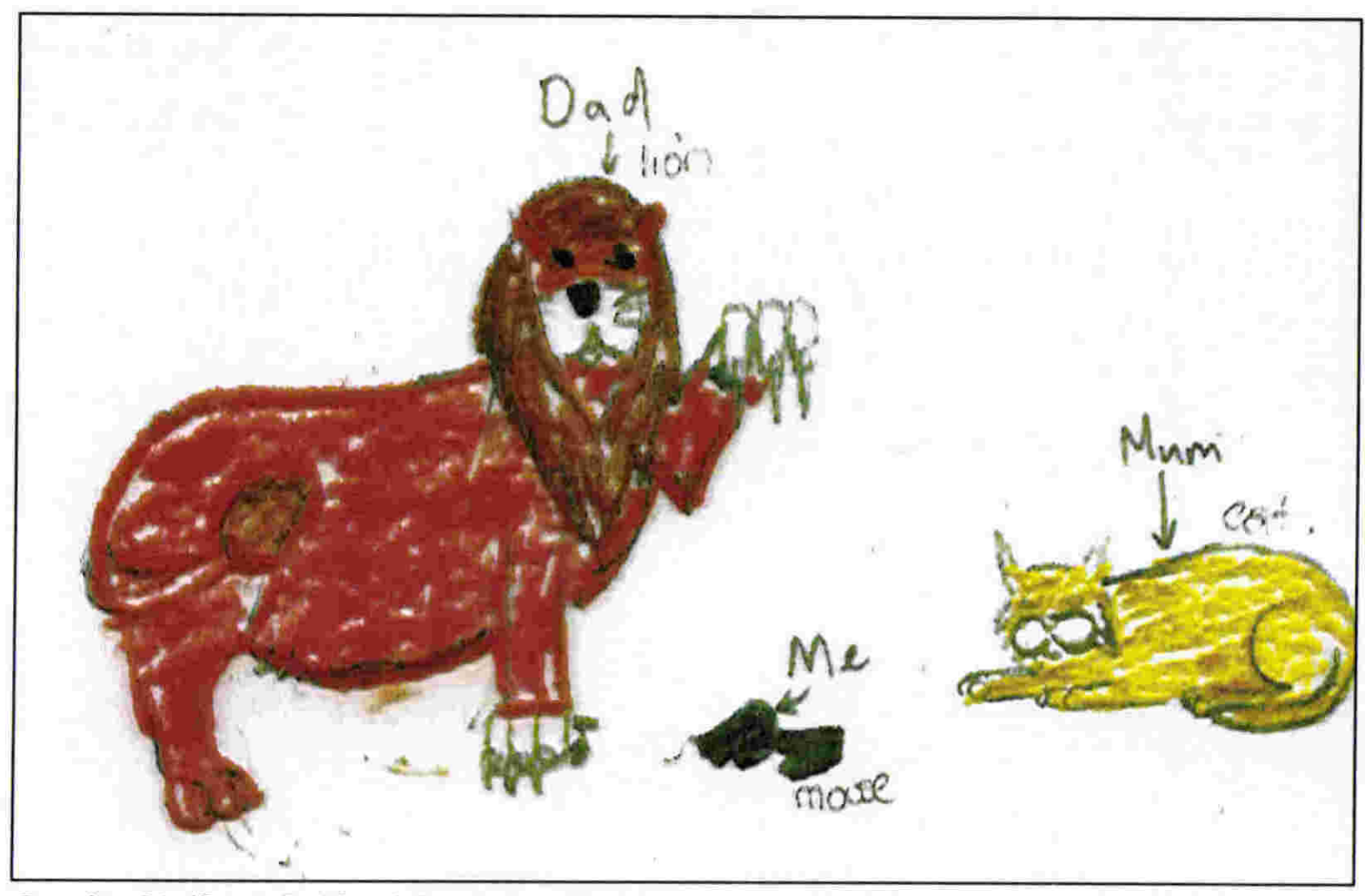

Drawing 16: (F-A-A-D, 12 yrs) The Father (lion) is ready to attack the Self (mouse), while the Mother (cat) looks on.

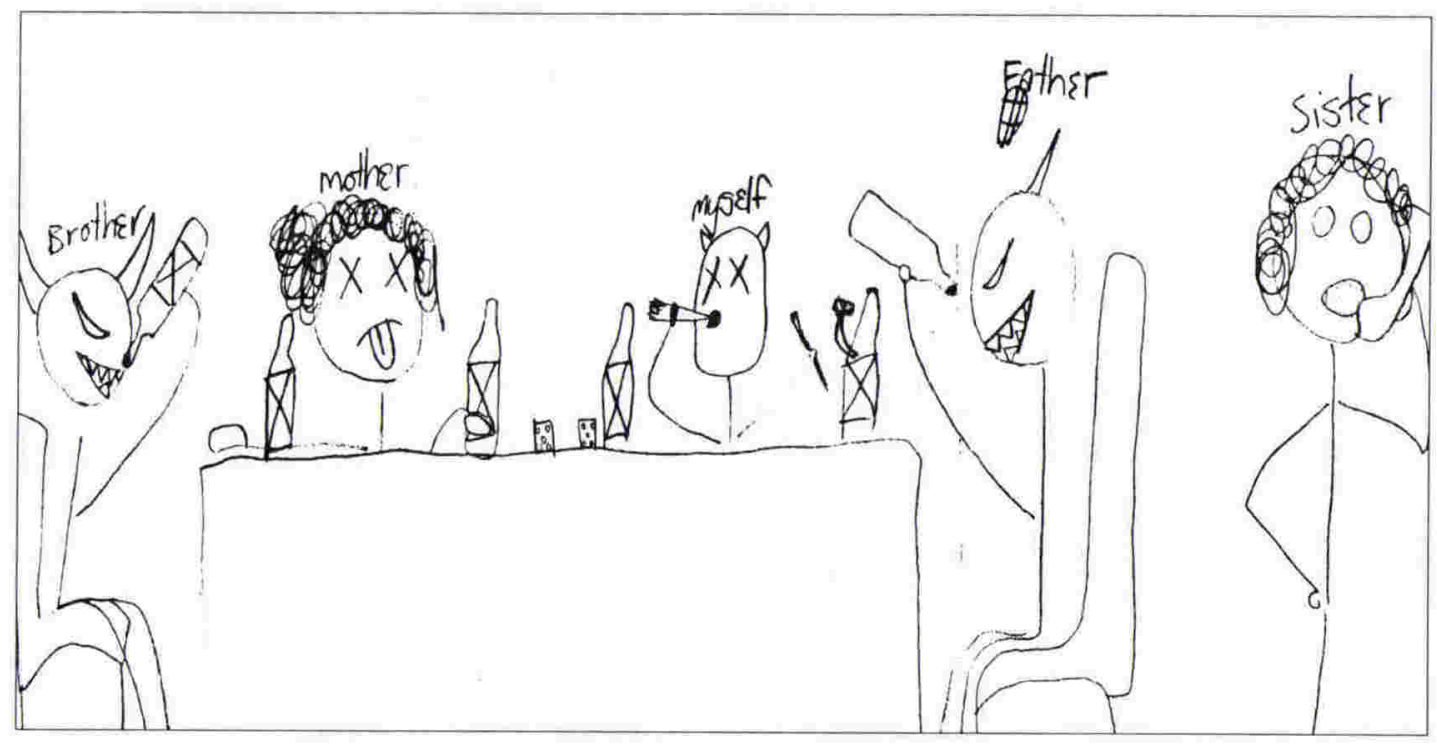

Drawing 17: (K-F-D, 16 yrs) The Family at dinner 


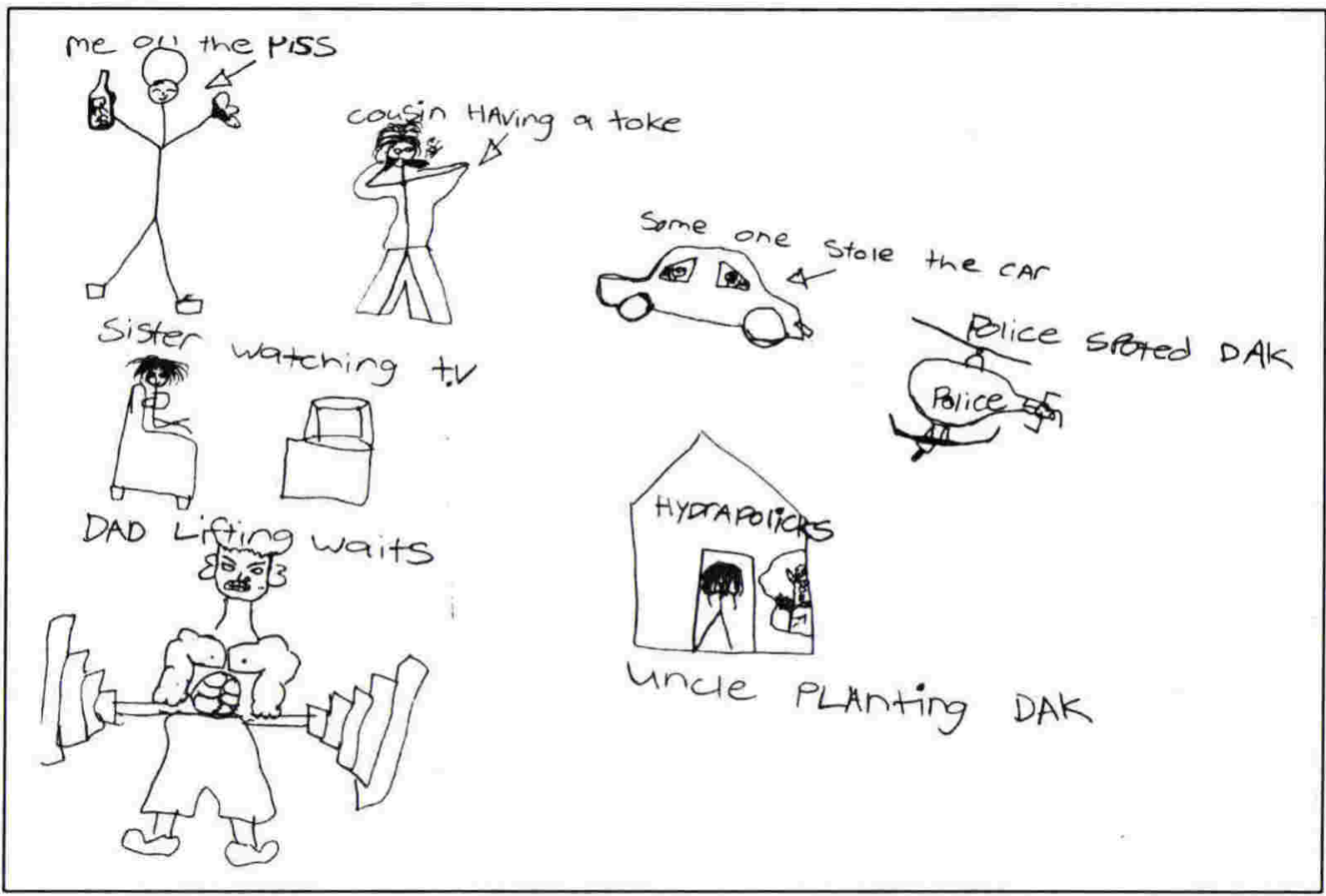

Drawing 18: (K-F-D, 16 yrs) "Me on the piss, cousin having a toke, some one stole the car, police spoted dak, Uncle planting dak, Dad lifting weights, sister watching TV"

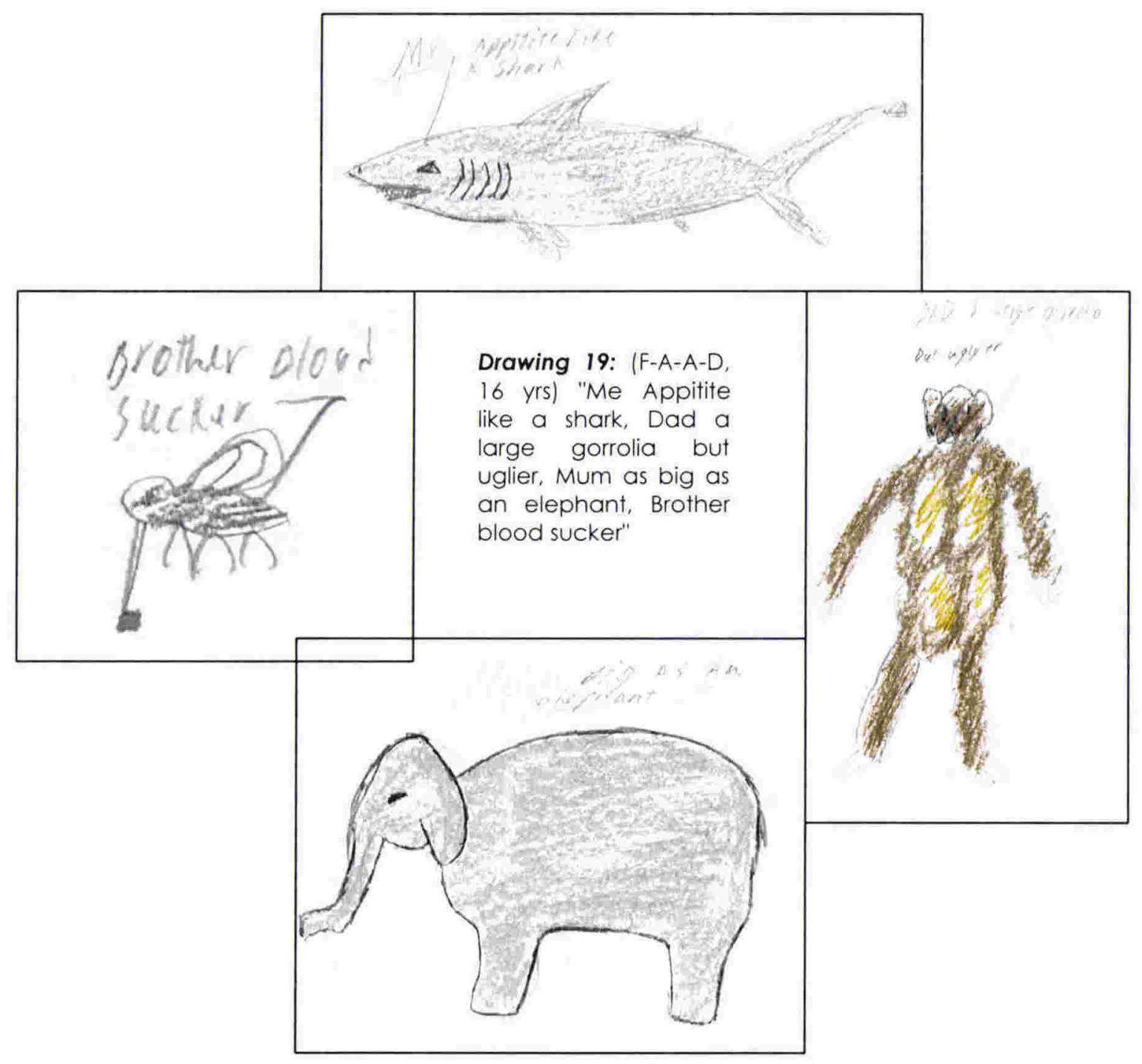




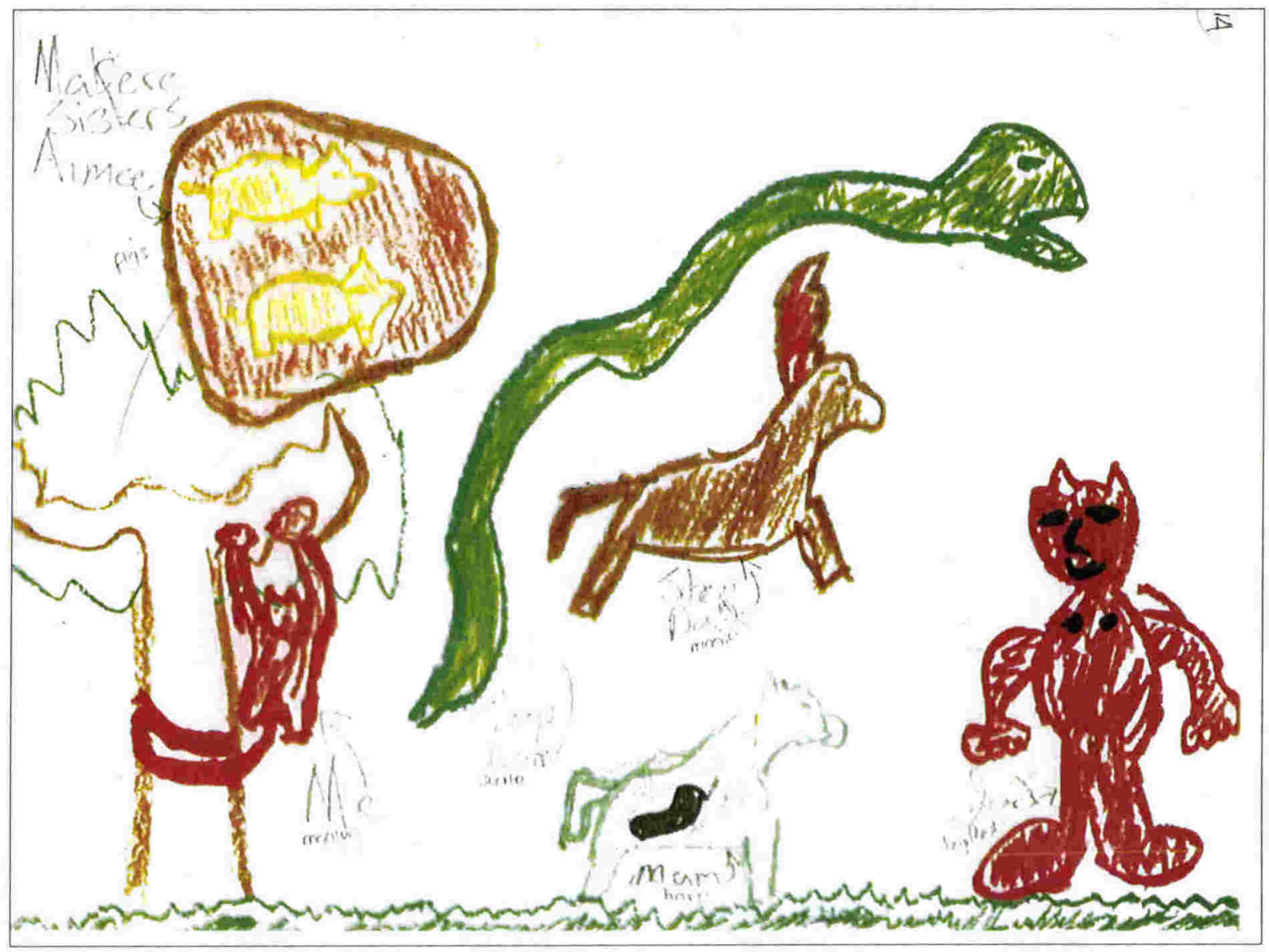

Drawing 20: F-A-A-D, 11 yrs) Fascinating drawing of connections. The Self (monkey) is linked with the Father (big-foot) in animal type and colour. However he is separated spatially from him by his Stepmother (snake), Stepfather (moose), and Mother (horse). The Stepmother holds a dominant position over the other adults. The Stepfather and Mother, although different animals, are similar in stance and proximity. The Self is connected to the same tree that connects his two sisters. The sisters are depicted as pigs, encapsulated and heavily 'protected' from the outside. The Mother and the Father are the only two connected to the ground, which also connects the tree on which the Self is hanging. 


\section{Findings of Analysis Three}

As can be seen from previous graphs the connection of the son with the mother is high at childhood and reduces significantly during pubescence. I was interested to see how the participant perceived himself when connected with his mother and to compare this when he was connected to his father. I combined the analyses one, two and three with the F-A-A-Ds. That is, whenever the mother and self were connected, I noted the choice of animal the participant had used to depict himself.

Figure 0-11: Self when connected with each parent (Graphs 18-19)

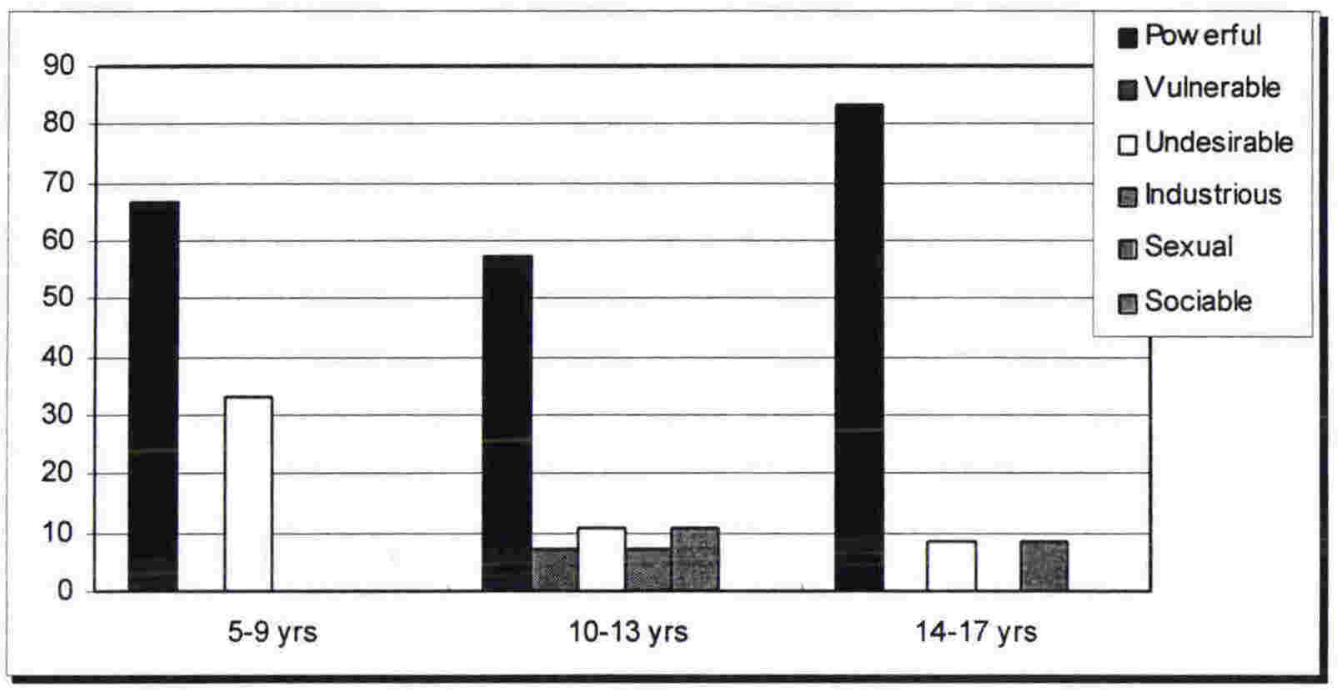

Graph 18: Self Connected to Mother

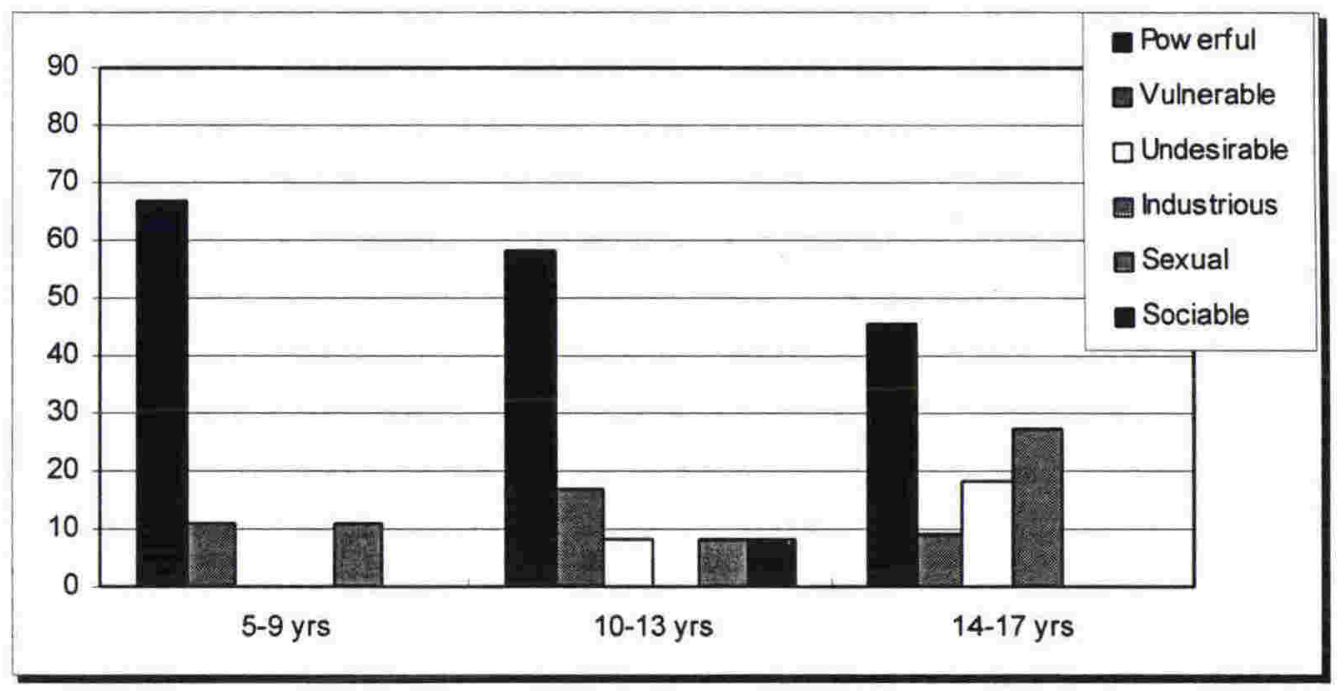

Graph 19: Self Connected to Father 
In the category, powerfulness, there does not seem to be a significant difference in the perception the self has of himself between connected with the Mother and with the Father. The sense of his own undesirability when connected with the Father in the childhood period is relatively high and does not compare with the sense of undesirability the Self has of the Father at this time. There does seem to be a more significant rise, however, in the level of industriousness shown by the son in the adolescent period when the Self is connected with the Father compared to when he is connected to the Mother.

\section{IMPLICATIONS OF FINDINGS AND THE LINK WITH THE MAIN PROJECT}

\section{Analysis One}

The findings of Analysis One can be reduced to four key suggestions. Firstly, that the Mother is portrayed as highly insignificant at pubescence. Secondly, that the connection between the Self and the Father increases at pubescence. Thirdly, that the Self depicts himself as more insignificant than both parents at all times. Fourthly, that the dominance of the Self over the Mother is greatest at adolescence.

\section{Analysis Two}

The findings of Analysis Two can be reduced to three key suggestions. Firstly, that the Mother is portrayed as most undesirable at pubescence. Secondly, that the Father is least undesirable at pubescence. Thirdly, that the Self sees himself as most undesirable at adolescence.

\section{Analysis Three}

The findings of Analysis Three can be reduced to five key observations. These include, gender separation within the family, stereotyping of family activity, denigration of the Self, aggression of the Self and the significance of the Brother.

The findings of the drawing project vindicate the experience of the mothers, that at pubescence the sons change significantly in their attitude. The participants in the Drawing Project depict themselves as most dominant over their mothers at 
pubescence. This is also the period when the mother-son connection is most tenuous and the son's portrayal of the insignificance and absence of the mothers is the highest. Interestingly this is not reflected as strongly during the adolescent period. A comment, "[y]our father doesn't live with you!" was made by one student to another during one of the intermediate school sessions and was answered with a "SO!". This gives reason to wonder whether the connections portrayed with the father are ones of desired as well as of real association. The pubescent males also depict a greater proportion of their mothers as absent. Is this desired or actual? The insignificance of the mother at this period suggests that it could be one of desire.

The 1996 NZ Census statistics for this area indicate that more than thirty percent of all families are one-parent families. It also reveals that nationally seventeen percent of sole parent families are headed by men. The principal of the intermediate school involved in the project states that "95 boys from [school] come from single parent families. Of these 16 live with a male caregiver and 79 with a female". This confirms the national average. It also indicates that around five percent of all families are headed by men and twenty five percent of all families being headed by women. In other words women are absent in five percent of families and men are absent from twenty five percent of all families.

Statistically it could be concluded that the dominance of the mother and the son's connection with her would be more than that of the father by twenty percent. Her absence should be less by the same proportion. If this difference of twenty percent is applied to the expected outcomes of this project then the real differentiation in the categories demonstrated in Graphs 1, $2 \& 4$ is further accentuated. One category reflects the national statistics, that of the connection between the son and the mother in the childhood period. There are statistical gaps in this breakdown, for example information is not currently available to indicate the percentages of father and mother headed single parent families across the age groups of the sons. It is not possible to know whether there is an increase or decrease of femaleheaded single parent families between childhood, pubescent and adolescent periods. Regardless of this, it is evident that there are major discrepancies between the depicted relationship a son either has, or desires to have, with his father than he has, or wishes to have, with his mother. 
One of the beginnings of this research emanated from the classical story of Bambi. When Bambi reaches his pubescence, the writer Felix Salten (1928), kills his (nameless) mother. Research in this project to date, including one-off interviews, and the ongoing involvement with a longitudinal group of mothers is showing that, as with the story of Bambi, written seventy years ago, the mother is 'killed' at pubescence, at least to the world destined for her son.

The following are quotes from several of the women interviewed who describe the change in their sons at pubescence and adolescence.

There was a stage, when he was 13 or 14 when he began to assert his authority...just sort of running me down...saying that $I$ have absolutely no memory and I was hopeless and no brain and this kind of thing. (4)

Another mother describes the collusion of the father at this time. "Once they [the boys] got older he [the father] started to tell jokes with them...shit this and bloody that ...occasional reference to penises and...breaking of wind...he was undermining [my parenting]...I used to feel very uncomfortable...made me very tense." She also describes how she was ignored in her protests and how, as a result, her "self esteem suffered" and she felt as if she was "becoming a whinger" (21).

And another: "He [adolescent son] withdrew...there was a distance...I felt a bit left out" (9).

Another expressed her concern that she didn't "want to get too clingy" in case this would incite "homophobic stuff [which was] lurking in the background" and "turn [him] into a wuss" (7).

And another, "It was hard to go through that thing of having someone [son] tell you to get fucked" (14). 


\section{CHAPTER 7}

\section{FATHERLESSNESS AND MASCULINITY}

Chapter Seven examines concepts of fatherlessness and masculinity. The first section addresses a major theme of the fieldwork and of the project as a whole the impact of fatherlessness and fatherlessness discourse on the mothers and the sons. The second section considers 'masculinity' and its impact on the construction and purpose of motherhood.

\section{FATHERLESSNESS - FATHER-ABSENCE}

'Fatherlessness' and the incidence of the 'absent father' has attracted increasing attention over the past several years as a matter of urgent social concern. Numerous books have been written on the subject, conferences held, large amounts of material made available on the Internet and new organisations of men have emerged across the Western World. The media has also intensified its focus on fatherlessness linking it with negative statistics for adolescent males reporting that unemployment, suicide or bad health, long term psychological problems and a disproportionate contribution to crime statistics among young men are the results of a lack of ongoing contact with their fathers.

The voices of three groups are included in this section, the mothers, the sons and the fathers. Investigation of the fathers has not been part of this research. They can more appropriately undertake their own research into these issues. The mothers' voices come from interviews with mothers of sons, including those involved in the longitudinal study. The voices of the sons are second-hand, as they have been told during interviews with their mothers. The father's voices have been taken from a review of current literature. The final part of this section provides a critique of the fatherlessness phenomenon. 


\section{The Mothers' Voices}

Although the voices of the mothers represented here do not claim to be representative, they come from a variety of family situations - single parent, twoparent, lesbian and heterosexual. The commonality among them is that they are mothers of adolescent or post-adolescent boys. The following themes raised by the participants highlight the complexity of the 'fatherlessness' construct. They broaden perspectives that have been evident in literature published to date.

Amidst the combination of mothers' voices, there was strong agreement that the presence of positive males in the lives of their sons was an important factor to the sons' sense of self and wellbeing. They saw that men had a role in reinforcing positive values.

[Father] had always been really accepting in anything that I've done. I have never felt any restrictions about what I can do and what I can't do with my life as I see fit. That [positively] influences my relationship with [Son]. (11)

The need for initiation of the sons into the male culture made the absent father an issue for this mother.

The bottom line is they are males and I think they need the male influence. (7)

Fathers need to get involved because boys need to be able to understand and play the rules of the male. (11)

There's a certain amount of truth that [the sons] do need a role model and the best time for them to have a role model, is when they really start questioning their masculinity. (16)

There were varying opinions about whether the males present needed to be the father. Some believed that the absence of the father impacted negatively on their sons. When she examined this belief further one mother explained that it was not so much that the father was the best role model but that it was the fact of his absence that caused difficulty. 
I think [father absence] is about the pain and the rejection, it's being rejected, it's been ignored, and it's not being given those positive messages about themselves and their importance. (9)

The lack of continuity of visits [from the father], of support, of being there when they're needed so I don't think it's just because there's not a man in their life or that the woman doesn't give them enough, I think because there's someone who's important to them who's treating them like shit really and like they're unimportant. (14)

They [the sons] need male contact to some degree ... but it doesn't have to be the father. (3)

I don't think it matters whether it's a grandfather or whether it's an uncle or a male friend but it there's somebody there if the father can't be there. (21)

Those who believed that the significant males in the lives of the sons did not necessarily need to be the father suggested that there were a number of other ways that their sons could have positive contact with males.

Meeting with his father is not necessary for him. He has good rapport with the soccer coach and the coach is a really nice person. He has another friend of mine, single man, who is a friend of the family. (19)

Writing letters to his uncle ... making contact with his dad and his grandfather. ... I don't think he is disadvantaged by not having a man in the house. ... He has got enough good role models outside of that. (6)

There were others who felt that merely being male wasn't enough and that what mattered about the fathers/male role models was what sort of role model they were. The mothers considered that there were three key qualities that were important for a male. The first, involved valuing the boys, taking an interest in them, offering them quality time, being prepared and able to listen to them and to enjoy their company. The second quality was the ability to communicate. That is, to talk with a level of openness, intimacy and honesty and for whom healthy conflict is normal and the resolution of that conflict is important. The third quality 
the mothers considered important in a male was the ability to model respect for women and to expect that boys would do the same. One participant commented,

[Feeling valued by a male] did actually make a difference to him, a big difference and what happened then was he began to value me. His increased self-esteem allowed him to step out of the victim role. (18)

One mother stated that she would "hate to see the children ... grow up without contact with the father - even if the father is less than ideal" (21). Even though her experience includes being derided by her ex-husband and being put-down by her sons with encouragement from their father, she believes that it is in her sons' best interest to support their alliance with the father. It was not appropriate to challenge this mother with my own thinking, but it is the insistence by this mother on the need for her sons to spend time with a father who encourages them to undermine her, that emphasises the strength of the father-need persuasion. Arcana argues, "to the extent that mothers of sons do not criticize and work against the standard socialisation of our children ... we will be supporting those qualities and actions that we abhor in most men ... that keep our sons - and ourselves - from full humanity" (1984, p.138). Discrimination in the encouragement of our sons toward specific male role models must be taken into consideration.

Silverstein argues that the notion that a young boy needs a male-role model in order to become a man is a "trendy psychological panacea for a host of societal ills" (1994, p.85). She believes that the male role model ideal obscures social disorders such as poverty and a lack of community, scapegoating the single mother and the absentee father and absolving governing systems from providing adequate support to families. She suggests also that current call for male role models is a way of "recentralizing the marginalized father" (1994, p.87). Furthermore she argues that the emphasis on the male role model could also be destructive by developing an unquestioning acceptance of, and desire for, the stereotypical hero figure (1994, pp.75-105).

The views of the single mothers as it related to fatherlessness and father-absence can be grouped into three general themes; fear and 'threat' of homosexuality, the highlighting of fatherlessness in the media and mother-blame. Participants expressed their own concern, and reported the anxiety shown by others, that 
parenting boys as mothers on their own would encourage homosexual preferences in them.

I think that one of the messages that we get given is that if we are close to our sons, we're going to turn them into queers ... homosexuals. (6)

The fear that if they don't play rugby and are being raised by their mothers that they'll turn out to be gay ... you've gotta get them into doing blokes things. (14)

I've got this fear-you hear the odd comment or read the odd thing about homosexuals and transvestites and things like that and that these are usually children who have been brought up in a single parent family. How right those comments have been I don't know but it worries me. (GP2)

I get the feeling from my parents that they're, they worried about [homosexuality] with my boys. ... I got the feeling from my father that they were at risk. (3)

What [Son's father] did say when he was a baby was that he would be a 'mummy's boy', whatever that meant? (2)

I do think that a lot of men's behaviour has slightly homophobic aspects to it where they're worried that their sons might have tendencies to be gay or sort of homosexual tendencies or something like that. (11)

But what they [researchers on the family] did say is that if boys don't have their fathers they have a tendency towards homosexuality. (5)

The mothers were vocal regarding the impact of the popularisation of fatherlessness through the media. They commented about the feelings of shame and unworthiness generated by the highlighting of father-need.

It makes me feel really bad, sometimes I feel like shit when I watch some of it. (1)

The newspaper clippings and the talk on the radio about fatherlessness and the statistics of suicide because their fathers aren't with them makes me feel like crap. I just don't agree with it. (5) 
They spoke also of their concern that highlighting fatherlessness would give young people, and others, an excuse to blame mothers or to treat them with disrespect.

[It gives] kids ammunition to chuck it at their mother's face because all kids are going to act ...adolescence is riddled with kids that are acting out. (14)

It can be thrown back at these women as an abuse issue for example - we had a neglected childhood because you didn't provide us with the financial ability to do this, that or the other therefore we had deprival and abused childhood but in fact the women are in a catch 22 situation, they've no money to do what their children want. (3)

One participant suggested that it would create the expectation in the sons' minds that they are disadvantaged.

When people talk about "these poor boys they haven't had their father with them", I think that it's absolute bullshit and it makes them more disempowered. It disempowers these boys because they think oh I have to stay a victim now for the rest of my life because their Daddy wasn't around. (8)

Issues raised by lesbian mothers indicated that there was an additional set of factors that they needed to negotiate. The fear of homosexuality, as described above with single mothers raising sons, was amplified and included also homophobic attitudes toward the mother and her lifestyle and the affect it could have on the sons' choices.

[Son] used to come out with all of it just repeat it. ... I was a dirty filthy rotten lesbian out of [Son's] mouth. [Father] was going to fight custody on the basis of the lesbianism. He said he'd never have [his son] growing up surrounded by women. He had had the whole stereotypical thing that it would be very very, very sick for [Son] to grow up in my lifestyle - he ran the risk of becoming homosexual (20)

I do worry and I wonder what on earths going to happen when he starts going out with girls if - he goes out with girls, I suppose - I don't wanna pre-empt anything but that freaks me out ... how do you explain to your girlfriend that your mother's a dyke? (13) 
I think it gave me a particular sort of added feeling of self-hatred. How was I going to integrate the bits of me that were important because I have no doubt, my kids are really important to me? (18)

\section{The Sons' Voices}

It seemed, from reports by their mothers, that the sons expressed various levels of need for their fathers. Several of the mothers thought that their sons probably liked "the concept of having his father live at home. That's what I think, it's the concept that you miss" (14). They also suggested that there must also be "huge periods of disillusionment when kids find out that their father's not Arnold Schwarzenegger" (GP5). In the same discussion another participant believed that,

Those boys whose fathers have a lot to do with them ... have to go through that disillusioning process. It's that disillusioning process that kicks kids in the guts. (GP5)

Other mothers felt as if their sons missed their fathers' involvement, that they bemoaned not having a father who was interested and supportive in the things they were interested in.

[Sons] used to envy their friend's fathers who would be involved in sports and he would take them to places ... was involved on a conscious everyday level. They began to notice that they were different. (18)

Writer's note: I watched my son play rugby today and after the game I congratulated his friend for scoring one of the winning tries. He has scored a try each game this season and when he does he shoots his arm in the air and points to his father. He explained to me how his father, who had been away from the family for several years, was his inspiration and it was for him that he played (June, 2000). 
Figure 0-1: Representation One of the Father by Males Aged 10 to 18 yrs

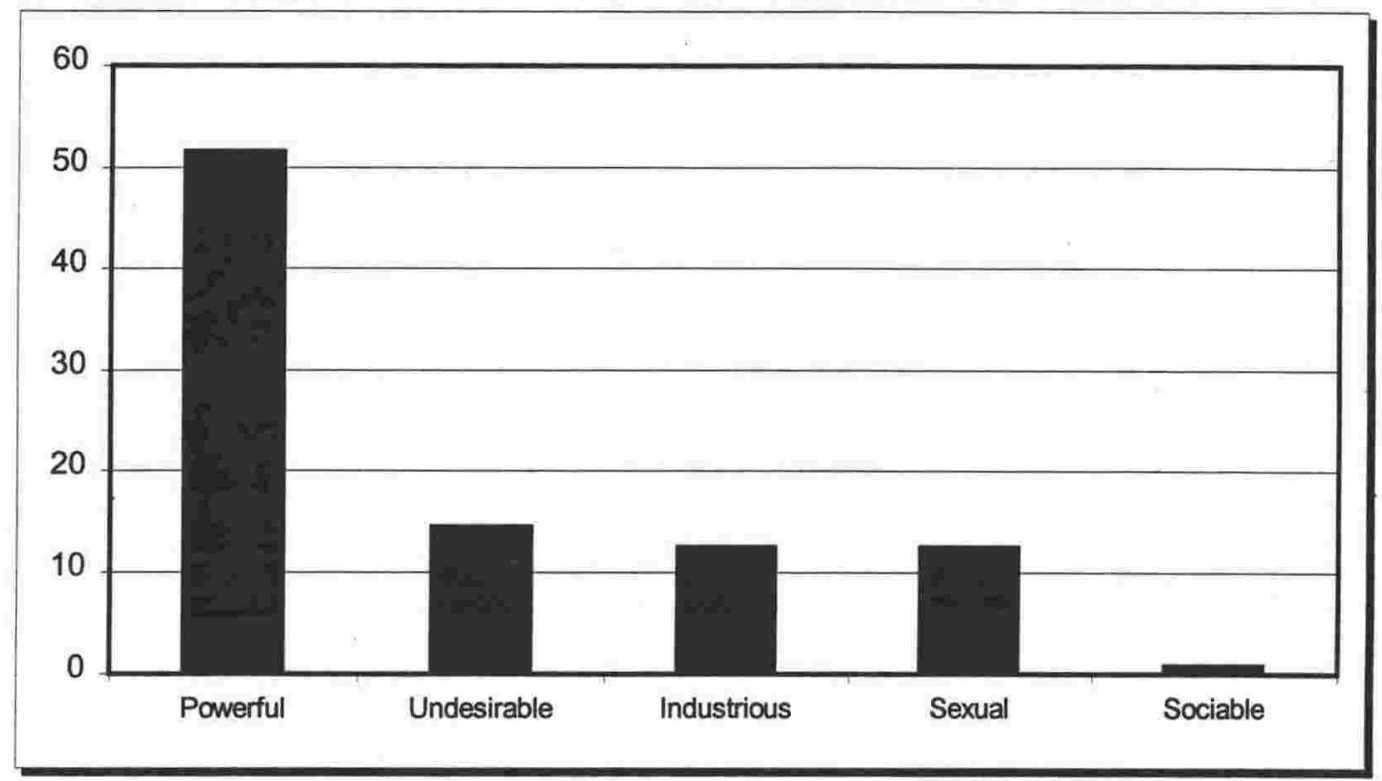

Figure 0-2: Representation Two of the Father by Males Aged $10-18$ yrs

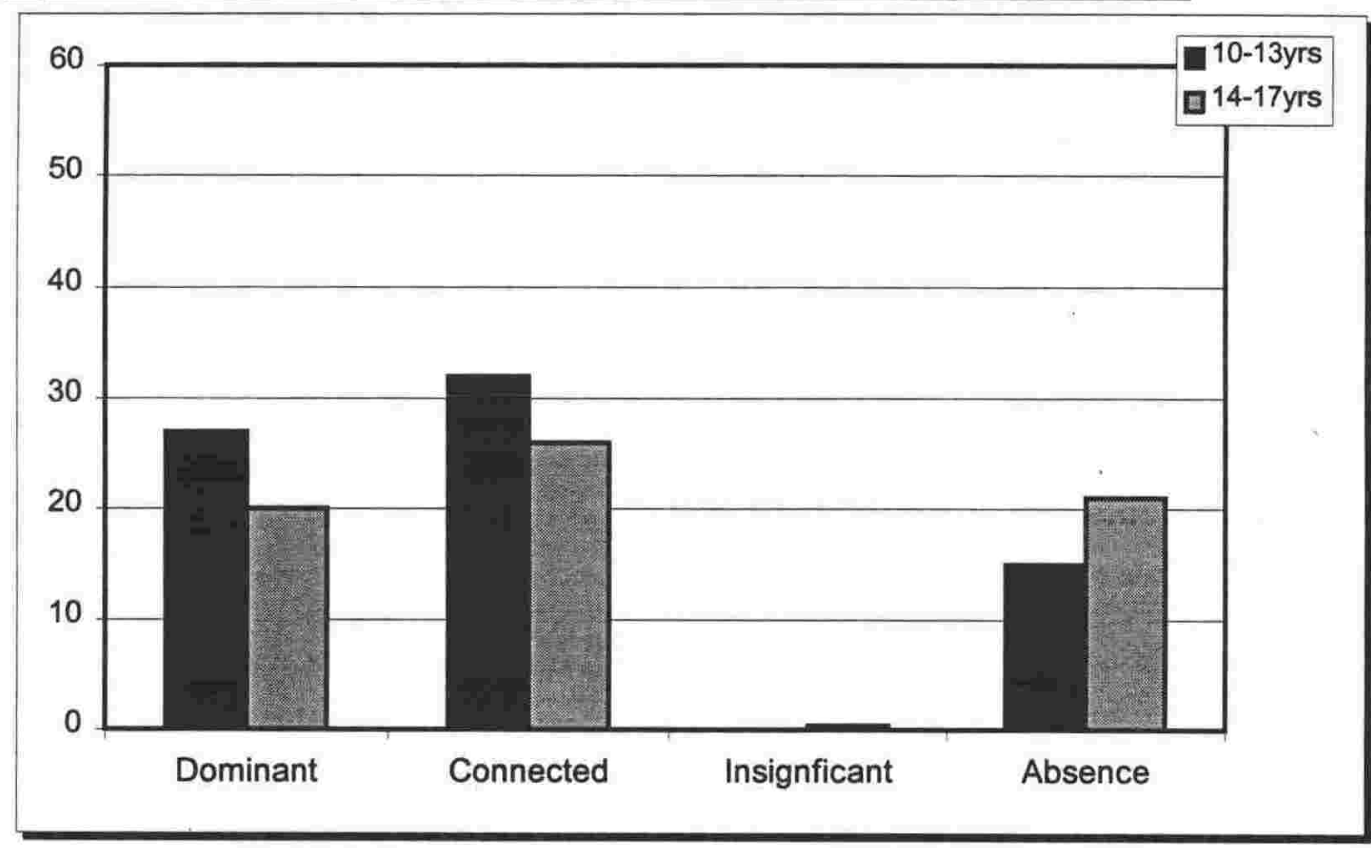

Figure 7.1 demonstrates representations of the father by ten to eighteen year old boys using the categories 'vulnerable', 'powerful', 'undesirable', 'sexual' and 'sociable', in one hundred and thirty two F-A-A-Ds in the Drawing Interpretation Project. Over fifty percent of these males depicted the father as powerful. A much smaller number of males, just over fourteen percent, depicted their fathers as undesirable. In descending order the remaining males depicted him as industrious, sexual and sociable. None were depicted as vulnerable. Graphs 13 and 14 in Chapter Six, divide these figures into the pubescent and adolescent periods, within which the representations differ slightly. Of all the drawings (K-F-Ds and F-A-A- 
Ds) and using the categories dominant, connected, insignificant and absent the father is represented by the sons as illustrated in Figure 7.2.

Mothers also talked of the grief the sons experienced from the absence of their fathers.

Over the last six months [sons] have actually initiated contact themselves. ... On each occasion they both went round to proudly show their father their car. They wanted approval and they wanted support, wanting the warm fuzzies from their dad. ... It's been very sad for them because I could see that they wanted something from their father that he can never give them. (3)

I think he was more hurt. Why wouldn't my dad want to know me? What's wrong with me? He would have been happy with the odd letter, the occasional visit. ... [We] went through about a year of 'yes I do want to find him, no I don't want to find him' sort of thing... because he was actually scared of meeting his father. (1)

[Son] felt separation from his father. The kids had become hungry for the type of person that [Father] was ... that is - he was not a traditional kiwi bloke. He talked his emotions, his own feelings and fears, his guilt.

I know that [Son] would like to be closer to his father but I think he's given up on that. (13)

One mother, when her sons in their late teens expressed their sadness at their father's lack of interest in them, said,

I guess it's another stab at the grief isn't it. ... I have decided that loss and grief are something that is not a process that begins at $A$ and finishes at Z. It's a cyclical thing. (3)

\section{The Fathers' Voices}

The role of 'father' and definitions of 'fatherly' differ among writers on the subject. There has been a radical increase in research on fathering over the past decade. In previous chapters I have connected this increase in interest about fathering to changing socio-political thinking around the family and the role of the state in the 
family. This agenda is supported by a group of theorists such as Biddulph (1995 \& 1997), Blankenhorn (1992 \& 1995), Popenoe (1996) and Pudney (1994), who make claim about the essential importance of fathers.

Biddulph (1995) talks about the role of the father in rituals of male initiation. The purpose of this function, he maintains, is to teach the boy to contain his strength, to discipline the son and take a tougher role. He also suggests that the absence of the father causes the son to become over-confident and aggressive or underconfident, a "mummy's boy" who has problems with "bedwetting or soiling" is "reluctant to try new things" and has "irrational fears". "Wimpish fathers," he continues, "are everywhere. Boys require a certain sort of combativeness in order to get the message through" (1995, pp.118-119). In a later chapter Biddulph develops his definition of fathering by suggesting that it is also to do with physical fun and play wrestling, adventures and experiences in the "big wide world", telling stories about your life, introducing your son to your friends, showing him what you do for a living, teaching him things like "fishing, making stuff in sheds, billycarts or computers" (1997, pp.66-67). Warwick Pudney, an Aotearoa New Zealand counsellor and therapist, adds to this by describing the father's role as "building the son's internal structure, his self esteem [through] discipline and rigour" (1994, p 2).

David Blankenhorn, writer and founder of the Institute for American Values, expressed his concern about the emasculating of the father in a speech to the American Family Research Council. He describes the 'New Father' as "an altogether more likeable guy. He is nurturing. He expresses his emotions. He changes diapers. He shares equally in the responsibilities of domestic life. ... Yet there is very little maleness to be found in the New Father". Blankenhorn appeals to men to rebuild their "historically masculine traits such as competitiveness, aggression, and protection and provision for wife and children" (1992, p.2). During Biddulph's visit to Aotearoa New Zealand in 1997, a national weekly magazine exhibited a sensationalist front cover of a forlorn-looking male child hugging the legs of, one assumes, the father (New Zealand Listener, May 3-9, 1997). The related article quoted from a Canterbury study carried out by family therapist Don Rowlands who found that "38 percent of children born in any one year would, by the age of 16 , spend time living in a single-parent family" and that 
"60 percent of all children born since 1987 will not be living with their birth fathers at 13" (Ansley, 1997). Ansley quotes Blankenhorn who contends that, "fatherless families are the most harmful demographic trend of this generation, the engine driving our most urgent social problems, from crime to adolescent pregnancy to child sexual abuse"'. Spokesperson for FREE - Father's Rights and Equality Exchange, reiterates the attack on single mothers as the root of social evil, a sentiment which is echoed in the Letters to the Editor by comments such as, "studies comparing children from single-mother families and single-father families find that the latter do better than average, the former far worse" (Ansley, 1997).

Sam Keen, writer and influential figure in recent American-originating movements of men seeking to rediscover their masculinity, focuses on the father's role as initiator of the son into the world of men. He argues that men need to father in order that they can heal their own childhood wounds (1991, p.227). Similarly Robert Bly, a colleague of Keene's, refers to psychological damage caused by fatherlessness. He argues, "when the father fails to father the son, a hole appears in the son's psyche and demons move into the place where the father would have been" (1990, p.1). John Lee, founder of the Austin Men's Centre, North Carolina, describes fatherlessness as man's deepest wound (1991, pp.3-8). He not only blames his sense of loss to an alcoholic father but also holds his mother responsible for making "her crises become mine" (1991, p.101). In the advice to other men in his self-help book Lee says that healing for men does not happen through emotional attachment with women, but with finding the femininity of oneself as a man (1991, pp.103-107).

One of the seven promises of the fundamentalist Christian men's movement, Promise Keepers, is to "build a strong marriage and family through love, protection and biblical values" by "uniting men through vital relationships to become godly influences in their world" (1996, p.1). When reading these works, when examining mens' movements such as, DADI, FACT, FREE, Institute for

\footnotetext{
1 This statement became a 'catch-cry' in this country for the next several years, used by politicians, theologists, and family therapists. Refer, for example, Deborah Morris cited in Chapter Five.
} 
American Values, Promise Keepers, SPERM², an agenda becomes clear. These men are looking to find a culture that is uniquely their own, uniquely male, bonding, nurturing, strong, and their role as fathers is to ensure the initiation of the sons into this culture. The agenda also involves a reinstatement of their dominance as men and a determination to ensure that their sons are also welcomed and initiated into that position.

Different and confusing messages are given. Some of the discourse originating from the men's movements discusses emotional illiteracy as an inadequacy that needs to be addressed in order that men may find their manhood and be successful fathers. Other more fundamentalist movements and writers express homophobic concern that boys and men are becoming 'wimpish' (Biddulph), 'sissified' (Blankenhorn) and 'motherbound' (Pudney) and that a reassertion of the authority of men as head of the family needs to take place. Deborah Lupton, Associate Professor of Cultural Studies at Charles Sturt University, Australia, and Lesley Barclay, Professor in Family Health at University of Technology, Sydney Australia, suggest that fatherhood as a concept and lived experience is "replete with competing imperatives in western societies at the end of the twentieth century" (1997, p.1) The uncertainty, as argued by Lupton and Barclay, involves for the father, on the one hand, full involvement with his children including exploring and enhancing the emotionally sensitive parts of his nature and on the other hand the full participation in the paid-arena maintaining his identity as provider and protector of the family. These ambiguities are also enacted among men. Although the desire is expressed to have more involvement with their sons it appears that men do not wish to perform more of the work that the parenting role entails. Their active participation in home-based work has not markedly increased over the past two decades even though the number of males not employed in work outside of the home has risen significantly (Statistics New Zealand, Census 1996).

\section{Analysis of the Father-Need Discourse}

Since the early 1990s, an increasing number of books and papers have being written about fatherlessness, father-absence and raising boys. I was unaware, until

\footnotetext{
${ }^{2}$ Discussed in Chapter One.
} 
the Silverstein and Auerbach study of the identities of fathering in mid-1999 ${ }^{3}$, of any comprehensive and rigorous research that has thoroughly addressed the issues. The majority of what has been written is populist, is based on anecdotal evidence and the works of like-minded writers and offers fatherness/fatherpresence as a remedy for suicide, mental ill-health, unemployment, drug abuse and high crime statistics among male youths. Underlying much of this text is often a subtle, and not so subtle, condemnation of the mothers.

Several themes arise. There are those who strongly argue for the separation of boys from their mothers such as Blankenhorn (1996), Keen (1991) Bruce Mackie (1997) and Ward (FREE spokesperson). There are those who are directly critical about the harm that women do to boys and men. For example, Biddulph describes his concern that the role of father has become diminished. "According to some feminists 'a world without men, would be a world full of fat, happy women' to which we would add ....and very screwed up children" (1995, p.106). Pudney talks of "Motherbound fathers who will hide in the background of their home". While the mother is entertaining Pudney claims, "the father is somewhere else in the back, being inarticulate. ... Lost [in] his purposefulness as a man and a father" (1994, p.5).

Men's groups such as listed above and social scientists such as Blankenhorn (1995), Bly (1991), Keen (1991), and David Popenoe (1996) advance a simplistic neoconservative position that espouses the replacement of the "earlier essentialising of mothers with a claim about the essential importance of fathers" (Silverstein \& Auerbach, 1999, p.2). The statements of those supporting this thinking portray the mother as insignificant or harmful. Mothers in the project highlighted their concern about some men's groups.

I'm thinking here of groups like 'Manline', that are supposed to be interested in feminist things but quite anti-feminist. That's going to make it harder for women

\footnotetext{
${ }^{3}$ The qualitative research undertaken by Silverstein and Auerbach, which has involved 200 men from ten different sub-cultures within the United States; Haitian Christian fathers, Promise Keeper fathers, gay fathers, Latino fathers, white, heterosexual divorced fathers, Jewish fathers and Greek grandfathers; has shown that "neither a mother nor a father is essential". They have concluded that, "children need at least one responsible care taking adult who has a positive emotional connection to them and with whom they have a consistent relationship" (1999. p.2).
} 
to have good relationships with their sons particularly ... run women down, under-value them. (12)

A further agenda for the increase in interest around fathering is expressed by those supporting 'male emancipation'. The flyleaf on Biddulph's book Manhood claims him to be a liberator of men. Lifeline Auckland Director, Bruce Mackie contributing to the argument for men's liberation, maintains that the most serious problem society faces is that of inadequately raised men. What is needed, he says, is men who are "tuned in to men, sensitive about men. Not women - men" (Sunday Star-Times, May 11, 1997). Although Biddulph claims that this new men's movement offers men the chance to change their lives, to heal the past and form true partnerships with women (New Zealand Listener, May 11, 1997), it doesn't take long on reading his book to realise the underlying assumptions and belief systems on which it is based. Biddulph, whilst claiming to enhance 'true' relationships between men and women writes,

Most men aged forty and under have lived their whole lives in the feminist era. Men over forty have usually had to come to terms with it too, in some shape or form. ... It is a world where the attitudinal tide, the best opinion, the enlightened stance is in favour of women's worth, women's qualities and women's rights. This is great if you are a woman - but for even a wellintentioned man, well, it sort of puts you on the sidelines. (1995, pp.21-22)

He continues an undermining of the mother in a chapter headed How to Stand up to Your Wife where he declares, "though it may surprise many male readers to know it, women are only human" (1995, p.84). Continuing on he describes what a father should do when, for example, a teenage son has an argument with his mother.

$[\mathrm{m}]$ any boys at this age start to have problems with their mother. The son knows deep down he must break free from her. Driven by this pressure, he may act ugly, lazy etc toward her. The father, hearing this start to happen (from behind his paper in the lounge room) goes into the kitchen...and intervenes...'You need to always talk to your mother with respect'. He may join in, but his role is not to take over for his wife - just ensure courtesy and respect. This isn't to imply that his wife can't take care of herself, only that she shouldn't need to. $(1995$, p.121) 
Underlying these words are implicit messages. When a son reaches his adolescent years a mother becomes troublesome, she does not have the ability to work through difficulties that may arise in her relationship with her son, the father has the power and authority achieve that and the mother needs his power and authority in order to survive. This exemplifies for me one of my major concerns about the developing agenda of this movement. Rather than being a movement of cooperation and the development of healthy and mutually beneficial relationships the message being given to women and to mothers is that they are not adequate, that they have no place in the lives of their sons and are seen as being destructive to men, robbing them of their power and their malehood.

On a socio-political level, returning the father into the family structure in a society that has 17.7 percent single parent families (NZ Census, 1996) conspires with current socio-economic policy that aims at withdrawing state-funded financial support leaving families to care for themselves. Alliance MP, Phillida Bunkle, while she was spokesperson for Health and Women's Affairs argued,

there is a need for men to take responsibility for themselves, but it depends how. ... Men have grabbed the individual ethic and there is a problem of them abandoning their families, but I do not think an authoritarian reassertion of the right to rule is going to do anything other than make that worse. (New Zealand Herald, November 1, 1997)

We, as parents, practitioners and policy makers, need to carry out a comprehensive examination of the current situation for mothers and their children. We need to be aware of the dangers of calling for the unconditional involvement by fathers and identifying the return of the father as the panacea for the plight of young men.

\section{MASCULINITIES}

When the mothers were asked to offer an analysis of their worlds one of the key themes raised was the impact of societally constructed gender divisions. The major issue within this theme was that of masculinity, the persuasive impact of stereotypical definitions of masculinity on boys and the confusion about their roles as mothers raising men. As fatherhood discourse is increasing, so too is that relating to masculinity. Similarly too, a variety of viewpoints is presented. 
Michael King, historian from Aotearoa New Zealand, suggests that "traditionally held views of masculinity in New Zealand have contributed to a cycle of emotional deprivation, use of drugs and alcohol, violence and crime, which ... threatens a whirlwind of social destruction if not checked" (1988, p.vii). Michael Kaufman, social and political scientist at York University, proposes that since masculinity in a patriarchal society is a highly valued ideology, rather than biological reality, the anxiety among males to perpetuate their privileged position, creates enormous tension (1987, pp.2-27). He maintains that it is this tension that creates men's violence against women and against themselves.

Alternatively Leanne Payne, president of Pastoral Care Ministries, believes that the development of masculinity within a man requires bonding with his father. "His deprivation of father-love, father-touch, father-communication," she suggests, can result in "compulsions to touch and be touched by other men" leading to an unnatural homosexual lifestyle (1993, p.77). The founders and supporters of the men's movements such as Biddulph, Bly, Lee and Keen contribute further input to the discussion of masculinity. In one of Keen's books, for example, is included a report of a survey he administered with six thousand men and women on Who is the Ideal Man (1991, pp.258-268). Outlining the results of the report Keen states that "average men are still defined by the traditional rites of the warrior - initiation into manhood by the ordeal of circumcision, getting a gun, going to war and achieving mastery over women" $(1991$, p.261) .

Pam and Rob Gilbert ${ }^{6}$, Associate Professors of Education at James Cook University, Australia, challenge the "mystical origins of masculinity woven into a history with no base in evidence" which they perceive as the "hallmarks of the populist men's movement propaganda" (1998, p.28). They contend that common definitions of masculinity include a privileging of masculinity over femininity and leads "to the conclusion that men need to 'pull away' from women in order to

\footnotetext{
${ }^{4}$ The survey appeared in Psychology Today (March 1989) requesting respondents.

${ }^{5}$ The same report described the ideal man's attitudes toward women as "sugar and spice, slightly more nurturing and intuitive than men, and less aggressive in general and in the bedroom than men" (Keen, 1991, p.263)

${ }^{6}$ Gilbert and Gilbert strongly challenge the essentialist notions of masculinity promoted by writers such as Bly, Biddulph et al
} 
become men" (1998, p.29). Along with Gilbert and Gilbert, Mairtin Mac an Ghaill, teacher at the University of Sheffield, argues that the formal education system is a key masculinising agency for boys. In his book, The Making of Men, Mac an Ghaill explores "beyond the essentialist sex/gender categories to look at the way masculinities are made and remade in schools" (1997, p.13). His work highlights the connectedness between traditional constructions of masculinity and new right moralistic thinking, structures of power relationships, the motivation of capitalist labour markets and the social positioning of gay male students.

\section{The Masculinity Dilemma for Mothers}

The mothers in the project discussed their wish to raise their sons to behave differently from the macho behaviour displayed by most of the men in their lives. They also spoke of their struggle to do so, about the dilemmas they experienced wanting to encourage their sons to resist prescribing to a macho form of maleness and yet not wanting to alienate them from their friends or the worlds that would acknowledge and affirm them. Rich explains that," the fear of alienating a male child from 'his' culture seems to go deep, even among women who reject that culture for themselves every day of their lives" (1986, pp.204-205). Arcana also discusses our role as mothers in the making of (macho) men. She argues that mothers have "deliberately contrived to protect [their] children from penalty, to ensure that they will be safe and successful adults" (1983, p.118).

One of the difficulties for the mothers was the lack of effective and available role models.

I don't know how you provide good role models for boys growing up because there are so few of us around who have actually experienced good models. (12)

That was the tension for me. It was always encouraging that gentleness in them ... [when] macho is the male thing. ... The male leaders of our country ... giving $a$ very clear message to young men of this world that women really haven't progressed that far. (8)

They talked also of the systemic definitions of masculinity as macho, the pressures for males to confirm to these image and female to accept the conformity. 
I think in terms of sport, the patriarchal nature of the media in terms of sport, there are so many changes to happen. ... The alcohol consumption, especially beer, and the lack of male role models who aren't macho and aggressive winners. (20)

Alternatively the males who did not conform to prescribed macho behaviours faced rejection.

When you're hurt ... can't talk to your father because he'll just sort of say it'll be okay, or for god's sake be a man. (8)

Well I think for a lot of boys is that whole macho thing when they're not allowed to feel ... affected my sons badly. ... I think those expectations are still very much there for most boys. It actually dehumanises men. (12)

I thought at that stage the boys at school have obviously sort of passed on some message to him that he's gotta be a man and sort his own problems out and don't be wuss. (1)

One of the things that I have found is that fathers of boys often get really worried if they think their sons are going to grow up like sissies, poofters. ... What [father] did say when he was a baby was that [son] would be a mummy's boy. (2)

The mothers talked about their ambivalence as it related to the behaviours of their sons.

My middle boy [acted violently] in a big way, and I was very worried about it. He was going to nightclubs and getting into fights and of course, because of his build and his agility, he was coming out the winner. I just kept talking about it and talking about it and saying 'look, violence just isn't what you do'. ... This went on for several months. I would hear that he had been in a fight which to me was totally abhorrent. (3)

They're not allowed to be a man by actually showing how they really feel. ... There are confusing messages given to men I give him confusing messages too. (5) 
The challenge to 'be a man' is also made by Bambi's father.

One day Bambi wandered for hours through the thicket. At last he began to call. He simply could not bear to be so utterly lonely any more. He felt that pretty soon he'd be perfectly miserable. So he began to call for his mother.

Suddenly one of the fathers was standing in front of him looking sternly down at him. Bambi hadn't heard him coming and was terrified. "What are you crying about?" the old stag asked severely. Bambi trembled in awe and did not dare answer. Bambi was completely dominated by his masterful voice and at the same time, he admired it. "Can't you stay by yourself? Shame on you!!" (Salten, 1988, p.123)

\section{The Initiation of the Sons into Manhood}

The entry into manhood for boys is one that is fraught with conflicting messages. In Bambi's story the point at which the 'manhood seed' is sown is the appearance of the fathers.

Bambi looked at them and did not stir. They looked like his mother and Aunt Ena. But their heads were crowned with gleaming antlers covered with brown beads and bright white prongs. ... one was smaller and his antlers narrower but the other was stately and beautiful. He carried his head up and his antlers rose high above it. They flashed from dark to light, adorned with splendour. (Salten, 1988 , p. 43)

Describing the symbolism used in mythological tales Nemann (1964), points out the common use of the tree to exemplify the phallus. Although the following paragraph appears later in Bambi's story, it extends Salten's use of imagery to the antlers of the stags, and helps explain the emphasis that he places on their size and shapes.

..... the kings had antlers branching like tall, strong trees. And it seemed to him that their voices were as strong as their antlers. Whenever he heard the deep tones of those voices he would stand motionless. Their deep voices rolled towards him like the mighty moaning of noble, maddened blood whose primal power was giving utterance to longing, rage and pride. (Salten, 1988, P.88) 
The story of Bambi's first encounter with his father continues.

The children did not dare to breathe until he had disappeared into the thicket. ... "Those were your fathers". [Bambi] was silent for a long time before he finally asked "Didn't they see us?"

His mother understood what he meant and replied, "Of course they saw all of us".

Bambi was troubled. "Then why, why didn't they stay with us?" "They don't ever stay with us" his mother answered, "only at times".

Bambi continued, "But why didn't they speak to us?" His mother said, "They don't speak to us now; only at times. We have to wait till they come to us. And we have to wait for them to speak to us. They do it whenever they like".

With a troubled heart, Bambi asked, "Will my father speak to me?"

"Of course he will", his mother promised. "When you're grown up he'll speak to you, and you'll stay with him sometimes".

Bambi walked silently beside his mother, his whole mind filled with his father's appearance. "How handsome he is!" he thought over and over again, "How handsome he is!" As though his mother could read his thoughts, she said "If you live, my son, if you are cunning and don't run into danger, you'll be as strong and handsome as your father is some time and you'll have antlers like his too". Bambi breathed deeply. His heart swelled with joy and expectancy. (Salten, 1988, pp.44-46)

I have quoted extensively from Bambi. This is where the seed is planted in Bambi's mind that there is a world for him to aspire to that is better and more important than the one he has shared with his mother. Salten makes a point of indicating that it is for Bambi, not for Faline (his female cousin), that this promised world exists. It is here that the ultimate betrayal of the mother and the female world begins. Ancient stories give numerous accounts of the juncture where the boy is shown (usually by his father/father-figure) the world that is his prize should he successfully meet the challenges presented to him. It is also made 
clear to him that if he should fail, however, he is doomed forever to live in the world of women, or better he should die. These stories have been told and retold in many forms, investigated and interpreted and represented. I have threaded together here those versions of the stories which best exemplify this turning point.

One of these is that of Theseus. As Arcana (1984, p.202) describes Theseus' beginning, he was raised by his mother 'in-waiting' for a pre-ordained time when she would send him out to find his father. He grew up knowing that under a stone, close to his home, were sandals and a sword put there by his father. His father had left the home, when Theseus was very young, to fight his enemies. When Theseus had grown to an age where he was strong enough to lift the stone and big enough to fit his father's sandals he left his home. The stories of his journey as retold by historian, Kathleen Daly (1992, pp.111-114), tell of how he went on to revile and destroy his mother's world and all that it represented. This included the abduction and later abandonment of Adriane after she helped him kill the Minatour, and his part in the pursuit of the Amazons. "The conquest of the Amazons, a warlike tribe of women, may represent an early version of an attempt by men to achieve supremacy over rebellious women" (1992, p.59).

The legend of Maui Tikitiki-o-Taranga as told by Maui Pomare, leader and contributor to the late nineteenth century survival of the Maori, is another that reflects this point of transformation from boy to man. Maui, prematurely born, was cast into the sea in the topknot of his mother's hair. He was rescued and brought up by Tangaroa, God of the sea. When he was told of his origins he returned to the place of his birth, revealing himself to his mother and brothers. Once there he wished to find his father. Observing that his mother frequently made secret journeys to the underworld Maui changed himself into a pigeon and followed her. The inhabitants of the world began to pelt him with stones. Maui's father's stone struck him dead. When his father picked up the dead pigeon Maui changed himself back into his human form. This way he was made known to his father, who then ritually named and purified him (1934, p.134).

There are many accounts of traditional rites or initiations characterising a boy's passage to manhood by acting out the separation of the boy from his mothers' world. The Jewish son at Bar Mitzvah leaves the gallery of women and children in 
the synagogue and moves downstairs where the men worship. Long hair is cut short and nipples are amputated. In innumerable ways there is a playing out of the rejection of anything that may be 'feminine', often accompanied by a subjection of extreme pain and hardship. This is the time when male children are taken away from women and branded incomplete until the men themselves have given them new life. Ironically this time can also be symbolised by men claiming the ability to be as woman, to create life and to make men for their own. Some of these ceremonies are characterised by men pretending to be women by playing midwife or the pregnant, labouring mother. Rita Gross, Associate Professor of Comparative Religions at the University of Wisconsin, has extensively researched the role of women in Australian Aboriginal religion. She describes the Australian Aboriginal men's secret rituals of initiation of boys, including subincision, an operation in which the underside of the penis repeatedly cut with a shell until it is grooved from root to tip emulating menstrual blood, and intricate ceremonies which re-enact the birthing process. Examples Gross offers, which are generic to a number of tribal groups include; the behaviour of the circumcisers at initiation as they carry their male novices about in the same way women carries babies; the initiates learning new roles, as if babies, including totemic languages unknown to women; and the final public exhibition of these 'new' beings created by the men (1987, pp.48-51).

Anthropologist David Greenberg describes aspects of the initiation rites in Papua New Guinea that are based on the belief that a boy will not mature physically until semen is planted in his body by a male adult. There are variations on the way this occurs. In some tribes initiates will leave the mother's hut at age twelve to thirteen to take up residence with the mother's brother in a homosexual relationship until he is a fully developed man (around seven years). In other tribes the mode of intercourse is oral or involves masturbation and the smearing of semen over the body of the younger partner. It is believed, according to Greenberg, that "valued male qualities, such as courage, proficiency in hunting and the ability to dominate women, are transmitted in [this] way" (1988, pp.26-29).

Although these traditional societies developed systems for the initiation of boys into manhood by blatant and complex rituals, it does not seem that there is one designated time when this initiation occurs in white Western society. It seems that 
a gradual and pervasive pull removes boys from their mothers' influence, taking them into arenas of male interest and action. An examination of the individual ways this separation is played out reveals significant themes. An anxiety seems to develop around the boy. Will he be tough enough to survive? Will he act like a 'woos' or a wimp? Will he be a 'Mummy's Boy'? Often this time is symbolised in the move from primary to secondary school where, according to Angela Phillips,

episodes of theft, extortion, bullying appear to be so prevalent amongst boys at secondary school (irrespective of social class) that they can almost be classified as initiation rites set by older children as the start of the hardening process that leads to adult masculinity. (1993, p.74)

Other informal rites are enacted. A first beer. A first trip away with his father on his own. Being taken to places where men congregate, most often sports functions. Watching a pornographic movie. Eastwood's report, commissioned by the Ministry of Youth Affairs (1998) on Young Male Risk Behaviours suggests that young males have very distinct contemporary "rites of passage" including "getting blind drunk with a group of mates, mutual bragging about sexual conquests, joy and speed riding" (1998, p.31).

Law, Campbell and Dolan include in Masculinities in Aotearoa/New Zealand (1999), a discussion about masculinity with social historian Jock Phillips. Phillips describes his experience of male behaviour and male-only situations in Aotearoa New Zealand. He describes the communication systems involving "a whole pattern of language, swearing and a kind of joking ribaldry" (1999, p. 47). He proposes that it is the colonial history of Aotearoa New Zealand and the significant involvement in war that have determined the behaviours and perceptions of (white) masculinity in this country (1999, pp.46-61). Annabel Cooper, Head of Women's Studies at Otago University, echoes this theme when she examines Maurice Shadbolt's play, Once on Chunuk Bair, which involves Aotearoa New Zealander's in World War I. In her discussion she highlights the connection of masculinity, war and nationalism. She describes the experiences on the battlefield through which Aotearoa New Zealand redefined itself and grew up and away from 'Mother England'. "New Zealandness"', she maintains, "is drawn into an equation with 'New Zealand masculinity'" (1999, p.99). 
The interest in masculinities, as a subject for study, is relatively new in this country. Continued study resulting in new knowledges could conceivably begin to inform the basis of new and healthier aspirations for our young men (so long as it does not compromise the academic ground won by feminist scholars). Law, Campbell and Dolan suggest six themes relating to an analysis of masculinity. Firstly, that masculinity is made invisible by treating male perspectives and experiences as the norm. Secondly, that masculinity is socially and historically, rather biologically, constructed. Thirdly, that masculinities are plural. Fourthly, that masculinities are actively constructed, rather than being roles, stereotypes and ideals that are passively incorporated by individual. Fifthly, that masculinities are relational constructs and, lastly, that masculinities must be understood with reference to issues of power (1999, pp.24-25). Perhaps examination of these themes could offer a starting place for mothers seeking to negotiate the boundaries between emasculating and nurturing their sons.

\section{CHAPTER SUMMARY}

This chapter has analysed fatherlessness and father-absence discourse through the voices of the mothers, the sons, and the fathers. It has illustrated its impact on the mother and on the mother-adolescent son relationship. The discussion has concentrated also on the initiation of boys into manhood and constructions of masculinity. The focus on fatherlessness and father absence as a societal ill sets up a no-win situation for the father, the mother and the son and I question seriously the motivations behind this accentuation. There has been much discussion nationally and internationally about the importance of the involvement of the father with the son. A common theme generating from the project fieldwork shows that it is more important for a parent to have self-esteem intact, the ability to show love and affirmation and also with a belief about who they are as an adult and a parent than it is to be a parent of either gender. The research currently being undertaken in the United States of America by Silverstein and Auerbach indeed confirm this. The significant variables that predicated positive child adjustment, they found were, "emotional connection and the predictability of the care taking relationship" (1999, p.2). 


\section{CHAPTER 8}

\section{THE UNDERMINING OF THE MOTHER}

Chapter Eight discusses the undermining of the mother and the reported impact it had on her confidence and self-esteem. The first section discusses the way that the mother, and mothering, is denigrated. It pays particular attention to the use of negative and oppressive imagery depicting mothers and mothering. The second section examines the manner that the mother as an individual and motherhood as a construct is held responsible for difficulties that young males may be experiencing. The final section examines issues of confidence and self-esteem of the mother and the link between the sense of self and the ability of the mother to parent her son(s) effectively.

\section{THE UNDERMINING OF THE MOTHER}

This section includes discussion from the mothers in the project about the undermining they experienced, who it was promulgated by and the impacts the undermining had on the mothers. Although this section discusses the experiences of the mothers with sons of all ages, attention is focused on the time when the sons reached adolescence. This appeared to be the time when the disapproval of the mother was intensified.

\section{Undermining by the Fathers}

As reported by the mothers in the project, the denigration they experienced from the fathers of their sons occurred in a variety of ways and was not limited to any one grouping of mothers.

It's also women who are also parenting with the father of their sons or with a man, that these issues are still happening. I thought it was a single-parent issue, but it's not. There's still the grief and withdrawal and the put-downs and all that sort of stuff. (GP4) 
The mothers described being labelled emotionally unstable and deficient as parents. One of the mothers expressed embarrassment and awkwardness at her husband's crudity. Another talked about the insults she received from her husband in front of the children.

[Husband] used to go chook chook chook chook chook chook chook chook, there she goes again, there she goes kids listen there she goes again chook chook chook chook chook chook chook (16)

[Father] was taking them [the children] aside and saying 'your mum's sick. Your mum's mad and I have to take care of you'. (15)

Another spoke of the impact of the father as a model of disapproving behaviour.

'Mum why don't you do this, you're not doing it properly'. So they learnt to actually criticise me seeing what their father had done. So I kind of took on this whole belief that I was weak and I couldn't do this and I wasn't a very good mother. (14)

Another felt her beliefs were attacked.

... like my more feminist stuff which I blabbered on about for years with them where they would roll their eyes and look to the ceiling and say 'Mum's going on about her thing. ' (11)

The use of 'blabbered on' in this last comment is indicative of the self criticism demonstrated by some of the participants when reflecting on their own ability as mothers and, I suggest is, in part, engendered by the ongoing faultfinding directed at them. There were also reports of claims of psychological instability of mothers made by fathers. One, for example, would declare openly to people within the community in which the mother and children lived,

[Mother's] unstable, that's why I'm leaving her. ... He was trying very hard to make me crumble. ... He goes to my children's school, he takes over their school, they think he's wonderful and they think I'm horrible. (15)

He was a very silent person who didn't speak a lot about his feelings and didn't share a lot of himself. [He would say] 'there she goes kids listen there she goes 
again'. ... He would then have them look right at me as if [to say] 'just look at her isn't she a silly bitch. Just look at her. This is what the sort of mother you've got.' (16)

The mothers reported feeling as if their authority as parents were undermined.

One of the things that I remember most was him saying, '[Mother] how can you let the children talk to you like that' in front of them. So the children learnt that if they misbehaved their mother was growled at, their mother was told off for their misbehaving. (18)

This mother described how her husband's criticism undermined her.

[Father] had this amazing string of stories but they gradually got worse ... They got more and more smutty and quite offensive and so did the language that he used. Every second word would be a swear word and it'd be shit this and bloody that you know that sort of thing. He used to make the children laugh and they would find this really funny and often I guess there would be just the occasional reference to penises or something like that in a joking sense and I felt, I could feel myself pulling back the other way and becoming more and more conservative if you like in terms of and trying to achieve a balance and saying to the children and this is where the tension sort of built up although we didn't argue and I think that was another thing too, he didn't control my parenting I suppose he did he was undermining it in some ways. (21)

Physical and psychological violence was another way that mothers experienced the condemnation of their sons' fathers.

It was much more a psychological fear. I knew that if we had an argument he would end up hitting me, so I just made sure we didn't have an argument. I just shut up. So I didn't challenge him. (GP 2)

A lack of personal support and affirmation was experienced by some of the mothers.

When I graduated ... he actually arranged to be [overseas] at the time of my graduation so he couldn't be there for that. Yet he knew how important that 
was. He didn't even ring on the day so I guess there was a feeling of he doesn't really respect me. (21)

\section{Undermining by the Sons}

During the interviews a number of the mothers described the attitudinal change of their pre-adolescent sons toward them, a change that was often challenging and negative'. They described the sons' identification with the male/father world considering it superior to the female/mother world. The mothers also spoke of physical and psychological violence and of being criticised for what they looked like or for what they thought.

[He would say] "I'm nearly as tall as you mum." Height is very important for [Son] and he is worried sick that he is not going to be taller than me. ... It is quite important for him to be taller than mummy. (7)

[Son] towered over me when he was 14. They make a big play on that and I think that's another reason why [Son] thinks he has control over the house because he's the biggest by far. ... He'll look down on me. (14)

He was actually lashing out at me a couple of times. He was 14. He was very chuffed when he got taller than me and it was just a big buzz in his head and he seemed to think that because he was taller than me he could dominate me. (GP 2)

One of the problems that I actually have is that my eldest teenage son is really quite into putting me down and gives me heaps of criticism, and heaps of put downs, and not very much positive stuff and I find that really hard. (GP 3)

I was working out in the garden and he comes out and looks at me and says, "gee mum, I thought my thighs were fat, but yours are ten times worse". (4)

[Son would] certainly [put down] my opinion on things ... The impression [my opinions] might have on him was much less. ... I suppose he was polite,

\footnotetext{
1 This attitudinal change is discussed more fully in Chapter Five under the section, 'The Disruption to the Mother-Adolescent Son Relationship'
} 
sometimes actually you reminded me now, I felt quite hurt often. I think he was polite, he was distant, he was probably scathing. (9)

He was saying heaps of rubbishy things to me. ... Just sort of running me down. ... Saying that I have absolutely no memory and I was hopeless and no brain. (GP3)

Best and Keller, use the popular American TV series Beavis and Butt-head to indicate how white youth think about their mothers. According to Best and Keller, Beavis' mother is constantly denigrated as a 'slut'. It is emphasised also that Beavis was born by artificial insemination (1988, pp.74-81). Silverstein, describes how the movie, Boyz $N$ the Hood, portrays the invisibility and inadequacy of mothers of adolescent males. Boyz $N$ the Hood, she explains, tells of an inadequate divorced black woman who believes she does not have the authority to discipline her son. Wanting to do the best for her son she hands him over to his father who takes him on a journey through violence and aggression to manhood (1994, pp.14-15). The Karate Kid is another film discussed by Silverstein that illustrates the achievement of masculinity for males. In this story the relationship between a mother and pre-adolescent son is deemed to be a barrier to his masculinity. His schoolmates pick on him and label him a 'sissy'. The story shows how an old Chinese man rescues the boy by teaching him the martial art, Karate. The film ends with the son lying bloody, but triumphant, on a stretcher with his mother standing terrified but proudly beside him (1994, pp.13-14). Other popular 'blood-and-guts' movies where the heroes do not have mothers are listed by Silverstein. Movies, such as, Rambo, Die Hard, Under Siege, Menace II Society (1994, p.13).

Further examples of films with this theme have been shown on television in Aotearoa New Zealand. One of these, Stand By Me (Sky TV, November 1998) told the story of four twelve year old boys who venture into a forest to look for a body. During the escapade one boy becomes afraid. In anger another boy yells abusively at him, "why don't you go home and fuck your mother!" An adult male character in A River Runs Through It (Sky TV December 1998) used the word 'woman' as a label when any of the boys were fearful. In a third film, Ruth Rendall's Fallen Curtain (TVNZ Channel 1, January, 99), one of the boys is 
teased by others who chant, "Richard loves his Mummy! Richard loves his Mummy! Mummy! Mummy! Mummy!"

\section{Father/Son Collusion in the Undermining of the Mother}

One of the negative aspects highlighted by a significant group of these participants was that of the collusion between the father(s) and the son(s) in the subjugation and denigration of who they were as women.

Once [the boys] got older [Father/Husband] started to tell jokes with them...shit this and bloody that ... occasional reference to penises and...breaking of wind...he was undermining [my parenting]. ... I used to feel very uncomfortable. ...[It] made me very tense. (21)

I've said things to [Husband] like I feel like you and [Son 1] and [Son 2] are united in attacking me and he has come back and said no that's not true. That's not happening. (12)

Others spoke of the sons emulating their fathers' negative behaviours.

I couldn't wear the fact that on one level I was being treated like that by my husband. I wasn't going to wear from [sons]. (8)

I was actually in tears one night because he just gave me heaps. He just gets frustrated and he's gotta unload it somewhere and it's me that takes it ... seems to be something that happens in society normally in marriages a guy unloads onto his wife all the frustrations of the day and unfortunately [Son] is following that. (4)

Mothers also reporting the fathers' condoning and encouraging of sons' sexist behaviour.

An issue for us was when he bought pornographic magazines home. ... [Father] just told me that it was part of boys growing up and I shouldn't worry about it which was really difficult because I wasn't just dealing with [Son] then I was dealing with [Father] too and my sense was like I'm the one who's got a problem. (9) 


\section{Undermining by 'Society'}

This thesis is built on centuries of discourse by powerful and influential feminist theorists and practitioners who have addressed the gender oppression of women' ${ }^{2}$. The undermining of mothers by society is part of a larger set of issues, some of which have been addressed throughout this dissertation. For the purposes of this research I am not interested in arguing that mothers of adolescent sons are any more discriminated against than any other group of women, but rather that we do experience discrimination. The mothers reported the expression of this societal marginalisation as follows,

There was actually something like that in the paper sort of saying that women deserved to be hit because they nag and nag and nag. (15)

There's still such a huge amount of sexism, machismo about and I see my boys picking it up and bringing it into the family and putting their sisters down. (4)

We have to be more strict and controlling on our children, because if they go to school and are naughty it is going to come back on us because 'look at those single parents, can't even bring those children up'. So we are taking a lot of things society is projecting upon us and actually projecting it back onto our children. (3)

Solo parents, single parents, whatever people call us, shouldn't be allowed. I still get that feeling. The message still comes across. On television, in the papers. They shouldn't be allowed. (1)

You often see [mothers] on TV or in magazines or whatever. Mothers with little kids are quite natural ... but with adolescent boys, particularly like on those TV shows, mothers are shown as shorter than their sons or they're in the background or they're in curlers. (GP4)

When examining how the mother is represented in popular imagery of today such as television, internet, magazines, videos, films, "the idyll and the actuality (is) held in a strange kind of double vision; the mother is either sentimentalised or

\footnotetext{
${ }^{2}$ Refer discussions in Chapters One \& Two
} 
ruthlessly caricatured" (Rich, 1986, p.202). The caricatures seem to be exaggerated when she is portrayed in relation to adolescent boys. She appears in curlers, she is shorter than her son, she is dithery, she is clucky or (s)mothering, she has little intelligence, she is quietly in the background or totally absent from view, she is to be spoiled and pampered, she is not allowed to be control and she is definitely not someone of whom the son feels proud. The archetypal 'domineering mother' image is one that can be seen reflected in socially constructed images particularly when the male son reaches adolescence. One mother described the way that the images and messages are given as "subtle" [and] "just the impression that is given" (GP 2). Participants recounted a variety of respects in which they were defined, as mothers and as women derogatorily.

Mother as sex object,

I haven't got any men friends. And the ones that you do start to develop become sexual - you get the sexual stuff on that. You get tired of it. I'm not a sexual being; I'm a human being who's a person. Just because I am a female it doesn't mean I'm here for what they want. (5)

My values of bringing up my children were often a conflict with their father. Like he thought it was okay to have those sort of nude posters on the wall. ... and sexist language and putting girls down and all that sort of stuff. (1)

It's not only the photo [of a large naked woman on the wall of a father's shed] that's a put down for woman. ... I didn't see a big fat nude man on any wall. (GP 8)

Mother as housekeeper and homemaker,

[I] never got caught up with the sideline culture or rugby. I loathe it. I just don't want to know. So what happens when it comes to prize givings? Mums bring plates and all that kind of stuff. (3)

Mothers are there just to provide you with all that sort of caring stuff. (8)

I am only a woman and a woman's place is in the home, and women do this and women do that. (5) 
I just felt like I was the maid around the house. There to do the washing, the dishes, the cooking, the cleaning and that was all I was there for. I asked him on several occasions why he had stopped helping, because he used to always help with housework. He would do the vacuuming and I would do the dishes, or visa versa, and he turned around and said 'that's women's work'. (1)

Mother as subservient and weak,

Are these boys giving me a hard time simply because I'm their mother and I don't have in their eyes as much authority as perhaps a man might have? (4)

Seems like the conditioning has been [that the] male [should] be the dominant one, because I went to Karate the other night, and the kids wouldn't listen to me and made fun of me in front of the [male] instructor. (2)

[A colleague said to me], "you will do well in a boys' school. ... You'll be fine, you're assertive, you're mean." It's really interesting to me though that when a women shows their strength that that then has to equal male. (1)

Mother as fussy, a worrier and someone who garrulous,

We're given a lot of those messages that come through as caricatures ... even if the sons wouldn't actually say that. ... We fuss, that we worry, we panic, that we try to control them, we don't let them grow up but we get involved in their lives that's none of our business. (9)

Mother as unintelligent,

You know you've got no brains. ... They were between 15,16,17. That sort of age of thinking "oh god what do you know about things". (8)

The statement of this mother was reiterated by a further attack from Anglican Canon Gerald Hadlow who compared mothers to fathers in his regular newspaper column. Apart from stating his concern about the harm of homosexual parents on children, he claimed that mothers are important for the nurturing of their children but, fathers, on the other hand, "have a powerful influence on the academic 
achievement of children" (November 11, 2000). His message was clear. A male was raised by his father. One participant was regarded by her son as "a manhating feminist". This sixteen-year-old son also told his mother that "women abuse children more than men do" (12).

One of the exercises, the Family-As-Animals-Drawing in the Interpretive Drawing Project, illustrated a further set of images that sons had of their mothers ${ }^{4}$. Of the one hundred and thirty two F-A-A-Ds, and using the categories vulnerable, powerful, undesirable, industrious, sexual and sociable outlined in Chapter Six, she is represented as illustrated in Figure 8.1. Almost forty percent of these boys depicted the mother as vulnerable, and half as many depicted her as powerful. In descending order the remaining males depicted the mother as industrious, undesirable, sexual and sociable. Graphs 13 and 14 (Chapter Six), divide these figures into the pubescent and adolescent periods, within which the representations differ slightly. Of the three hundred and thirty nine drawings and using the categories dominant, connected, insignificant and absent the mother is represented by the sons as illustrated in Figure 8.2.

\section{Figure 0-1: Representation One of the Mother by Males Aged $10-18$ yrs.}

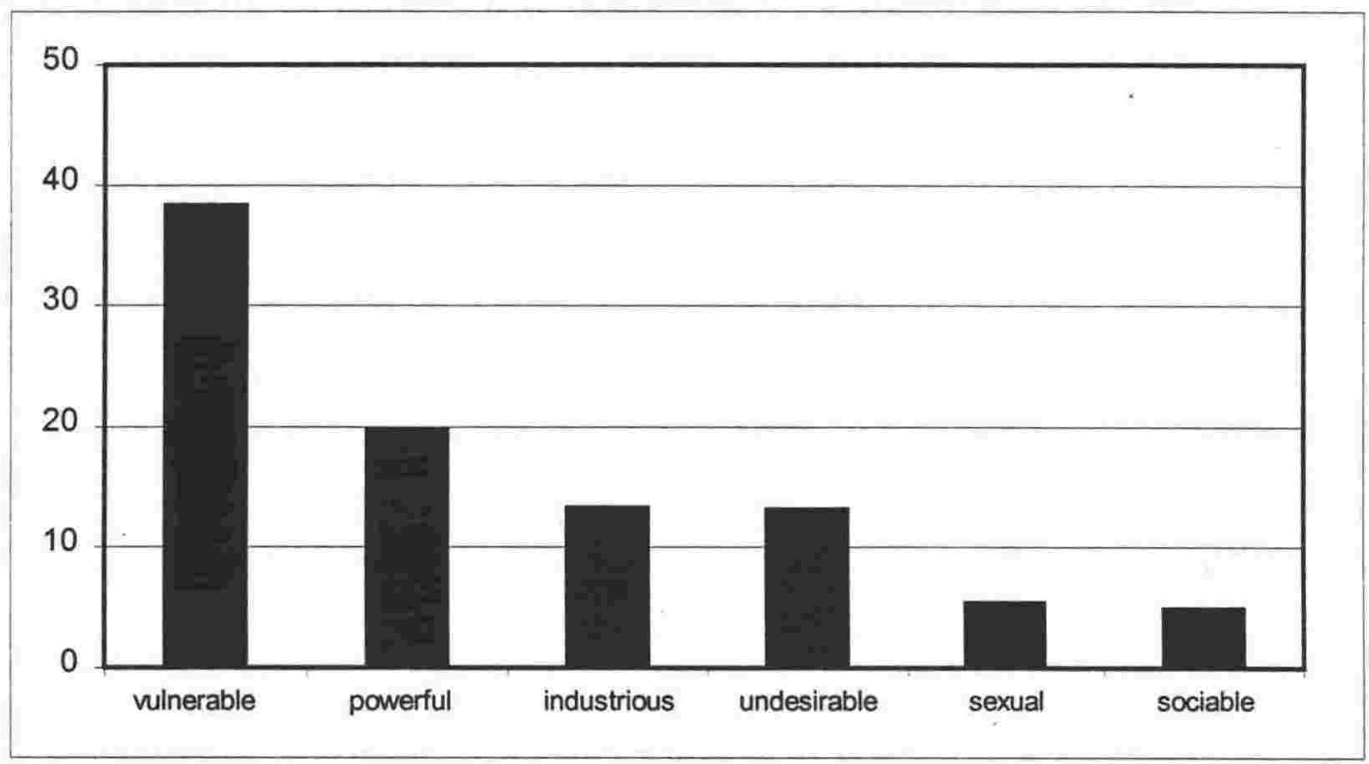

${ }^{3}$ One of the son's of the a longitudinal focus group(single mother) participant was Head Boy of his school. .My son (raised by a lesbian, single mother) was awarded one of the top ten sixth form scholarships recently.

${ }^{4}$ Note the comments in Chapter 9 about the limitations of the drawing interpretation. 


\section{Figure 0-2: Representation Two of the Mother by Males Aged 10-18 yrs.}

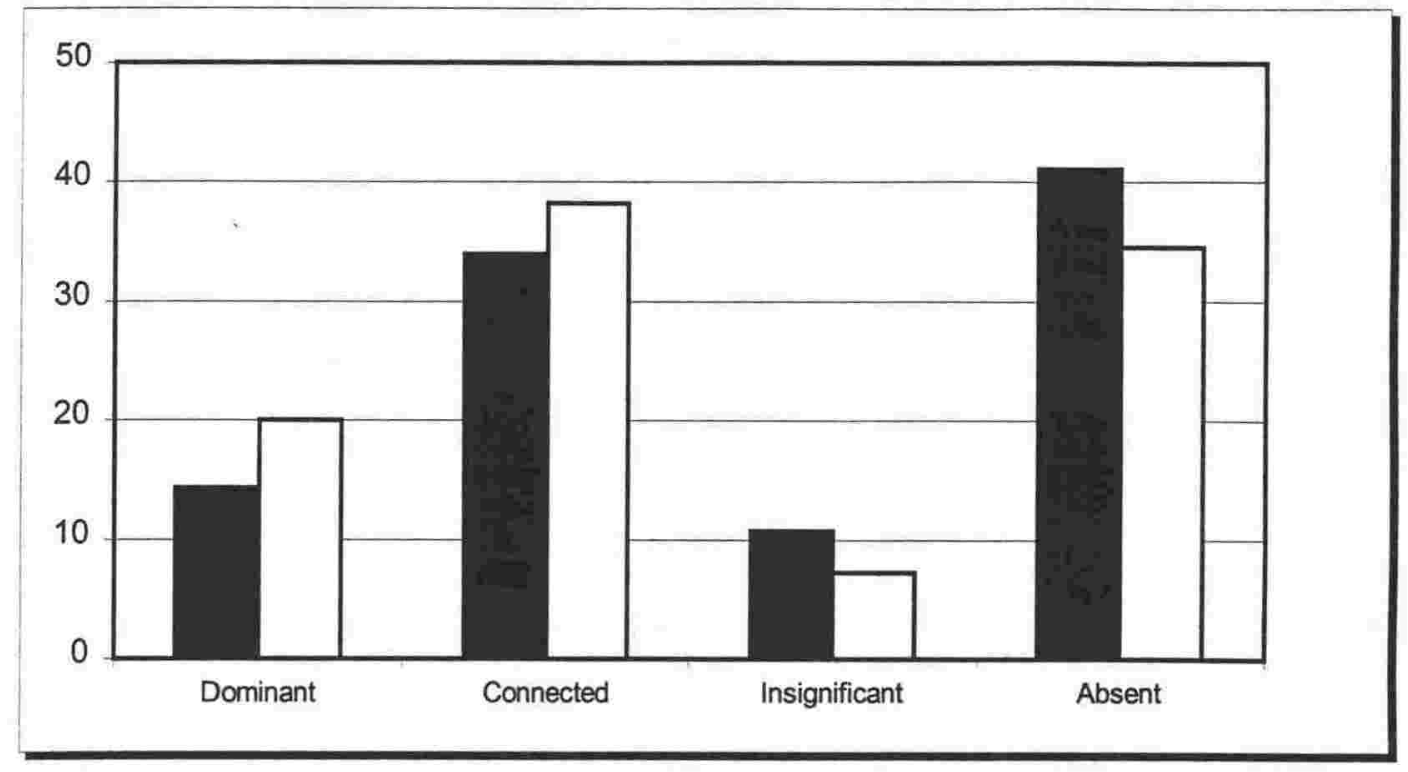

Derogatory comments about 'being a girl' contributed to the overall devaluation of mother and women.

There was much of that kind of talk among the boys and their friends ... put downs that are attached to girls, like 'don't be a girl', that kind of stuff. (GP5)

[Father and coach of the rugby team] screams out to this little boy '[Son's friend] pull your socks up you're playing like a girl!' The humiliation for [Son] and me that I've ever been related to this man. (20)

Although in the minority, mothers also reported a positive image of themselves in relation to their sons. It is interesting to note however that the images that are perceived as positive are male-like, for example, being the external house maintainer and provider for the family.

I perceive myself as having been a very strong role model for the boys. ... [T] hey saw me paint the outside of the house from the roof down. ... I was able to do basic maintenance on the car. ... [Do] basic maintenance on my lawn mower. I am sure they have got that image of me being able to do these things. (3)

$[\mathrm{M}]$ e being the breadwinner and the one that kept the family. (18) 
Chapters Four and Five have addressed issues about the prominence of the nuclear family. The image of the mother in the nuclear family is worth mentioning in this context as well. Participants reported descriptions given to their sons at school in reading material.

That's another thing. I went into battle about that at school too. Exactly the same issue. My kids coming home with nuclear family pictures. (3)

They taught the kids to read using poems. The first poem that came back for this six year old was, 'This is Dad, this is Mum, This is Me and that makes three. (GP2)

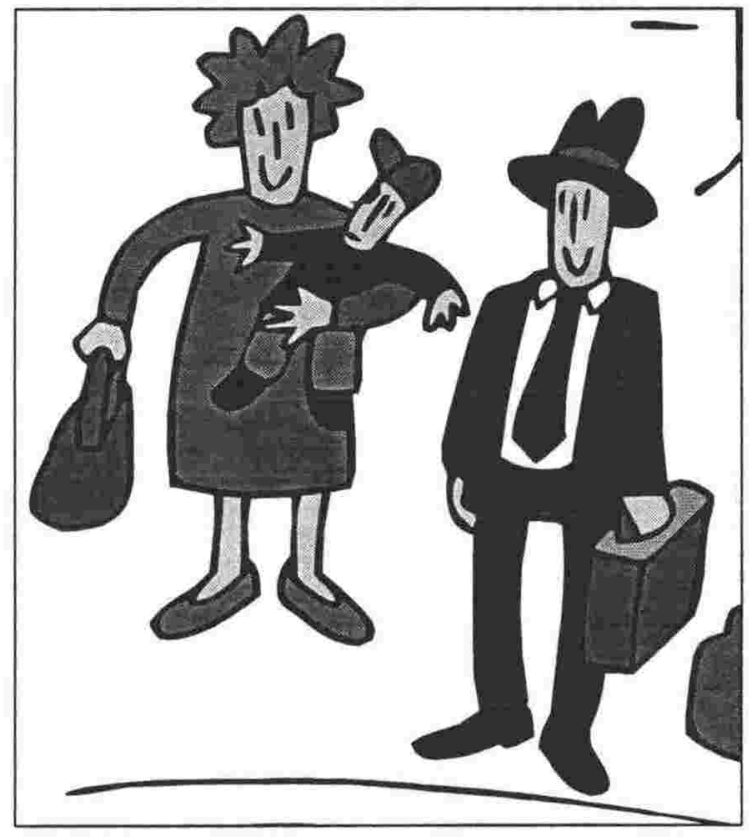

This participant continued on to describe the diagram that accompanied the poem- the 'Dad' was in a suit and tie and carried a brief case, the 'Mother' had an apron on and was holding the hand of the 'Me'. Not only was the traditional nuclear family described but also it was a middle class white professional family.

The final area of 'image' highlighted by the mothers was that of body image. One of the early foci of the second wave of feminism centred on the freeing of women from the cultural restrictions placed on body shape. More recent contributions have been made by feminist writers such as Shelley Bovey (1989), Kim Chernin (1989), Rita Freedman (1990), and Naomi Wolf (1994). Using social and psychological frameworks these writers speak about the extent to which women struggle with body size and image. They make connections between woman-size and multinational politics of the dieting industry (Bovey, pp.220-232), between 
women's perceptions of themselves and their self-esteem (Freedman, 1990), between a woman's obsession with reduction of her flesh and the alienation of her natural female power and reverence for her body (Chernin, 1989, p.2). The mothers in the project reported,

Something that is chucked in my face all the time by my teenage kids ... is body image. They're really swallowed up by very popular images that women need to be extremely slim and if you're not extremely slim at all, you're not acceptable.

The boys [at school] said things about the girls' bodies and [Son] wasn't used to that talk. (9)

[Son] always giving me lectures about how fat I am. (4)

That's another reason why [Son] thinks he has control over the house because he's the biggest by far. ... He'll look down on me and say 'oh hello shorty'. (14)

In 1998 a series of "Fat Mama" jokes became popular among the young people attending the schools involved in the Drawing Interpretation Project. Their popularity seemed to be worldwide by the number of 'hits' indicated on the American originated web site that listed the jokes. A download of four pages of the jokes produced the first few as follows,

Yo mama so fat they have to grease the bathtub to get her out.

Yo mama so fat when she back up she beep.

Yo mama so fat that when I drive around her I ran out of gas.

Yo mama so fat when she goes to an all-you-can-eat buffet, they have to install speed bumps.

(Retrieved November 1998 from the World Wide Web)

The connections made by Freedman between body image and self-esteem usefully reflect the experiences reported by a number of mothers in the project. Using the results of a Bodylove Survey with 200 women Freedman suggests, "body image is a social affair. It may be housed in your head, but it's grounded in everyday 
experiences that surround you" (1988, p.8). The findings in Freedman's report suggest that the influence of self-esteem on body image and body image on selfesteem is strong. When women who deemed themselves to be attractive and unattractive completed a self-esteem survey, a high correlation between the scores was evident (1988, p.21). The self-esteem of the mothers of the project, functioning within an environment where messages of body size are confusing and illusory, is reflected by the image of themselves. Likewise their (mostly) low image of themselves, embroidered by significant others, media images, and advertising, affects their self-regard and self-respect.

\section{Mothers' Undermining of Themselves}

Mothers also contributed to their own undermining. This research project did not examine the reasons, but conjecture can be made. Being a woman does not create immunity against sexism. Powerful forces in society ensure that all people assume the values of that society. The insidiousness of the values transference influences women who live in a society that discriminates against women. Interviewees reported feelings of self-doubt that were generated from the constant undermining from others. Paulo Freire (1970) talks about the processes of horizontal violence, meaning the violence from one oppressed group to another, when marginalised groups perceive a powerlessness to improve their situations.

I know what to do with them most of the time but it's just like inside of me I can't stop worrying that maybe this [impact of fatherlessness on sons] is right because he [Father] keeps pushing it. (15)

I think it gets back to the self-esteem, self-worth and getting back to that thing you know. If you deserve better you would have better so you get what you deserve. (14)

I kept thinking I was second best because my marriage had broken up. I was putting myself down a lot and it's taken a good couple of years to come through that ... to start finding some strength and direction. (GP2)

They also talked about the conflict they felt between wanting their sons to be happy and to fit into their worlds and also not wanting them to conform to patriarchal values and behaviours. 
We make our boys like the men that we have difficulty with. ... We want our boys to succeed in the world and therefore to do that they need to be staunch, they need to be tough, they need to survive, they need to be independent, they need to be all these things because that's what we see men out there are like but in doing so we're giving our boys over to the world that in fact has damaged ourselves. (GP 5)

There were a variety of ways that interviewees described their undermining of themselves. One way was to condone and encourage the son's domination of the mother.

I will actually go and do some of the things that he might like to do, like play soccer. I will let him win of course. (2)

Another was by putting herself and other mothers down.

I was such a domineering cow. I look back on it now and I kept thinking if I'd been, maybe if I'd been maybe a little bit more; it's all this 'if' and 'maybe' stuff and that retrospective and if I'd been a bit less controlling and much more negotiable. (8)

A further way that mothers contributed to their marginality was to privilege the needs of their sons over their own.

I came across this book called The Sacrificial Mother. I didn't have a chance to read it, but I'm going to get a hold of it because it sounded just like me. ... The mother that does everything for [the children] and has no life of her own ... doesn't feel like she's got a right to a life of her own. It took me ages to buy myself some decent clothes, because when [Husband] and I first separated, there was just hardly any money and the little bit that went on clothes, went for the kids, because I just felt it had to. (3)

I put heaps of energy into the kids, probably too much and I think I sort of put myself on hold without even being aware that I'd done that. (12)

The following discussion was recorded in an interview with one of the participants, 
I usually say what a clever kid I've got, why didn't I think of that, and he says cause you're not as smart as me Mum and he really gets a kick out of that.

- What do you think about encouraging your son to be smarter than you?

I think that's quite good really because I'm not that smart. I think he's smarter than I was at his age. I think I've got a kid that's really clued up with a lot of things, ways of life and things that matter. (7)

The 'dumbing' down of herself as a mother as demonstrated here was not uncommon among the participants of the project. As has been included in previous chapters, one of the approaches mothers have used is to call for the return of the father even if it acts against their own sensibilities.

[Father]'s kept saying how bad I was and how I was not a good mother, I know the children are well and happy and everything, but I am so nervous ... I look at my son and I'm always saying to him, 'he's your father, don't you need a man in your life? Are you going to blame me when you grow up and say why didn't you make me go to my father, are you going to tell me it's all my fault?' ... You know, I'm pushing

- $\quad$ you're pushing him towards his father?

Yes, because I think maybe; I keep saying to them, 'what if you say next time you needed him and I didn't let you have him, then what?' (15)

\section{MOTHER BLAME}

Silverstein attributes much of the mother blaming that is evident in Western society to Sigmund Freud and his disciples. She believes that Freud's emphasis on the relationship of the post-infant male to his father came at an historical time, after the Industrial Revolution, when male and female-dominated spheres were clearly delineated. The Oedipus complex, she suggests, "was a sexualised theoretical model of the potential destructiveness of a woman to her sons" (1994, p.20). Woollet and Phoenix extend Silverstein's argument by proposing that mothers, who are assumed to have major responsibility for their children's development and behaviour, are blamed by "psychological writing and childcare manuals (implicitly or explicitly) when children demonstrate behavioural or other problems" (1993, p.216). 
Rich offers two further perspectives. She uses the term "powerless responsibility" to describe the failure a mother can feel if she believes she has fallen short of her responsibilities, despite the impacts that economic forces and political oppression may have had on her (1986, p.52). She refers also to the unconscious acceptance of guilt bestowed on a woman seeking to "broaden and deepen her own existence, on the grounds that this must somehow damage her children. That guilt is one of the most powerful forms of social control of women" (1986, p.205). Wollet and Phoenix contribute a further perspective. Failure to theorise differences, they argue, "helps to maintain the status quo as 'normal mothers' being white, middleclass, married women and other mothers being deviant" (1993, p.217). Nicholson suggests that mother-blaming occurs on a number of levels, "from individual attributions to mothers as the cause of psychological insecurities, to the portrayal of the cold, rejecting, neurotic or inadequate mother in popular culture" (1997, p.377). She believes that the recent attention that has been paid to the role of the father increases the blame accorded to mothers. "Fathers", she argues, "are represented as adding positive ingredients to the beleaguered and insufficient mother-child relationship" (1997, p.381).

A national newspaper reporting the 1998 Twelfth International Congress on Child Abuse and Neglect ran an article entitled 'Mothers blamed while dads remain invisible' (NZ Herald, September 10, 1998). The article reported from welfare analysts who stated that mothers are often blamed in child-neglect cases because of entrenched stereotyping. In an article published a year previously another national newspaper covered the increase in reported home-alone situations. Of the thousand cases reported between 1994 and 1997 this paper chose to report eighteen cases (Sunday Star-Times, October 26, 1997). Figure 8.2 shows the breakdown of the caregivers accorded responsibility for the home-alone cases. Mothers are blamed six times more than fathers for instances of children being left at home. There was no comparison or analysis of the percentage of children being raised by their mothers contrasted with other caregivers raising children. 
Figure 0-3: Reported Responsibility for Home-Alone Cases in Aotearoa New Zealand

(Source: Sunday Star Times)

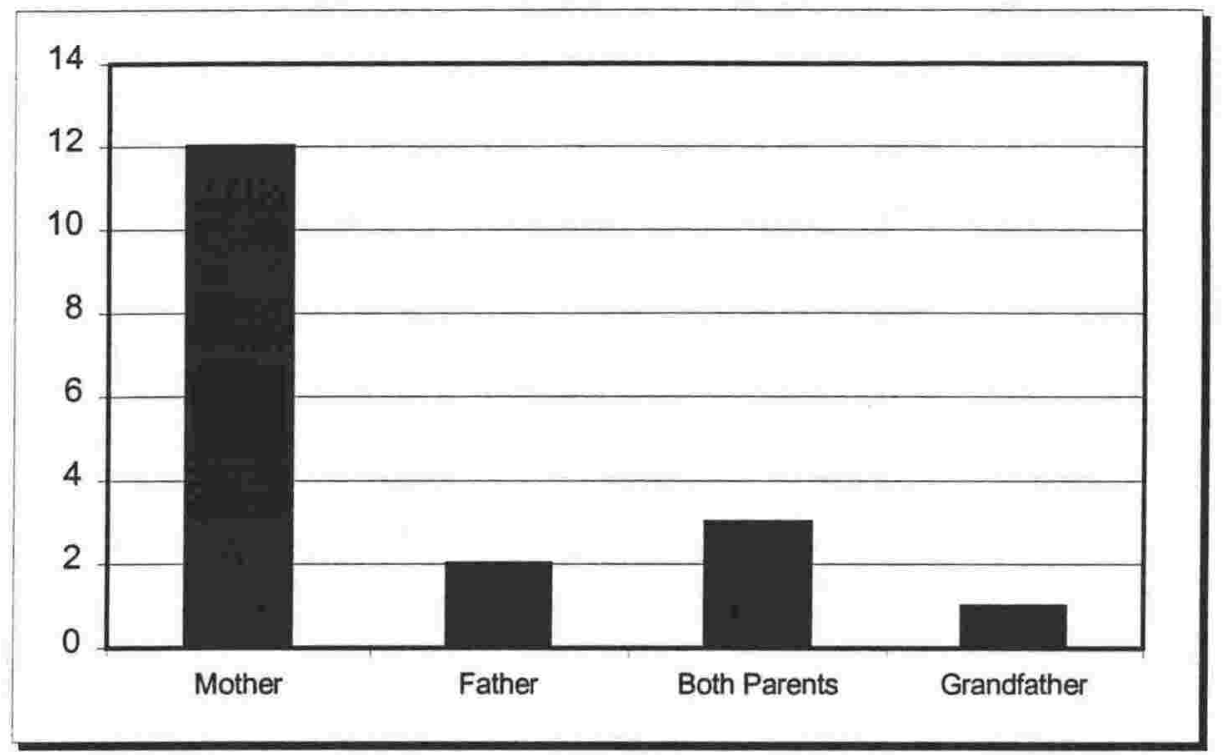

When describing their own experiences of mother-blame, the participants of the project talked about that accorded to them by society in general, by specific professional groups, by their sons, the fathers of their sons and by their families. They also talked of self-criticism.

\section{Blame by 'Society'}

It was principally the mothers who were raising their sons on their own who reported condemnation from 'society' as a whole.

The assumption is because the father is not there; the boys are, by necessity, disadvantaged. (GP 8)

This is just me perceiving what the public will think you know ...or what sort of mother has he got you know, if he's [demonstrating negative behaviour]. (14)

One of the things that's out there is mother blame... that message that you are given that if you get too actually close to the boys [it may damage them]. (11)

I think that once again they're been blamed for a lot of this sort of stuff. It's another way of society trying to control women. (8) 
The implication that comes through from society is that because boys or children were brought up by a single parent there is instability in their life. (3)

I was in a meeting the other day in my own agency ... they were talking about the things that were happening - [One person said] "we've got this waiting list of these 16 year old angry boys and interestingly enough they're all from solo parents and you know they have absentee fathers". (8)

Somehow a woman who has lost her husband in death is more worth of sympathy or support than a woman who has walked out from someone who is violent. (4)

\section{Blame by Professionals}

The mothers highlighted three specific professional groups. These included; those involved with the judiciary, lawyers and judges; those involved with mental health, psychiatrists, therapists and counsellors; and those involved with the formal education system, teachers and principals. One of the mothers discovered the following newspaper article quoting Judge Beecroft, a senior member of the judiciary in Aotearoa New Zealand, and took it to one of the focus group discussions. It reported,

District Court Judge Andrew Beecroft, says 'today's youth are the most underfathered in the history of the western world'. He makes reference to the 13,000 women who receive solo parent benefits, who won't or can't name their child's father and it goes on about the social problems of an absent father. (GP5)

The following discussion among the mothers ensued.

It happens more and more. More and more of this stuff-teachers worried about boys at school without male teachers ... that TV programme [about fathering] with Sean Fitzpatrick.

So are we breeding a generation of boys that are really going to be in an absolute shambles, because we're single mothers?

Well you read that editorial in the Daily Post and it says, that person, that judge is assuming that. These children are in trouble because of not having a father figure? 
- $\quad$ That's what he seems to be saying, yes. What does it make you feel like as a mother when you hear that comment?

Really incapable. ... It's bullshit. My son has never been in any trouble. (GP5)

One of the mothers told the story of counselling sessions organised for her son by his father. Her distrust of the counsellor was confirmed.

All this stuff about what a dreadful parent I am has come out. I'm blamed for things that have gone wrong in [Son's] life and ... some of the things that I've had no control over. (12)

It was an issue for the father at that stage for me to put this kid into his own bed. Although [3 year-old son] does sleep on his own bed, he will come in the morning and jump into bed with me. ... [Psychologist] was actually pushing my buttons, trying to find out ... taking [husband's] side against [me].[I felt]quite small ...I didn't actually say anything. I just listened. (2)

The mothers also described the blame they felt from the school for the lack of success of their sons.

[Teachers] really had me believing that I was the cause of all the problems [about son at school]. (5)

Like the teachers. They would sort of talk to me like I was a half-wit. It was my fault he wasn't able to read or talk properly. I really got angry about that. (1)

\section{Blame by Sons}

One of the more difficult situations some of the mothers had to manage was the blame accorded to them by their sons, particularly when the family had separated.

[Sons] calling me stupid and saying, "If it wasn't for you leaving Dad we would be all right. We'd have more money. We'd be able to do things. We'd be like such and such a family". (18)

[Son] said to me on more than one occasion that some of the things he does [acting out] would be different ... if I hadn't of kicked Dad out. (14) 
In the following situation the older son chose to live with his father when their parents separated. The younger son followed a year or so later and, as his mother explained, began counselling.

[Son] showed me a painting. ... It was a self-portrait of him with his mouth open and tears running down his face and it had words around it 'why have you done this to me your own child' (12).

By the time of the second interview with this mother, eighteen months after the first, the older son had moved overseas.

[Son] sends me these shitty letters telling me how bad I've been and how I've damaged him. ... said that I was pre-occupied with myself, I never really knew him, Inever listened to him. That I was lost. That I was incapable of loving him because he was a man and I didn't like men. (12)

\section{Blame by Fathers}

Several of the fathers also reportedly contributed to the culpability of the mother when difficulties occurred.

He [father] told [mutual acquaintance] that when something went wrong in a relationship he always supported the man because women get heaps of support anyway and he's made other noises to the affect that it's usually women who are in the blame, in the wrong. (15)

\section{Blame by Family}

Some mothers were blamed for mistakes and difficulties by their parents and their sons' grandparents.

My mother and father told me when I got out of my marriage that I was foolish girl, that I had everything and that they would not support me. ... told me I deserved it because I was too verbal if only I could keep my mouth shut I would be much better off. ... [Parents] portray me as a bad mother to my children ... I've done some things that they highly disapprove of and not been forgiven for doing. (16) 
I did get a few negative comments when [Sons] were 13 and 14 and being ghastly, from different members of my family that they probably needed a man to straighten them out. ... I distinctly remember my parents saying to me that these boys needed to go to boarding school.

- What happened with your daughter?

She has been dynamite. The last twelve months she has just been horrible.

- Have you had similar comments from your family?

Oh God no! (3)

My mother-in-law [was] very angry with me, saying it's a terrible thing to leave a man alone with his children. ... There was absolutely none of that coming back when I had them on my own and working full-time. (18)

\section{Self Blame}

Mothers also talked about taking responsibility for the difficulties of others, particularly their children. They blamed themselves when things went wrong or believed others accusations of them.

I felt very responsible for the hassles he was having. I took it as a reflection on me at that time, which I now understand was pretty unhelpful for him but that's where I was. I was getting a lot of my self esteem from who my kids were. ... Being honest with myself. I'm blaming myself in the way that they are. (12)

I thought I failed. I failed. I've brought up these surly oafs who can't even speak to each other. ... There were times when I thought maybe they are right. Maybe I stuffed it up and haven't done it right, and these kids are just totally out of hand. But you get through it. I have just had to believe in myself. Had to believe in the kids. (3)

[Son] went through a whole time where all he would talk about was dying and how he was going to do it and what toys he would put on you know, have in his coffin with him and all this sort of stuff. It made me feel really guilty and I didn't know what to do about it. (14)

I know that for me when I read that ... [I] thought, 'fuck, I'm not good as a mother', or 'my son is being disadvantaged because I am who I am' and it's hard to hear. (GP 8) 
I felt that they had actually continued on the criticism. ... So I kind of took on this whole belief that I was weak and I couldn't do this and I wasn't a very good mother. So I became horrendously guilt-ridden and tried to kind of be there and over compensate and become mother and father to them. (18)

One of the interviewees offers a pertinent summary to this section. She expresses her frustration at being blamed for making mistakes raising her children when resources are not sufficient and when research on mothering holds mothers responsible for societal inadequacies.

We're given the responsibility of raising these kids we've got. We're given no resources to do that. We're constantly being put down because we do things wrong even when we take on unemployed work and voluntary work. It's not enough. It seems like it's never enough. We never ever do enough for them. ... When [researchers] tell us that, whoever the hell they are! Now we've discovered this about women. Now we've discovered this about you ... and it's somehow framed in the negative. (8)

Nicholson supports this mother's perspective. She suggests that social prescriptions for contemporary motherhood are constructed by patriarchy to suit the needs of patriarchy. Informing dominant ideologies, Nicholson claims, these constructs contribute to the everyday understanding of women themselves, resulting in an interpretation by mothers that the accompanying stresses of motherhood are due to their own inadequacies (1997, pp. 377-379).

\section{CONFIDENCE / SELF-ESTEEM ISSUES}

A prevailing impact of the undermining and blame of mothers, reported by the mothers in the project, was the damage to their levels of confidence and selfesteem. One of the participants described how uncomfortable she felt by the actions and undermining of her husband. She was ignored in her protests, felt as if she was "becoming a whinger" and, as a result, her "self esteem suffered" (21).

\section{Factors that Diminished Mothers' Confidence}

One of the causes of the decrease in mothers' confidence and self-esteem was the high levels of stress they experienced. 
Our life was pretty stressful because I was too stressed out. I was having such high expectations of myself, going to work and caring for them and doing the whole bit at home and I was going off to this assertive discipline course and it seemed that I was trying to put on someone else's thinking as it were. I was trying to adopt someone else's style instead of just going with the flow and going with my own self and my self-esteem was pretty low. (4)

I do feel bad sometimes, what I scream at him, the words I can use sometimes I think how cruel. How do you take them back once you've said them. ... I'm getting frustrated about work and he's rambling on about something and I say for gods sake shut up will ya, I haven't got time for that right now.I know it's totally unfair. I know it is but it comes out. It comes out. (7)

I had a lot of time while his father was working. I was there and not happy to have him. I would do things like dump him in his cot and saying 'stay there shut up!' shriek at him.I talk about this with him now and you know I'd hit him too and I just couldn't cope with being a mother at all. (10)

Apart from the societal marginalisation of their positions as mothers other areas of major stress reported by the mothers included financial worries, stigmatisation of being single mothers and/or being lesbian mothers, (Chapter Four), relationships with their sons, (Chapter Five), and the publicly expressed concern about fatherlessness (Chapter Seven). Another factor limiting confidence and selfesteem was guilt; that is guilt about being a bad parent.

I didn't really have the time. ... I used to worry about it sometimes and think I was letting him down and think I should be spending more time with him doing stuff and most of the time I was too tired and there was times too that that was the last thing I wanted to do. ... I felt a little bit guilty about that. (13)

I guess I felt terribly guilty because there was so much going on in my marriage. ... I escaped from the house a lot. And that pushed the guilt buttons.

I feel really guilty about my ... university work. ... It's 'hang on a minute' or 'I'll listen later' and I'll make a time and then I don't keep the time. My guilt as a mother [is about] not always being around and listening. (11) 
These feelings also included guilt about the breakdown of the relationship with the sons' fathers.

I felt like I wasn't good enough and I had to make up for [separating from father]. (18)

Well I still have some feeling of guilt. ... You know I talked to a lot of people, but it sort of never got me over that feeling that it was all my fault perhaps because if I was a better person then all those things [marriage ending] would not have happened. (14)

I'm interested in youth suicides not so much just the fact that it's been becoming more publicly obvious but that there are the links being drawn to fatherlessness. I'm concerned that we as woman feel guilty for not having our men around. (GP5)

\section{Factors that Enhanced Mothers' Confidence}

Mothers in the project highlighted also those factors that contributed to a positive sense of self. Some had role models or mentors who provided strength and inspiration.

I think I had my grandmother as a role model. She was a single parent, my Dad's mother. She brought up her two children basically on her own (GP 4)

Others indicated that not having the tension of a destructive relationship enhanced their confidence and ability to be good parents.

As I have come into myself as a mother on my own, it seems to me that my ability to parent the boys positively has been enhanced. (4)

I think the problems with my sons are ongoing but I think I've gotten stronger and stronger at dealing with it and feeling good about being me in spite of that. (12b)

I guess it wasn't until we separated that I did relax and when the children came out with the odd thing I could laugh with them and think I could feel myself moving back into a more central position. (21) 
Success in the public sector contributed to an increase in mothers' confidence.

There's over 300 consultants in the country. So I'm number two. Up until last week I was actually number one for November. ... All these people that poopooed me when I was first starting. ... 'You know you're just wasting your time in doing all this and you'll never succeed'. I'm just finally able to prove to all those people. (14)

Affirmation from others also contributed.

I'd been invited out by a couple of males who obviously enjoyed my company so therefore I felt I'd been feeling really unattractive as a woman because I'd been rejected. So I was feeling better in myself. (21)

One of the major factors that increased levels of self-esteem and confidence was the ability and preparedness of the mothers to live their own lives.

I'm in a stage now where I know that I'm ready to move on to something else. It's a damn sight harder to find out how to live my life just for me and then for them. (9)

If I could do things again and start parenting I would say it's terribly important to try and keep a sense of your own identity separate from the kids not let yourself be totally identified with only the role of being mother because it makes it harder for everybody if you do. (12)

I got lost. Utterly lost. I know that I was utterly lost at being [Son l's] mother, [Son 2's Mother] mother, [Son 3's] mother and [Husband's] wife. (8)

I read somewhere that one of the sad things you can do to your kids is to bathe in their glory and that your own sense of achievement and your own sense of purpose is what your kids do because it can't be, we have to be our own.

- Have our own space, our lives

Ours as well as theirs is separate

If motherhood is a career (the only way you are a mother) and when your kids go, what does that do to your career?

- $\quad$ walks out the door with the kids

(GP 4) 


\section{Link Between Confidence and Effective Parenting}

One of the key findings of this research project has been the recognition that the strength, confidence and enhanced self-esteem of the mother contributes positively to her ability to parent her adolescent son and maintain an effective relationship with him. This thought was initiated at the second focus group session when one of the mothers talked about how she stood up to her potentially abusive son.

I wasn't scared. ... We were fighting and feelings were bad. He just seemed to realise, the penny dropped, that he wasn't actually getting very far with it. It was all just bravado. He has come to terms with the fact that just because he is taller and bigger. He is not the authority. Things are okay now.

- What has been happening to your own strength and your self-confidence through that process?

It seemed to really just grow because of that. I felt that I had really achieved something.

- I'm just wondering whether this whole thing is not about men at all, but is about our strength as women, and that often in a marriage situation, particularly if it is not healthy, we lose ourselves and we lose our confidence and we lose our strength as women, and that by getting out of our relationships, often our strength can come back. And it has been strong women that allow our boys to be strong men.

Yes I agree, definitely!

These mothers' views are supported by Joyce Hamilton Berry, a clinical psychologist in Washington D.C., who says "the best way for a mother to teach her son to respect women is by demanding respect herself" $(1988$, p.2). A mother, I contend, can only demand respect from others when she is able to respect and feel confidence in herself. The examination of the link between self-concept and effective parenting was continued into the questions and analyses of following interviews. Generalisations are not possible or appropriate with a feminist participatory action research methodology. However, there seemed to be an indication from interviews, group discussion and journaling, however, that there was a relative relationship between stress factors, confidence and self-belief of the mothers, functioning family systems and adjustment of sons. That is, stress factors 
lessened the confidence of the mothers, causing difficulty for them to function as parents and contributing to the maladjustment of the sons. Conversely the positive impact of increasing strength as women and mothers on their ability to effectively parent their sons was demonstrated in the journaling of two mothers throughout the project.

\section{THE NEED FOR SUPPORT STRATEGIES}

Another one of the themes coming out of the fieldwork was the appeal by mothers for support from the community and from society in general. The type of support identified by the mothers included two aspects. Firstly they wanted support to have equitable positions in society as mothers of adolescent sons and secondly they want support to parent effectively. I individually interviewed three mothers who were part of a community organisation. They each spoke about the importance of the connection they had with the other two mothers. When difficulties had arisen with their adolescent sons they had been able to talk with each other knowing that there would be a level of understanding. Being able to talk together minimised the feelings of failure, hopelessness and self-blame. The isolation, reported by other mothers in the research also, was reduced by this contact with other mothers. Those who felt the necessity for support articulated it as follows,

I can't identify anywhere in my community where there's support available for women raising boys on their own, except for friends. [Mothers] seem to be sending them off to boarding school when they get big and angry and difficult to handle, which seems awfully sad. (20)

I think I would've liked to have been able to talk more about the feeling of being blamed a lot more and I would've liked to have had some strong support from other women. ... I did get some support... but my friends are all busy. Everyone is busy. So snippets of support was what I got. (18)

No there wasn't a hell of a lot of support [during Son's teenage years]. I would have appreciated backup of any sort. (1) 
There is support for them. I don't think there's much support for me as being the mother of the adolescents. I think family support's important. ... I have very very good friends here and they understand. They've been through it. (14)

I think a lot of those mothers on their own need a lot of support so that they don't continue to be victimised or blamed. ... But where do they go with it, where do they get the support? (8)

What I would've liked was contact with peers and I think this is a real problem that once [Sons] leave primary school the relationships with parents of other children just fade into the blue. ... You don't even have a set-up where if they are going off the rails if there are problems that you can ring up and check what's up. (11)

\section{Friends and Family}

The major source of support identified by the mothers came from informal structures, through friends and family.

My circle of friends has become bigger and bigger and I think people can see themselves in my situation and say, 'gosh, goodness' and 'wow, she's pretty good, she's doing a good job with the kid, isn't she.' There's some kind of recognition from people around us. ... It's so nice to have that recognition'. (19)

I feel more confident as a person, as a woman. ... I think realising that I don't really have to be on my own. That even if [x-partner] is not here I have got friends. I have built up relationships, friendships with different people within this group. (2)

[I have developed] a number of different circles and networks that I'm part of and I feel very much loved and cared for and valued and I'm able to just let them [sons] have their opinion. It doesn't get to me too much. (12b)

The particularly useful connections reported by the participants were with other mothers in similar situations.

There was one main support in that I have a very close woman friend. ... It was good for me to keep in contact with her to be able to bounce ideas off her and to have a moan down the phone ... and to see her children at a similar age doing 
similar things. So then I knew that this is teenage stuff. This isn't single parent stuff. (3)

I am fortunate to have friends, at work particularly. I have got a good mate at work who has been there herself. ... She has been a really good support because she has had two teenage sons who have given her a really hard time.

I think it's really important to be able to talk with other mothers... to know what to expect from kids that age. ... There are some quite major changes around 14 and 16. It can be quite scary because it's real stuff. ... It's really important to have that information I think ... and to have strategies and skills. Those things are always helpful in dealing with things. (9)

There were four of us women and we met and gave each other tremendous support because [even though we were married] we did see ourselves very much as solo mothers. (21)

Just the support of other women around, it was the support of - there were three or four of us at the time with kids the same age and we kind of had similar sorts of things although I use to get often envious at some of the stuff like where the other women appeared to have a lot more support from their husbands and whatever, so I thought oh well I can try things, it was just the support of knowing there were women who had sons of kids and they were having similar difficulties as what I was. (8)

\section{Support Groups}

Others took advantage of support groups. The usefulness of these support groups however was not consistent. One of the mothers talked about a weekly maraebased group for women that met her needs for company and parenting support.

I was on my own. I was quite isolated really in my thinking and behaviour. ... I actually went along to [group] for support for parenting. ... [Group] is a parenting programme for not just Maori women, but for all women. They have a creche and they do different things, like they have a free doctor on hand. It is marae based. All the women get together and help out, make salads, cook food, prepare food, put the food on the table that kids like. They have different guest speakers from the community, like someone from the police department, 
lawyers, Plunket. And all these people are supporting mothers to take their children along. There are different health issues. No charge whatsoever. (2)

Several others spoke of attending groups for parenting and assertiveness training classes. For some, particularly the single mothers, these classes increased the feeling of isolation and marginalisation. One mother talked about attending sessions at a Playcentre.

I probably felt inferior to them to be honest, and it was like they were all married and had this, that and the other. I just felt like I was out on the limb.

She also talked about attending a parenting class, which, she states, "wasn't aimed at single parents. It was aimed at both parents and most of the people there were couples" (5). Another talked about attending a positive parenting programme that was not able to support her with the difficulties she was facing with her adolescent son.

I bought into it for a little while and then I found that life was just getting a hell of a lot tougher. ... I brought into their - it was like 'I have told you to do this, now you go and do it right now', and 'you go and do this right now or I'm going to put you in your bedroom for five minutes'. It might be all right for a two year old, but it's not okay with a twelve year old. He would just say get stuffed and climb out the window. (GP2)

\section{Professional Support}

Mothers reported two levels of professional support, one for their sons and one for themselves.

As the boys became older and came towards the end of their secondary school years, there were teachers and mentors who were extremely good to the boys through school. (3)

I reached burn-out point at work. I took sick leave ... had a really good counsellor and then I went to part-time work rather than full-time work, so I think I created spaces in my life to look after me: (12) 
Of the support structures highlighted by mothers, access to tertiary education stood out. The availability of the Department of Social Welfare Training Incentive Allowance for mothers on long term benefits, such as the Domestic Purposes and Widows Benefits, has enabled financial access to tertiary training. The extent of financial support has varied during the course of the research. It was decreased by a National Party led government (1993 - 1999) from one hundred percent to sixty percent and then restored to a full-subsidy by the Labour Party-led government in 2000. Beneficiaries can claim for enrolment fees and course-related expenses, such as child-care, transport and stationary. Mothers in the project reported taking part in part-time community education programmes and in longer full-time training toward qualifications. The benefits of tertiary education for these mothers were many. There was a potential increase in income that higher qualifications could generate. The financial situation for three of the mothers in the longitudinal focus group increased as a result of gaining qualifications. Mothers also experienced an increase in levels of self-worth, affirmation from family members, the opportunity to create friendships with other students and exposure to new and stimulating ideas.

\section{CHAPTER SUMMARY}

This chapter has concentrated on the mothers' experiences of marginalisation, disempowerment and invisibility through processes of undermining and blame. It has discussed the father, the son and at times the father and son in collusion, as the key protagonists in these processes. The research has found that these reported experiences are not limited to mothers and non-resident fathers but involved those situations where both parents lived together. The research found also that mothers took part in their own undermining and blame. Although it is not possible, within the bounds of the project, to determine causual factors in the processes of marginalisation and disempowerment, mothers suggested several reasons. They spoke of the contribution to their undermining through general societal practices such as the privileging of the nuclear family structure, the inequitable resource sharing and the colonisation and colonising of the judiciary, mental health and education systems. To come to a conclusion about the individual versus the societal role in the perpetuation of the marginalisation of mothers of adolescent sons is difficult. I would suggest that as much as fathers, sons and mothers are 
part of a society that discriminates against mothers the relationships are associative.

As has been discussed in previous chapters, the research has found a convincing link between the ability of mothers to effectively parent and their levels of confidence and self-esteem. Chapter Eight has developed this theme by reporting on the factors that mothers found enhanced and diminished their self-confidence and significantly, the need for informal and formal support structures to be developed. 


\section{Part 4}

\section{RESEARCH}

CONCLUSIONS 


\section{CHAPTER 9}

\section{RESEARCH FINDINGS, LIMITATIONS, STRENGTHS AND FUTURE DIRECTIONS}

Chapter Nine concludes this dissertation by presenting an overview of the research project, the limitations and strengths of the research, a summary and discussion of the findings and implications for further research.

\section{OVERVIEW OF THE RESEARCH PROJECT}

\section{Purpose of the Research}

This project aimed to investigate the mother and adolescent-son relationship in Aotearoa New Zealand, the interventions to the relationship and the impact of these interventions on the mother and on the son. It was hoped that the investigation would achieve several goals. The first was that it would give rise to a more in depth understanding and recognition of the dilemma of the mother-son relationship and the pressures on, it in order that practitioners and policy-makers would be more fully informed. The second was to involve mothers, who were also experiencing marginalisation and disenfranchisement as mothers of adolescent sons, in the investigation in order that their own situations would be enhanced. The project developed from a review and comparison of literature that offered an insight to the exploration of the mother-son relationship in social, cultural, historical and political contexts. It explored the situation for mothers of sons, including lesbian mothers, those parenting on their own, and those raising their sons in an existing heterosexual relationship. It investigated the determinations of societal institutions to separate the son from the mother-world and to enhance his position over that world. 


\section{Rationale for the Research}

A negative incident with a Family Court Judge resulted for me in a sense of marginalisation and disempowerment as a single mother of an eleven-year-old son. This incident stimulated a desire to investigate the interventions to the mother-adolescent son relationship. I wished to examine its history, its foundation, its manifestation, the impact it had on mothers and the impact it had on the relationships between mothers and their sons. I had worked in tertiary education with women for twenty years. Some of them had expressed anguish, uncertainty, anger and much frustration with the attitude of people around them to their status as single mothers, particularly in relation to raising boys. The stories from these women had revealed several themes. These included; their concern to 'do the right thing'; the doubt they had in their ability to parent as their son(s) grow older; the pressure some felt from the sons' father for increased if not total involvement with their sons; the invalidation of themselves as they became increasingly isolated supporting their sons in male-dominated arenas and the financial struggle to provide for their son's growing needs often against the background of a more affluent father.

\section{The Research Context}

The research project was situated in Aotearoa New Zealand, a country of 3.5 million people with a history of European colonisation of Maori, the indigenous people. Current societal, political, cultural structures and frameworks are strongly influenced by other Western nations such as Australia, Canada, the United Kingdom and the United States of America. The two key components of the research problem, motherhood and adolescence, have been constructed within an historical, social, and economic framework underpinned by capitalist and patriarchal values.

\section{The Research Participants}

Three groups of participants were involved with the research, seven mothers of adolescent sons who participated in a longitudinal focus group, fourteen mothers of adolescent sons who participated in semi-structured interviews, and one 
hundred and seventy six boys who participated in drawing interpretation. The longitudinal focus group came from one geographical location in Aotearoa New Zealand. The population of this provincial district is 65,000 . The members of the group ranged in age from late twenty to mid-forty. They had all been born in Aotearoa New Zealand with five identifying as Pakeha, one as Maori and one as Pakeha/Maori. During the four years of the project all mothers were raising their sons as single mothers. Three of the group identified as lesbian and four as heterosexual. Although all the mothers had various partnerships during this time only one of the lesbian mothers lived with her partner. At the commencement of the project four of the mothers earned an annual taxable personal income under $\$ 12,500$ pa, two between $\$ 12,500$ and $\$ 35,000$ and one over $\$ 35,000$.

The remaining mothers came from various rural and urban places throughout the North Island of Aotearoa New Zealand. Most ranged in age from mid thirty to mid fifty with one recently turned sixty. Ten classified themselves as New Zealand Pakeha while four had immigrated to Aotearoa New Zealand from European and Asian countries. Nine of the mothers in this group identified as heterosexual. Three of these lived with the fathers of their sons and one with a second husband. Of the five mothers who identified as lesbian, two lived with their partners. At the time of interview seven of the mothers earned an annual taxable personal income under $\$ 12,500 \mathrm{pa}$, four between $\$ 12,500$ and $\$ 35,000$ and three over $\$ 35,000$. The household income of three of the mothers at this time was under $\$ 12,500 \mathrm{pa}$, five were between $\$ 12,500$ and $\$ 35,000$ and six were over $\$ 35,000$.

The young males involved in the drawing project were aged from five to eighteen years and came from the same geographic location as the longitudinal focus group. They attended three schools that have a contributory relationship, with the majority of students from the primary school moving through the intermediate school to the secondary school. The catchment area for the three schools is made up of rural and urban communities with a higher than average unemployment rate and a NZ96 Deprivation score of $6-10$ points. 


\section{Methodological Objectives and Research Processes}

The theoretical approach that informed the research methodology was feminist participatory action research, as distinct from action research, and was concerned with the following methodological questions; deconstructing the 'participantempowerment' agenda; examining the insider/outsider relationship, when the subject-object relationship between researcher and researched that occurs in conventional research is converted into a subject-subject relationship; and negotiating a community and social-change based feminist research project that is also located within the academy.

The objectives as they related to the research processes included; enhancement of the position of women through individual and social change; engagement of the participants in the research processes; participant benefit from involvement in the research; combining research methods to provide rigour in the research process and emphasising participants' realities and stories within the framework of the research issues. In order to achieve these objectives the research methods included; a longitudinal focus group, focus group sessions and interviews that were audiotaped and transcribed, semi-structured individual one-off interviews that were audiotaped and transcribed, journaling, drawing interpretation and a review of literature.

\section{Data Analysis}

The data from the project was analysed in three key ways. In the first instance a thematic conceptual approach was used to make sense of the data. Key issues began to emerge from the first set of transcripts and focus group discussions. The comments made by the participants during this session were recorded. These issues were clustered into themes and checked against the results of further interviews and focus group discussions and also against secondary literature sources. Once the themes had become clarified the computer assisted qualitative data analysis software, NUD*IST, was used to advance the analysis.

Secondly, a conceptual clustered approach was used to work with the qualitative material. The key themes identified from the collated information were tested 
against clustered groupings of mothers; heterosexual living with partner, heterosexual living as single parent, lesbian living with partner and lesbian living as single parent (Appendix 3.13). The sections in the fieldwork chapters of the dissertation represent the differences in responses between these clustered groupings.

Lastly, a time-ordered approach was used. The participant focus group, through group sessions and journaling, provided another set of data that could be analysed against a series of time periods. In accordance with the intent of participatory action research, the longitudinal group tested strategies for enhancing their positions as mothers of adolescent sons and reported the results of these tests. They also reported changing issues as their sons grew older. This has given an indication of the situation for mothers of adolescent sons over a period of time. The analysis of these issues contributed further information to the research findings.

The quantitative material from the three hundred and thirty nine drawings in the drawing project was analysed using clustering, counting, contrasting and comparing and noting relations between variables. That is, the drawings were analysed and plotted onto a table of clusters. The cluster groupings included; the relationship depicted, a commentary of the drawings and the animal signifier. Instances of certain clusters were counted to create a further set of tables. The results of these tables were developed into graphs that demonstrate variables for comparison.

\section{LIMITATIONS AND STRENGTHS OF THE RESEARCH PROCESSES}

Feminist participatory action research has been under-utilised as a research process. Using a multiple-method approach the project has demonstrated one way that this change-based research model can be effectively practised. As a research model that espoused emancipatory change, several issues required negotiation. These included; deconstructing the 'participant-empowerment' agenda, examining the insider/outsider relationship, and negotiating a community and social-change based feminist research project that is also located within the academy. This 
section summarises the level to which these issues were successfully negotiated by the research project.

\section{Longitudinal Focus Group - Limitations and Strengths}

From the original focus group of seven, four remained at the end of the four-year fieldwork period. At the end of the first year, between the fourth and fifth group sessions, three mothers discontinued their involvement in the group. I am not sure whether the outcomes of the project would have been different should all seven mothers have chosen to stay with the process. At this stage, initial sets of interviews had been completed, themes had been gauged and the direction and framework of the research had been determined. The analysis of the collated data from the drawing project and individual interviews undertaken from 1998, however, would have benefited from contribution that was more diverse. In acknowledging this however, I do not believe that the analysis gained is deficit.

A charge directed at participatory action research is about the claim, and yet impossibility, of equitable power sharing between the researcher and researched. Early on in the project I recognised that the power relationships between us as group members were unequal. Added to that I recognised that a participatory action research process that predicated equal contribution from the participants would be defective. As individuals with standpoints, shared in part by the others but also unique, the participants posed individual truths, varying observations of the worlds they inhabited and their own ideas of how they were perceived within those worlds. It was recognised that inattention to the dynamics created by these differences could have perpetuated within the project those inequalities that were reflected outside it. My involvement in the project was quantitatively larger than that of the other participants but I also had more to gain. I sought to recognise that my position as 'principal' researcher was privileged and to use it to facilitate and support collective change. Participants were involved to the extent that they were able. Empowerment through participation was a key tenet of the project and there could not be an insistence on a certain level of involvement.

It is therefore both a limitation and strength of the longitudinal focus group that participants were involved differently. Recognition of the differences of each 
member meant that participants were able to match their needs of the project with their level of involvement.

As part of the group process I wanted to capture the changes that were occurring among us during the research and the connections that were being made between our experiences as mothers' and our public and private contexts. The participants were invited to create their own research journals with a request that they would be part of the documentation of the situation and transition of the participants. Although seven mothers constituted the longitudinal focus group, only three participants submitted their journals as part of the collective data for the project. This, I believe, is a weakness of the project and it has meant that the journals can be considered as peripheral only to the main research activity. Could the journaling invitation or process have occurred differently? Were women shy of the academic nature of the dissertation and did not want to 'expose' their own writing? Did some feel, as Elliot discovered from using diaries in a research study, that they "could not see the point in writing about [their ] 'boring' life" (1997, para. 4.3).

One of the important strengths of the research was that by identifying four objectives for their involvement, the members of the longitudinal focus group claimed ownership of the project. Firstly, they wished to talk with other women about their experiences as single mothers of raising adolescent sons. Secondly, they wanted to improve their parenting ability as single mothers of sons. Thirdly, they sought to highlight the issues facing mothers of adolescent sons and lastly, they wanted to improve the situation for single mothers of sons. The achievement of these objectives is summarised in one of the final discussions of the group.

I'm involved in the project and when [Son] does things or his mates do things I notice them a whole lot more I think, than if I wasn't.

- I'm just wondering if there's been any changes in the decisions that we have made because we have these intimate discussions or because we've been involved in the project.

Not so much changing the way I do things. It's sort of validated what I've been doing, as right for me and my son. .... I've been more aware, more aware of how I've coped. 
- $\quad$ Coming here and talking, helps you to be more objective. I find that ... everything's so hectically busy and ... I'm working and I'm bring up kids and all of that. You get smothered by it all ... like being washed over by a wave all the time and I can't sort of stand back sometimes and be objective. Coming and talking like this really helps, it really does.

In terms of being able to have a chance to sit back and look at...

- Yes, instead of being underneath it all the time

One of the things I found really useful is that I'm not the only one? One of the things that I found is being able to know that it's nothing wrong with me, the way my boy is reacting. ... Either I can go under with it and become less of a parent in some ways, or I can try and maintain some strength to be a mother and I actually think that's made a difference to my ability ... confidence in my mothering of him. Having the structure here to talk about it has been really, really good. I find myself thinking, 'I must discuss this with the women'.

- Yes, I think that was something else that has been good about this process, is that it's been a bit of confidence building, because I didn't feel especially confident in what I was doing after the early days of the separation and it did help me to have a bit more, to believe in myself in what I was doing.

(GP 8)

\section{Semi-Structured Interviews - Limitations and Strengths}

Rigorous attention was given to the conducting of the interviews. This included; the information given to the informants, the nature of the consent form, the clarity about ownership of the information, and the ability for the informants to revisit their interviews by reading and editing written transcripts. Interviews were held at venues selected by the interviewees, costs were minimised or reimbursed and as much discussion time as requested by the interviewees, before and after the interview, was ensured.

A less positive outcome from the interviews occurred at the return of the transcripts. Most of the participants were concerned at their seeming lack of coherency. Should I have prepared them for this, their concern may have decreased. This will be taken into account in future oral history research. At the point of returning transcripts there was another unexpected outcome. The reading of the transcripts, as expressed by several of the participants, had also provided an 
effective point of reflection about how things had changed for them since the interview had occurred.

Well-recognised among oral historians is the limited capacity for written transcription of semi-structured interviews involving storytelling, discussing, explaining and reflecting to replicate the richness of the oral voice. In the process of translating the spoken word to writing, crucial elements of spoken communication such as intonation, silence and non-verbal explanation that are obvious in a face-to-face encounter become invisible. I tried to minimise this deficit by linking the transcripts with the audiotaped interviews during their initial analysis. This was difficult. When interviews were transcribed, entered into computer assisted qualitative data analysis software (Nud*ist) and collated with hours of other interviews, the uniqueness of each participant became merged with the collective data. With a thematic conceptual approach to collating information using a reduction of data, I guess this is inevitable. It is hoped that within the grouped findings that have been presented in this dissertation, individual mothers voices are also discernible.

\section{The Drawing Interpretation Project - Limitations and Strengths}

Three potential limitations were identified at the beginning of the project. The first was the concern that the skill level and/or developmental stage of the drawer would influence the data. The second, that the drawings would reflect the participants' attitude of the moment rather than create a longer term generalised pattern of attitude and behaviour. The third that interpreted meaning is governed by the values and ideologies of the interpreter. As indicated earlier, my perception at the beginning of the project was that any developmental variation in the drawing level of the participant would not impact negatively on the quality of the data collected. Although it is obvious right through the drawings that the participants have a wide range of drawing ability, and that the more sophisticated drawings were not always executed by the older participants, the value of the material collected in the drawings was not deficient. The drawing competency of the participant did not prevent the availability of rich content from which analysis could occur. For example it was clear to understand where the thirteen year old, 
who drew at the 'Schematic Stage' (7 - 9 year old), saw himself in relation to the other key people in his family.

Likewise I do not believe that the data collected from the drawings has been detrimentally influenced by the participants' representations of recent occurrences. The drawings offer enough similarities within the age cohorts to indicate that they represent a generalised and indicative portrayal of each age group. If a number of drawings had been influenced by recent tension in the family, then this would become indicative of the age cohort rather than an exception. Although the diversity of possible analyses was reduced with a combination of interpretive tools, categorical meaning was difficult. It had not been possible to have each boy individually explain his drawings and secondly, as argued by Foucault, interpretation can never be stable $(1977,1982)$. In recognition of the fluidity of interpretation conclusive meaning for each drawing has not been alleged.

As the drawing project progressed it was obvious that there were other factors that had the potential to impair the quality of data extracted from the drawings. An example of this is well demonstrated by the session of intermediate boys who had been drawn from two classes, which was held in a room next to the sports field. Half way through the session the boys noticed that the girls from one of the classes were playing softball. The drawings were rushed through and the boys were out the door. The other class of boys had Maths to return to when their drawings were completed. They stayed until the very end of the allocated time. I was initially concerned that the first set of drawings would not offer the same quality as the second. And, although that was correct as far as the 'competency' of each drawing was concerned, they still denoted individuals involved in activities and with which it was possible to determine spatiality and predominance.

One factor that did make a difference to the quality of the data was the lack of certainty about the intention of the participant. For this reason I was not able to use thirty five drawings as part of the first category of analysis. 


\section{Limitation of Involvement in Academic Research}

The irony of being a community activist involved in academic research has been apparent. In order to keep up with academic production for this dissertation I found that for much of the time I would otherwise have spent 'out in my community' I was on my own reading, thinking, writing. It was difficult when people called to see me, at work or at home, and seemed to stay 'forever'. Communication with people invariably became part of the 'gathering of information'. I sought opportunities to talk with other academics and other students working on doctoral degrees. I wanted to believe that all the time I was spending on this project was going to benefit mothers raising adolescent sons, the practitioners with whom they will come in contact, the boys themselves and in the end the whole of society. However, as well as being grandiose, I fear this could be delusionary. This piece of work will make little or no difference if it is not followed up by accessible and pertinent information useful to families or those who interact with them.

\section{Validity Scoping for the Project as a Whole}

Figure 9.1 presents a scoping of the validity of this project. The scoping is correlated with nine selected principles, compiled from a combination of those offered by Anderson et al (1998), Eisenhart \& Howe (1992), Guba (1989), Herschell (1999), Hill \& Capper (1999), Kelle and Laurie (1995), Lather (1991), and Stanley (1997) with three key research components - participants, process and outcomes. Sections of the dissertation that evidence validity are incorporated into the matrix. Although not all of the named sections focus on validity issues specifically, each of them addresses one or more of the principles included in this table. 


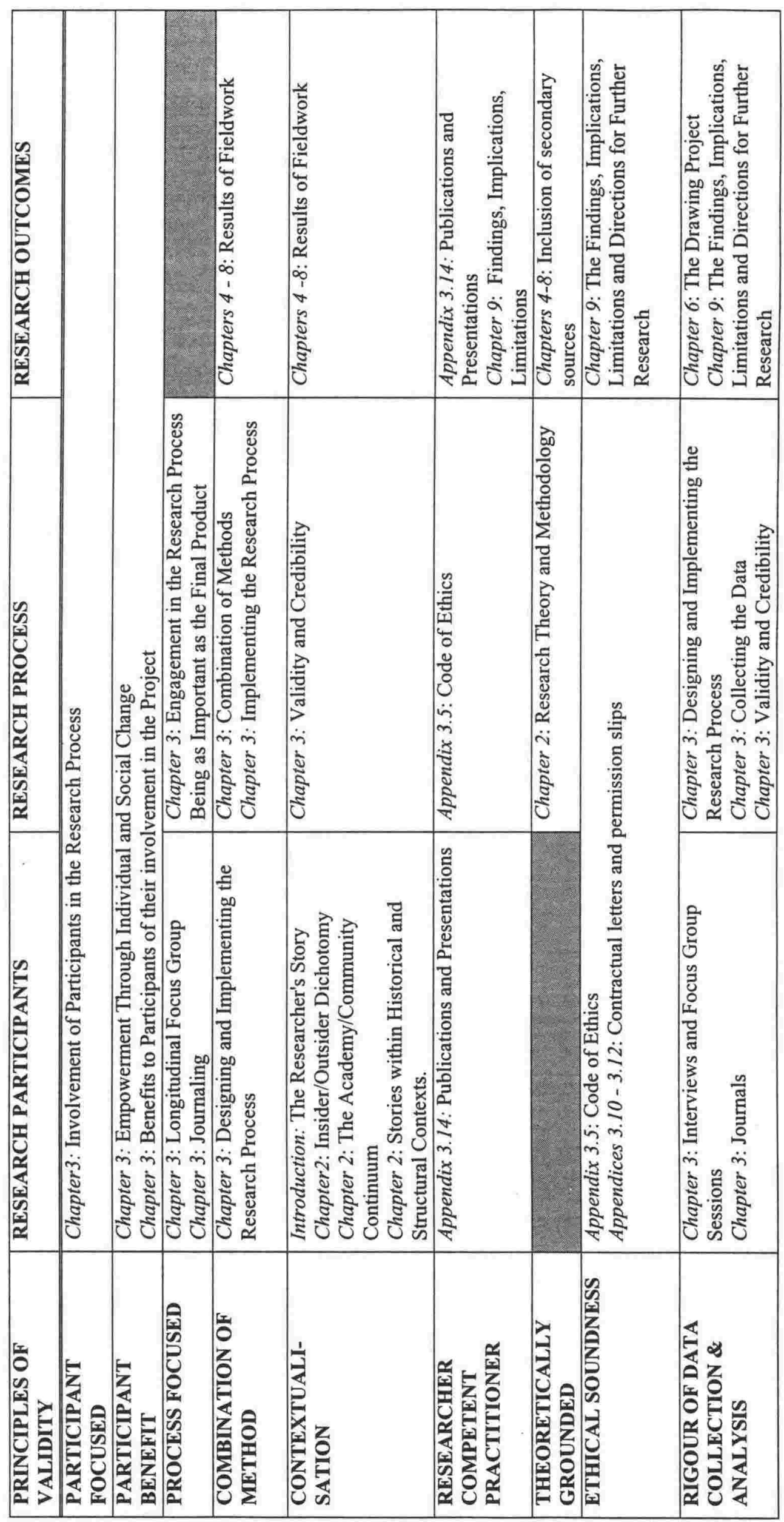




\section{SUMMARY OF FINDINGS AND IMPLICATIONS}

The findings of this study are both methodological and substantive. That is, they arise from the research theory and processes used in the investigation as well as from the subject of the project. Chapter Two discusses the theory and methodology relating to the feminist participatory action research processes in the study, Chapter Three examines the research techniques used and the previous section in this chapter has examined the limitations and strengths of the research processes. In summary, it was found that the combination of feminist research theory and practice with participant-owned objectives of individual, collective, political and social change has the ability to create outcomes that are powerful and robust. These outcomes were obvious during the project and were evidenced by the participant feedback in discussion, in letters and in journals. It is too early to tell whether the summative research outcomes will effect positive change for mothers and adolescent sons.

A major finding of the study was that the strength, confidence and enhanced selfesteem of the mother contributes positively to her ability to parent her adolescent son and maintain an effective relationship with him. This finding was initially constructed as an "aha!" during one of the longitudinal focus group discussions when the participants were reviewing their journals and reflecting on their experiences as mothers of adolescent sons. The conclusion that the confidence and self-esteem of the mother contributes positively to her ability to parent her adolescent son is underpinned by the recognition that certain factors undermine the confidence and self-esteem of the mother disrupting the mother-adolescent son relationship, and other factors are supporting and strengthening in a way that is constructive to both the mother and the son. The factors that disrupt this relationship have been grouped into three categories - the socio-economic situation of the household; the historical and contemporary constructs of 'mother' and 'motherhood', 'adolescent' and 'adolescence'; and the public accentuation that fatherlessness is a key reason for current negative statistics about adolescent males. It became evident that those factors that are conducive to a healthy motheradolescent son relationship are directly related to these three categories. One of the further conclusions that became apparent was the need for informal and formal community and national support for the mothers of adolescent sons. This next 
section will summarise each of these findings in turn. It is important to note that the conditions for the mothers were not homogenous. Factors, such as family structure, levels of disposable income, formal education levels, ethnicity, sexual orientation and age, contributed to differences in experiences for the mothers. At times the differences for single and lesbian mothers in the project are highlighted but as discussed in Chapters Two and Three the findings do not claim generalisability. They represent the experiences, thinking and perceptions of twenty-one mothers and to a much lesser extent, one hundred and seventy six boys.

\section{The Impact of Socio-economic Factors on the Mother-Adolescent Son Relationship}

The Equal Worth Report (1999), written from a study commissioned by the Australian Commonwealth/State and the New Zealand Standing Committee of Advisors for the Commonwealth Office of the Status of the Status of Women showed that females on average in Aotearoa New Zealand hold approximately 85 percent of the wealth holdings of males (1999, p.26). Categorisation into family type and age grouping showed further discrepancies. Within all broad categories of family groupings the mean wealth of males was higher than that of females by 15 percent. The difference between males and females increased to 33 percent for families with dependent children and increased still further to 47 percent when comparing single male parents and single female parents.

The move toward privatisation and a user-pays economy by the previous government over the past decade has severely disadvantaged single mothers. Adequate income for the increasing costs associated with education, health and safe and appropriate housing is often out of reach. Social welfare expenditure on benefit support against Gross Domestic Income decreased from 1991 to 1997 although the numbers of beneficiaries increased. The project mothers, particularly those living on a government-funded benefit, reported difficulties providing for the basic needs of their families. The significant areas of financial struggle as reported by the mothers included; housing, food and clothing shortages; limited access to education, health and transport systems and an inadequacy to fully support their sons' co-curricula interests. It seemed that the lack of these basics 
impacted in several ways. Physically the health and well being of family members declined, impeding the sons' abilities to successfully achieve at primary, secondary and tertiary study, and consequently to compete for rewarding and sufficiently-paid employment. The costs associated with maintaining social contact with others isolated the family. Psychologically the families battled with external and internal pressures. It seemed that the tensions that make up part of any family were amplified by the lack of resources available to the family members and the low-self esteem generated by that.

A USA study by Lempers and Clark-Lempers, initiated in 1996, reported that "more financial strain on the mothers led to a decrease in the quality of the mother-child relationship, as perceived by the children" $(1997, \mathrm{p} .8)$. This finding, endorsed by other studies cited by the authors such as, Clark-Lempers et al. 1990; Conger et al. 1992; Elder et al. 1985; Lempers et al. 1989, reflected the experiences of the mothers from this project. The experiences of these mothers are also supported by Lynette Ebborn, coordinator of Solo Women as Parents, who claims that a family living in poverty prioritises the material needs of that family over the emotional needs (New Zealand Herald, September 5, 1997). In other words, the quality of relationships between family members becomes less important to the family system than does the effort that is required to find enough money to live on.

Eastwood describes the group of males with 'problem behaviours' as those who "had impoverished and disadvantaged childhoods" (1998, p.12). This statistical evidence included in his report on Young Male Risk Behaviours supports my claim that the ability of mothers to keep their sons safe is dependent on the support they receive from society-wide social and economic policy and interventions.

The Impact of Historical and Contemporary Constructions of 'Motherhood' and 'Adolescence' on the Mother-Adolescent Son Relationship

A review of literature has highlighted the historical and contemporary constructs of motherhood. Acknowledging the concept of motherhood as biological and 
social, its development is discussed through three time periods as outlined by Ann Ferguson. These are; father patriarchy - pre-1800, husband patriarchy - 1800-1900 and public/capitalist patriarchy - 1900 - onwards (1997, pp.39-60). Comacchio suggests that three fundamental processes have been central to the modernising of the mother in the Western world; the public recognition of the mothercenteredness of the nations' welfare; education and supervision of the mother by an emerging group of professional workers; and the promotion of education and supervision of the mother through state regulation (1997, p.322).

An analysis of the interpretations of 'mother' and 'motherhood' according to psychoanalysts, Jungian analysts and mythologists Bachofen (1861), Bettleheim (1976) Briffault (1927), Campbell (1959), Freud (1913) and Neumann (1949 \& 1955), results in a recognition of the 'primacy' and the 'fall' of the mother. In her summation of the fall of the mother, Rich argues that the creation of the patriarchal family has violated the fundamental human unit, the mother and child. "Woman in her full meaning," she claims, "is domesticated and confined within strictly defined limits." As the maternal "she remains an object of mistrust, suspicion, misogyny in both overt and insidious forms" (1984, p.127).

Thompson maintains that motherhood has been discussed, analysed, dissected and strategised by feminists over the ages (1997, pp. 204-205). Because of the pervasiveness of 'motherhood' ideologies in patriarchal societies it has perhaps been one of the earliest foci of analysis for feminist theorists. Explanations and constructions of motherhood by feminist theorists have been varied and, at times, oppositional. Explanations have tended to respond to dominant paradigms that privilege specific oppressions, for example, ethnicity, class, culture, sexual orientation, physical abilities, age, religion and the place of one's nation in the international order. Whatever the reasons given by feminist theorists, it is generally accepted that 'mother' as construct is a marginalised and reduced identity.

Aotearoa New Zealand was managed by a National led government from 1984 to 1999. This government with a socio-economic agenda toward self-reliance and independence from the state added momentum to the pro-nuclear family lobby. National and international organisations such as DAD (Dads against the Divorce 
Industry), the Essentially Men Programme, FACT (Fathers are Capable Too), Families Need Fathers, Fathering the Future, Fathers Without Children, FREE (Father's Rights and Equality Exchange), Christian men's movement The Promise Keepers, and SPERM (The Society for the Protection and Encouragement of Righteous Manhood), have flourished in this country as a result. Individuals such as Steve Biddulph, Stuart Birks, David Blankenhorn, Robert Bly, Sam Keen, Rex McCann, David Popenoe, Warrick Pudney, Don Rowlands, Peter Zohrab to name a few, have contributed to an escalating concern among professionals working with families, politicians and the public in general about the role of mothers in the lives of (particularly) adolescent males.

Sprinkled as an underlying theme throughout parts of the fieldwork chapters is the story of "Bambi's" mother. This mother had no name. Created in 1928 by writer, Felix Salten, she is the vessel by which her son, Bambi, was born, and who needed to be destroyed before Bambi was able to become an adult male.

As with motherhood, the historical and contemporary constructs of adolescence were reviewed. Similarly also there are varying accentuations of adolescence as interpreted by philosophers, Christian theologists, psychologists, human development theorists, sociologists and anthropologists. According to Simon (1996, p.59), there are five 'constituencies' for whom adolescence is significant. The first group comprises those professionals who specialise in the production and commodification of knowledge and wisdom regarding adolescences. The second group is made up of those who are parenting or supervising adolescents. The third group includes those who market and service goods to adolescents. The fourth group is made up of the adolescents themselves in the varying guises this includes and the fifth group, those who have been adolescents and have sought to find meaning for their experiences as adolescents. This research focused primarily on the experiences of the second group in the hope that it will be of benefit to both the first and second groups.

Although Conger reports sixteenth and seventeenth century interest in adolescence by Greek philosophers such as Plato, Aristotle, Constantine and Isidore, he supports the generalised belief that the social and economic influences of the industrial revolution separated the stages of childhood and adulthood to such an extent and 
in such a manner that a visible category of segregated youth developed (1988, pp.6-10). Human development theorist, Helen Bee, suggests that adolescence is defined by "a time of transition in which significant change occurs in virtually every aspect of the child's functioning" (1998, p.328). Likewise influential theorists Freud, Piaget, Erikson and Kohlberg maintain that adolescence is the period when identities are developed and are acted out through the formation of sub-cultures. Calabrese proposes that adolescence is conducive to alienation because of the tension between childhood freedom and adult responsibility in the period in which it exists (1998).

Examining contemporary constructions of adolescence, Locher discusses the multiple identities of young people, the multiple constructions of adolescence, and argues that the youth sub-culture of the 1990's, in the United States, failed to come together (1998, pp.100-117). Best and Keller contend that the media culture is having "catastrophic effects on the current generation of youth " (1998, p.81), maintaining negative aspects of adolescent culture. Epstein expresses his concern that young people are presented as 'problems' and challenges those working with adolescents and theorising adolescence to move away from the concept of youth as a problem to an analysis of the society in which young are being raised (1998, p.21). Papalia and Olds (1998) also question the universality of the expected trauma associated with adolescence.

Most theorists seem to agree that adolescence is a time of change, a time when young people become independent from parents and identify with peers in search of a personal identity. It seems that this time can be destructive and traumatic or can be managed in a way that enables the young person to experiment, express their individuality and separate from adults healthily and constructively. Although there has been strong critique, predominately from feminist and social scientists, about the theories developed by Freud and Erikson (and modified and adapted by more current writers such as mentioned above) they still underpin teacher, social worker, health practitioner and counselling and parenting training in this country. They also impact on the constructs and frameworks of the mothers within this study. 
The participants described the controls imposed on them, and on their situations, by professionals and professional organisations, particularly the justice, social welfare, education, mental health, religious and sports sectors. Although the research did not attempt to analyse the primary sources of the predominant values, attitudes, beliefs and cultures represented and reinforced by these sectors it gives an account of the reported impact they had on the research mothers. I argue that interpretations of motherhood and adolescence, and the expectations of family members within these interpretations, by these sectors would be powerfully influenced by the predominant constructions discussed earlier.

The impacts of these structural and cultural frameworks on mothers parenting adolescent sons were multiple. Discussing the nature of their relationships with their sons, a predominant issue reported by the mothers and supported by the results of the Drawing Interpretation Project, was that there was a perceived and negative change in the attitudes and behaviours of their sons toward them at adolescence. Conflicting explanations are proposed. Some theorists claim this negativity as a normal stage of adolescent development; others, as indicated above, discount the universality of tension associated with adolescence; others suggest that the difficulty is more likely to be with mothers than fathers because most mothers have been more closely involved with their children; while others maintain that the mother-son relationship is by nature regressive and must be disrupted in order that the sons may gain entry into the adult world. As a result of this research my contention is that the undermining and putting down of the mother by the son is not part of the separation that is natural between a mother and son at adolescence. As stated by Rich, "we need to understand that there is a difference between handing our sons over to patriarchy on its term, figuratively or literally allowing them to victimize us as tokens of their manhood; and helping them to separate from us, to become themselves" (1986, p. 211). The nature of motherhood and adolescence, as constructed by a western capitalist society that is dominated by patriarchy, confines us within a belief that not only will the son not succeed until separated from the world he has inhabited with his mother, but that this world is inferior. As claimed by Silverstein, the mother herself conforms to 
this belief by colluding with other disruptive agents to elevate her son and perpetuate the domination of the male ${ }^{1}$.

Interviews with the mothers drew attention to the way they felt undermined and blamed, as individuals and just because they were mothers, particularly for the potential harm that they may cause their sons. They described the use of negative and oppressive imagery of mothers and the involvement of the fathers, sons, mothers and society in general in the undermining of mothers. Almost forty percent of the pubescent and adolescent males in the Interpretive Drawing Project depicted the mother as vulnerable, while twenty percent depicted her as powerful. In descending order the remaining males depicted the mother as industrious, undesirable, sexual and sociable.

As experienced by several of the mothers in the project, societal sanction is not granted to lesbian mothers. As well as experiencing the discrimination of homophobic communities, mothers reported incidences of direct abuse by the fathers and the sons. Specific issues for lesbian mothers included; the apprehension (and sometimes fear) of being visible, the multiple complexities of parenting a new generation of men, and the public and insidious insistence of father-presence. Some of the mothers felt a lack of acceptance within the lesbian community, and with other lesbians. Horizontal violence has been theorised by structural analysists, such as Franchette and Freire, as the abuse that can occur within a group experiencing oppression by the dominant paradigms of a society. Although this project didn't explore the reasons for the uneasiness some of the mothers felt within the lesbian community as mothers of sons, the systemic discrimination of lesbians within our society could account for its occurrence.

The single mother group also felt battered by their non-conformity to the privileged structure of the heterosexual nuclear family. This undermining was perpetuated by the communities and groups within which the families existed and

\footnotetext{
${ }^{1}$ In October 2000, the NZ Education Review reported on a four year Vienna-based research project studying teenage males. One of the major contentions of this research is that "mothers withdraw their attention from their sons much too early out of fear of turning them into mummy's boys. ... The early loss of motherly love is a major factor contributing to poor school results" (Reported by Werner, 2000, p.13).
} 
related and was also produced and sustained by those who determine social and economic direction. Apart from the major issue of poverty for single mothers, further issues that related specifically to them included; the desire and added pressure to parent effectively, stigmatisation, exhaustion and stress of parenting on their own, isolation and the difficulty of forming an intimate relationship with another adult. Parental separation and difficulties of custody and access arrangements were also disruptive to the mother-adolescent son relationship. The majority of single parent families are headed by women. It is these mothers who tended to be at the receiving end of the normal grief and anger felt by the children.

Examining their sons' worlds, the project mothers highlighted several aspects. Firstly, they described the seeming necessity for a boy to be sporty and demonstratively macho in their behaviour in order to attract male friends. They discussed current studies that show that boys are not achieving educationally as well as girls. The under achievement of boys in education is a complicated issue and one that is used by nuclear family and father-involvement lobbyists as an example of the 'feminisation' of the education sector. The concerns and fears expressed by mothers for their sons focused predominantly on safety issues. These included; alcohol and drugs, driving, safe sex, anti-social activity, low self-esteem and suicide. The Young Male Risk Behaviour Report identified "the most significant cause of death and hospitalisation for young males [as] road related injury" (1998, p.15). Addressing the issue of male role models the mothers felt their boys needed access to positive male figures, however they were conflicted about whether it was necessary for this person to be the father. Reportedly stigmatisation experienced by boys from single-mother households contributed to feelings of alienation and low self-esteem. As the interviews with the mothers progressed over the four years of the study, it also became apparent that there was a link between the son's self-esteem and the quality of their relationships with their mothers. A further outcome suggested by the drawing interpretation project and reported by mothers was that of the significance of (particularly older) brothers to adolescent males. The lack of substantial material relating to this however has meant that no convincing conclusion could be drawn.

As reported by the mothers, the role of the father in a boy's life was mixed. There was no evident connection between the health of the father/son relationship and 
the living arrangements. Two key themes became evident. The majority of relationships between the adolescent sons and fathers were reportedly fraught and some fathers who had not spent much time with their sons appeared to increase their level of interest in them when the sons reached pubescence/adolescence. Mothers, who did not live with their sons' fathers, raised issues of custody, access and financial child support.

\section{The Impact of 'Fatherlessness' on the Mother-Adolescent Son Relationship}

The third major factor that impacted on the ability of a mother to effectively parent her adolescent son and one that is gaining currency in Aotearoa New Zealand, Australia, Canada, the UK and the USA, is the concern that the current generation of boys is fatherless. The voices of two groups are highlighted by the research - those of the mothers, and those of the sons. Although the voices of the mothers have not claimed to be representative, they come from a variety of family situations - single parent, two-parent, lesbian and heterosexual. The commonality among them is that they are mothers of adolescent or post-adolescent boys. The issues raised by the mothers highlight the complexity of the 'fatherlessness' debate and provide a broader perspective than has been evident in literature published to date.

The mothers were vocal regarding the impact of the popularisation of fatherlessness. They commented about the feelings of shame and unworthiness generated by the highlighting of father-need. They spoke also of their concern that highlighting fatherlessness would give young people, and others, an excuse to blame mothers or to treat them mothers with disrespect.

Since the early 1990s, an increasing number of books and papers have been written about fatherlessness, father-absence and raising boys. The majority of what has been written is populist, based on anecdotal evidence and offers fatherpresence as the panacea for current concerns about adolescent males. Underlying much of this text is often a subtle, and not so subtle, condemnation of the mothers. Several themes arise. There are those who strongly argue for the separation of boys from their mothers. There are those who are directly critical about the harm 
that women do to boys and men. A further agenda for the increase in interest around fathering is expressed by those supporting male liberation and men's emancipation. Mackie claims that the most serious problem society faces is that of inadequately raised men and that what is needed is men who are "tuned in to men, sensitive about men. Not women - men" (Sunday Star-Times, May 11, 1997). One of my major concerns about the developing agenda of this rhetoric is that rather than encouraging co-operation between mothers and fathers, the messages being given to women and to mothers is that they are not adequate, that they have no place in the life of their sons and are seen as being destructive to men, robbing them of their power and their male hood.

There was no evidence in the Drawing Interpretation Project of a connection between low self-esteem of the adolescent male and father-absence. That is, in one of the fifteen drawings where the son indicated a low sense of self, the father was absent, in two the mother was absent and in the remaining twelve both parents were drawn. There was also no evidence to suggest that there is a link between father-absence and adolescent male aggression. The need for boys to grow away from their mothers in order to connect more with their fathers is also questionable.

The father is seen as one of the prime promulgators of father-need, particularly as it relates to sons. However, it is important, I believe, that he is recognised as merely, although significantly, an agent of this societal concern. This study has not so much dwelt on the issue surrounding the relationship between father and son but has examined the agencies that use this to perpetuate the undermining of a woman's ongoing role in her son's upbringing.

In summary, the key implications of the research findings for this project are inextricably linked with the key findings. The ancient coalition of the Church, the State and the medical profession, in particular the mental health sector, to ensure the moral, social and economic values was evident from the stories of the mothers in the project. Without exception the participants reported instances of being subjected to inflexibility and limitation about how to behave, what to believe, their status as mothers and their status as mothers of adolescent sons. These instances weren't restricted to public sectors but involved as well their sons, the 
fathers, family members and other mothers, including other lesbian mothers. A sense of self-sabotage was also evident. The implications are clear. In order for mothers to parent effectively, support from all sectors, public and private, is necessary. Those who champion the unnatural and forced separation of sons from mothers and who berate single mothers with sons not only miss the mark but also exacerbate the problems they claim to minimise.

\section{FURTHER RESEARCH}

The potential for future research originating from this project is also both methodological and substantive. The research methodology, feminist participatory action research, has the potential to be applied in a number of research contexts. The topic of this investigation has also generated further questions.

The research tools available to feminist participatory action research are unlimited as are the possible locations for the application of such research. The feminist participatory action research methodology used in this project is principally untested in Aotearoa New Zealand. I have observed groups at a number of levels undertaking community development projects using the key processes of needs analysis, investigation, definition, reflection, and redefinition. My hunch is that many more are also occurring in this country. Concerningly, but understandably given the limited resources and time frames that most community groups are operating from, the outcomes of these projects remain localised. The new knowledges created within these projects are not tested in similar situations. They are also not considered significant to political and social amendments, which tend to rely on quantitative research data sources. Feminist participatory action research also has significant potential in circumstances where there is a need for positive change for women in areas such as, legislation, organisational culture and behaviour, individual and group practice and community attitude and behaviour.

The Drawing Interpretation Project, although a research method rather than a methodological process, is also worth extending as an investigative technique. As discussed in Chapter Three, drawing interpretation is more commonly used for therapeutic purposes than as a data collection tool. In this project it has also been used as part of a triangulating process rather than a main source of information. Its 
potential could be greatly extended particularly with children, with people who could be uncomfortable verbal communicators or when wanting to gauge reaction/unconscious response rather than considered thought.

As it relates to the substantive component of the research, the mother-adolescent son relationship, possible further issues to research have been separated into two categories; necessary research and possible research. In the category of necessary research four distinct areas for investigation become apparent.

The first immediate issue that needs investigating is the effects of socio-economic hardship on the ability of single mothers to effectively parent their sons. This study has highlighted the difficulties for the mothers in the project. Given that the research methods chosen for the mother-adolescent son project were such that generalisation is not possible, transferability of outcome is not appropriate. Although these participants highlighted the negative impact of poverty on their ability to parent their sons effectively, the situation for other mothers of sons in Aotearoa New Zealand is unknown. It is possible to hypothesise that this finding may reflect the situations for other mothers. Further research is necessary, perhaps involving substantial numbers of mothers raising sons, triangulated with more indepth focus groups. The outcomes of research such as this could add to the poverty studies currently being undertaken in Aotearoa New Zealand by Charles Waldegrave, director of the Family Centre Social Policy Research Unit.

A second, comparative study would include research with adult males that have been raised predominately in female-headed families where resources were adequate; where the families received appropriate community support, and when the stigma of being a female headed household did not exist (for example, during the World Wars when women heading families were seen as exemplary).

Allied to the above question, a third research focus would be a study of femaleheaded families with sons, where the family dynamics are constructive, where the sons value women and girls equitably and where the development of the sons is healthy and positive. The value-laden criteria for this area of study would create interesting challenges when it came to research processes, parameters and 
measurements of outcome. However, if undertaken robustly, the findings could be illuminating to discourse around nuclear family preference.

A fourth area of research that should be given the chance to develop from this work is a study of the determination of the effects on the son caused by an 'unnatural' and early separation from the mother. This separation could be defined in several ways. The mother and son may be forced to be non-residential. The marginalising, diminishing and degradation of the mother may make her 'disappear' as a parent. The mother may chose to withdraw herself from her son out of a belief that it is for his benefit.

Further possible areas for research have infinite options. One of those that was generated by the Drawing Interpretation Project involved the brother-brother relationship and stimulated questions such as; does an older brother become a father figure to the younger brother in the father-absent family; does an older brother feel as if he needs to take a 'father role' in the family; does this occur more frequently in single mother families; are there different patterns for boys with and without older brothers?

Another future study relating directly to this research project would be a comparative analysis for fathers raising adolescent sons. Likewise comparative studies could be undertaken in areas outside Aotearoa New Zealand where social, economic and political structure are similar and dissimilar.

\section{CONCLUDING COMMENTS}

Is it necessary for a boy to separate from his mother in order to prepare his place as an adult male? Does the traditional division of society into private / nurturing / female and public / intellectual / male provide the concern that at this age a boy needs to not only separate from but to downgrade the mother and her world in order to become a man? Is the woman (his mother) seen as separate from this public world and therefore incapable of providing the stimulus, and knowledge to support him to be part of this world? 
Statistically the well being of New Zealand children is low on the international scale for developed countries. A report written by the Committee on the Rights of the Child (Geneva, 1997) was critical of this government's record of compliance. It outlined four key areas of concern for Aotearoa New Zealand; child poverty, fragmented and poorly resourced services, violence against children and a high youth suicide rate. The public response emerging from this situation is an incongruent need for 'father', focused particularly on boys and accompanied by urgency and concentration. The wider and more endemic issues of poverty, child abuse, and emotional and physical ill health appear to be disregarded.

Interviews with mothers suggest that factors such as poverty, isolation, stereotypical messages, lack of self esteem and the lack of positive male role models have a major impact on the well-being of the family and its members. A common theme generating from the project fieldwork indicated that it was more important for a parent to have self-esteem intact, the ability to show love and affirmation and also with a belief about who they are as an adult and a parent than it is to be a parent of either gender. All mothers in the project, whether single, partnered, lesbian or heterosexual, highlighted the impact on their confidence and self-esteem of being undermined, being blamed for the concern about adolescent males, being marginalised and rendered invisible. Clinical psychologist, Joyce Hamilton Berry, maintains, "the best way for a mother to teach her son to respect women is by demanding respect herself" $(1988$, p.2). A mother, I contend, can only demand respect from others when she is able to feel confident and respect who she is. The interviews, group discussion and journaling indicated that there was a correlation between stress factors, confidence and self-belief of the mothers, functioning family systems and adjustment of sons. Stress factors lessened the confidence of the mothers, causing an inability to function as parents and contributing to the maladjustment of the sons.

The health of current and future generations of adolescents is reliant on the health of the mother-adolescent son relationship. The task surely therefore is to cease the attack on this relationship and to elevate the status of the mother empowering her to parent her son as effectively as possible. As one of the participants exclaimed, 
When we as mothers begin to be strong ... our kids actually fare better. It's not so much whether the father or the mother is there. It's the fact that the adult or parent that is there is strong. One of the hopes for me that comes out of parenting our kids on our own is that we're able to demonstrate as strong women but also caring loving mother and that our boys should all be strong men and caring loving men and that if we can encourage that ... but that's all very 'pie in the sky' the reality that you're talking about is sometimes bloody tough! (GP 4)

Important research undertaken by Silverstein and Auerbach with 200 men in the USA endorses this comment. Their findings have shown that neither a mother nor a father is essential, but rather "children need at least one responsible care taking adult who has a positive emotional connection to them and with whom they have a consistent relationship" (1999. p.2).

While I have unmitigated support for the right and need of a boy to have a beneficial relationship with his father, I also defend, and advocate for, his right to the benefit of a healthy interdependent relationship with his mother (Chrisp, 1998a, 1998b, 1999a, 1999c). I suggest that part of the government agenda, as it moves from a public to a private ethos of social and economic responsibility, is to mandate the father to take up his individual obligation for his children thereby lessening the requirement for state support. As the government has been captured by an individualistic monetarist philosophy so too the social context of the country is being influenced by right wing-pro-family precepts with an accompanying persuasion for the reinstatement of traditional family values and the father as head and protector of his wife and children.

It tears a child apart to have one parent devalued by the other. My concern and the thesis that underpins my work is that as they develop, sons learn to devalue their mothers and the world that women inhabit. 'Father-absence speak' and the call for the return to traditional nuclear family values can serve to further perpetuate this. One of the complexities of the fatherlessness phenomenon is that it is articulated by a wide spectrum of political and social sectors, with a diversity of agendas and as many solutions. Superficial reproach for the increase in negative statistics for male youth is aimed at the single mother family. Key figures determining the socio-economic policies of this country have not yet effectively considered more 
complex reasons underlying issues such as poverty, emotional well-being, lack of social support and isolation of the care giving parent. The view that boys are severely disadvantaged without a father, who is present, magnifies this burden of existing at survival level. A mother's sense of not being enough becomes heightened by the rhetoric of fatherlessness made public - her guilt about her children being separated from their father, her self-blame for the difficulties the children may be having, the stress of ensuring her children do not go without and her feelings of isolation. Given that women in Aotearoa New Zealand are raising the majority of adolescent males, it is imperative that policy-makers, professionals involved with families and fathers take cognisance of the need to support, not disrupt, this relationship. These issues must be judiciously investigated, and thoroughly addressed, if environments are to be created that will enable boys to develop into healthy men who have negotiated the challenges of their adolescence and are accordingly able to contribute to a rapidly changing society. 
APPENDICES

AND

BIBLIOGRAPHY 


\section{APPENDICES}

\section{APPENDIX Pr.1: Publications, Presentations of Information from the Research}

Nov 1996: Boyz II Men Paper given to Post-Graduate. Conference at Victoria University of Wellington.

Feb 1997: Paper given to the Women's Studies National Conference and published in proceedings.

Chrisp, J. (1997). Who is Bambi's mother? In National Women's Studies Conference Papers. Palmerston North: WSA

May 1997: Paper given at National Action Research Conference and published in proceedings.

Chrisp, J. (1997). Action research for personal, social and political change - A feminist approach. In Action Research for Social and Educational Change - NZARN Conference Papers. New Zealand: Waiariki Institute of Technology.

June 1997: Chrisp, J. (1997.) The men's movement. In Broadsheet Winter/Hotoke 25 Birthday Issue 214. New Zealand: Womanfile Inc.

Nov 1997: Paper presented at the social policy conference, Massey University.

Chrisp, J. (1998). The debate on fatherless sons. In Celia Briar and Gill Gurjeet (Eds.) Work, Families and The State: Problems and Possibilities for the $21^{\text {st }}$ Century. Palmerston North, New Zealand: Massey University Publishing.

June 1998: Paper presented at the WSA National Conference, Palmerston North 
Chrisp, J. (1998) My mother is a crow - how the sons see us. In National Women's Studies Conference Papers. Palmerston North: WSA

July 1998: Paper presented to NZARN National Conference, Wellington.

Chrisp, J. (1998). Where equal is not equitable - a critique of the action research process where participants marginalised by societal structures take this into the research context. In Action Research: Challenges and Choices - NZARN Conference Papers. Wellington, New Zealand: Wellington Polytechnic Publishing.

August 1998: Seminar presentation at Victoria University of Wellington in the Department of Women's Studies seminar series. Using Drawing Interpretation as a tool for Data Collection.

May 1999: Seminar presentation at the Waiariki Institute of Technology $\mathrm{PhD}$ Seminar Series.

Feb 1999 Paper presented at the National Oral History Conference. The use of oral histories in feminist action research - The mother-adolescent son project.

June 1999: Paper presented to the NZARN National Conference.

Chrisp, J. (1999). Between action and inaction - contradictions in the emancipatory research process. In Collaboration for Collective Change - NZARN Conference Papers. Auckland, New Zealand: Auckland University Publishing.

Sept 1999: Chrisp, J. (2000). The use of oral histories in feminist action research - The mother-adolescent son project. In Byrne, Evans and Hutching. (Eds.) Oral History in New Zealand. Vol 10. New Zealand: National Oral History Association New Zealand.

Oct 1999: Chrisp, J. (1999). Fatherless sons - a review of the voices. In Stuart Birks and Paul Callister. (Eds.) Perspectives on Fathering II. 
Palmerston North: Centre for Public Policy Evaluation. Massey University.

Nov 1999: Two papers presented at the Women's Studies Association National Conference, Wellington

Chrisp, J. (1999). Strengthening (white, heterosexual, employed, nuclear) Families. The increasing divergence between the state and the single mother family. In National Women's Studies Conference Papers. Wellington: WSA.

Briar, C. \& Chrisp, J. (1999). Solo mothers' poverty: problems and prevention. In National Women's Studies Conference Papers. Wellington: WSA.

2000 Chrisp, J. (2000). That four lettered word, Sons. Lesbian mothers and adolescent sons. In Alison J. Laurie (Ed.) International Journal of Lesbian Studies. Aotearoa New Zealand Issue Fall 2000 
APPENDIX 1.1: The Government Narrative and the Mothers' Narrative

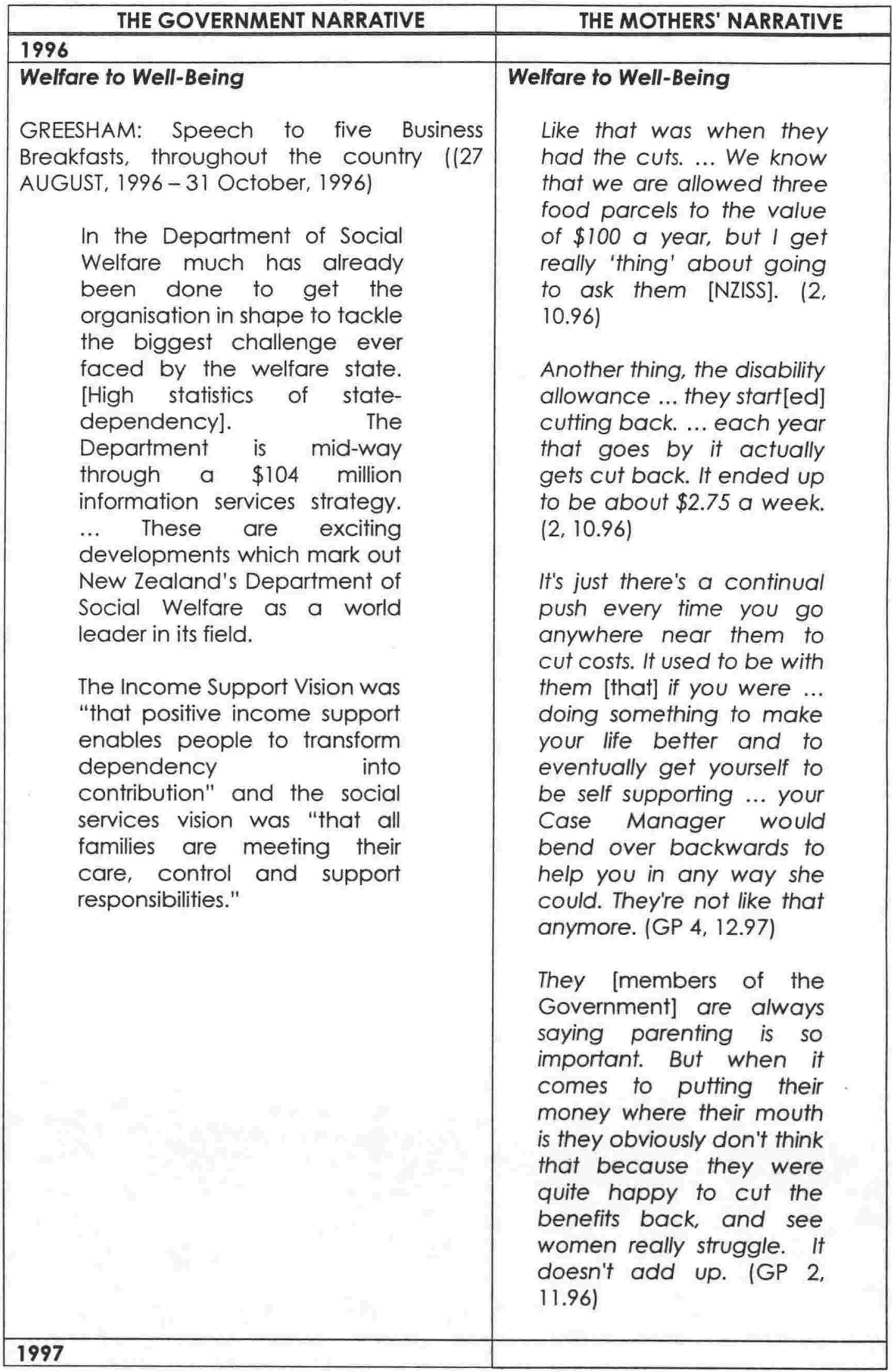




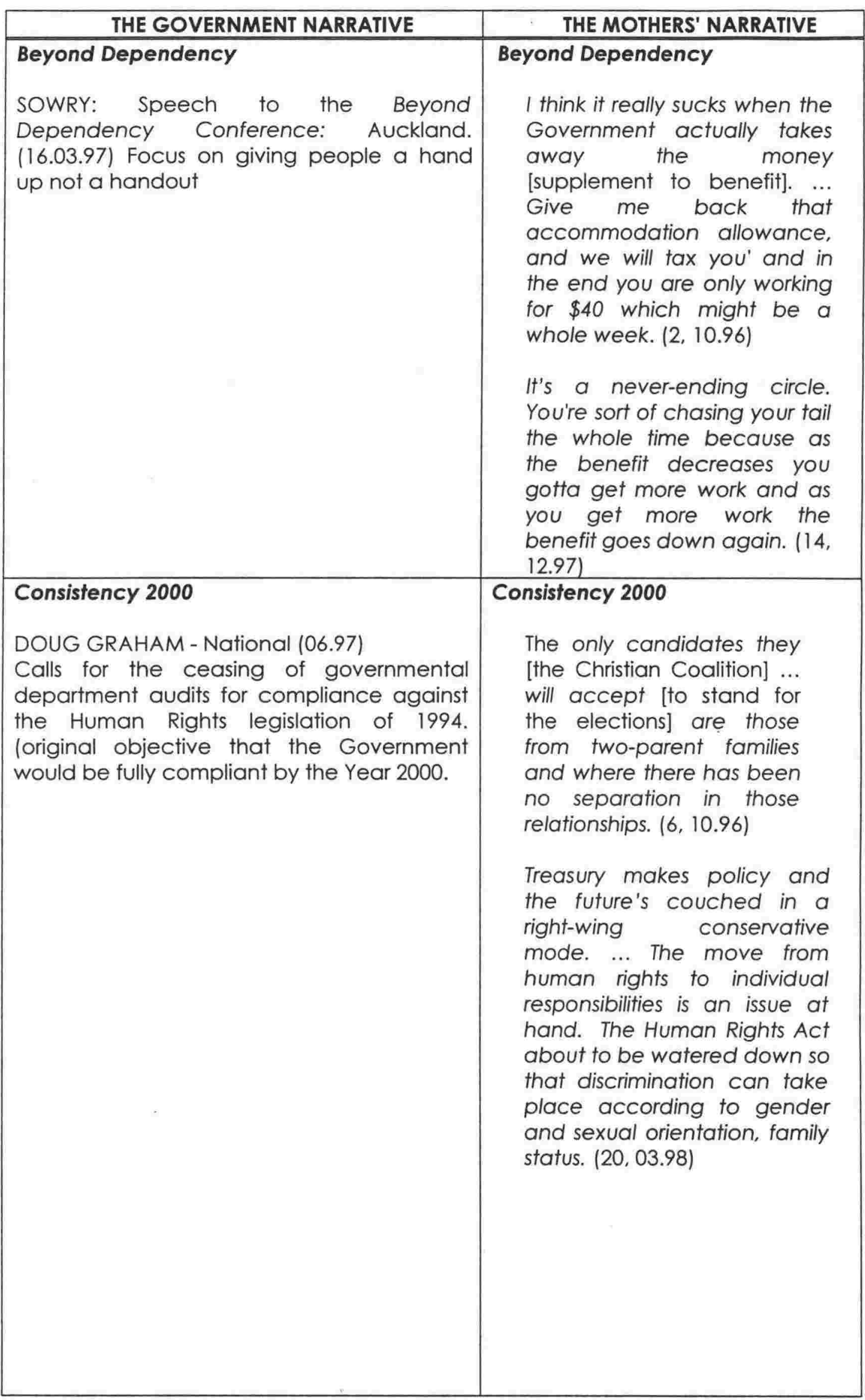




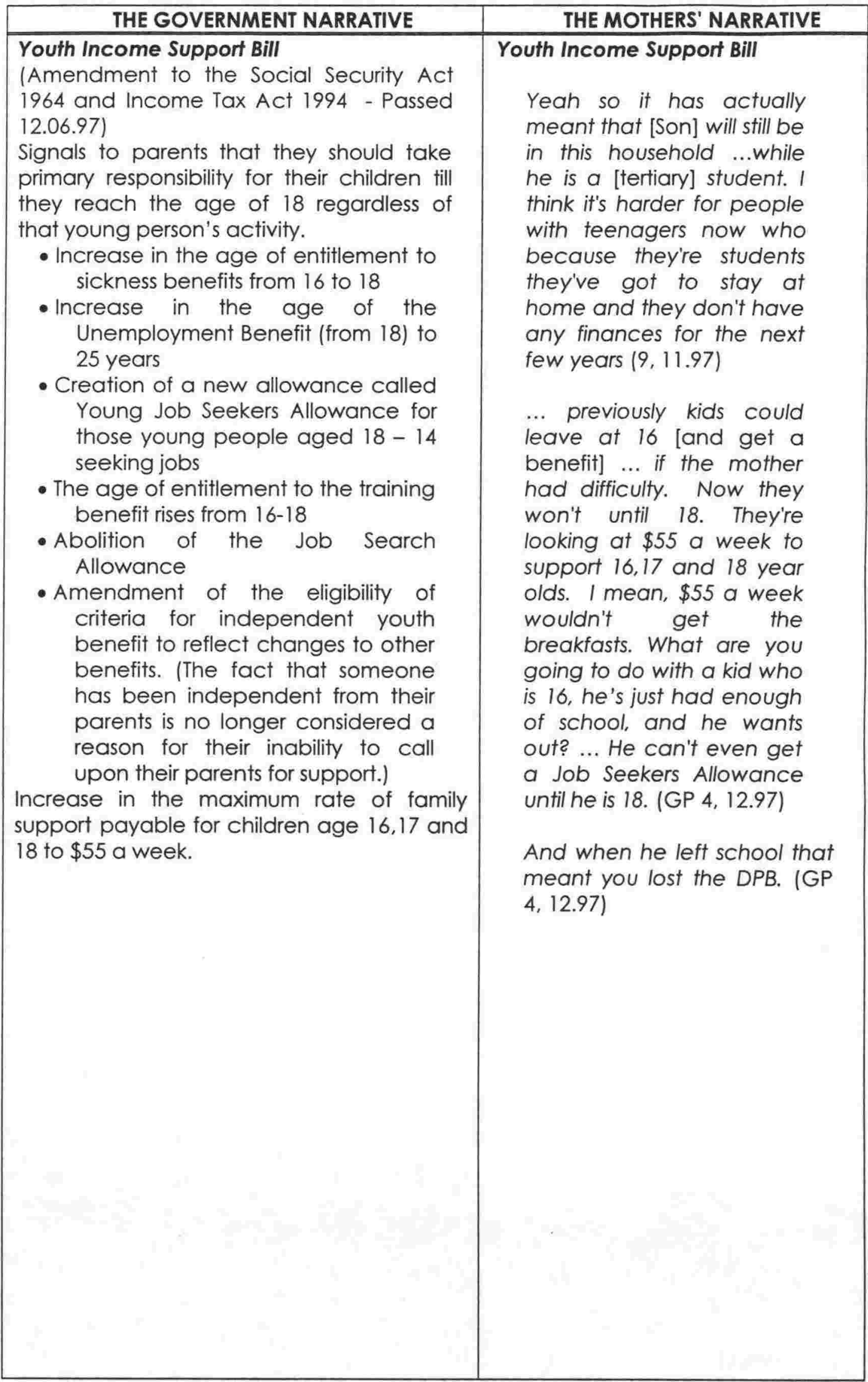




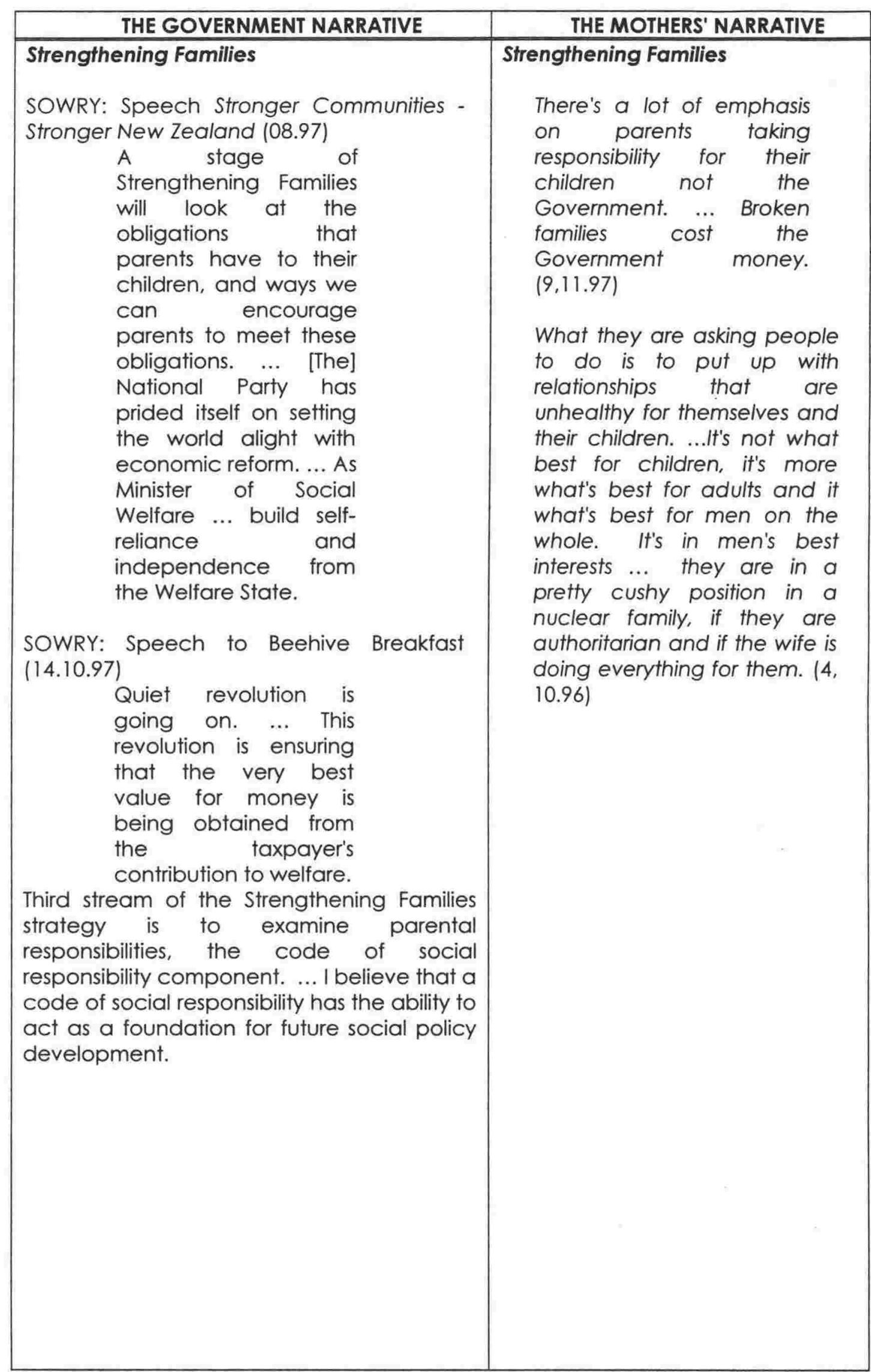




\begin{tabular}{|c|c|}
\hline THE GOVERNMENT NARRATIVE & THE MOTHERS' NARRATIVE \\
\hline $\begin{array}{l}\text { Conjugal Status Bill } \\
\text { ( Amendment to the Social Security Act } \\
1964 \text { and introduced 16.09.97) } \\
\text { - Grants an emergency } \\
\text { benefit in lieu of a domestic } \\
\text { purposes benefit in certain } \\
\text { circumstances. } \\
\text { - Has the discretion to grant } \\
\text { an emergency benefit (for } \\
\text { up to } 6 \text { months) where } \\
\text { battered woman's syndrome } \\
\text { is present. (After which time } \\
\text { the women is to have } \\
\text { extricated herself from the } \\
\text { relationship-my note) } \\
\text { Assessment of correct entitlement is } \\
\text { dependent on the conjugal status of the } \\
\text { relationship - (whether single or 'married' } \\
\text { rates are appropriate.) }\end{array}$ & $\begin{array}{l}\text { Conjugal Status Bill } \\
\text { I think Income Support for } \\
\text { Women is being fast } \\
\text { eroded with punitive } \\
\text { measures in Income } \\
\text { Support and the Code of } \\
\text { Social Responsibility. I think } \\
\text { it's going to go far and } \\
\text { wide, I can't see adequate } \\
\text { childcare being a provision } \\
\text { for women and that will } \\
\text { directly impact on women } \\
\text { alone. The Conjugal Status } \\
\text { Bill is truly frightening for } \\
\text { women. The future's a bit } \\
\text { bleak [especially] the } \\
\text { under-resourcing of Social } \\
\text { Services. (20, 06.98) } \\
\text { So you can see what in fact } \\
\text { the state is doing by } \\
\text { withdrawing its support is } \\
\text { actually having the battle } \\
\text { between those low-income } \\
\text { people rather than with the } \\
\text { State. And it's the children } \\
\text { who suffer. (GP 4, 12.97) }\end{array}$ \\
\hline $\begin{array}{l}\text { Child Support Amendment Bill } \\
\text { Put by John Wright (Alliance) in an } \\
\text { attempt to amend: } \\
\text {..the mandatory imposition of a } \\
\$ 520 \text { [ } \$ 10.00 \text { per child per } \\
\text { week] minimum annual } \\
\text { payment of child support. } \\
\text { (defeated at the second } \\
\text { reading 24.09.97) }\end{array}$ & $\begin{array}{l}\text { Child Support Amendment Bill } \\
\text { I only received } \\
\text { maintenance after } 1992 \\
\text { once the Inland Revenue } \\
\text { Act came in then I only } \\
\text { ever received \$40 a a } \\
\text { month. And that was } \\
\text { what Inland Revenue } \\
\text { claimed against the kids } \\
\text { father's income, he was } \\
\text { assessed it. \$40 a month } \\
\text { for three children. (GP } 3 \text { ) } \\
\text { But if you are on a benefit you } \\
\text { don't get that money } \\
\text { anyway. Social Welfare does. } \\
\text { And then you have got all } \\
\text { these people looking down } \\
\text { on you and your husband } \\
\text { could be paying more in child } \\
\text { support than what the benefit } \\
\text { is and you still don't see any of } \\
\text { it. (GP 2, 12.96) }\end{array}$ \\
\hline & \\
\hline
\end{tabular}




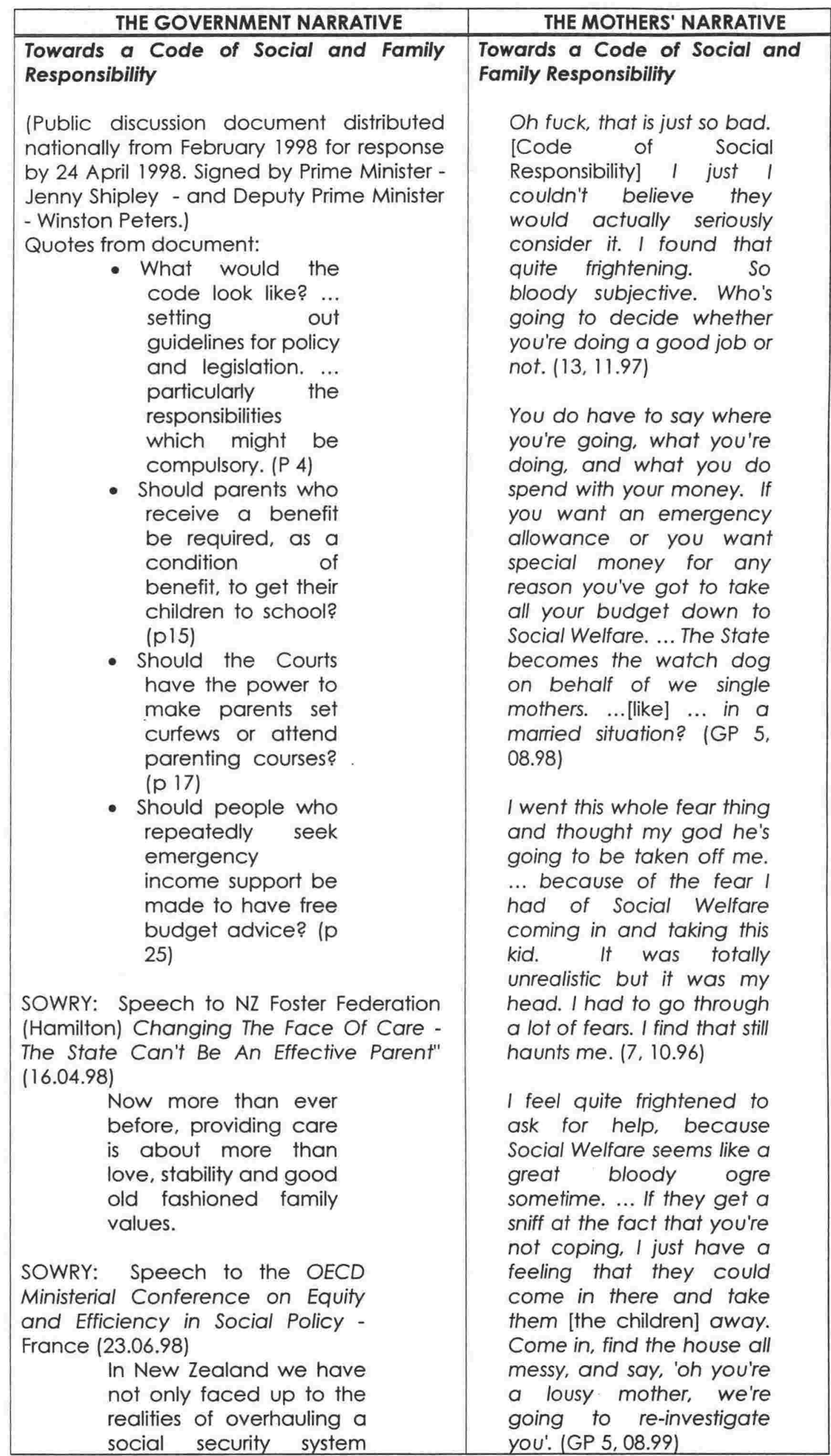




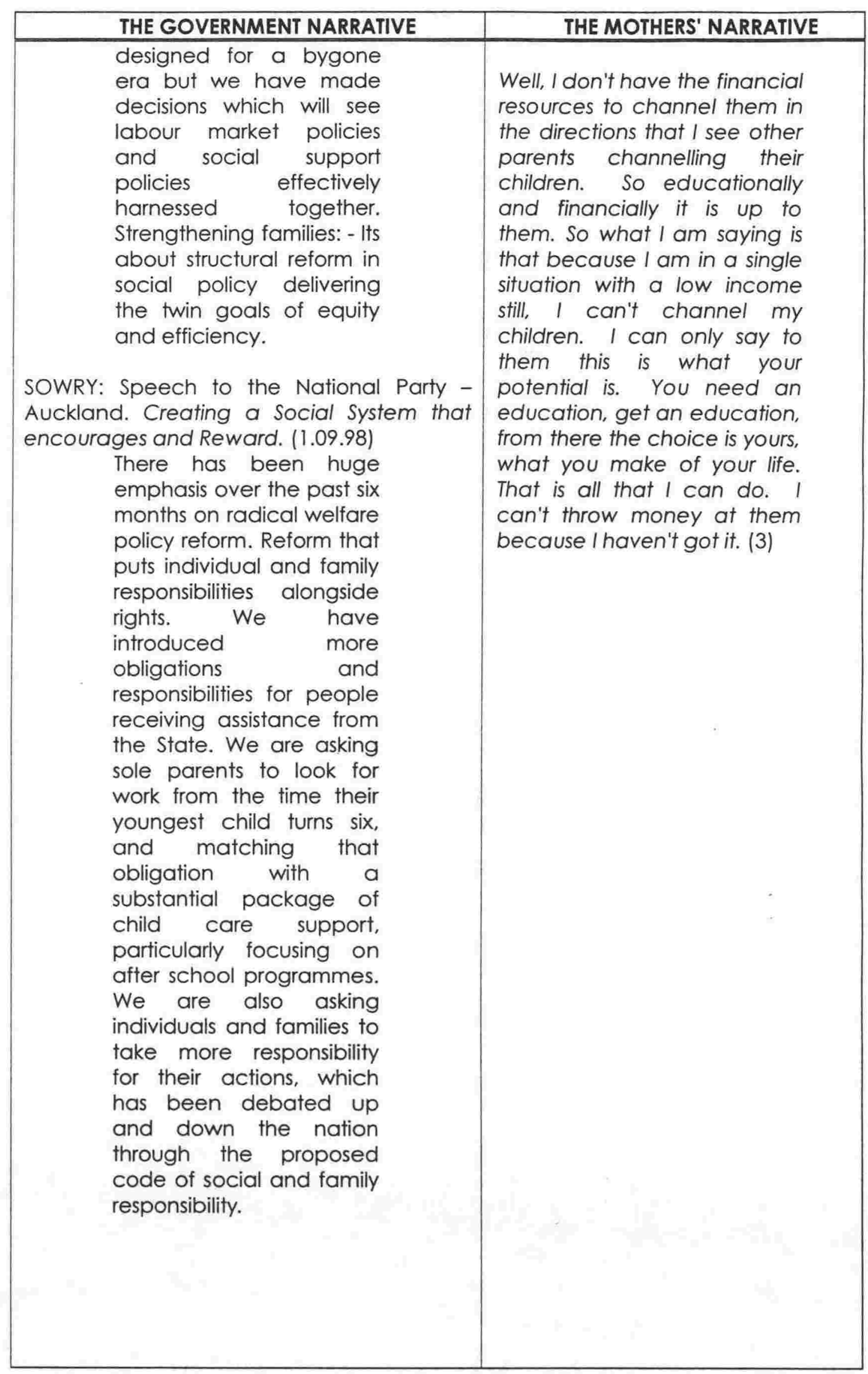




\begin{tabular}{|c|c|}
\hline THE GOVERNMENT NARRATIVE & THE MOTHERS' NARRATIVE \\
\hline $\begin{array}{l}\text { Community Wage } \\
\text { MCCARDLE : } \\
\text { All job seekers receiving the } \\
\text { Community Wage will have a } \\
\text { contract which specifies their } \\
\text { obligations, including being } \\
\text { available for community work } \\
\text { and actively seeking paid } \\
\text { employment. There will be } \\
\text { penalties for failing to comply. } \\
\text { (22 April 1998) }\end{array}$ & $\begin{array}{l}\text { Community Wage } \\
\text { I was working nine tenths } \\
\text { so I was virtually full-time. } \\
\text {.. It was pretty demanding } \\
\text { doing that full-time and } \\
\text { caring for the kids on my } \\
\text { own ... but I was too } \\
\text { scared to stop. In } \\
\text { retrospect and in terms of } \\
\text { looking after family } \\
\text { relationships I think I } \\
\text { should've gone on the } \\
\text { DPB, and said to hell with } \\
\text { the finances. }(12,06.99)\end{array}$ \\
\hline $\begin{array}{l}\text { Government Goals and Priorities 1999-2002 } \\
\text { SHIPLEY: Prime Minister, Speech } \\
\text { (9.12.98) } \\
\text { To extend economic and social } \\
\text { opportunities by: } \\
\text { strengthening families, } \\
\text { especially through } \\
\text { intervening and targeting } \\
\text { services to break cycles of } \\
\text { disadvantage; } \\
\text { significantly improving the } \\
\text { health, employment, } \\
\text { education and housing } \\
\text { status of Maori; } \\
\text { preventing youth offending } \\
\text { and re-offending; } \\
\text { expecting and encouraging } \\
\text { active participation in work }\end{array}$ & $\begin{array}{l}\text { Government Goals and } \\
\text { Priorities 1999-2002 } \\
\text { Training Incentive Allowance } \\
\text { for long-term beneficiaries } \\
\text { dropped from } 100 \% \text { to } 60 \% \text { for } \\
\text { the } 1999 \text { study year. }\end{array}$ \\
\hline
\end{tabular}




\section{APPENDIX 3.1: Group Contract and Ground Rules}

\section{Group Contract - Ground Rules}

\section{Confidentiality}

All personal information/disclosure stays within the group

General information that cannot be associated with any one member of the group may be shared outside of the group

\section{Consenting Parties}

Although the focus of the project is on the mothers of sons consent will be sought by the participants from their sons, in whatever way they see appropriate, to have their personal information included in the project.

\section{Affirming Differences}

It is recognised that the realities, perspectives and truths of the participants will be different. Participants of the group contract to respect these differences without judgement.

Participants will discuss the project with their sons as they see fit, recognising the above ground rules.

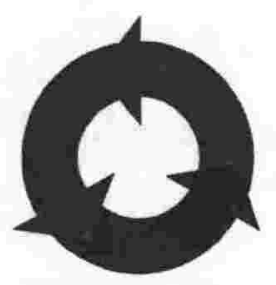




\section{APPENDIX 3.2: The Questions for Individual Interviews}

An investigation of the mother-adolescent son relationship, the interventions to this relationship and the implications these interventions have for the mother, the son and for the women and men of our future.

\section{Interview Questions}

The interviews will be conducted informally and will be recorded on audiotape (Ref Oral History Interview and Consent Forms). Although I would like to cover the following areas - this is by no means a comprehensive list. Participants are welcome to add those questions they feel would contribute to a deeper understanding of the issues.

It will take longer to cover these areas with some interviewees than others. However it is expected that the interview should take around 90 minutes.

1. Biographical details - including age of the participant/children, numbers of children in the family, family structure, employment, socio-economic status, ethnicity, disability, housing, contact with the boy/s father/s, relationship with family of origin, other key adults in the participant's/boys lives.

2. Participant's story

3. Relationship between boy/s and father/s

4. General issues for participant as mother of boy/s

5. Specific issues at the time of adolescence - education, sport, custody/access, interests, relationship between mother \& son

6. Messages about participant as a mother of an adolescent son

7. Support/or otherwise available to mother

8. (For single mothers) Positives and negatives about raising boy/s on own

9. Participant's view as an ideal situation for raising adolescent son/s.

10. Feelings about the future - own and son/s

11. Other...? 


\section{APPENDIX 3.3: Interview Contract Form}

\section{Victoria University of Wellington \\ Oral History Consent Form}

Name:

Date:

Address:

1. I understand that Jill Chrisp is undertaking research through Victoria University and is conducting this interview as part of a Doctoral Thesis.

2. I understand that the information from this interview will be used as part of the research.

3. Following the completion of the research project I would like:

- interview tapes to be returned to me

- interview tapes to be erased by the interviewer

- interview tapes to be archived at Women's Studies for use as stated on the attached form

4. In the recorded/written parts of the research I give permission for my name to be used as follows: (please circle one)

$$
\text { full name first name only pseudonym }
$$

5. In the recorded/written parts of the research I give permission for the inclusion of information which can identify me as follows: (please circle one)

$$
\begin{aligned}
& \text { full information modified information fully disguised information } \\
& \text { as specified in \# } 6
\end{aligned}
$$

6. Other special conditions: (please use reverse side if required)

7. I understand that I may listen to the tapes and that any material I wish to erase will be erased accordingly.

8. I understand that I have full control of the interview and may withdraw from the process at any time.

9. I have read the paper "Privacy Act (1993) - How you as a PERSON INTERVIEWED are affected", Alexander Turnbull Library, and understand the implications to me.

Signed:

Date:

Witness: 


\title{
APPENDIX 3.4: How the Person Interviewed is Affected
}

\section{Privacy Act (1993)}

\author{
How you as a \\ PERSON INTERVIEWED \\ are affected
}

I am very grateful to you for agreeing to part part in an oral history interview for the research project: An investigation of the mother - adolescent son relationship, the interventions to this relationship and the implications of these interventions.

I hope that you will feel free during the interview to say everything that you wish to be placed on record. However, it is important that you be aware of your rights and responsibilities under the Privacy Act (1993)

The main purpose of the Act is to protect the rights of individuals when any information is recorded about them.

1. If you record information about yourself, there is no problem

2. If you talk about other living people without identifying them, there is no problem

3. If you restrict access to the material recorded. For example - so that it is not available publicly, or to researchers, during the lifetime of any people you identify, there is no problem

4. If you record information about another identifiable living person, that person has the right if they wish, to know what you have recorded. They also have the right to cause that information to be corrected if, in their view, it is wrong or damaging to them.

5. If you record information about yourself and others and you subsequently wish to correct or amend it by adding further information - or as a last resort deleting it - you have the right to do so.

It is in your interests to be familiar with the Privacy Act.

Thank you, once again, for agreeing to be interviewed

Jill Chrisp

Researcher

Note: This information has been prepared by Hugo Manson - Curator of the Oral History Centre, Alexander Turnbull Library, Wellington. 


\section{APPENDIX 3.5: Code of Ethics for the Research Project}

\section{Code of Ethics}

An investigation of the mother- (adolescent) son relationship, the interventions to this relationship and the implications these interventions have for the mother, the son and for the women and men of our future.

This research project requires the researcher to have direct contact with participants both as a group and also individually. It is assumed that working relationships will be formed between the researcher and participants and among the participants themselves.

The following code of ethics has been adapted from that of the New Zealand Association of Counsellors and the New Zealand Association of Social Workers.

It will provide a guideline for these relationships to develop in openness and trust. Although it cannot resolve all ethical issues it will serve to provide a framework for addressing them.

\section{General Principle}

The researcher shall respect the dignity and worth of each of the participants, the integrity of families and the diversity of culture. Each participant has the right to make decisions that affect their own lives and to have their privacy maintained.

The researcher shall actively support the principles of partnership as embodied in the Treaty of Waitangi.

\section{Consent}

Participants must be fully informed of what is required from them in their involvement with the project. Full information implies comprehension, and free consent implies a lack of pressure.

\section{Confidentiality}

All communication with the participants shall be confidential and treated as privileged information. Information used for research purposes is used with the informed consent of the participant and with the protection of identity.

\section{Implication of involvement}

The researcher should inform participants of available support systems should their involvement raise issues that need to be dealt with. If necessary participants access to these should be facilitated. 


\section{Abuse of power.}

The researcher shall not take advantage of participants for purposes of personal, professional, political, financial or sexual gain. The researcher is responsible for monitoring boundaries in the researcher - participant relationship and for making these clear to the participant.

\section{Supervision}

The researcher's work shall be monitored through regular supervision by professionally competent supervisors. Competency in this instance refers to:

- Academic

- An up-to-date knowledge of the research theory \& methodology employed

- Recent experience of research for academic purposes of at least doctorate level

- A knowledge of key theorists in the field.

- Clinical

- is governed by a clear code of ethics and practice such as outlined in this document.

- has recognised experience in working with people and with relationships between people.

\section{Competence}

The researcher's own personal resources \& competency will determine the boundaries of the research. 


\section{APPENDIX 3.6: Audiotape: Transcriber Contract for Services}

\section{Waiariki Academic Board Research Committee Contract for Services}

This contract sets out the respective rights and obligations of the institution's employee who has the research project identified below approved and funded by the academic board and the research assistant employed as the contractor.

\begin{tabular}{|l|l|}
\hline $\begin{array}{l}\text { Research Project Name: } \\
\text { An investigation of the Mother- } \\
\text { Adolescent Son Relationship. }\end{array}$ & $\begin{array}{l}\text { Principal Researcher "the researcher": } \\
\text { Jill Chrisp }\end{array}$ \\
& $\begin{array}{l}\text { Approved Research Project Accoun } \\
\text { Code: } \\
556.597 .20020\end{array}$ \\
\hline $\begin{array}{l}\text { Research Assistant "the contractor": } \\
\text { [Name] }\end{array}$
\end{tabular}

Services/outputs to be delivered by the Contractor:

Transcription of audio-tapes (\# hours)

NOTE: The Contractor is bound by the Code of Ethics of the research project, which has been provider to the Contractor by the Researcher.

Timeframe: [Date] to [Date]

Responsibilities of the Researcher:

- To provide clear tapes to the Contractor

- To supply paper and computer discs

- To be available if concerns arise

Timeframe: [Date] to [Date]

Total Cost of Contract (The Contract Sum) \$ GST) (incl.

Timeframe for the payment for the Contract Sum: Contractor to invoice monthly from [date]

\begin{tabular}{l|l|}
\hline Signed by the Contractor: & Signed by the Researcher: \\
\hline Date: & Date: \\
\hline & \\
\hline $\begin{array}{l}\text { NOTE: You have been employed as an independent contractor. This contract } \\
\text { is not a contract of service. You will be responsible for all accounting, PAYE, } \\
\text { GST, accident compensation levies, licence fees and any other payments, } \\
\text { levies, and taxes payable by an independent contractor }\end{array}$ \\
\hline
\end{tabular}




\section{Wanted}

\section{Mothers of Teenage Sons \\ to take part in interviews for a research \\ project}

This 4 year project is exploring the issues that are part of the mother/adolescent son relationship. It is also interested in the interventions to this relationship as the boy grows into the 'world of men' and what impact these have for mothers and the sons, as well as for women and men in the future.

I will be in Auckland on Thursday and Friday 7 November. If you are willing to be interviews please let [NAME] know.

Interviews will be audio-taped and will take from $1-1.5$ hours. Before the interview begins you will have the chance to ask about the project, and to sign an interviewee contract to ensure your confidentiality and safety. The interviews will involve asking you to give a brief story of your life with your son/s, and then will cover more in-depth issues about your life with him/them as teenagers.

The project is covered by the Ethics Committee of Victoria University, Wellington. If at any point in the interview process you decide not to continue then this will be respected, the interview will be discontinued and the tape material wiped.

A copy of the interviewee contract form and more information about the project is available at [NAME] Centre.

I look forward to meeting you.

Jill Chrisp

Rotorua: 07-346 2687 


\section{APPENDIX 3.8: Letter to Interviewees re Return of Transcripts}

[Date]

113 Kawaha Point Road

Rotorua

Dear [Name]

RE: Research Project

Please find enclosed:

1. Your transcription

2. Your consent form, if not photocopied and given to you at the time of interview.

3. A self-addressed envelope to return comments.

Thank-you again for your involvement in this project. Could you please read your scripts for:

- Any areas that you are not prepared to have used in the research within the boundaries as set by your individual contract.

- Changes/additions you would like to make.

And return these to me in the envelope provided by [date].

I am very impressed with the collective information that is being generated from the interviews and hope that the final results offer something back to you, your families and your communities.

With thanks and very many kind regards,

[Signed]

Jill Chrisp 
APPENDIX 3.9: Techniques used in Drawing Analysis.

\begin{tabular}{|c|c|c|}
\hline Tools & Method & Results \\
\hline K-F-D'Actions & $\begin{array}{l}\text { Movement of energy between people } \\
\text { drawn demonstrated by balls or other } \\
\text { objects (throwing, bouncing, kicking } \\
\text { etc), use of shapes, barriers (objects, } \\
\text { walls or lines) }\end{array}$ & $\begin{array}{l}\text { Strangers } \\
\text { Lovers } \\
\text { Competitors } \\
\text { Non-Competitors } \\
\text { Conflict } \\
\text { Anxiety } \\
\text { Avoidance } \\
\text { Harmony }\end{array}$ \\
\hline $\begin{array}{l}\text { K-F-D Characteristics of } \\
\text { Individuals }\end{array}$ & $\begin{array}{l}\text { Distinguishing features of figures drawn } \\
\text { arm extensions, elevated figures } \\
\text { erasures, figures on the back } \\
\text { hanging/falling, omission of body parts } \\
\text { omission of figures, rotated/distorte } \\
\text { figures }\end{array}$ & $\begin{array}{l}\text { Dominance } \\
\text { Submission } \\
\text { Conflict \& tension } \\
\text { Refusal of recognition } \\
\text { Disconnection }\end{array}$ \\
\hline $\begin{array}{l}\text { K-F-D Styles } \\
\text { Graphomotor Factors }\end{array}$ & $\begin{array}{l}\text { The way the drawing has been } \\
\text { completed: compartmentalisation, } \\
\text { encapsulation, lining at the bottom, } \\
\text { underlying individual figures, edging, } \\
\text { lining at the top, size, organisation, use } \\
\text { of space. }\end{array}$ & $\begin{array}{l}\text { Link between people } \\
\text { Isolation } \\
\text { Separation } \\
\text { Disturbance \& stress } \\
\text { Instability } \\
\text { Anxiety \& Worry } \\
\text { Marginalisation }\end{array}$ \\
\hline Heat, Light, Warmth & $\begin{array}{l}\text { The use of fire, electricity, lighting, } \\
\text { sunshine }\end{array}$ & $\begin{array}{l}\text { Anger } \\
\text { Need for warmth/love } \\
\text { Power \& control } \\
\text { Giving of } \\
\text { warmth/love }\end{array}$ \\
\hline K-F-D Symbols & $\begin{array}{l}\text { The use of interpretative symbols. } \\
\text { Careful of over-simplification of } \\
\text { interpretation. }\end{array}$ & Various \\
\hline Individual H-F-D2's Features & $\begin{array}{l}\text { The characteristics of individual figure } \\
\text { drawings: belt, buttons, emphasis; } \\
\text { disproportion of body parts, expression, } \\
\text { use of limbs, omission of body parts }\end{array}$ & Various \\
\hline Drawing Techniques & $\begin{array}{l}\text { Use of drawing styles: shading, } \\
\text { scribbling, pressure, erasure }\end{array}$ & $\begin{array}{l}\text { Attention given to } \\
\text { figure }\end{array}$ \\
\hline Graphic Development3 & $\begin{array}{l}\text { Drawing outside age level: } \\
\text { Scribbling Stage (2-4 yrs) } \\
\text { Preschematic Stage (4-7 yrs) } \\
\text { Schematic Stage (7-9 yrs) } \\
\text { The Gang Age (9-12 yrs) } \\
\text { Pseudo-Naturalistic (12-14) }\end{array}$ & $\begin{array}{l}\text { Trauma, tension at } \\
\text { age of arrested } \\
\text { development }\end{array}$ \\
\hline Family as Animals & $\begin{array}{l}\text { The use of animals as interpretative } \\
\text { symbols. Careful of over-simplification } \\
\text { of interpretation. Use of colour. }\end{array}$ & $\begin{array}{l}\text { Dominance, } \\
\text { Connection } \\
\text { Invisibility, } \\
\text { Insignificance }\end{array}$ \\
\hline
\end{tabular}

\footnotetext{
' Robert Burns and S. Harvard Kaufman: Actions Styles and Symbols in Kinetic Family Drawings

${ }^{2}$ Ibid - Human Figure Drawings

${ }^{3}$ Viktor Lowenfeld (1987) Creative and Mental Growth
} 


\section{APPENDIX 3.10: Consent Request to Schools: Letter 1}

\section{[LETTERHEAD]}

13 March, 1998

[SCHOOL PRINCIPAL]

[ADDRESS]

\section{Dear [PRINCIPAL]}

\section{RE: Doctoral Research Project}

I am at present undertaking a 5-year doctoral research project investigating "the mother-(adolescent) son relationship, the interventions to this relationship and the implications these interventions have for the mother, the son and for the women and men of our future".

The research is now just over two years old and aims to be in its final draft form by June 2000 . It is already uncovering key themes that offer some explanations around recently highlighted issues such as youth suicide, adolescent ill health, unemployment, socio-economic implications of single parenting/mothering. Meetings are presently being held with Deborah Morris, Minister of Youth Affairs, who has highlighted adolescent males in the ministry's objectives for 1998 with a view to contributing to current social policy development. Discussions are also being held about the necessity of parallel, or post-doctoral, research involving male adolescents.

The main pieces of research fieldwork involve:

- a longitudinal (4 year) study of single mothers using a participatory action research process

- a series of one-off interviews of mothers throughout New Zealand

As the key research activities for the project have been designed to gather stories from, and explore issues of, mothers of teenage sons, the perspective of the male adolescent is missing. With the support and advice of an Auckland-based Registered Art Therapist, I have developed a Drawing-Interpretation Project that will involve male students from 5 - 16 years old in two drawing activities.

I am writing to ask whether your school (and your parent community) would be prepared to allow me to work with your students for this part of the data collection.

The Code of Ethics (attached) of the research project has been given approval by the University Ethics Committee, Victoria University of Wellington, and has strict guidelines about participant safety and confidentiality. Although there will be a description of the communities from which the students are drawn in the reporting from the findings, there will be no specific mention of the student, the school or the district. The two pieces of work from each student will be identified by the age of the students and a code that enables each to be paired for analysis. 
I have made the same request of the principals of [NAME] School and [NAME] School. If the three schools were amenable to being involved, it would ensure a link between the cohorts of students and the catchment area from which they are drawn. This would lessen the impact of differing environmental/socio-economic factors between student cohorts on the results.

The exercises are yet to be piloted and therefore I am not sure of the time each will take and this will also vary with the age of the child. I am surmising that the first will take 10-15 minutes and the second, 20-30 minutes - total time, including introduction of the exercises approximately $50-60$ minutes.

I am assuming also that participation by students will need to be optional, as this is a non-curricula activity. It also will not directly benefit the students or schools involved but hopefully will contribute to a deepening understanding of the issues, contribute to social policy development at a local and national level and offer further insight to practitioners working with children and families.

The ideal range of male students would be as follows:

\begin{tabular}{|l|r|}
\hline \multicolumn{1}{|c|}{ AGE } & NUMBER \\
\hline $5-6$ & $10-15$ \\
\hline $7-8$ & $10-15$ \\
\hline $9-10$ & $15-20$ \\
\hline $11-12$ & $20-25$ \\
\hline $12-13$ & $20-25$ \\
\hline $13-14$ & $20-25$ \\
\hline $14-15$ & $20-25$ \\
\hline $15-16$ & $20-25$ \\
\hline $16-17$ & $20-25$ \\
\hline TOTAL & $155-200$ \\
\hline
\end{tabular}

If this request is met favourably, I would like to meet with you to discuss the proposal more fully. In order to fit within the research project, the preferable time to administer the drawing tests would be during the last 3 weeks in May.

I look forward to hearing from you

Jill Chrisp

Researcher 


\section{APPENDIX 3.11: Consent Request to Schools. Letter 2}

\section{[LETTERHEAD]}

April, 1998

\section{[3 SCHOOL PRINCIPALS]}

[3 ADDRESSES]

\section{Dear [3 PRINCIPALS]}

\section{RE: Doctoral Research Project}

Thank you very much for agreeing to be part of the research project.

Attached, as discussed, a draft letter to parents. Please feel free to amend this as suits your parent community and to also add a contact name for each of your schools.

I will be at [NAME] School on Thursday 21 May, [NAME] School on Friday 22 May and am yet to finalise dates for [NAME] School.

I will call each of you several days before I am due in your school to finalise numbers of students involved and to confirm any other details as required.

I look forward to this stage of the project and appreciate your willingness to contribute to the data collection.

Yours sincerely

Jill Chrisp 


\section{APPENDIX 3.12: Draft Consent Letter to Parents}

Dear Parents

[NAME], [NAME] and [NAME] Schools have agreed to be part of a research exercise which is investigating the development of inter-family relationships for boys. This exercise involves 200 boys (from 5 - 16 years old) and is part of a larger 5-year project that is researching current issues for adolescent boys.

The exercise will involve each boy completing 2 drawings. It is anticipated that the comparison of the drawings across the ages will highlight the relationship transition for boys within the family. The research project is supervised by Victoria University of Wellington and is covered by a strict code of ethics and confidentiality. Accordingly the boys, the schools and the community will not be identifiable. The information on each of the drawings will be limited to the age of the boy and the roles of the members within the family - that is 'mother', 'father', 'brother', 'sister', 'grandmother', 'uncle', 'cousin' etc.

A report of this project will be available from the schools mentioned above in December 1998. The results of this will be widely disseminated; including to those who work with teenage boys and their families - teachers, social workers, counsellors, lawyers, youth workers, health practitioners etc.

If you would like to withdraw your son from participating in this project please complete the attached form and return it to the appropriate school by May 20.

With thanks.

For further information contact:

(School Contact) OR Jill Chrisp

Researcher

Ph: 3468954

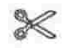

Please withdraw the following from involvement in the "Drawing Interpretation Project" as detailed above:

(boy's name and teacher/form class)

Signed: (parent/guardia

n) 


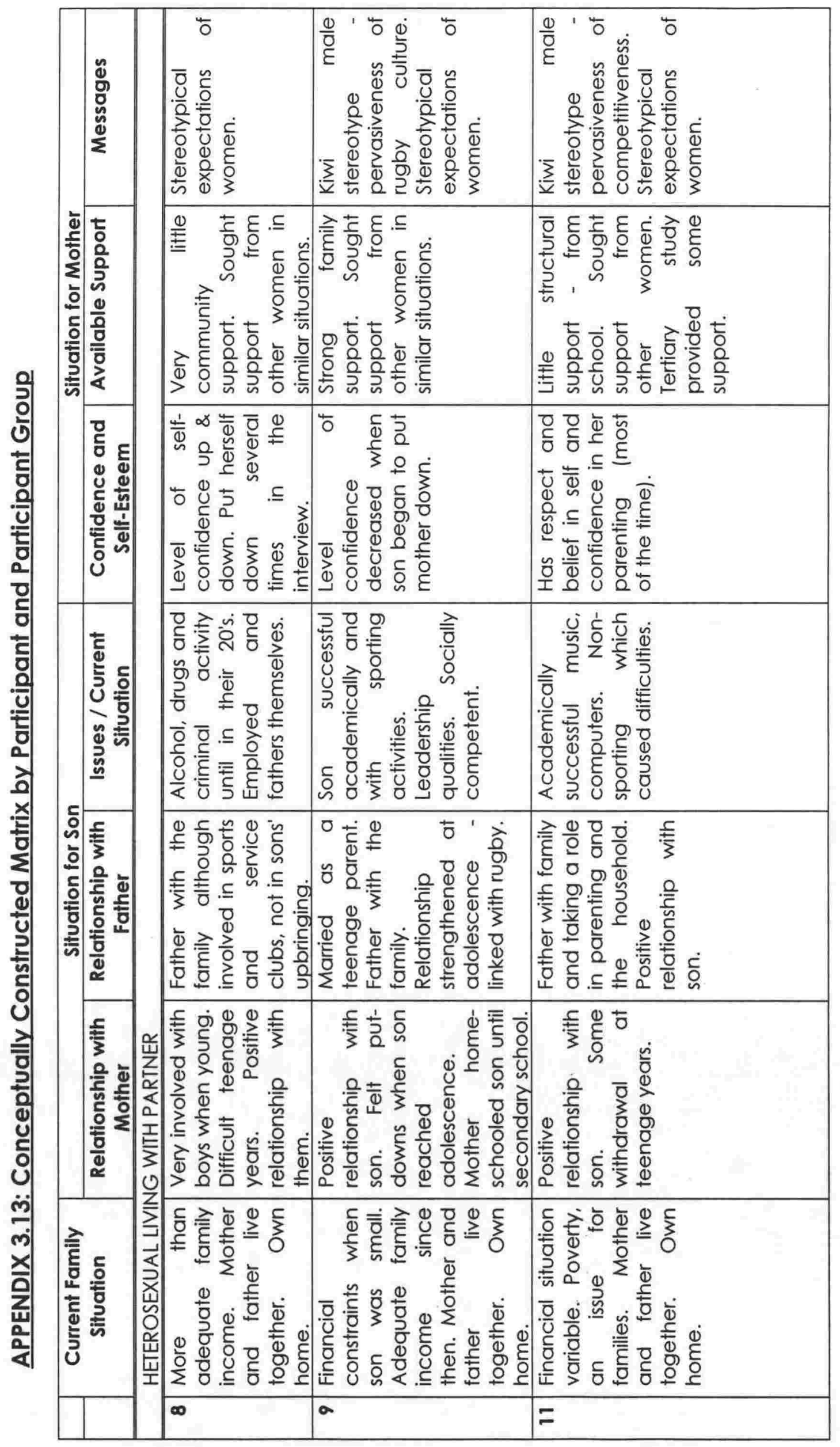




\begin{tabular}{|c|c|c|}
\hline \multirow{3}{*}{ 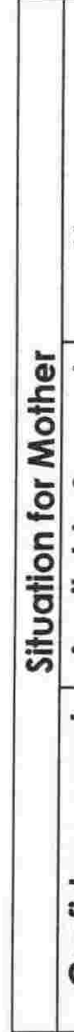 } & 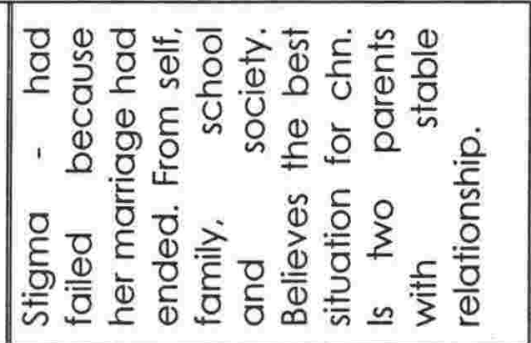 & 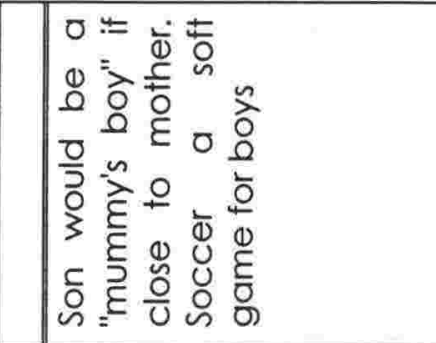 \\
\hline & 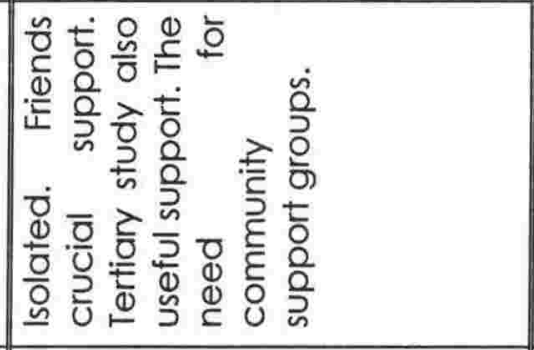 & 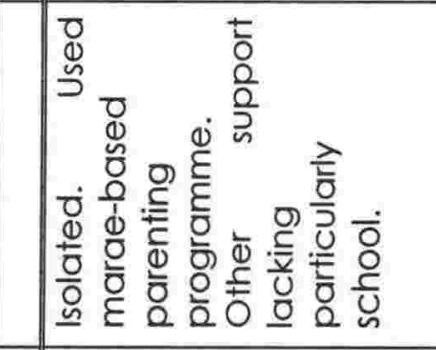 \\
\hline & 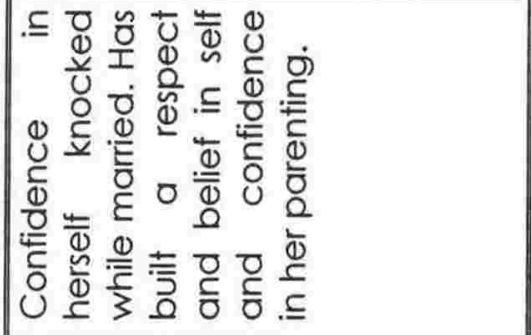 & 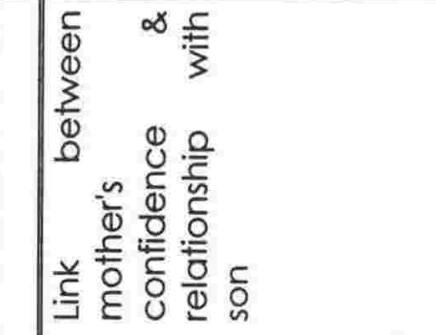 \\
\hline 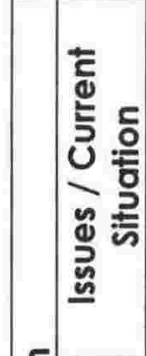 & 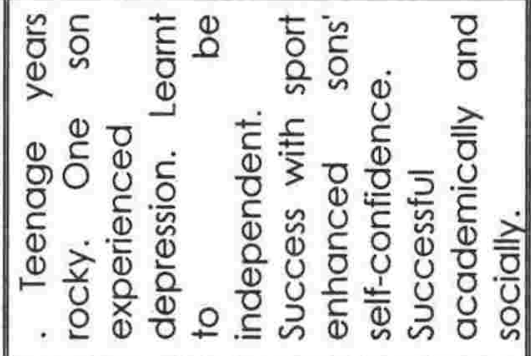 & 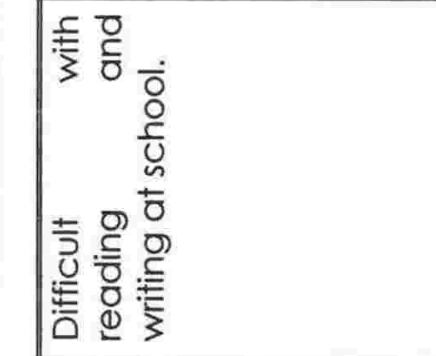 \\
\hline 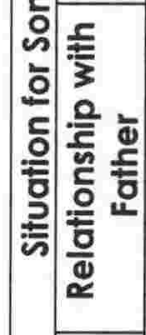 & 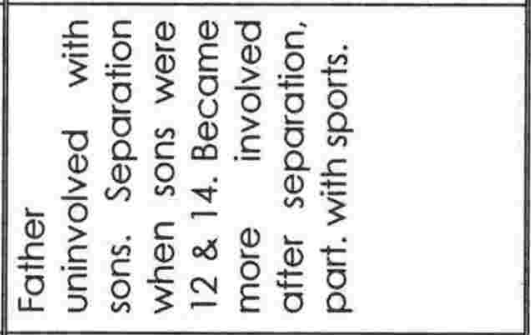 & 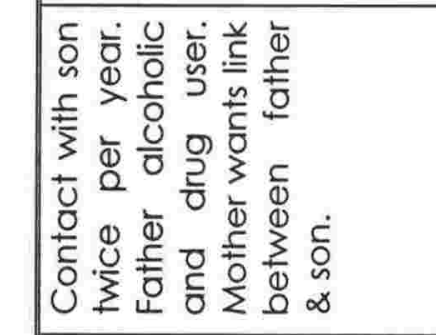 \\
\hline 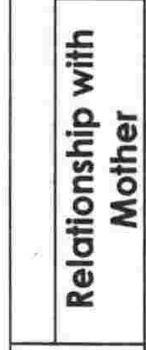 & 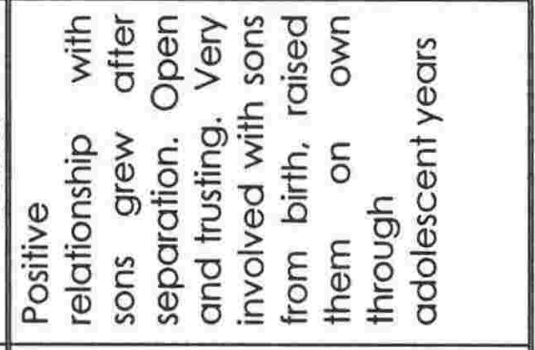 & 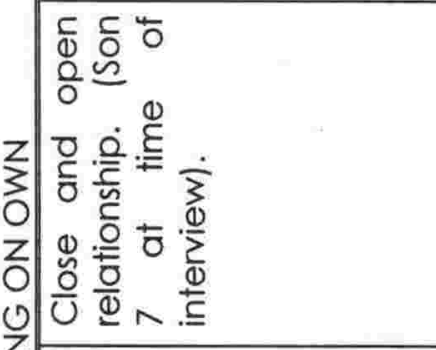 \\
\hline 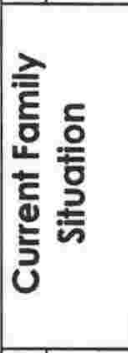 & 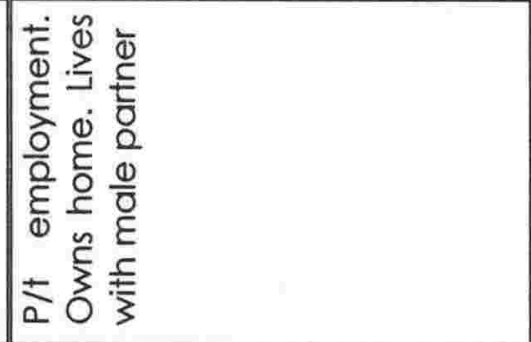 & 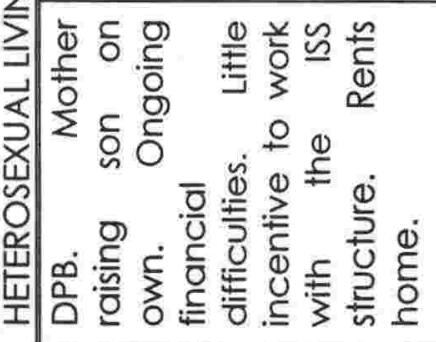 \\
\hline & $\overline{\text { N }}$ & N \\
\hline
\end{tabular}




\begin{tabular}{|c|c|c|c|}
\hline 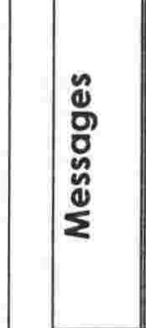 & 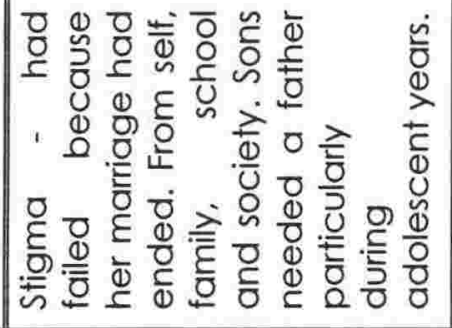 & 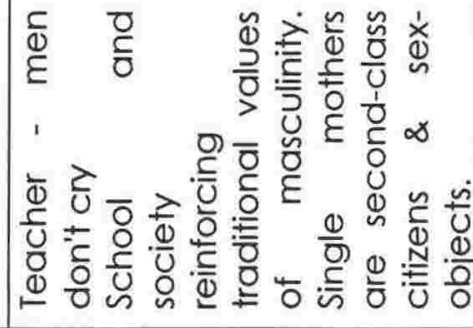 & 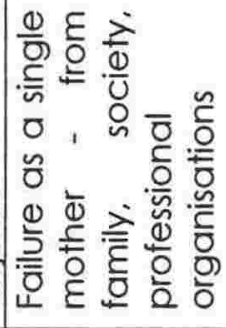 \\
\hline 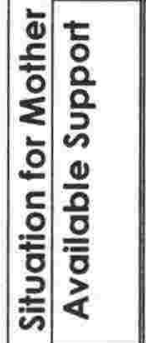 & 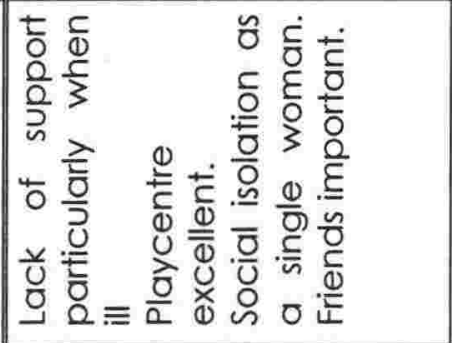 & 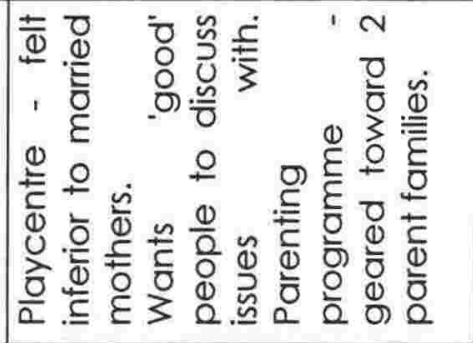 & 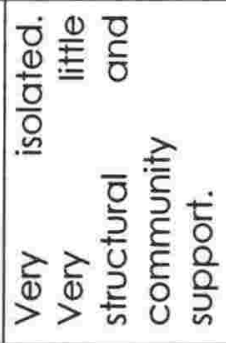 \\
\hline 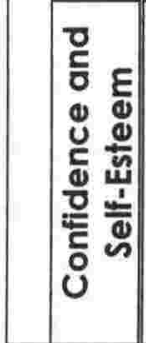 & 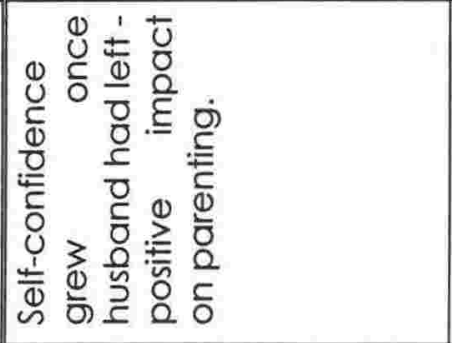 & 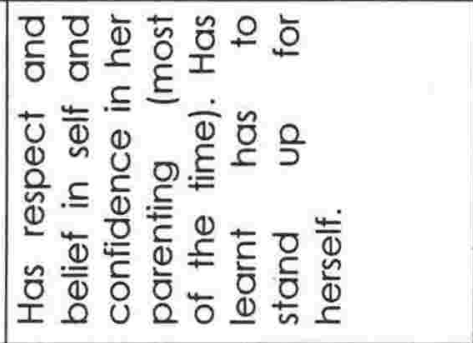 & 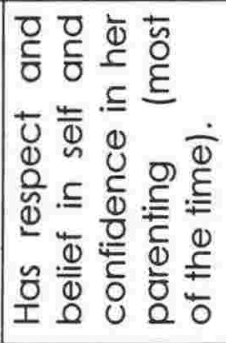 \\
\hline 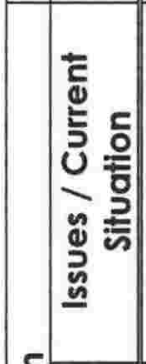 & 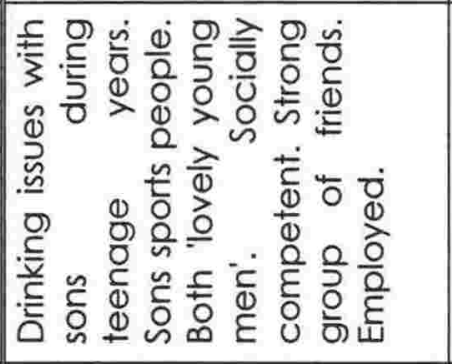 & 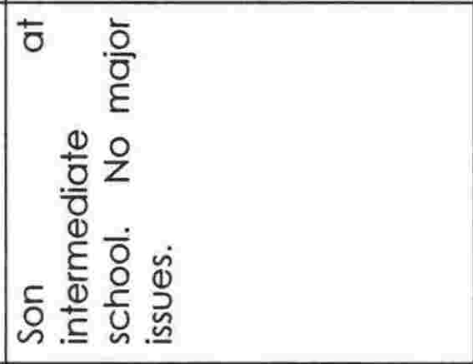 & 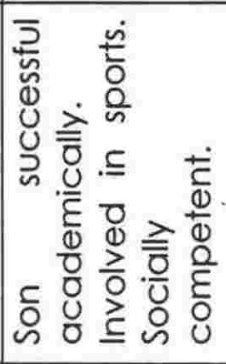 \\
\hline 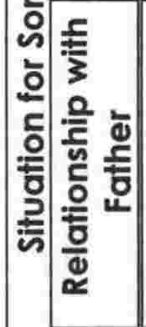 & 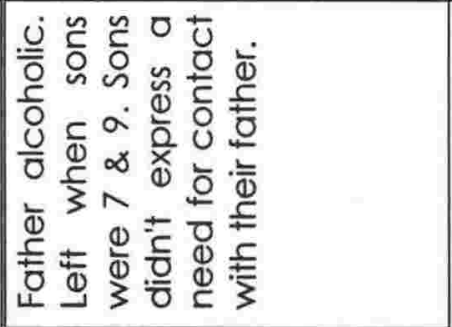 & 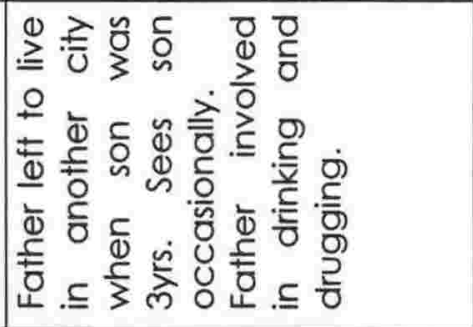 & 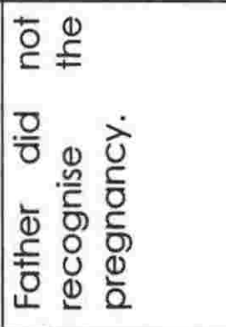 \\
\hline 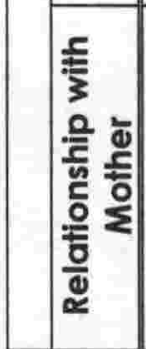 & 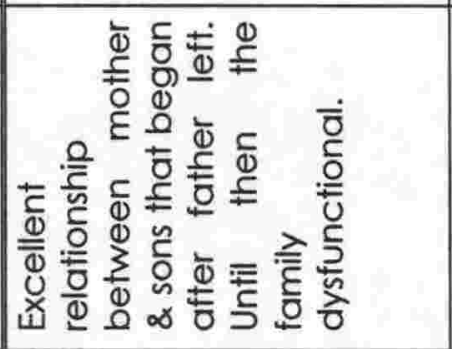 & 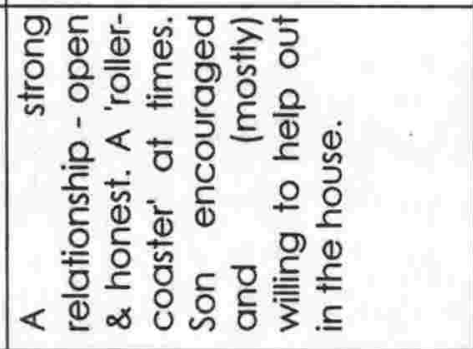 & 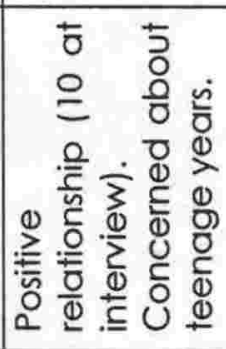 \\
\hline 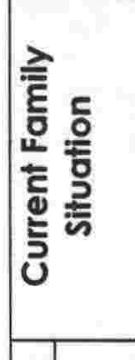 & 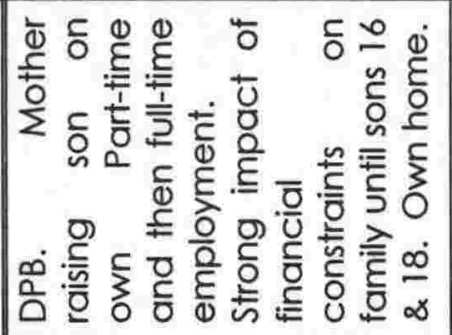 & 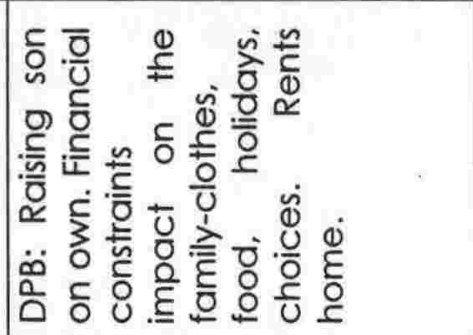 & 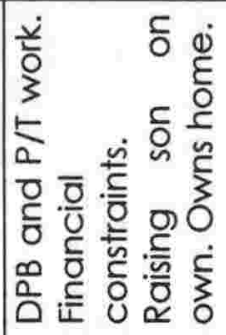 \\
\hline & $m$ & in & $N$ \\
\hline
\end{tabular}




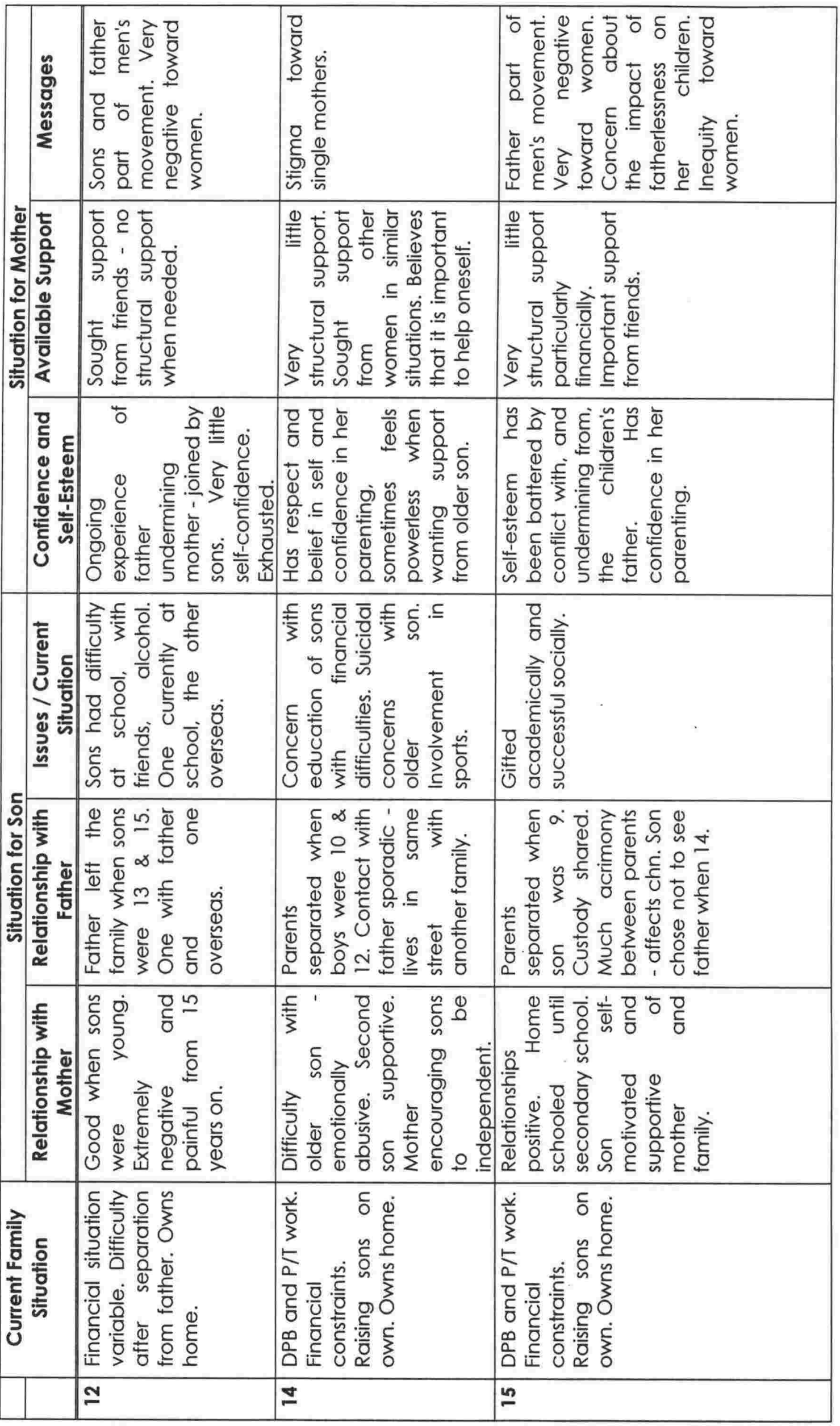




\begin{tabular}{|c|c|c|c|}
\hline 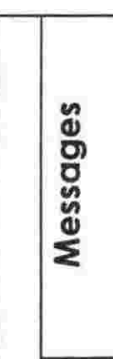 & 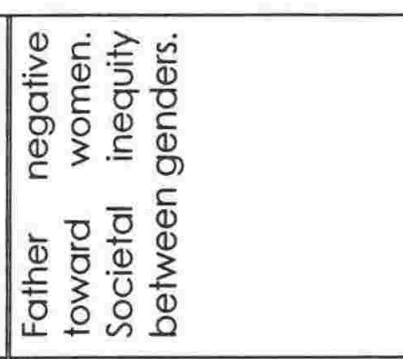 & 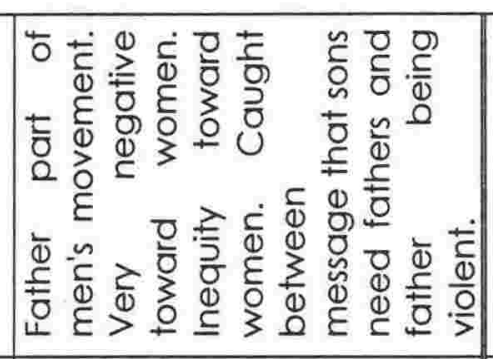 & 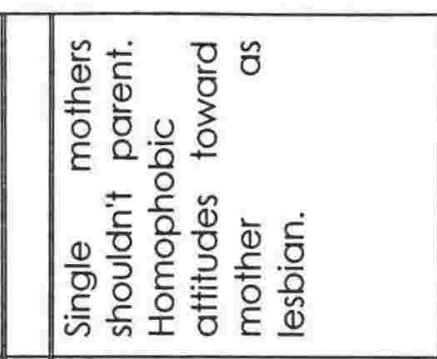 \\
\hline 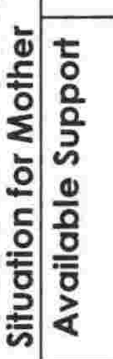 & 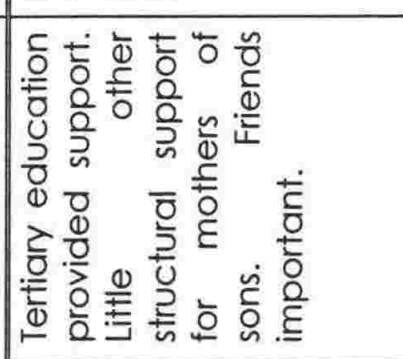 & 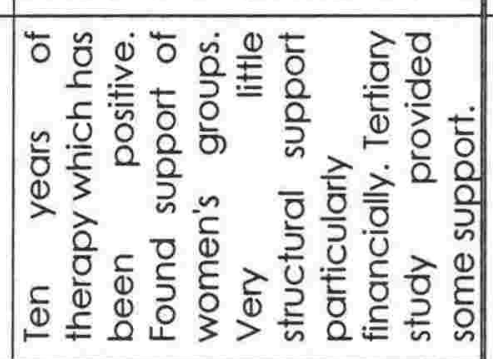 & 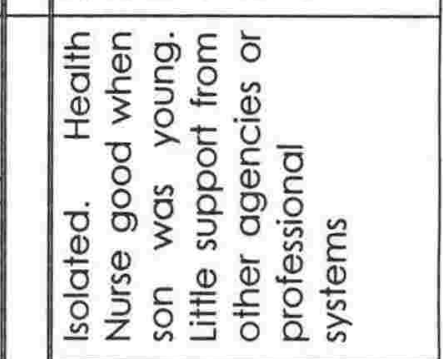 \\
\hline 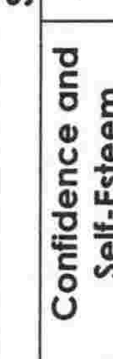 & 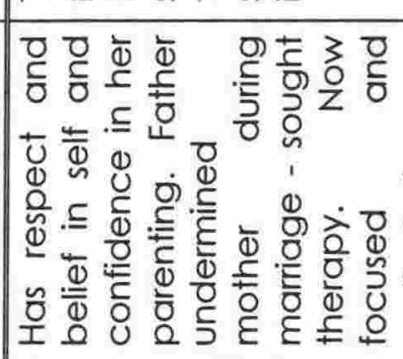 & 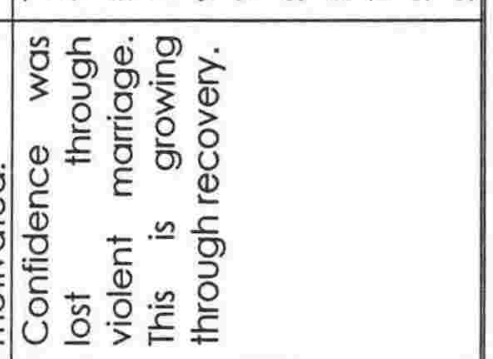 & 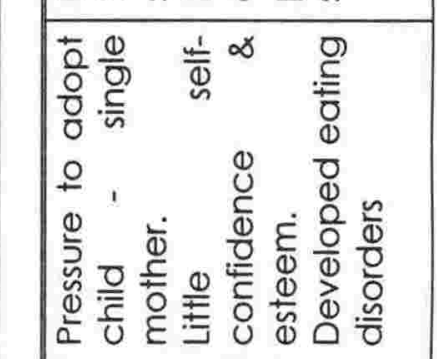 \\
\hline & 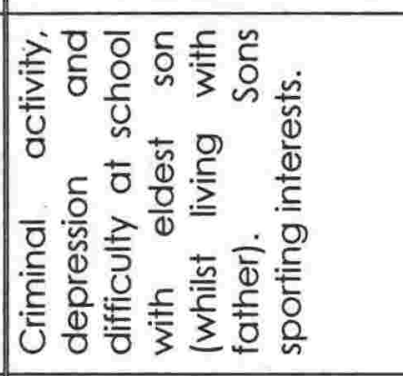 & 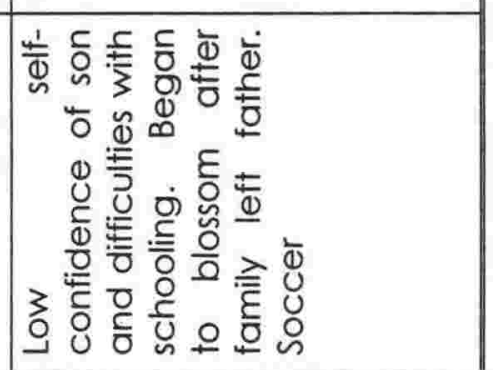 & 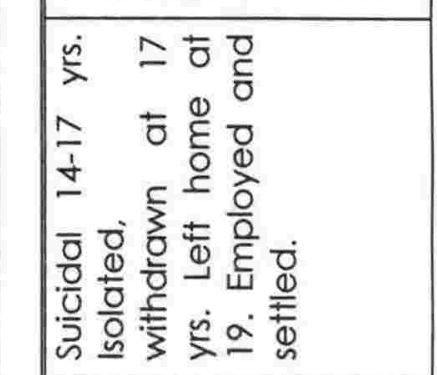 \\
\hline 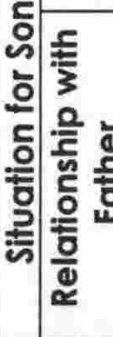 & 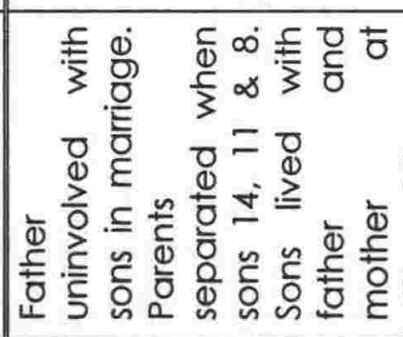 & 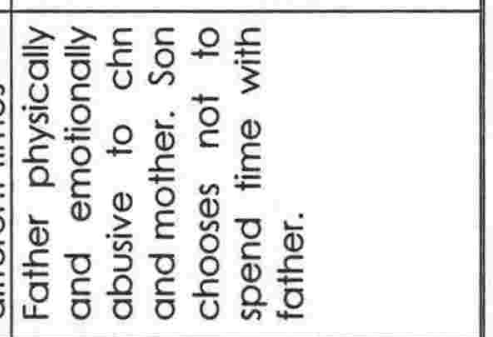 & 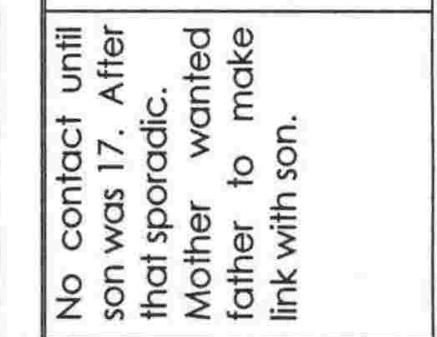 \\
\hline 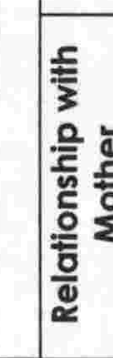 & 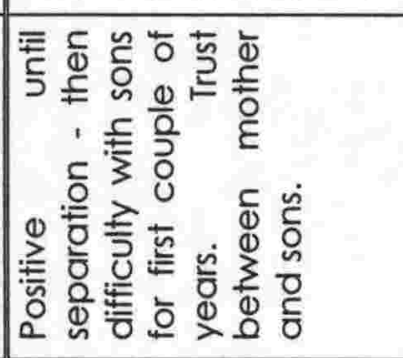 & 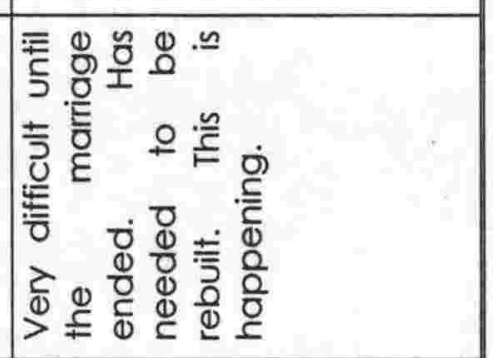 & 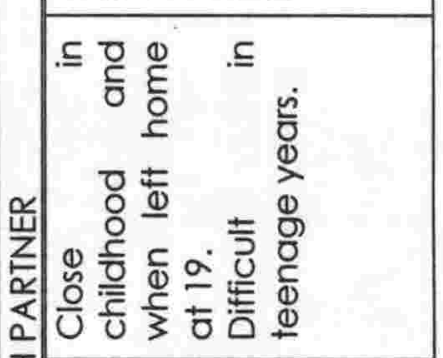 \\
\hline 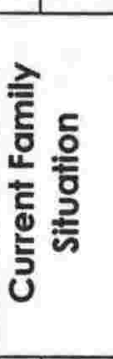 & 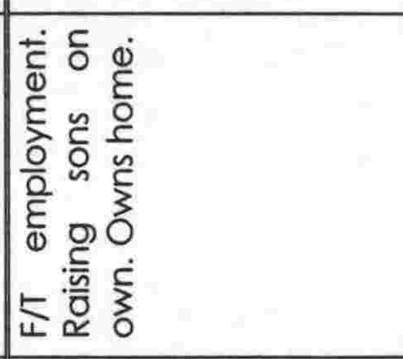 & 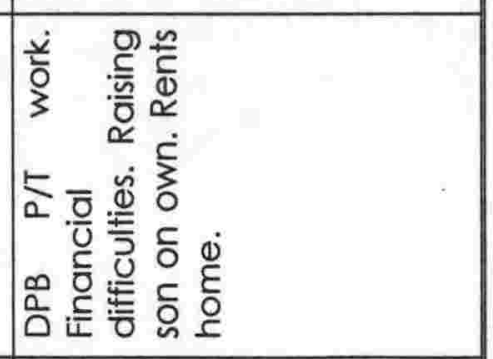 & 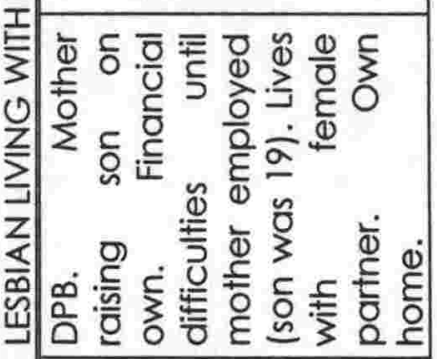 \\
\hline & $\simeq$ & 2 & - \\
\hline
\end{tabular}




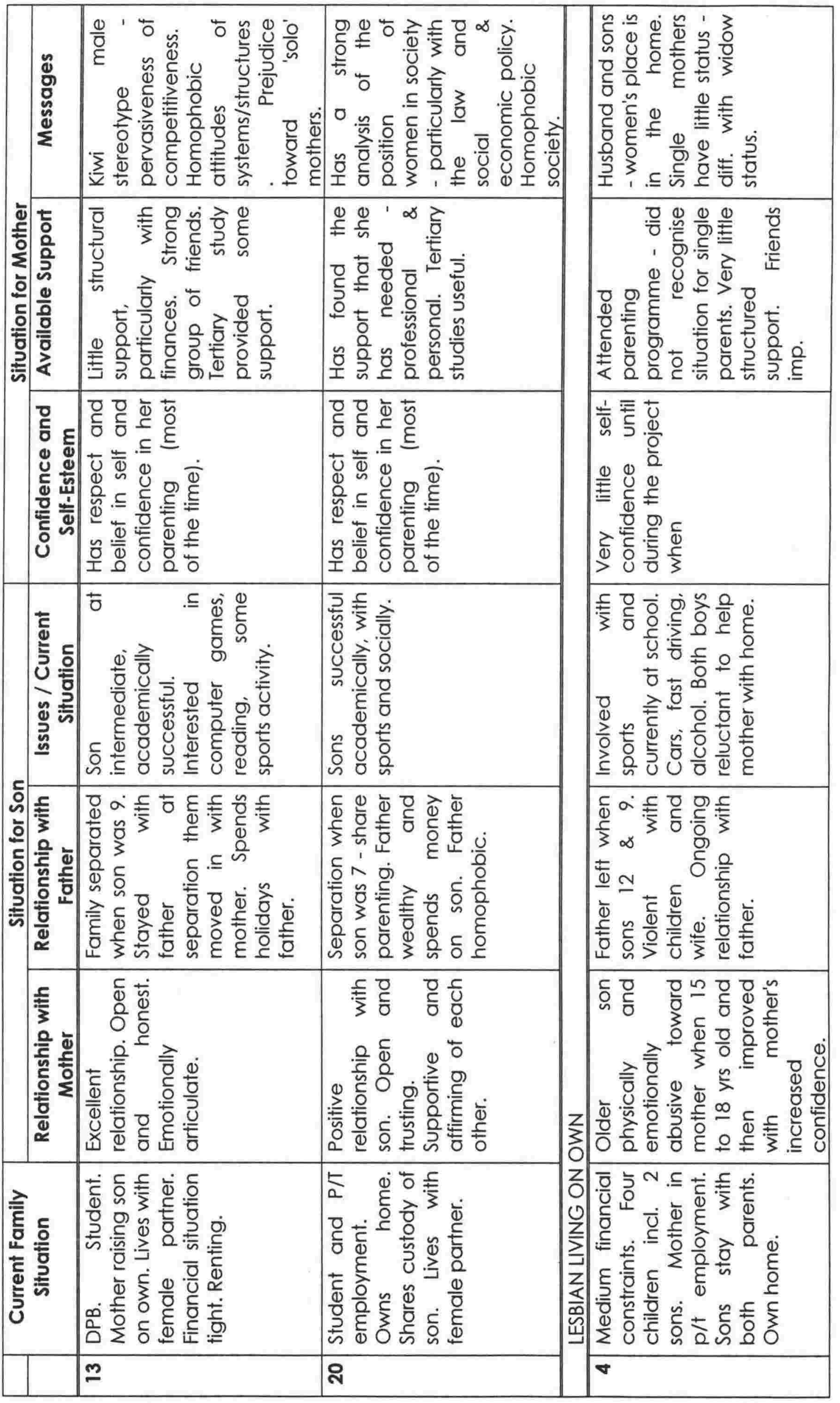




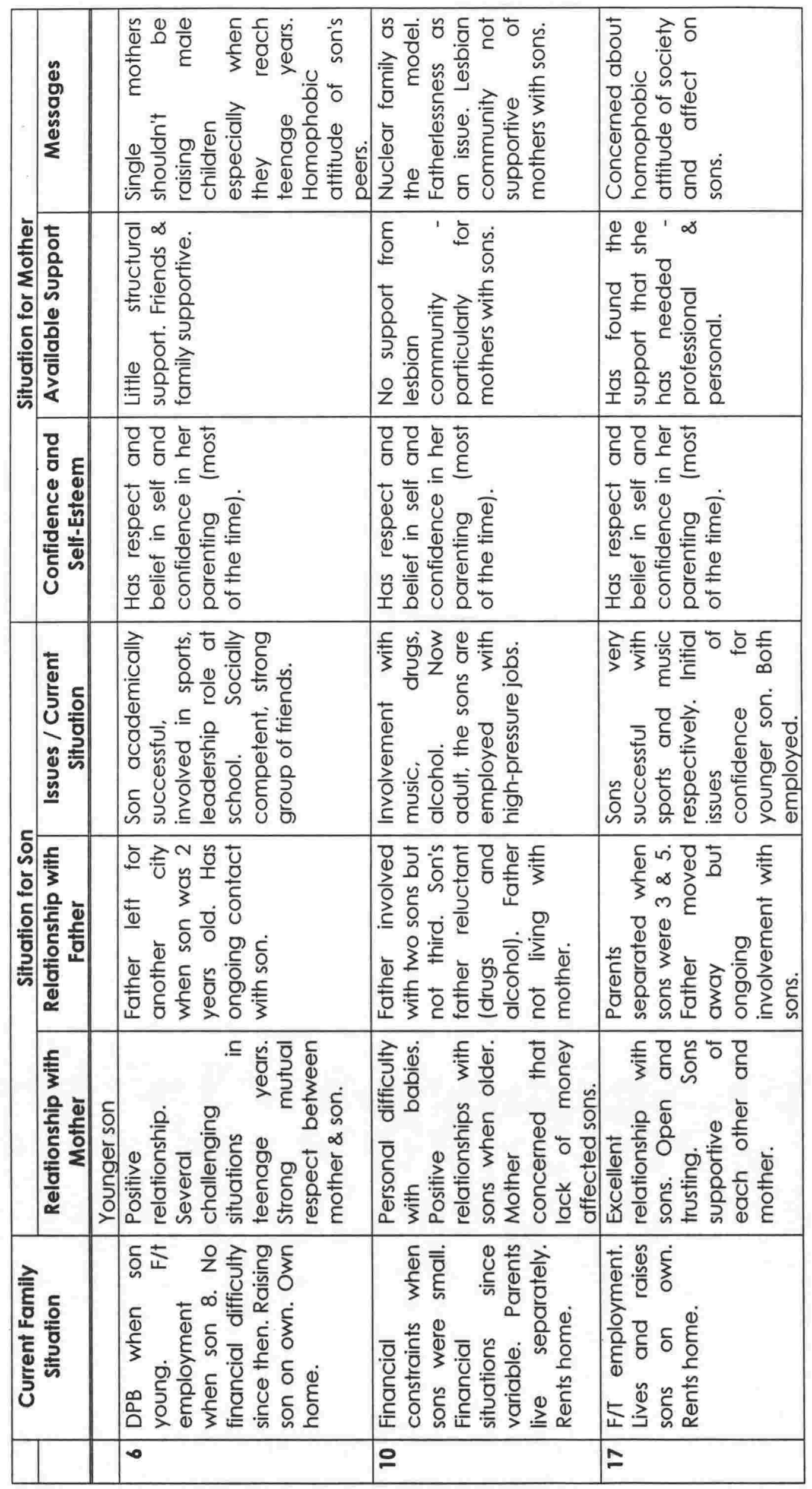




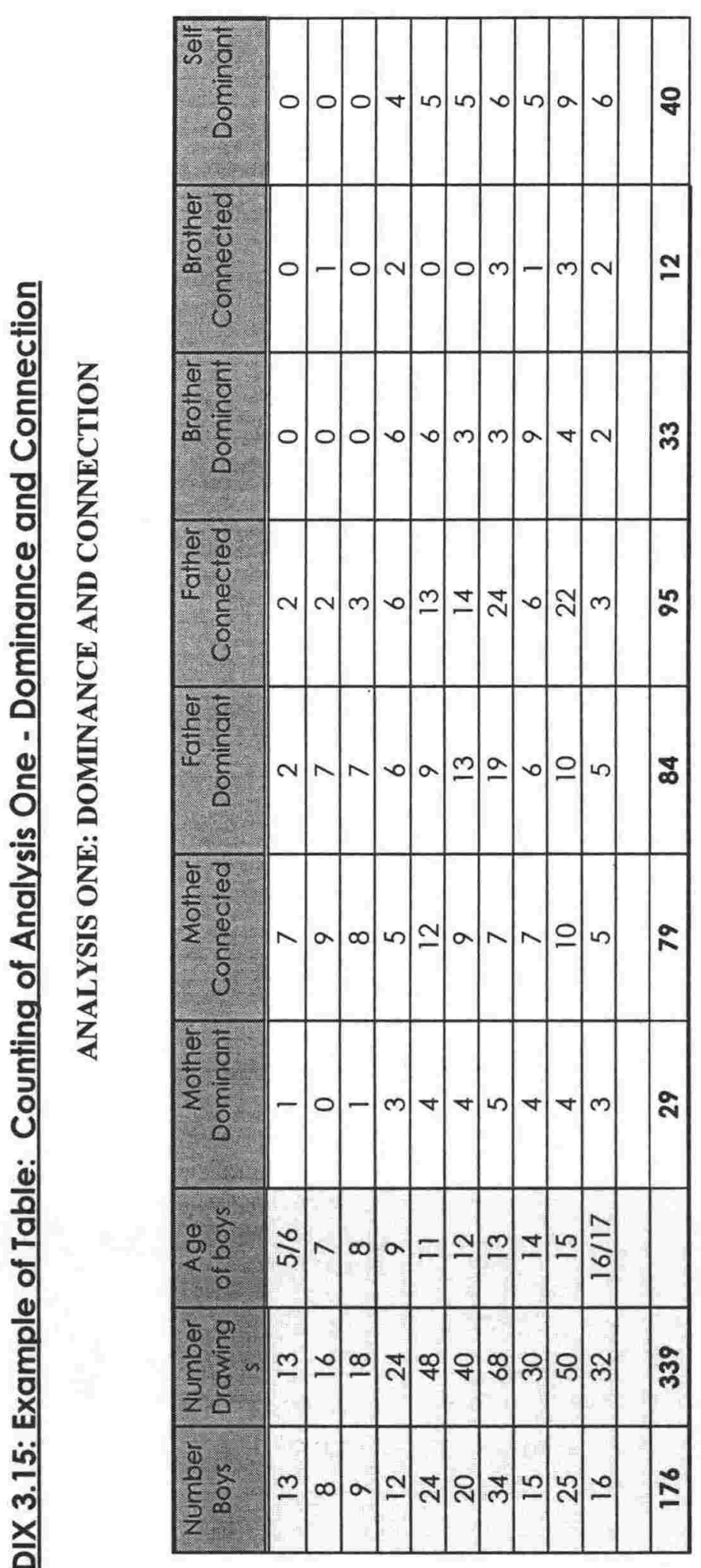




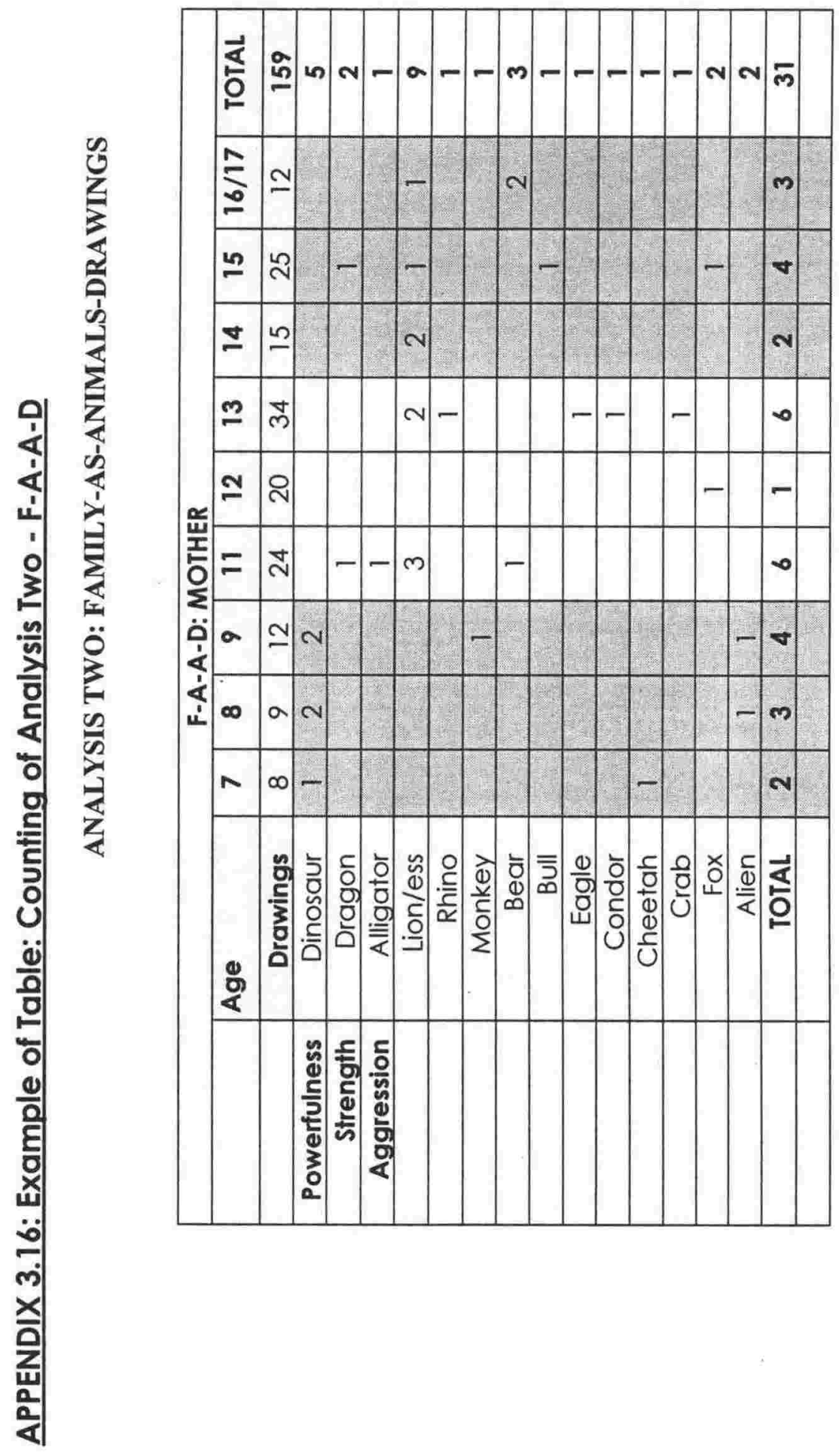




\section{APPENDIX 7.1: Media Coverage about Fatherlessness and Father-}

Absence

FATHERLESSNESS MEDIA COVERAGE: MAY - NOVEMBER 1997

New Zealand Listener. (3-9.05.97). Missing dad: absent fathers and mixed up sons.

New Zealand Listener. (3-9.05.97). Father Hunger. "Fatherless families, and their impact on boys in particular is shaping up to be one of the most pressing issues. Absent fathers cripples the boy child."

Sunday Star Times. (11.05.97). Searching for the man within. "Single parent families, headed by women for boys is a disaster. Problem of inadequately raised men as the most serious society faces."

New Zealand Listener. (6-12.09.97). Cover and inside article. Being There How Distant Dads Ruin Kids. An article full of alarming statistics including those of male youth suicide statistics (third worst of 32 countries in a UNICEF study)."

New Zealand Herald. (11.09.97). Absentee fathers harming society. "Fatherlessness could be the most harmful democratic trend of this generation especially to young males.

Newspapers \& Television. (6 - 12.10.97). Movement gains momentum. Articles about the Promise Keepers rally in Washington DC of 500,000 (exclusively) men. NZ membership is around 4000.

Sunday Star Times. (26.10.97). Bridging the dad gap. A review of two books. Steve Biddulph's, Raising Boys, and Bill Sewell's, Sons of the Fathers, that have been written on fatherhood and the importance of sons relationships with their fathers. 


\section{BIBLIOGRAPHY}

Abelove, H, Barale, M, Halperin, D. (Eds.) (1993). The Lesbian and Gay Studies Reader. New York, London: Routledge.

Adams, Alice (1994). Reproducing the Womb: Images of Childbirth in Science, Feminist Theory and Literature. USA: Cornell University Press.

Alcoff, Linda (1988). Cultural feminism versus poststructuralism. In Signs: Journal of Women in Culture and Society. Spring 1988. University of Chicago.

Alice, Lyn (1999). Power, experience and process in feminist research. In Carl Davidson, and Martin Tolich. (Eds.). Social Science Research in New Zealand. Many Paths to Understanding. New Zealand: Longman.

American Coalition for Fathers and Children. The Costs of Father-Absence. Retrieved May 1997 from the World Wide Web. http://www.acfc.org/

Anderson, G.L., Herr,K. \& Nihlen,A.S. (1994) Studying your School. An Educator's Guide to Qualitative Practitioner Research. Thousand Oaks.Corwin Press.

Anderson, Jill (1996). Yes, but is it empowerment? Initiation, implementation and outcomes of community action. In Humphries (Ed.). Critical Perspectives on Empowerment. Great Britain: Venture Press.

Anderson, Petrea (1998). Projective Use of Drawings. Retrieved March 1998 from the World Wide Web: http://home.ican.net/ phansen/pages/bookproj

Ansley, Bruce (1997). Father Hunger. [Article] in the New Zealand Listener May 3, 1997.

Arcana, Judith (1984). Every Mother's son: The Role of Women in the Making of Men. Great Britain: The Women's Press, USA: Anchor Press/Doubleday.

Arditti, Rita, Duelli Klein, Renate \& Minden, Shelley (Eds.) (1984). Test-tube women: What Future for Motherhood? London: Pandora Press.

Atweh, Bill, Christensen, Clare \& Dornan, Louise (1998). Students as action researchers: partnerships for social justice. In Bill Atweh, Stephen Kemmis and Patricia Weeks. Action Research in Practice: Partnerships for Social Justice in Education. USA \& Canada: Routledge.

Atwood, Margaret (1985). The Handmaids Tail. New York: Fawcett Crest Books.

Aziz, Razia (1992). Feminism and the challenge of racism: Deviance or difference? In Crowley \& Himmelweit. Knowing Women: Feminism and Knowledge. New York: Polity Press.

Bales, Norman (1996). Boys Need Dads. In All About Families. Vol 1, Number 9 March 25. Retrieved May 1997 from the World Wide Web http://wwwsoftdisk. $\mathrm{com} / \mathrm{comp} / \mathrm{mcoc} / \mathrm{family} / \mathrm{fm} 9$

Barry, Christine A. (1998). Choosing qualitative data analysis software: Atlas/ti and Nud*ist Compared. In Sociological Research Online, Vol 3, no 3. Retrieved December 1998 from the World Wide Web: http://www.socresonline.org.uk /socresonline $3 / 3 / 7 . h t m l$ 
Bassoff, E. (Ed.) (1995). Between Mothers and Sons. London: Judy Piatkus Publishers.

Bathes, Roland (1961). The photographic message. Transl. Richard Howard. The Responsibility of Forms: Critical Essays on Music, Art, and Representation. Berkley: University of California Press.

Beautrais, A. (1997). In Our Hands: The Research Evidence. Wellington: Ministry of Health.

Bee, Helen (1998). Lifespan Development. USA: Addison-Wesley Educational Publishers.

Beecroft, Andrew (August 5, 1997). [Editorial] in the Rotorua Daily Post.

Bell, Diane \& Klein, Renate (Eds.) (1996). Radically Speaking: Feminism Reclaimed. Melbourne, Australia: Spinifex.

Bender, L. \& Rapoport, J. (1994). Animal drawings of children. In American Journal of Orthopsychiatry 14.

Benmayor, Rina (1991). Testimony, action research and empowerment. In Gluck \& Patai (Eds.). Women's Words: The Feminist Practice of Oral History. New York: Routledge.

Benn, Melissa (1996). Contented, complacent women. (current state of feminism in UK.) In New Statesman. Nov. 1996. New Statesman Ltd. Retrieved September 1997 from World Wide Web. http://www.findarticles.com/cf_0/m0FQP/n4311v125/ 19087201/201/print.jhtml

Bernard, Jessie (1973). The Future of Marriage. London: Souvenir Press.

(1974). The future of motherhood. In Alison M. Jaggar \& Paula S. Rothenberg. (Eds.) Feminist Frameworks: Alternative Accounts of the Relations Between Women and Men. Second Edition. USA: McGraw-Hill.

Best, Elsdon (1978). Some Aspects of Maori Myth and Religion. New Zealand: Government Printer.

Best, Steven \& Keller, Douglas (1998). In Epstein, Jonathon S. (Ed.). Youth Culture: Identity in a Postmodern World. Massachusetts: Blackewell Publishers.

Bettleheim, Bruno (1984). Fathers shouldn't try to be mothers. In Alison M. Jaggar \& Paula S. Rothenberg. (Eds.) Feminist Frameworks: Alternative Accounts of the Relations Between Women and Men. Second Edition. USA: McGraw-Hill.

Berry, Joyce (1998). In Lynn Norment. Back to back: the truth about mama's boy and daddy's girl (mothers' influence on offsprings choices). In Ebony. Retrieved July 2000 from the World Wide Web. http://www.findarticles.com/cf_0/m1077/ n9v53/20847772/print.jhtml

Bhavani, Kum Kum (1988). Talking racism and the editing of women's studies. In Dianne Richardson \& Victoria Robinson (1993). (Eds.). Introducing Women's Studies: Feminist Theory and Practice. London: Macmillan.

(1997). Women's studies and its interconnection with race, ethnicity and sexuality. In Victoria Robinson \& Dianne Richardson (Eds.). Introducing Women's Studies. New York: NY University Press. 
Biddulph, Steve (1995) Manhood: An Action Plan for Changing Men's Lives. Sydney: Finch Publishing. (1997) Raising Boys. Sydney: Finch Publishing.

Birks, Stuart (Current). A wide range of articles and information on Web Site. http://www.massey.ac.nz/ Birks/

Birks, Stuart \& Callister, Paul (Eds.) (1999a). Perspectives on Fathering: Issues Paper No. 4. Palmerston North: Centre for Public Policy, Massey University.

(Eds.) (1999b). Perspectives on Fathering II: Issues Paper No. 6. Palmerston North: Centre for Public Policy, Massey University.

Bittman, Michael (1997). Changing Family Responsibilities: The role of the Social attitudes, Markets and the State. In Celia Briar and Gurjeet Gill (Eds.) Work Family \& the State - Problems and Possibilities for the $21^{\text {st }}$ Century. Palmerston North: Massey University.

Blakely, Mary Kay (1995). An outlaw mother tells all. [Article] in Ms January/February 1995.

Blankenhorn, David (1994). Fatherless America: Confronting our Most Urgent Social Problem. USA: Family Research Council.

Blankenhorn, David (1995). Fatherless America: Confronting our Most Urgent Social problem. New York: Basic Books. Retrieved May 1997 from the World Wide Web. http://www.frc.org/frc/insight/

Bly, Robert (1991). Iron John: A Book about Men. London: Element.

Bombyk, M., Bricker-Jenkins, M. and Wedenoja, M. (1991). In Gluck \& Patai (Eds.), Women's Words: The Feminist Practice of Oral History. New York: Routledge.

Bovey, Shelley (1989). Being Fat is Not a Sin. London: Pandora.

Bowes, A.M. (1996). Evaluating an empowering research strategy: Reflections on action research with South Asian women. In Sociological Research Online, Vol 1, no 1. Retrieved on July 1998 from the World Wide Web: http://www. socresonline.org.uk/ socresonline/ 1/1/1.html

Bowles, Gloria \& Klein, Renate (Eds.) (1983). Theories of Women's Studies. London and New York: Routledge \& Kegan Paul.

Brannen, Julia \& Moss, Peter (1995). Managing mothers. In Stevi Jackson (Ed.) (1995). Women's Studies: A Reader. New York \& London: Harvester Wheatsheaf.

Briar, Celia (1997). Women and Children Last? Priorities in Introducing a Universal Basic Income. In Celia Briar and Gurjeet Gill (Eds.) Work Family \& the State Problems and Possibilities for the $21^{\text {st }}$ Century. Palmerston North: Massey University.

Briar, C. and Chrisp, J. (2000). Solo mothers' poverty: Problems and prevention. In Women's Studies Association Conference Proceedings, 1999. Wellington: WSA.

Brickell, John (1998). An Overview of Parenting Programmes for Fathers. In Fathers Who Care: Partners in Parenting. Wellington New Zealand, Office of the Commissioner for Children. 
Britannica, Encyclopaedia. Human Behaviour-Self Concept and Problems in Development. Retrieved April 2000 from the World Wide Web. http://www.britannica. com/bcom/eb/article/1/0,5/16,119311+8+110429,00.html

Brodribb, Somer (1992). Nothing Mat(t)ers: A Feminist Critique of Postmodernism. Melbourne, Australia: Spinifex.

(1996). Nothing mat(t)ers. In Bell \& Klein (Eds.). Radically Speaking: Feminism Reclaimed. Melbourne, Australia: Spinifex.

Brofenbrenner, U. (1979). The Ecology of Human Development: Experiments by Nature and Design. Cambridge, MA: Harvard University Press.

Brooks-Gunn, J \& Reiter, E.O (1990). In Helen Bee Lifespan Development (1998) USA: Addison-Wesley Educational Publishers.

Bullen, Esther (1999). A Matter of Gender. In NZ Education Review, March 19, 1999 NZ.

Bunch, Charlotte (1987). Passionate Politics: Feminist Theory in Action. New York: St Martin's Press.

Burgess, Adrienne (1997). Fatherhood reclaimed: The making of the modern father. Cited in Jayne Buxton. (1999) Ending the Mother war: Starting the Workplace Revolution. London: Pan Books, MacMillan Publishers.

Burns \& Kofman (1987). Actions, Styles and Symbols in Kinetic Family Drawings. New York: Brunner/Mazel Publishers.

Burt, Helen (1996). Beyond Practice: A Post-Modern Feminist Perspective on Art Therapy Research. ARTherapy: Journal of the American Art Therapy Association Vol 13, Number 1.

Butler, Judith (1990). Subjects of sex/gender/desire. In Gender trouble: Feminism and the Subversion of Identity. New York \& London: Routledge.

Buxton, Jayne. (1998). Ending the Mother war: Starting the Workplace Revolution. London: Pan Books.

Calabrese, (1998). In Jonathon S. Epstein, (Ed.). Youth Culture: Identity in a Postmodern World. Massachusetts: Blackwell Publishers.

Callaghan, Gill (1998). The interaction of gender, class and place in women's experience: A discussion based in focus group research. In Sociological Research Online, Vol 3, no 3 Retrieved December 1998 from the World Wide Web: http://www. socresonline.org.uk/ socresonline $3 / 3 / 7 . \mathrm{html}$.

Campioni, Mia \& Gross, Elizabeth (1978). Little Hans: The production of Oedipus. In Paul Foss and Meaghan Morris (Eds.). Language, Sexuality and Subversion. New York: Feral Publication.

Caron, Ann F. (1995). Strong Mothers, Strong Sons: Raising Adolescent Boys in the 1990 's. Harperperennial.

Chanfrault-Duchet, Marie-Francois (1991). Narrative and socio-symbolic analysis. In Sherna Berger Gluck \& Daphne Patai (Eds.). Women's Words: The Feminist Practice of Oral History. USA: Routledge. 
Chernin, Kim (1989). Womansize: The Tyranny of Slenderness. Great Britain: The Women's Press Ltd.

Chodorow, Nancy (1978). The reproduction of mothering: Psychoanalysis and the sociology of gender - An extract. In Maggie Humm. (1992). (Ed.). Feminisms: A Reader. London: Harvester Wheatsheaf.

(1984). Gender personality and the sexual sociology of adult life. In Alison M. Jaggar \& Paula S. Rothenberg. (Eds.) Feminist Frameworks: Alternative Accounts of the Relations Between Women and Men. Second Edition. USA: McGraw-Hill.

(1992). The psychodynamics of the family. In Helen Crowley and Susan Himmelweit. (Eds.). Knowing Women: Feminism and Knowledge. UK: Polity Press.

(1992). Gender, relation and difference in psychoanalytic perspective. In Hester Eisenstein and Alice Jardine. (Eds.). The Future of Difference. Massachusetts, Boston: G.K. Hall \& Co.

Chrisp, Catherine (1999). Travelling with Sophia. [Unpublished Manuscript].

Chrisp, Jill (1992). Women's studies: Kitchen sink or lecture theatre? In What is Women's Studies. Women's Studies Journal. Vol. 8. New Zealand: Women's Studies Association.

(1997). Action research for personal, social and political change - A feminist approach. In Action Research for Social and Educational Change. NZARN Conference Papers. New Zealand: Waiariki Institute of Technology Publishing.

(1998a). The debate on fatherless sons. In Celia Briar and Gill Gurjeet. (Eds.) Work, Family and the State: Problems and Possibilities for the $21^{\text {st }}$ Century. Palmerston North, New Zealand: Massey University Publishing.

(1998b). Who is Bambi's Mother? In Women Studies Association Conference Proceedings 1997 Auckland: WSA.

(1998c). Where equal is not equitable - a critique of the action research process where participants marginalised by societal structures take this into the research context. In Action Research: Challenges and Choices. NZARN Conference Papers. Wellington, New Zealand: Wellington Polytechnic Publishing.

(1999a). My mother is a crow. In Women's Studies Association Conference Proceedings 1998. Auckland: WSA.

(1999b). Between action and inaction - Contradictions in the emancipatory research process. In Collaboration for Collective Change - NZARN Conference Papers. Auckland, New Zealand: Auckland University Publishing.

(1999c). Fatherless sons - A review of the voices. In Stuart Birks and Paul Callister. (Eds.) Perspectives on Fathering II. Palmerston North: Centre for Public Policy Evaluation. Massey University.

(2000a). The use of oral histories in feminist action research - The motheradolescent son project. In Byrne, Evans and Hutching. (Eds.) Oral History in 
New Zealand. Vol 10. New Zealand: National Oral History Association New Zealand.

(2000b). Strengthening (white, heterosexual, employed, nuclear) families: The increasing divergence between the state and the single mother. In Women's Studies Association Conference Proceedings 1999. Wellington: WSA.

(2001). That Four-Lettered Word - Sons: Lesbian Mothers and Adolescent Sons. [In Press] in Alison Laurie (Guest Editor). International Lesbian Studies Journal - 2001.

Clements, Elizabeth (1985). Solo Mothers - An Oppressed Group. Chapter [Unpublished Manuscript]. Masters Thesis. Wellington: Victoria University.

Comacchio, Cynthia (1997). Motherhood in Crisis: Women, Medicine and State in Canada, 1900 - 1940. In Rosemary Hennessy and Chrys Ingraham. Materialist Feminism: A Reader in Class, Difference and Women's Lives. NY \& London: Routledge.

Commonwealth Office of the Status of Women (1999). Women's Economic Status. Equal Worth - Final Report: Output 4. Retrieved October 2000 from the World Wide Web: http//www.dpmc.gov.au/osw/content/publications/ec_worth/index.html

Conger, John (1991). Adolescence and Youth: Psychological Development in a Changing World U.S.A: HarperCollins Publishers Inc.

Cooper, Annabel (1999). Once on Chunuk Bair. In In Robin Law, Hugh Campbell, \& John Dola. (1999) (Eds.). Masculinities in Aotearoa/New Zealand. New Zealand: Oxford University Press.

Corea, Genea (1985). The Mother Machine: Reproductive Technologies from Artificial Insemination to Artificial Wombs. New York: Harper \& Row.

Corti, Louise (1993). Using diaries in social research. In Social Research Update: Issue Two. England: University of Surrey. Retrieved October 1999 from the World Wide Web: http://www.soc.surrey.ac.uk/sru/SRU2.html

Cory, David (1989). The Secrets of Fascinating Womanhood. Tauranga: David Cory Publishing.

Court, Helen \& Court, Marion (1998). Positioning, subjectivity and stories: Feminist poststructuralist research narratives. In Rosemary Du Plessis \& Lynne Alice (Eds.), Feminist Thought in Aotearoa New Zealand. New Zealand: Oxford University Press.

Crowley, Helen and Himmelweit, Susan (Eds.) (1992). Knowing Women: Feminism and Knowledge. UK: Polity Press.

Daly, Kathleen N (1992). Greek and Roman Mythology. UK: Roundhouse Publishing Ltd.

Davidson, Carl \& Tolich, Martin (Eds.) (1999). Social Science Research in New Zealand. Many Paths to Understanding. New Zealand: Longman

Davis, Laura (1997). Having something in common. In Jess Wells (Ed.) Lesbians Raising Sons. Los Angeles. Alyson Books. 
Deegan, Mary Jo \& Hill, Michael (1991). Doctoral dissertations as liminal journeys of the self: Betwixt and between in graduate sociology papers. In Teaching Sociology, Vol 19, July.

Delamont, Sarah (1985). Fighting familiarity: Strategies of qualitative research in education. In Gluck \& Patai (Eds.) (1991). Women's Words, the Feminist Practice of Oral History. New York: Routledge.

Dick, Bob (1999). Sources of rigour in action research: addressing the issues of trustworthiness and credibility. Presented to the Association for Qualitative Research Conference: Issues of Rigour in Qualitative Research. Retrieved March 2000 from the World Wide Web: http://www.latrobe.edu.au/www/aqr/otter /papers/Bdick.htm

Du Bois, Barbara (1983). Passionate scholarship: notes on values, knowing and method in feminist social science. In Bowles and Klein (Eds.). Theories of Women's Studies. London: Routledge \& Kegan Paul.

Dworkin, Andrea (1983). Right-Wing Women. New York: Coward-McCann.

Eastwood, John (1998a). Young Male Risk Behaviours: A Scoping of Their Impact and Possible Policy Responses. Ministry of Youth Affairs. Wellington: Bright Futures Group, NIHS.

(1998b). Young Male Risk Behaviours: Statistical Data \& Annotated Bibliography. Ministry of Youth Affairs. Wellington: Bright Futures Group, NIHS.

Ebborn, Lynette (1997). Absence of fathers not the root of the problem. [Article] in The NZ Herald, September 5, 1997.

Education Review Office (1999). The Achievement of Boys, Number 3 Winter. Wellington: Ministry of New Zealand. Retrieved September 1999 from the World Wide Web. http://www.ero.govt.nz/Publications/eers1999/Boys.

Ehrenreich, Barbara and English, Deidre (1979). For Her Own Good: 150 Years of the Experts' ${ }^{\prime}$ Advice to Women. London: Pluto Press Ltd. First published in the USA: Anchor Press/Doubleday.

Eisenhart,M. \& Howe, K. (1992). Validity in qualitative research. In M. LeCompte, W. Milroy \& J. Preissie (Eds.) The Handbook of Qualitative Research in Education.

Elliot, H. (1997). The use of diaries in sociological research on health experience. In Sociological Research Online, vol. 2, no.2. Retrieved April 1999 from the World Wide Web: http://www.socresonline.org.uk/socresonline/2/2/7.html San Diego: Academic Press.

Elliot, J. (1991). A practical guide to action research In Action Research for Educational Change. Milton Keynes: Open University Press.

Encyclopaedia Britannica (Current). An overview of human behaviour and human development theories. Retrieved from the World Wide Web. http://britannica. $\mathrm{com} / \mathrm{bcom}$

Elium, Don \& Elium, Jeanne (1992). The trouble with boys. What are little boys made of? In Raising $A$ Son. Celestial Arts 
Epstein, Jonathon S. (Ed.) (1998). Youth Culture: Identity in a Postmodern World. Massachusetts: Blackewell Publishers.

Erikson, E. H. (1968). Identity: Youth and Crisis. New York: Norton.

An overview of human behaviour and human development theories. In the Encyclopaedia Britannica. Retrieved September 2000 from the World Wide Web. http://www. britannica.com/bcom/eb/article/9/0,5716,119309+4,00.html.

Evans, Mary (1983). In praise of theory: The case for women's studies. In Bowles and Klein (Eds.). Theories of Women's Studies. London: Routledge \& Kegan Paul.

Evans, Tony (Co-Ed.) (1996). Seven promises of a Promise Keeper. In The Progressive. Retrieved November 1997 from the World Wide Web. http://www.now.org/press /10-97/10.02.97.html.

Evans, W. \& Reilly, J. (1996). Drawings as a Method of Program Evaluation and Communication with School-Age Children. In Journal of Extension. Vol 34, Number 6, December 1996. Retrieved October 1998 from the World Wide Web: http://www.joe.org/joe/1996december/a2.

Faludi, Susan (1992). Backlash: The Undeclared War Against Women. London: Chatto \& Windus.

Fanon, Frantz (1967). Black Skin, White Masks. NY: Grove Press. (1990). The Wretched of the Earth. NY: Grove Press.

Fat Mama Jokes. Retrieved September 1998 from the World Wide Web: http://expage.com.page/ fatmama2.

Ferrere, Debbie (1989). A Quiet Revolution. [Article] in Broadsheet June 1989. New Zealand: Broadsheet Collective.

Ferguson, Ann (1991). Sexual Democracy - Women, Oppression and Revolution. USA: Westview Press.

Ferguson, Ann (1997). On conceiving motherhood and sexuality: a feminist materialist approach. In Diana Tietjens Meyers. (Ed.) Feminist social thought: A reader. Great Britain \& New York: Routledge.

Figes, K. (1994). The Myth of Equality for Women in Britain. London: Macmillan.

Firestone, Shulamith (1970). The Dialectic of Sex. New York: Bantam Books.

Flannery, D.J., Montemayor, R. \& Eberly, M.B. (1994) The influence of parent negative emotional expression on adolescents' perceptions of their relationships with their parents. In Helen Bee (1998). Lifespan Development. USA: Addison-Wesley Educational Publishers.

Fonow M., \& Cook, A. (Eds.) (1991). Beyond Methodology: Feminist Scholarship as Lived Research. USA: Indiana University Press.

Forna, Aminatta (1998). Mother of all Myths: How Society Moulds and Constrains Motherhood. UK: HarperCollins.

Foucault, Michel (1977). What is an author? In Donald F. Bouchad. (Ed.) Language, Counter-Memory, Practice. New York: Cornell University Press. 
(1978). The Archaeology of Knowledge. London: Tavistock Publishing.

(1982). This is Not a Pipe. Trans. James Harkness. Los Angeles: University of California Press.

(1993). Space, power and knowledge. In S. During (Ed.). The Cultural Studies Reader. London: Routledge.

Fraser, I.H., Fish, T.A. and MacKenzie, T.M. (1994). Reactions to child custody decisions involving homosexual and heterosexual parents. Retrieved July 1997 from the World Wide Web: http://www.cycor.ca/Psych/cjbs/fraser/html.

Fraser, Nancy \& Nicholson, Linda (1997). Social criticism without philosophy: An encounter between feminism and postmodernism. In Diana Tietjens Meyers. (Ed.), Feminist Social Thought: A Reader. NY \& London: Routledge.

Frean \& Swain (1998). Fathers with no names who won't pay their fair share. [Article] in The Dominion 31 July, 1998.

Freedman, Rita (1988). Bodylove: Learning to Like Our Looks - and Ourselves. Glasgow, Great Britain: Collins.

(1990). Bodylove: Learning to Like our Looks - and Ourselves. London: Grafton Books.

Freire, Paulo (1970). The Pedagogy of the Oppressed. New York: Seabury Press.

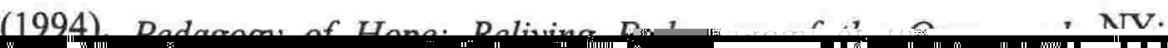

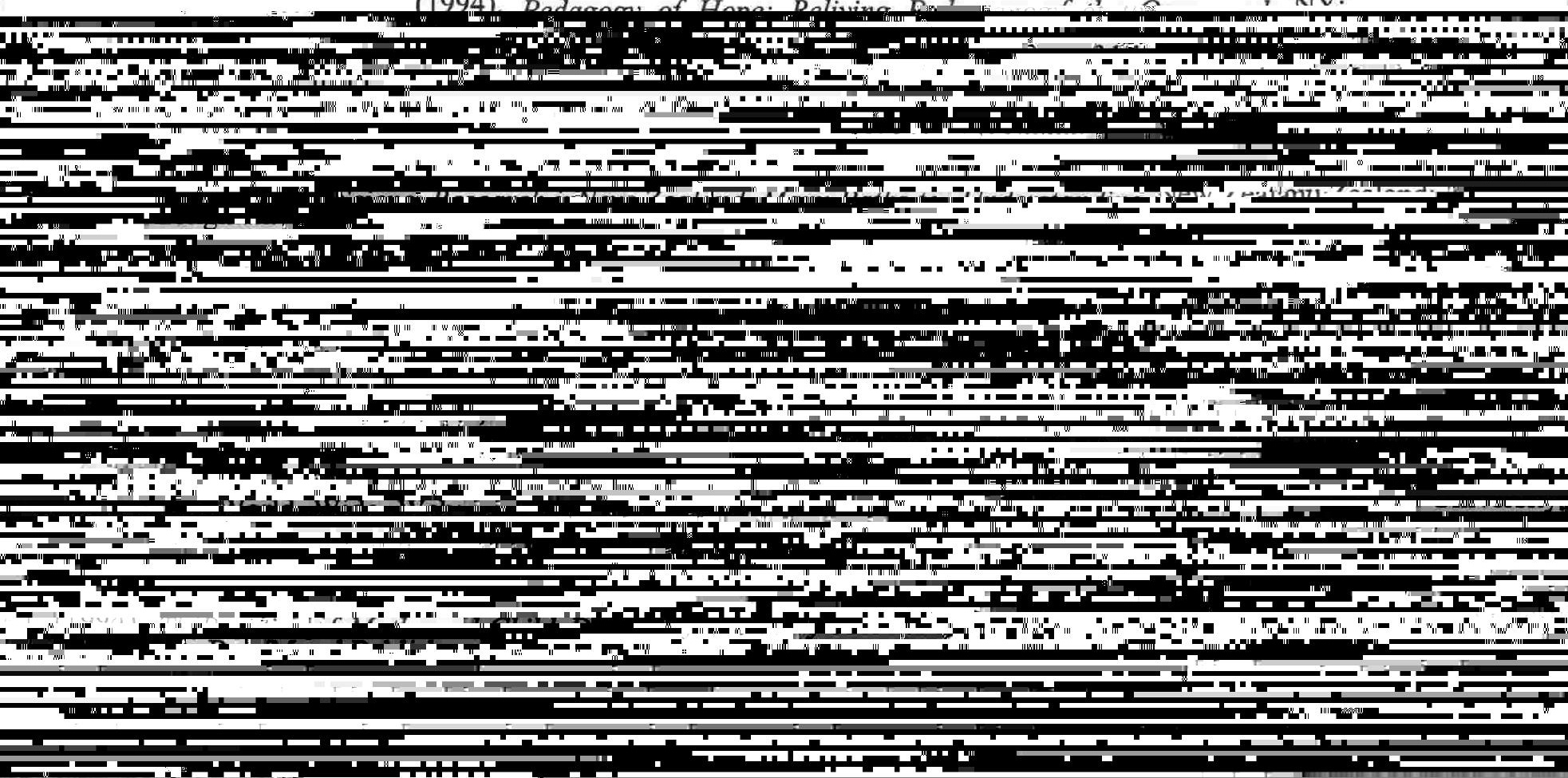


Gillman, Maureen (1996). Empowering professionals in higher education. In Humphries. (Ed.). Critical Perspectives on Empowerment. Great Britain: Venture Press.

Gittens, Diana (1994). What is the family? Is it universal? In Linda McDowell and Rosemary Pringle. (Eds.) Defining Women: Social Institutions and Gender Divisions. Cambridge: Polity Press.

Gluck, Sherna Berger \& Patai, Daphne (Eds.) (1991). Women's Words: The Feminist Practice of Oral History. USA: Routledge.

Gomaz, Joan (1993). Psychological and Psychiatric Problems in Men. London: Routledge.

Goodger, Kay (1997). Sole parents and employment: Recent trends and their policy implications. In Celia Briar and Gurjeet Gill (Eds.) Work Family \& the State Problems and Possibilities for the $21^{\text {st }}$ century. Palmerston North: Massey University.

Gough, Kathleen (1975). The origin of the family. In Trayna R. Reiter (Ed.) Toward an Anthropology of Women. New York: Monthly Review Press.

Gottfried, Heidi (Ed.) (1996). Feminism and Social Change: Bridging Theory and Practice. Champaign, IL: University of Illinois Press.

Greed, Clara (1990). The professional and the personal: A study of women quantity surveyors. In Liz Stanley (Ed.). Feminist Praxis: Research. Theory and Epistemology in Feminist Sociology. London \& New York: Routledge.

Green, Maureen (1976). Fathering. New York: McGraw-Hill Book Company.

Greenberg, David F. (1988). The Construction of Homosexuality. USA: The University of Chicago Press.

Greenwood, Robbie (1989). Bringing up boys. [Article] in Broadsheet June 1989. New Zealand: Broadsheet Collective.

Gross, Rita (1987). In Sharma, Arvind (Ed.). Women in World Religions. State University of New York Press, USA.

Guba, E.G. \& Lincoln, Y.S. (1989). Fourth Generation Evaluation. California: Sage Publications.

Guba, E.G. \& Lincoln, Y.S. (1994). Competing paradigms in qualitative research. In N. Denzin and Y. Lincoln. (Eds.) Handbook of Qualitative Research. Thousand Oaks: Sage Publications.

Hadlow, Canon Gerald (February 2, 2000). Two parent families the ideal. [Column]. Canon's Roar. The Daily Post.

(November 11, 2000). Same-sex 'marriages' hit children. [Column]. Canon's Roar. The Daily Post.

Hammer, Emanuel (1997). Advances in Projective Drawing Interpretation. USA: Charles C. Thomas - Publishers Ltd.

Hansard Supplements (dates as indicated in text). Parliamentary Debates House of Representatives, Wellington: NZ Govt. Print. 
Hanscombe, Gillian E., \& Forster, Jackie. (1982). Rocking the Cradle: Lesbian Mothers. A Challenge in Family Living. London: Sheba Feminist Publishers.

Harne, Lynne (1993). Lesbian custody and the myth of the father. In Sue Faulkner \& Stevi Jackson (Eds.) Women's Studies: A Reader Marriage and Motherhood. Chapter 6. New York: Harvester Wheatsheaf.

Harding, Sandra (Ed) (1987). Feminism and Methodology. USA: Open University Press.

Harne, Lynne (1993). Lesbian custody and the new myth of the father. In Stevi Jackson et.al. (Eds.) Women's Studies: A Reader Great Britan: Harvester Wheatsheaf.

Hartmann, Heidi (1984). The family as the locus of gender, class and political struggle: The example of housework. In Alison M. Jaggar \& Paula S. Rothenberg. (Eds.) Feminist Frameworks: Alternative Accounts of the Relations Between Women and Men. Second Edition. USA: McGraw-Hill.

Hartsock, Nancy (1987). The feminist standpoint: Developing the ground for a specifically feminist historical materialism. In Sandra Harding (Ed.). Feminism \& Methodology. Indiana: Indiana University Press \& Open University Press.

(1990). Foucault on power. In Linda Nicholson (Ed.). Feminism / Postmodernism. New York \& London: Routledge.

Hauschild, Myra \& Rosier, Pat (2000). Get Used to It: Children of Gay and Lesbian Parents. Christchurch: Canterbury University Press.

Henaghan, Mark (1999a). Above and beyond the best interests of the child. In Stuart Birks and Paul Callister (Eds.) Perspectives on Fathering: Issues paper No. 4. Palmerston North: Massey University Press.

(1999b). Fatherhood and family law. In Stuart Birks and Paul Callister (Eds.) Perspectives on Fathering: Issues paper No. 6. Palmerston North: Massey University Press.

Henderson, Mark (1999). Sex slurs forcing men out of teaching. [Article] in The Sunday Star-Times August 1, 1999.

Herschell, R.M. (1999). Paper presented to the Association for Qualitative Research Conference: Issues of Rigour in Qualitative Research. Retrieved March 2000 from the World Wide Web: http://www.latrobe.edu.au/www/aqr/otter/papers /RHershe.htm.

(1997). Conceptions of Thinking Legally: An Interpretive Approach. [Unpublished Manuscript] PhD Thesis. New South Wales: University of New England.

Hill, Roberta \& Capper, Phillip (1999). Action Research. In Carl Davidson \& Martin Tolich, (Eds.) Social Science Research in New Zealand: Many Paths to Understanding. New Zealand: Longman.

Hockenberry-Eaton, Marilyn et.al. (1996). Mother and adolescent knowledge of sexual development: The effects of gender, age and sexual experience. In Adolescence. Spring 1996 v31 n121.

Hoek, Janet \& Gendall, Philip (1999). Survey research. In Carl Davidson \& Martin Tolich. (Eds.) Social Science Research in New Zealand. Many Paths to Understanding. New Zealand: Longman. 
Holdom, Karen (1998). A man's world - Have men become the victims of society? [Article] in SHE \& MORE. (April, 1998). New Zealand.

hooks, bell (1995). Killing Rage: Ending Racism. New York: Henry Holt and Co.

Hoskins, Betty B., \& Holmes, Helen Bequaert (1984). If you would be the mother of a son. In Rita Arditti, Renate Klein \& Shelley Minden. Test-tube Women: What Future for Motherhood? London: Pandora Press.

Humm, Maggie (Ed.) (1992). Feminisms: A Reader. USA: Harvester Wheatsheaf.

Humphries, B. (Ed.) (1996). Critical Perspectives on Empowerment. Great Britain: Venture Press.

(1997). From critical thought to emancipatory action: Contradictory research goals? In Sociological Research Online, Vol 2, no 1 Retrieved December 1998 from the World Wide Web: http://www.socresonline /socresonline/2/1/http.

Iles, Colin (1996). Out of control. Wellington: Pacific Education Resources Trust.

Jackson, Brian (1983). Fatherhood. London: Allen \& Unwin.

Jackson, Stevi (Ed.) (1995). Women's Studies: A Reader. New York \& London: Harvester Wheatsheaf.

Jaggar, Alison \& Rothenberg, Paula (1984). Feminist Frameworks: Alternative Theoretical Accounts of the Relations Between Women and Men. New York: McGraw-Hill.

James, Joy (1996). Experience, reflection, judgement and action: teaching theory, talking community. In Diane Bell \& Renate Klein (Eds.) Radically Speaking: Feminism Reclaimed. Australia: Spinfex Press.

Jerry, Paul (1998). The house-tree-person projective drawing technique. Retrieved October 1998 from the World Wide Web. http://www3.memlane.com/ jerry.html

Johnson, Matt (1997). Bridging the dad gap. Article in the Sunday Star Times October 26, 1997.

Julian, Rae (1998). Focus on fathers. In Father Who Care: Partners in Parenting. New Zealand: Office of the Commissioner for Children

Kahukiwa, R. \& Grace, P. (1984). Wahine Toa: Women of Maori Myth. New Zealand: Penguin Books.

Kaplan, L. J. (1988). Adolescence: The Farewell to Childhood. New York: Jason Aronson.

Karraka, Meg Wilkes (1995). Divorce, the impact on half of all children. In ViewsSummer 1995. Minnesota: Minnesota Council on Family Relations. Retrieved September 2000 from the World Wide Web. http://www.cytc.umn.edu/parenting/ viewssummer 95. html

Kaufman, Michael (Ed.) (1987). Beyond Patriarchy: Essays by Men on Pleasure, Power and Change. New York: Oxford University Press. 
Keen, Sam (1991). It's a Women's World. In Fire in the Bell: - On Being a Man. USA: Bantam Books.

Kelle, U. \& Laurie, H. (1995). Computer use in qualitative research and issues of validity. In U. Kelle. (Ed.) Computer-aided Qualitative Data Analysis: Theory Methods and Practice. Thousand Oaks: Sage. (19-28)

Kemmis, S. \& McTaggart, R. (Eds.) (1988). The Action Researcher Reader. Geelong, Australia: Deakin University Press.

Kemp, Sandra \& Squires, Judith (1997). Feminisms. Oxford \& New York: Oxford University Press.

Kett, J.F. (1967). The Universal Experience of Adolescence. Boston: Beacon Press.

King, Michael (Ed.) (1988). One of the Boys? Changing Views of Masculinity in New Zealand. Auckland: Heinemann Publishers.

Kingman, Daphne Rose (1993). The Men We Never Knew: Women's Role in the Evolution of a Gender. Auckland: Tandem Press.

Kinsey, Alfred (1953). Sexual Behaviour in the Human Female. Philadelphia: Saunders.

Klein, Renate D. (Ed.) (1989) Infertility: Women Speak out about their Experiences of Reproductive Medicine. London: Pandora Press.

Klein, Renate D., Raymond, Janice G. \& Dumble, Lynette J. (1991). $R U$ 486: Misconceptions, Myths and Morals. Australia: Spinifex.

Kopel, David (1997). Fatherlessness and Crime. Article in the Dillon Press. Retrieved June 1997 from the World Wide Web. http://ourworld.compuserve.com/ homepages/Dreyer_infonet/singlepr.

Kritsberg, Wayne (1986). The Adult Children of Alcoholics: Syndrome from Discovery to Recovery. USA: Health Communications Inc.

Lather, Patti (1991). Getting Smart: Feminist Research and Pedagogy With/in the Postmodern. New York: Routledge.

(1993). Fertile obsession: Validity after poststructuralism. Sociological Quarterly, 34 (4).

Law, Robin, Campbell, Hugh \& Dolan, John (Eds.) (1999). Masculinities in Aotearoa/New Zealand. New Zealand: Oxford University Press.

Laursen, B (1995). Conflict and social interaction in adolescent relationships. In Journal of Research on Adolescence, 5.

Lee, John (1991). At My Father's Wedding: Men Coming to Terms With their Fathers and Themselves. New York: Bantam Books.

Lempers, Jacques D. \& Clark-Lempers Diana S. (1997). Economic hardship, family relationships and adolescent distress: An evaluation of a stress-distress mediation model in mother-daughter and mother-son dyads. In Adolescence Summer 1997. (Retrieved on November 1998 from the Expanded Academic ASAP. Article A19619414) 
Lerner, RM (1987). A life-span perspective for early adolescence. In RM Lerner \& TT Foch (Eds.) Biological-Psychosocial Interactions in Early Adolescence. New Jersey: Erlbaum.

Lerner, R.M. (Ed.) (1993). Early Adolescence: Perspectives on Research, Policy and Intervention. New Jersey: Erlbaum.

Lerner, R.M. (1998). Adolescent development: Challenges and opportunities for research, programmes and policies. In Annual Review of Pyschology. Retrieved August 2000 from the World Wide Web. http://www.findarticles.com/cf_0/ m0961/v49/21036274/print.jhtml.

Levy, David M. (1957) Maternal Overprotection. New York: Columbia University Press.

Lincoln, Y. (1995). Emerging criteria for quality in qualitative and interpretative research. Qualitative Inquiry, 1 (3)

Lincoln, Y.S. \& Guba, E.G. (1985). Naturalistic Inquiry. California: Sage Publications.

Locher, David (1998). In Epstein, Jonathon S. (Ed.) Youth Culture: Identity in a Postmodern World. Massachusetts: Blackewell Publishers.

Logan, Harriet (February 5, 2000). Father 'figures' challenged. [Article] in The Daily Post.

Long, N. and Long, A. (1992). In A.M. Bowes. Evaluating an empowering research strategy: Reflections on action research with South Asian women. In Sociological Research Online, Vol 1, no I (1996). Retrieved December 1998 from the World Wide Web: http://www.socresonline.org.uk/socresonline/1/1/1.html

Lorde, Audre (1984). Sister Outsider. New York: The Crossing Press.

(1992). Age, race, class and sex: Women redefining difference. In $\mathrm{H}$. Crowley and S. Himmelweit (Eds.) Knowing Women: Feminism and Knowledge. Cambridge: Polity Press.

(1997). Man child: A black lesbian feminist's response. In Jess Wells (Ed.) Lesbians Raising Sons. Los Angeles. Alyson Books.

Lowenfeld, Victor (1987). Creative and Mental Growth. USA: MacMillan Publishers.

Lupton, Deborah \& Barclay, Lesley (1997). Constructing Fatherhood. London: SAGE Publications.

Luff, Donna (2000). British 'Moral Right' women and feminism. In Sociological Research Online, Vol.5, no.1, http://www.socresonline.org.ek/5/1/1uff.html

Mac an Ghaill, Mairtin (1997). The Making of Men: Masculinities, Sexualities and Schooling. Buckingham: Open University Press.

McCann, Rex (1999). Fatherless Sons: The Experience of New Zealand Men. New Zealand: HarperCollins Publishers.

McCartney, Bill (1996). The Progressive. Retrieved November 1997 from the World Wide Web. http://www.now.org/press/10-97/10.02.97.html

McDowell \& Pringle (Eds) (1992). Defining Women: Social Institutions and Gender Divisions. New York: Polity Press. 
McMahon, Martha (1995). Engendering Motherhood: Identity and Self-transformation in Women's Lives. New York: The Guilford Press.

MacKinnon, Catharine (1996). From practice to theory, or what is a white woman anyway? In Dianne Bell and Renate Klein (Eds.) Radically Speaking: Feminism Reclaimed. Australia: Spinifex Press.

McMahon, Martha (1995). Engendering Motherhood: Identity and Self-transformation in Women's Lives. New York: The Guilford Press.

McNay, Lois (1992). Foucault and Feminism: Power, Gender and the Self. Cambridge: Polity Press.

McTaggart, Robin (1994). Participatory action research: issues in theory and practice. In Educational Action Research, Volume 2, No.3.

(1998). Enhancing validity in participatory action research. Key note address presented to the New Zealand Action Research Annual Retreat. Wellington Polytechnic. Wellington, New Zealand.

Maguire, Patricia (2000). Feminisms and participatory, action-oriented research. Chapter Five in Peter Reason \& Hilary Bradbury. Handbook of Action Research: Participative Inquiry and Practice. London: Sage Publications.

Mahoney, Kathleen (1995). Gender Bias in Family Law - Deconstructing Husband Privilege. NZLS Family Law Conference.

Malchiodi, Cathy (1997). Art therapy in schools - Editorial and special issue. ARTherapy: Journal of the American Art Therapy Association Vol 14, Number 1.

Marcia, James (1980). Identity in adolescence. In J Adelson (Ed.) Handbook of Adolescent Psychology $(159-187)$. New York: Wiley.

Marin-McDonald, Kristine (1999). Once upon a time. ... Narratives and research. In Contemporary Nurse Volume 8, Issue 1. Australia: John Libbey \& Co. Pty. Ltd.

Matthews, Philip (February 5 - 11, 2000). Big day Out: Will the new government allow same sex partners to walk down the isle at last. [Article] in The New Zealand Listener.

Matahaere-Atariki, Donna (1998). At the gates of the knowledge factory: Voice, authenticity and the limits of representation. In Rosemary Du Plessis \& Lynne Alice (Eds.) Feminist Thought in Aotearoa New Zealand. New Zealand: Oxford University Press.

Meyers, Diana Tietjens (Ed.) (1997). Feminist Social Thought: A Reader. New York \& London: Routledge.

Mies, Maria (1984). In Altbach, Clausen et.al. (Eds) Towards a Methodology for Feminist Research. New York: State University of New York Press.

Millen, D. (1997). Some methodological and epistemological issues raised by doing feminist research on non-feminist women. In Sociological Research Online, Vol 2, no 3 Retrieved December 1998 from the World Wide Web: http:// www.socresonline $/ 2 / 3 / \mathrm{html}$

Miles, Matthew B. \& A. Huberman, Michael (1994). Qualitative Data Analysis: An Expanded Sourcebook. USA: Sage Publications. 
Mills, A.,Cohen, B. \& Meneses, J. (1993). Reliability and validity tests of the Diagnostic Drawing Series. The Arts in Psychotherapy.

Minh-ha, Trinh, T. (1989). Women Native Other. Bloomington \& Indianapolis: Indiana University Press.

(1991). When the Moon Waxes Red: Representation, Gender and Cultural Politics. New York, London: Routledge.

The Ministry of Justice (1999). Discussion Paper; Same-sex Couples and the Law. Wellington: Government Print.

Moodie, Jane (1998). 'But I must tell you' The importance of story-telling In life narrative. In Judith Byrne, Linda Evans \& Megan Hutching (Eds.) Oral History in New Zealand. Vol.10. New Zealand: NOHANZ.

Moore, John Noell (1994). Motherly Business and the Moves to Manhood. Article in Online Journal: Virginia Tech. http://scholar.lib.vt.edu/ejournals/ALAN/fall94/ Moore.

Morgan, Robin. (1992). Every mother's son. In Jess Wells (Ed.) Lesbians Raising Sons. Los Angeles. Alyson Books.

Morris Matthews, Kay (1994). Feminist Research Methodology in Educational History: A Case Study. Auckland: Department of Education, University of Auckland.

Mudge, Ben (1998). Responding to the Australian Men's Movement. Paper given at the Australian Women's Studies Association Conference. http://www.adelaide.net.au / benmudge.

Munford, Robin (1997). Constructing Families: Whose Responsibility? In Celia Briar and Gurjeet Gill (Eds.) Work Family \& the State - Problems and Possibilities for the $21^{\text {st }}$ century. Palmerston North: Massey University.

Neumann, Erich (1954). The Origins and History of Consciousness. Princeton, New Jersey,USA: Princeton University Press. Originally published in German (1949).

Newth, Kim (March, 2000). Fighting a custodial sentence. [Article] in Sunday Star Times.

New Zealand Health Information Service (1997). Youth Suicides. Retrieved April 2000 from the World Wide Web: http://www.nzhis.govt.nz/stats/youthsuicide.html

(1997). Youth Suicide Statistics. Retrieved April 2000 from the World Wide Web: http://www.nzhis.govt.nz/publications/youth_suicide.html

(2000). Kia Piki Te Ora o te Taitamariki. Retrieved April 2000

from the World Wide Web: http://www.nzhis.govt.nz/stats/youthsuicide.html

New Zealand Herald (October 6-12, 1997). Movement Gains Momentum: Promise Keepers.

New Zealand Herald (November 01, 1997). Disastrous Derelictions. A review of Bill Sewell. Sons of the Fathers.

New Zealand NGO (May 1998). The Status of Women Report. National Council of Women. 
New Zealand Post Primary Teachers' Association (1999). Boys' Issues Newsletter No.1 New Zealand: PPTA. Retrieved September 1999 from the World Wide Web. http://www.ppta. org.nz.

Nicholson, Linda J. (Ed.) (1990). Feminism/Postmodernism. New York \& London: Routledge.

Nicolson, Paula (1997). Motherhood and Women's Lives. In Victoria Robinson and Diane Richardson. (Eds.) Introducing Women's Studies. New York: New York University Press.

Norton, Drs. B. \& C. (1988). Symbolic Meanings of Animals. [Unpublished Manuscript].

Oakley, Ann (1981). Interiewing women: A contradiction in terms. In Helen Roberts (Ed.) Doing Feminist Research. London: Routledge \& Kegan Paul.

(1995). Becoming a mother. In Stevi Jackson (1995). (Ed.). Women's Studies: A Reader. New York \& London: Harvester Wheatsheaf.

(1995). Taking it like a women. In Stevi Jackson (1995). (Ed.). Women's Studies: A Reader. New York \& London: Harvester Wheatsheaf.

O'Brien, Mary (1981). The Politics of Reproduction. Boston: Routledge \& Kegan Paul.

O'Brien, Mike (Ed.) (1999). Social Responsibility: Whose Agenda. Auckland: AUWRC.

Ogdon, Donald (1989). Projective drawings. In Pyschodiagnostics and Personality Assessment: A Handbook. California: WPS Publishers \& Distributors.

Oppawsky, Jolene (1991). Utilising children's drawings in working with children following divorce. In the Journal of Divorce and Remarriage, Vol. 15(3/4). USA: Haworth Press Inc.

Opie, Anne (1999). Unstructured interviewing. In Carl Davidson \& Martin Tolich. (Eds.) Social Science Research in New Zealand. Many Paths to Understanding. New Zealand: Longman.

O'Reilly, Laurie (Sept 20, 1997). Brian Edwards Show. New Zealand: National Radio.

Ostriker, Alicia (1995). A wild surmise: Motherhood and poetry. In Frances Bonner et.al. (Eds.) Imagining Women: Cultural Representations and Gender. (1992). Cambridge: Polity Press.

Papalia, Diane; Olds, Sally \& Feldman, Ruth (1998) Human Development. USA: McGraw Hill.

Parker, Rozsika (1995). Torn In Two: The Experience of Maternal Ambivalence London: Virago Press Ltd.

Parry, O. (1996). In one ear and out the other: Unmasking masculinities in the caribbean classroom. Article in Sociological Research Online Vol.1, no.2. http://www. socresonline.org.uk/socresonline/1/2/2.

Patai, Daphne (1991). U.S. academics and third world women: Is ethical research possible? In Sherna Berger Gluck \& Daphne Patai, (Eds.) Women's words: The Feminist Practice of Oral History. New York \& London: Routledge. 
Payne, Leanne (1993). Crisis in Masculinity. (Seventh Printing). Illinois: Good News Publishers.

Phare, Jane (January 28, 1995). Splitting headache. [Article] in New Zealand Herald.

Phelan, Shane (1993). (Be)Coming out: Lesbian identity and politics. In Signs: Journal of Women in Culture and Society Summer 1993, Vol. 18. Chicago: University of Chicago Press.

Phillips, Angela (1993). The Trouble With Boys - Parenting the Men of the Future. Great Britain: HarperCollins Publishers.

Phillips, Jenny (1987). Mothers Matter Too. Auckland: Reed Methuen Publishers.

Phillips, Jock (1983). Mummy's Boys: Pakeha Men and Male Culture in New Zealand In A Man's Country? New Zealand: Oxford University Press.

(1999). A man's country. In Robin Law, Hugh Campbell, \& John Dola. (1999) (Eds.). Masculinities in Aotearoa/New Zealand. New Zealand: Oxford University Press.

Phoenix, Ann (1994). Narrow definitions of culture: The case of early motherhood. In Linda McDowell and Rosemary Pringle. (Eds.) Defining Women: Social Institutions and Gender Divisions. Cambridge: Polity Press.

Piaget, Jean. An overview of human behaviour and human development theories. In the Encyclopaedia Britannica. Retrieved September 2000 from the World Wide Web. http://www. britannica.com/bcom/eb/article/9/0,5716, 119309+4,00.html.

Pomare, Sir Maui \& Cowan, J (1934). Legends of the Maori - Volume 2 New Zealand: Southern Reprints.

Pool, Prof. Ian (1998). The Legacy of Laurie O'Reilly. Unpublished paper given at the Fathering the Future Forum. Christchurch.

Popenoe, David (1996). Life Without Father: Compelling New Evidence that Fatherhood and Marriage are Indispensable for the Good of Children and Society New York: Martin Pressler Press.

Promise Keepers. Retrieved November 1997 from the World Wide Web. http://www. promisekeepers.org/2cd2.htm

Pudney, Warrick (1994). Absent fathers, angry sons. In Journal NZ Association of Counsellors Vol XVI, No 2. New Zealand: NZAC.

Ramazanoglu, Caroline (1989). Feminism and the Contradictions of Oppression. London: Routledge.

Reason, P. (1994). Three approaches to participative inquiry. In N. Denzin \& Y. Lincoln (Eds.). Handbook of Qualitative Research. Thousand Oaks, CA: Sage.

Reinharz, Shulamit (1992). Feminist Methods in Social Research. New York: Oxford University Press.

(1997). Who am I? The need for a variety of selves in the field. In R.Hertz (Ed.) Reflexivity and Voice. Thousand Oaks: Sage Publications. 
Rendall, Kate (1997). Lesbians, sons and the courts. In Jess Wells (Ed.). Lesbians Raising Sons. Los Angeles. Alyson Books.

Reynolds, William M. \& Johnston, Hugh F. (Eds.) (1994). Handbook of Depression in Children and Adolescents: Issues in Clinical Child Psychology. USA: Plenum Pub Corp.

Richardson, Diane (1993). Women, Motherhood and Childrearing. London: Macmillan.

Rich, Adrienne (1976). Of woman born: Motherhood as experience and institution - An extract. In Maggie Humm. (1992). (Ed.) Feminisms: A Reader. London: Harvester Wheatsheaf.

(1986). Of Woman Born: Motherhood as Experience and Institution. London: Virago.

Riley, Shirley (1997). Art therapy for women and their families. In ARTherapy: Journal of the American Art Therapy Association Vol 14, Number 2.

Rizvi, Fazal (1998). Some thoughts on contemporary theories of social justice. In Bill Atweh, Stephen Kemmis and Patricia Weeks. Action Research in Practice: Partnerships for Social Justice in Education. USA \& Canada: Routledge.

Rotorua Daily Post (September 28, 1999). Mum's Education Key to Child. Wellington: New Zealand Press Association.

Rowbotham, Sheila (1995). To be or not to be: the dilemmas of mothering. In Stevi Jackson (1995). (Ed.) Women's Studies: A Reader. New York \& London: Harvester Wheatsheaf.

Rowland, Robyn (1992). Living Laboratories: Women and Reproductive Technologies. Australia: Pan McMillan Publishers.

Royal College of Psychiatrists (March 2000). The Impact on Children and Adolescents of Divorce or Separation of Parents. Retrieved September 2000 from the World Wide Web. http://www.ridgeway-surgery.demon.co.uk/health/divorce.htm.

Rubin, Herbert J. \& Rubin Irene, S. (1995). Qualitative Interviewing: The Art of Hearing Data. Thousand Oaks: Sage Publications.

Russell, (1983). The changing role of fathers. Evelyn Bassoff, (1995). Between Mother and Sons. London: Judy Piatkus Publishers.

Salner, Marcia (1999). Self-deception in qualitative research: Validity issues. Presented to the Association for Qualitative Research Conference: Issues of Rigour in Qualitative Research. Retrieved 22/08/99from the World Wide Web: http://www.latrobe.edu.au/ www/aqr/otter/papers/MSalner.htm

Salten, Felix (1988). Bambi. The edition used in this thesis by London: Piper Edition, Pan Books.

Sandoval, C (1991). Cyborg feminism and the methodology of the oppressed. In Gray, C.H et.al., (Eds.) (1995). The Cyborg Handbook. New York: Routledge.

Sawicki, Jana (1993). Disciplining mothers: Feminism and the new reproductive technologies. In Jackson et.al. (Eds.) Women's Studies: A Reader. New York: Harvester Wheatsheaf. 
Schulman, Alix Kates (1984). A marriage agreement. In Alison M. Jaggar \& Paula S. Rothenberg. (Eds.) (1984). Feminist Framework: Alternative Theoretical Accounts of the Relations Between Women and Men. New York: McGraw-Hill.

Sedgwick, Eve Kasofsky (1990). Introduction: Axiomatic and Epistemology of the Closet. In Epistemology of the Closet. California: University of California Press.

Sewell, Bill (1997). Sons of the Fathers: New Zealand men write about fathers. New Zealand, Tandem Press.

Scott, Joan W. (1993). Deconstructing equality-versus-difference: Or, the uses of poststructuralist theory for feminism. In Diana Tietjens Meyers (Ed.) (1997). Feminist Social Thought: A Reader. New York and London: Routledge.

Sears, Theresa Ann (1997). Feminist misogyny. In Devoney Looser and E.Ann Kaplan, (Eds.) Generations: Academic Feminists in Dialogue. Minneapolis, USA: University of Minnesota Press.

Sharma, Arvind (Ed.) (1987). Women in World Religions. State University of New York Press, USA.

Silverstein, Louise \& Auerbach, Carl (1999). Deconstructing the Essential Father Lbsremsen@Aol.Com

Silverstein, Olga \& Rashbaum, Beth (1994). The Courage to Raise Good Men: A Radical Reassessment of the Mother-Son Relationship. USA: Penguin Books.

Simon, William (1996). Postmodern Sexualities. London \& New York: Routledge.

Sinclair, Jan (May 11, 1997). Searching for the man within. [Article] in the Sunday Star Times.

Sissons, Jeffrey (1999). Ethnography. In Carl Davidson, and Martin Tolich. (Eds.) Social Science Research in New Zealand. Many Paths to Understanding. New Zealand: Longman.

Smith, Babette (1996). Mothers and Sons: The truth about Mother-Son Relationships USA: Allen \& Unwin.

(1992). Sociology from women's experience: a reaffirmation. In Sociological Theory $10(1)$.

Sokoloff, Natalie J. (1984). Motherwork and working mothers. In Alison M. Jaggar \& Paula S. Rothenberg. (Eds.) Feminist Frameworks: Alternative Accounts of the Relations Between Women and Men. USA: McGraw-Hill.

Somer, David I. Projective Drawings. Retrieved March 1998 from the World Wide Web. http://www.hicom.com/ davids/gallery.htm

Sowry, Roger (1997). Youth Income Support Bill - Briefing Notes.

(1997). Social Security (Conjugal Status) Amendment Bill - General Policy Statement \& Analysis.

Spender, Dale in Bowles, \& Klein (Eds.) (1983). Theories of Women's Studies. London and New York: Routledge \& Kegan Paul. 
Spitz, Rene A. (1965). The First Year Of Life: A Psychoanalytic Study of Normal and Deviant Development of Object Relations. New York: International Universities Press.

Stabile, Carol A. (1994). Feminism and the Technological Fix. Manchester and New York. Manchester University Press.

Stacey, Judith (1991). Can there be a feminist ethnography? In Sherna Berger Gluck \& Daphne Patai. (Eds.) Women's Words: The Feminist Practice of Oral History. USA: Routledge.

Stanley, Liz (Ed.). (1990a). Feminist Praxis: Research, Theory and Epistemology in Feminist Sociology. London \& New York: Routledge.

(1990b). Recovering women in history from feminist deconstructionism. In Sandra Kemp \& Judith Squires (Eds.) (1997). Feminisms. Oxford \& New York: Oxford University Press.

(1992). The Auto/biographical I. Manchester \& New York: Manchester University Press.

(Ed.) (1997a). Knowing Feminisms: Academic Borders, Territories and Tribes. London: Sage.

(1997b). Social transformation? Exploring issues in comparison, development and change. Editorial and call for papers in Sociological Research Online, Vol 2, no 4. http://www.socresonline.

(1997c). Methodology matters. In Victoria Robinson and Diane Richardson. (Eds.) (1997). Introducing Women's Studies. New York: New York University Press.

Stanworth, Michelle (1997). Reproductive technologies: Tampering with nature? In Sandra Kemp and Judith Squires (Eds.) Feminisms. Oxford \& New York: Oxford University Press.

Statistics New Zealand (August, 1999). New Zealand Now: Family and Households. Retrieved September 2000 from the World Wide Web. http://www.stats.govt.nz

Statistics New Zealand/Te Tari Tatau (1997). What the Census Told Us: Total Population. Retrieved September 2000 from the World Wide Web. http://www.stats.govt.nz

Steinberg, L (1988). Reciprocal Relation between parent-child distance and pubertal maturation. In Developmental Psychology.

Stirling, Pamela (1997). Being There. Article in the New Zealand Listener, Sept 6, 1997.

Strecker, Edward A. (1951). Their Mothers' Sons. USA: J.B.Lippincott and Co.

Stoltenberg, John (1994). The End of Manhood: A Book for Men of Conscience. New York: Penguin Group.

Strecker, Edward A. (1946). Their Mother's Sons: The Psychiatrist Examines an American Problem. Philadelphia: Lippincott.

Swift, Karen (1995). Manufacturing Bad Mothers: A Critical Perspective on Child Neglect. Toronto: University of Toronto Press. 
Tacey, David (1997). Remaking men: Jungian thought and the post-patriarchal psyche. In Australian Humanities Review. Retrieved September 1998 from the World Wide Web. http://www.lib.latrobe.edu.au/AHR/copyright

Tacey, David (1997). Finding the truth in men's experience: Masculinity, change and healing. In Remaking Men. http://www.cgjung.com/cgjung/tacey2

Te Awekotuku, Ngahuia (1996). Maori-lesbian-feminist radical. In Diane Bell \& Renate Klein (Eds.) Radically Speaking: Feminism Reclaimed. Melbourne, Australia: Spinifex.

Thompson, Alistair (1994). Oral history and popular memory. In ANZAC Memories Living with the Legend. Melbourne, Australia: Oxford University Press.

Thompson, Denise (1996). The self contradiction of "post-modernist" feminism. In Diane Bell \& Renate Klein (Eds.) (1996). Radically Speaking: Feminism Reclaimed. Melbourne, Australia: Spinifex.

Thompson, Ruthe (1997). Working mother. In Devony Looser and E. Ann Kaplan (Eds.) Generations: Academic Feminists in Dialogue. Minneapolis: University of Minnesota Press.

Threatt, S., Buchanan, J., Morgan, B., Strieb L.Y., Sugarman, J., Swenson,J., Teel, K. \& Tomlinson, J. (1994). Teachers voices in the conversation about teacher research. In S. Hollingsworth \& H. Sockett (Eds.) Teacher Research and Educational Reform. Chicago: University of Chicago Press.

Tong, Rosemary (1995). Feminist Thought: A Comprehensive Introduction. London: Routledge.

Towle, Alexandra (1986). Fathers. Sydney: Watermark Press.

Trebilcot, Joyce (Ed.) (1984). Mothering: Essays in Feminist Theory. New Jersey: Rowman \& Allanheld.

Tuhiwai-Smith, Linda (1999). Decolonising Methodologies: Research and Indigenous Peoples. London \& New York: Zed Books Ltd. Dunedin: University of Otago Press.

Vaden-Kiernan, Nancy et al (1995). Household family structure and children's aggressive behaviour: a longitudinal study of urban elementary school children. In Journal of Abnormal Psychology Oct 1995 v23 p533 (16).

Van Tilburg, Emmalou (1987). Evaluation with a new twist. In American Evaluation Journal Volume 25, Number 4 Winter.

Waitere-Ang, Hine \& Rahui, Maria (1998). The teller and the telling. In Women's Studies at the end of the $20^{\text {th }}$ Century - Where Next. Palmerston North, New Zealand: Women's Studies Association.

Walby, Sylvia (1992). Post-post-modernism? Theorising social complexity. In Michele Barrett and Anne Phillips. (Eds.) Destabilizing Theory: Contemporary Feminist Debates. Cambridge: Polity Press.

Waldegrave, Charles (1999). Focus groups: participation in poverty research. In Carl Davidson, and Martin Tolich. (Eds.) Social Science Research in New Zealand. Many Paths to Understanding. New Zealand: Longman. 
Wallerstein, Judith (1989). The long term effects of divorce on children: A Review. Journal of the American Academy of Child Adolescent Psychiatry, Vol. 30 (1991).

Waters, Kristin (1996). (Re)turning to the modern: radical feminism and the post-modern turn. In Bell \& Klein (Eds.) (1996), Radically Speaking:Feminism Reclaimed. Melbourne, Australia: Spinifex.

The Westchester Art Therapy Association: Art Therapy Resource Materials: Retrieved April 1998 from the World Wide Web: http://www.cyburban.com/ zenart/wizzd

Weinstock, Nicholas (1997). How We Men Feel About Our Mothers, and Why We Never Tell. USA: Reed Publishing.

Wells, Jess. (Ed.) (1997). Lesbians Raising Sons. Los Angeles, New York: Alyson Books.

Werner, Swantje (October 13, 1000). Beyond the cool façade. [Article] in NZ Education Review. New Zealand: APN Educational Media (NZ) Ltd.

Wetolicky, Dr. Cecilia (1996). The Teenage Survival Guide. Western Australia: Australian Art Max Publishers. Retrieved September 2000 World Wide Web. http://www.oregoncounseling .org/Handouts/Divorced Children.htm

Wilson (1990). Single Fathers: Australian Men Take on a New Role. Melbourne: Oxford University Press.

Wolf, Naomi (1991). The Beauty Myth. London: Virago Press.

Wolf, Naomi (1992). Father Figures: Bush and the Patriarchy. Article in the New Republic Magazine, Oct 5, 1992.

Woollet, Anne and Phoenix, Ann (1993). Issues related to motherhood. In Stevi Jackson et. al. (Eds.) Women's Studies: A Reader. Great Britain: Harvester Wheatsheaf.

Woon, Linda (1999). Woah, neddy! Here comes the next bandwagon! [Article] in Good Teacher-Term Three, 1999. New Zealand: Metacog Ltd.

Wright, John (1997). Child Support (Minimum Annual Rate Waiver) Amendment General Policy Statement \& Analysis.

Wylie, Cathy, Thompson, Jean \& Lythe, Cathy (1999). Eight Years Old and Competent: The Third Stage of the Competent Children project - A Summary of the Main Findings. Wellington: New Zealand Council for Educational Research.

Wylie, Philip (1942). Generation of Vipers. New York, Toronto: Reinhart Inc.

Yates, Miranda (1998). Community service and political identity development in adolescence. In the Journal of Social Issues, Fall 1998. Retrieved August 2000 from the World Wide Web. http://www.findarticles.com.cf_0/m0341/ $354 / 53870358 /$ print.jhtml

Yeatman, Anna (1997). The place of women's studies in the contemporary university. In Sandra Kemp \& Judith Squires (Eds.) Feminisms. Oxford \& New York: Oxford University Press.

Young, Andrew (September 10, 1998). Mothers blamed while dads remain invisible. [Article] in The New Zealand Herald. 
Zeichner, Kenneth and Noffke, Susan, (1998). In Virginia Richardson (Ed.) Handbook of Research on Teaching. Washington D.C.: American Educational Research Association.

Zohrab, Peter (Continuous). A wide range of articles and information on Web Site: http://www.geocities.com/CapitolHill/6708 